\title{
Final Report: Pilot-Scale X-Flow Filtration Test - Env C + Entrained Solids + Sr/TRU
}

by

M. R. Duignan

Westinghouse Savannah River Company

Savannah River Site

Aiken, South Carolina 29808

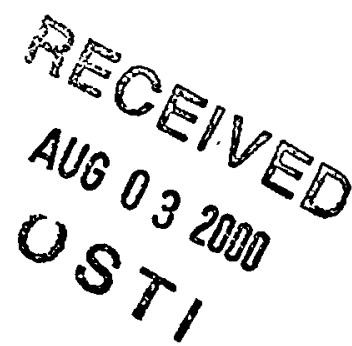

This paper was prepared in connection with work done under the above contract number with the U.S. Department of Energy. By acceptance of this paper, the publisher and/or recipient acknowledges the U. S. Government's right to retain a nonexclusive, royalty-free license in and to any copyright covering this paper, along with the right to reproduce and to authorize others to reproduce all or part of the copyrighted paper. 
Final Report: Pilot-scale Cross-flow Ultrafiltration Test Using a Hanford Site Tank 241-AN-107 Waste Simulant -
Envelope C + Entrained Solids + Strontium-Transuranic Precipitation

March 24, 2000

M. R. Duignan, 786-5A

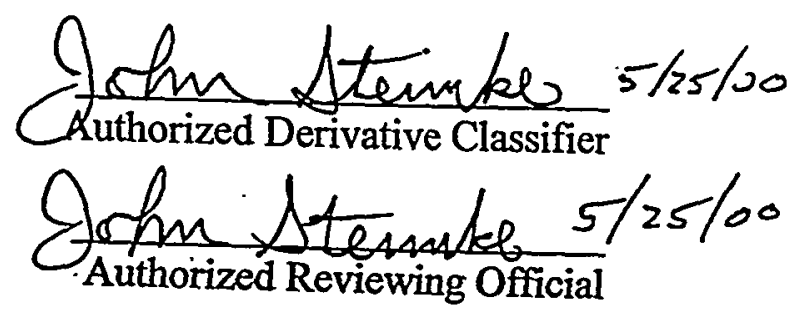

DISCLAIMER

This report was prepared as an account of work sponsored by an agency of the United States Government. Neither the United States Government nor any agency thereof, nor any of their employees, makes any warranty, express or implied, or assumes any legal liability or responsibility for the accuracy, completeness, or usefulness of any information, apparatus, product or process disclosed, or represents that its use would not infringe privately owned rights. Reference herein to any specific commercial product, process or service by trade name, trademark, manufacturer, or otherwise does not necessarily constitute or imply its endorsement, recommendation, or favoring by the United States Government or any agency thereof. The views and opinions of authors expressed herein do not necessarily state or reflect those of the United States Government or any agency thereof.

This report has been reproduced directly from the best available copy.

Available for sale to the public, in paper, from: U.S. Department of Commerce, National Technical Information Service, 5285 Port Royal Road, Springfield, VA 22161, phone: (800) 553-6847

fax: (703) 605-6900

email: orders@ntis.fedworld.gov

online ordering: http://www.ntis.gov/ordering.htm

Available electronically at http://www.doe.gov/bridge

Available for a processing fee to U.S. Department of Energy and its contractors, in paper, from: U.S. Department of Energy, Office of Scientific and Technical Information, P.O. Box 62, Oak Ridge, TN 37831-0062, phone: (865) 576-8401

fax: (865) 576.5728

email: reports@adonis.osti.gov 
Summary

Nomenclature

List of Figure

Introduction

Experimental

Results and Discussion

Conclusions

Recommendations

Approvals

References

Appendix A: Experimental Data - Water and Cleaning

Appendix B: Experimental Data - Low Solids Concentration

Appendix C: Experimental Data - High Solids Concentration- .

Distribution 


\section{DISCLAIMER}

Portions of this document may be illegible in electronic image products. Images are produced from the best available original document. 


\section{SUMMARY}

This report discusses the results of the operation of a cross-flow filter in a pilot-scale experimental facility that was designed, built, and run by the Experimental Thermal Fluids Laboratory of the Savannah River Technology Center of the Westinghouse Savannah River Company. This filter technology was evaluated for its inclusion in the pretreatment section of the nuclear waste stabilization plant being designed by BNFL, Inc. The plant will be built at the U.S. Department of Energy's Hanford Site as part of the River Protection Project.

The filter element under study was recommended by BNFL, Inc. and it was manufactured by the Mott Metallurgical Corporation in Connecticut. The filter unit was made of seven 316 stainless steel sintered metal tubes. Each was a nominal-rated 0.1-micron filter with an inside diameter of $0.375 \mathrm{inch}$, an outside diameter of $0.5 \mathrm{inch}$, and a porous length of 40 inches. These dimensions give an active filter surface area of $2.29 \mathrm{ft}^{2}$. At the time of this task these aforementioned dimensions were given as prototypic; therefore, each filter tube was considered full size to the filter, which would be built for the plant. Only the number of tubes was expected to change. [However, prior to the issuance of this report, the dimensions of the filter elements were changed to an inside diameter of 0.5 inch and a porous length of 90 inches. Therefore, the results presented herein must be considered in light of those changes.]

The filter was tested with a simulated nuclear waste of Tank 241-AN-107, which is referred to as an envelope $\mathrm{C}$ waste. The recipe for the simulant was developed by the Waste Process Technology section of SRTC and the simulant was made by TFL personnel specifically for this task. The supernatant portion of the simulant contained soluble organics, had a $\mathrm{pH} \approx 12$, and had molarities of sodium, nitrates, and nitrites, of approximately $6.8 \mathrm{M}, 3.0 \mathrm{M}$, and $1.1 \mathrm{M}$, respectively. To the supernatant were added insoluble solids to simulate entrained solids in the real waste. The particle size - distribution was designed to be bimodal; one group ranged from 1 to 2 microns and the other ranged from 5 to 10 microns. Finally, to this slurry three precipitating agents were added: Sodium Hydroxide, Strontium Nitrate, and Sodium Permanganate, which raised the $\mathrm{pH}$ to approximately 14 . After all the additions, the insoluble solids loading started at $2 \mathrm{wt} \%$ and then was eventually raised to about $38 \mathrm{wt} \%$ during the test. The total solids ranged from as low as $19 \mathrm{wt} \%$ for post-washed slurry to as high as $50 \mathrm{wt} \%$ for the prewashed slurry. At $25^{\circ} \mathrm{C}$ and a solids loading of $2 \mathrm{wt} \%$, this slurry had a density of approximately $1.27 \mathrm{~g} / \mathrm{mL}$, a viscosity of $4 \mathrm{cP}$, and Newtonian rheological characteristics. However, as the solids loading increased a yield stress was. present. At the highest loading the slurry rheology showed time dependent characteristics of a thixotropic fluid, e.g., certain paints, inks, and foods like ketchup. The flow conditions for the test varied as follows: Axial slurry velocities ranged from $9 \mathrm{ft} / \mathrm{s}$ to $15 \mathrm{ft} / \mathrm{s}(2.7 \mathrm{~m} / \mathrm{s}$ to $4.6 \mathrm{~m} / \mathrm{s})$ and transmembrane pressures ranged from 30 psid to 70 psid $(207 \mathrm{kPa}$ to $480 \mathrm{kPa})$ at a temperature of $25^{\circ} \mathrm{C}$. 
The results showed a good filtrate flux and separation. Under the optimum flow conditions of a slurry velocity of $11.6 \mathrm{ft} / \mathrm{s}$ and a transmembrane pressure of $56 \mathrm{psid}$ ( 3.5 $\mathrm{m} / \mathrm{s}$ and $386 \mathrm{kPa}$ ), the observed filtrate flux was consistently greater than $0.05 \mathrm{gpm} / \mathrm{ft}^{2}(2$ $\mathrm{lpm} / \mathrm{m}^{2}$ ). However, only a filtrate flux between $0.01 \mathrm{gpm} / \mathrm{ft}^{2}$ and $0.02 \mathrm{gpm} / \mathrm{ft}^{2}$ could be maintained as the insoluble solids loading increased above $14 \mathrm{wt} \%$; at no time did the filter plug from a slurry cake build up. To free the filter surface of the slurry cake, a backpulse volume of only $0.036 \mathrm{gal} / \mathrm{ft}^{2}\left(1.17 \mathrm{liters} / \mathrm{m}^{2}\right)$ was needed. This filtrate volume leads to a lost flux of $0.0012 \mathrm{gpm} / \mathrm{ft}^{2}\left(0.05 \mathrm{lpm} / \mathrm{m}^{2}\right)$ for a backpulse frequency of 30 minutes. Finally, for all test runs the measurable amount of insoluble solids in the filtrate was insignificant. 


\section{ACKNOWLED.GMENTS}

The author would like to thank all that were involved in this task. Andy Foreman's care and dedication in running this experiment allowed it to be successfully completed. Support from the other Experimental Thermal Fluids Laboratory personnel: Mike Armstrong, Vern Bush, Jimmy Mills, and Jerry Corbett was instrumental in keeping the experiment on track and maintaining the test rig ready, from instrumental calibration to last minute changes that were needed due to unforeseen difficulties. The Lab supervisor, Susan Hatcher, is to be commended for keeping us safe, even when things seemed to be the most hectic. A special thanks is in order to all those individuals just mentioned for the long hours they invested in the experiment, which at times disrupted their family life. I would also like to thank Charles Nash and John Steimke for their help in planning the test from their expertise and past work in filtration. Thanks to Russell Eibling for his simulant development work and theology assistance, and to Tommy Edwards' statistical expertise. The management of both Dan Burns and Martha Ebra made this task's successful completion a sure thing. Thanks to Hector Guerrero who had the unenviable task of reviewing this report. Finally, I would like to thank both my SRS customers, Steve Wach and Harold Sturm, and my BNFL customers, Paul Townson and Mike Johnson, for their support and insight, which made this work possible. 


\section{NOMENCLATURE}

AN107 Department of Energy Hanford Site Tank 241-AN-107

BNFL BNFL, Inc. (Design Authority)

DF Decontamination Factor: (Slurry Molarity / Filtrate Molarity) ionX

DIF Deionized and Filtered (0.2 micron) Water

DOE United States Department of Energy

$\gamma \quad$ Shear Rate, $\sec ^{-1}$ (Rheology Parameter)

i.d. Inside Diameter

LAW Low Activity Waste

$\mu$

Dynamic Viscosity, $\mathrm{cP}$, (Rheology Parameter)

$\mu_{0}$

Consistency or Plastic Viscosity, cP, (Rheology Parameter)

nominal The word "nominal" for a filter rating is a vague term because its meaning is manufacturer dependent. Further, a "nominal" rating does not give an exact size to a filter medium, but rather an approximation to the expected performance of a filter. In the case of Mott, a nominal rated $0.1-\mu \mathrm{m}$ filter means that approximately $95 \%$ of particles greater than $0.1 \mu \mathrm{m}$ will not pass the filter.

RPP - River Protection Project

o.d. Outside Diameter

SRTC Savannah River Technology Center (Design Agency - part of WSRC)

Sr/TRU Strontium/Transuranic

$\tau$

$\tau_{0}$

TFL

TMP

TR

TTR

$\mathrm{V}$

WPT

WSRC

XF
Shear Stress, dynes/cm², (Rheology Parameter)

Yield Stress (Shear Stress at Shear Rate $=0$ ), dynes $/ \mathrm{cm}^{2}$, (Rheology

Parameter)

Experimental Thermal Fluids Laboratory

Transmembrane Pressure (the average pressure drop across the thickness of the filter medium - perpendicular to the slurry flow.)

\section{Test Rig}

Technical Task Request

Velocity of the slurry flow along the length of the filter tubes

Waste Processing Technology (Design Agency - part of WSRC/SRTC)

Westinghouse Savannah River Company (Design Agency)

Cross-flow Filter 


\section{LIST OF FIGURES}

This list only includes those figures in the body of this report. The figures in each of the appendices are listed at the beginning of each appendix.

Figure 1. Schematic of the Pilot-scale Cross Flow Ultrafiltration Test Facility

Figure 2. Pilot-scale Cross Flow Ultrafiltration Test Facility

Figure 3a. 7-tube bundle of a nominal rated 0.1 micron filter, 3/8" i.d., 1/2" o.d., 40" long

Figure $3 \mathrm{~b}$. Upstream view of the seven-tube bundle

Figure 3c. Support plate at the mid-section of the seven-tube bundle

Figure 4. Approximately $150 \mathrm{X}$ of two different pore size rate Mott filters

Figure 5. Cross-flow Filter Housing

Figure 6. Cross-flow Filter in Test Rig

Figure 7. Main Mixing Tank for the Experiment

Figure 8. Envelope C Simulant: Supernate Only

Figure 9. Envelope C Simulant: Solids Only $-0.5 \mathrm{wt} \%$

Figure 10a. Pre-test Insoluble Solids Distribution by Volume

Figure 10b. Pre-test Insoluble Solids Distribution by Number

Figure 11. Long-term settling volumes of insoluble solids and precipitants

Figure 12. Settled solids in simulant: Envelope C+ES+Sr/TRU precipitants

Figure 13. Flow curves for Newtonian and Bingham fluids

Figure 14. Fitting a Bingham rheological model to data from the end of run 1.08

Figure 15. Solids settling rate in simulant: Envelope $\mathrm{C}+\mathrm{ES}+\mathrm{Sr} / \mathrm{TRU}$ precipitants

Figure 16. Filtrate flux immediately following a backpulse

Figure 17. Axial pressure drop vs. axial velocity of water in the cross-flow filter

Figure 18. Filtrate flux vs. axial velocity of water in the cross-flow filter

Figure 19. Reynolds Vs. axial velocity of water in the cross-flow filter

Figure 20. Normalized TMP vs. filtrate velocity in the cross-flow filter

Figure 21. Test matrix as stated in a modification to the test specification

Figure 22. Insoluble solids in the slurry and the filtrate throughout the test

Figure 23. Particle size based on a volume distribution

Figure 24. Particle size based on a number distribution

Figure 25. Reduction of sodium with successive washings

Figure 26. Filtrate density vs. sodium during washing

Figure 27 . Filtrate viscosity vs. sodium during washing

Figure 28. Oxalate changes in the filtrate during the test

Figure 29. Separation of several ions from the slurry

Figure 30. Initial water runs

Figure 31 . Final water run 1.17 before chemical cleaning

Figure 32. Cleaning run 1.18 with $1 \mathrm{M} \mathrm{NaOH}$

Figure 33. Final Water Run 1.19, after chemical cleaning

Figure 34. Composite of all 18 low solids concentration test runs

Figure 35. Effect of slurry circulation time on filter flux performance

Figure 36. Pre-wash dewatering from 2 to 22 wt\% insoluble solids

Figure 37. Composite of all 7 high solids concentration test runs

Figure 38. Pre-wash steady state slurry run at $22 \mathrm{wt} \%$ insoluble solids

Figure 39. Pre-wash steady state slurry run at $14 \mathrm{wt} \%$ insoluble solids

Figure 40 . Pre-wash steady state slurry run at $14 \mathrm{wt} \%$ insoluble solids: Run 1.12

Figure 41. Post-wash plugging run from $18 \mathrm{wt} \% 38 \mathrm{wt} \%$ of insoluble solids

Figure 42. Beginning of the post-wash plugging run: $18 \mathrm{wt} \%$ of insoluble solids

Figure 43. End of the post-wash plugging run: $38 \mathrm{wt} \%$ of insoluble solids 


\section{INTRODUCTION}

BNFL, Inc. (BNFL) has been contracted by the Department of Energy to design a facility to stabilize liquid radioactive waste that is stored at the Hanford Site. Because of its experience with radioactive waste stabilization, the Savannah River Technology Center (SRTC) of the Westinghouse Savannah River Company is working with BNFL to help design and test certain parts of the waste treatment facility. One part of the process is the separation of radioactive solids from the liquid wastes by cross-flow filtration. This task tested a cross-flow filter with a simulated radioactive waste, made to prototypically represent the waste chemical and physical characteristics.

This technical baseline research and development work was initiated by a Technical Task Request (TTR) (1) that was issued in October of 1998. This TTR came about from the BNFL specification $(2,3,4)$ to design and test a pilot scale cross-flow filtration system. With initial documentation in place $(5,6,7)$ the task began by defining a slurry to be filtered. A recipe for a low activity waste (LAW) slurry simulant, which would contain entrained solids, was developed by the Waste Process Technology (WPT) section of SRTC to represent the waste in Hanford Tank 241-AN-107 $(8,9,10)$. This waste, along with other complexant containing wastes, is referred to as Envelope C. Even though the simulant was made during this task, the recipe was taken only as input. How well this simulant matched the actual waste is beyond the scope of this task and not addressed. Finally, to this simulant several compounds were added to simulate the step of precipitating Strontium and Transuranic constituents (11). At the beginning of this task the total make-up of the complex slurry was not totally known, however, enough information did exist to begin work by modifying an existing test rig and getting the appropriate approvals to insure its safe operation $(12,13,14)$. Previous work $(15,16,17)$ assisted in guiding the plan of this task. With the test rig modifications complete a test procedure (18) was written, and due to last minute changes to the slurry makeup and equipment changes, additional operational instructions (19) were issued to keep the task running smoothly. On completion of this test a preliminary set of results $(20,21)$ were sent to BNFL in advance of this final report.

Envelope $\mathrm{C}$ simulant was the second in a series of two that would be used in this task. This report deals solely with this second simulant to evaluate a cross-flow filter. The first evaluation (22) was for a simulant representing the waste in Hanford Tank 241-AN105, called Envelope A.

The chosen filter was manufactured by the Mott Metallurgical Corporation to meet the required specification $(2,3,4)$ :

7 filter tubes with each having an inside diameter of 0.375 -inch 40-inch porous length for each filter tube and made of stainless steel Nominal rated 0.1 micron filter element (the Nomenclature explains 'nominal') 
and the test rig was modified to meet the required specification $(2,3)$ :

Maximum recirculation flow of $5 \mathrm{~m} / \mathrm{s}(16 \mathrm{ft} / \mathrm{s})$

Maximum transmembrane pressure (TMP) of $80 \mathrm{psid}$

Maximum recirculation flow to be achievable at the maximum TMP

Instrumentation to monitor the recirculation flow rate, the filtrate flow rate, the

TMP, and the slurry temperature

All materials to be compatible with $1 \mathrm{M}$ nitric acid solution

All specifications were met or exceeded. A short history of task activities is as follows:

Arrival of the filter from Mott - February 19, 1999.

Shakedown activities began - March 1, 1999

Envelope A simulant test was done - May 12 to July 26, 1999

Entrained solids recipe for the envelope C simulant was approved - July 26, 1999.

Precipitant recipe was approved and issued - August 17, 1999

Simulant supernate was made on Sept. 3, 1999

Permission was received from BNFL to begin testing - Sept. 28, 1999.

Simulant with entrained solids and precipitants was made - Oct. 5, 1999.

Test was completed -Dec. 16, 1999. 


\section{EXPERIMENTAL}

\section{Equipment}

In general, the equipment assembled for this task was done to conform to the Test Specification $(2,3,4)$. To facilitate understanding of the experimental equipment an explanation of the salient features follows.

Test Rig

Figure 1 is a schematic of the entire Test Rig (TR) and Fig. 2 is a photograph of the same. It stood approximately 25 -feet tall and was serviced by a two-level mezzanine. The TR was much taller than the 3 -foot tall filter element because it originally was used to test a 10 -foot tall filter in 1994 (15). Several modifications were made in order to install the meter-long cross-flow filter. The entire TR was made of 300 series stainless steel with the majority being of 304 stainless steel.

The TR is made up of three basic flow loops:

1. Slurry loop, which contains the filter and its housing and serves as the primary flow path for circulating slurries. This loop has an internal volume of approximately 20 liters, excluding the reservoir tank. It was made of primarily* 1.5 -inch sch40 pipe, which has an inside diameter of 1.610 inches.

[*Some sch 10 pipe was used, which has an inside diameter of 1.682 inches.]

2. Filtrate loop, which begins at the filter housing and allows the separated filtrate liquid to flow up through the backpulse piston before returning to the top of the slurry loop to close the circuit. This loop has an internal volume of approximately 6 liters. It was made of primarily* 0.5 -inch tubing with an inside diameter of 0.43 inch. [*The pipe from the filter housing to the backpulse piston was 1.0 sch 40 pipe, which has an inside diameter of 1.049 inch.]

3. Cleaning loop, which enables the cleaning of the filter in place without having to remove the slurry from the test rig by correctly orienting two 3-way valves (V7 and V12). This loop has an internal volume of approximately 15 liters. It was made of 1.5 -inch sch40 pipe, which has an inside diameter of 1.610 inches.

Two other flow circuits that are subsections of the other loops are the backpulse and the recirculations loops:

1. The backpulse loop is part of the filtrate loop and stands ready to reverse the flow of filtrate. A pulse forces filtrate back through the seven filter elements in order to knock off built-up slurry cake on the inside diameter of the porous tubes. [The backpulse piston assembly controls the amount of filtrate used for a backpulse. The maximum piston travel was 2 inches, but it was initially set at $3 / 4$ inch to inject 0.041 gallon back through the filter (the piston housing inside diameter is 4.026 inches) to attain a $0.018 \mathrm{gal} / \mathrm{ft}^{2}$ (the filter inside surface area was $2.29 \mathrm{ft}^{2}$ ), as was found in a previous filtration test (15). However, during the test with Envelope A simulant (22), starting with test run 2.09 on $5 / 20 / 99$, the injection volume was doubled to 0.036 $\mathrm{gal} / \mathrm{ft}^{2}$ because it showed a considerable improvement in the filtrate flux recovery. 
Pilot scale X-flow: EnvC+ES+Sr/TRU Page 12 of 256

BNF-003-98-0226

Revision 0
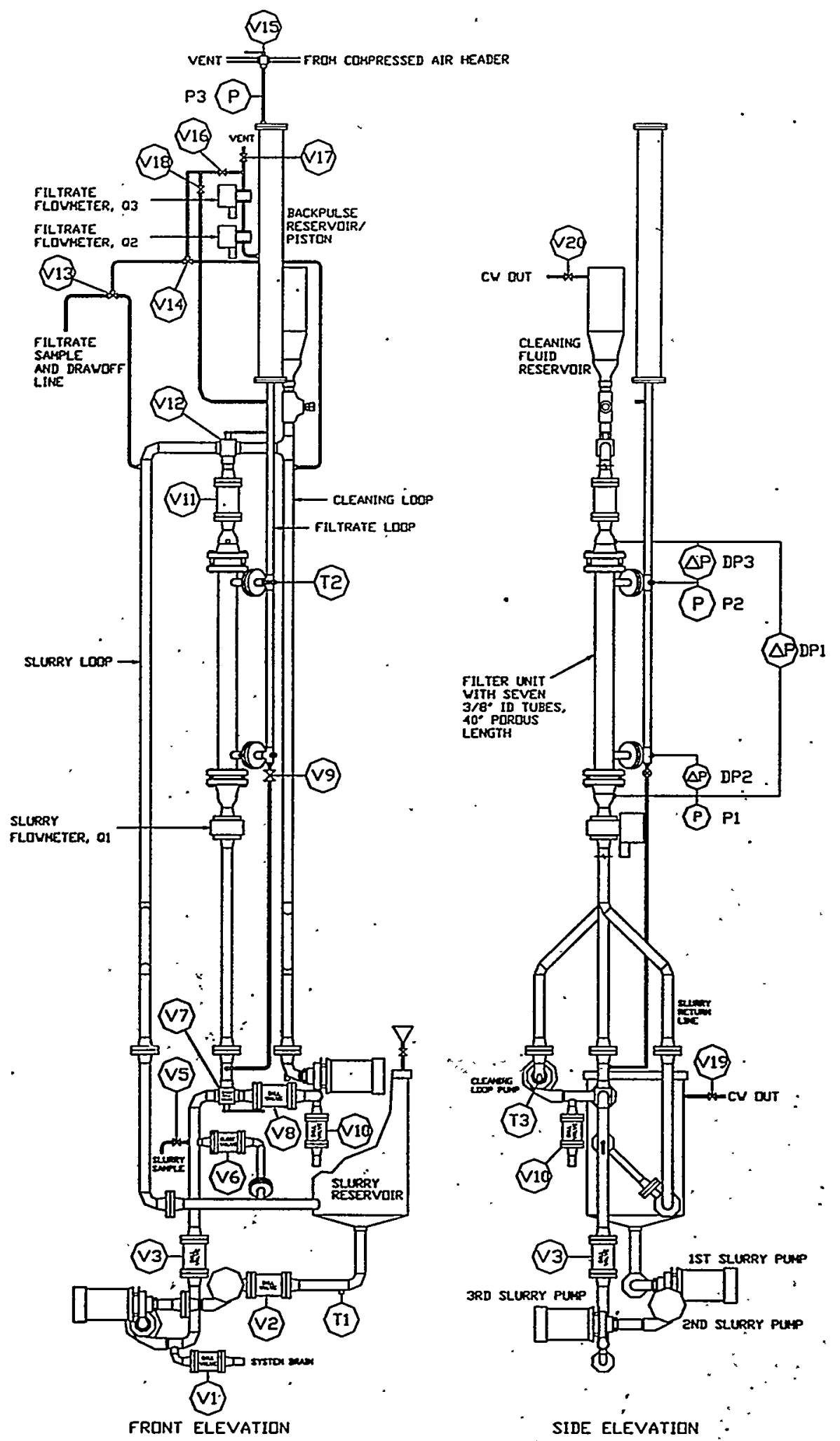

Figure 1. Schematic of the Pilot-scale Cross Flow Ultrafiltration Test Facility 


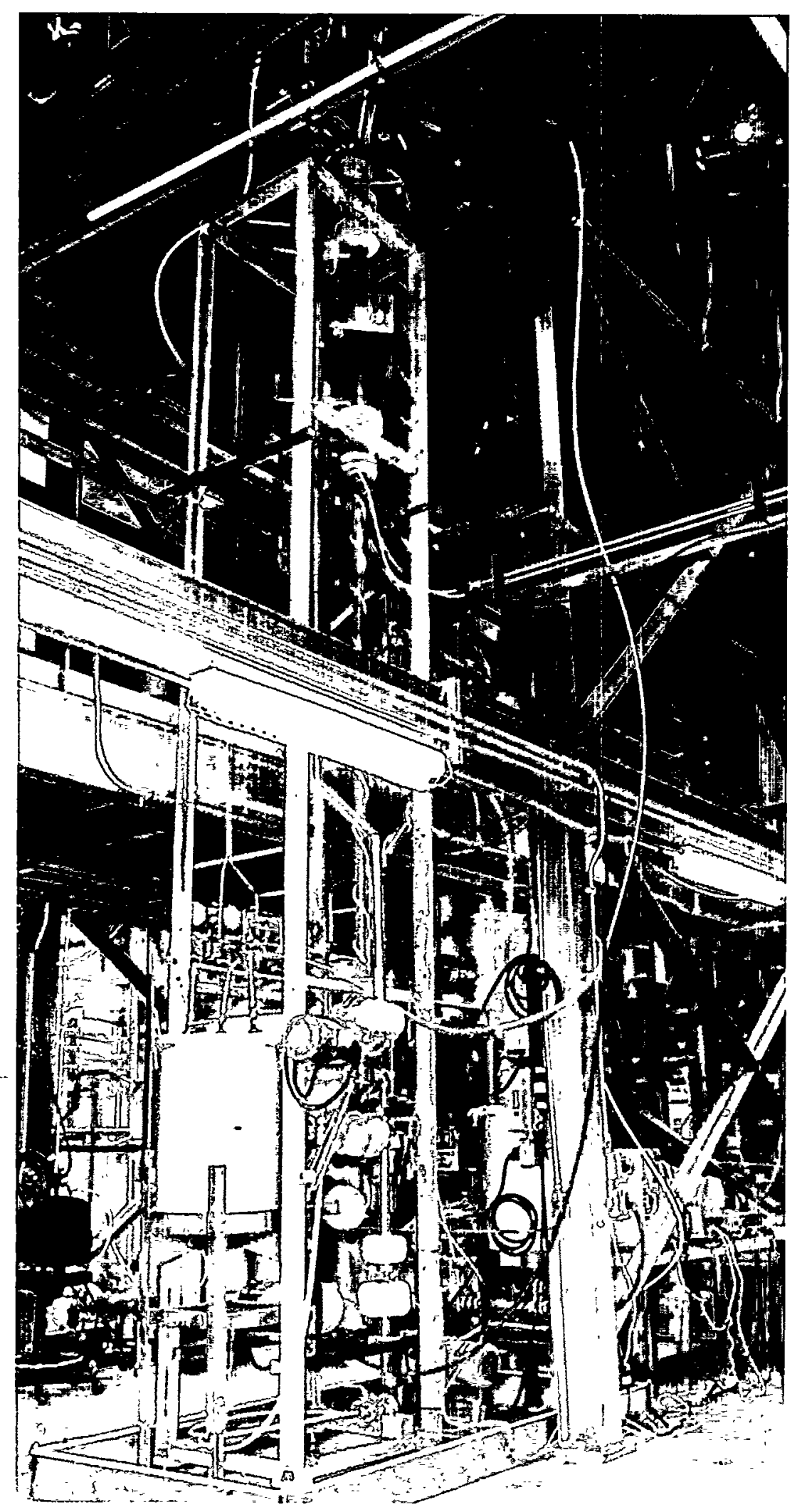

Figure 2. Pilot-scale Cross Flow Ultrafiltration Test Facility 
Even with this volume a backpulse frequency of 30 minutes would cause an insignificant reduction in mean filtrate flux of $0.0012 \mathrm{gpm} / \mathrm{ft}^{2}$.]

2. The recirculation loop is part of the slurry loop (by using valve V6) and is used to better control the slurry flow. The recirculation loop helps to increase mixing and to maintain the slurry well mixed when flow through the filter needs to be stopped.

The TR is controlled through a series of valves, which are described below:

V1: Drains slurry from the test rig

V2: Isolates the slurry reservoir from the pumps

V3: Controls the slurry flow upstream of the filter and isolates the slurry loop from the pump

V4: Allows liquid to be introduced to the slurry reservoir

V5: Allows slurry to be samples (not used for this test)

V6: Recirculates slurry to the reservoir

V7: Directs either slurry (cleaning fluid) to the filter; 3-way valve

V8: Used for the same functions as V3 but for the cleaning loop

V9: Drains the filtrate loop

V10: Drains the cleaning loop

V11: Controls the slurry (cleaning fluid) flow downstream of the filter

V12: Directs either slurry (cleaning fluid) from the filter, 3-way valve

V13: Directs filtrate to the sample port or back to the slurry loop; 3-way valve

V14: Directs filtrate to the to the slurry loop or to the cleaning loop; 3-way valve

V15: Allows air to pressurize the backpulse piston

V16: Shuts filtrate flow from the backpulse piston

V13: Directs either filtrate to the sample port or back to the slurry loop; 3-way valve

V17: Vents the test rig

V18: Allows filtrate to bypass the backpulse piston

V19: Allows coolant flow to the cooling coil in the slurry reservoir

V20: Allows coolant flow through the cooling coil in the cleaning fluid reservoir

To circulate slurries and liquids the test rig and mixing tank were serviced with five TEEL stainless steel centrifugal pumps:

Materials

Location'. 'Model hp Housing Shaft Impeller-Sleeve

1.Slurry Loop 2P392 3 304SS 304SS

2.Slurry Loop 2P392 3 304SS 304SS

3.Slurry Loop. 2P392 3 304SS

4.CleaningLoop 2P392 3 304SS

304SS

303SS

303SS

303SS

304SS 303SS

5.Mixing Tank 1P701B 3/4 304SS

304SS

416SS

Seals

Graphite/Ceramic/Viton

Graphite/Ceramic/Viton

Graphite/Ceramic/Viton

Graphite/Ceramic/Viton

Graphite/Ceramic/Viton

Three $3 \mathrm{hp}$ pumps were used in series on the slurry loop to attain a head of 80 psig at 40 gpm $(-5 \mathrm{~m} / \mathrm{s}$ in each filter tube), since one pump is able to produce about $28 \mathrm{psi}$ at 40 gpm with water. 


\section{Cross Flow Filter}

The heart of this entire experimental task was the cross-flow filter element that was to be tested to define its operational characteristics under required flow conditions when using the Sr/TRU precipitation simulant. There were several candidates that could have been used for this test but due to availability and past experience in robust designs, a Mott filter was chosen. The specifications for the filter unit were:

$\begin{array}{ll}\text { Material: } & 316 \text { stainless steel (sintered metal) } \\ \text { Porosity: } & \text { nominal rated } 0.1 \text { micron } \\ \text { Length: } & 40 \text { inches } \\ \text { Diameter: } & 3 / 8 \text {-inch I.D., 1/2-inch O.D. } \\ \text { Number: } & 7 \text { tubes }\end{array}$

The unit which was received from Mott met the requirements, see Figs. 3, 4, 5, and 6. The 40-inch length was made from two 20-inch lengths that were welded together at the center. [When subtracting the weldments at the end and middle of the tubes, the actual active porous length was $393 / 4$ inches (1.01 meter)]. The 7 tubes were welded together with the tube sheets and extra support was made with a central stabilizing plate and supporting solid metal 1/4-inch rods which ran the length of the tube bundle, Fig. 3c. From the figures it is possible to see that some of the porous surfaces were slightly marred. Because of the large surface area this marring was not expected to affect results and no effects were notice during testing. Besides, the stainless steel sintered surface has a fairly robust construction. Figure 4 shows an enlargement of two different pore-size filter elements, 0.5 and 100 microns. (Mott did not have a picture of a nominal rated 0.1 micron filter but stated that the appearance is identical to the larger sizes.) The tube housing, Figs. 5 and 6, was made from a 3 -inch schedule 10 pipe with two pipes connected at either end to remove filtrate. For this test the filter unit was oriented vertically in the test rig, see Figs. 1, 2, and 6. The tube bundle sat in the housing such that the large tube sheet (right side of Fig. 3a) was secured to the top flange of the housing; this tube sheet also supported the weight of the assembly. The smaller, lower, tube sheet (foreground in Fig. 3b) was able to pass through the housing and separated the slurry side of the flow channel from the filtrate side with an " $O$ " ring between the outer perimeter of the lower tube sheet and the inside diameter of the filter housing.

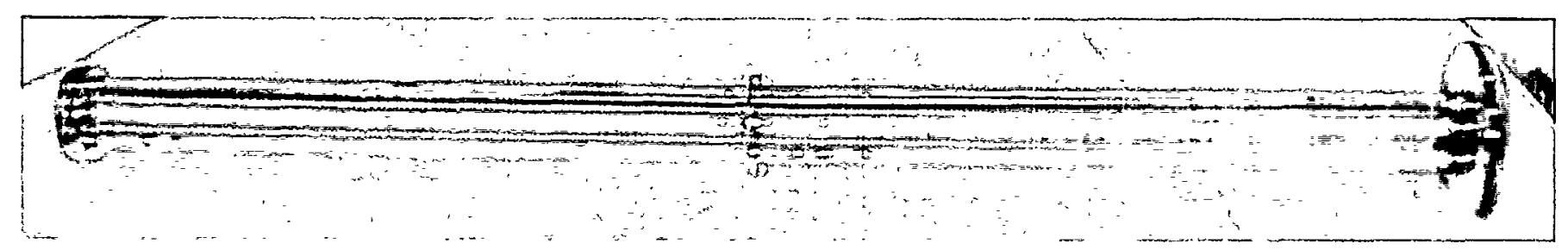

Figure 3a. 7-tube bundle of a nominal rated 0.1 micron filter, 3/8" i.d., 1/2" o.d., 40 " long 


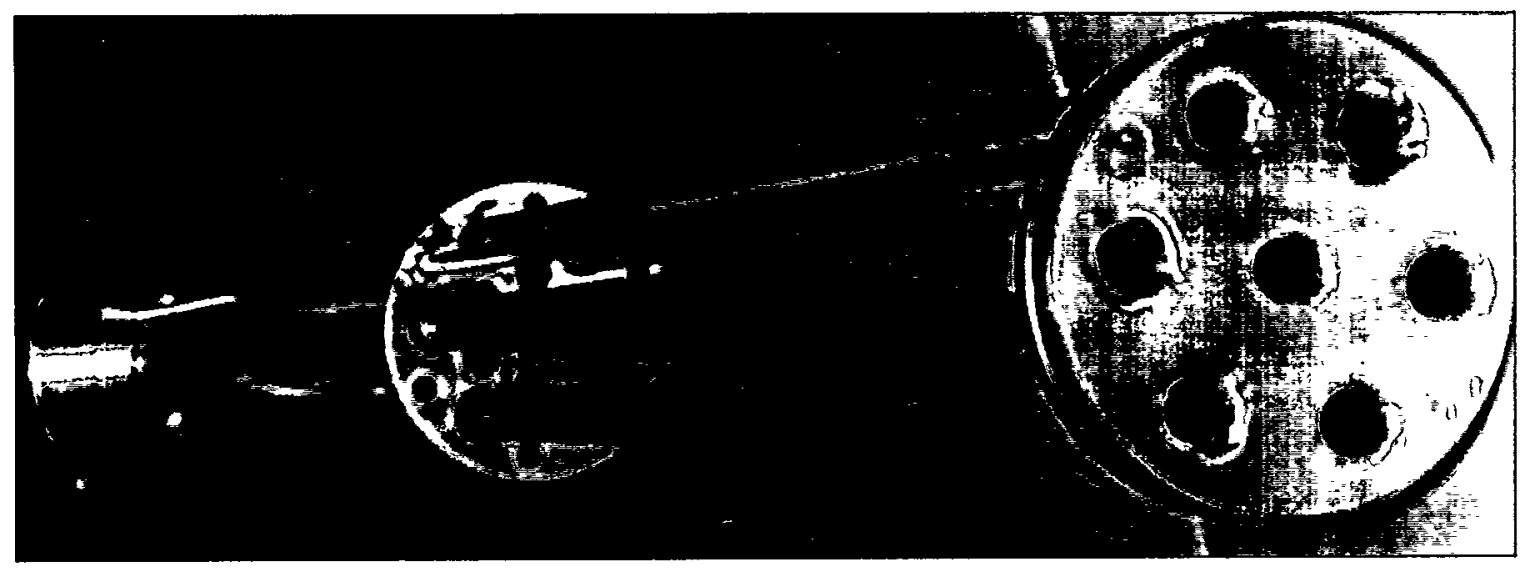

Figure $3 b$. Upstream view of the seven-tube bundle

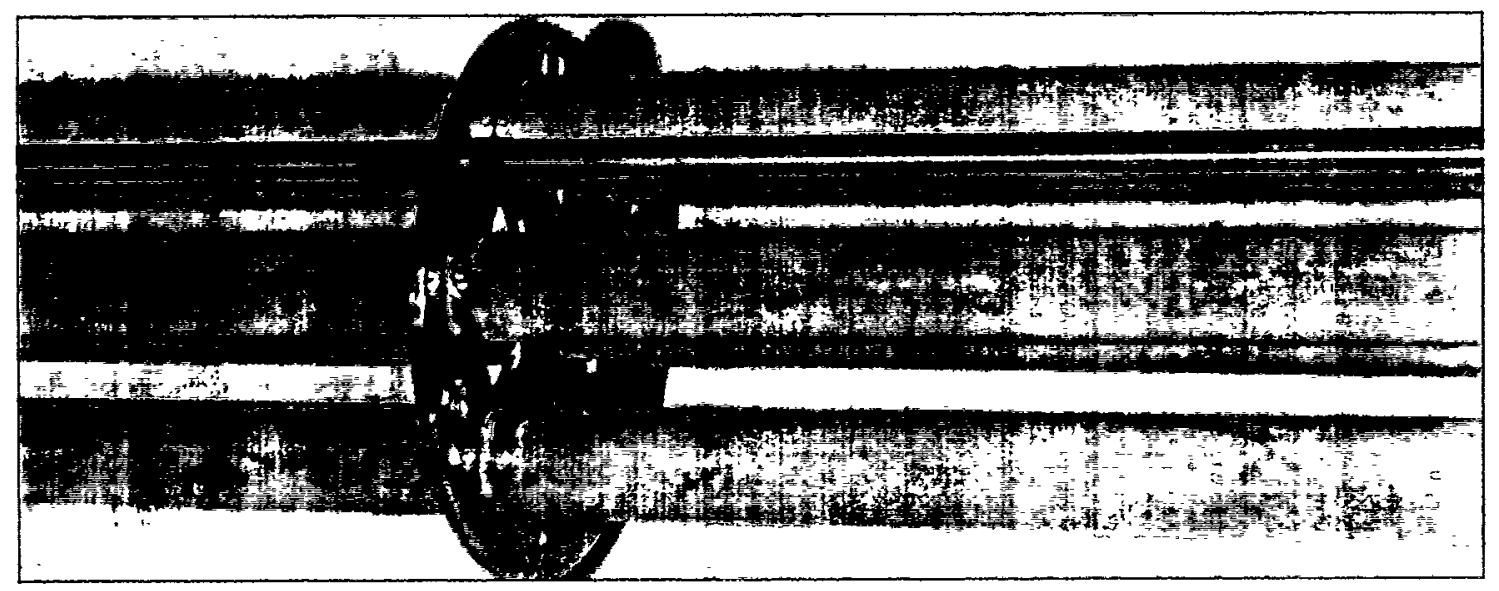

Figure 3c. Support plate at the mid-section of the seven-tube bundle
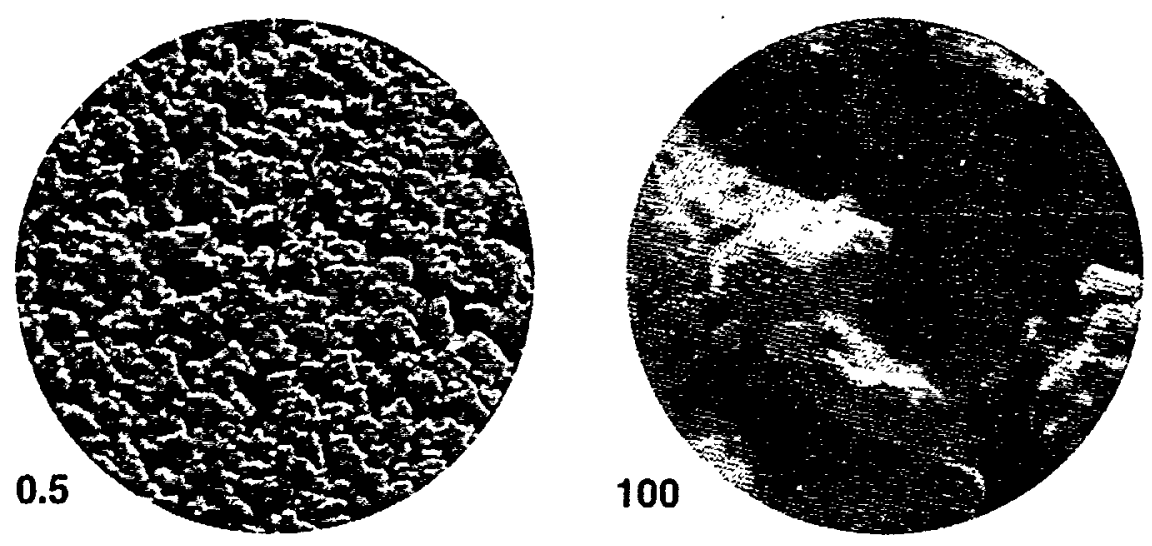

Figure 4. Magnified views (approximately $150 \mathrm{X}$ ) of surfaces of two different pore-size rated Mott filters (the number to the left of each figure is the pore-size rating in microns) 


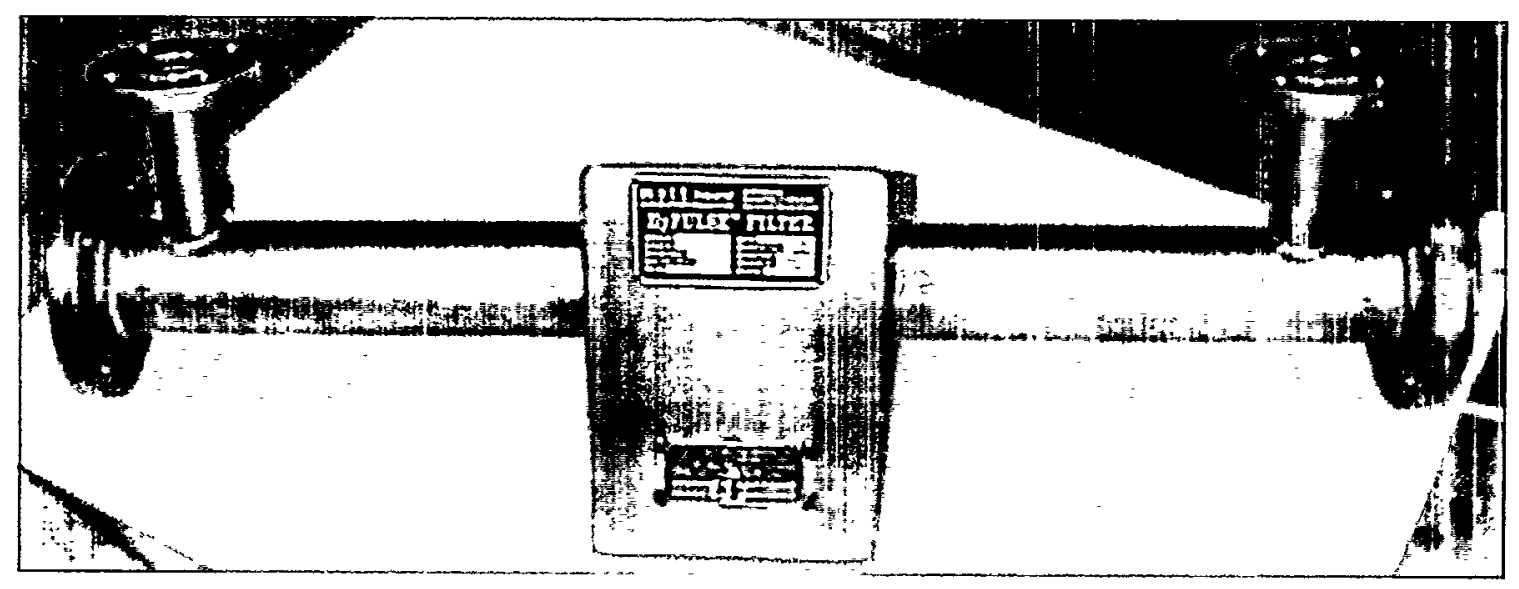

Figure 5. Cross-flow Filter Housing

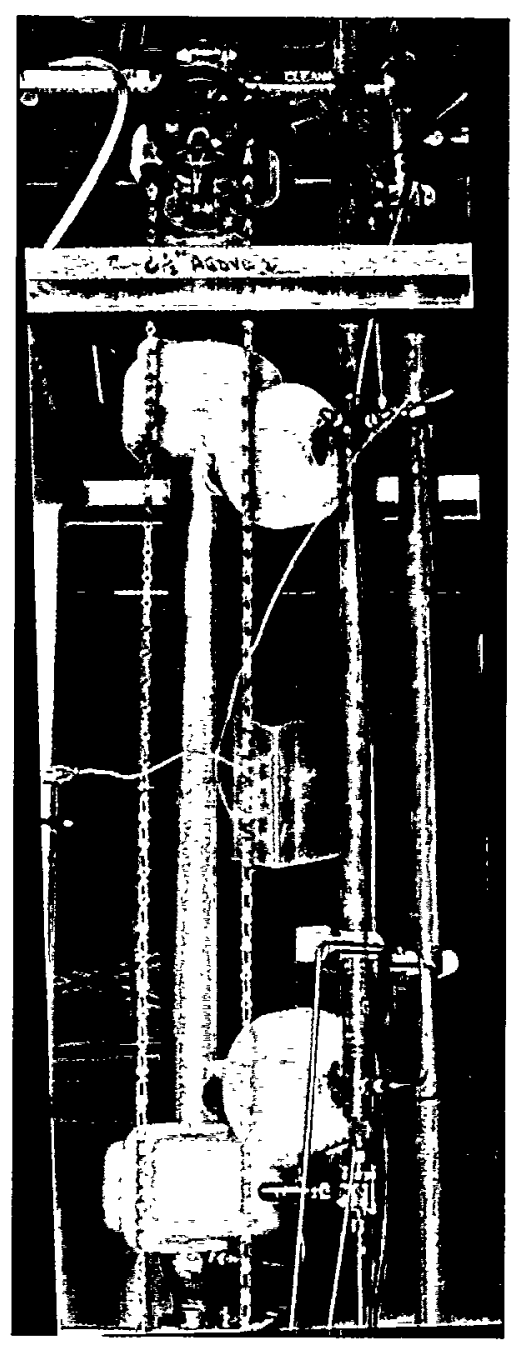

Figure 6. Cross-flow Filter in Test Rig 


\section{Mixing Tanks}

There were two* main tanks used for mixing and preparing the slurry solutions:

1. The slurry reservoir was a 110 -liter plastic tank that primarily served as the Test Rig reservoir. It was also used (along with the recirculation loop) as a mixing tank when solids had to be added to the slurry and was the location from where slurry samples were taken. Mixing was accomplished with the recirculation loop by using valve V6. [The slurry reservoir is shown in Fig. 1 and is the large white tank in the foreground of Fig. 2.]

2. The mixing tank (MT) was a separate 110 -liter plastic tank. It served to make the 75liter batch of simulant supernate before the solids were added to complete the slurry. Since it was hard-piped to the slurry reservoir it was also used to make the cleaning fluid ( $1 \mathrm{M}$ nitric acid) as well as the cleaning solution used to clean the entire test rig during shakedown activities (1\% Alconox solution - phosphate). Mixing was accomplished with the recirculation loop by using valve V23. [Figure 7 is a schematic of this tank and can be found in Fig. 2 as the lower white tank behind the vertical I-beam at the lower right side of the photograph.]

[*a separate 340-liter tank, with its own agitator and heater, was used when the 618-liter batch of simulant had to be made.]

The MT is controlled through a series of valves, which are described below:

V21: Contols the flow to the pump

V22: Drains the MT

V23: Recirculates the contents of the MT

V24: Allows the mixed contents to enter the slurry reservoir

V25: Allows liquid to be introduced into the MT

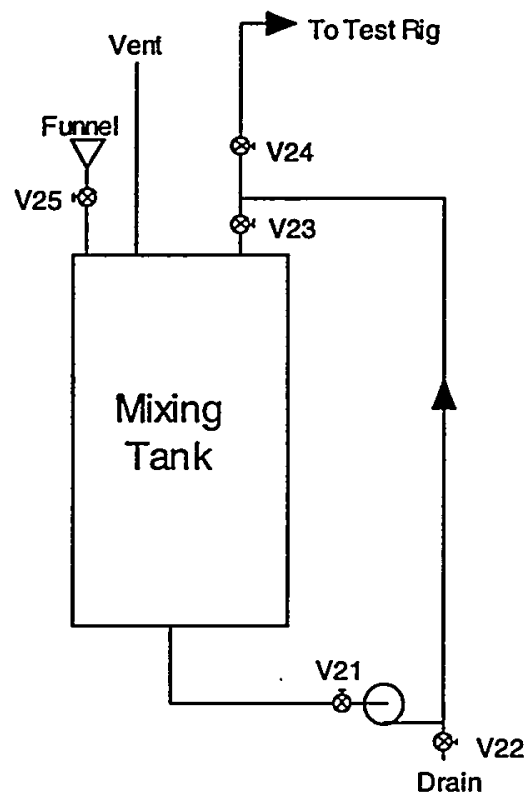

Figure 7. Main Mixing Tank for the Experiment 
Pilot scale X-flow: EnvC+ES+Sr/TRU Page 19 of 256

BNF-003-98-0226

Revision 0

\section{Instrumentation}

The measurement equipment used for this experiment was:

5 Type $\mathrm{E}$ thermocouples with accuracies* from 1.2 to $1.3^{\circ} \mathrm{C}$, 6 Variable capacitance pressure transducers with accuracies* from 0.05 to $0.40 \mathrm{psi}$, and 3 Magnetic flow meters with accuracies* from 0.012 to $0.26 \mathrm{gpm}$.

[*accuracies are a function of the instrument and calibration. The uncertainty introduced through the use of the 16-bit data acquisition system was insignificant $(<0.1 \%$ reading) and was not included in the values above.]

Figure F1, Appendix F, shows two tables which list all those instruments and data acquisition system (DAS) channels for each of the non-thermocouple instruments. The thermocouples had their own dedicated computer card to interface and convert the temperatures properly. The calibration of the DAS was checked and that information can also be found in Fig. F1, which includes tables and graphs that show the results and the transfer functions used for each channel.

Two instrument changes were made during this task:

1. On 3/24/99 the pressure transducer used for dP2 (No. TR-00532) was recalibrated to reduce the calibrated pressure range so that the measurement uncertainty was reduced to 0.13 psid from 0.42 psid. Even though the Envelope C test did not begin until September of 1999 , the pre-3/24/99 calibration was used in obtaining certain shakedown data for water and thus it is included for completeness.

2. Near the end of the Envelope A test (22), and before the Envelope $C$ test, on 7/14/99, another filtrate flowmeter was added (Q3; No. TR-03562). This new flow meter increased the measurable range for filtrate flow from a maximum of $1.2 \mathrm{gpm}$ to $5 \mathrm{gpm}$, or the flux from $0.52 \mathrm{gpm} / \mathrm{ft}^{2}$ to $2.18 \mathrm{gpm} / \mathrm{ft}^{2}$, respectively. This new range is above the expected flux range for the simulant slurry, however, it is useful to measure the higher fluxes with just water and for the slurry fluxes immediately after a backpulse.

From Figs. 1, F1, and F2 the location and the usage of each instrument can be determined, however the following list will better describe the placement and usage of all the measurement instruments:

T1 - A thermocouple located in the exit pipe of the slurry reservoir to measure the slurry temperature on its way to the filter.

T2 - A thermocouple located in the filtrate line at the end of the upper filter housing filtrate exit pipe to measure the filtrate temperature as it leaves the filter housing. T3 - A thermocouple located in the cleaning loop at the exit of the cleaning loop pump. $\mathrm{T} 4$ - A thermocouple located at the top of the test rig near valve V13 to measure ambient temperature.

T5 - A thermocouple located at the bottom of the test rig near valve V5 to measure ambient temperature. 
For the 6 pressure transducers also refer to Fig. F2 which indicate pressure-line locations as well as their heights.

P1 - A gauge pressure transducer located at the beginning of the filter housing to measure the pressure of the slurry just before entering the filter tubes.

P2 - A gauge pressure transducer located in the filtrate line at the end of the upper filter housing filtrate exit pipe to measure the pressure of the filtrate as it leaves the filter housing.

P3 - A gauge pressure transducer located at the air side of the backpulse piston to measure the pressure applied to produce a backpulse.

dP1 - A differential pressure transducer located across the slurry side of the filter to measure the drop in pressure along the filter tubes.

dP2 - A differential pressure transducer located across filter and housing at the filter entrance to measure the transmembrane pressure at the beginning of the filter.

dP3 - A differential pressure transducer located across filter and housing at the filter exit to measure the transmembrane pressure at the end of the filter.

[The transmembrane pressure is determined from the average of dP2 and dP3.]

Q1 - A magnetic flowmeter located at the entrance of the filter to measure the slurry flowrate.

Q2 - A magnetic flowmeter located at the filtrate line between the exit of the backpulse piston and valve V16 to measure the filtrate flowrate (0 to $1.2 \mathrm{gpm}$ ).

Q3 - A magnetic flowmeter located at the filtrate line between the exit of the backpulse piston and valve V16 to measure the filtrate flowrate ( 0 to $5 \mathrm{gpm}$ ).

\section{Measurement Uncertainty}

Appendix $\mathrm{F}$ has all the pertinent information on the uncertainties. The measurement uncertainties (95\% confidence level) for the important calculated quantities are:

$\begin{array}{llll}\text { Slurry Velocity in a Filter Tube } & = & \mathrm{V} & \pm 8.09 \% \\ \text { Transmembrane Pressure } & = & \mathrm{TMP} & \pm 1.10 \% \\ \text { Temperature Corrected Filtrate Flux } & = & \text { Fc } & \pm 11.69 \% \\ \text { Permeability } & = & \mathrm{P} & \pm 11.74 \%\end{array}$

These number are based on a pre- and post-test calibration of the instruments.

\section{Simulated Waste Slurry}

Beside the cross-flow filter, the most important aspect of this experiment was the slurry used to simulate a Hanford Site waste. The waste that was simulated is referred to as Envelope C + ES. Envelope C are radioactive wastes that include that of tank 241-AN107 from the Handford Site, which is made up of organic and other complexants. The ES refers to the Entrained Solids contained in that tank. The simulant used for this task was cold (non-radioactive), but chemically it was made as close as was known to actual waste. The actual simulant development is beyond the scope of this task and not elaborated here. However, the following information was used to make the simulant. 


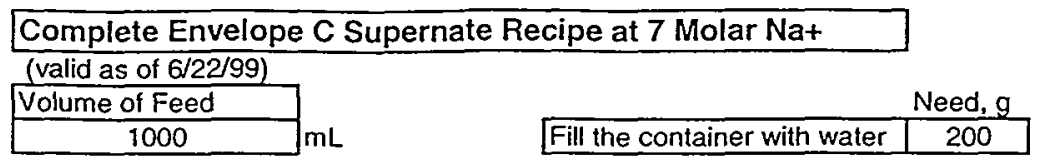

Transition Metals and Complexing agents

\begin{tabular}{|c|c|c|c|}
\hline Compounds & Formula & Conc., PPM & $M$ \\
\hline Calcium Nitrate & $\mathrm{Ca}(\mathrm{NO} 3) 2.4 \mathrm{H} 2 \mathrm{O}$ & 2083 & $1.18 \mathrm{E}-02$ \\
\hline Cerium Nitrate & $\mathrm{Ce}(\mathrm{NO} 3) 3.6 \mathrm{H} 2 \mathrm{O}$ & 98 & $3.01 \mathrm{E}-04$ \\
\hline Cesium Nitrate & CsNO3 & 14 & $9.58 E-05$ \\
\hline Copper Nitrate & $\mathrm{Cu}(\mathrm{NO}) 2.2 .5 \mathrm{H} 2 \mathrm{O}$ & 66 & $3.78 \mathrm{E}-04$ \\
\hline Ferric Nitrate & $\mathrm{Fe}(\mathrm{NO} 3) 3.9 \mathrm{H} 2 \mathrm{O}$ & 7315 & $2.42 E-02$ \\
\hline Lanthanum Nitrate & $\mathrm{La}(\mathrm{NO} 3) 3.6 \mathrm{H} 2 \mathrm{O}$ & 85 & $2.61 E-04$ \\
\hline Magnesium Nitrate & $\mathrm{Mg}(\mathrm{NO} 3) 2.6 \mathrm{H} 2 \mathrm{O}$ & 158 & $8.21 E-04$ \\
\hline Manganous Chloride & $\mathrm{MnCl} 2.4 \mathrm{H} 2 \mathrm{O}$ & 1213 & $8.18 E-03$ \\
\hline Neodymium Nitrate & $\mathrm{Nd}(\mathrm{NO} 3) 3.6 \mathrm{H} 2 \mathrm{O}$ & 174 & 5.31E-04 \\
\hline Nickel Nitrate & $\mathrm{Ni}(\mathrm{NO} 3) 2.6 \mathrm{H} 2 \mathrm{O}$ & 1571 & $7.21 E-03$ \\
\hline Potassium Nitrate & KNO3 & 2755 & $3.64 \mathrm{E}-02$ \\
\hline Strontium Nitrate & $\mathrm{Sr}(\mathrm{NO} 3) 2$ & 8 & 5.16E-05 \\
\hline Zinc Nitrate & $\mathrm{Zn}(\mathrm{NO}) 2.6 \mathrm{H} 2 \mathrm{O}$ & 123 & $5.53 E-04$ \\
\hline Zirconyl Nitrate & & 114 & $6.13 E-04$ \\
\hline EDTA* & Na2EDTA & 4343 & $1.56 \mathrm{E}-02$ \\
\hline HEDTA* & HEDTA & 1294 & $6.21 \mathrm{E}-03$ \\
\hline Sodium Gluconate & & 2349 & $1.44 \mathrm{E}-02$ \\
\hline Glycolic Acid & & 16112 & $1.98 \mathrm{E}-01$ \\
\hline Citric Acid & & 5648 & $3.59 E-02$ \\
\hline Nitrilotriacetic Acid & & 341 & $2.38 \mathrm{E}-03$ \\
\hline Iminodiacetic Acid & & 3613 & 3.62E-02 \\
\hline Boric acid & $\overline{\mathrm{H} 3 \mathrm{BO} 3}$ & 120 & $2.58 \mathrm{E}-03$ \\
\hline Sodium Chloride & $\mathrm{NaCl}$ & 1088 & $2.48 E-02$ \\
\hline Sodium Fluoride & $\mathrm{NaF}$ & 176 & 5.59E-03 \\
\hline Sodium Sulfate & $\mathrm{Na2SO4}$ & 7299 & $6.86 \mathrm{E}-02$ \\
\hline Potassium Molybdate & $\mathrm{K} 2 \mathrm{MoO} 4$ & 53 & $2.98 \mathrm{E}-04$ \\
\hline
\end{tabular}

Need Mass, g \begin{tabular}{l}
\hline 2.779 \\
\hline 0.131 \\
\hline 0.019
\end{tabular} 0.019 0.088 9.758 0.113 0.211 1.619 0.233 2.096 3.675 0.011 0.165 \begin{tabular}{l}
0.153 \\
\hline 5.794 \\
\hline 1.727
\end{tabular} 1.727 3.134 21.494 7.535 0.455 4.820 0.160 1.452 0.235 9.737 0.071 Need, $\mathrm{g}$ \begin{tabular}{ll|r|r|}
\hline In separate container mix the following: & Fill the container with water & 200 \\
\hline
\end{tabular}

\begin{tabular}{|l|l|c|c|}
\hline Add & Formula & Conc., PPM & M \\
\hline Sodium Hydroxide & $\mathrm{NaOH}$ & 15047 & $5.02 \mathrm{E}-01$ \\
\hline Aluminum Nitrate & $\mathrm{Al}(\mathrm{NO} 3) 3.9 \mathrm{H} 2 \mathrm{O}$ & 3211 & $1.14 \mathrm{E}-02$ \\
\hline Sodium Phosphate & $\mathrm{Na3PO} 4.12 \mathrm{H} 2 \mathrm{O}$ & 2658 & $9.33 \mathrm{E}-03$ \\
\hline Sodium Formate & $\mathrm{NaHCOO}$ & 9401 & $1.84 \mathrm{E}-01$ \\
\hline Sodium Acetate & $\mathrm{NaCH} 3 \mathrm{COO} .3 \mathrm{H} 2 \mathrm{O}$ & 1418 & $1.39 \mathrm{E}-02$ \\
\hline Sodium Oxalate & $\mathrm{Na2C2O4}$ & 752 & $7.49 \mathrm{E}-03$ \\
\hline
\end{tabular}

-(EDTA=Ethylenediaminetetraacetic Acid Disodium Salt Dihydrate)

-(HETDA=N-(2-Hydroxyethyl)ethylenediaminetriacetic Acid))

Mix thoroughly. Then add this solution to the container. Then

\begin{tabular}{|l|l|c|c|c|}
\hline Add & Formula & Conc., PPM & $\mathrm{M}$ \\
\hline Sodium Carbonate & $\mathrm{Na2CO} 3$ & 88703 & $1.12 \mathrm{E}+\infty$ \\
\hline
\end{tabular}

Mix thoroughly. Then

\begin{tabular}{|l|l|c|c|}
\hline Add & Formula & Conc. PPM & $M$ \\
\hline Sodium Nitrate & NaNO3 & 178069 & $2.79 \mathrm{E}+00$ \\
\hline Sodium Nitrite & NaNO2 & 54741 & $1.06 \mathrm{E}+00$ \\
\hline
\end{tabular}

Mix thoroughly and dilute to the mark.

The final addition of water would be $=385.02$ grams (grams based upon a density of $1.334 \mathrm{~g} / \mathrm{mL}$ )

\begin{tabular}{|l|l|l|}
\hline Final Weight, grams & 1334.00 \\
\hline
\end{tabular}

Figure 8. Envelope C Simulant: Supernate Only 
A recipe for the simulant suipernate, Fig. 8, and one for the simulant solids, Fig. 9, were obtained from the WSRC Waste Processing Technology group. Each recipe is shown on a per-liter basis. The test was to use a batch of approximately 75 liters; therefore, the quantities shown in both recipes were increased accordingly. (A volume of 75 liters was chosen to fill the slurry reservoir to the half-way mark, since the test rig proper held approximately 25 liters and the reservoir tank held 110 liters. The extra space was needed for foaming if it had occurred.)

\begin{tabular}{|c|c|c|c|}
\hline Envelope C Entained Solids & & & \\
\hline Approximate Supernate Volume & \multicolumn{3}{|c|}{$1000.0 \mathrm{~mL}$} \\
\hline Approximate Supernate Density & \multirow{2}{*}{\multicolumn{3}{|c|}{$\begin{array}{c}1.334 \mathrm{~g} / \mathrm{mL} \\
1334.0 \mathrm{grams}\end{array}$}} \\
\hline Approximate Supernate Mass & & & \\
\hline At 0.5 wt $\%$ solids loading & \multicolumn{3}{|c|}{6.70 grams } \\
\hline Total Mass Supernate + Solids & \multicolumn{3}{|c|}{1340.7 grams } \\
\hline $\begin{array}{l}\text { Compouind } \\
\text { Name }\end{array}$ & $\begin{array}{l}\text { Compound } \\
\text { Formula }\end{array}$ & $\begin{array}{l}\text { Concentration } \\
\text { g/100g solids }\end{array}$ & $\begin{array}{c}\text { Needed } \\
\text { grams }\end{array}$ \\
\hline Alumina $\quad \cdot$ & $\mathrm{Al} 2 \mathrm{O} 3$ & $5.10 \%$ & 0.34 \\
\hline Calcium Phosphate, tribasic & $\mathrm{Ca} 3(\mathrm{PO} 4) 2$ & $0.10 \%$ & 0.01 \\
\hline Chromium Oxide & $\mathrm{Cr} 2 \mathrm{O} 3$ & $0.40 \%$ & 0.03 \\
\hline Ferric Oxide & Fe302: 1-2 micron & $2.40 \%$ & 0.16 \\
\hline Ferric Oxide & Fe3O2: 5-10 micron & $2.40 \%$ & 0.16 \\
\hline Manganese Oxide & MnO2: 1-2 micron & $1.55 \%$ & 0.10 \\
\hline Manganese Oxide & MnO2: 5-10 micon & $1.55 \%$ & 0.10 \\
\hline Sodium Aluminosilicate & $\mathrm{Na} 2 \mathrm{OA} 12 \mathrm{O} 3$ (SiO2). $2.5 \mathrm{H} 2 \mathrm{O}$ & $1.60 \%$ & 0.11 \\
\hline Sodium Oxalate & $\mathrm{Na} 2 \mathrm{C} 2 \mathrm{O} 4$ & $34.20 \%$ & 2.29 \\
\hline Sodium Carbonate Monohydrate & $\mathrm{Na} 2 \mathrm{CO} 3 . \mathrm{H} 2 \mathrm{O}$ & $32.30 \%$ & 2.17 \\
\hline Sodium Fluoride & $\mathrm{NaF}$ & $5.00 \%$ & 0.34 \\
\hline Sodium Sulfate Decahydrate & $\mathrm{Na} 2 \mathrm{SO} 4.10 \mathrm{H} 2 \mathrm{O}$ & $4.10 \%$ & 0.27 \\
\hline \multirow[t]{2}{*}{ Sodium Phosphate Dodecahydrate } & $\mathrm{Na} 3 \mathrm{PO} 4.12 \mathrm{H} 2 \mathrm{O}$ & $9.30 \%$ & 0.62 \\
\hline & Total & $100.00 \%$ & 6.70 \\
\hline
\end{tabular}

Figure 9. Envelope C Simulant: Solids Only $-0.5 \mathrm{wt} \%$

[Combined with the Sr/TRU precipitants the total insoluble solids began at $2 \mathrm{wt} \%$ ]

Along with the recipe for the solids, Fig. 9, the particle size distribution was specified: the particles were to have a bimodal distribution, with the small-size range from 1-2 microns and the large-size range from 5-10 microns, Fig. 10. Therefore, all the solids indicated in Fig. 9 were purchased to that specification. [The last six compounds in Fig. 9 do not indicate size because they were all expected to dissolve to some degree, where the size would have changed anyway. They were purchased at the smallest size commercially available without special grinding requirements. The first three 
compounds had been previously purchased for the Envelope A test (22) and had a size of 0.5 to 5 microns that was deemed acceptable for this test.] Before adding the solids to make the slurry, BNFL requested to evaluate the actual solids distribution. It was important to know if the purchased solids were of the correct size, as well as, what the distribution would be after the simulant was prepared. On 9/27/99, a slurry was made of distilled and filtered water with the appropriate solids, in the proportions shown in Fig. 9; the sample was submitted to determine the solids distribution. A volume distribution, Fig. 10a, and a number distributions, Fig 10b, were obtained by Microtrac on 9/28/99 and sent to the customer by facsimile transmission. On the same day the approval to begin testing was obtained.

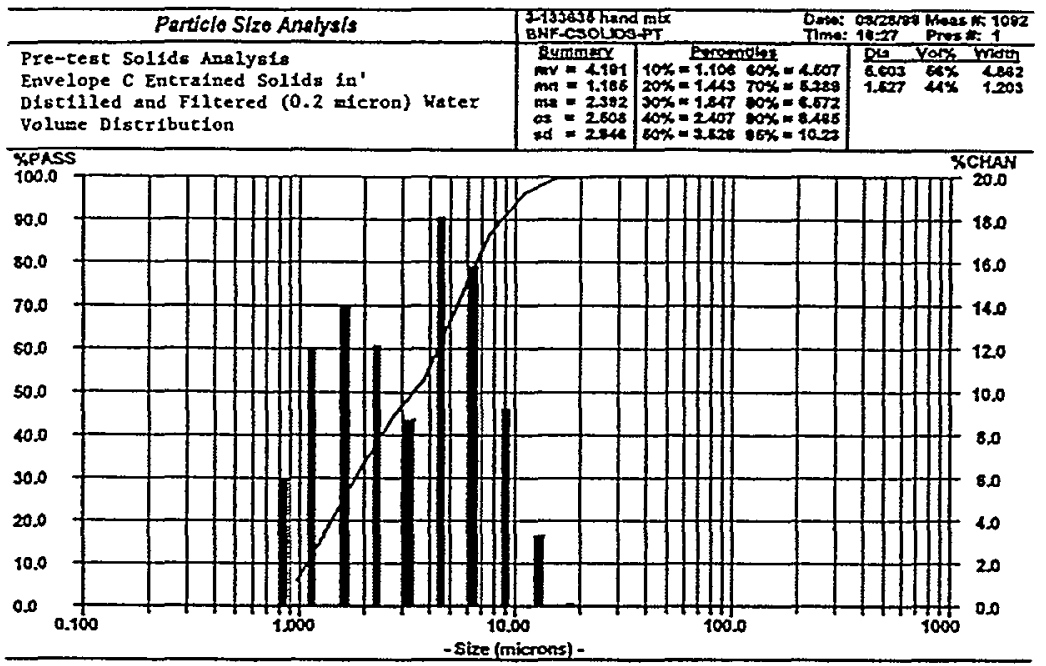

Figure 10a. Pre-test Insoluble Solids Distribution by Volume

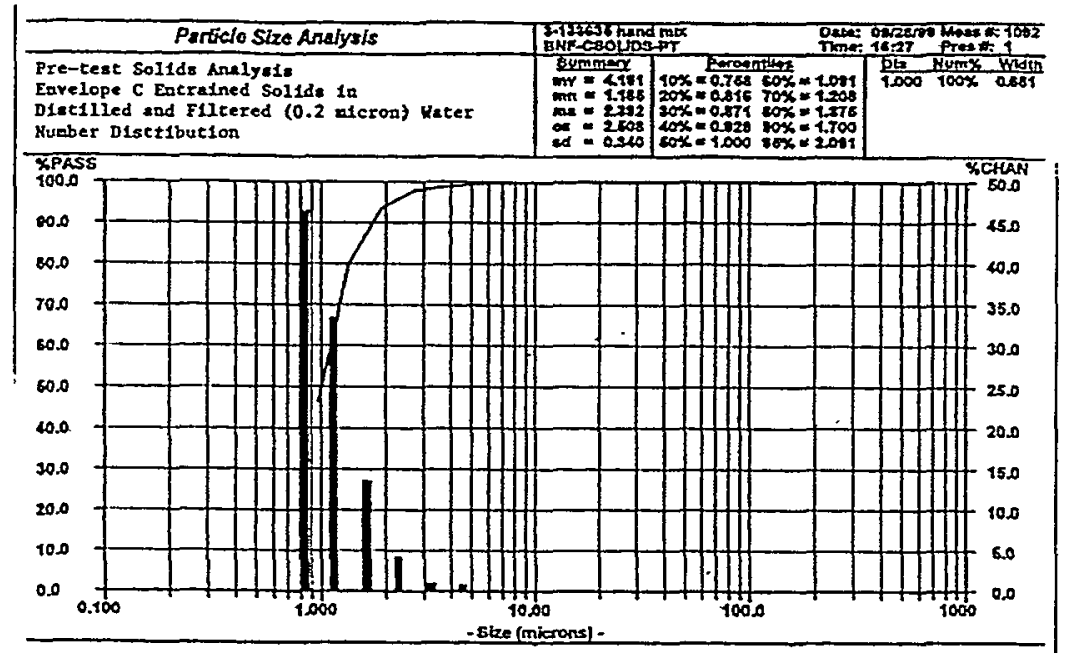

Figure 10b. Pre-test Insoluble Solids Distribution by Volume 
An important feature in preparing the simulant used in this experiment is the creation of precipitants, which will also be part of the treatment of the real waste. With this addition the simulant is referred to as Envelope $\mathrm{C}+\mathrm{ES}+\mathrm{Sr} / \mathrm{TRU}$. The general steps in making the precipitants were as follows:

1. A fixed amount of Envelope $C$ supernate $\left(7 \mathrm{M} \mathrm{Na}^{+}\right)$was made ready, as listed in Fig. 8.

2. The supernate was agitated and its temperature was increased to $50^{\circ} \mathrm{C} \pm 5^{\circ} \mathrm{C}$. These conditions were maintained while all additions were made.

3. The appropriate amount of insolube solids, Fig. 9, was added and the mixture was allowed to mix for 10 to 15 minutes before the next addition.

4. $166.7 \mathrm{ml}$ of deionized and filtered water per liter of the $7 \mathrm{M} \mathrm{Na}^{+}$supernate were added. (This was done to reduce the sodium molarity to $6 \mathrm{M}$ ) The mixture was allowed to mix for 10 to 15 minutes before making the next addition.

5. $55.6 \mathrm{~mL}$ of $19 \mathrm{M} \mathrm{NaOH}$ solution per liter of $6 \mathrm{M} \mathrm{Na}^{+}$supernate were slowly added and then the mixture was allowed to mix for 10 to 15 minutes before making the next addition.

6. $90.5 \mathrm{~mL}$ of $1 \mathrm{M} \mathrm{Sr}\left(\mathrm{NO}_{3}\right)_{2}$ solution per liter of $6 \mathrm{M} \mathrm{Na}^{+}$supernate were slowly added and then the mixture was allowed to mix for 10 to 15 minutes before making the next addition.

7. $60.3 \mathrm{~mL}$ of $1 \mathrm{M} \mathrm{NaMnO}_{4}$ solution per liter of $6 \mathrm{M} \mathrm{Na}^{+}$supernate were slowly added.

8. The agitated mixture was then maintained at $50^{\circ} \mathrm{C} \pm 5^{\circ} \mathrm{C}$ for 4 hours.

9. Finally, the mixture was cooled to $25^{\circ} \mathrm{C}$ for the test to begin.

The above mixing procedure was followed, as per the test specification $(4,11)$. However, there was one deviation made. Because of expected difficulties in handling and fully incorporating the $19 \mathrm{M} \mathrm{NaOH}$ solution into the mixture, the water addition of step 4 was used to make a more dilute mixture of $\mathrm{NaOH}$. That' is, steps 4 and 5 were combined to make $216.2 \mathrm{~mL}$ of $5.3 \mathrm{M} \mathrm{NaOH}$ solution per liter of the $7 \mathrm{M} \mathrm{Na}^{+}$supernate. This solution was then added to the $7 \mathrm{M} \mathrm{Na}^{+}$supernate before doing step 6 . [The developer of the slurry simulant, WPT, believed that this deviation would still result in the targeted Sr/TRU mixture.] The resulting mixture was estimated to have $5.89 \mathrm{M}$, $0.075 \mathrm{M}$, and $0.05 \mathrm{M}$, of sodium, strontium, and manganese, respectively. Subsequent measurements of those quantities confirmed those values. (See the filled square symbols on Figs. E16, E17, and E10 in Appendix E). Note that the color of the mixture changed while making the solution. The supernate started at a deep caramel color, a color similar to a cola drink. The addition of the clear $\mathrm{NaOH}$ solution did not seem to have any effect on the color but the clear strontium nitrate solution caused the mixture to turn a light brown. When the deep purple sodium permanganate solution was added, the mixture turned a dark brown once again, but not as dark as the original supernate color.

Because of the important interactions among the solids particles and the different precipitants, solids could not be simply added to the slurry to increase the solids 
concentrations. Therefore, when the time came to run the test with a higher concentration of insoluble solids and precipitants, i.e., near $20 \mathrm{wt} \%$, a large batch (618 liters) of slurry had to be made. This batch was then reduced to approximately 50 liters by dewatering through the filter, and had a measured insoluble solids content of $22 \mathrm{wt} \%$. The volume was subsequently increased to 75 liters by returning some of the filtrate, reducing the solids content to $14 \mathrm{wt} \%$, because the thick slurry caused pump and temperature problems in the test rig.

In general, the resulting slurry had significant precipitants, and depending on the level of dewatering, the precipitants occupied considerable volume. After the filtration test the heights of settled solids in several samples were measured. Figure 11 shows the approximate volume occupied by the insoluble solids and precipitants.

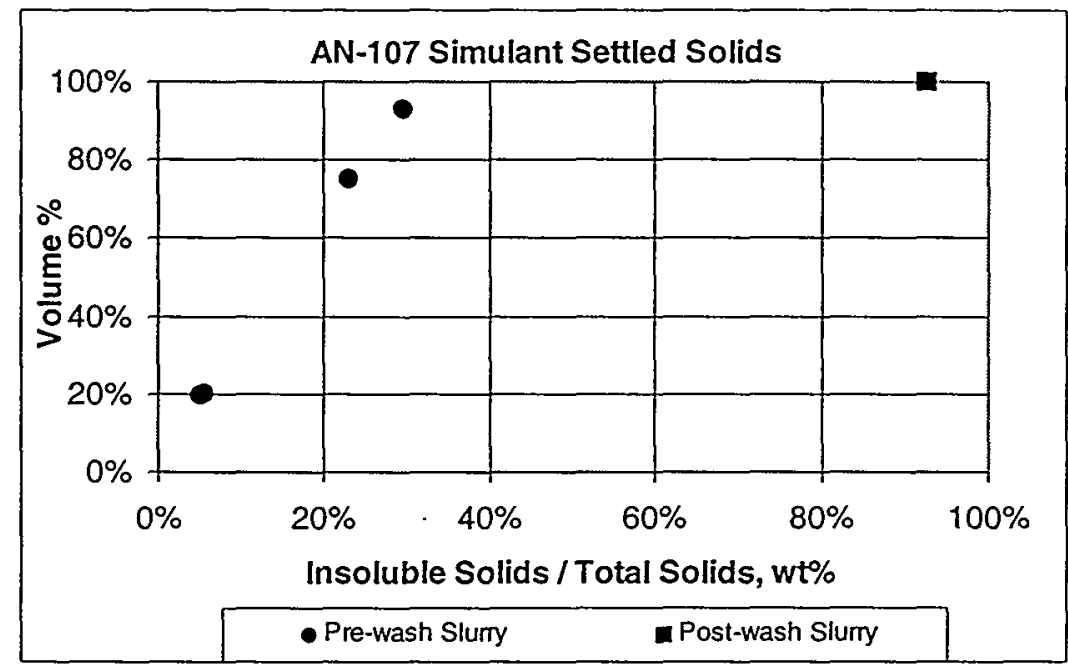

Figure 11. Long-term settling volumes of insoluble solids and precipitants

The ordinate of Fig. 11 is simply the height of the solid/supernate interface in a straightwalled container multiplied by the cross sectional area of that container. The abscissa is the wt\% of insoluble solids divided by the wt\% of the total solids in a sample. It must be noted that the measurement was made on samples that were sitting around for a couple of months. A similar test (23), with fresh simulant, indicated that the settling volume is larger, but reduces to the volumes indicated in Fig. 11 within several days of fabrication.

Figure 12 shows several samples of the slurry in Nalgene containers that were drawn during the test. (Note: the solids concentrations indicated in the figure were estimated when the picture was taken. Subsequently, the actual amounts were measured; they were: 1.9 wt $\% \rightarrow 1.8 \mathrm{wt} \%, 9 \mathrm{wt} \% \rightarrow 8.75 \mathrm{wt} \%$, the $15 \mathrm{wt} \% \rightarrow 14.3 \mathrm{wt} \%$, the $20 \mathrm{wt} \% \rightarrow$ $22.1 \mathrm{wt} \%$ ) With the centimeter scale in the center of the figure, the numbers in Fig. 11 can be roughly verified, once the total solids loading is known. Those, and other pertinent numbers, are shown below. 


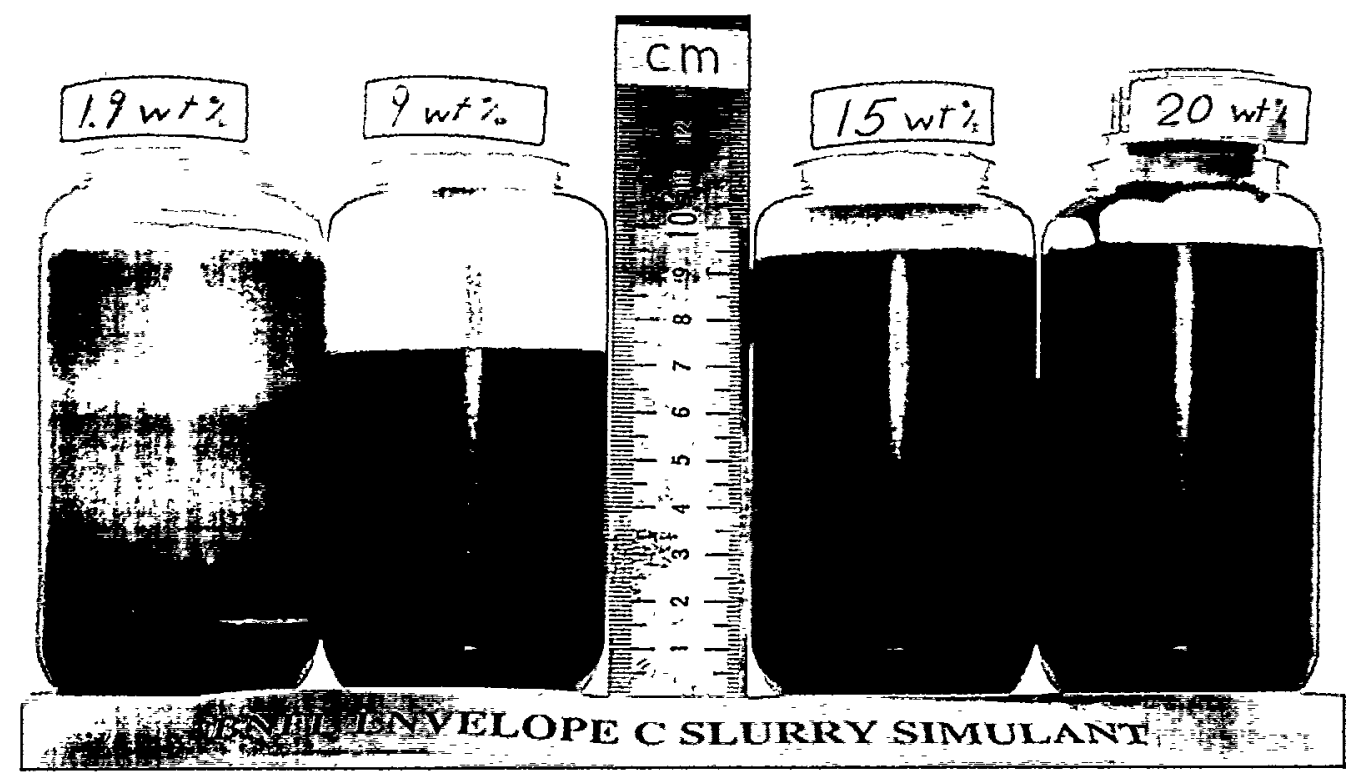

Figure 12. Settled solids in simulant: Envelope $\mathrm{C}+\mathrm{ES}+\mathrm{Sr} / \mathrm{TRU}$ precipitants

[Photograph was taken on 12/7/1999]

Specifics about the simulant can be found in Appendix E: Analytical Data, but some general properties at $25^{\circ} \mathrm{C}$ were:

Slurry Density:

Pre-washed $\sim 1.29 \mathrm{~g} / \mathrm{mL}$ at $2 \mathrm{wt} \%$ insoluble solids, $36 \mathrm{wt} \%$ total solids

Pre-washed $\sim 1.36 \mathrm{~g} / \mathrm{mL}$ at $9 \mathrm{wt} \%$ insoluble solids, $41 \mathrm{wt} \%$ total solids

Pre-washed $\sim 1.39 \mathrm{~g} / \mathrm{mL}$ at $14 \mathrm{wt} \%$ insoluble solids, $44 \mathrm{wt} \%$ total solids

Pre-washed $\sim 1.47 \mathrm{~g} / \mathrm{mL}$ at $22 \mathrm{wt} \%$ insoluble solids, $49 \mathrm{wt} \%$ total solids

Post-washed $\sim 1.15 \mathrm{~g} / \mathrm{mL}$ at $18 \mathrm{wt} \%$ insoluble solids, $19 \mathrm{wt} \%$ total solids

Post-washed $\sim \mathrm{N} / \mathrm{A} \mathrm{g} / \mathrm{mL}$ at $38 \mathrm{wt} \%$ insoluble solids, $41 \mathrm{wt} \%$ total solids

Slurry Rheology

$\sim$ Newtonian* at the lowest insoluble solids concentration ( $2 \mathrm{wt} \%)$ and changes to a pseudoplastic* at the higher solids concentrations.

(See Figs, E1 and E2 and the explanation below on Bingham* fluids)

Slurry Viscosity/Consistency* (Yield Stress* is in parentheses):

Pre-washed $\sim \mu=4 \mathrm{cP}$ at $2 \mathrm{wt} \%$ insoluble solids

Pre-washed $\sim \mu_{0}=7.4 \mathrm{cP}$ at $9 \mathrm{wt} \%$ insoluble solids $\left(\tau_{0}=3.4 \mathrm{dynes} / \mathrm{cm}^{2}\right)$

Pre-washed $\sim \mu_{0}=11.6 \mathrm{cP}$ at $14 \mathrm{wt} \%$ insoluble solids $\left(\tau_{0}=9.2 \mathrm{dynes} / \mathrm{cm}^{2}\right)$

Pre-washed $\sim \mu_{0}=23.4 \mathrm{cP}$ at $22 \mathrm{wt} \%$ insoluble solids $\left(\tau_{0}=55.4 \mathrm{dynes} \mathrm{cm}^{2}\right)$

*See the discussion on the next page of the rheological terms 
Post-washed $\sim \mu_{0}=4.1 \mathrm{cP}$ at $18 \mathrm{wt} \%$ insoluble solids and $19 \mathrm{wt} \%$ total solids

$$
\left(\tau_{0}=22.0 \text { dynes } / \mathrm{cm}^{2}\right)
$$

Post-washed $\sim \mu_{0}=24.0 \mathrm{cP}$ at $38 \mathrm{wt} \%$ insoluble solids and $41 \mathrm{wt} \%$ total solids

$$
\left(\tau_{0}=684.0 \text { dynes } / \mathrm{cm}^{2}\right)
$$

Filtrate at $34 \mathrm{wt} \%$ soluble solids:

Density $\sim 1.27 \mathrm{~g} / \mathrm{mL}, \mu=\sim 3.2 \mathrm{cP}$, Sodium $\left[\mathrm{Na}^{+}\right]$Conc $\sim 5.9 \mathrm{M}$

[Discussion of rheology terms (24): For the 5 out of the 6 slurry solids loadings show above, the slurry did not behave as a Newtonian fluid and therefore the concept of viscosity changes. The bottom curve in Fig. 13 represents the characteristics of a Newtonian fluid model. That is, the fluid shear stress, $\tau$, is directly proportional to the fluid shear rate, $\gamma$.

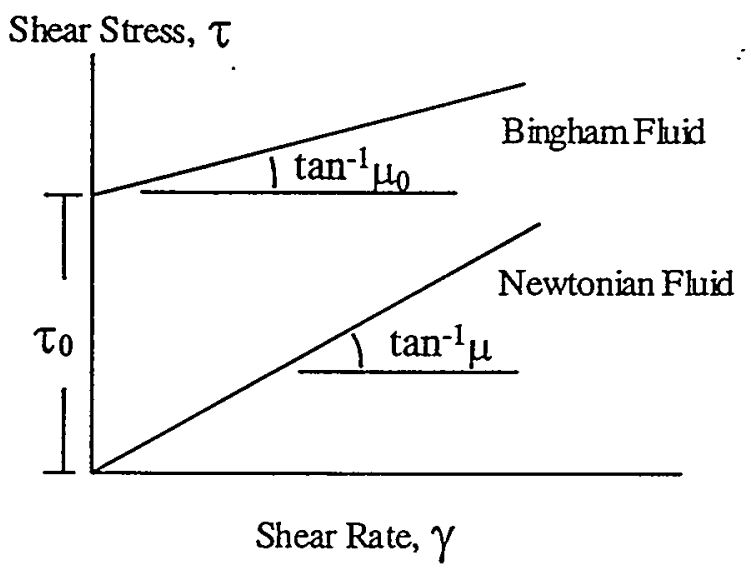

Figure 13. Flow curves for Newtonian and Bingham fluids

Generally the quotient of the ratio of $\tau / \gamma$, in simple shear flow, is a constant defined as the dynamic viscosity, $\mu$. Fluids that do not follow this model are referred to as nonNewtonian. The simularit used is this task, at elevated.insoluble solids loadings, has the rheological properties of a thixotropic fluid, or a pseudoplastic fluid where the properties are time dependent. A pseudoplastic fluid in known for its shear-thinning properties which means that there is a reduction in viscosity as the rate of shear increases in a steady shear flow. For certain pseudoplastics the rheological properties change with time. A close look at the curves in Figs. E1 and E2 (in Appendix E) show hysteresis, which indicates the time dependence. However, for engineering purposes the rheological Bingham fluid model captures most of the salient features of the slurries. The top curve in Fig. 13 shows the Bingham fluid model. The model, $\mu_{0}=\left(i-\tau_{0}\right) / \gamma$, is the same as for a Newtonian fluid except that there is a yield stress; a finite shear stress when the shear rate is zero. That is, a finite stress, $\tau_{0}$, needs to be overcome before a fluid begins to move.

A Bingham model has two constants, $\tau_{0}$ and $\mu_{0}$, instead of the single dynamic viscosity, $\mu$, of a Newtonian fluid. The shear stress at zero shear rate is $\tau_{0}$, and $\mu_{0}$ is referred to as 
consistency, or plastic viscosity. These two constants completely define a Bingham fluid and these are the values given above for the slurries above $2 \mathrm{wt} \%$ in insoluble solids.

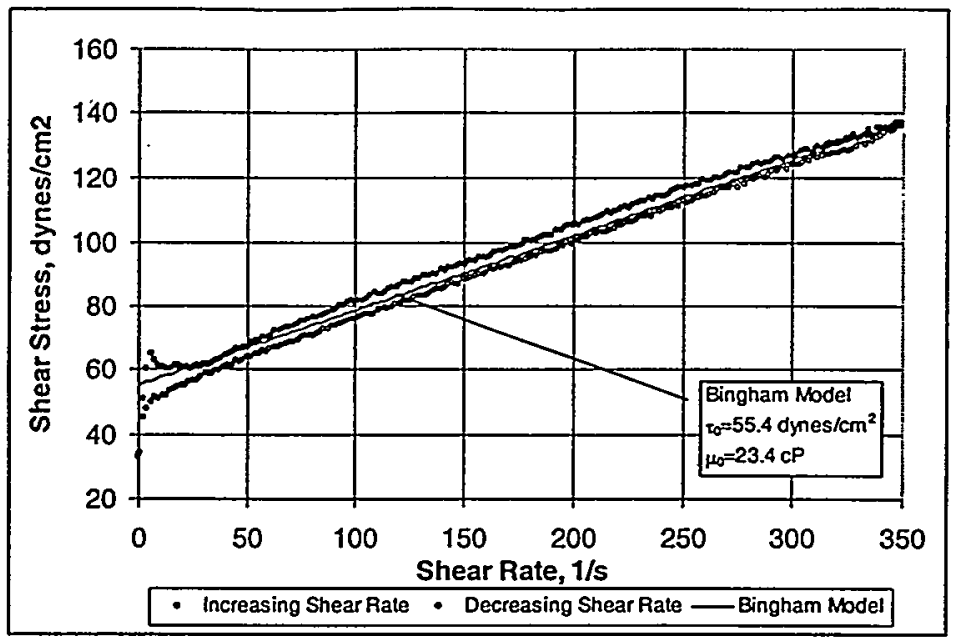

Figure 14. Fitting a Bingham rheological model to data from the end of run 1.08

To see how well the Bingham model fits one slurry sample, Fig. 14 shows the results of sample taken just as run 1.08 was completed. It had an insoluble solids loading of 22 wt\% and a total solids loading of $49 \mathrm{wt} \%$.]

Finally, a question was raised as to how fast the precipitants settles $(25,26)$. Several slurry samples were mixed well and placed in straight-walled glass vials to obtain a more accurate measurement of the settling volumes. Figure 15 shows the change in the volume of the space occupied by solids with time under the action of gravity alone. Once again, that volume is determined by the height of the slurry/supernate interface multiplied by the cross-sectional area of the container; therefore, the volume is really a mixture of the solid particles, the liquid within the particles, and the liquid between the particles.

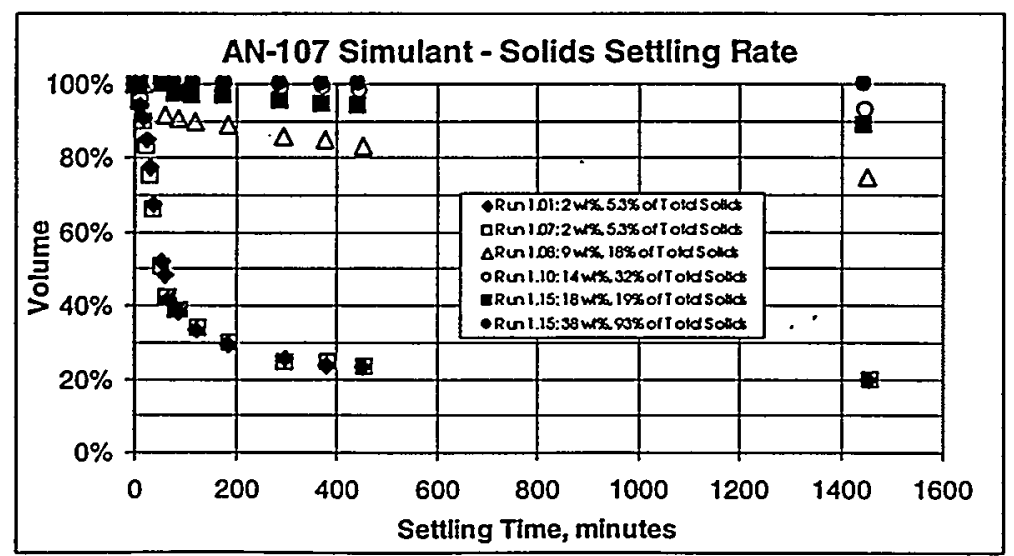

Figure 15. Solids settling rate in simulant: Envelope C+ES+Sr/TRU precipitants 


\section{Test Procedure/Matrix}

Details of the test matrix and procedure that were carried out can be found in the Test Procedure (18) and the accompanying Operational Instructions (19), which are also listed in the task notebook (5). However, to facilitate understanding the general operation of the test, the procedural steps are summarized below (see Fig. 1 for valve locations):

Daily pre-test activities -

1. Equipment is turned on to warm up if not already on.

2. The equipment was checked for functionality and after each of the four liquid-filled pressure sensing lines (see Fig. F2; Appendix F) were purged with $5 \mathrm{ml}$ of distilled and filtered water, the transducers were checked at their zeroes for drift. The zeroes are recorded for 2 to 3 minutes by the DAS. Those data are included in each day's data sheets.

Daily testing activities for constant solids runs (low and high concentrations) -

3. Begin circulating the slurry in the recirculation loop until the temperature reached $25^{\circ} \mathrm{C}$.

4. Turn on the reservoir cooling coil.

5. Allow the slurry to flow through the cross-flow filter.

6. Set the appropriate flow conditions as per the test procedure by iterating between valves $\mathrm{V} 3$ and $\mathrm{V} 11$.

7. When the slurry and filtrate loops establish steady flows adjust the backpulse piston pressure to at least 30 psi over the slurry pressure in the filter.

8. Set the DAS to read every minute.

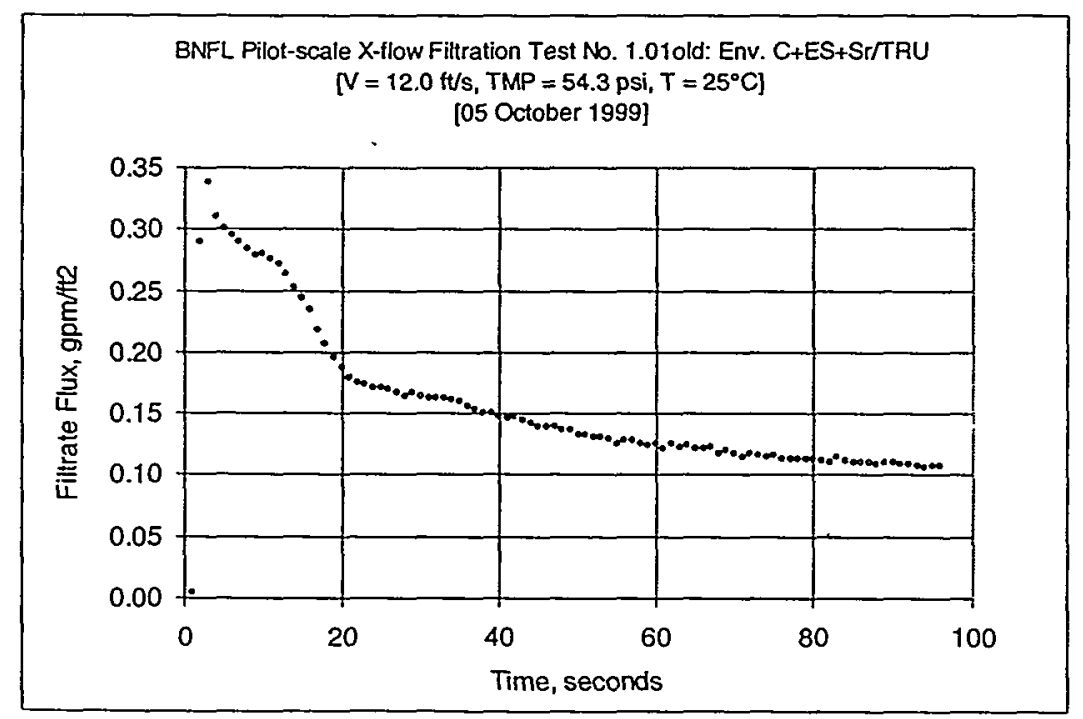

Figure 16. Filtrate flux immediately following a backpulse 
9. Backpulse the filter, hold the piston down for 10 seconds, then allow the filtrate flow to return. [At times this step had to be repeated so that the flow parameters could be set correctly. Also, because the filtrate had to refill the backpulse piston plenum, the filtrate-flow return-time was a function of the filtrate flux. As mentioned in item 1 of the Test Rig description, the volume of plenum was 0.036 gallon $/ \mathrm{ft}^{2}$; therefore, the recovery time at $0.3 \mathrm{gpm} / \mathrm{ft}^{2}$ was approximately $0.036 / 0.3 \times 60=7$ seconds. A flux of $0.3 \mathrm{gpm} / \mathrm{ft}^{2}$ was taken because that was close to the filtrate flux right after a backpulse, Fig. 16.]

10. Allow the test rig to run for approximately 2 hours.

11. Backpulse the filter once again.

12. Repeat from Step 6 for next set of flow conditions or shut down the test rig, if near the end of the work day.

13. End the test run.

Daily testing activities for wash test runs -

[Do Steps 3 to 9 from above, but just before Step 6 pour in a volume of distilled and filtered water (with $0.01 \mathrm{M} \mathrm{NaOH}$ ), equal to the volume in the test rig ( $\sim 75$ liters).]

10. Switch valve V13 to the open-loop position so that the filtrate is not returned to the slurry loop, but is collected outside the test rig.

11. Allow the test rig to run until a volume of filtrate is removed that is equal to the volume of water that was put in. (Slightly more mass is taken out than was put in because of the filtrate's higher density.)

12. Switch valve V13 to the close-loop position.

13. Backpulse the filter once again.

14. Repeat from Step 6 for each wash run until finished with all wash runs.

15. End the test run.

Daily testing activities for post-wash dewatering/plugging test run -

[Do Steps 3 to 9 from above.]

10. Switch valve V13 to the open-loop position so that the filtrate is not returned to the slurry loop, but is collected outside the test rig.

11. Continue run until either the filter or pumps do not allow further operation.

12. End the test run.

\section{Shakedown}

Part of the test matrix of the Envelope A test, which was completed in July 1999, was to clean the filter, and the test rig, with $1 \mathrm{M}$ nitric acid, followed by a water rinse (22). This was the state of the test rig and filter to begin the Envelope. $C$ test. However, before beginning any test with any simulant, the test rig (TR) was cleaned to remove any foreign contamination that may have been left inside the system from past testing or that could have been introduced when modifications were made. In March of 1999, before the new seven-tube filter unit was installed, the entire TR was cleaned with 1 wt\% solution of Alconox in distilled and filtered ( 0.2 micron) water (referred to as DIF water). Fifty liters of this phosphate based solution was circulated in the TR for several hours at $35^{\circ} \mathrm{C}$. This was followed with several DIF water rinses, until the water returned crystal clear. During 
the cleaning and rinsing the filter tubes were soaked in water for 4 days. With the TR clean and the filter installed, the slurry reservoir was filled with 75 liters of DIF water. Several runs were done with water to characterize the Mott filter.

A cross-flow filter (XF) is significantly different from a dead-end filter in that the main slurry flow is not forced through the filter medium. Instead the slurry flow rushes past (crosses) the filter substrate while allowing the filtrate to be removed perpendicularly, as a result of the transmembrane pressure (TMP). In this way the XF is basically self cleaning as the turbulent slurry flow tend to shear solids away from the filter wall as they try to adhere. However, because of this cross flowing stream, there is an added degree of freedom. For instance, an increase in slurry velocity may, but not necessarily, lead to an increase in filtrate flux. This is because the slurry system pressure can be made to decrease. That is, the slurry system pressure can be controlled independently from the slurry axial velocity and both of these quantities will affect the rate of filtrate flow. With this in mind, the following figures are shown to illustrate the character of the XF with DIF water, which contains no solids.

Figure 17 shows the axial pressure drop versus the axial velocity. Those velocities came from the TR flow settings of $10,20,30,40$, and $50 \mathrm{gpm}$. These results were expected because a pre-test calculation indicated that the pressure drop at $12.6 \mathrm{ft} / \mathrm{s}$ should be close to 4 psid, and it was. The calculation was not straight forward because to determine an accurate pressure drop involves knowing the several contributions to that drop.

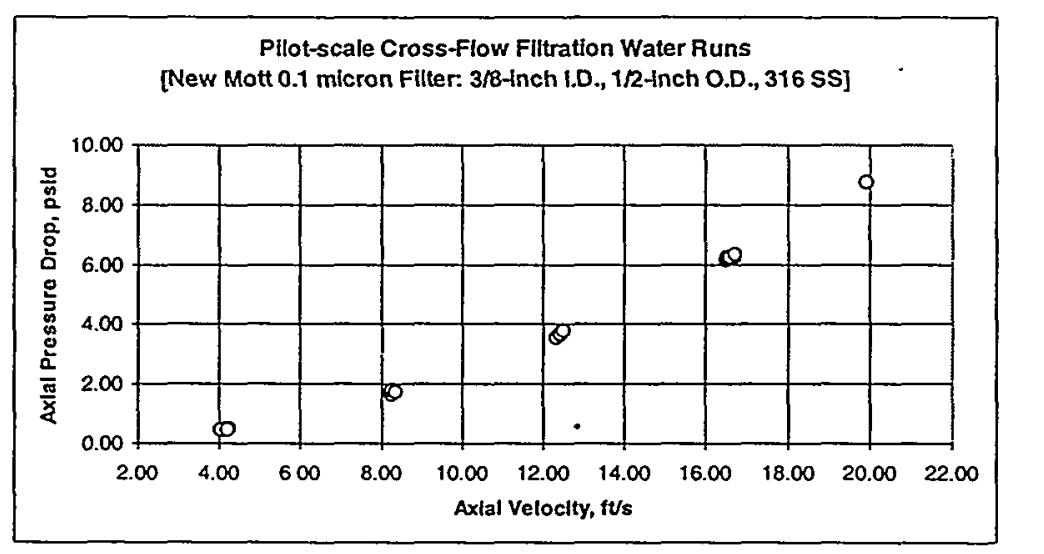

Figure 17. Axial pressure drop vs. axial velocity of water in the cross-flow filter

Figures 1 and 6 show that the pressure taps were located in a diverging/converging plenum region on either side of the filter housing. Therefore the pressure drop is not only the drop along the porous filter tube, but it also includes the effects of the tube sheet inserts, expansion and contraction into the plenums, and the diverging and converging plenums themselves (where the pressure taps are located). A rough calculation determined that the actual axial pressure drop along just the porous section of tube is between $60 \%$ and $70 \%$ of the measured drop. Another aspect of Fig. 17 is the grouping 
of several data points for each combination of pressure drop and velocity. For example, nine points make up the group at $4 \mathrm{ft} / \mathrm{s}$ of axial velocity. Likewise, the groups of points at $8,12.5,16.5$, and $20 \mathrm{ft} / \mathrm{s}$ of axial velocity are made up of $5,4,7$, and 1 point, respectively. The different points within a group correspond to a changing system pressure at the filter. That pressure was increased three fold from approximately 5 to 16 $\mathrm{psig}$, which resulted in filtrate fluxes from approximately $0.1 \mathrm{gpm} / \mathrm{ft}^{2}$ to $0.5 \mathrm{gpm} / \mathrm{ft}^{2}$. This result means that the changing system pressure had an insignificant effect on the axial pressure drop.

The effect of system pressure on filtrate flux at a fixed axial velocity is apparent in Fig. 18. The lines on the graph are isobars, or better, lines of constant transmembrane pressure (TMP). These data were obtained by adjusting the valves on the test rig to maintain a constant axial velocity while changing the system pressure. The highest TMP measured was at 4.4 psid due to the limitation of measuring filtrate flux to a maximum of $0.52 \mathrm{gpm} / \mathrm{ft}^{2}$. This limitation existed because the expected filtrate flowrate of slurry was to be between 0.02 and $0.2 \mathrm{gpm} / \mathrm{ft}^{2}$. Therefore, a flowmeter was calibrated to accurately measure that target range. However, it did limit measurement with water. Near the end of the Envelope A test (22) another meter was installed to measure up to $2.2 \mathrm{gpm} / \mathrm{ft}^{2}$ but it wasn't available during shakedown.

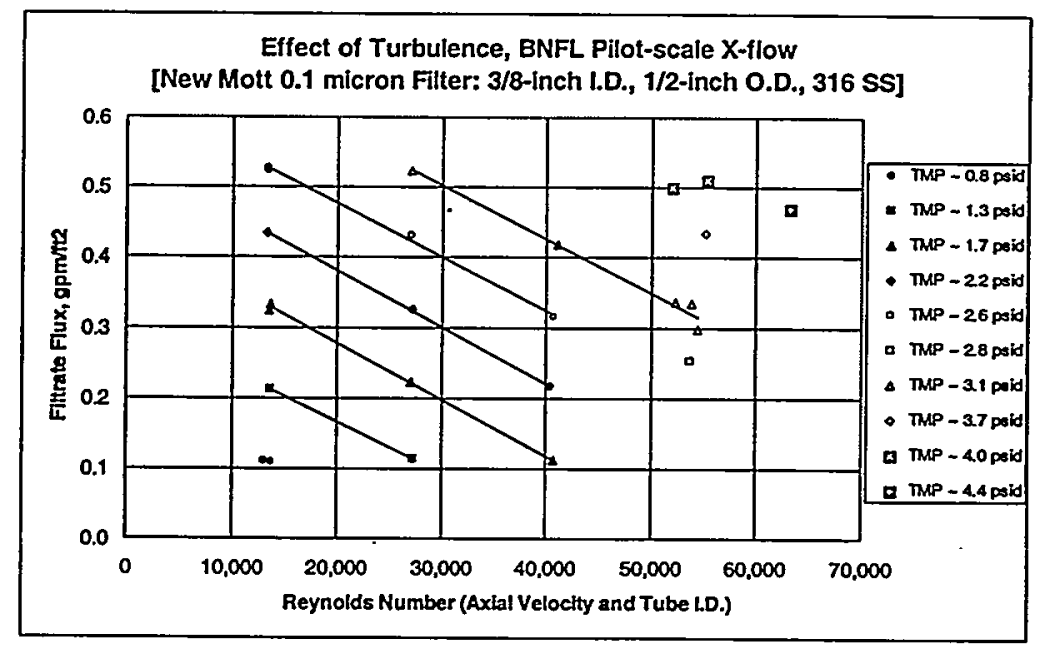

Figure 18. Filtrate flux vs. axial velocity of water in the cross-flow filter

What is interesting in Fig. 18 is that for a constant TMP the filtrate flux decreases as the velocity increases. This is understood when considering that a cross-flow filter is really only useful when there is something to filter. That is, when filtering a slurry, solids form a filter cake, which creates resistance to filtrate flow. As the slurry velocity increases more cake is sheared from the surface, thus allowing more filtrate to flow. However, when no solids exist in the liquid only the fluid dynamics affect the flow. As can be seen in Fig. 19 the increase axial velocity leads to an increase in the Reynolds number. 


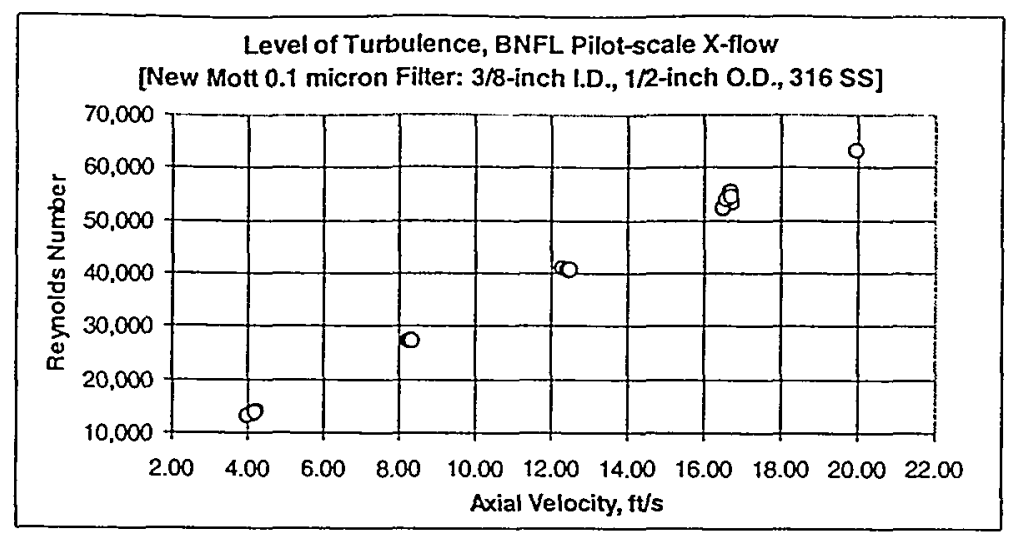

Figure 19. Reynolds vs. axial velocity of water in the cross-flow filter

This is not surprising since the Reynolds number is directly proportional to the velocity, along with the diameter of the flow stream, and inversely proportional to the kinematic viscosity. The purpose of Fig. 19 is to show the intensity of turbulence. As turbulence increases the laminar sublayer decreases, the inertial sublayer is created and then increases, and the scale of energy dissipating eddies become increasingly smaller (27). What this means is that increasing the shear environment at the tube wall forces the water to enter into the main stream more than forcing the water through the thin laminar sublayer which coats the porous-tube wall.

Finally, due to the added degree of freedom the filtrate flux cannot be simply determined from just the axial flow velocity; the TMP must also be specified, leading to the family of curves in Fig. 18. However, an attempt was made to collapse those curves into a single curve to be more useful by normalizing TMP with the axial pressure drop versus normalizing filtrate velocity with the axial velocity. Figure 20 show the results of that attempt.

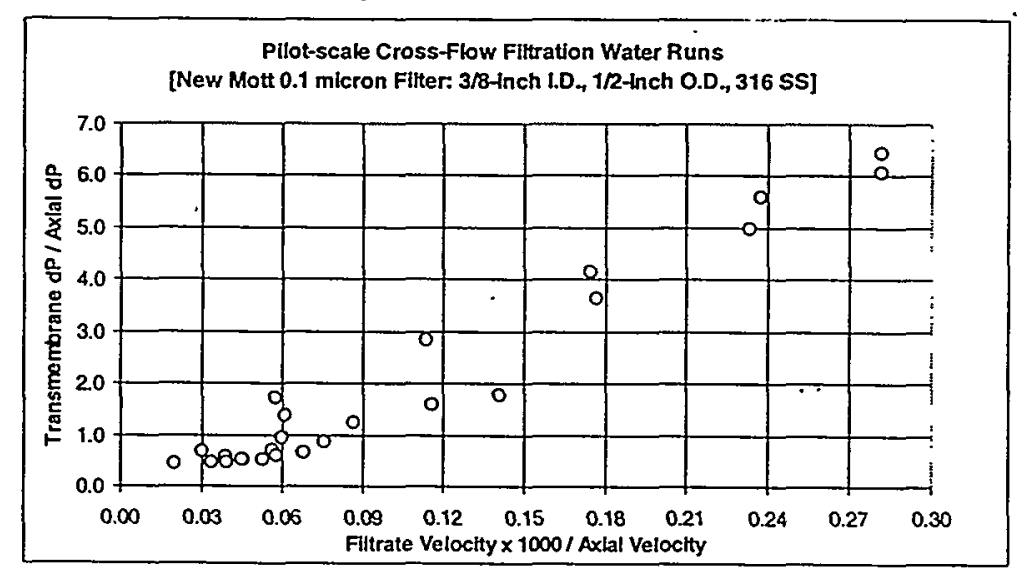

Figure 20. Normalized TMP vs. filtrate velocity in the cross-flow filter 


\section{RESULTS AND DISCUSSION}

\section{General}

The different phases of the test matrix that we shall discuss are: initial water baseline, low solids concentration, pre-wash dewatering, high solids concentration, slurry wash, plugging, water rinse, final water baseline (without chemical cleaning), cleaning, and final water baseline. After a discussion on some of the analytical and washing results, a discussion of the hydraulic results will follow that chronological order with the exception of the water and cleaning runs. Those runs will be given together in order to show any lasting effect of the slurry on the filter medium and thereby have a clear perspective of the test runs. The test matrix (4) was:

\begin{tabular}{|c|c|c|c|c|}
\hline Run(1) & $\begin{array}{ll}\text { Test Specif } \\
\text { Duration } \\
\text { minutes }\end{array}$ & $\begin{array}{l}\text { cation Target V } \\
\text { Slurry Velocity } \\
\mathrm{ft} / \mathrm{s}\end{array}$ & $\begin{array}{l}\text { 'alues } \\
\text { TMP } \\
\text { psid }\end{array}$ & Condition \\
\hline 1.00 & 120 & 12.2 & $10,20,830$ & Water \\
\hline 1.01 & 120 & 12.2 & 50 & Low Solids Concentration \\
\hline 1.02 & 120 & 9.1 & 30 & Low Solids Concentration \\
\hline 1.03 & 120 & 15.2 & 70 & Low Solids Concentration \\
\hline 1.04 & 120 & 15.2 & 30 & Low Solids Concentration \\
\hline 1.05 & 120 & 9.1 & 70 & Low Solids Concentration \\
\hline 1.06 & 120 & 12.2 & 50 & Low Solids Concentration \\
\hline 1.07 & 120 & best(2) & best & Low Solids Concentration \\
\hline 1.08 & time needed & best & best & Dewater \\
\hline 1.09 & 120 & 12.2 & 50 & High Solids Concentration \\
\hline 1.10 & 120 & 9.1 & 30 & High Solids Concentration \\
\hline 1.11 & 120 & 15.2 & 70 & High Solids Concentration \\
\hline 1.12 & 120 & 15.2 & 30 & High Solids Concentration \\
\hline 1.13 & 120 & 9.1 & 70 & High Solids Concentration \\
\hline 1.14 & 120 & 12.2 & 50 & High Solids Concentration \\
\hline wash 1 & $\mathrm{n} / \mathrm{a}$ & $\mathbf{n} / \mathbf{a}$ & $\mathrm{n} / \mathrm{a}$ & Wash $0.01 \mathrm{M} \mathrm{NaOH}$ (3) \\
\hline wash 2 & $\mathrm{n} / \mathrm{a}$ & na & $\mathrm{n} / \mathrm{a}$ & Wash \\
\hline wash 3 & $n / a$ & n/a & $\mathrm{n} / \mathrm{a}$ & Wash \\
\hline wash 4 & $n / a$ & $\mathrm{n} / \mathrm{a}$ & n/a & Wash \\
\hline 1.15 & time needed & best & best & Plugging \\
\hline 1.16 & time needed & $\mathrm{n} / \mathrm{a}$ & $\mathrm{n} / \mathrm{a}$ & Water Rinse \\
\hline 1.17 & 120 & 12.2 & 20 & Water \\
\hline 1.18 & $18->24$ hrs & $\mathrm{n} / \mathrm{a}$ & $n / a$ & Cleaning $1 \mathrm{M} \mathrm{NaOH}$ (3) \\
\hline 1.19 & Ii) 120 & 12.2 & $10,20, \& 30$ & Later \\
\hline \multicolumn{5}{|c|}{$\begin{array}{l}\text { (1) This is the matrix as it was modified on } 10 / 18 / 99 \text { by BNFL } \\
\text { (2) The word "best" refers to the best filtrate flux obtained in the preceding runs } \\
\text { (3) Distilled and filtered ( } 0.2 \text { micron) water was used }\end{array}$} \\
\hline
\end{tabular}

Figure 21. Test matrix as stated in a modification to the test specification (4)

\section{Test Run Sequence and Nomenclature}

As will be explained in the following sections there were some deviations from the Fig. 21. The largest change was the modification to the test matrix made on $10 / 18 / 99$ by BNFL, as requested by DOE. By that date, all of the low concentration runs were already done. However, those runs, i.e., 1.01 to 1.07 , were repeated before run 1.08 began. The 
runs that were made before the mid-test change are referred to as (old), e.g., 1.01(old). All other deviations that occurred were to better understand the filter operation during the test. For example run $1.01 \mathrm{a}$ (old) was done to have three data points at the same flow conditions to determine if the filter performance was degrading as the slurry aged in the test rig. Test runs 1.04 (old), 1.05 (old), and 1.07 were repeated to better evaluate "best" conditions. The repeat runs numbers are followed by the letter "a", e.g., run 1.01 a(old).

\section{Analytical Test Results}

[See Appendix E for the entire set of data sheets.]

\section{Filter Effectiveness}

One goal of this task was to determine if the nominal rated 0.1 micron Mott filter could remove all the insoluble solids from the simulant. As already mentioned in the preceding experimental section of this report, the insoluble solids were made of 10 compounds and 6 metals ( $\mathrm{Al}, \mathrm{Ca}, \mathrm{Cr}, \mathrm{Fe}, \mathrm{Mn}$, and $\mathrm{Na}$ ), with Sodium being the quantity largest by mass, and Sodium Oxalate, which was the largest compound by mass (Fig. 9). Based on a sample analysis (Fig. 10), the particle sizes purchased for the solids ranged from approximately $\mathrm{l}$ to 10 microns. From the filtrate results in Fig. 22 it is apparent that the filter removed all the solids.

\begin{tabular}{lccc} 
& Total Solids, wt\% & \multicolumn{2}{c}{ Insoluble Solids, wt\% } \\
\cline { 3 - 4 } Test Run & Slurry & Slurry (1) & Filtrate \\
\hline 1.00 (water) & not measured & $<0.002$ & \\
Pre-wash & 44.1 & 14.3 & \\
Wash 1 & 32 & 15.3 & $0.015(2)$ \\
Wash 2 & 24 & 16.4 & $<0.0001$ \\
Wash 3 & 20 & 17.5 & not available \\
Wash 4 & 19 & 18.5 & $<0.0001$ \\
1.19 (water) & 0.014 & $<0.0001$ & \\
\hline
\end{tabular}

(1) Wash values were estimated from pre- and post-wash values

(2) No solids were visible when the sample was drawn. However, during the 1 month before the sample was tested a small amount of precipitants formed causing this non-zero result

Figure 22. Insoluble solids in the slurry and the filtrate throughout the test

The insoluble solids filtrate value for Wash 3 is not shown because the sample became contaminated. The amount of solids that was measured for the water runs is shown to indicate the state of the test rig before and after the test. All measured quantities can be found in Appendix $\mathrm{E}$. The filter was very effective in removing all the insoluble solids. Furthermore, the basic sizes of the solid particles did not change during the course of the experiment. Particles smaller than 0.1 micron could have compromised the filter. Figure 23 shows that the particle diameter (by a volume distribution analysis) remained at approximately the same size throughout the test, i.e., a bimodal distributions with averages of 1.5 microns, for the small-size, and 5.5 microns, for the large-size. The 
standard deviations from these averages were on the same order of magnitude as the particle diameters. This was expected since the two different particle sizes were purchased to be between 1-2 microns and 5-10 microns. However, the largest number particles were closer to 1 micron. When analyzing the particles by a number distribution, Fig. 24, the mean particle size is very close to 1 micron, with one standard deviation being 0.3 micron. In general, the particle sizes did conform to the required sizes and those particle sizes remained basically intact throughout the experiment. The complete set of Volume and Number distributions can be found as Figs. E24-E30 in Appendix E.

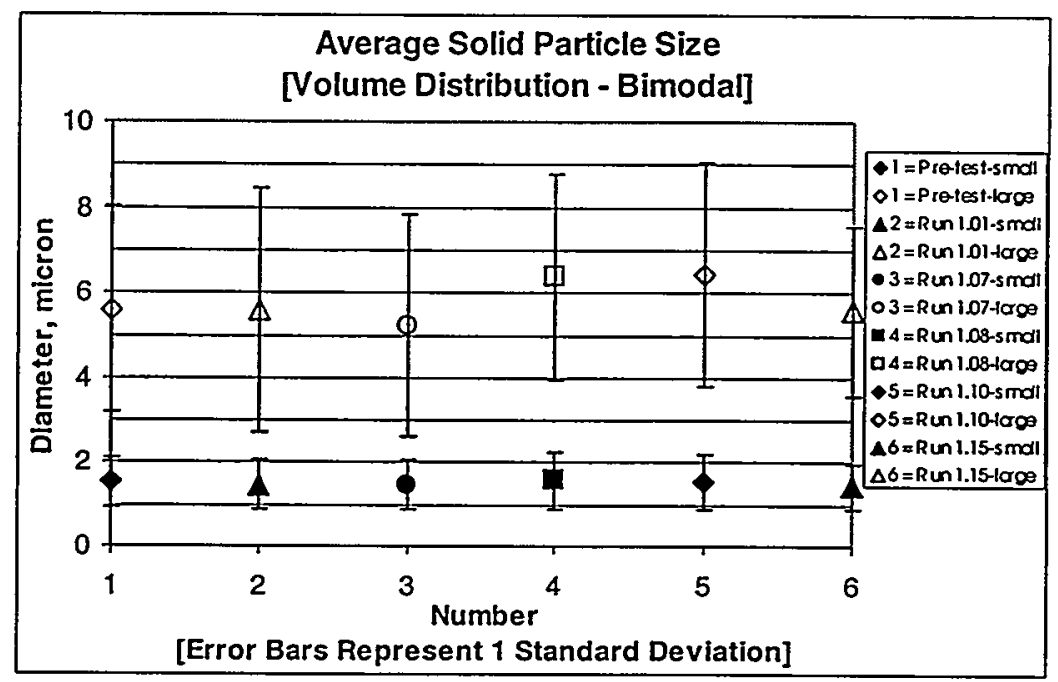

Figure 23. Particle size based on a volume distribution

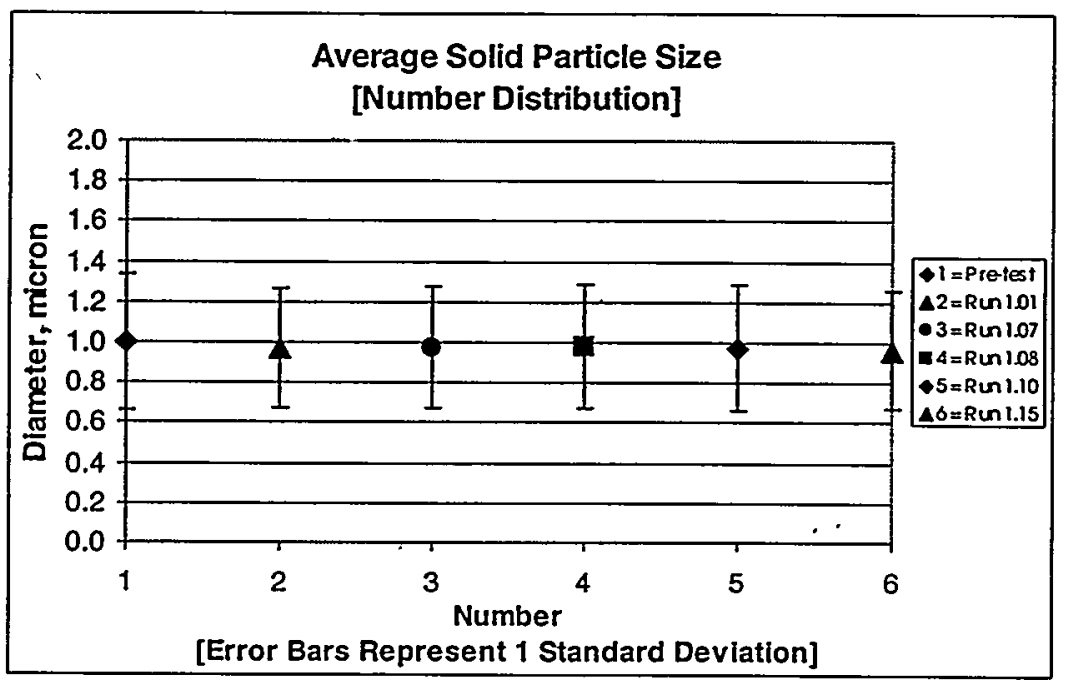

Figure 24. Particle size based on a number distribution 


\section{Washed Slurry}

After all steady state test runs, the slurry was ready to be washed. At the end of run 1.14 there were approximately 75 liters of slurry in the test rig, containing about $14 \mathrm{wt} \%$ of insoluble solids and $44 \mathrm{wt} \%$ of total solids, see Fig. 22 (pre-wash). The wash runs were done in four 75-liter batches. However, the full 75 liters could not be put in the slurry reservoir all at once. (A completely full reservoir and test rig holds approximately 136 liters.) The slurry reservoir was filled with 40 to 50 liters of wash solution to start and as the filtrate was removed from the test rig the remaining solution was added. Samples were drawn when the washed slurry was with 5 liters of the original 75 liters. The wash solution was distilled and filtered ( 0.2 micron) water with a little bit of sodium hydroxide added, i.e., $0.01 \mathrm{M} \mathrm{NaOH}$, as per BNFL direction. This process was repeated until 300 liters of wash solution were used.

\section{* Sodium *}

One of the major reasons for washing is to reduce sodium content. Figure 25 shows the $\mathrm{Na}^{+}$reduction. Point number 1 was the sodium concentration, $6.5 \mathrm{M}$, of the pre-washed slurry (containing $14.3 \mathrm{wt} \%$ of insoluble solids). Point number 2 shows the sodium concentration, $5.5 \mathrm{M}$, of the pre-washed filtrate. Numbers 3 to 6 show the sodium level after each batch of 75 liters of water was added to the slurry reservoir that held approximately 75 liters of slurry.

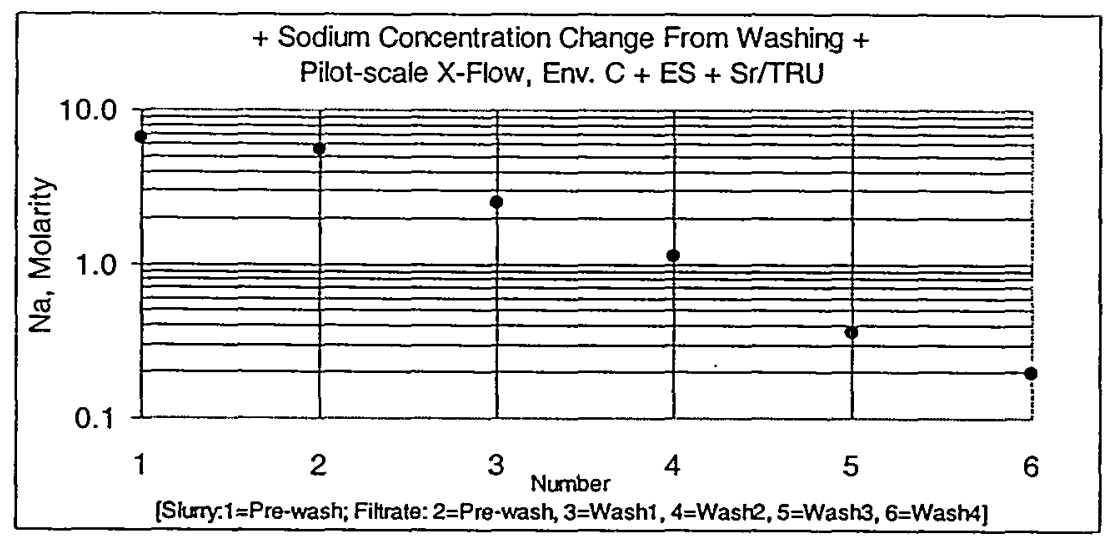

Figure 25. Reduction of sodium with successive washings

The line of points in Fig. 25 from number 2 to 6 is fairly straight on the semi-log scale, which was not unexpected. Figs. 26 and 27 show how the filtrate density and viscosity changed as the sodium level decreased from approximately $6 \mathrm{M}$ to $0.2 \mathrm{M}$. 


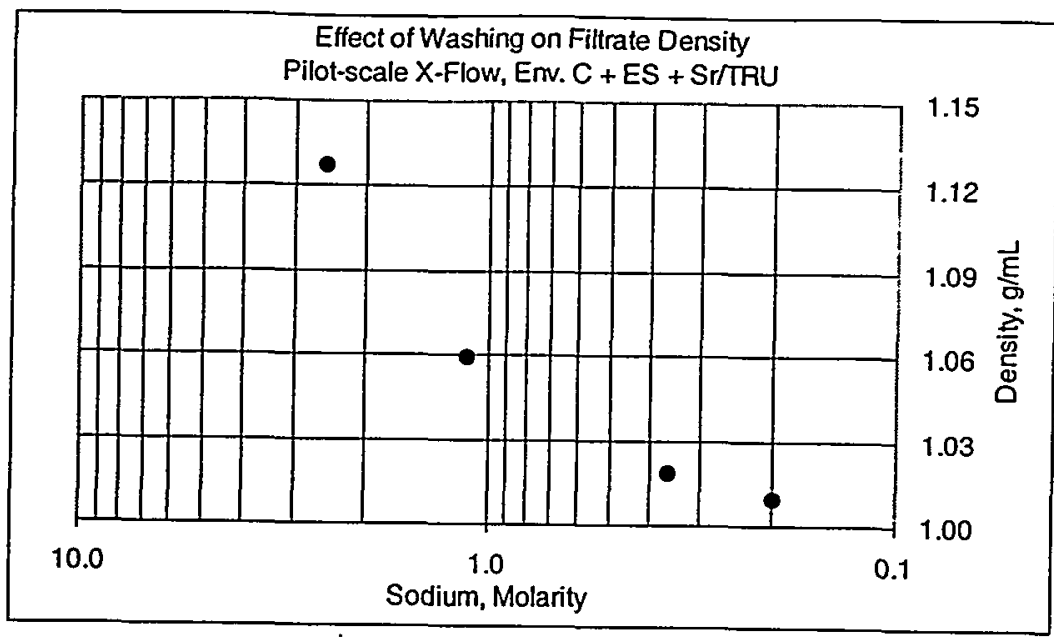

Figure 26. Filtrate density vs. sodium during washing

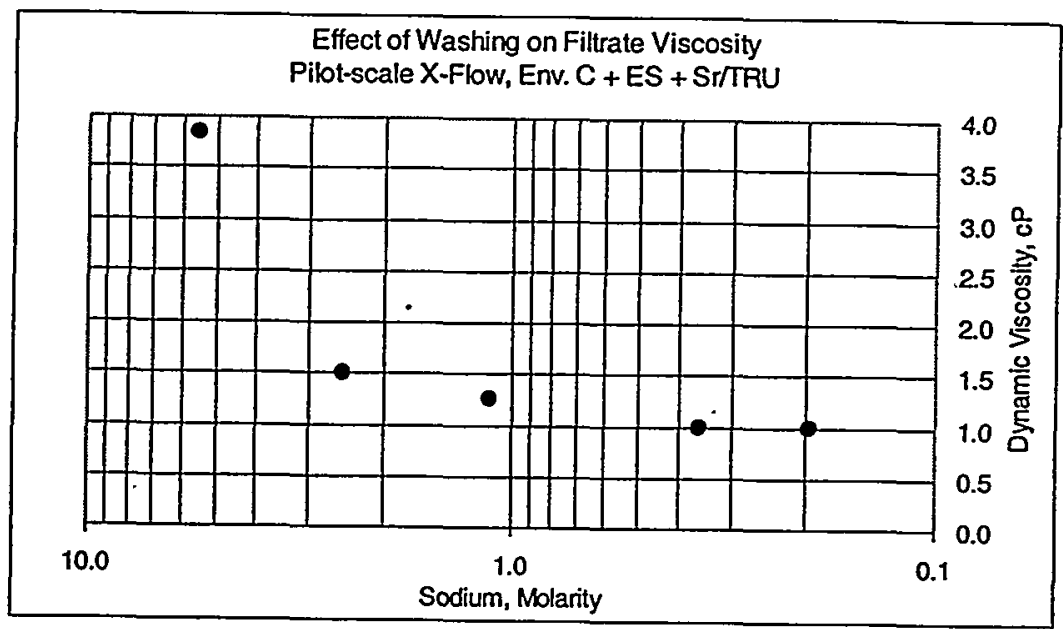

Figure 27. Filtrate viscosity vs. sodium during washing

\section{* Oxalate *}

A chemical that may have had an impact on the changes in solids loading was the chemical compound of oxalate. As seen in Fig. 9, approximately $34 \%$ of the "insoluble" solids that were added to the slurry was comprised of sodium oxalate. Of all the solids this one was expected to give the largest problem. The simulant was designed such that the added oxalate would remain in an undissolved form. To do this the liquid portion of the simulant, the supernate, was to be saturated with sodium oxalate before adding the solids. 


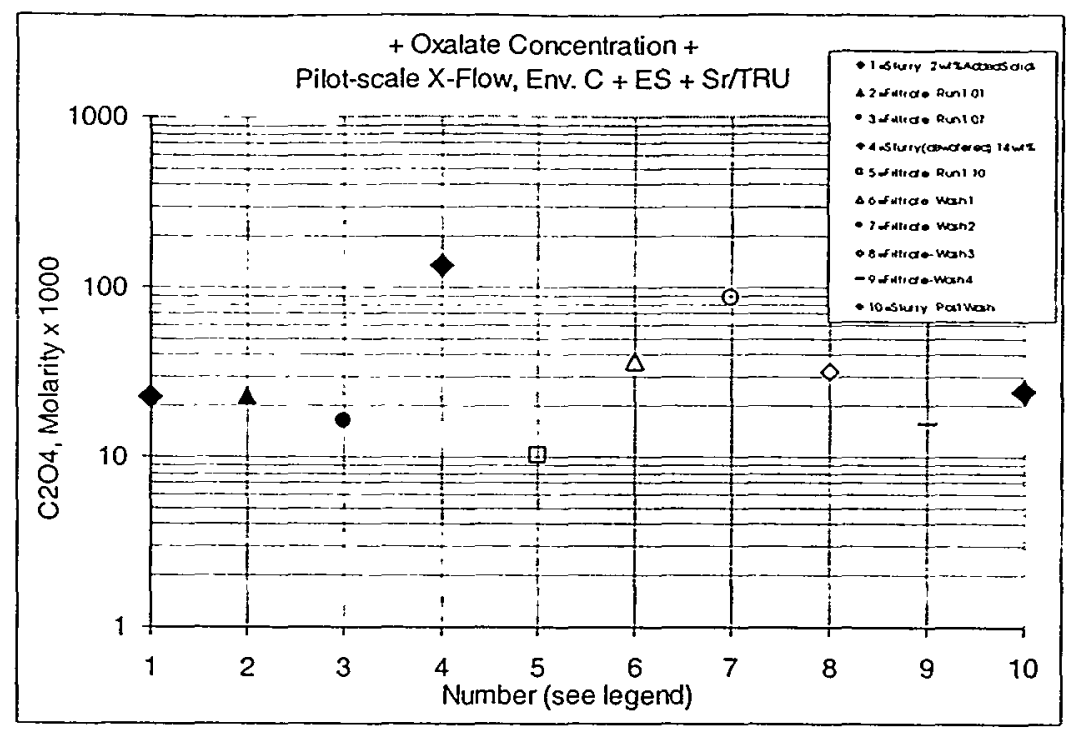

Figure 28. Oxalate changes in the filtrate during the test [Note: Except for nos. 1, 4, and 10 all oxalate values are from the filtrate]

However, Fig. 28 implies that for the low solids concentration slurry (Numbers 2 and 3 in the Fig. 28) most of the oxalates in solid form dissolved. The oxalate concentration in the filtrate was between $0.017 \mathrm{M}$ and $0.023 \mathrm{M}$; the sodium concentration was $5.9 \mathrm{M}$. Number 1 is the value of the oxalate concentration from all its sources in the slurry, 0.023 $\mathrm{M}$, and of this amount 0.005 was already included in the supernate. Therefore, it seems that the supernate was not fully saturated with oxalate. The value of number 4 , i.e., 0.14 $\mathrm{M}$, is the amount of oxalate in the slurry for all test runs starting with run 1.09. The oxalate values for numbers 5 through 9 are from the filtrate samples that came from the slurry with this higher oxalate concentration before washing. However, the supernate of the slurry before washing should have still been saturated at the $0.023 \mathrm{M}$ level; the saturation level may have been a little different because in concentrating the slurry the sodium level increased to $6.5 \mathrm{M}$. Therefore, the oxalate concentration could only increase as the saturation level increased during the wash runs. Looking at the results from all the wash runs (numbers 6 to 9), the oxalate in the supernate does increase as more and more water is added, but it showed a maximum of $0.087 \mathrm{M}$ on the second wash. Afterwards, the concentration decreased on the third and fourth wash runs. Note that all 4 wash runs were done in succession, and all on the same day. The time frame was short between water additions and the oxalate values, i.e., 6 to 9 , may not be from a mixture in equilibrium. The oxalate value in the slurry at the beginning of run 1.15 was $0.024 \mathrm{M}$, shown as No. 10 in Fig. 28. (After 4 washes, this slurry was basically water and insoluble solids. In fact, Fig. 22 shows that the total solids in the wash 4 slurry only differed from the insoluble solids by about $1 \mathrm{wt} \%$.). The slurry sample that gave the result as number 10 was taken the day after washing; just before run 1.15, the plugging run. This may indicate that the slurry was not at equilibrium on the preceding day. Sitting overnight may have allowed the slurry to come to equilibrium. On the other hand, 
it is more likely that most of the oxalate was removed from the slurry during the wash and a small amount of oxalate remained, which dissolved overnight.

*Decontamination*

As already mentioned, the simulant for this test was made to represent the radioactive waste. Whenever possible non-radioactive isotopes of radioactive elements were used. It is of interest to see how well the precipitation and filtration separated various chemical species. Figure 29 shows a composite of several chemical species in the slurry and in the filtrate. The ordinate is a ratio of the slurry molarity to the filtrate molarity for selected ions, and will be called a decontamination factor (DF). The results came from one filtrate sample and one slurry sample. The filtrate sample was from run 1.07(old); the final steady-state run with the low concentration of insoluble solids, $2 \mathrm{wt} \%$. The slurry sample was from the slurry used just before the dewatering, run, 1.08; that is, it was taken just before the simulant at $2 \mathrm{wt} \%$ of insoluble solids was concentrated.

The slurry simulant had many components and complexant interactions. It is beyond the scope of this task to explain the chemical interactions of the slurry but some observations of the chemical and mechanical separations are possible. From Fig. 29 it is immediately obvious that the main contributors to the precipitation have the highest DFs, i.e., $\mathrm{DF}=69$ for $\mathrm{Sr}$ and $\mathrm{DF}=187$ for Mn. Iron, which was 5\% of the mass of the solids, Fig. 9, had a $\mathrm{DF}$ of 22. Lanthanum, representing the TRU waste, had a DF $=20$. Calcium and copper had DFs close to 2. Finally, phosphate, sulfate, nickel, and aluminum remained in soluble forms and therefore little or no separation was measured, $\mathrm{DF} \approx 1$.

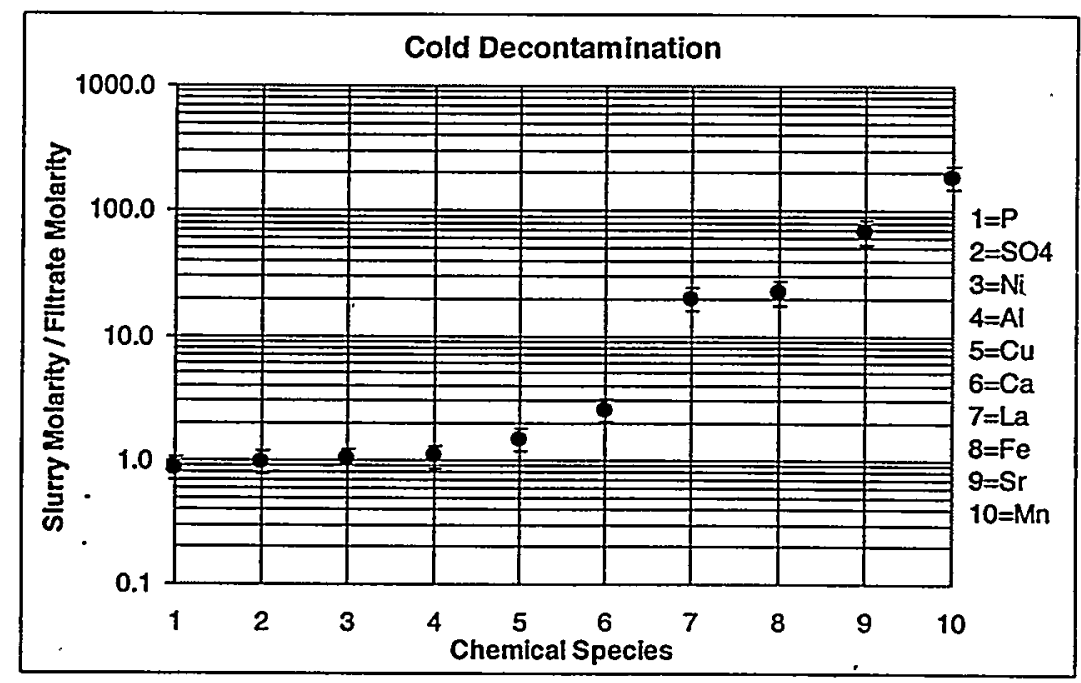

Figure 29. Separation of several ions from the slurry

For further information on the concentration of the many species in the simulant slurry, see Appendix E. All the analytical data taken and graphical results for many of the chemical concentrations can be found behind Table E1 in that appendix. 


\section{Hydraulic Test Results}

Water Test Runs 1.00,1.17, and 1.19 and the Cleaning Run 1.18

[See Appendix A for the entire set of data sheets.]

Permission to start the test was received on 9/28/99 and testing began on the same day with the first required test: water, run 1.00. As explained in the shakedown section, the added filtrate flowmeter allowed fluxes above $0.5 \mathrm{gpm} / \mathrm{ft}^{2}$ to be measured. However, the two highest TMPs indicated in the test matrix, Fig. 21, could not be obtained, i.e., 20 and 30 psid. With a clean filter and all three pumps operating, and with the axial filter velocity of $12.3 \mathrm{ft} / \mathrm{s}$, the highest TMP obtainable was approximately 18 psid. Figure 30 shows the results for run 1.00. Five runs were made from 3 to 17.7 psid. At highest flowrate attainable the TMP was 17.7 psid, which may be the reason the filter flux fluctuated. These results are compared to the final water runs to determine if the filter could be returned to its initial condition.

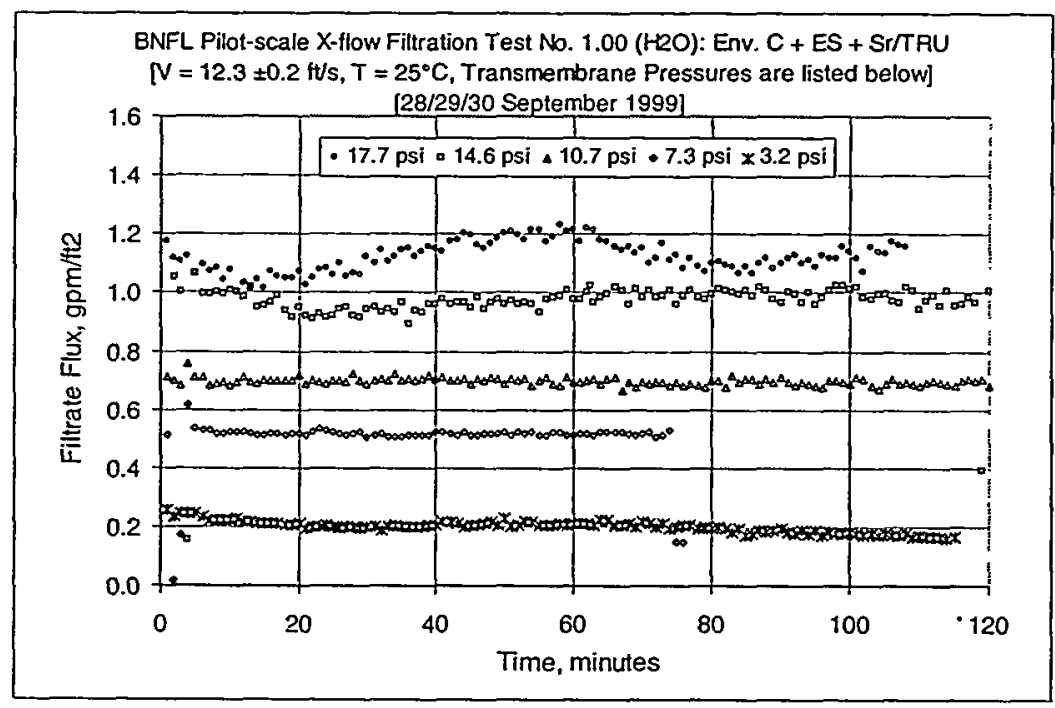

Figure 30. Initial water runs

Figure 31 shows the results of the water run, 1.17, just after the slurry test. Run 1.16 was done to rinse the filter and test rig with distilled and filtered water. To make sure that it was rinsed well, eight batches of $50^{\circ}$ liters of water were used at several different flow conditions. Each batch was run for approximately 30 minutes. However, the 400 liters water did not return the filter filtrate flux back to its initial values. Both water test runs (1.00 and 1.17) had the same axial velocity of $12 \mathrm{ft} / \mathrm{s}$. Comparing Fig. 31 data to the high TMP data set in Fig. 30 there was an order of magnitude difference in the filtrate fluxes. Run 1.17 was then followed with a cleaning run of $1 \mathrm{M} \mathrm{NaOH}$, run 1.18 . 


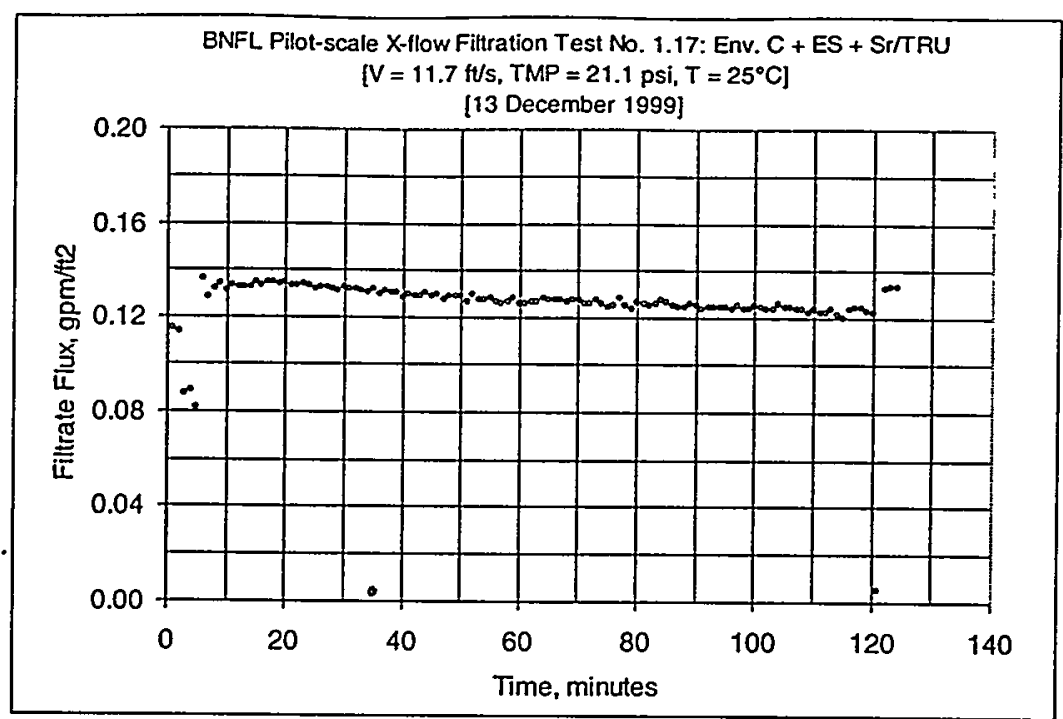

Figure 31. Final water run 1.17 before chemical cleaning

Figure 32 show the results of the cleaning run. To explain the data in the figure the filtrate flux curve can be broken down into different phases of active cleaning, when the cleaning solution was circulated through the filter. The cleaning was done over three days. During the first two days the $1 \mathrm{M} \mathrm{NaOH}$ cleaning solution was isolated in the cleaning loop, which limits cleaning to the filter and its immediate filter leg, Fig. 1. Cleaning began at the end of the day on 12/13/99 and the solution was circulated for about 4 hours. The tight cluster of data on the left-hand side of the graph, from 0 to 250 minutes, were taken at 1 minute intervals.

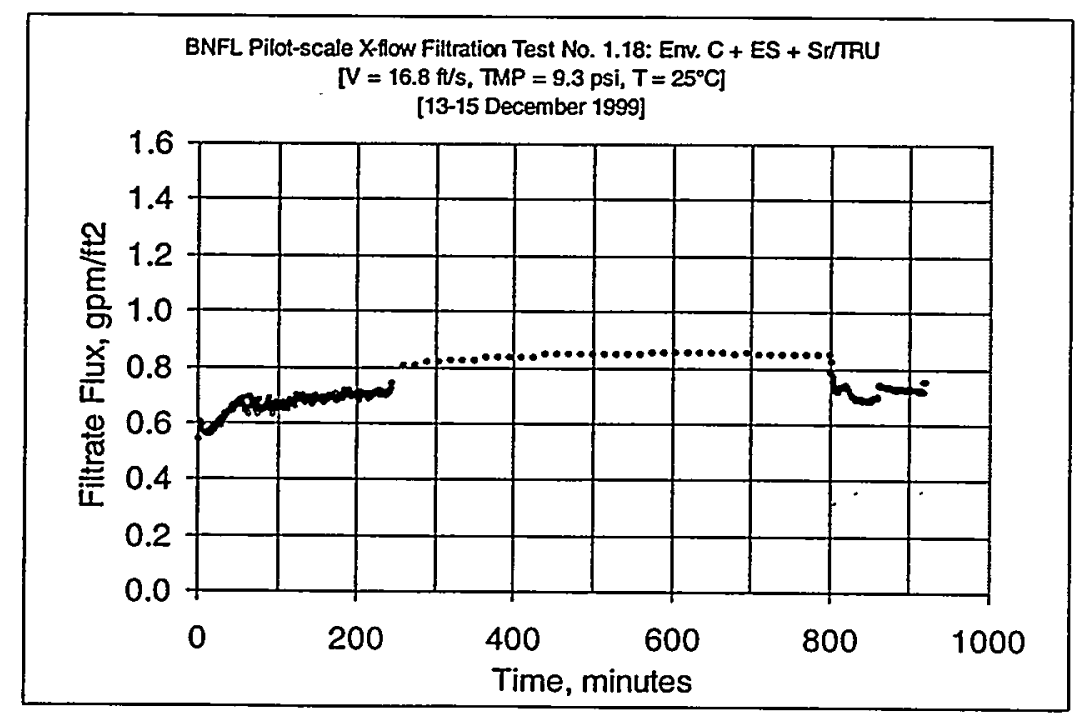

Figure 32. Cleaning run 1.18 with $1 \mathrm{M} \mathrm{NaOH}$ 
The entire next day, 12/14/99, was dedicated to cleaning. The large jump in filtrate flux at the 250-minute mark was probably due to "passive" cleaning which may have occurred from the filter being submerged in the cleaning solution overnight for approximately 15 hours. The cleaning continued on that day for about 9 hours and the data were acquired at a frequency of 15 minutes, from 250 to 800 minutes. At about 600 -minute mark the filtrate flux no longer increased with time and therefore it was assumed no further filter cleaning would occur. Therefore, on the final day, 12/15/99, the cleaning solution was allowed to circulate throughout the entire test rig. The immediate drop in filtrate flux on this last day was probably due to the solids that remained in the entire test rig, i.e., pumps, slurry reservoir tank, recirculation loop, valves, etc. After two backpulses the filtrate flux began to return. The cleaning was stopped and the rig was readied for the final water run 1.19. Figure 22 shows that the test rig was free of solids from a sample taken during the final water run.

Acid cleaning was effective but after approximately 95 hours of Envelope $C$ slurry circulation there seemed to be some permanent losses of filtrate flux. Figure 33 shows the results from the final water run 1.19. Once again, as for run 1.00, at an axial filter velocity of $12 \mathrm{ft} / \mathrm{s}$ with water, the highest TMP indicated in the test matrix, Fig. 21, could not be attained, even with all three pumps running. To have three data sets with water, a TMP midpoint between 10 and 20 psid was chosen; it turned out to be 15.9 psid. A comparison between the two final water runs, run 1.17 and 1.19, Figs 31 and 33, indicate that at a TMP of 21 to $22 \mathrm{psid}$ the filtrate flux increased from $0.13 \mathrm{gpm} / \mathrm{ft}^{2}$, to 1.1 $\mathrm{gpm} / \mathrm{ft}^{2}$. However, comparing the final water result to the initial water result indicates a loss in filter performance. At a TMP of 11 psid, Fig. 33 shows a filtrate flux of about $0.42 \mathrm{gpm} / \mathrm{ft}^{2}$, which is only $60 \%$ of the initial water result of $0.7 \mathrm{gpm} / \mathrm{ft}^{2}$ from run 1.00 . At a TMP of $16 \mathrm{psid}$, Fig. 33 shows a filtrate flux of about $0.7 \mathrm{gpm} / \mathrm{ft}^{2}$, which is $70 \%$ of the initial water result of $1.0 \mathrm{gpm} / \mathrm{ft}^{2}$ at a TMP of $15 \mathrm{psid}$ from run 1.00 .

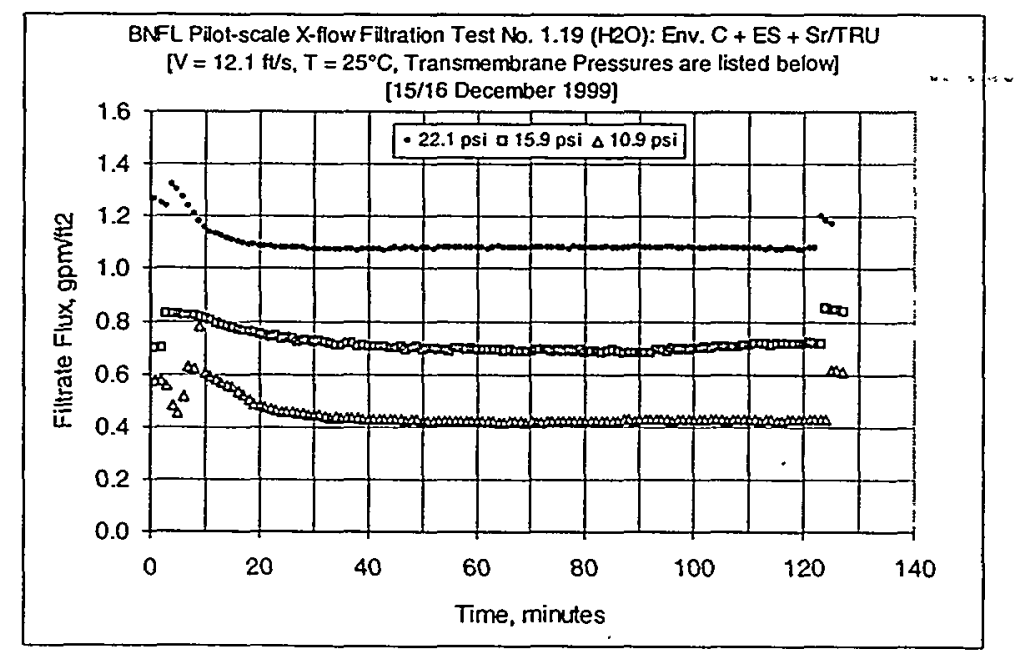

Figure 33. Final Water Run 1.19, after chemical cleaning 
Low Solids Concentration Test Runs 1.00 to 1.07

[See Appendix B for the entire set of data sheets.]

Included in this series of test runs were 14 planned and 4 unplanned runs [1.04a(old), $1.05 \mathrm{a}$ (old), 1.01a(old), and 1.07a]. This series of runs comprised the largest amount of data taken. The reason why there were 14 planned runs [1.01(old) to 1.07(old) and 1.01 to 1.07] is because just as the low concentrations runs were being completed BNFL requested a change of the test matrix order, as requested by DOE, to improve the statistical design of the matrix. Therefore, the first 7 runs were repeated and both sets were planned.

Figure 34 is an attempt to compare all the low solids concentration test runs together. Unfortunately, a direct comparison among all the runs is not straight forward since run times differed because of many reasons. In general, the values for the filtrate flux given in the graph are averages over the time of the test. Note that the there is a "Duration" time and a "Backpulse" time, shown in the table. The former is the total time for which the specific test was run. The latter is the approximate time between successive backpulses. The average filtrate fluxes given in table are based on the time between backpulses, which usually was close to the two hours requested by the test specification $(3,4)$.

Also included in Fig. 34 is the measured solids loading. For these runs, samples were only taken during run 1.01 (old) and 1.07 (old). The numbers in the table are the measured results. For the other 16 runs those two measurements were simply rounded off and repeated since the solids loading should not have changed between run 1.01 and 1.07. This is the reason why the " $\sim$ " symbol is shown before all of those numbers. Even though runs 1.01 (old) through 1.07 (old) were repeated, new samples were not taken.

From Fig. 34 it would appear that the flow conditions of number 1 [run 1.01(old)], i.e., $\mathrm{V}=12 \mathrm{ft} / \mathrm{s}$ and $T M P=56 \mathrm{psid}$, gave the highest filtrate flux. (These same conditions gave close to the highest filtrate flux in a previous test, with a different simulant, when the filter was new and relatively clean. See Fig. 25 of Ref. 22.) A close second are the runs of numbers 5,7 , and 9 , with an axial velocity of $15 \mathrm{ft} / \mathrm{s}$ and TMP $=31$ to $55 \mathrm{psid}$. They all had a filtrate flux of $0.07 \mathrm{gpm} / \mathrm{ft}^{2}$, or better. Note, the error bars that bound each data point on the graph are based on the measurement uncertainty determined in Appendix F. Further, as was shown from the Envelope A test (22), the filtrate flux is not as strongly affected by TMP as it is by the slurry velocity. However, direct comparisons are made difficult by the effect of filter, or slurry, degradation with time. From the database several examples could be used to study degradation, but the test runs done at an average set of flow conditions of $\mathrm{V}=12 \mathrm{ft} / \mathrm{s}$ and $\mathrm{TMP}=52 \mathrm{psid}$, had the largest number of data points. 


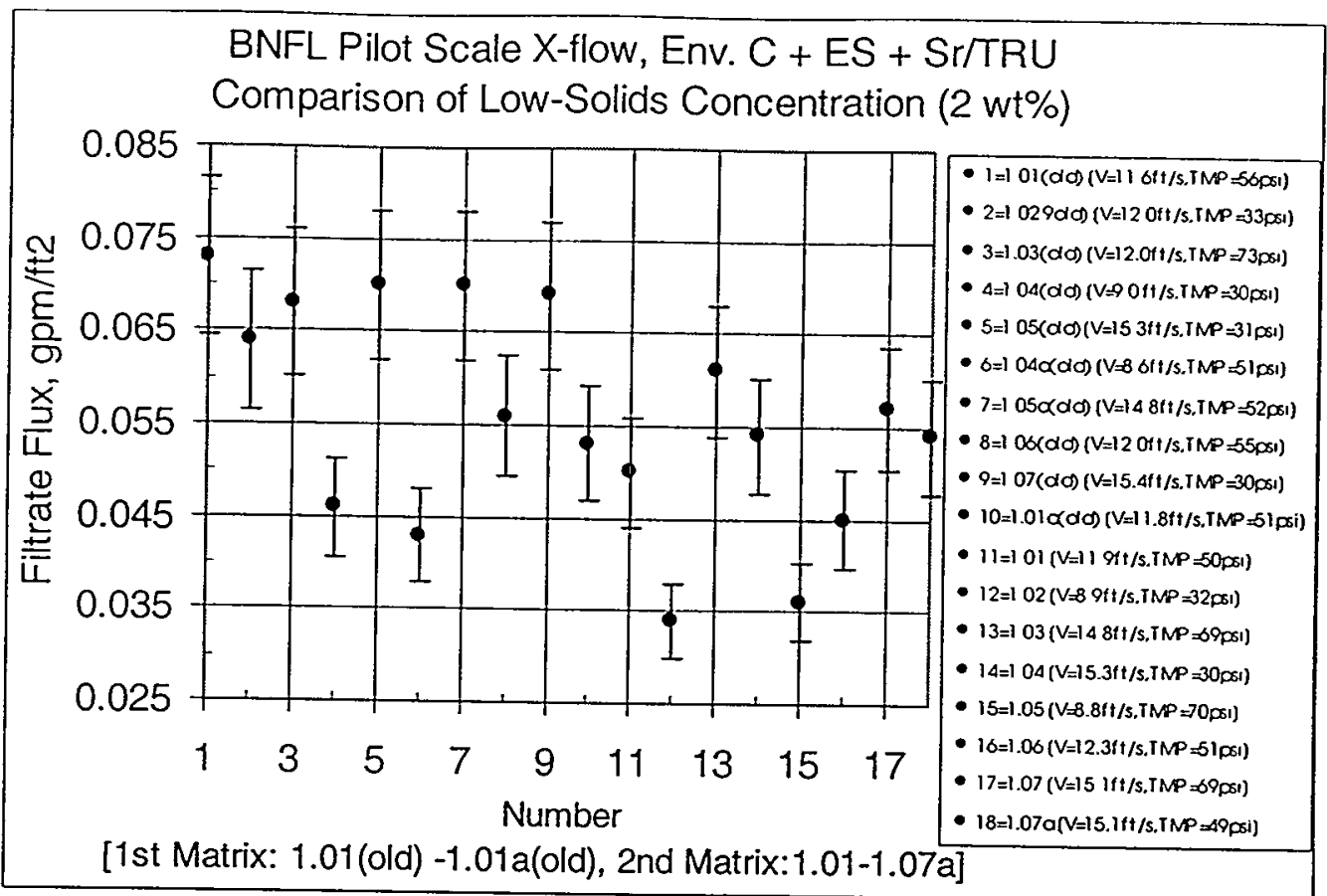

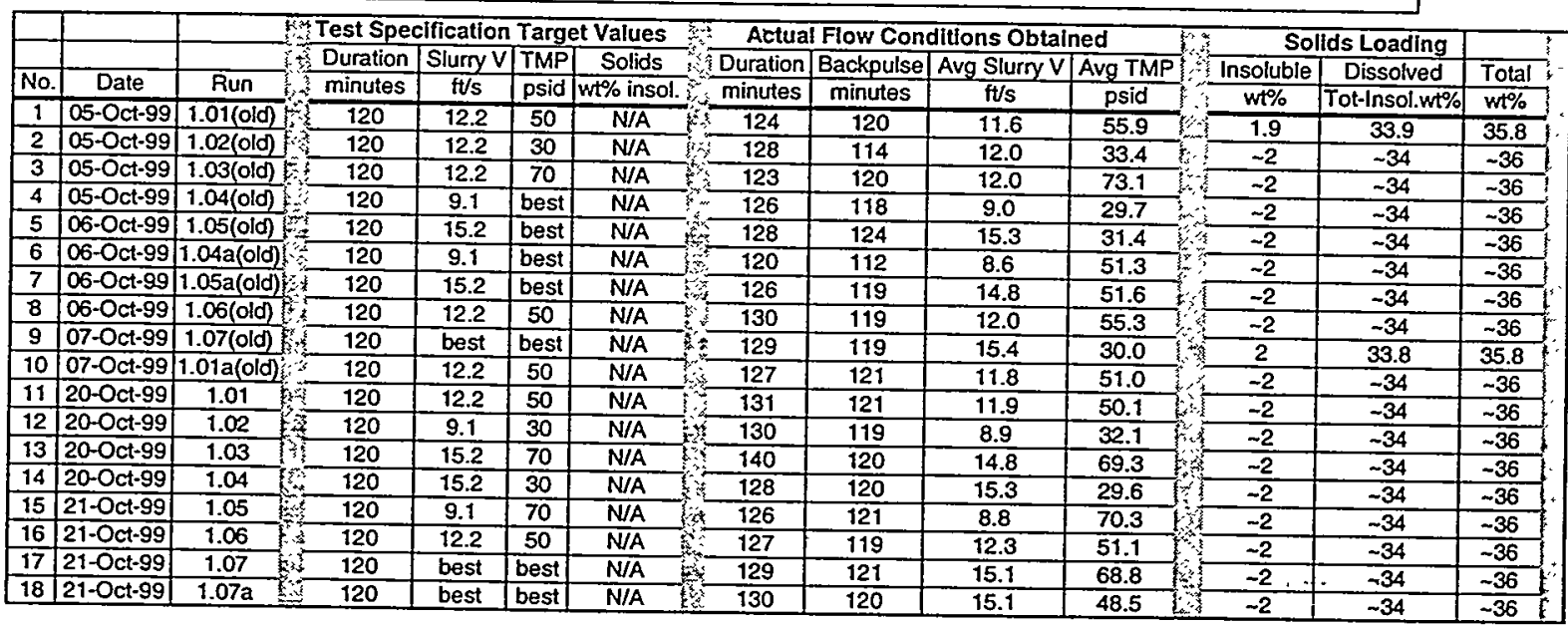

Figure 34. Composite of all 18 low solids concentration test runs

Figure 35 shows the average filtrate fluxes from five test runs [i.e., 1.01(old), 1.06(old), $1.01 \mathrm{a}$ (old), 1.01, and 1.06]. The curve and equation in Fig 35 are from a least squares best fit of the data. Over the 35 hours of slurry circulation through the filter the filtrate flux decreased by approximately $60 \%$. Therefore, during the period of each test, which had durations of approximately 2 hours, the filtrate flux would degrade by approximately $[1-\exp (-0.0151 \times 2$ hours $)] \times 100 \%=3 \%$ (see the relation on Fig. 35$)$. This $3 \%$ is a permanent loss of filter performance until it can be cleaned. The time showin in Fig. 35 is from the end of each completed test. That is reason the first data point begins just after 2 hours. 


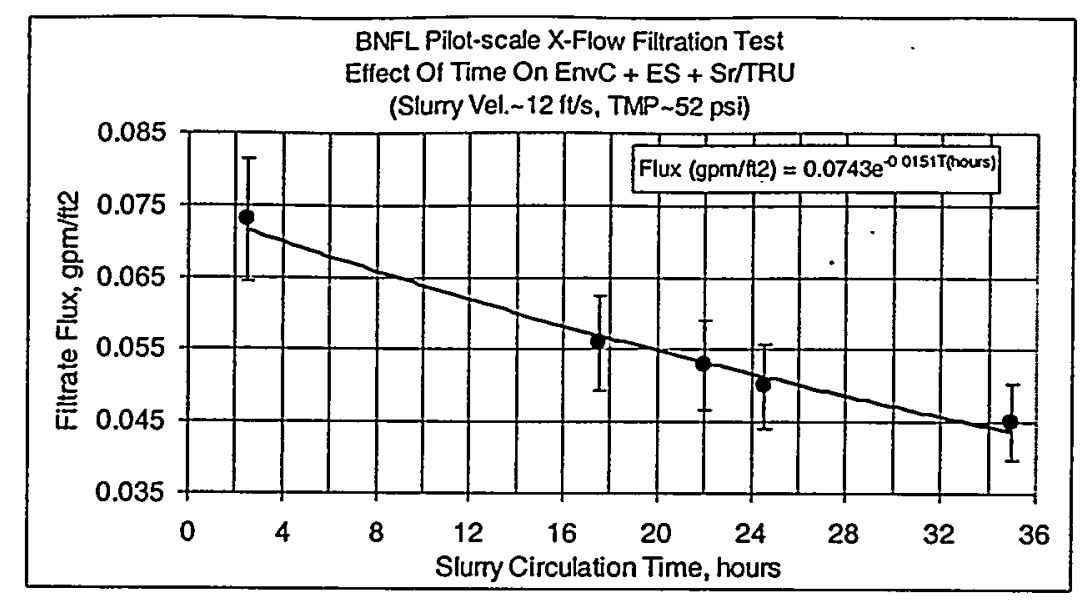

Figure 35. Effect of slurry circulation time on filter flux performance

Considering the effect shown in Fig. 35, then the general trend shown in the graph of Fig 34 makes sense. That is, independent of the flow condition, the overall trend of the filtrate flux data is to decrease with time. The data shown in Fig. 34 are in chronological order, as can be verified from the table shown below the graph. The conclusion here is that results can only be compared which are close to each other in time, if statements of superior flow conditions are to make sense. To reiterate, due to the $3 \%$ filtrate flux degradation, time must be considered when making comparison among the test runs. The test was designed to have a 2-level, 2-factor, full-factorial 2-centerpoint matrix, but this is confounded by a degradation time factor. However, because of repeat runs there is sufficient information to perform a meaningful statistical analysis of the data (e.g. using a linear model, Filtrate Flux = f[V, TMP, (V)(TMP)]). Unfortunately, because of the measurement uncertainty in the factors, the analysis is complicated by the errors-invariables and is beyond the scope of this report. In lieu of a statistical analysis, quantitative statements can be made on test runs that are in chronological close proximity. That is, since the measurement uncertainty for the temperature corrected filtrate flux is $11.7 \%$, which is mentioned in the Experimental section of this report (also in Appendix F), the 3\% filtrate flux degradation is insignificant between runs that are less than 8 hours apart.

Figure 34 implies that the highest slurry velocities were the best for obtaining the highest filtrate flux and the TMP played a much smaller role. For number 1,2, and 3, within measurement uncertainty, all TMP values for a slurry velocity of $12 \mathrm{ft} / \mathrm{s}$ were the same. The same result is seen when comparing numbers 13 and, 14 at $15 \mathrm{ft} / \mathrm{s}$. Comparing numbers 7 and 8 at an average TMP of 54 psid, the reduction of slurry velocity from 15 $\mathrm{ft} / \mathrm{s}$ to $12 \mathrm{ft} / \mathrm{s}$ had a significant reduction in filtrate flux. The same can be stated for numbers 6,7 , and 8 at an average TMP of 53 psid where the filtrate flux increased with increased slurry velocity; the largest increase occurring when the velocity increased from $6.8 \mathrm{ft} / \mathrm{s}$ to $14.8 \mathrm{ft} / \mathrm{s}$. The trend in clear: the higher the slurry velocity the higher the filtrate flux. An increase in TMP also leads to increased filter performance but the increase is 
barely significant. It appears that good performance can be achieved if the slurry velocity is maximized while keeping the TMP at low to moderate levels, i.e., $\sim 30$ to 50 psid.

\section{Concentrating (Dewatering) Test Run 1.08 (Pre-wash)}

[See Appendix $C$ for the entire set of data sheets.]

Before the seven (pre-wash) steady-state high solids-concentration test runs were to be done, the slurry had to be dewatered to obtain the desired solids concentration. Because of the Sr/TRU precipitants, the slurry solids concentration could not be increased by simply adding more solids. That is, a large slurry volume of $2 \mathrm{wt} \%$ insoluble solids slurry was needed to be dewatered to a concentration of $20 \mathrm{wt} \%$. Therefore, run 1.08 started with a batch of 618 liters of fresh simulant with a $2 \mathrm{wt} \%$ insoluble solids concentration. That batch was then dewatered for approximately 29 hours to a volume of 50 liters, resulting in a concentration of $22 \mathrm{wt} \%$ of insoluble solids. (The total solids increased from $36 \mathrm{wt} \%$ to $49 \mathrm{wt} \%$.)

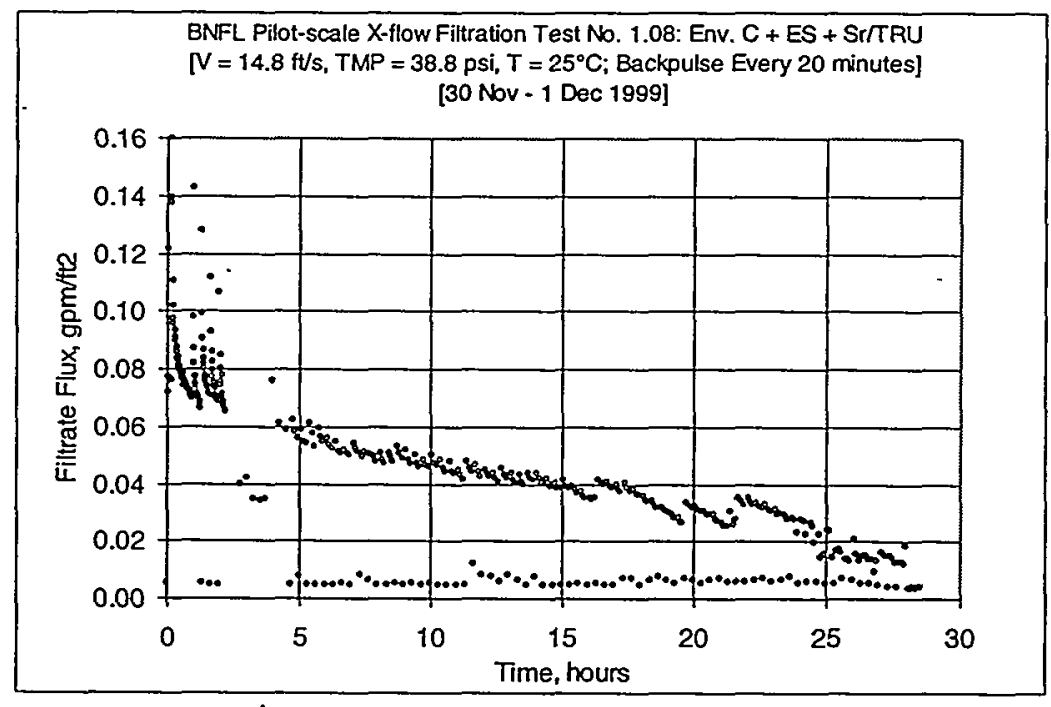

Figure 36. Pre-wash dewatering from 2 to $22 \mathrm{wt} \%$ insoluble solids [Data points near $0 \mathrm{gpm} / \mathrm{ft}^{2}$ are when the flux was interrupted during backpulsing]

Figure 36 shows the operation of the test rig throughout the dewatering process. On 11/30/99 from 03:40 to 09:30 hours a batch of 618 liters of simulant was made. After preliminary checks on the test rig were made, and after approximately 100 liters of this new simulant were placed in the rig, the dewatering test run began at 09:53 hours that same morning. The rest of the 500 liters of simulant was kept well mixed in a large separate tank and was periodically added to the test rig as the dewatering allowed. The backpulse overpressure was set to 40 psid and then the test began with an initial backpulse. The flow settings were: slurry velocity of $15 \mathrm{ft} / \mathrm{s}$ and a TMP of $48 \mathrm{psid}$. After approximately 1 hour the filtrate flux dropped to $0.07 \mathrm{gpm} / \mathrm{ft}^{2}$; therefore, another backpulse was made. At that point the backpulse frequency was set to every 1300 
seconds ( 21.7 minutes), with a 10 second hold time, in order to maintain the flux high. A high flux was desired to minimize the dewatering time. At 12:30 hours the data acquisition was slowed from 1 reading per minute to once every 15 minutes, and it continued at that rate until 14:30 hours, when the rate was increased to once every 5 minutes so that the backpulse data point could be captured. During most of the run the flow conditions were maintained at a slurry velocity of $15 \mathrm{ft} / \mathrm{s}$ and a TMP of $48 \mathrm{psid}$. However from about 12:30 to 14:00 hours the conditions dropped to $10 \mathrm{ft} / \mathrm{s}$ and $16 \mathrm{psid}$, which caused the filtrate flux to drop to $0.04 \mathrm{gpm} / \mathrm{ft}^{2}$. At 14:00 hours the original flow conditions were reestablished and the flux increased to $0.06 \mathrm{gpm} / \mathrm{ft}^{2}$. (Note: the lower TMP shown in Fig. 36, i.e., 38 psid, was the result of all the backpulse data points lowering the average.) By 07:00 hours the following morning, on 12/1/99, the slurry volume was reduced to approximately 130 liters and therefore was completely contained within test rig, which had a capacity of 135 liters. It took another 5 hours to reduce those 130 liters to 50 liters, when the slurry reached an insoluble solids concentration of 22 wt\%. At that point the filtrate flux was close to $0.01 \mathrm{gpm} / \mathrm{ft}^{2}$.

The magnitude of this highest solids concentration was good, but the test runs could not be sustained. As will be explained in the next section, the thick slurry created problems in the test rig. The pumps developed leaks because of seal failure and the thick slurry prevented good mixing in the reservoir tank, causing large temperature gradients. The slurry temperature slowly increased and eventually exceeded the test specification of a maximum of $30^{\circ} \mathrm{C}$.

High Solids Concentration Test Runs 1.09 to 1.14 (Pre-wash)

[See Appendix C for the entire set of data sheets.]

After the dewatering test run, 1.08, there were seven steady-state runs, 1.09/1.10, and 1.09 to 1.14 , that were to have a concentration as close to $20 \mathrm{wt} \%$ of insoluble solids as attainable. Run 1.09 immediately began at the end of the test run 1.08 when reaching 50 liters because the test rig was showing signs of not being able to handle the thick slurry for a significant time period, as explained above. The first high-solids concentration steady-state slurry run was 1.09 , but the flow conditions of run 1.10 were used because they were less challenging to the pumps and only two pumps were needed. Therefore, that run was called 1.09/1.10. Unfortunately, the test rig had to be stopped after about 35 minutes due to the pump and temperature problems. The flow conditions for that run and the others are in Fig. 37.

Figure 37 is an overall comparison of the all the test runs with the pre-washed dewatered slurry and the structure of the table is similar to that shown as Fig. 34. The results of 1.09/1.10 are show in Fig. 38. Even though the slurry had a high insoluble solids concentration of $22 \mathrm{wt} \%$, there was measurable filtrate flux, albeit very low. The flux of $0.01 \mathrm{gpm} / \mathrm{ft}^{2}$ appeared to be maintainable, if the test did not have to be stopped because of pump leaks. After the test was stopped, the seals in the pumps were changed so that the next run could begin. However, before beginning again, the slurry was diluted with filtrate to reduce the solids concentration. The slurry reservoir was filled to approximately the 75-liter level, where the estimated solids concentration was $15 \mathrm{wt} \%$. 
Subsequently, an analytical measurement showed the insoluble solids concentration to be $14.3 \mathrm{wt} \%$. With this solids loading the remaining steady-state slurry runs, i. e, 1.09 to 1.14 , were done.

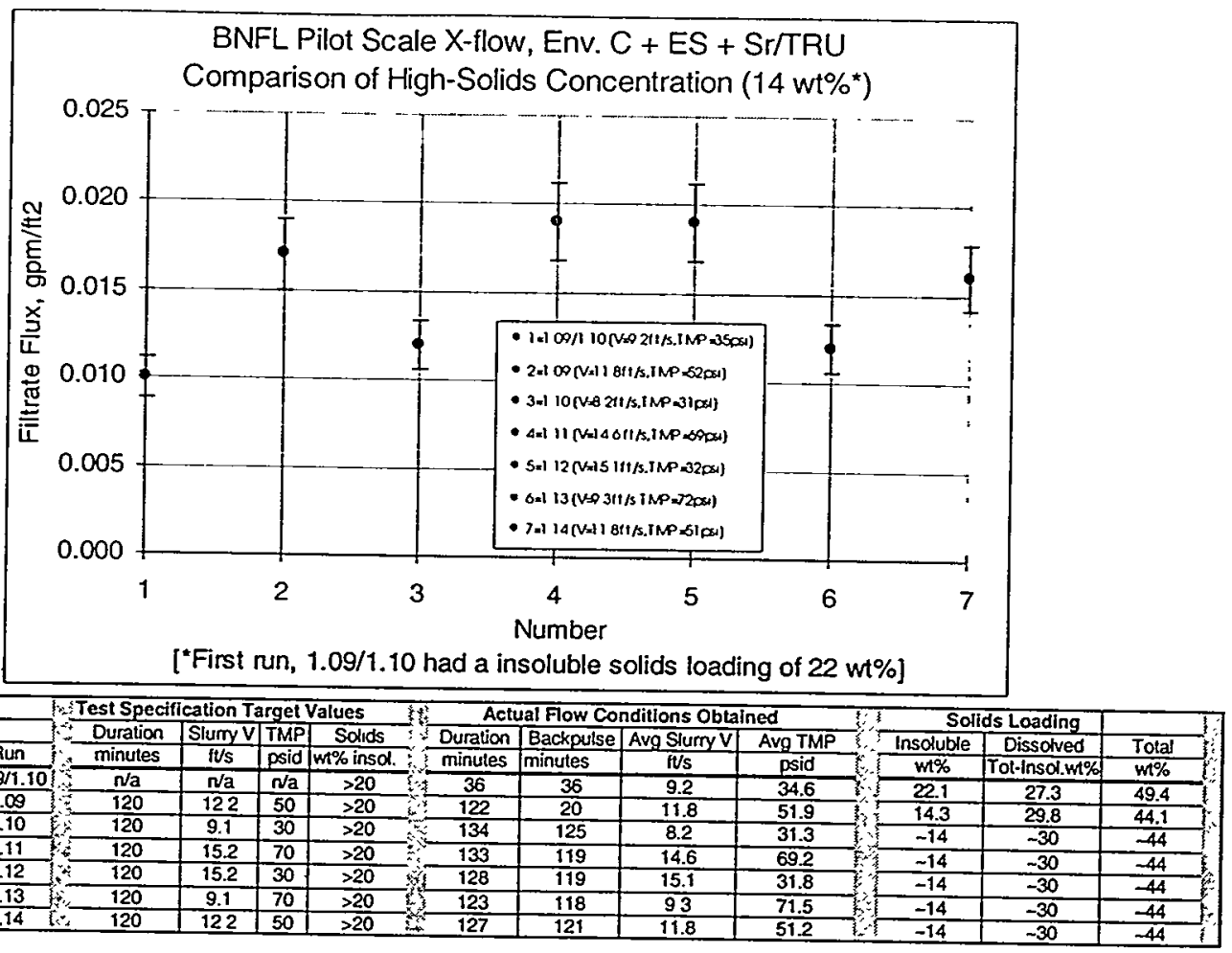

Figure 37. Composite of all 7 high solids concentration test runs

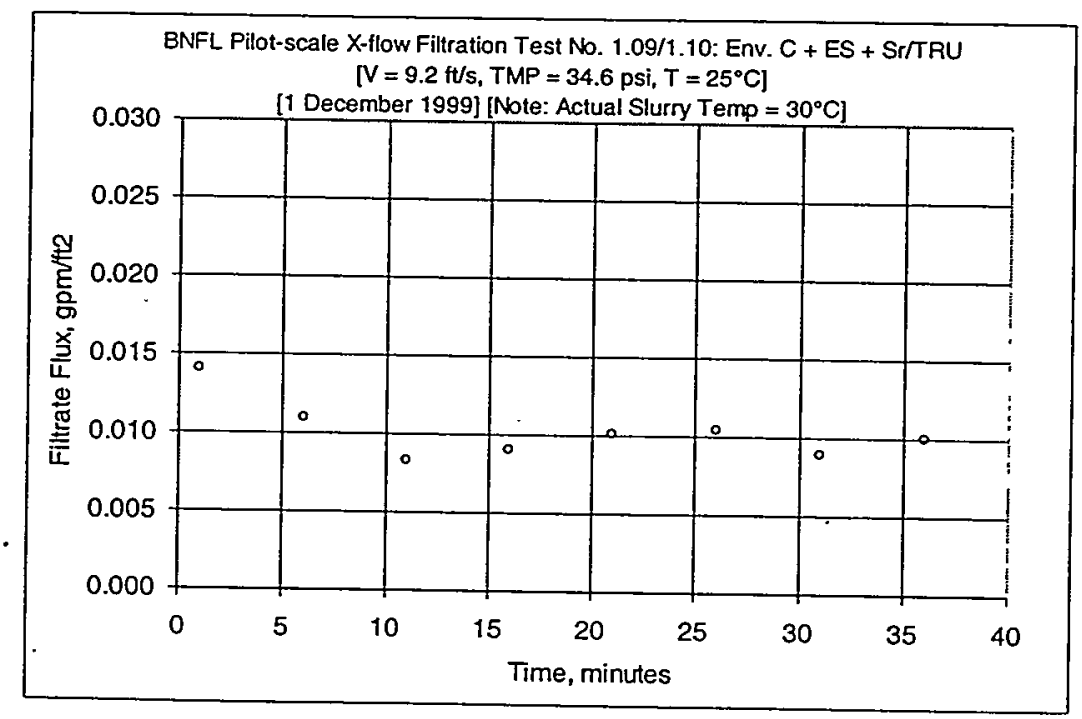

Figure 38 . Pre-wash steady state slurry run at $22 \mathrm{wt} \%$ insoluble solids 


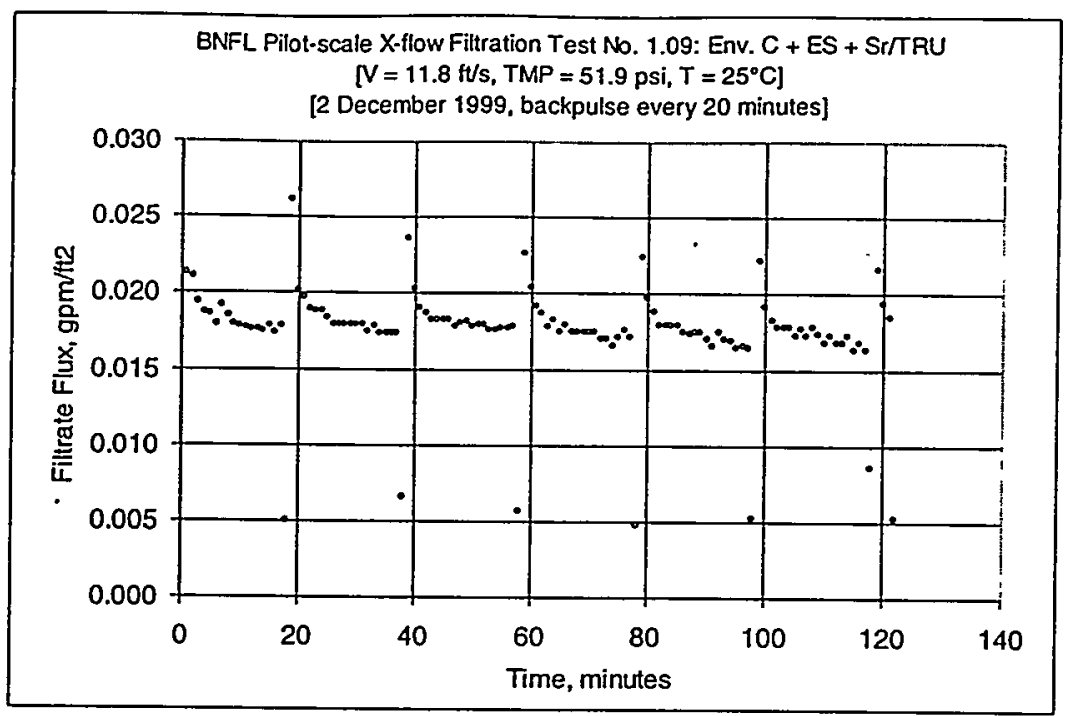

Figure 39. Pre-wash steady state slurry run at $14 \mathrm{wt} \%$ insoluble solids

Figure 39 shows results for run 1.09, with a backpulse frequency of 15-minutes. The interval was arbitrary but the backpulsing was found not to be effective because the filtrate flux decreased within minutes to the value the filter had just before the backpulse. Therefore, the remaining high concentration runs where done without backpulsing, except at the start and finish of each run, like all preceding test runs. All the high concentration runs show similar results and can be found in Appendix C. However, the best of all the runs, with respect of the filtrate flux, is shown below, run 1.12, Fig. 40 .

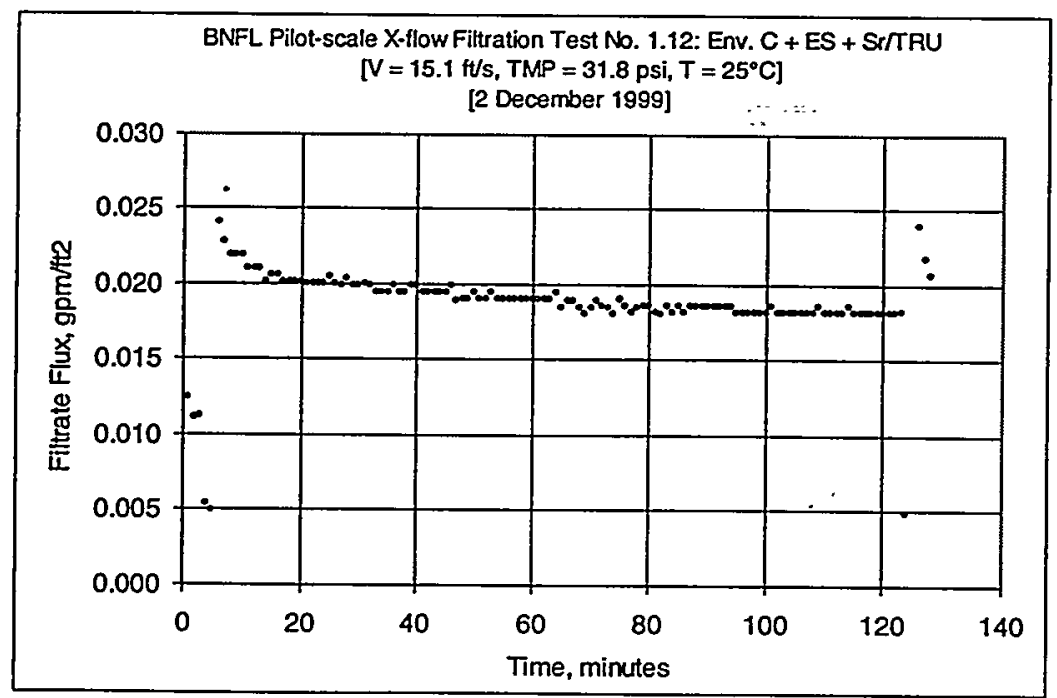

Figure 40. Pre-wash steady state slurry run at 14 wt\% insoluble solids: Run 1.12 
From Fig. 37 it can be seen that run 1.11 also had the same filtrate flux, but since it had a TMP of 69 psid, instead of the 32 psid of run 1.12, then the latter was considered better. In general, the conclusions of the low solids concentration runs hold here. That is, higher slurry velocities cause a significant increase in filter performance, while increasing TMP has a much less significant impact.

\section{Dewatering/Plugging Test Run 1.15}

[See Appendix C for the entire set of data sheets.]

After the high solids concentration runs were completed, the slurry was washed with four equal volumes of water, each equal to the volume of slurry to be washed, 75 liter, as already explained. For the pre- to post-washed slurry the solids concentration changed from $14 \mathrm{wt} \%$ of insoluble solids and $44 \mathrm{wt} \%$ of total solids to $18 \mathrm{wt} \%$ and $19 \mathrm{wt} \%$, respectively. Run 1.15 used the washed slurry to increase the solids concentration until the test rig could not concentrate further. The intention was to determine if the filter would become plugged, and then try to recover from the pluggage. The plugging run began on 12/9/99 and continued for just over two hours. Figure 41 shows that even with a relatively high value of insoluble solids, i.e., $18 \mathrm{wt} \%$, the filter performance was very good. The filtrate flux of $0.08 \mathrm{gpm} / \mathrm{ft}^{2}$ was better than any run thus far. This improved filter performance is attributable to the very low concentration of soluble solids, i.e., 19 $\mathrm{wt} \%-18 \mathrm{wt} \%=1 \mathrm{wt} \%$.

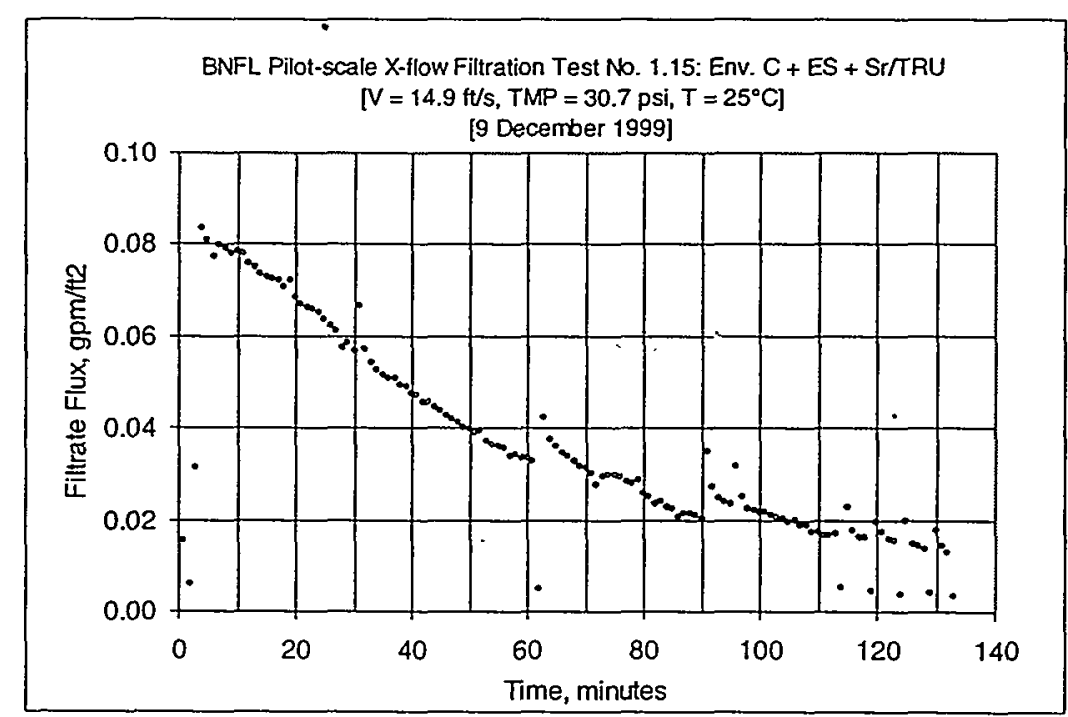

Figure 41. Post-wash plugging run from $18 \mathrm{wt} \%$ to $38 \mathrm{wt} \%$ of insoluble solids

Basically, the slurry was a mass of hard solids in water. In fact, the filtrate density was $1.009 \mathrm{~g} / \mathrm{cc}$ at $25^{\circ} \mathrm{C}$. However, after the two hours of dewatering and several backpulses the slurry became very viscous and the temperature was close to $40^{\circ} \mathrm{C}$. At that point the slurry volume was approximately 31 liters. The entire test rig itself takes about 26 liters 
to be filled. That left only a small amount of slurry in the slurry reservoir, which just covered the suction opening to the pumps. Finally, the slurry became so thick that it could not drain fast enough into the bottom of the reservoir and the pump suction began to ingest air, which stopped the filter flow and the test. At no time did filtrate flow stop. During the dewatering the Bingham plastic rheological properties of the slurry changed from a consistency of $4 \mathrm{cP}$ and a yield stress of 22 dynes $/ \mathrm{cm}^{2}$, to a consistency of $24 \mathrm{cP}$ to a yield stress of $684 \mathrm{dyns} / \mathrm{cm}^{2}$. The final solids concentration was $38 \mathrm{wt} \%$ of insoluble solids and $41 \mathrm{wt} \%$ of total solids.

The run would have been stopped in any case because of the increasing temperature and leaking pumps. At the end, all three pump seals had failed, but because the slurry was so thick the leaks were almost self contained. Figure 42 shows the slurry just before beginning the run.

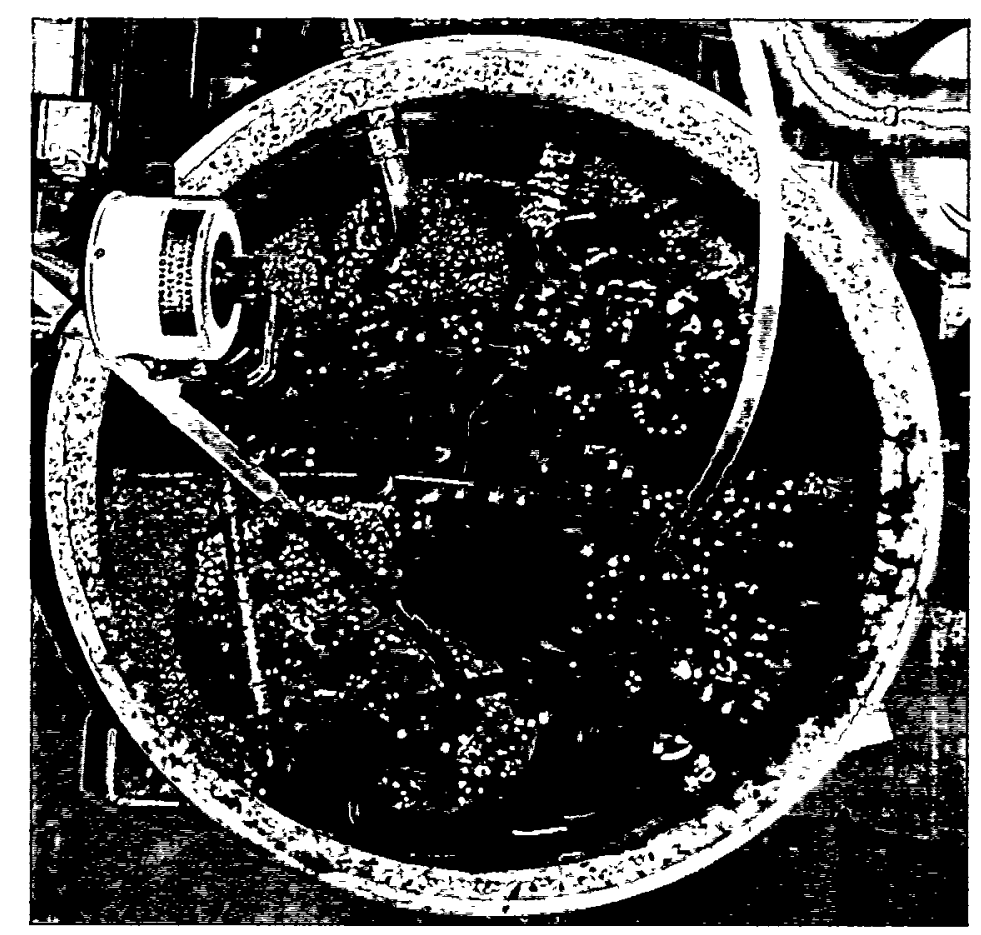

Figure 42. Beginning of the post-wash plugging run: $18 \mathrm{wt} \%$ of insoluble solids

Notice the portable mixer and two plastic lines entering the top of the reservoir. Both of these items were added to help keep the slurry mixed and cool. Unfortunately, these lastminute additions had little effect because of the very thick slurry. Figure 43 is a picture of the slurry that leaked out of one of the pumps. The slurry was basically sludge at that point. It was rigid enough to stand up by itself as can be seen by the layers in the photograph. The sludge had a ketchup-like characteristic. When poured, the sludge remains intact and needs some agitation to flow, e.g., a $250-\mathrm{mL}$ sample was taken and it 
would not flow out of the bottle without a lot of shaking. However, once the sludge began to move it flowed relatively free.

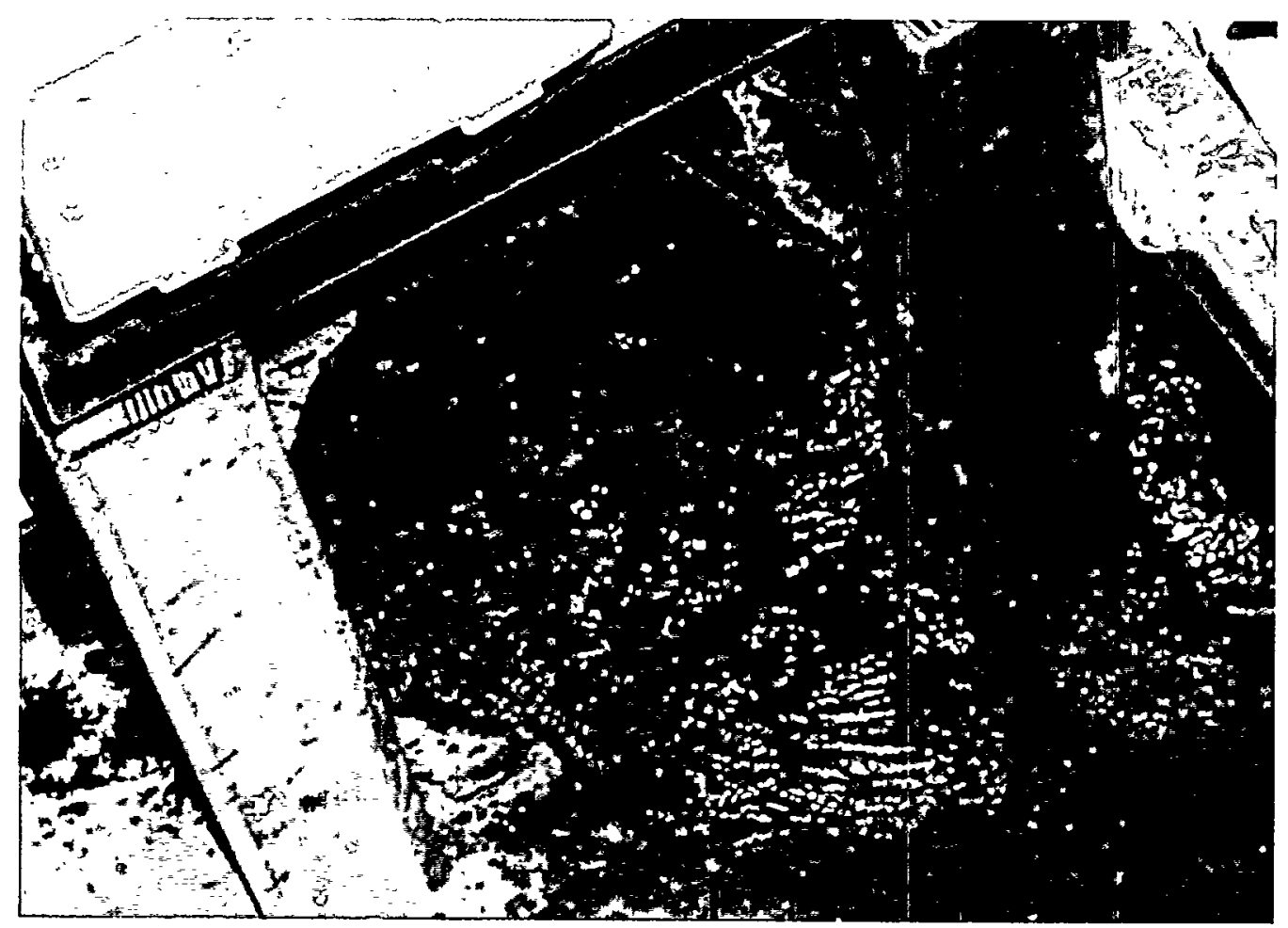

Figure 43. End of the post-wash plugging run: $38 \mathrm{wt} \%$ of insoluble solids

\section{Backpulse Frequency and Filter Fouling}

The main focus of this test was to determine an optimum filtrate flow for different slurryflow parameters and solids loadings. Therefore the effect of backpulse frequency was not addressed. For the steady-state solids loading test runs (low-and high-solids concentrations), backpulsing was specified (3) to be done only at the beginning and end of each test run (usually 2 hours in length), so that the filter always started from the same condition. More frequent backpulsing was allowed during the dewatering runs but those runs were not conducive to optimizing backpulse frequency because of the changing slurry solids loading. However, the frequency used, 2 hours, is within the manufacturer's, Mott, recommendation of not more than once an hour. Since the filter is made from sintered metal with a thickness of 0.0625 inch $(1.6 \mathrm{~mm})$, there is a concern of depth fouling of the filter wall. Once a filter cake is established on the filter wall, the cake itself does the filtering, preventing particles from entering into the porous-tube pores. When a backpulse is done, the cake is cleared from the wall, exposing the pores to the smallest particles in the slurry. Therefore, surface fouling (the filter cake) mitigates depth fouling. The effect of backpulse frequency was investigated in a preceding test, which used an envelope A slurry simulant (see Fig. 30 of reference 22). In that test, 
increasing the backpulse frequency by a factor of 90 only doubled the filtrate flux. (The test compared several backpulse frequencies between 7.5 hours and 5 minutes). It was found (22) that increasing the backpulse frequency increased the filtrate flux. However, the amount of increase many not compensate the increased frequency of filter cleaning due to depth fouling. In fact, that test showed that for the 7.5-hour run the filtrate flux was still above that requiring a backpulse. Therefore, backpulsing only one or twice a day may be be sufficient for adequate operation. Finally, Figure 35 of this report implies that with time, even a 2-hour backpulse frequency leads to some depth fouling. However, since at the end of each 2-hour test the filtrate flux returns to approximately its original value (e.g. Fig. 39), the predominant mode of fouling is surface fouling.

\section{CONCLUSIONS}

The following conclusions are for the nominal rated 0.1 micron MOTT cross-flow filter that was used under the conditions stated herein at a slurry temperature of $25^{\circ} \mathrm{C}$.

\section{Filter Effectiveness}

1. There was no measurable quantity of insoluble solids in the filtrate under any circumstance from the filtered slurry that had a solids loading from $2 \mathrm{wt} \%$ to greater than $38 \mathrm{wt} \%$ and for particle sizes measured as small as 0.75 micron.

\section{Slurry Wash}

2. Using 4 equal quantities of distilled and filtered water (each quantity equaling the volume of the slurry to be washed), the sodium molarity of the filtrate decreased from $6 \mathrm{M}$ to $0.2 \mathrm{M}$, while the dynamic viscosity decreased from $4 \mathrm{cP}$ to $1 \mathrm{cP}$ and the density decreased from $1.28 \mathrm{~g} / \mathrm{mL}$ to $1.01 \mathrm{~g} / \mathrm{mL}$.

\section{Hydraulic Characteristics}

3. Filter can be cleaned with $1 \mathrm{M} \mathrm{NaOH}$ such that the water flux before and after use returns to 60 to $70 \%$ of the initial filtrate flux.

4. Simple water rinsing is not sufficient to clean the filter.

5. Higher slurry velocities and higher transmembrane pressures lead to higher filtrate fluxes. However, the increase in filtrate flux is strongly affected by the slurry velocity but only weakly by TMP.

6. Slurry velocities for steady-state operation should be $12 \mathrm{ft} / \mathrm{s}$ or higher.

7. A TMP of $30 \mathrm{psid}$ or $55 \mathrm{psid}$, with the velocity in conclusion 6 , will give close to the best filter flux performance. Increasing the TMP to 70 psid will increase the filtrate flux slightly but that small increase may not justify the larger energy expenditure for the higher pressure.

8. For a low concentrations of insoluble solids ( $2 \mathrm{wt} \%$ ), run 1.01(old), shown in Fig. 34, gave the best overall filtrate flux of $0.07 \mathrm{gpm} / \mathrm{ft}^{2}$ at the conditions of a slurry velocity of $11.6 \mathrm{ft} / \mathrm{s}$ and a TMP of $56 \mathrm{psid}$. This flux is an average taken over the two hours of that test. However, run 1.05 (old) gave a similar performance at a velocity of $15 \mathrm{ft} / \mathrm{s}$ and a TMP of 31 psid. 
9. When the insoluble solids of the pre-wash slurry was increased to $14 \mathrm{wt} \%$ the filtrate flux decreased to between $0.01 \mathrm{gpm} / \mathrm{ft}^{2}$ and $0.02 \mathrm{gpm} / \mathrm{ft}^{2}$. The best flux was 0.018 $\mathrm{gpm} / \mathrm{ft}^{2}$ at a slurry velocity of $15 \mathrm{ft} / \mathrm{s}$ and a TMP of $31 \mathrm{psid}$.

10. For the single test run (1.09/1.10) with an insoluble solids concentration of $22 \mathrm{wt} \%$, the filtrate flux was maintained at $0.01 \mathrm{gpm} / \mathrm{ft} 2$ for approximately 35 minutes. (The run was stopped due to a pump seal failure and not from a filter pluggage.)

11. The cross-flow filter still functions for the post-washed slurry with an insoluble solids loading of up to $38 \mathrm{wt} \%$. At that loading the filtrate flux of was approximately 0.02 $\mathrm{gpm} / \mathrm{ft}^{2}$.

12. Surface fouling of the filter is dominant mechanism of fouling.

13. A backpulse filtrate volume of $0.036 \mathrm{gal} / \mathrm{ft}^{2}$ with a filter overpressure of 31 psi was found to be sufficient to knock the filter cake off the filter element. At a backpulse frequency of 30 minutes leads to a filtrate flux loss of $0.0012 \mathrm{gpm} / \mathrm{ft}^{2}$ rate, which is only a few percent of the lowest steady-state filtrate flux measured, $0.05 \mathrm{gpm} / \mathrm{ft}^{2}$.

\section{RECOMMENDATIONS}

The following recommendations are for the nominal rated 0.1 micron MOTT cross-flow filter when used for an Envelope C slurry at a temperature of $25^{\circ} \mathrm{C}$.

1. Use a slurry axial velocity of at least $12 \mathrm{ft} / \mathrm{s}$. Lower velocities significantly reduce filtrate flux.

2. Use a transmembrane pressure of 30 to 55 psid. Lower pressures significantly reduce filtrate flux and higher pressures do not increase the filtrate flux significantly.

3. Backpulse the filter twice to three times in a 24-hour period of continuous use to maintain an average filtrate flux of $0.05 \mathrm{gpm} / \mathrm{ft}^{2}$ and to minimize filter cleaning.

4. Investigations into other types of cleaning methods may lead to a method that returns the filter flux to better than 60 to $70 \%$ of the initial filter flux.

5. Use a backpulse of $0.036 \mathrm{gal} / \mathrm{ft}^{2}$ to minimize the loss of filtrate flux. 


\section{APPROVALS}

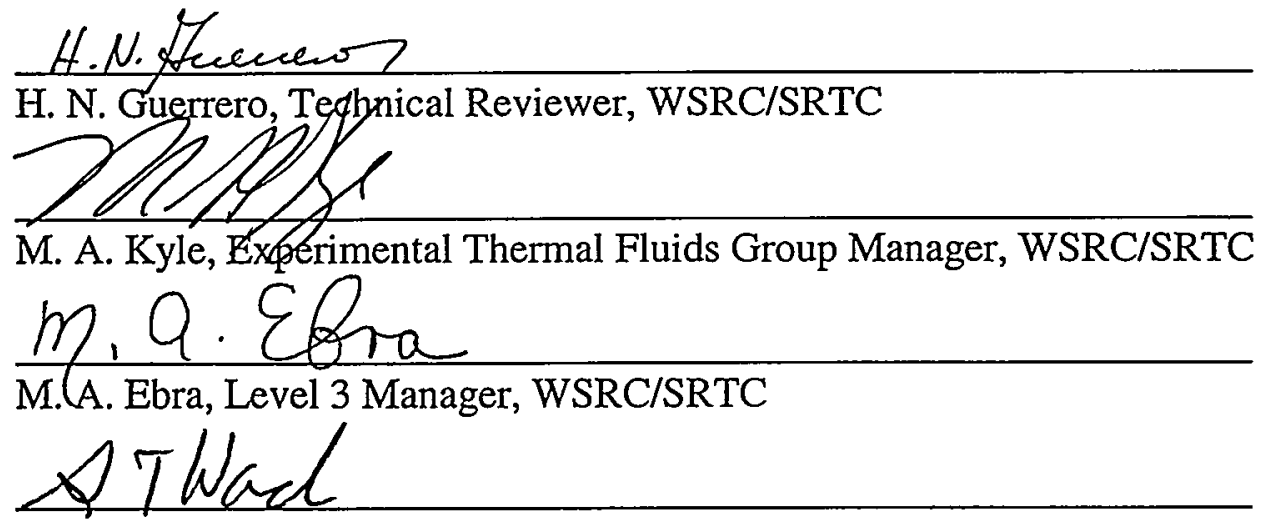

S. T. Wach, Waste Processing Technology Manager, WSRC/SRTC

Signature not required as per BNF-003-98-0239, April 24,

P. S. Townson, Ultrafiltration Development Manager, BNFL

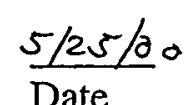

Date
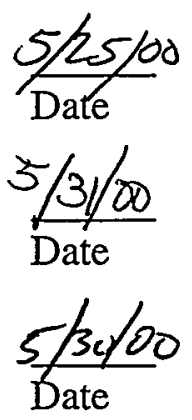

Date

\section{REFERENCES}

1. Nash, C. A., Technical Task Request, Document No. BNF-003-98-0014, Rev. 0, Oct. $15,1998$.

2. Johnson, M. E., "TWRS-P Contract No. DE-AC06-96RL13318 - W375 Equipment for the Pilot Scale Cross-Flow Filter Unit." Letter to S. T. Wach No. 000427, Oct. 29, 1998.

3. Townson, P. S., Ultrafiltration and Solids Dissolution Test Specification, Revision 1, Document No. 000750, Nov. 23, 1998.

4. Townson, P. S., Pilot scale inactive HLW Sludge Filtration Test Specification, Revision 0, Document No. 005931, Aug. 27, 1999 (also TSP-W375-99-0010, Rev.0). [Note: On 10/18/99 an e-mail was received from P. S. Townson to modify the test matrix to incorporate suggestions made by DOE.]

5. Duignan, "BNFL Pilot-scale Cross-flow. Filter Test," Task Notebook, Document No. WSRC-NB-00254. [Pages 5 (Sept. 31, 1998) to 41 (Apr. 28, 1999) are for the test rig construction and shakedown activities, Pages 74 (June 28, 1999) to 140 (Dec. 16, 1999), are for the test run.].

6. Duignan, M. R., "BNFL Pilot Scale Cross Flow Filtration Test," Task Technical and Quality Assurance Plan, Document No. BNF-003-98-0015, Rev. 1, Sept. 17, 1999.

7. Duignan, M. R., "TWRS Privatization Part B, SRTC WFO-98-003, Submittal of Pilot X-flow Test Rig Conceptual Design," Document No. BNF-003-98-00445, January 12, 1999. (Accompanied with the WSRC drawing: "BNFL Pilot Scale Crossflow Filter Test: Test Rig Assembly," Document No. EES-22699-M6-001, Rev. 0., by T. J. Steeper.)

8. Jo, J., J. D. Franklin, D. J. Morris, L. C. Amato, "Tank Characterization Report for Double-Shell Tank 241-AN-107," Report No. WHC-SD-WM-ER-600, Rev. 0, August 1996.

9. Urie, M. W., J. J. Wagner, L. R. Greenwood, O. T. Farmer, S. K. Fiskum, R. T. Ratner, C. Z. Soderquist, "Inorganic and Radiochemical Analysis of AW-101 and AN-107 
Pilot scale X-flow: EnvC+ES+Sr/TRU Page 57 of 256

“Diluted Feed" Materials," PNNL Doc. PNWD-2463 (BNFL-RPT-003, Rev. 0), May 1999.

10. Lumetta, G. J., F. V. Hoopes, "Washing of the AN-107 Entrained Solids," PNNL Doc. No. PNWD-2469 (BNFL-RPT-007, Rev. 0), June 1999.

11. Johnson, M. E., "Contract No. DE-AC06-96RL13318 - W375 - ENVELOPE C SIMULANT FOR PILOT-SCALE ULTRAFILTRATION TESTS," Letter to S. T. Wach No. 005463, Aug. 17, 1999.

12. Fowley, M. D., Screening Process Hazards Review Report, Feb. 22, 1999

13. Duignan, M. R. Environmental Evaluation Checklist, EEC Document No. TC-99-002, Approved on Feb. 24, 1999.

14. Duignan, M. R., SRS Final Acceptance Inspection of New or Altered Facilities or Equipment (SM-51), Approved on Mar. 24, 1999.

15. Steimke, J. L., C. M. Hart, and S. E. Sponseller, "Results from Tests of Du Pont Crossflow Filter (U)," Document No. WSRC-TR-94-0322, October 1994.

16. Nash, C. A. and J. Siler, "Filtration of Nonradioactive Handford Waste Simulants (U)," Document No. SRTC-BNFL-016, Rev. 0, Sept. 31, 1997.

17. Nash, C. A., S. W. Rosencrance, W. W. Walker, and W. R. Wilmarth, "Investigation of Varied Strontium-Transuranic Precipitation Chemistries of Crossflow Filtration," Document No. BNF-003-98-0171, Rev. 0, Mar. 23, 2000.

18. Duignan, M. R., "BNFL Pilot-scale Cross-flow Filtration Test," EDS Field Procedure, Document No. FP-801, Rev. 1., Sept. 27, 1999.

19. Duignan, M. R., Operational Instructions Nos. 1-7 (shakedown activities: March 1 to April 12, 1999), Nos, 18-27 (test activites: June 25, 1999 to November 31, 1999).

20. Wach, S. T., "RPP Privatization Part B, SRTC WFO-98-Transmittal of Preliminary Filtration Data - Envelope C," letter to P. S. Townson No. BNF-003-98-0202, Dec. 20, 999. [Attachment contains a partial set (187 pages) of preliminary data for the Envelope C Test.]

21. Wach, S. T., "RPP Privatization Part B, SRTC WFO-98-Transmittal of Preliminary Filtration Data - Envelope C," letter to P. S. Townson No. BNF-003-98-0205, Jan. 12, 2000. [Attachment contains the remaining set (56 pages) of preliminary data for the Envelope C Test.]

22. Duignan, M. R., "Final Report: Pilot-scale Cross-flow Ultrafiltration Test Using a Hanford Site Tank 241-AN-105 Waste Simulant - Envelope A + Entrained Solids," Document No. BNF-003-98-0221, Rev. 0, Feb. 23, 2000.

23. Personal Communications (e-mail) with Richard T. Hallen and Dean E. Kurath of PNNL on March 6 and 7, 2000.

24. Barnes, H. A., J. F. Hutton, and K. Walters, An Intoduction to Rheology, Rheology Series, 3, Elsevier Science B. V., Amsterdam, 1989. (ISBN 0-444-87140-3)

25. Personal Communications (e-mail) with Charles A. Nash of WSRC on March 1, 2000.

26. Personal Communications (e-mail) with Michael E. Johnson of BNFL, Inc. on March 6, 2000.

27. Tennekes, H. and J. L. Lumley, A First Course in Turbulence, MIT Press, Cambridge, Mass., 1983. (ISBN 0-262-20019-8)

28. Mandel, J., The Statistical Analysis of Experimental Data, National Bureau of Standards, Dover Publications, New York, 1964. (ISBN 0-486-64666-1) 


\section{APPENDIX A}

\section{EXPERIMENTAL DATA: WATER AND CLEANING}

\section{Appendix Contents}

1. Nomeclature sheet for data tables

2. Experimental data:

Fig. Run Solution Done on

A1 $1.00 \quad$ Initial Water 9/28-30/99

A2 1.17 Final Water(before cleaning) 12/13/99

A3 $1.19 \quad$ Final Water 12/15-16/99

A4 $1.18 \quad 1 \mathrm{M} \mathrm{NaOH}$ Cleaning $12 / 13-15 / 99$

General Note: For measurement uncertainties see Appendix F

Special Notes:

a. The data for every test run are highlighted with two graphs: Filtrate Flux vs. Time and Permeability vs. Time. Those graphs include all the data taken during the run period.

b. The beginning and end of the data for most graphs show large deviations from the overall series of points. Those deviations were caused by backpulsing the filter that temporarily stopped the flow of filtrate.

c. All columns of data, in all the tables, are ended with several statistical values of those columns, i.e., Average, Maximum, Median, Minimum, Standard Deviation, and Number of Points Used (in calculating the 5 statistical quantities).

d. To calculate those quantities mentioned in the preceding item, only those data points that start from the end of a backpulse to just before the ending backpulse were included. This is the reason why the quantity of Number of Points Used was given.

e. The data for the graphs, and all the data taken for the individual test run that the graphs represent, immediately follow the specific figure.

f. Note that the cleaning run, Fig. A4: Run 1.18, which was done over 3 days, was performed in different parts of the test rig. From December 13 and 14, only the cleaning loop was used, Fig. 1, to direct all the cleaning solution to clean the filter. On December 15 all the cleaning solutions was drained into the test rig proper, (that is, out of the cleaning loop) to clean the lower portion of the test rig, which includes the pumps. This is the reason why the filtrate flux drops. On that last day the entire test rig was operated for two hours with a backpulse made after 60 minutes of operation. As usual, a backpulse began and ended the test. 
Nomenclature For Data Sheets

(See Figure 1: Main Test Rig - Pilot Scale Cross Flow for the Instrument Location)

\begin{tabular}{|c|c|}
\hline Column & Heading \\
\hline$A=$ & DATE \\
\hline$B=$ & TIME \\
\hline$C=$ & SOLENOID \\
\hline$D=$ & FLTRT (deg \\
\hline$E=$ & CLLOOP (C \\
\hline$F=$ & SLLOOP $(\mathrm{C}$ \\
\hline $\mathbf{G}=$ & UP AMB (dE \\
\hline$H=$ & BOT AMB \\
\hline $1=$ & T6 (deg C) \\
\hline$J=$ & BOT DP (pS \\
\hline$K=$ & FLTR (psig) \\
\hline $\mathrm{L}=$ & FLTRDP ( \\
\hline$M=$ & TOP DP (DS \\
\hline$N=$ & FLTRATEA \\
\hline $0=$ & PISTON ( $\mathrm{pS}$ \\
\hline$P=$ & SLFLOW \\
\hline$Q=$ & Q2,FLTRFL \\
\hline $\mathbf{R}=$ & O3,FLTRFL \\
\hline
\end{tabular}

Full Heading

DATE

TIME

SOLENOIO

FLTRT (deg C) T2

CLLOOP (deg C) T3

- Eay the lest was done

Time data entry was made

$\therefore 1=y e s, 0=$ no: for the pressure to the backpulse piston

SL LOOP $(\operatorname{deg} C) T 1$

Fitrate Temperature in Fitter at exit of the Filter Housing

UP AMB (deg C) T4

Temperature of Liquid in the Cleaning Loop

Ambient Temperature at the top of the Test Rig - 3rd level

BOT AMB (deg C) T5 Ambient Temperature at the bottom of the Test Rig - 1st level

T6 (deg C) SPARE Spare Thermocouple - Currently Not Being Used

BOT DP ( $p$ sid) dP2 "Differential Pressure between the Filter Slury Entrance and the bottom Fittrate Exil

FLTR ( $p s i g) P 1$

FLTR DP (psid) dP1 $\quad$ Differential Pressure between the Filter Slurry Entrance and Exit

TOP DP (psig) dP3 Differential Pressure between the Filter Slurry Exit and the Top Fittrate Exit

FLTRATE (psig) P2 Gauge Pressure at the Filter Filtrate Exit

PISTON (psig) P3 Air Gauge Pressure Applied to Backpulse Piston

SL FLOW (gpm) Q1 Flow Rate of the Slurry Flow

FLTR FLOW (gpm) Q2 Fin Rate of the Filtrate Flow from $0101.2 \mathrm{gpm}$

The following columns are calculated results based on the appropriate columns

\begin{tabular}{|c|c|}
\hline$S=$ & Number \\
\hline$T=$ & Number \\
\hline $\mathbf{U}=$ & Vel, fts \\
\hline$V=$ & TMP,PSI \\
\hline$W=$ & TMP, bar \\
\hline$x=$ & GPM/FT2 \\
\hline$Y=$ & GPMFT2 \\
\hline$z=$ & 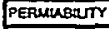 \\
\hline$A A=$ & $\times 1000$ \\
\hline$A B=$ & PERMuluturt \\
\hline
\end{tabular}

\begin{tabular}{|c|c|}
\hline$=$ & Number \\
\hline & Number \\
\hline & Vel, $\mathrm{ft} / \mathrm{s}$ \\
\hline$=$ & TMP. PSI \\
\hline & TMP, bar \\
\hline & GPMFI2 \\
\hline & GPMFT 2 at $25^{\circ} \mathrm{C}$ \\
\hline & 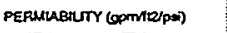 \\
\hline & PERMIABILTY $\times 1000$ \\
\hline
\end{tabular}

Data numbers which is (usually) equivalent to 1 minute since this was the acquisition frequency

tData numbers which are equal to or a subset from Column $S$ to facilitate graphing of sorro data sets

4 T Transmembrane Pressure $=([$ Column $\mathrm{J}]+[$ Column M $]) / 2$

: I Column U]/14.504 bar/psi

[ $\left[\right.$ Column $Q$ ] / inside diameter filter surface area $\left(=2.29 \mathrm{ft} 2^{*}\right)$

Test Spec. correction factor: [Column W] $\times \exp (2500 \times((1 /(273+[$ Column $T]))-(1 / 298)))$

[Column X] / [Column U]

PERMIABILTY $\times 1000 \%$ [Column $Z$ ] $\times 1000$

-Axial sturry flow area is based on 7 porous tubes with an inside diameter of $3 / 8 \mathrm{inch:} 7 \times \mathrm{pi} / 4^{\circ}(0.375 \mathrm{inch} / 12 \text { inches/ft })^{\wedge} 2=0.005369 \mathrm{ft}$

*.Inside diameter fitter surface area for 7 tubes with an inside diameter of $3 / 8$ inch, 40 -inches long: $7 \times$ pi $\times(0.375$ inch $) \times 40$ inches $/ 144$ im2/tn2 $=2.29 \mathrm{ft} 2$ 

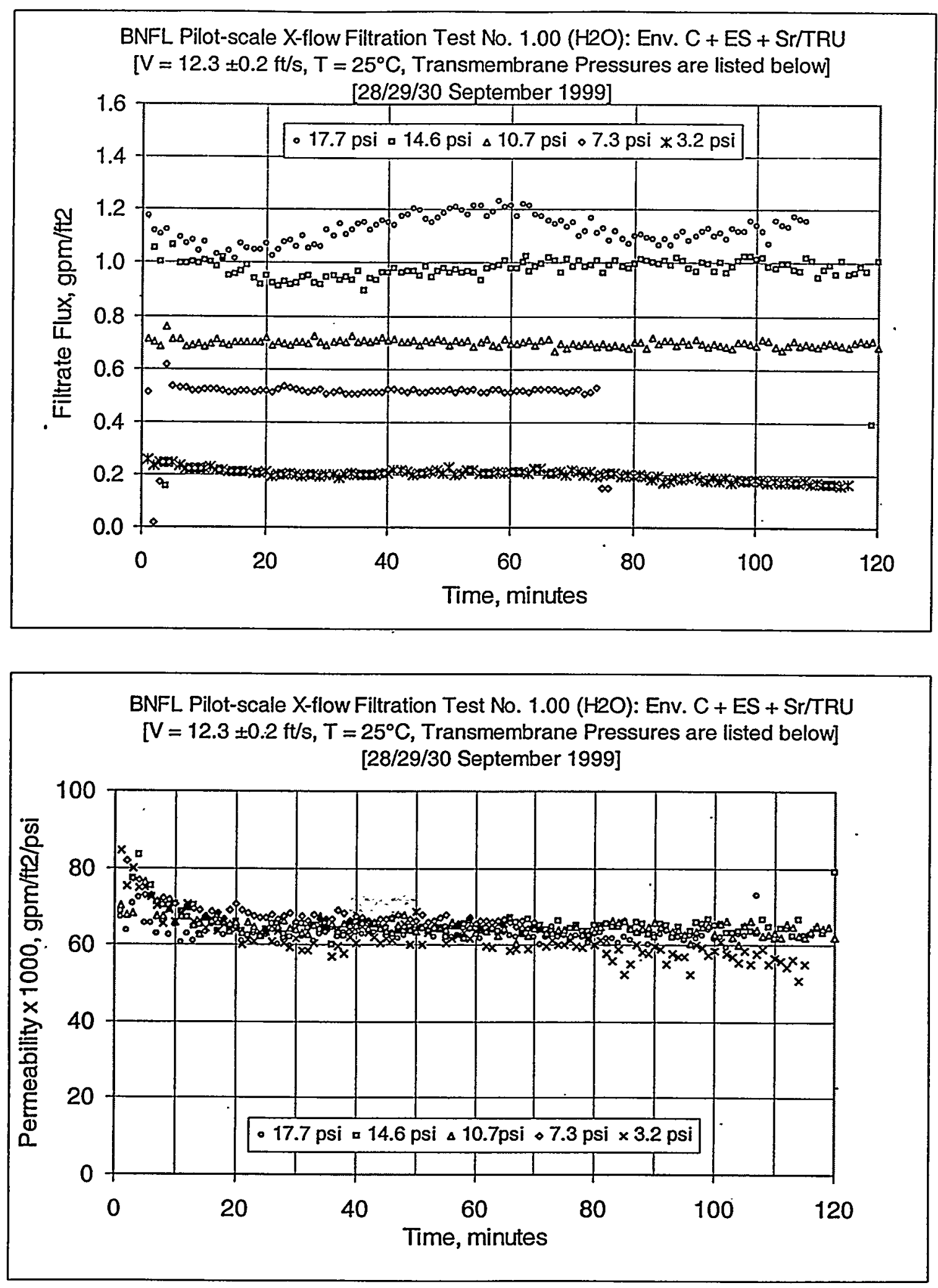

Figure A1: Test Run 1.00, Initial Water 
Pilot X-flow: EnvC+ES+Sr/TRU Page 61 of 256

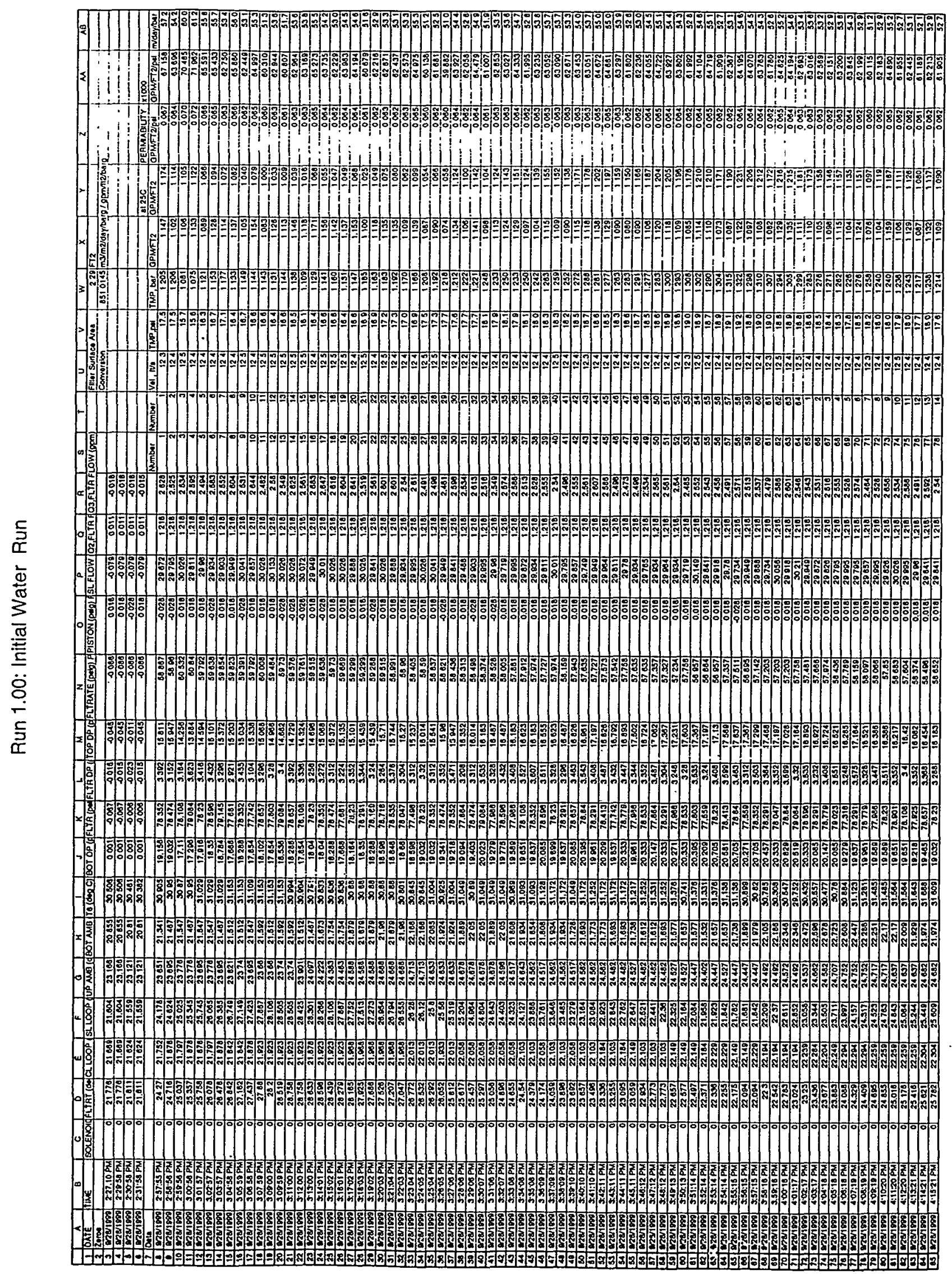


Pilot X-flow: EnvC+ES+Sr/TRU Page 62 of 256

BNF-003-98-0226

Revision 0

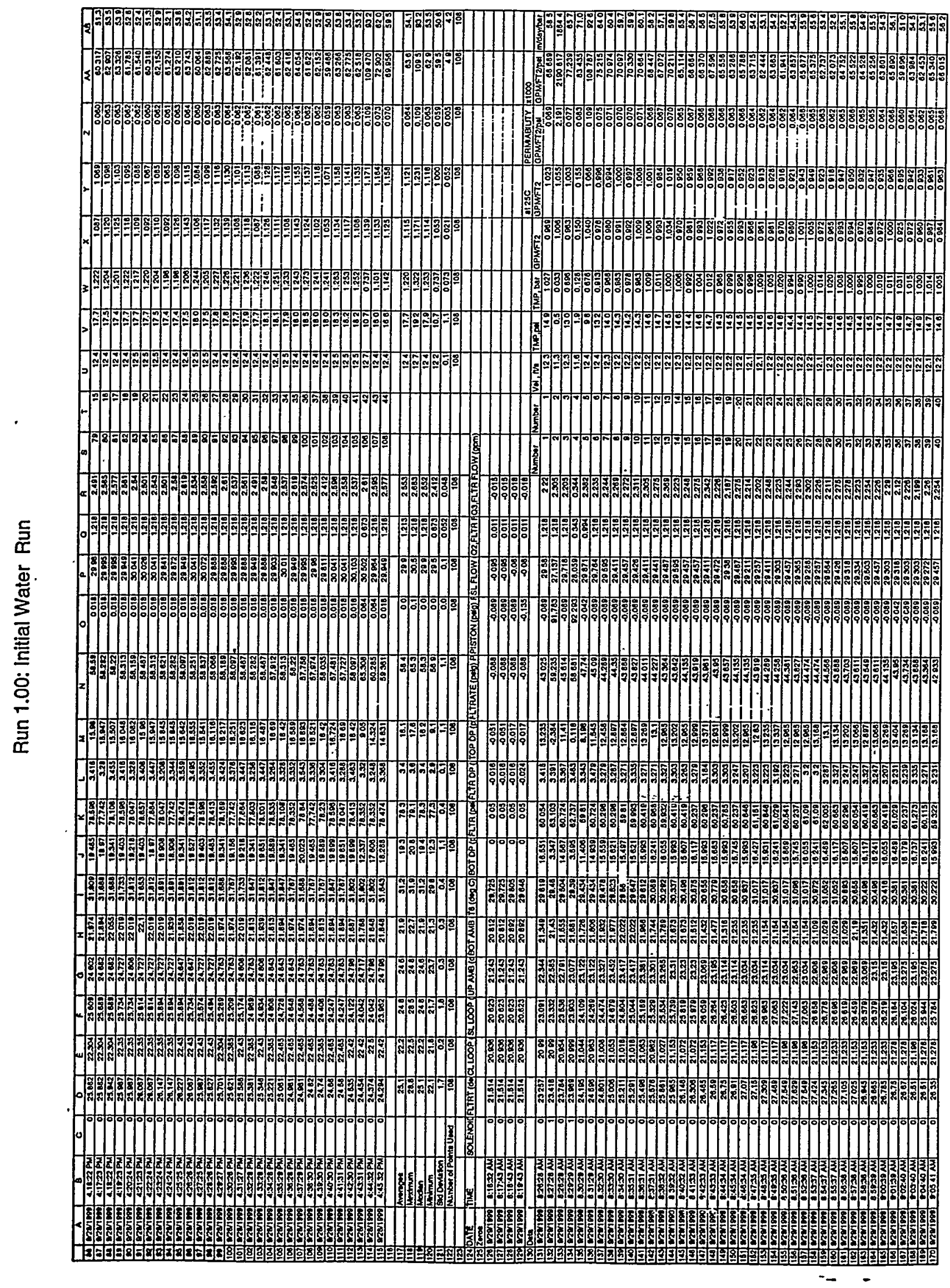


Pilot X-flow: EnvC+ES+Sr/TRU Page 63 of 256

BNF-003-98-0226

Revision 0

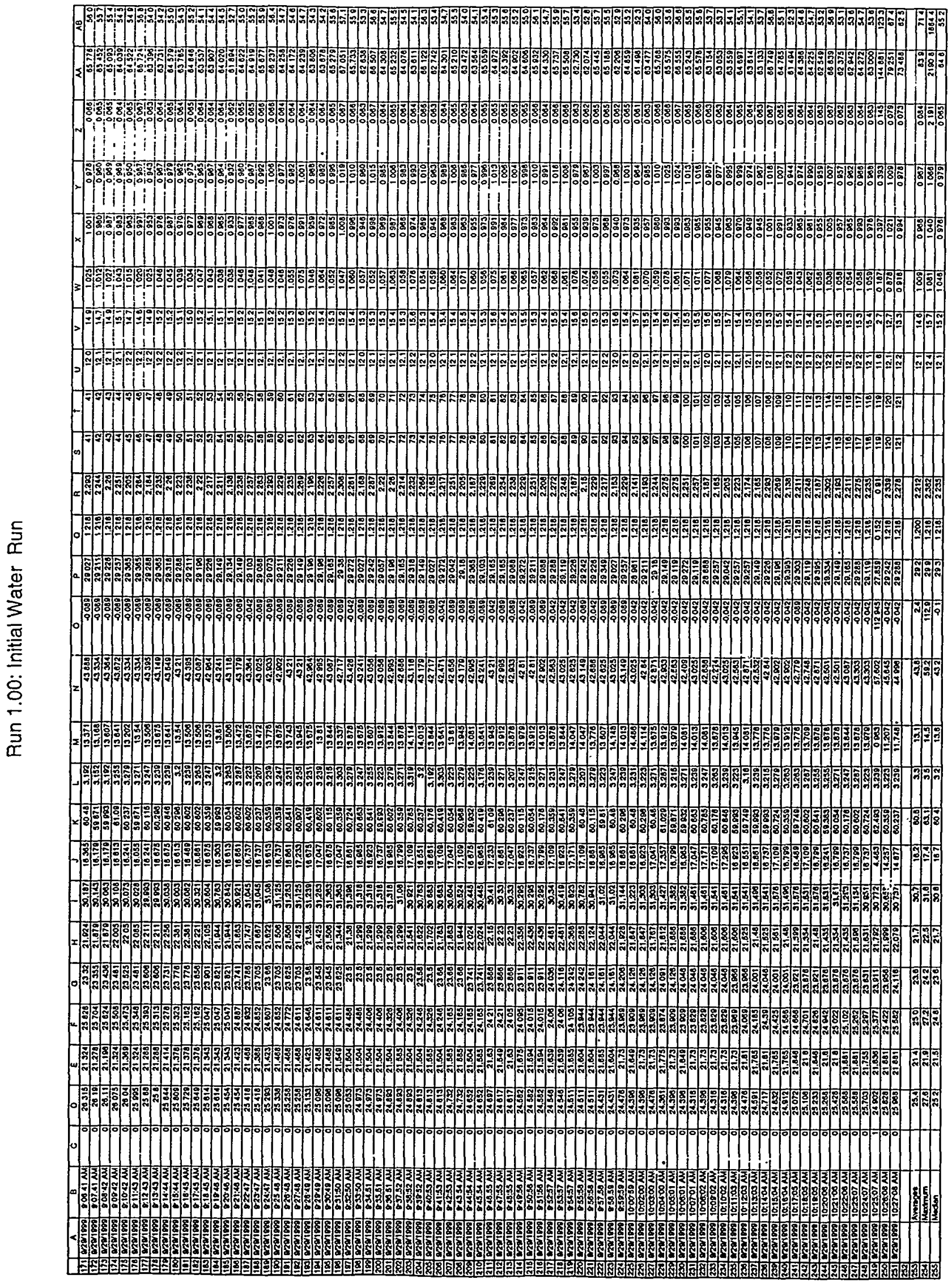


Pilot X-flow: EnvC+ES+Sr/TRU Page 64 of 256

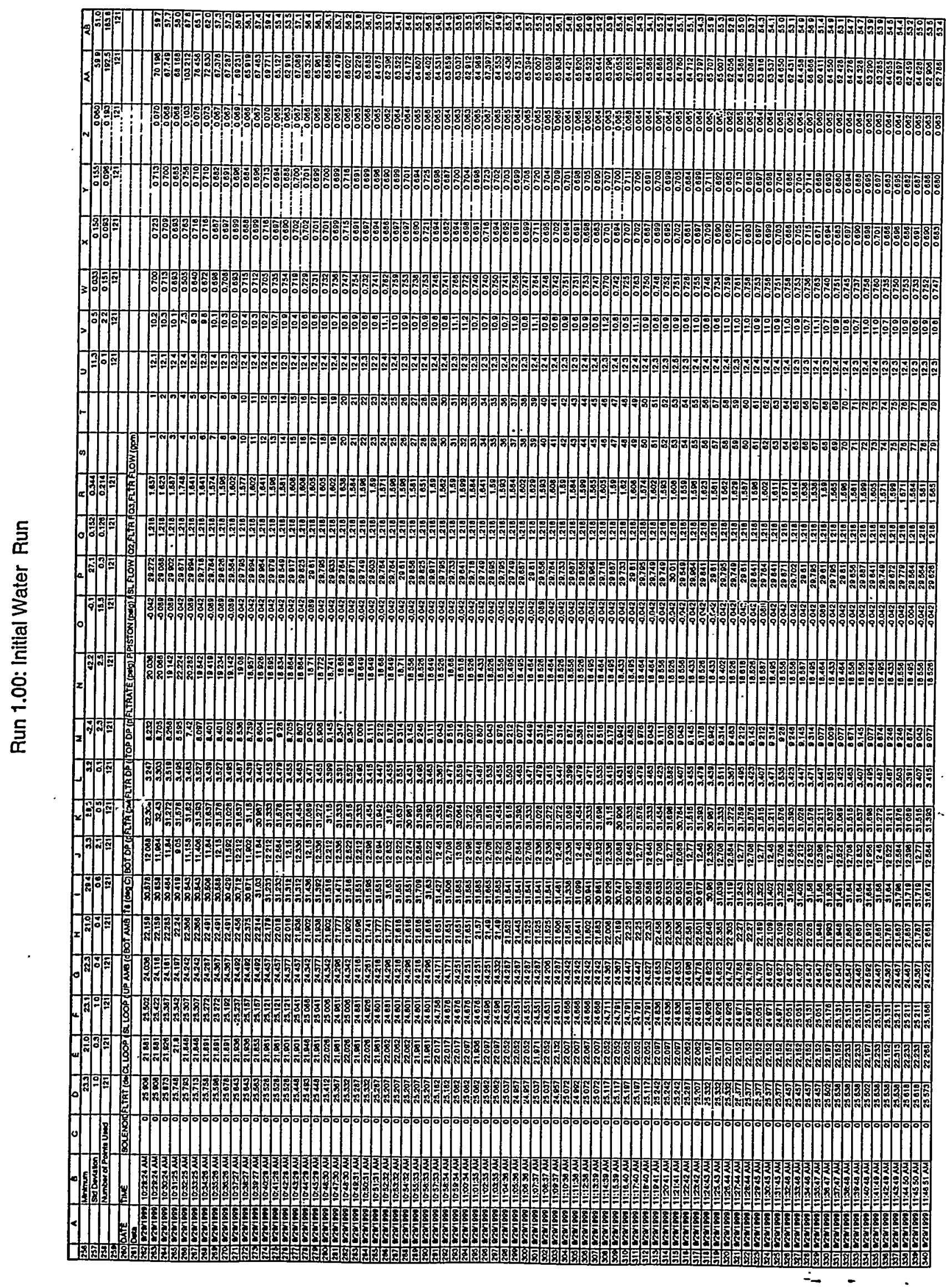


Pilot X-flow: EnvC+ES+Sr/TRU Page 65 of 256

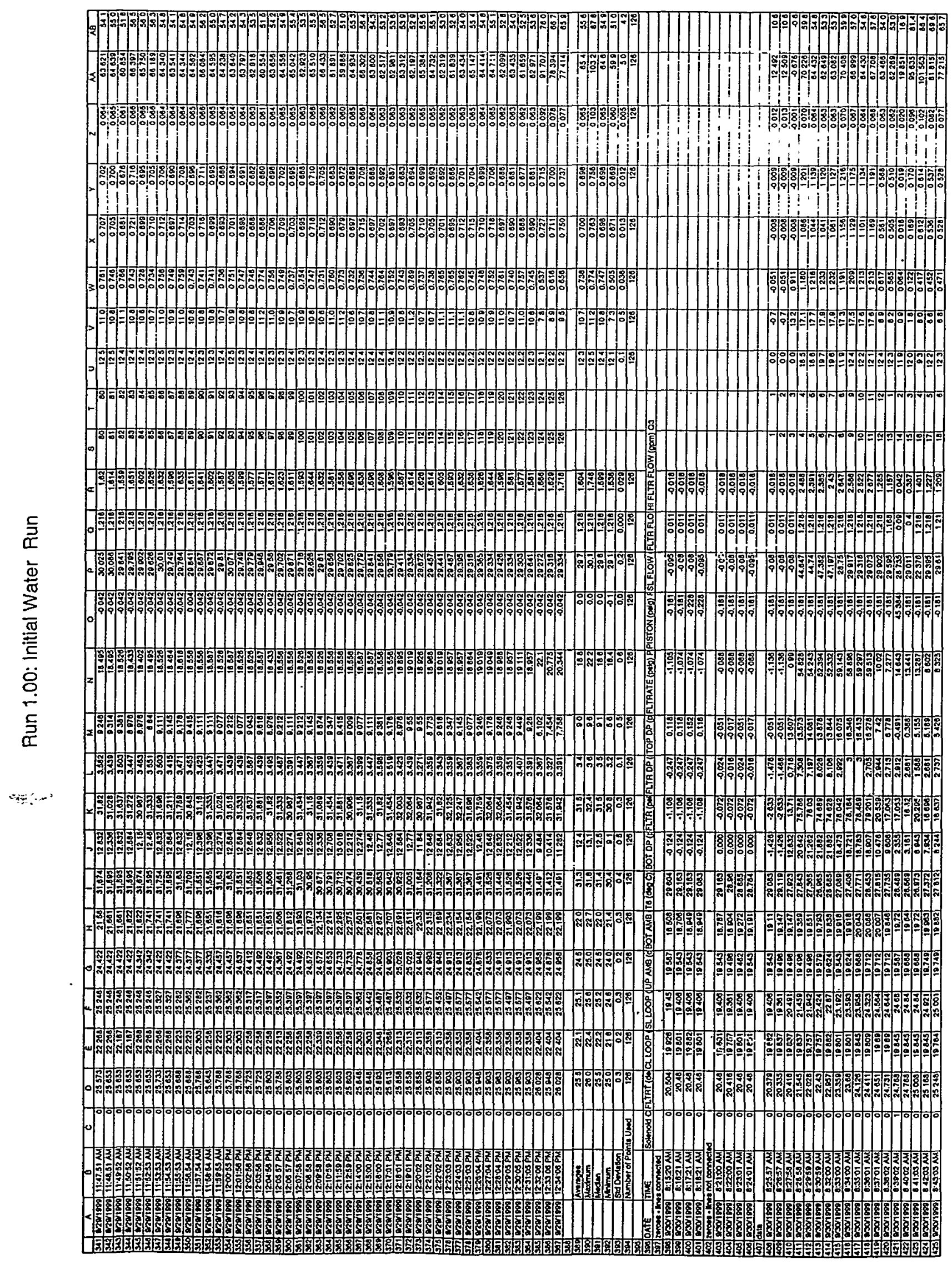


Pilot X-flow: EnvC+ES+Sr/TRU Page 66 of 256

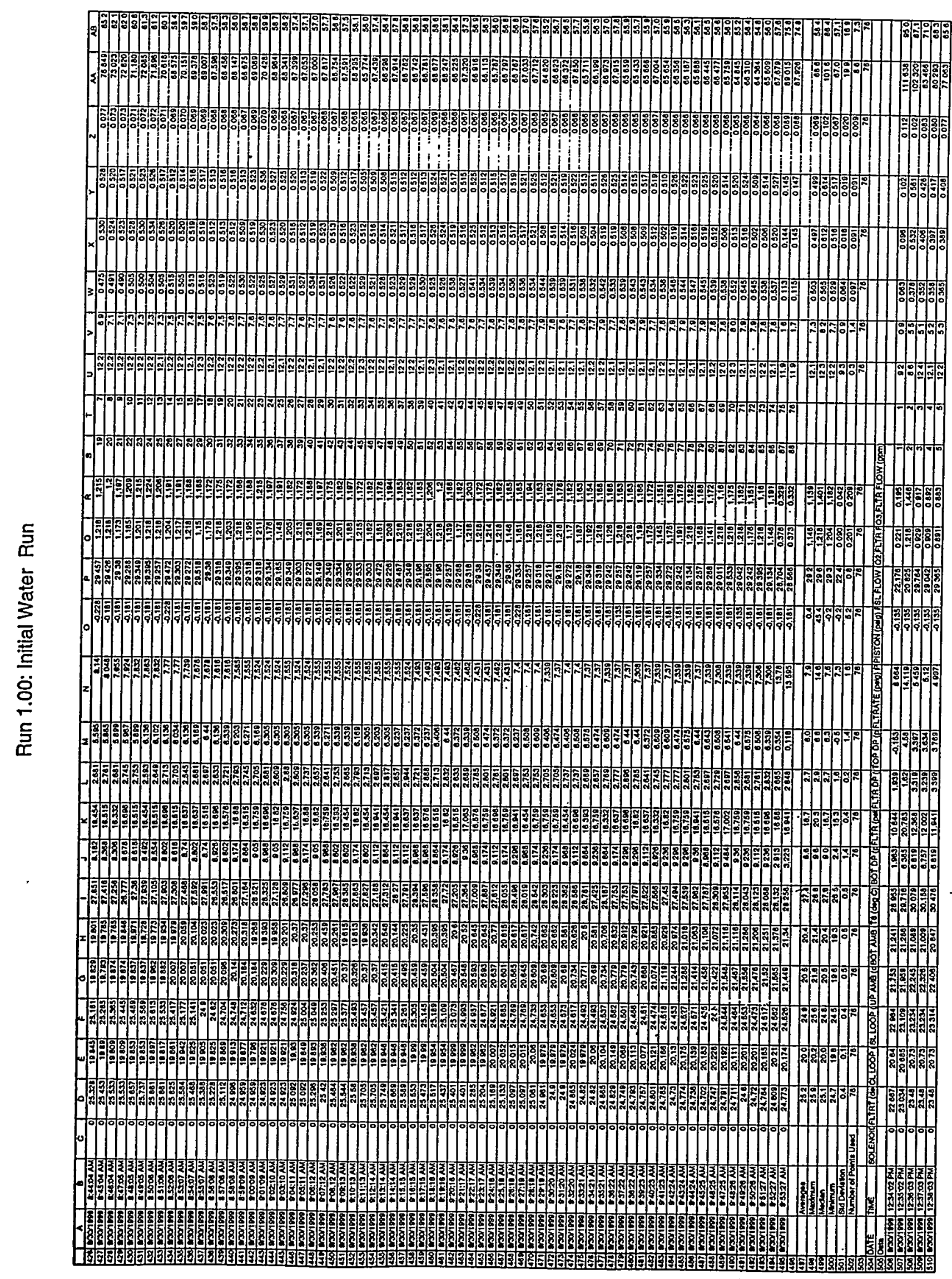




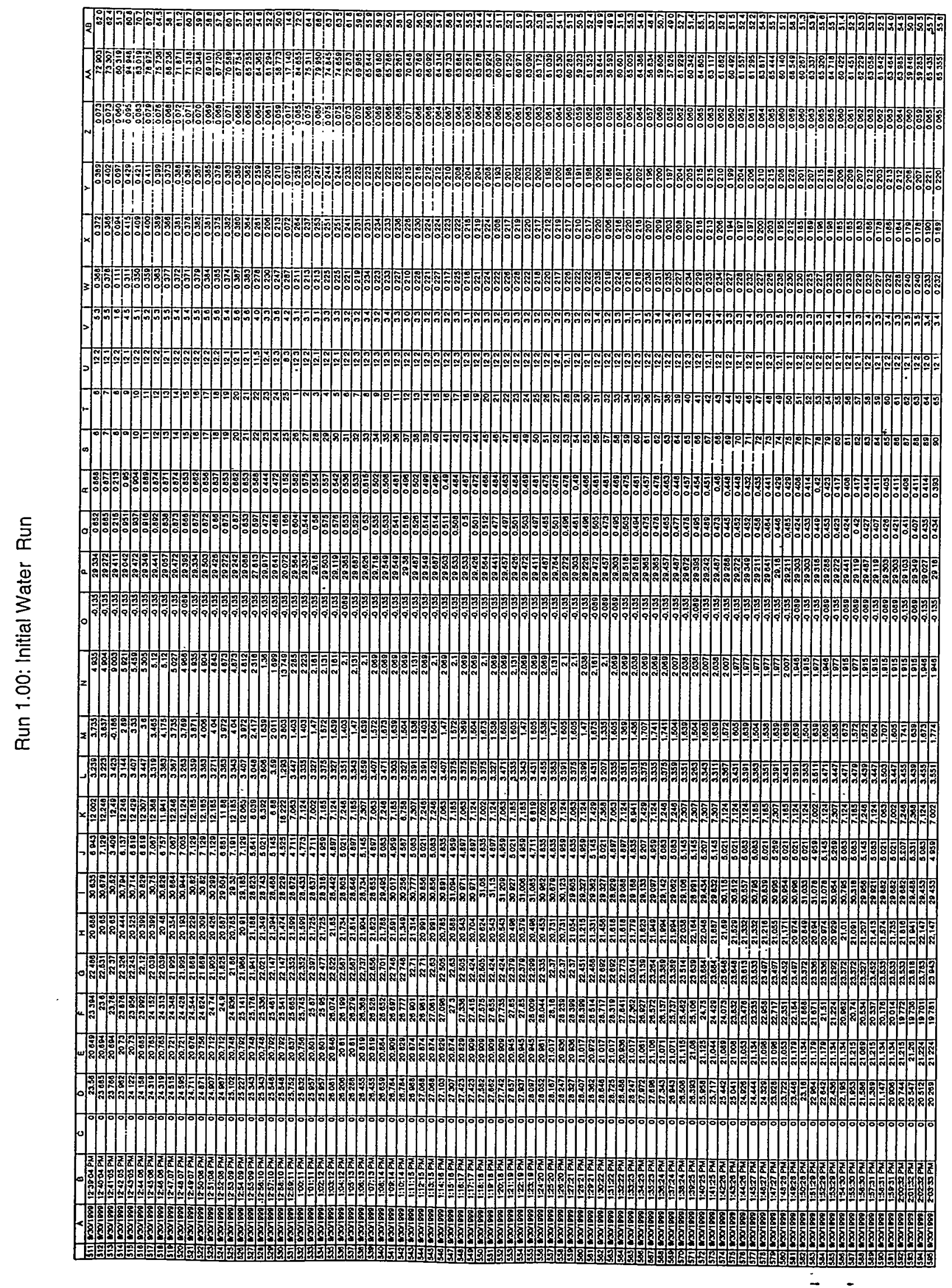


Pilot X-flow: EnvC+ES+St/TRU Page 68 of 256

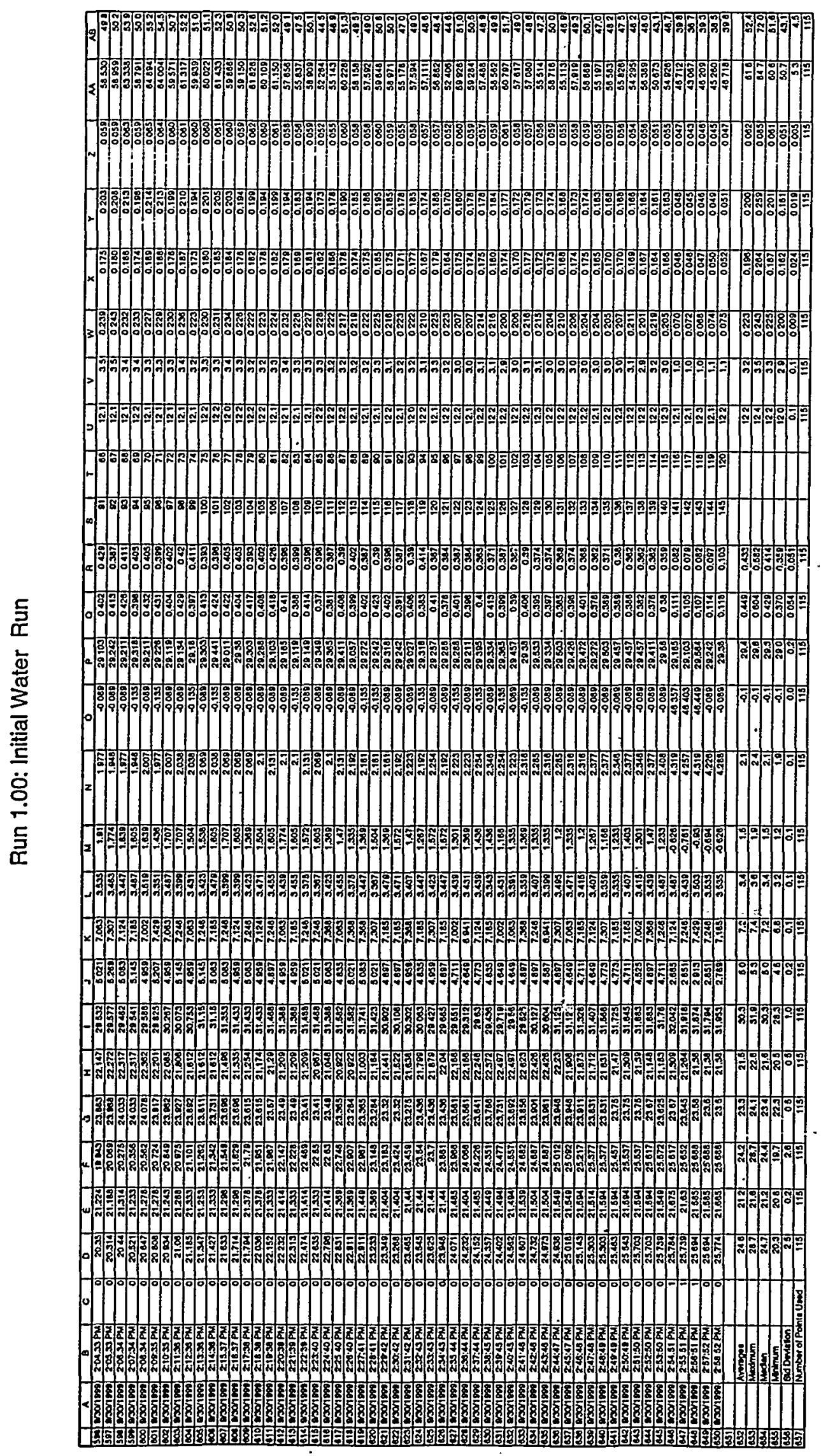



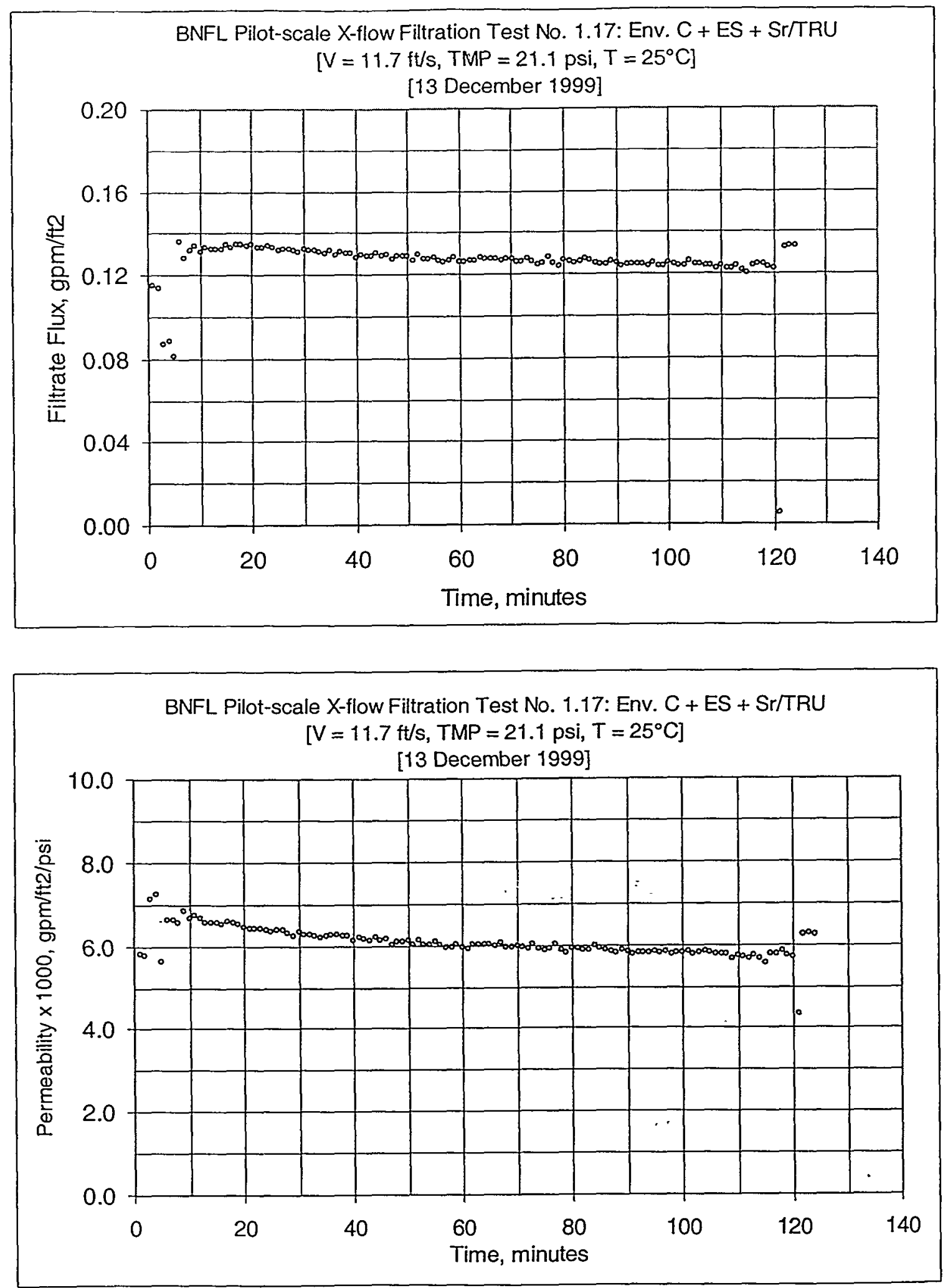

Figure A2: Test Run 1.17, Final Water (before chemical cleaning) 


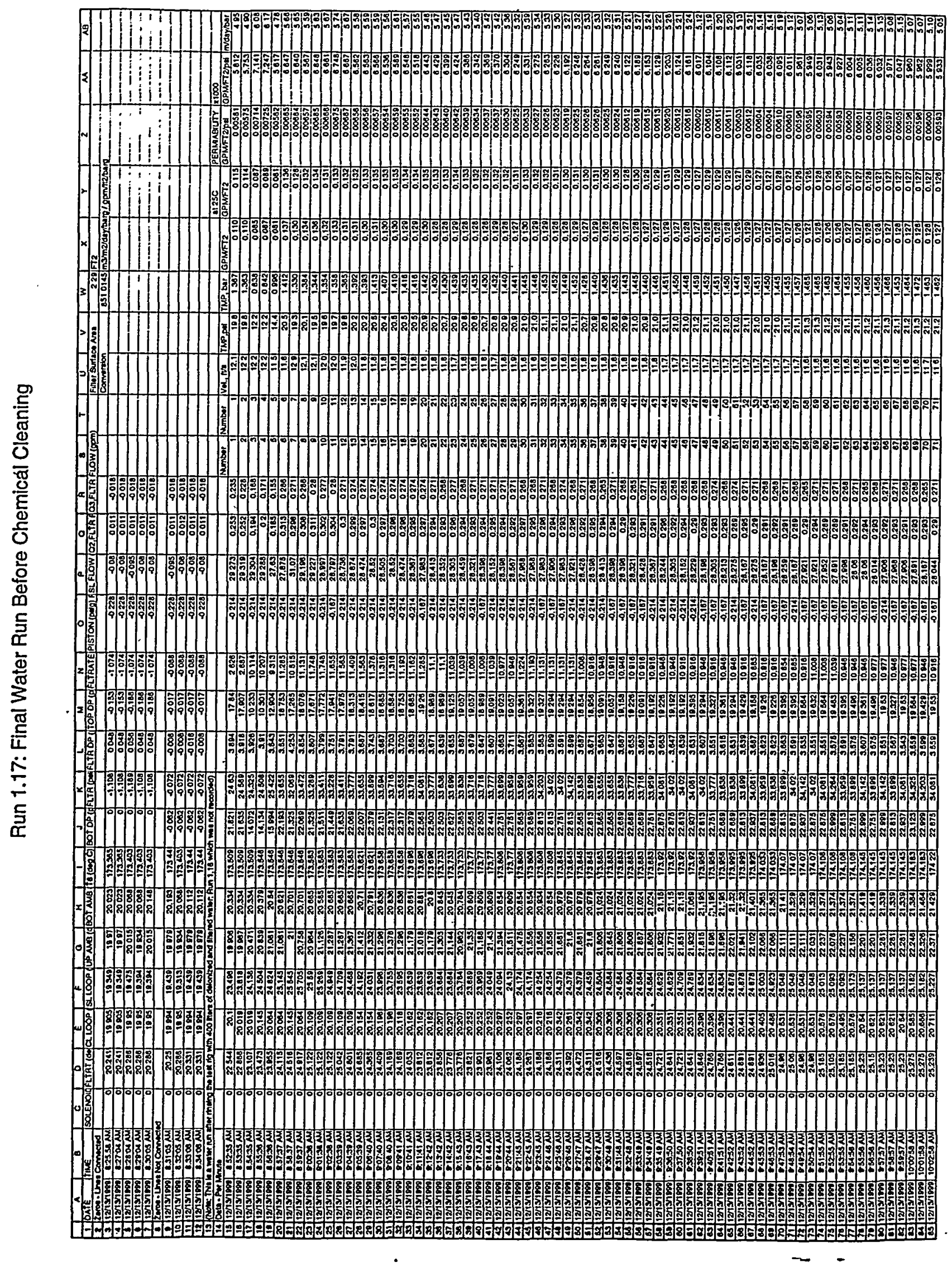


Pilot X-flow: EnvC+ES+Sr/TRU Page 71 of 256

BNF-003-98-0226

Revision 0

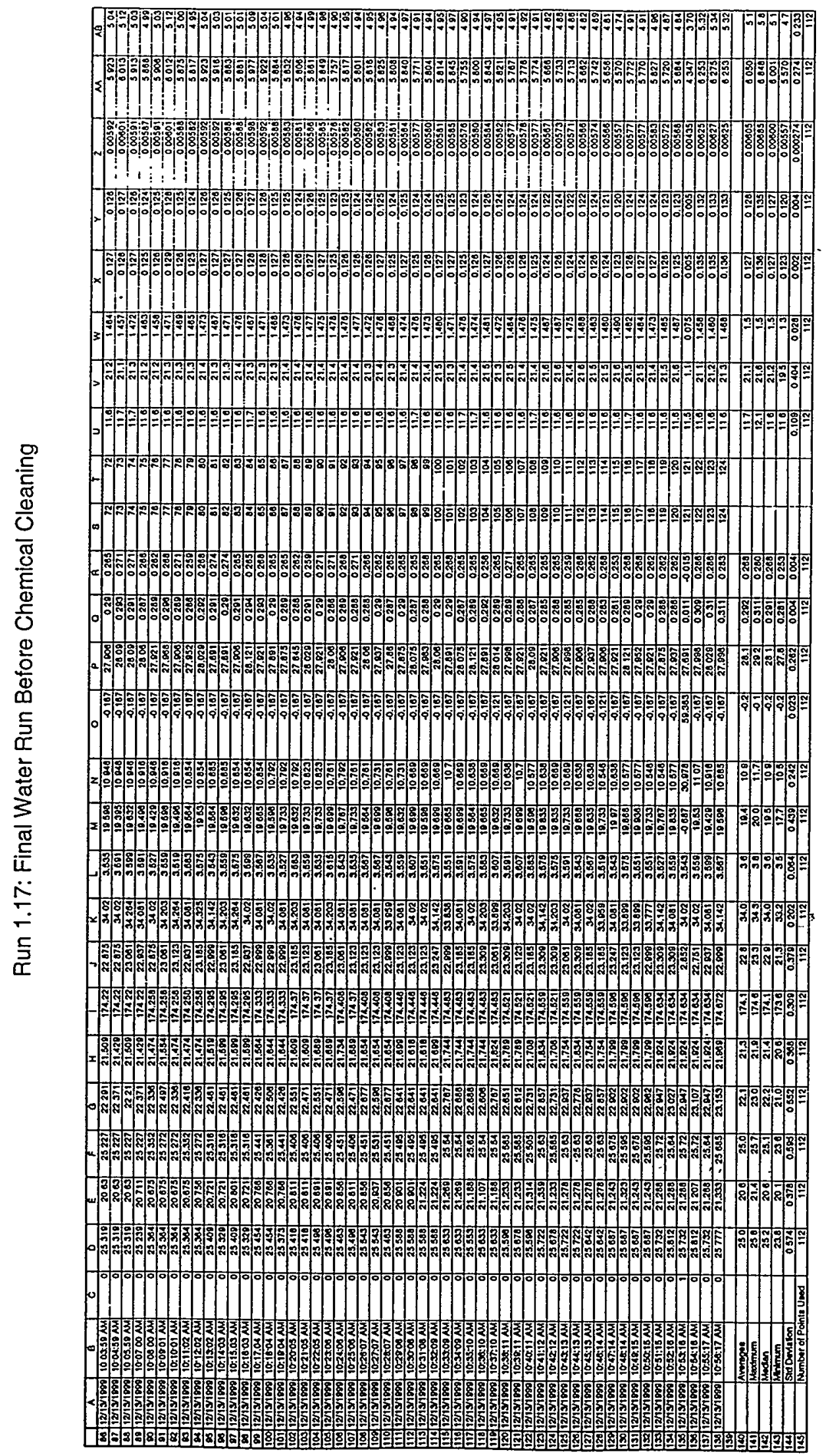



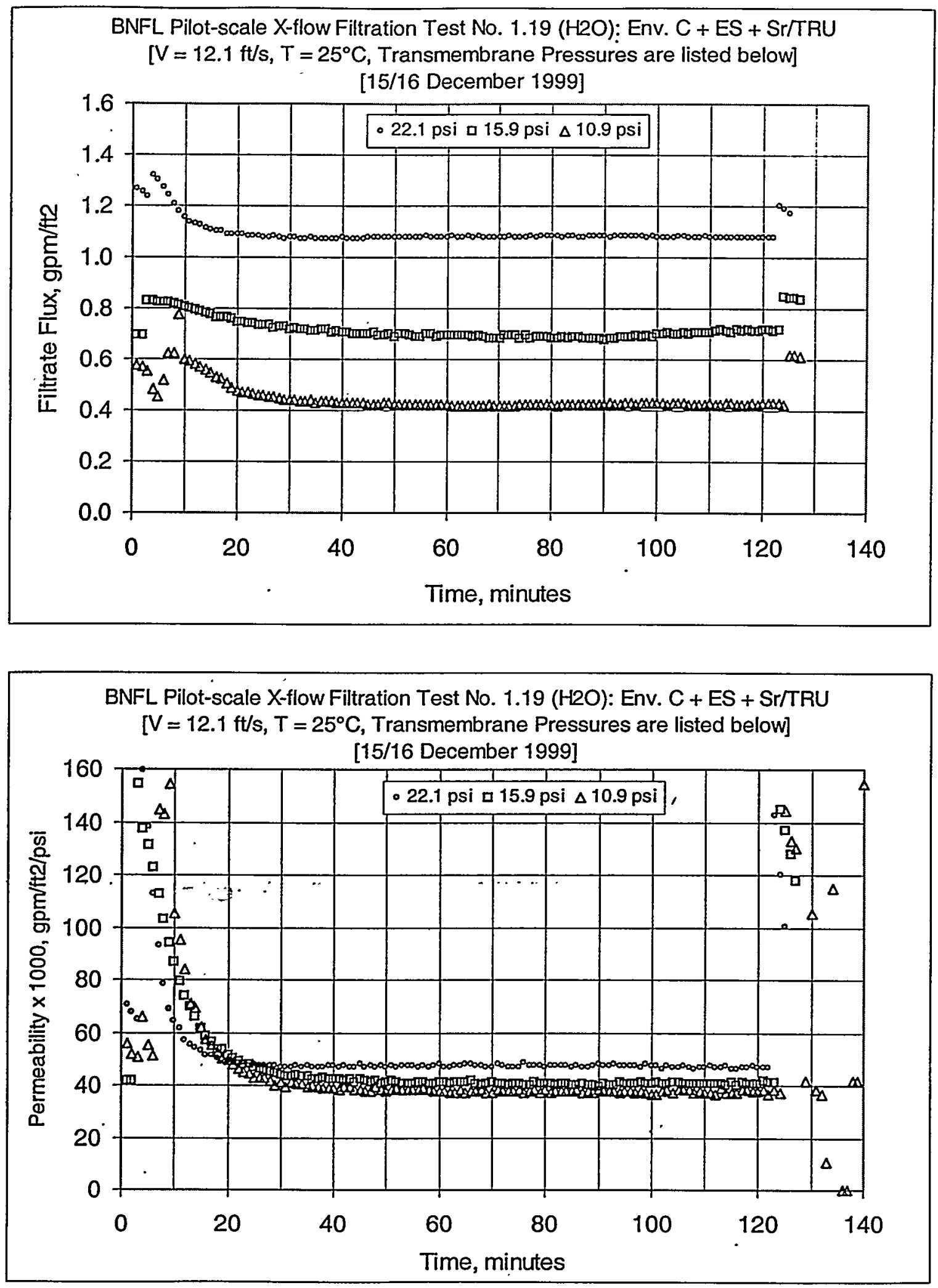

Figure A3: Test Run 1.19, Final Water 
Pilot X-flow: EnvC+ES+Sr/TRU Page 73 of 256

BNF-003-98-0226

Revision 0

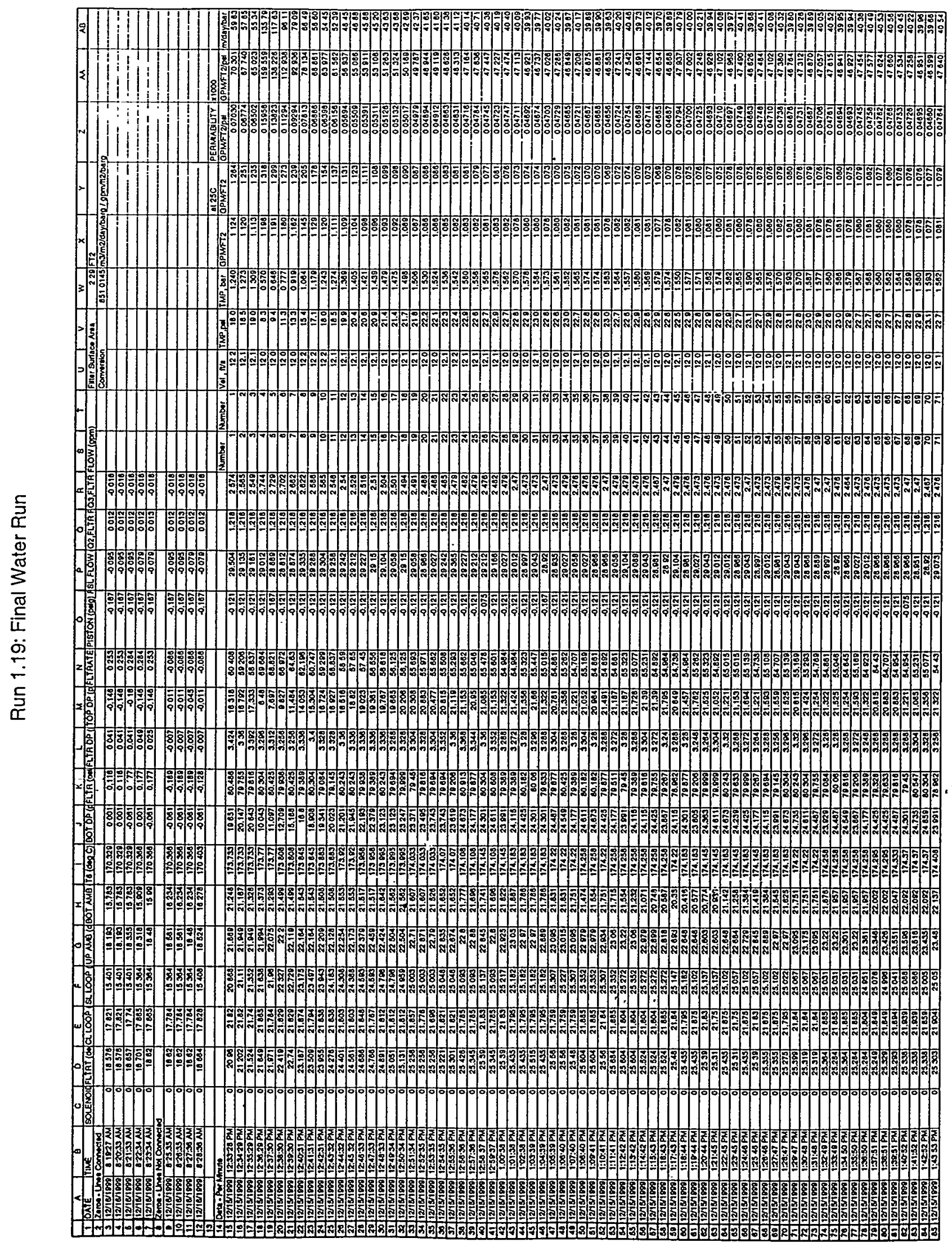




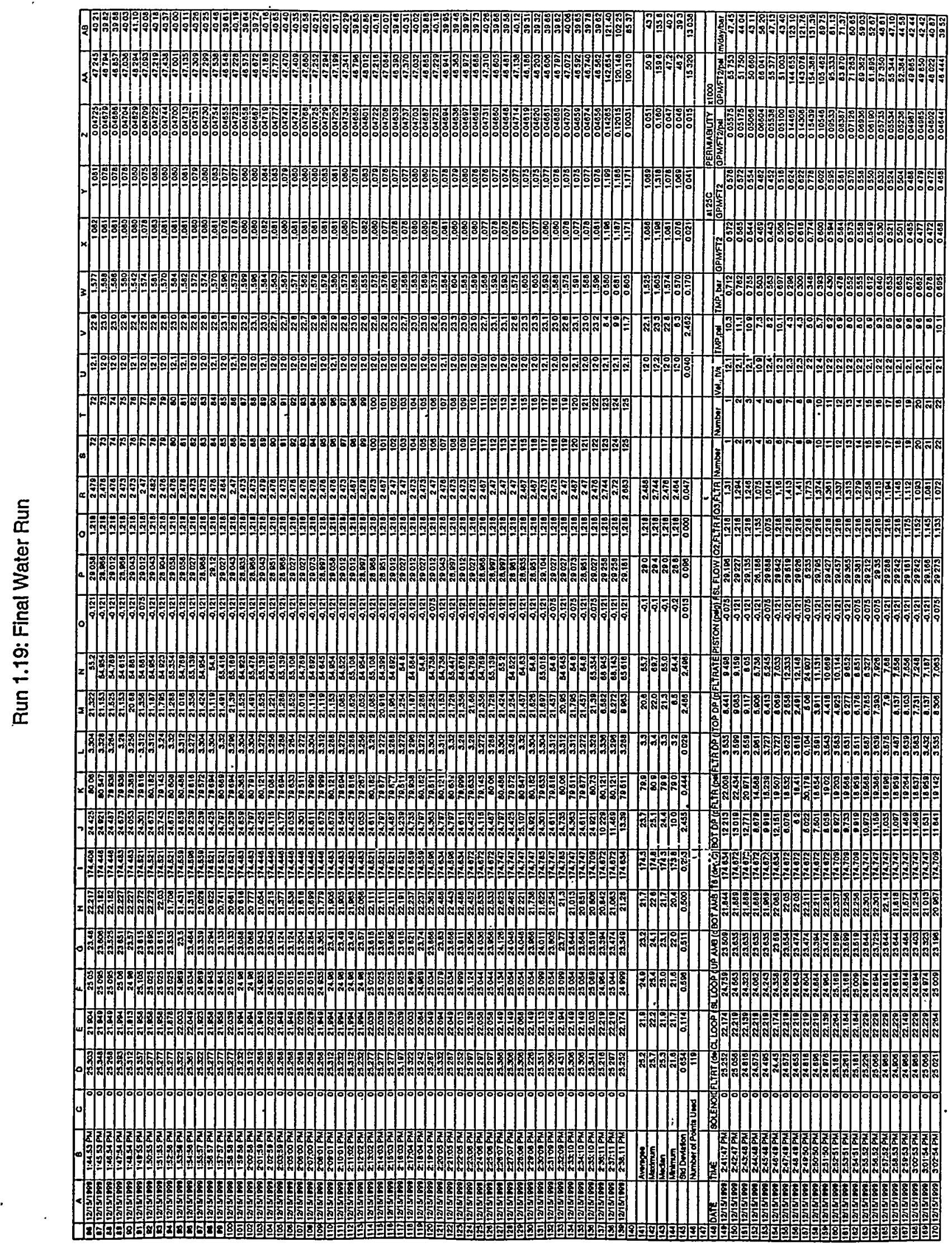




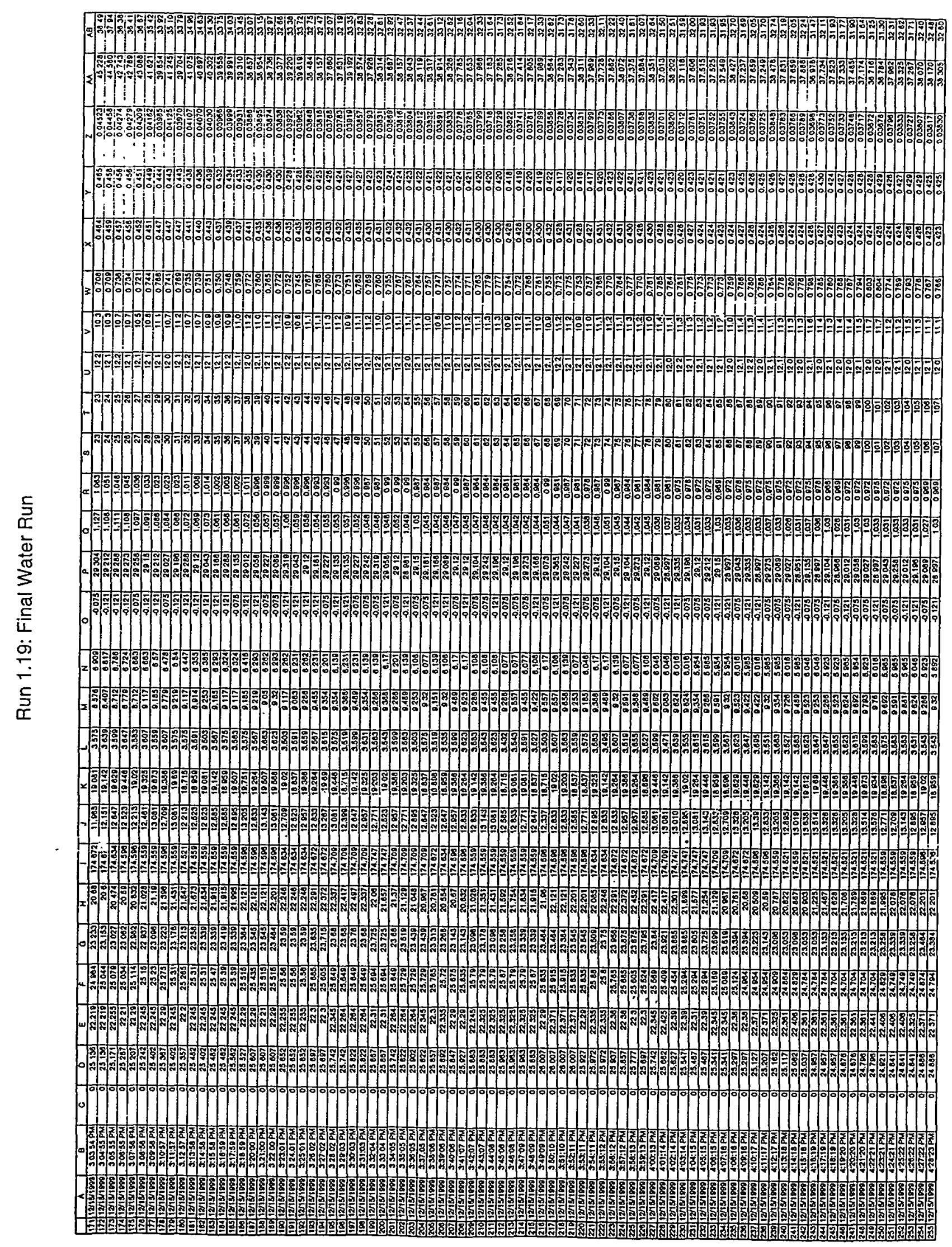




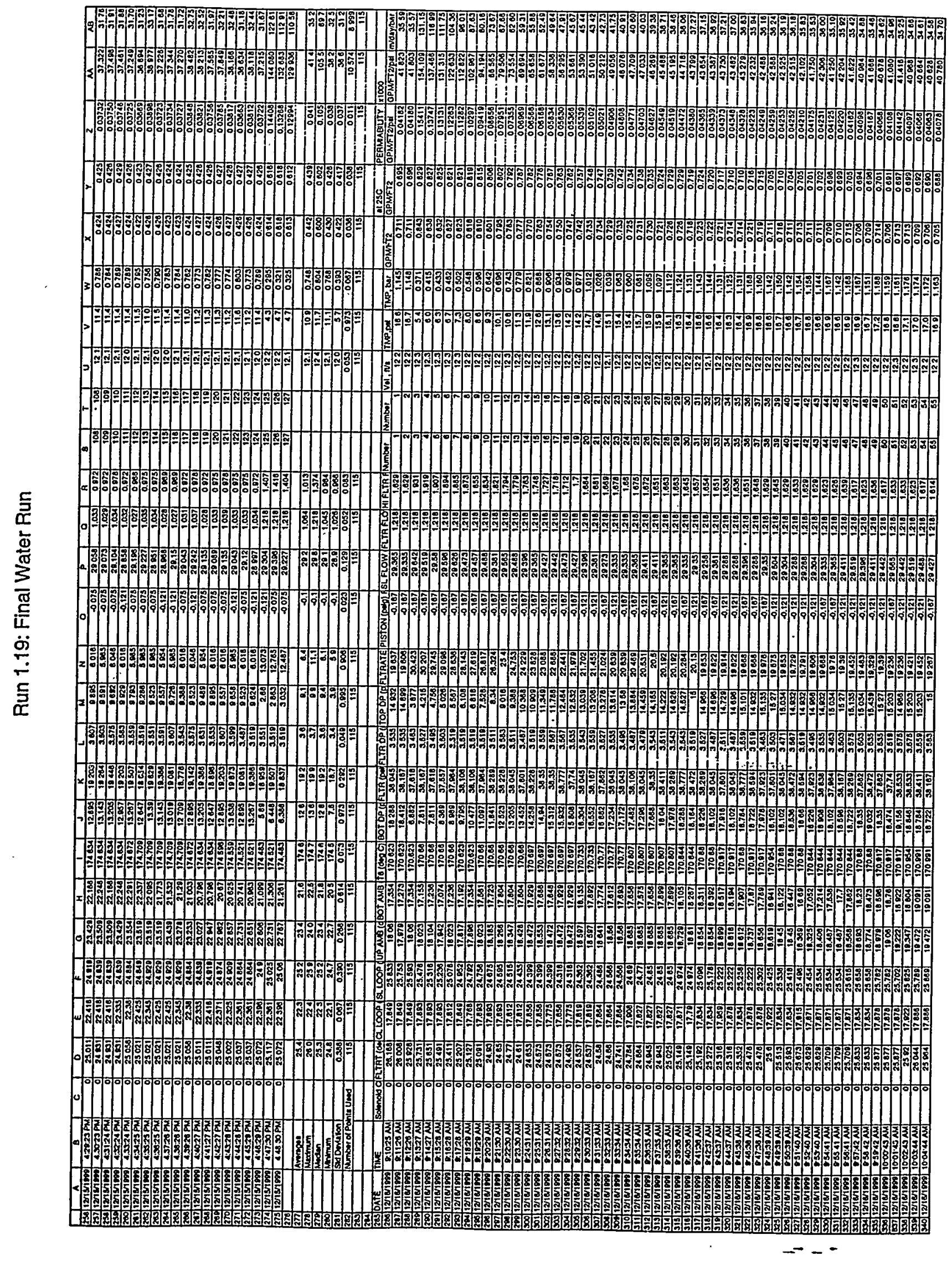


Pilot X-flow: EnvC+ES+Sr/TRU Page 77 of 256

BNF-003-98-0226

Revision 0

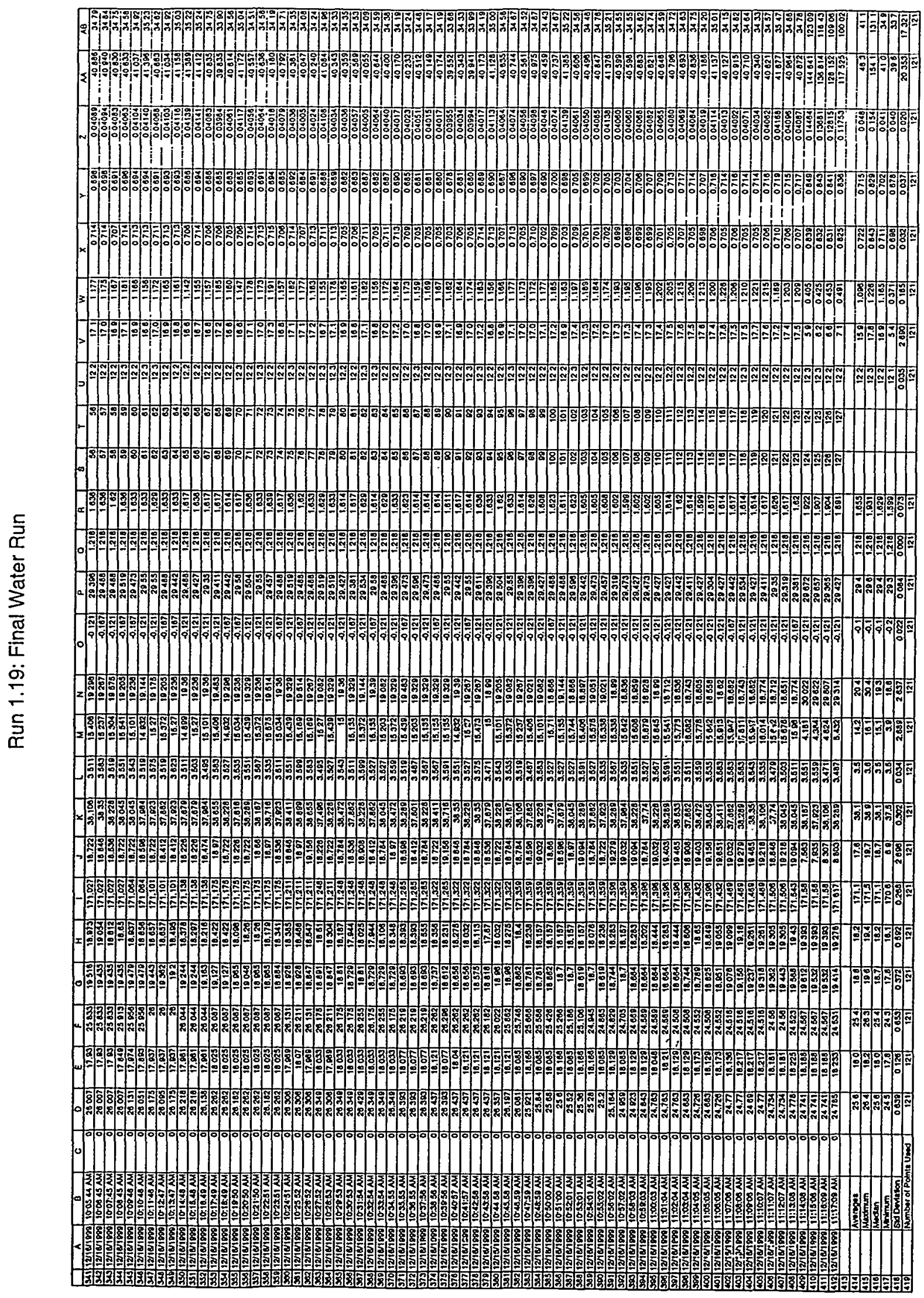



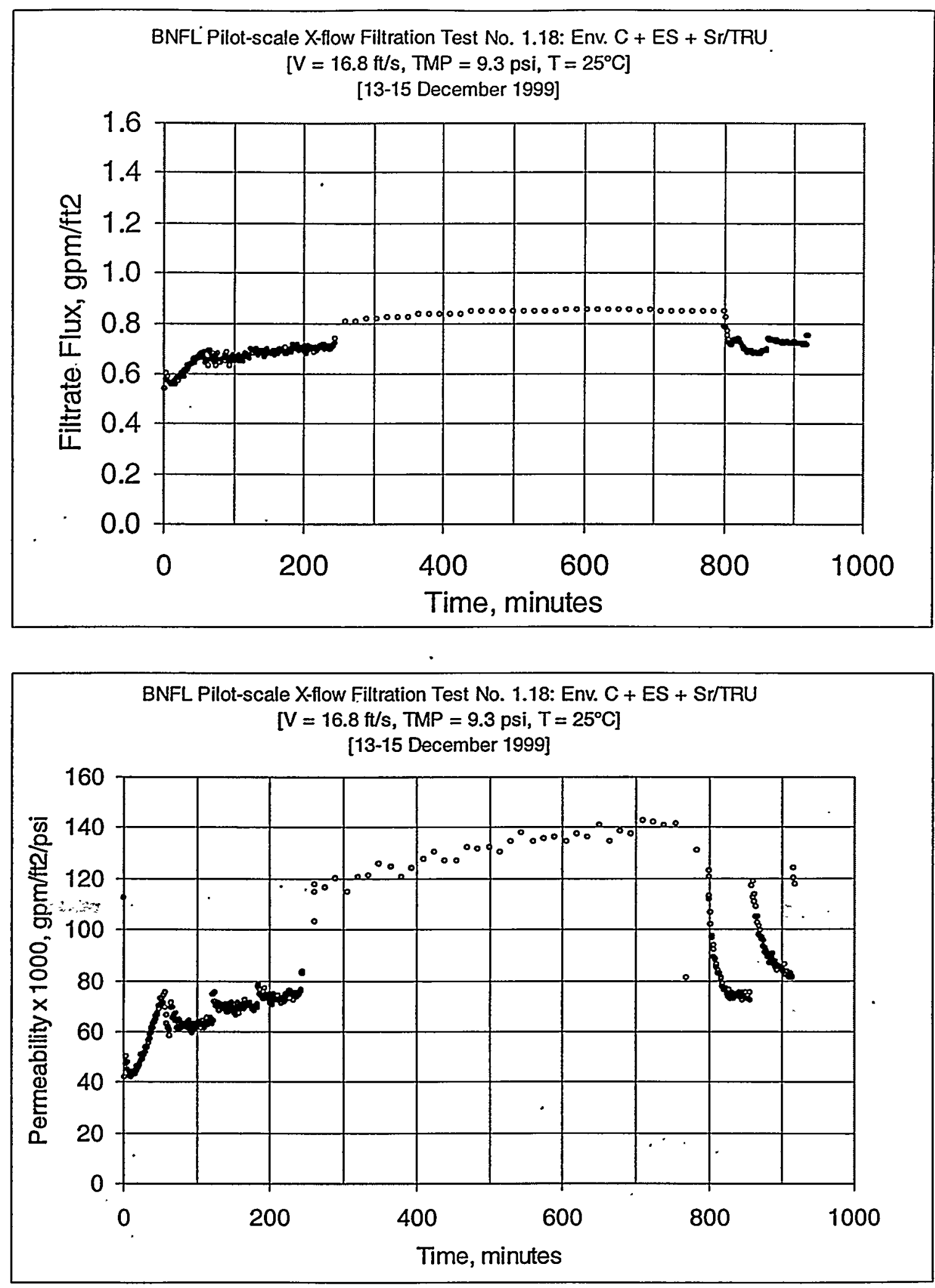

Figure A4: Test Run 1.18, $1 \mathrm{M} \mathrm{NaOH}$ Cleaning 
Pilot X-flow: EnvC+ES+Sr/TRU Page 79 of $256 \quad \cdot \quad \begin{array}{r}\text { BNF-003-98-0226 } \\ \text { Revision } 0\end{array}$

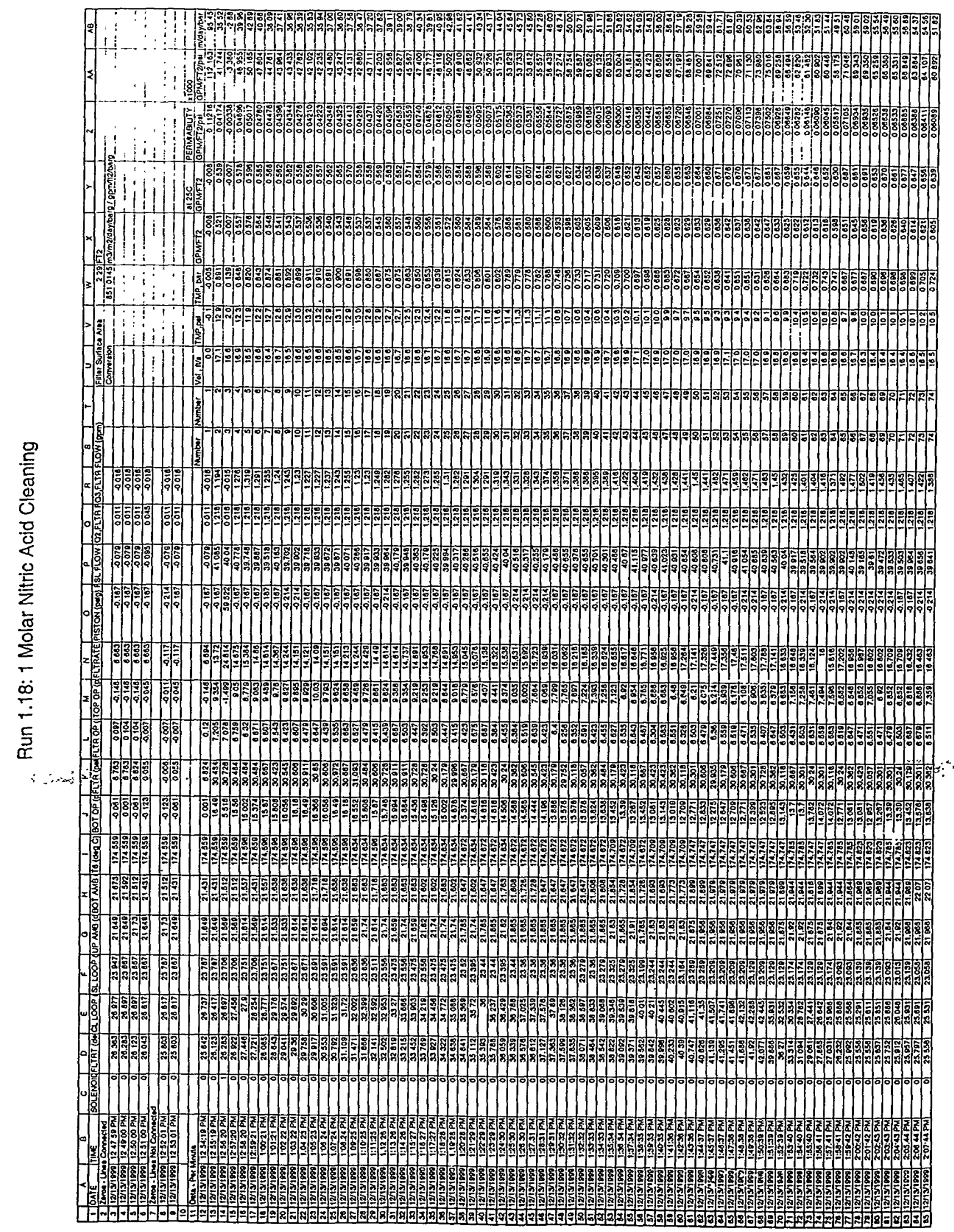


Pilot X-flow: EnvC+ES+St/TRU Page 80 of 256

BNF-003-98-0226

Revision 0

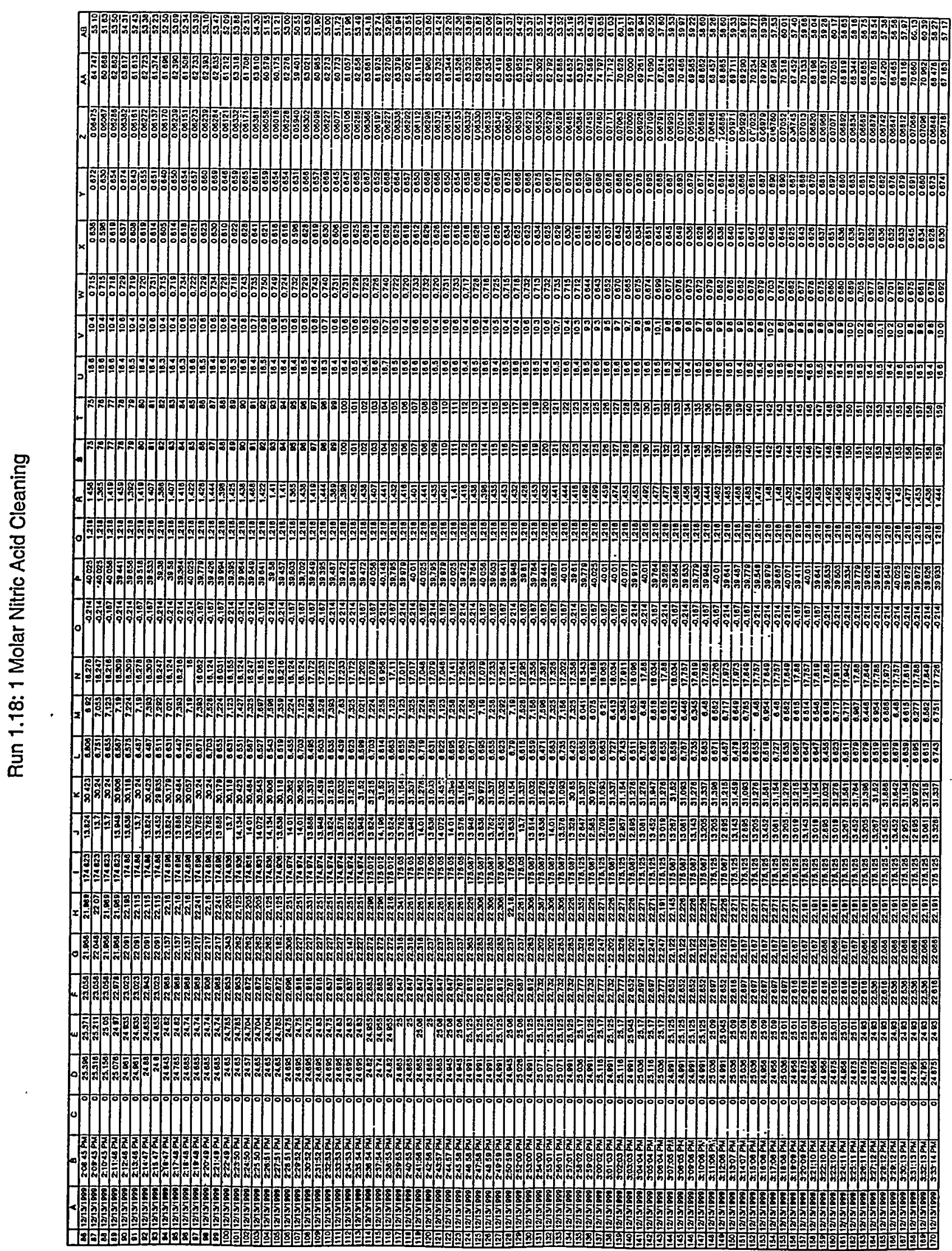




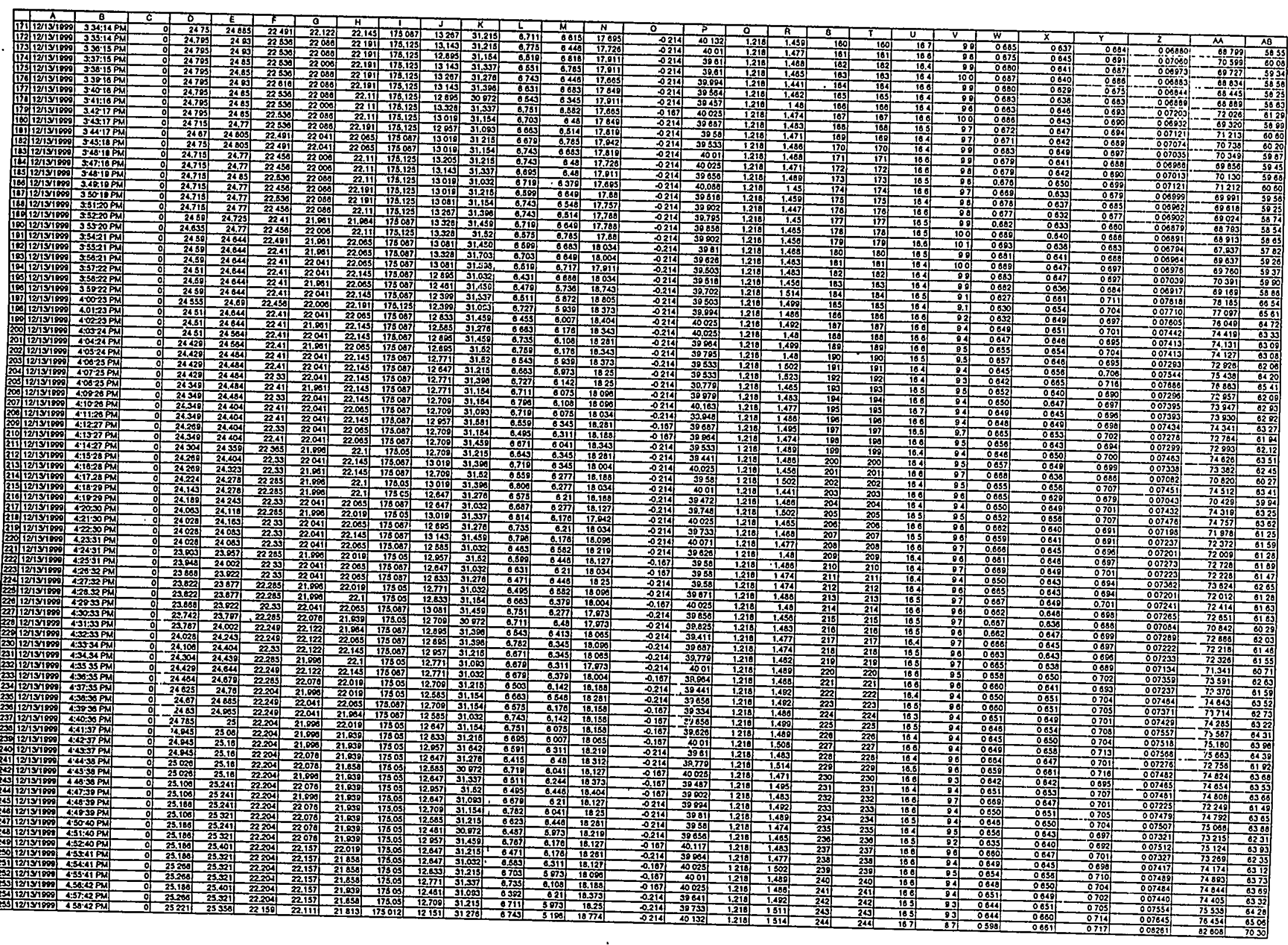




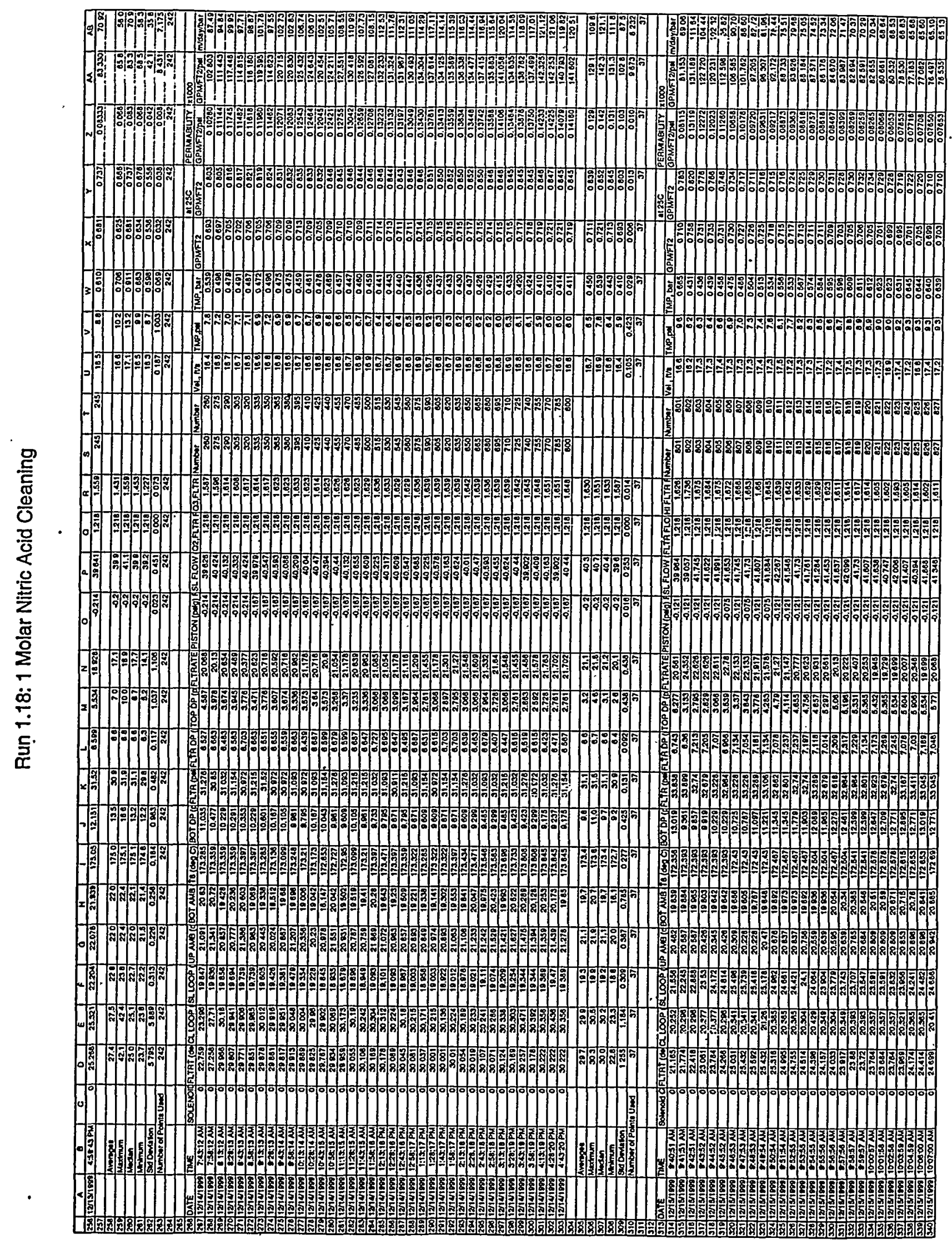


Pilot X-flow: EnvC+ES+Sr/TRU Page 83 of 256

BNF-003-98-0226

Revision 0

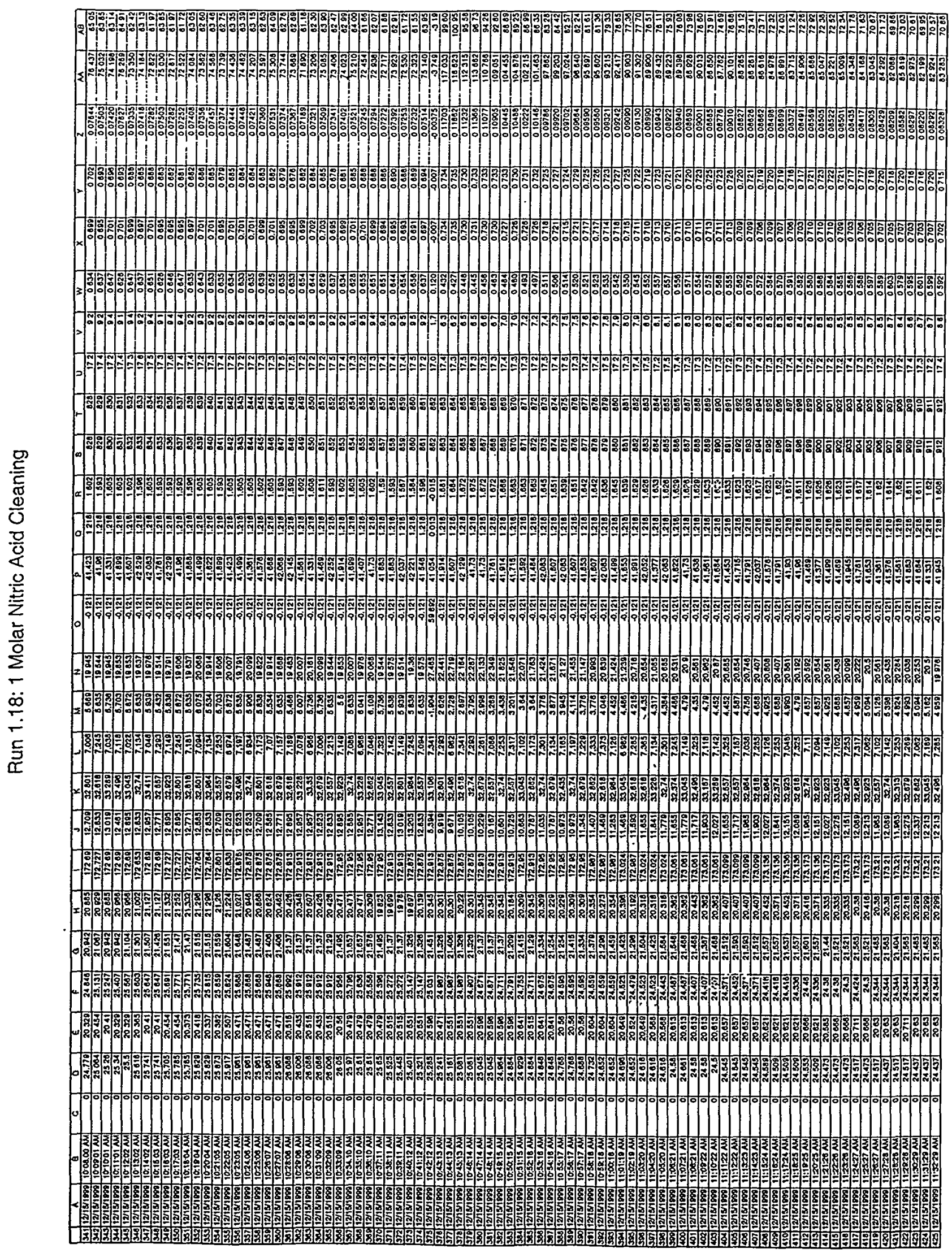




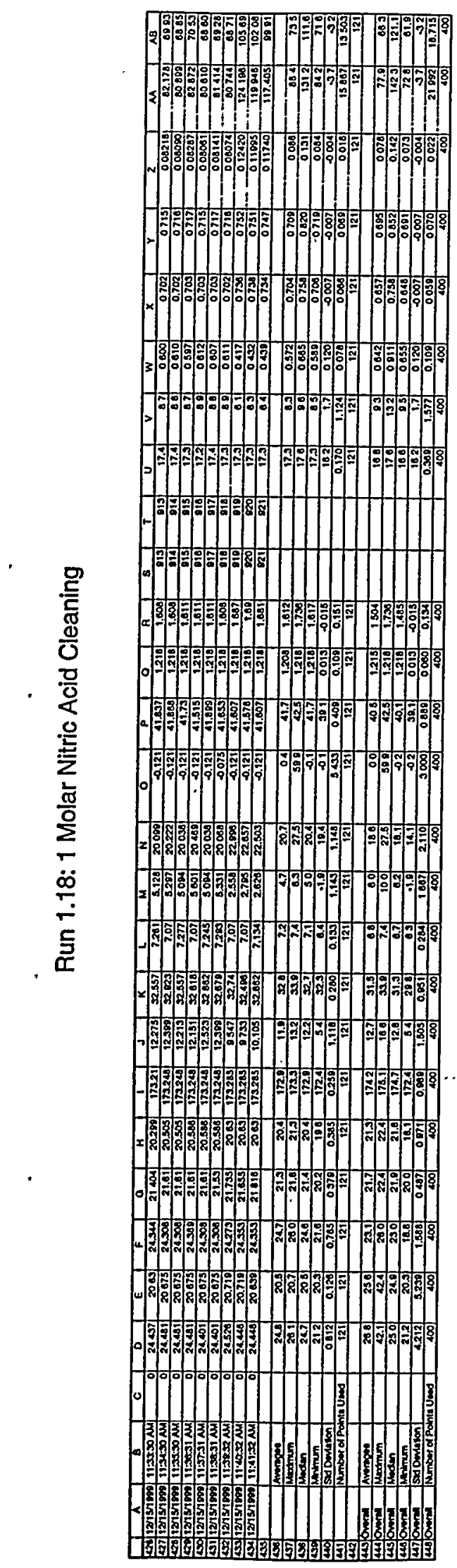




\section{APPENDIX B}

\section{EXPERIMENTAL DATA: LOW SOLIDS CONCENTRATION}

\begin{tabular}{|c|c|c|c|}
\hline \multicolumn{4}{|c|}{$\begin{array}{l}\text { 1. Nomeclature sheet for data tables } \\
\text { 2. Experimental data: }\end{array}$} \\
\hline Fig. & Run & Solution & Done on \\
\hline $\mathrm{B} 1$ & 1.01 & 2 wt\% Solids & $10 / 20 / 99$ \\
\hline $\mathrm{B} 2$ & 1.02 & 2 wt\% Solids & $10 / 20 / 99$ \\
\hline B3 & 1.03 & 2 wt\% Solids & $10 / 20 / 99$ \\
\hline B4 & 1.04 & $2 \mathrm{wt} \%$ Solids & $10 / 20 / 99$ \\
\hline B5 & 1.05 & 2 wt\% Solids & $10 / 21 / 99$ \\
\hline B6 & 1.06 & 2 wt $\%$ Solids & $10 / 21 / 99$ \\
\hline B7 & 1.07 & $2 \mathrm{wt} \%$ Solids & $10 / 21 / 99$ \\
\hline B8 & $1.07 \mathrm{a}$ & $2 \mathrm{wt} \%$ Solids & $10 / 21 / 99$ \\
\hline
\end{tabular}

On 10/18/99 the customer changed the Test Matrix to further randomize the flow conditions of the test runs. The 10 test runs below were already complete when the change was received. Those runs are indicated by the word "old" in the run number and are included for completeness.

\begin{tabular}{|c|c|c|c|c|}
\hline B9a & 1.01 & (old) & 2 wt\% Solids & $10 / 05 / 99$ (time in seconds) \\
\hline B9b & 1.01 & (old) & 2 wt $\%$ Solids & $10 / 05 / 99$ (time in minutes) \\
\hline $\mathrm{B} 10$ & 1.02 & (old) & 2 wt $\%$ Solids & $10 / 05 / 99$ \\
\hline B11 & 1.03 & (old) & $2 \mathrm{wt} \%$ Solids & $10 / 05 / 99$ \\
\hline B12 & 1.04 & (old) & 2 wt\% Solids & $10 / 05 / 99$ \\
\hline B13 & 1.05 & (old) & 2 wt\% Solids & $10 / 06 / 99$ \\
\hline B14 & $1.04 \mathrm{a}$ & (old) & 2 wt\% Solids & $10 / 06 / 99$ \\
\hline B15 & $1.05 \mathrm{a}$ & (old) & 2 wt\% Solids & $10 / 06 / 99$ \\
\hline $\mathrm{B} 16$ & 1.06 & (old) & 2 wt\% Solids & $10 / 06 / 99$ \\
\hline B17 & 1.07 & (old) & 2 wt\% Solids & $10 / 07 / 99$ \\
\hline B18 & $1.01 \mathrm{a}$ & (old) & 2 wt\% Solids & $10 / 07 / 99$ \\
\hline
\end{tabular}

General Note: For measurement uncertainties see Appendix F

Special Notes:

a. Run 1.07a was done at the end of the day on 10/21/99 to obtain one more data point with the slurry axial velocity of $15 \mathrm{ft} / \mathrm{s}$. Run 1.04 was $15 \mathrm{ft} / \mathrm{s}$ at a TMP $=30 \mathrm{psid}$ and run 1.07 was $15 \mathrm{ft} / \mathrm{s}$ at a TMP $=70$ psid. Previously experience indicated that increasing the TMP to 70 psid was generally not necessary since most of the benefit of the high pressure appear to taper off as the pressure goes higher. Three data points would be needed to facilitate the analysis.

b. The data for every test run are highlighted with two graphs: Filtrate Flux vs. Time and Permeability vs. Time. Those graphs include all the data taken during the run period. 
c. The beginning and end of the data for most graphs show large deviations from the overall series of points. Those deviations were caused by backpulsing the filter that temporarily stopped the flow of filtrate.

d. All columns of data, in all the tables, are ended with several statistical values of that column, i.e., Average, Maximum, Median, Minimum, Standard Deviation, and Number of Points Used (in calculating the 5 statistical quantities). Most of the data with time were maintain constant, and therefore the statistics are meaningful for normally distributed data, however Filtrate Flux and Permeability decrease with time and therefore are not normally distributed.

e. To calculate those quantities mentioned in the preceding item, only those data points that start from the end of a backpulse to just before the ending backpulse were included. This is the reason why the quantity of Number of Points Used was given.

f. The data for the graphs, and all the data taken for the individual test run that the graphs represent, immediately follow the specific figure.

Nomenclature For Data Sheets

(See Figure 1: Main Test Rig - Pilot Scale Cross Flow for the Instrument Location)

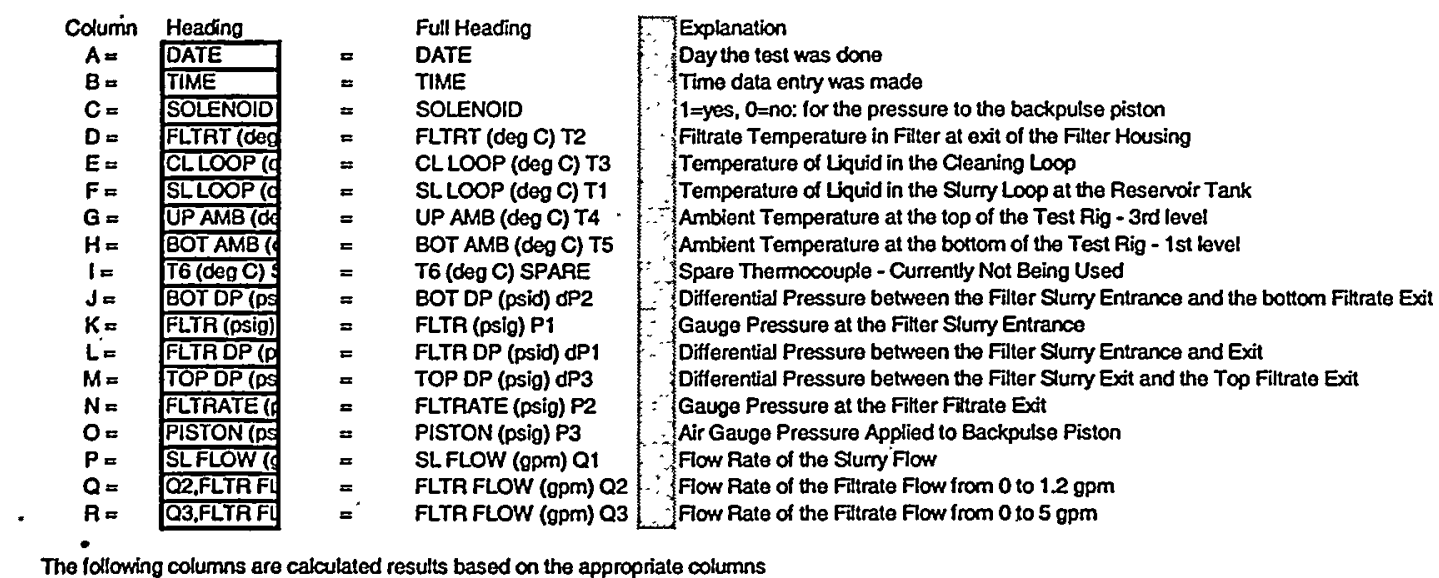

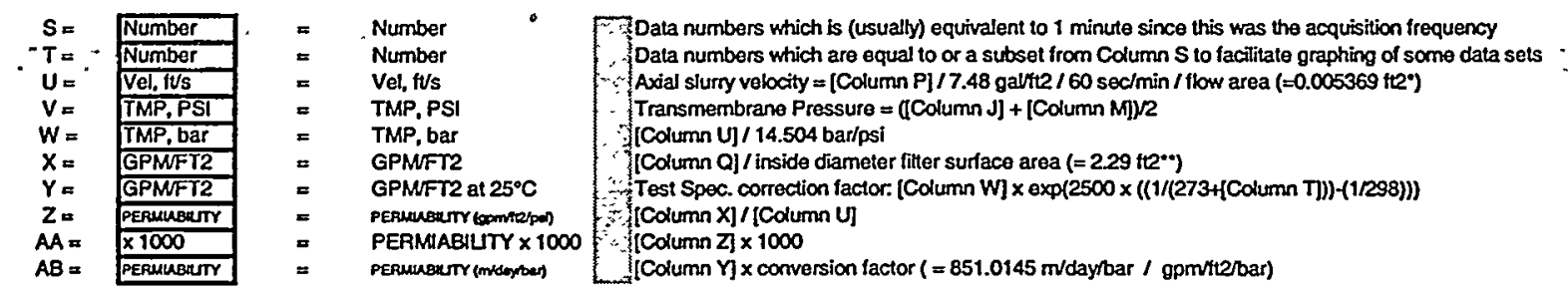

-Axial slurry flow area is based on 7 porous tubes with an inside diameter of $3 / 8 \mathrm{inch:} 7 \times \mathrm{pi} / 4{ }^{*}(0.375 \mathrm{inch} / 12$ inches/tt) $2=0.005369 \mathrm{ft} 2$ - Inside diameter fitter surface area for 7 tubes with an inside ciameter of $3 / 8$ inch, 40 -inches long: $7 \times$ pi $\times(0.375$ inch $) \times 40$ inches $/ 144$ im $2 / t^{\wedge} 2=2.29$ ft2 

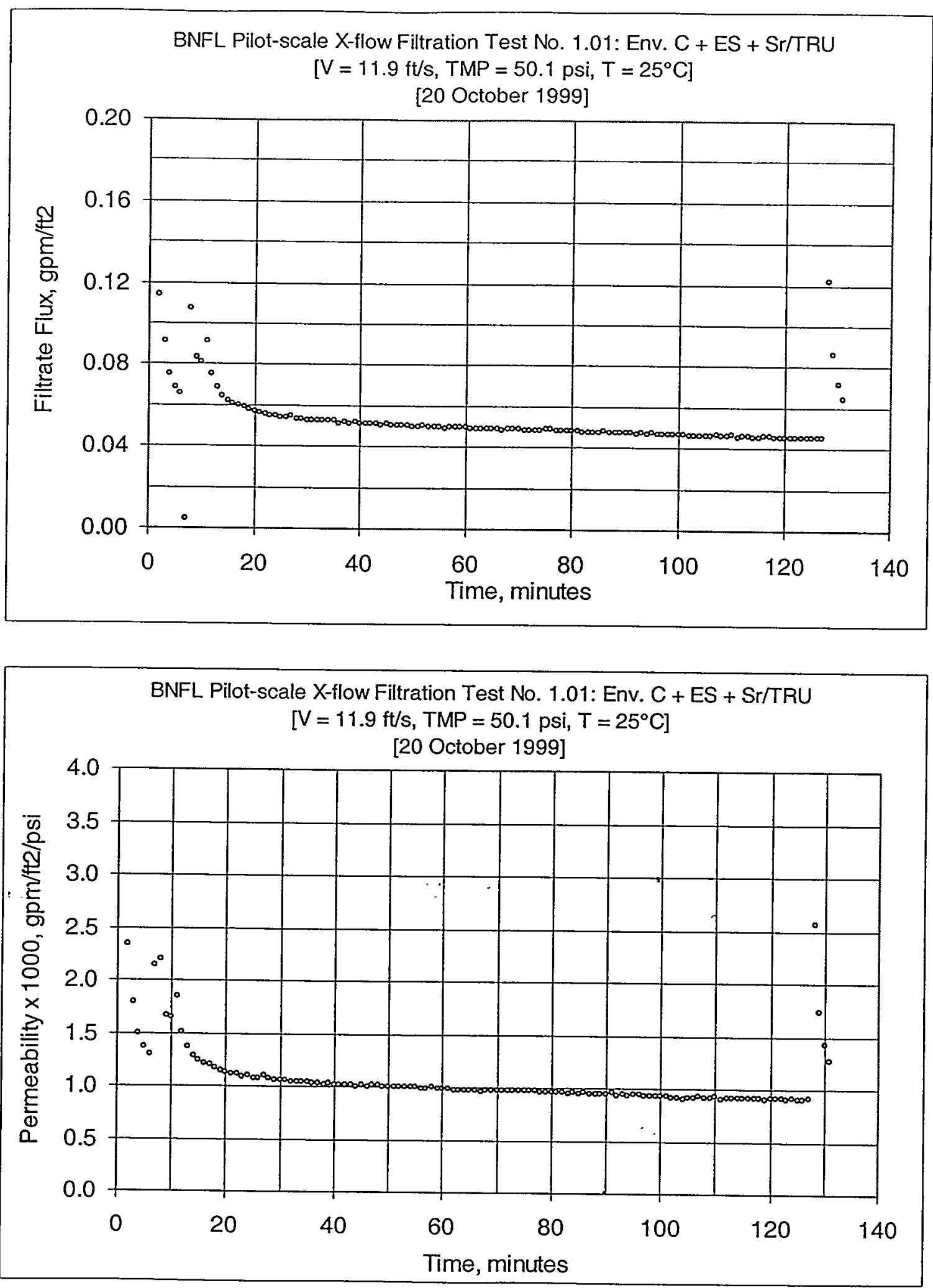

Figure B1: Test Run 1.01, 2 wt\% Insoluble Solids Concentration 
Pilot scale X-flow: EnvC+ES+Sr/TRU Page 88 of 256

BNF-003-98-0226

Revision 0

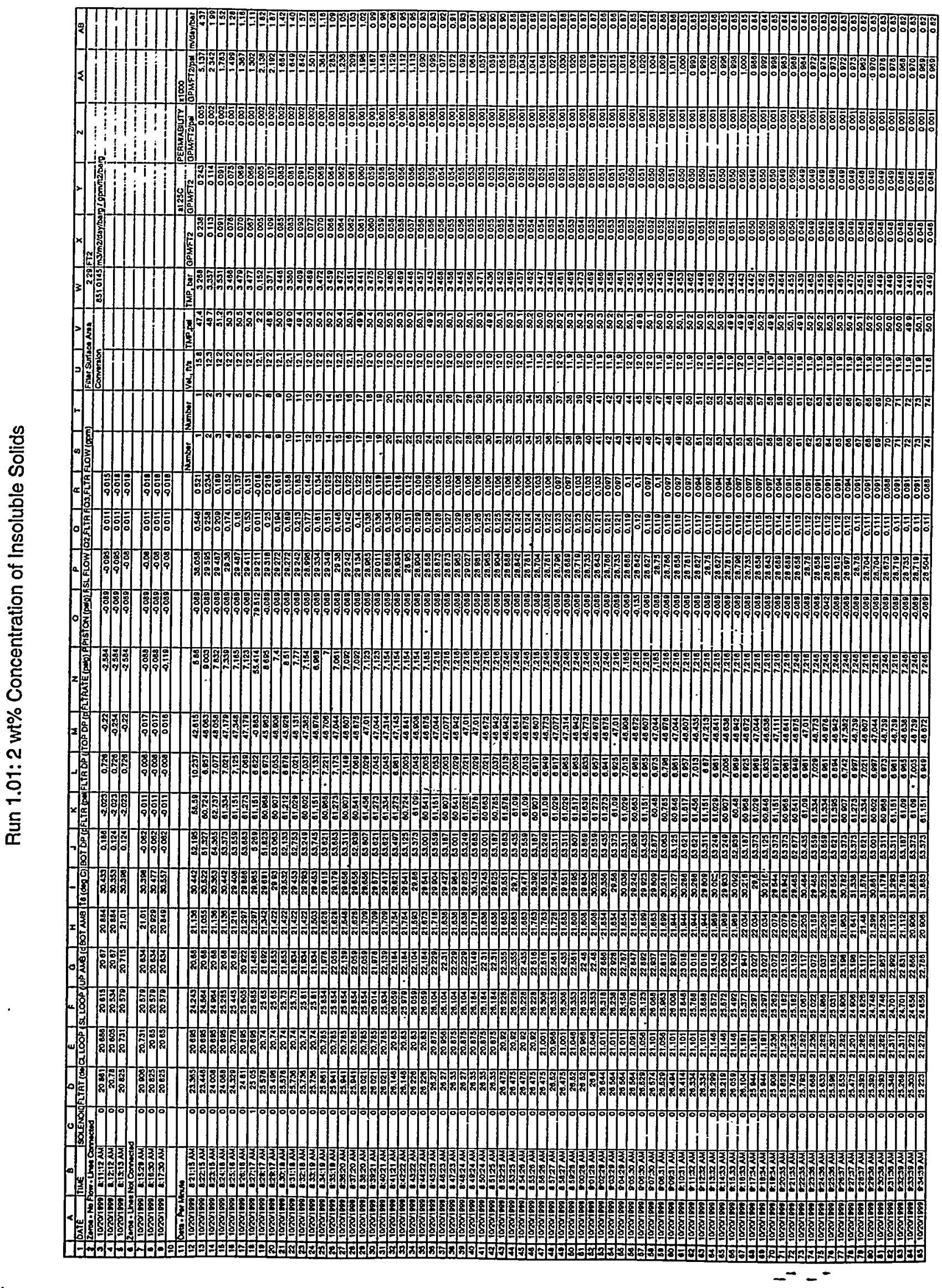


Pilot scale X-flow: EnvC+ES+Sr/TRU Page 89 of 256

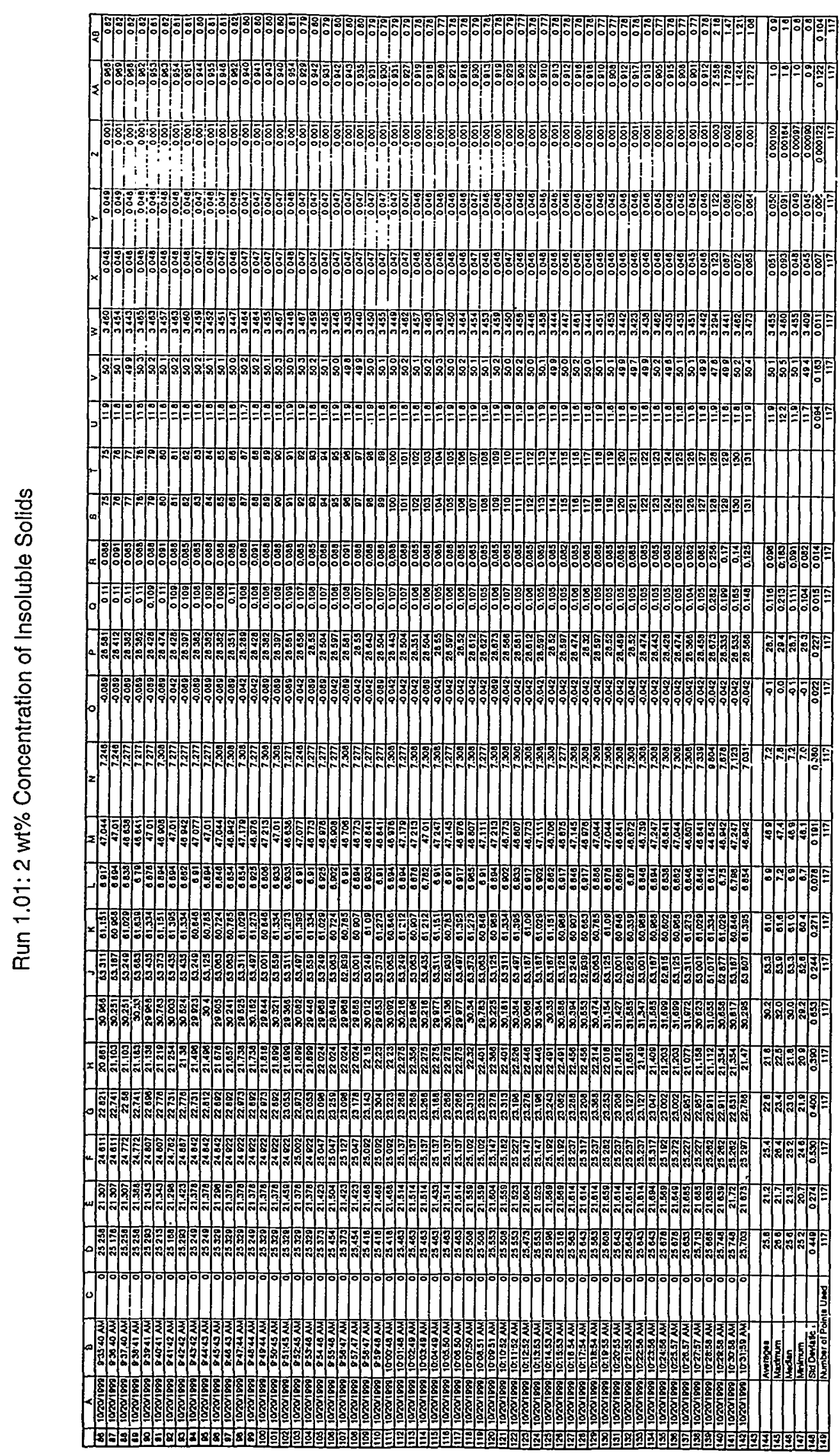



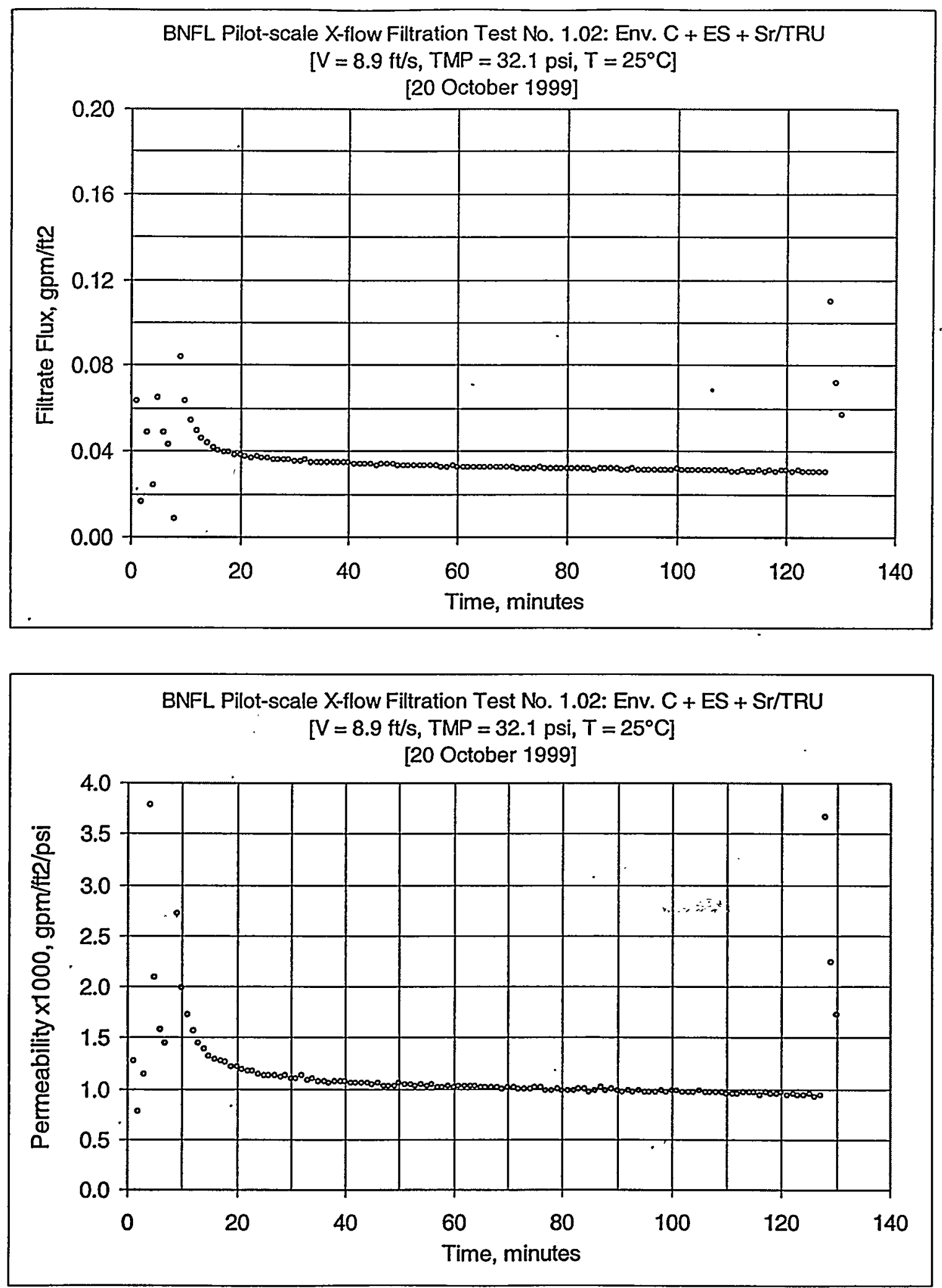

Figure B2: Test Run 1.02, 2 wt\% Insoluble Solids Concentration 
Pilot scale X-flow: EnvC+ES+Sr/TRU Page 91 of 256

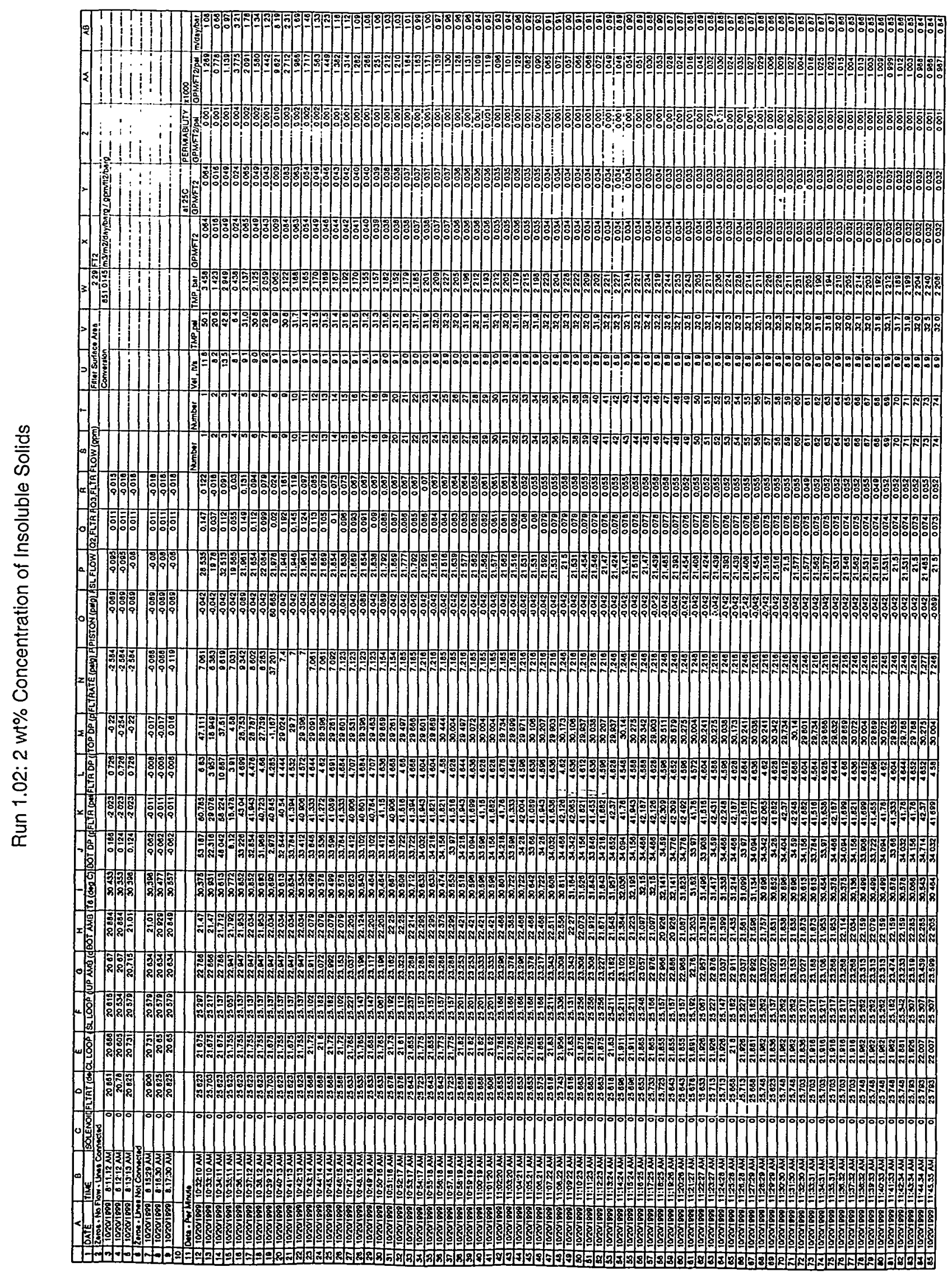


Pilot scale X-flow: EnivC+ES+St/TRU Page 92 of 256

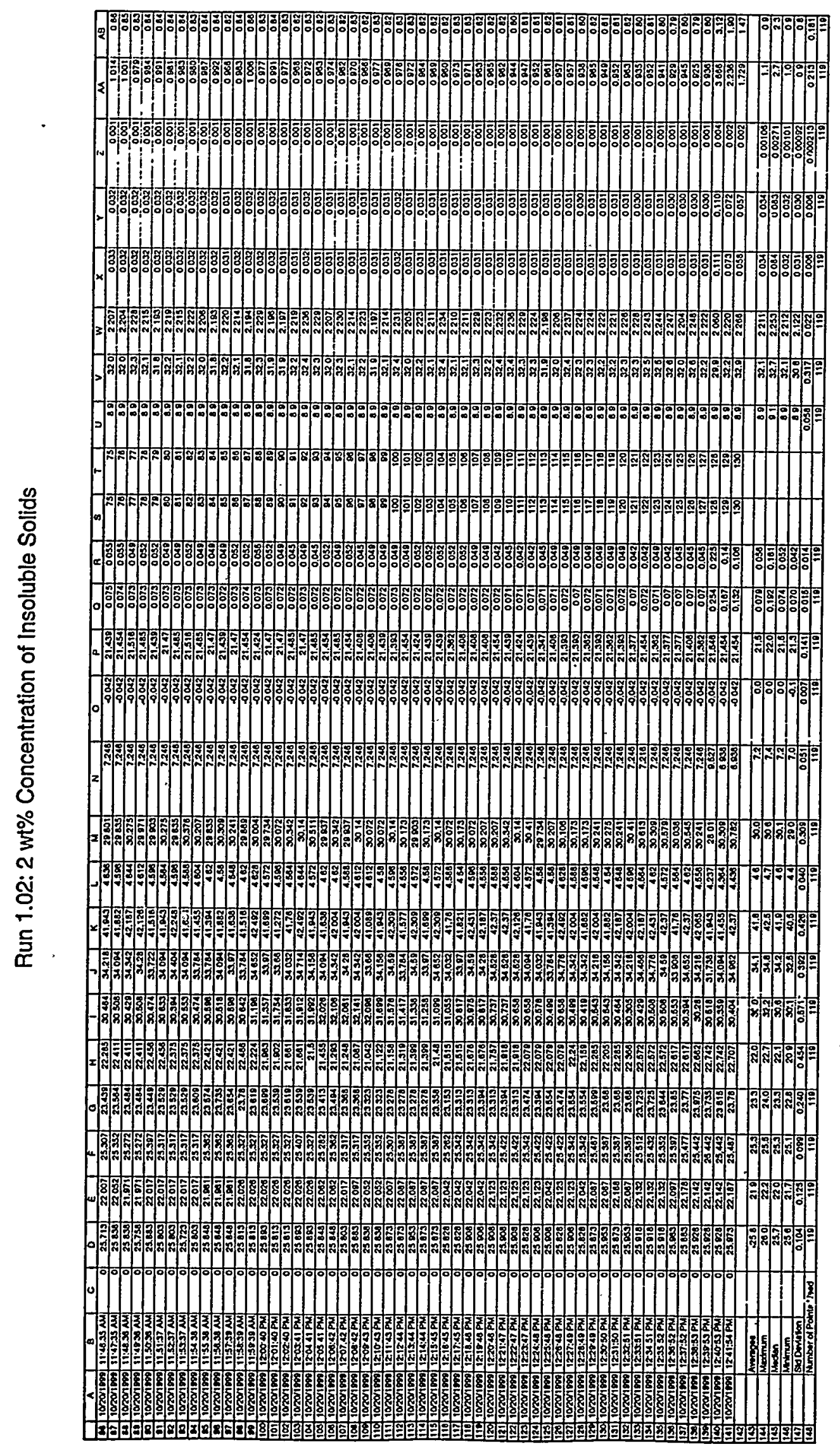



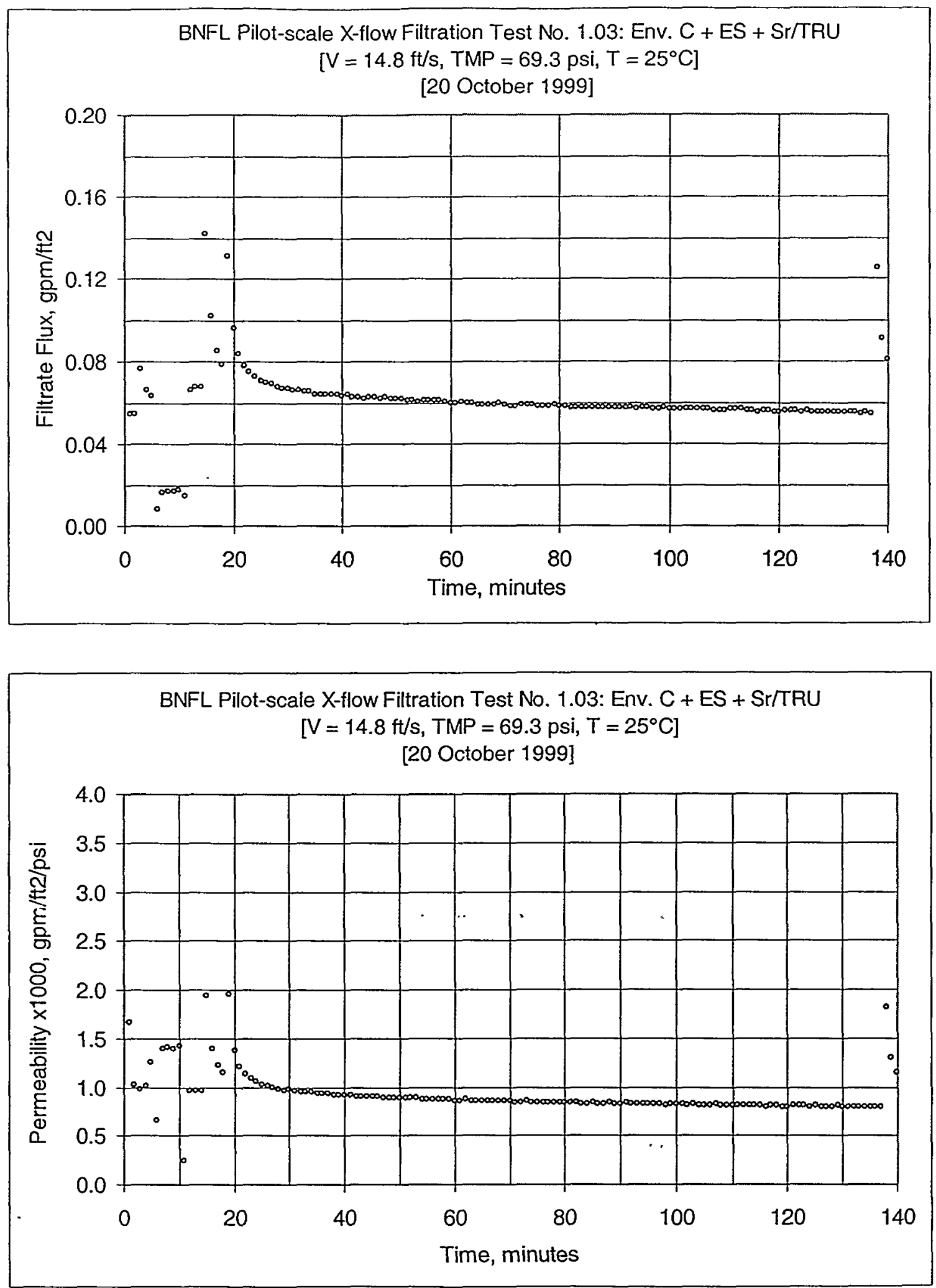

Figure B3: Test Run 1.03, 2 wt\% Insoluble Solids Concentration 
Pilot scale X-flow: EnvC+ES+St/TRU Page 94 of 256

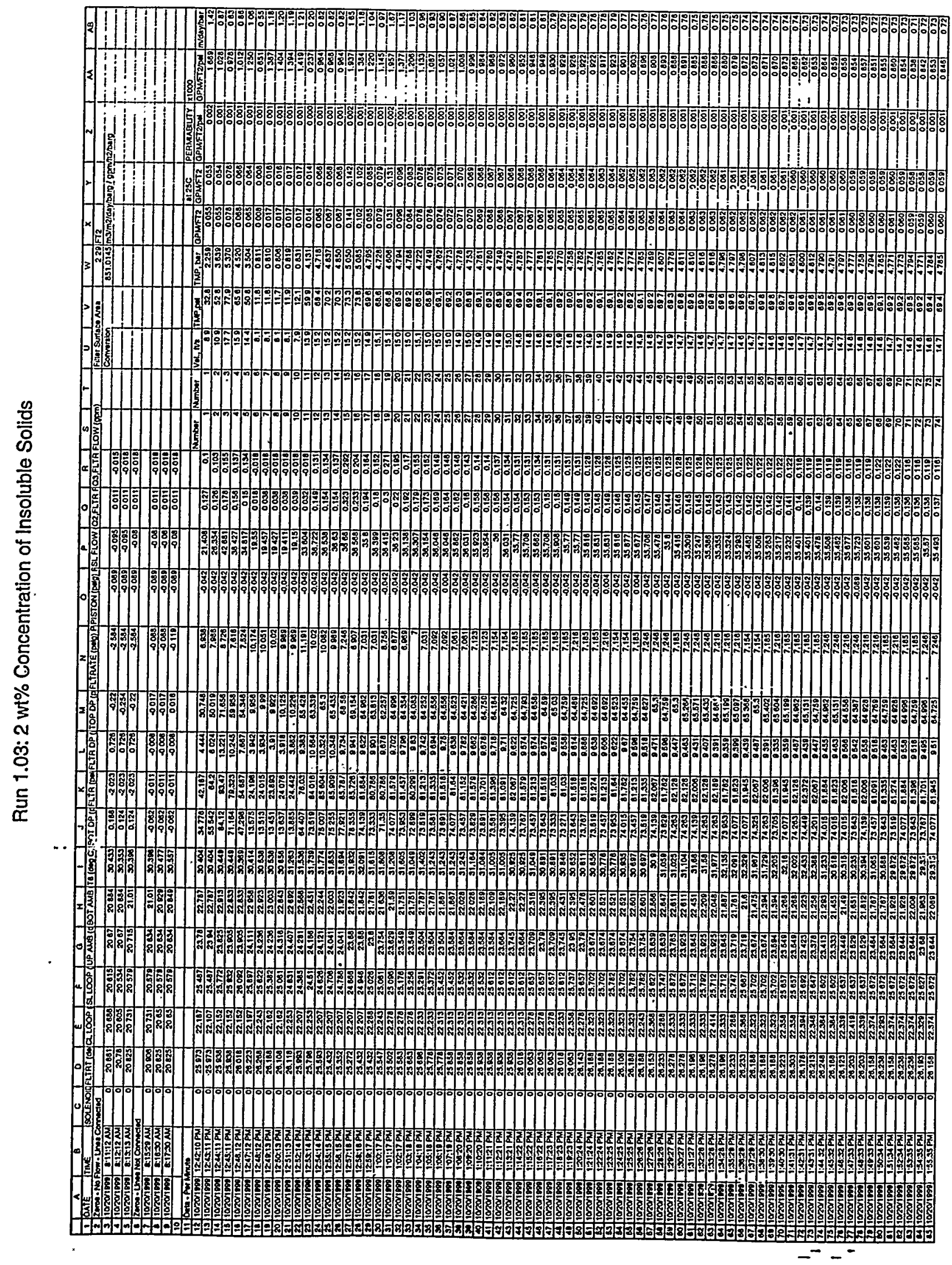


Pilot scale X-flow: EnvC+ES+St/TRU Page 95 of 256

BNF-003-98-0226

Revision 0

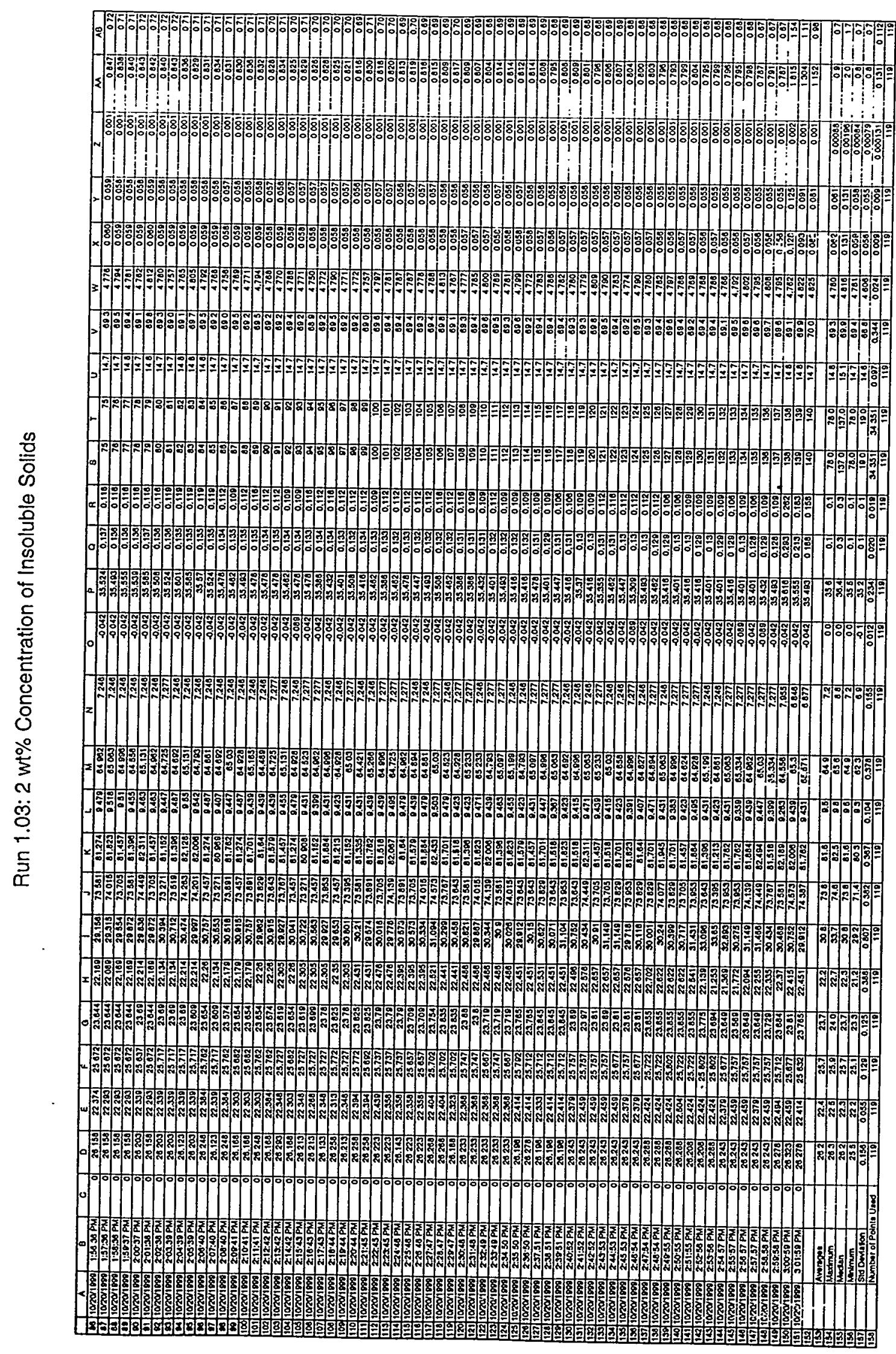



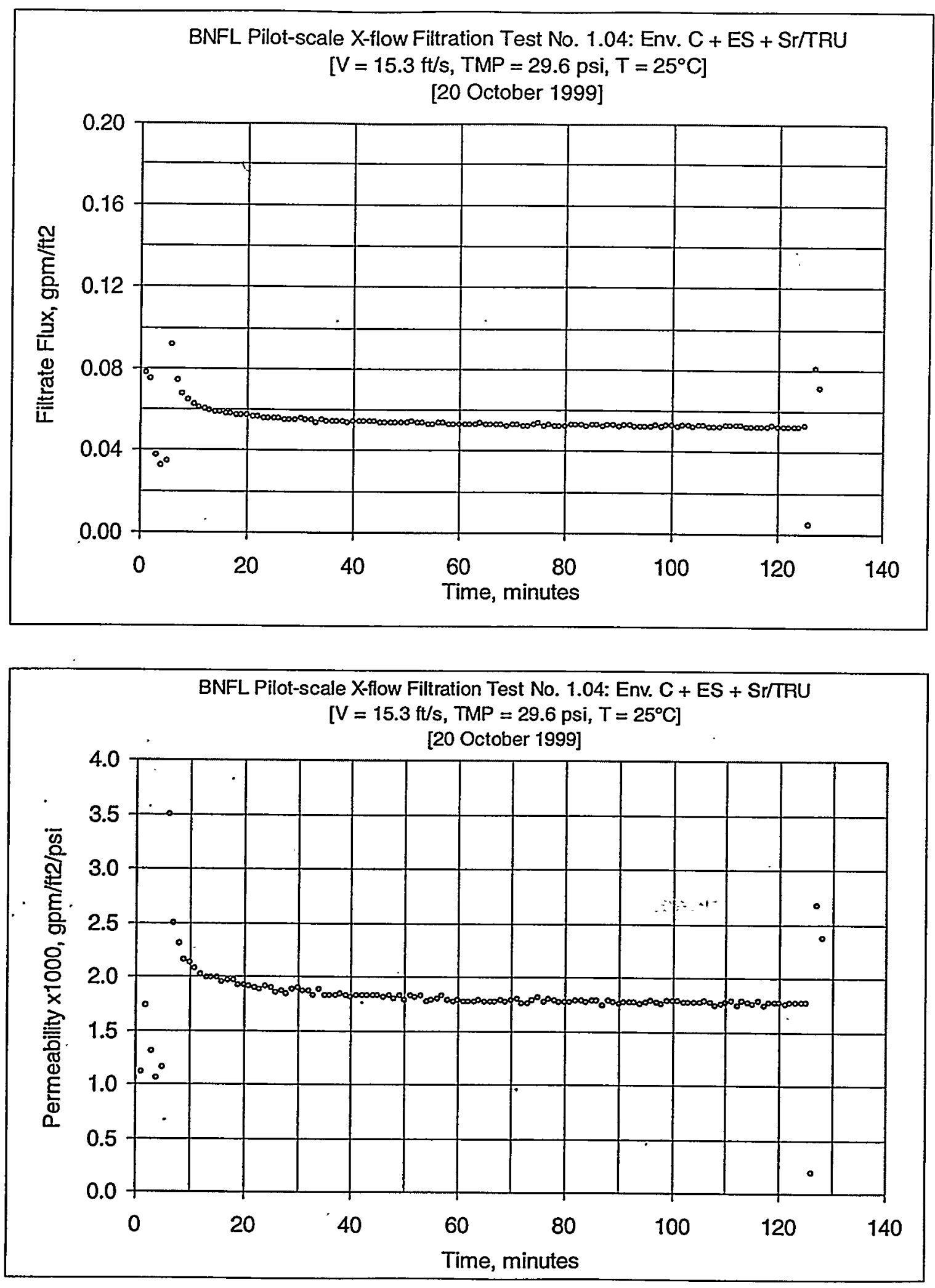

Figure B4: Test Run 1.04, 2 wt\% Insoluble Solids Concentration 
Pilot scale X-flow: EnvC+ES+Sr/TRU Page 97 of 256

BNF-003-98-0226

Revision 0

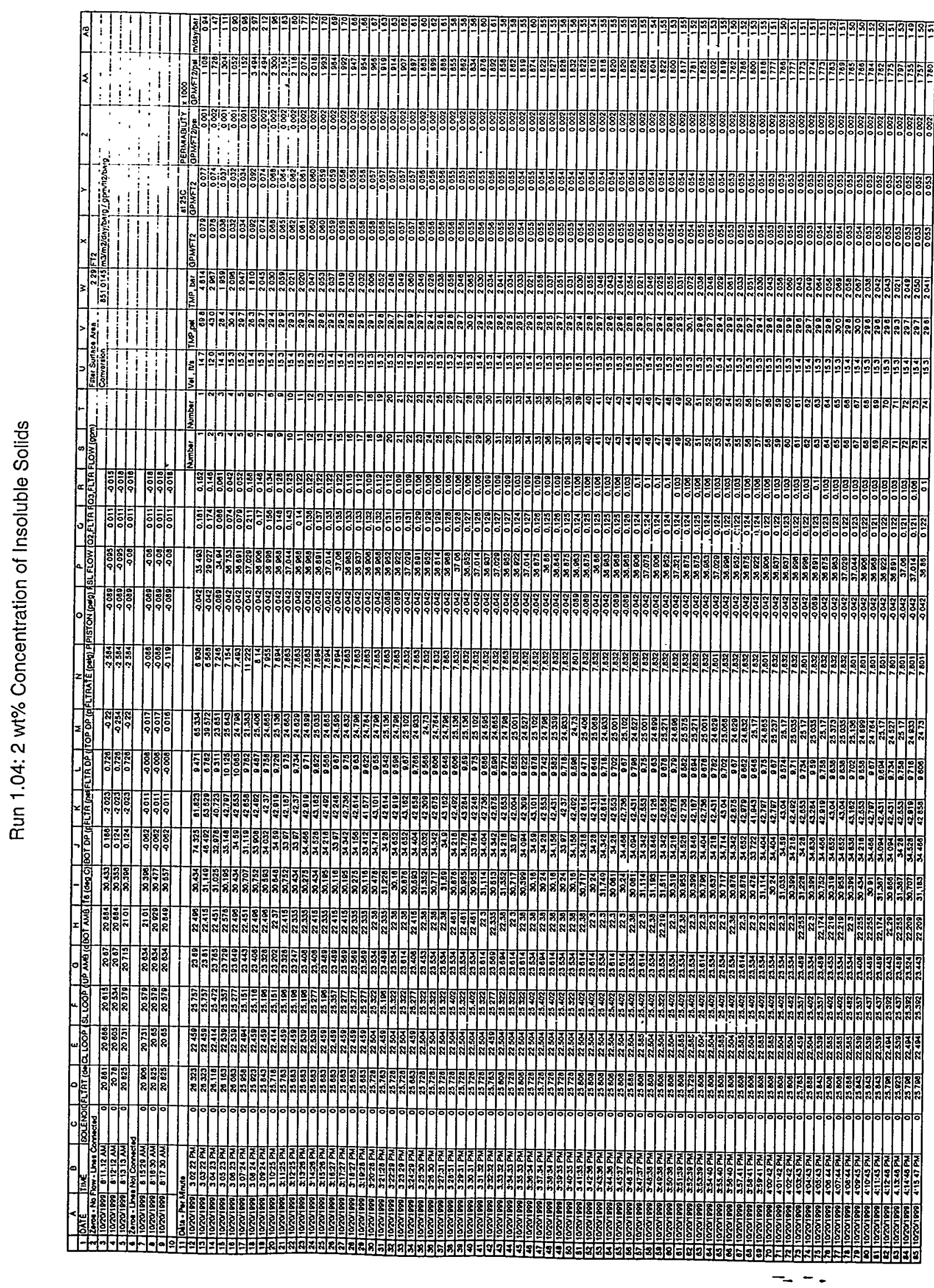




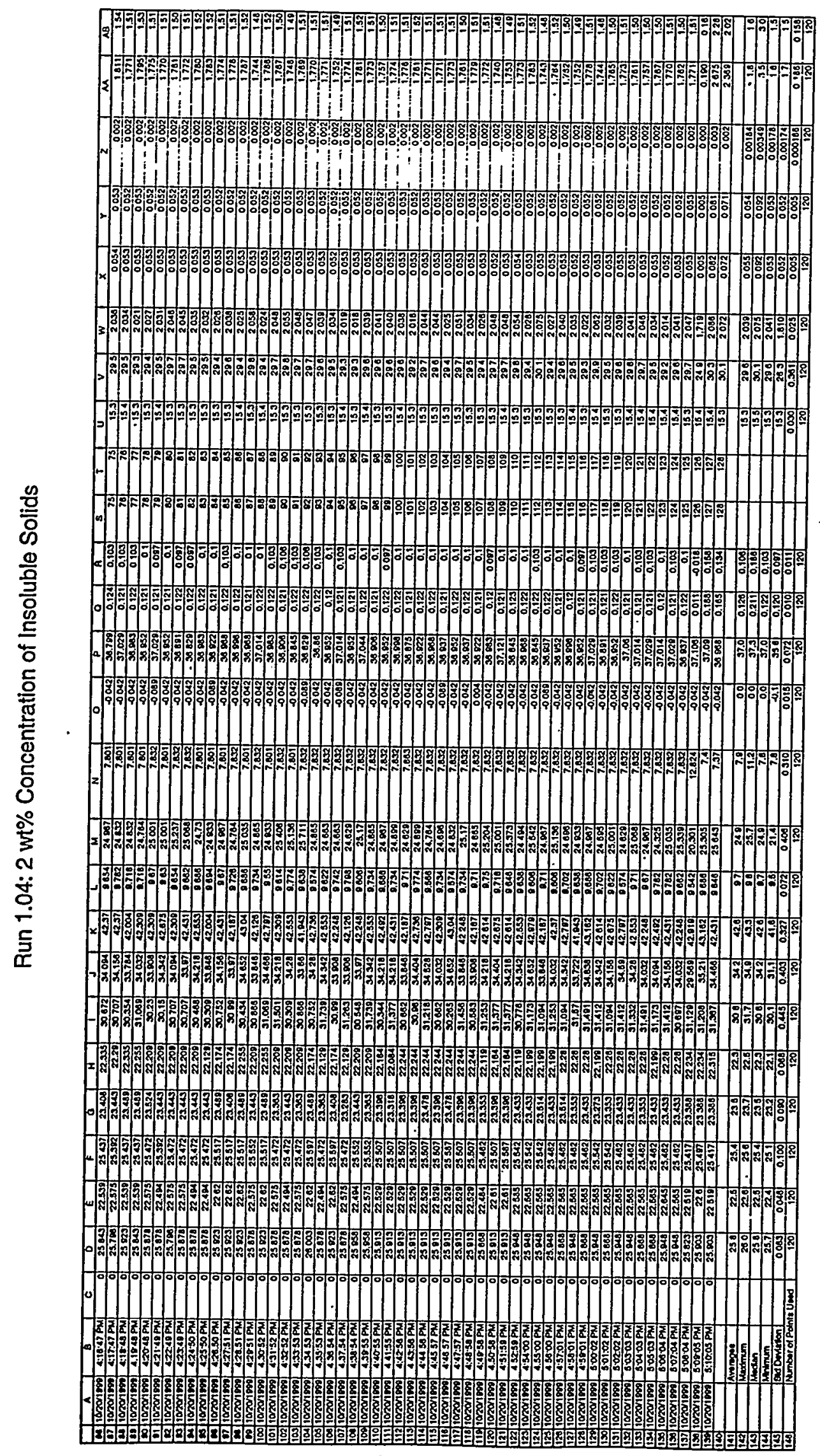



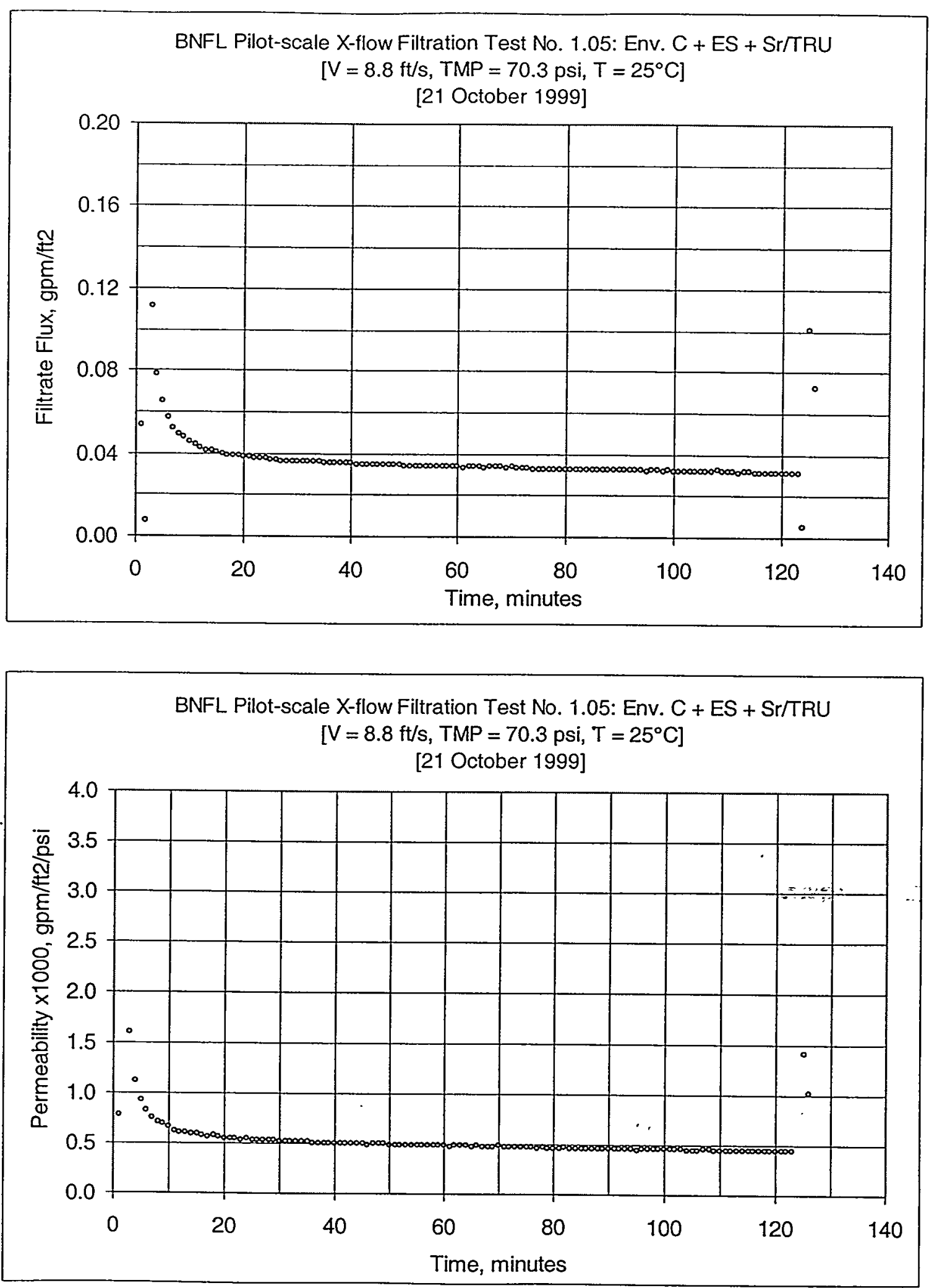

Figure B5: Test Run 1.05, 2 wt\% Insoluble Solids Concentration 
Pilot scale X-flow: EnvC+ES+Sr/TRU Page 100 of 256

BNF-003-98-0226

Revision 0

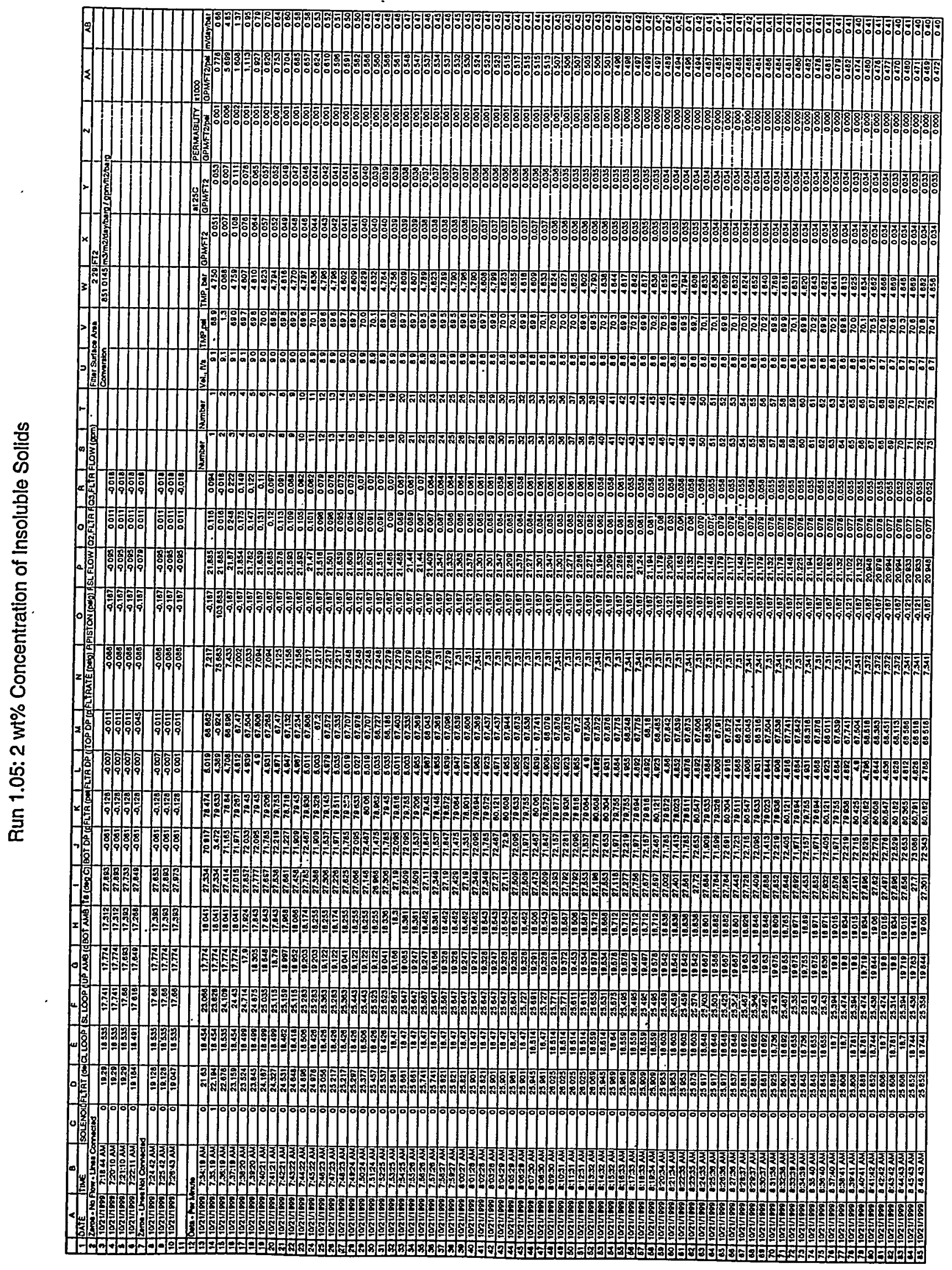


Pilot scale X-flow: EnvC+ES+St/TRU Page 101 of 256

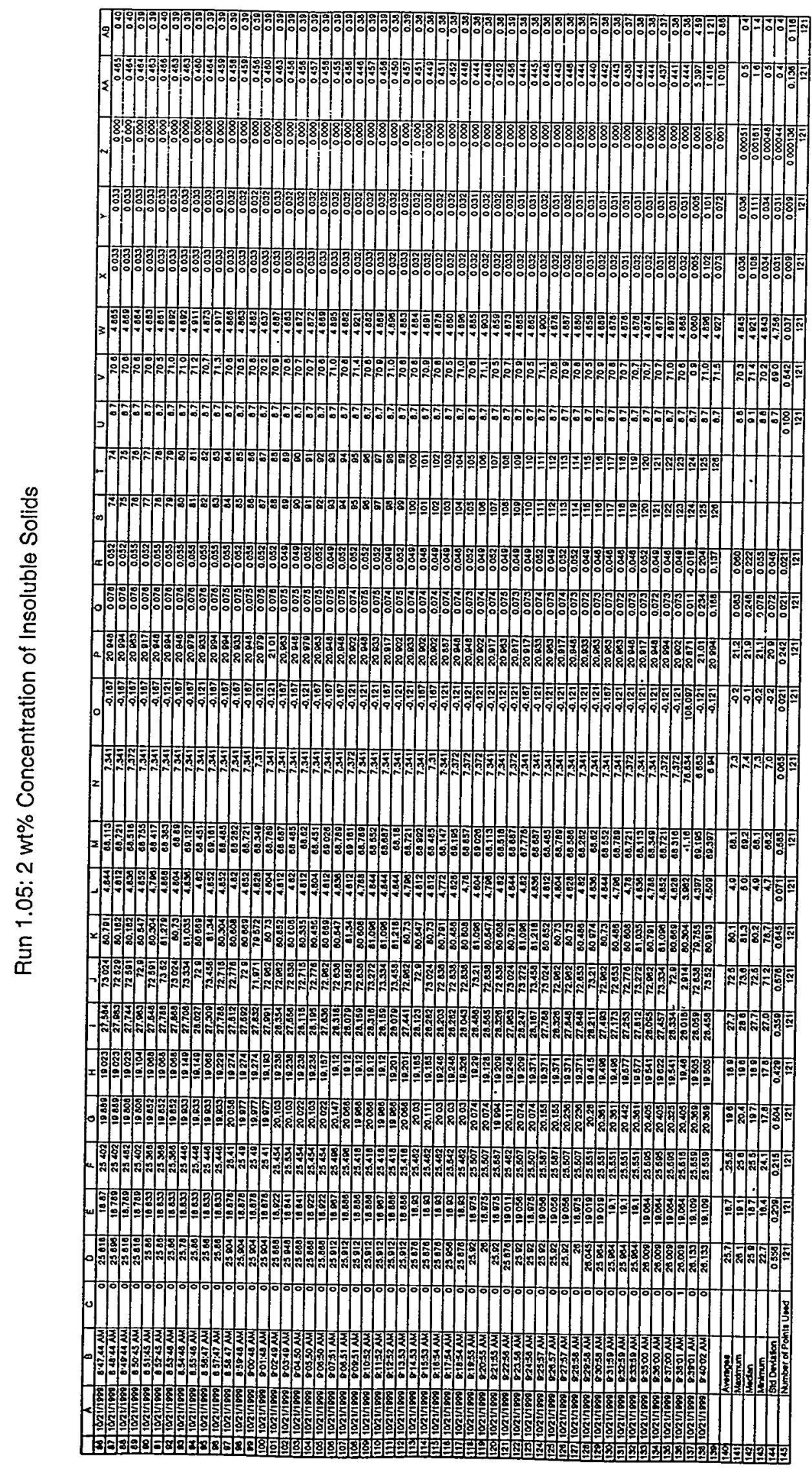




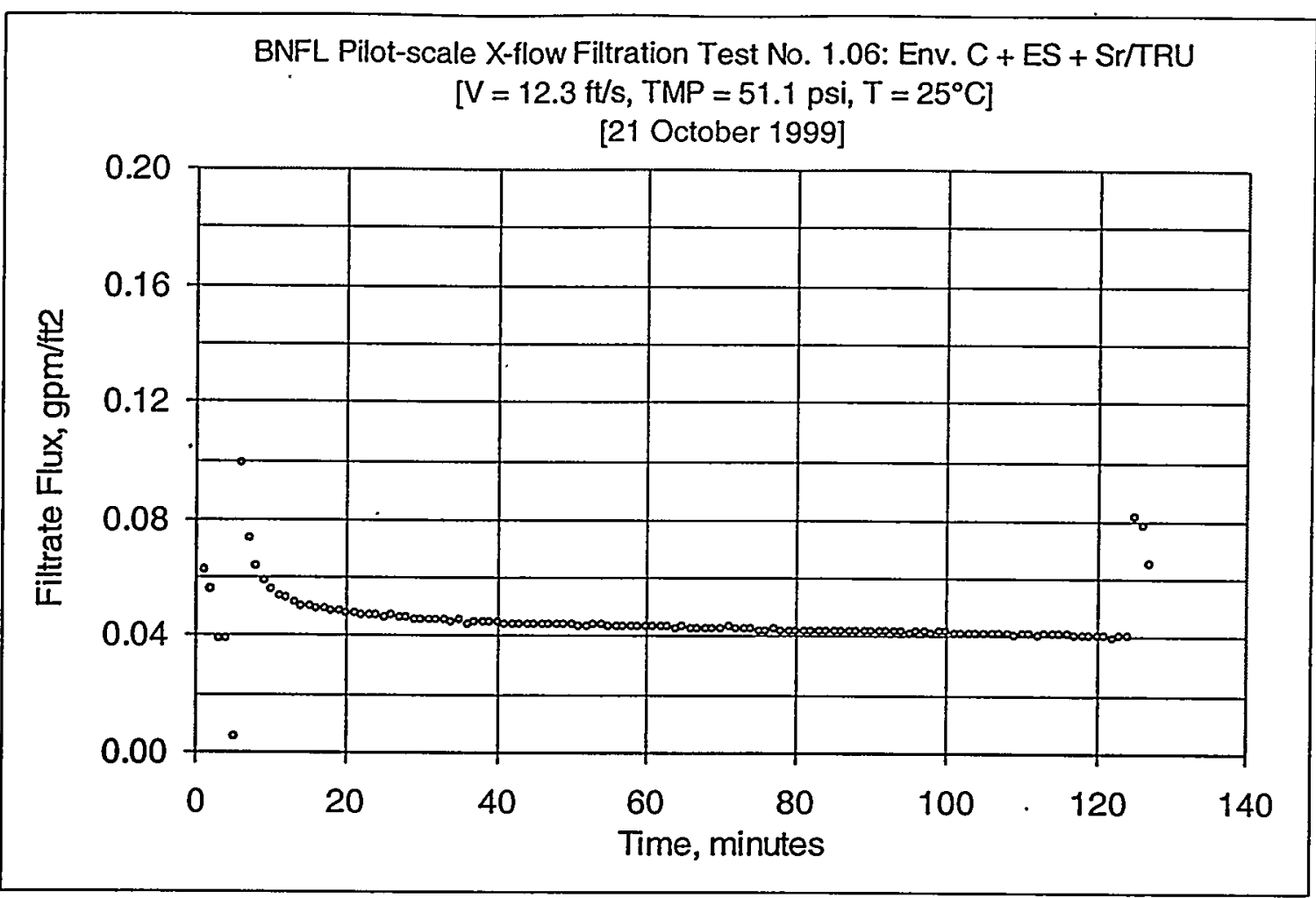

BNFL Pilot-scale X-flow Filtration Test No. 1.06: Env. $C+E S+S r / T R U$ $\left[\mathrm{V}=12.3 \mathrm{ft} / \mathrm{s}, \mathrm{TMP}=51.1 \mathrm{psi}, \mathrm{T}=25^{\circ} \mathrm{C}\right]$

[21 October 1999]

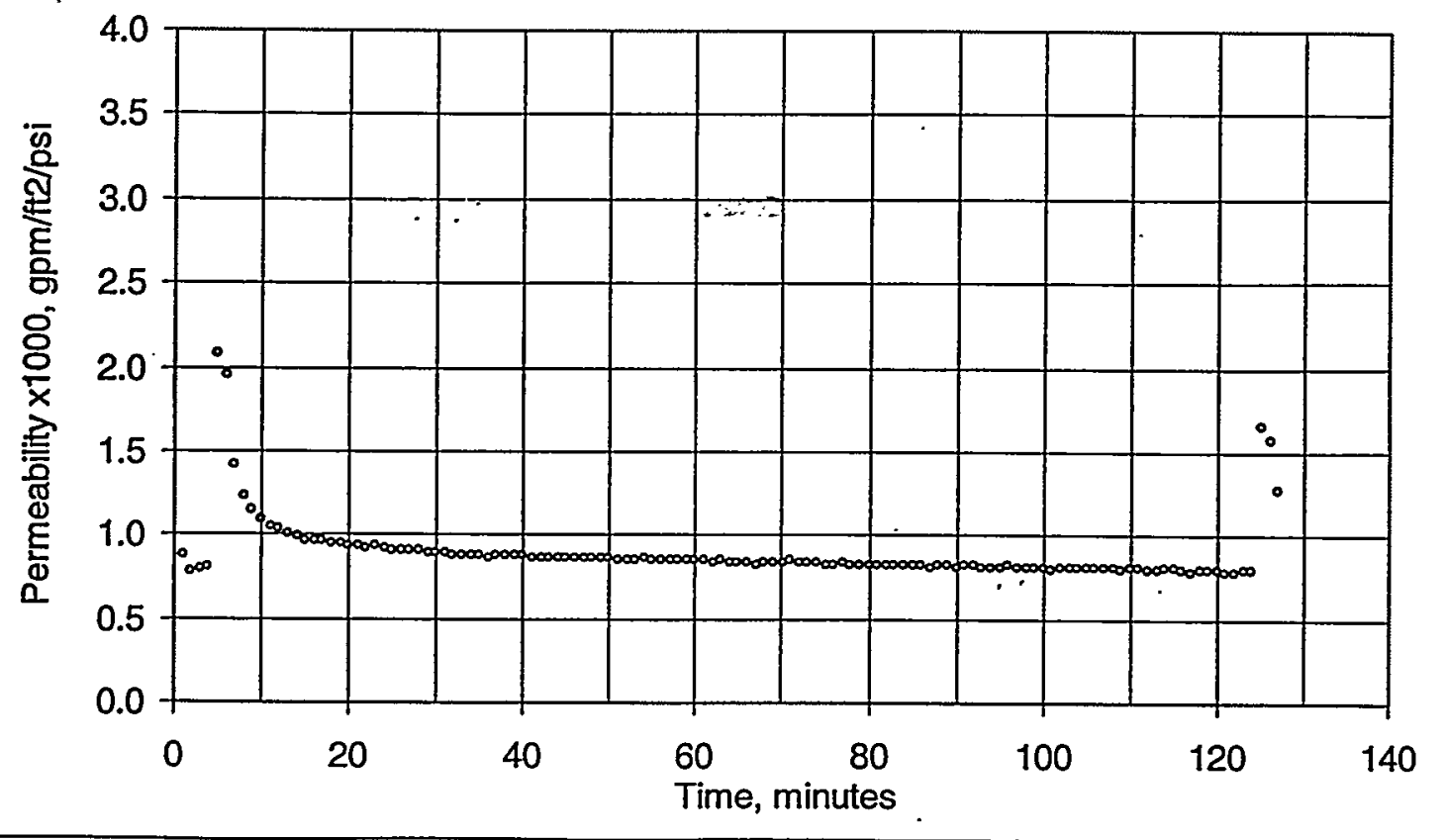

Figure B6: Test Run 1.06, 2 wt\% Insoluble Solids Concentration 
Pilot scale X-flow: EnvC+ES+Sr/TRU Page 103 of 256

BNF-003-98-0226

Revision 0

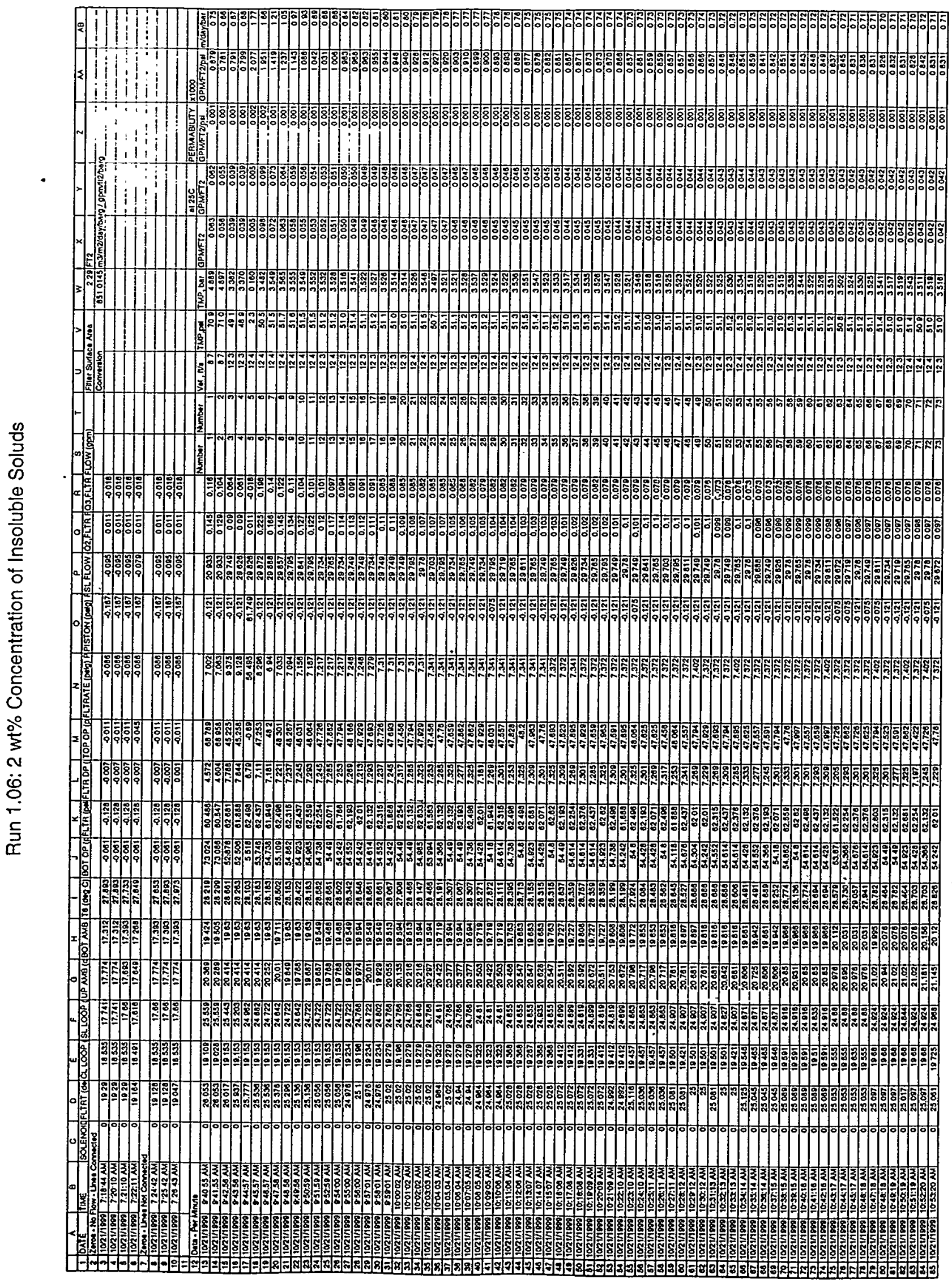


Pilot scale X-flow: EnvC+ES+St/TRU Page 104 of 256

BNF-003-98-0226

Revision 0

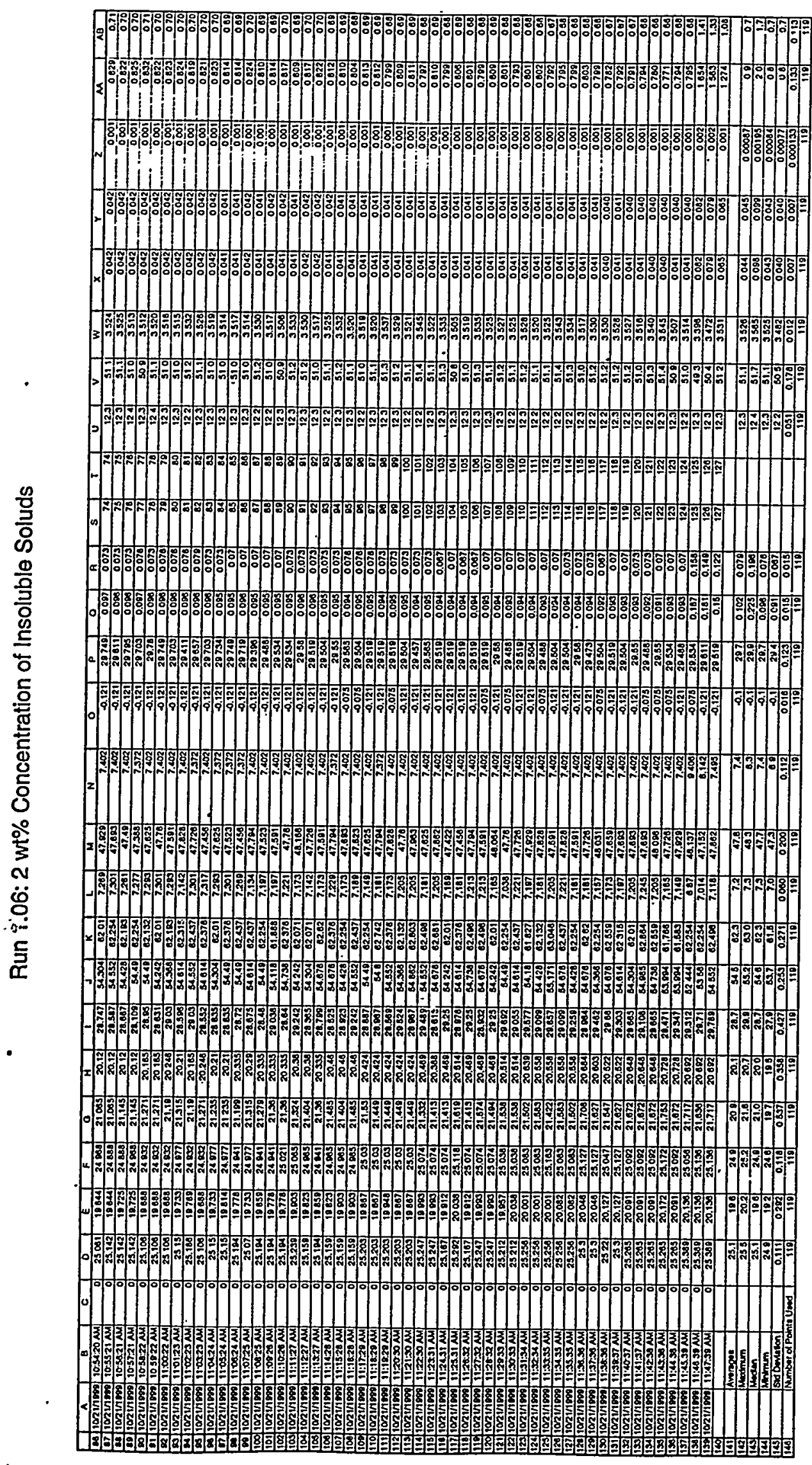



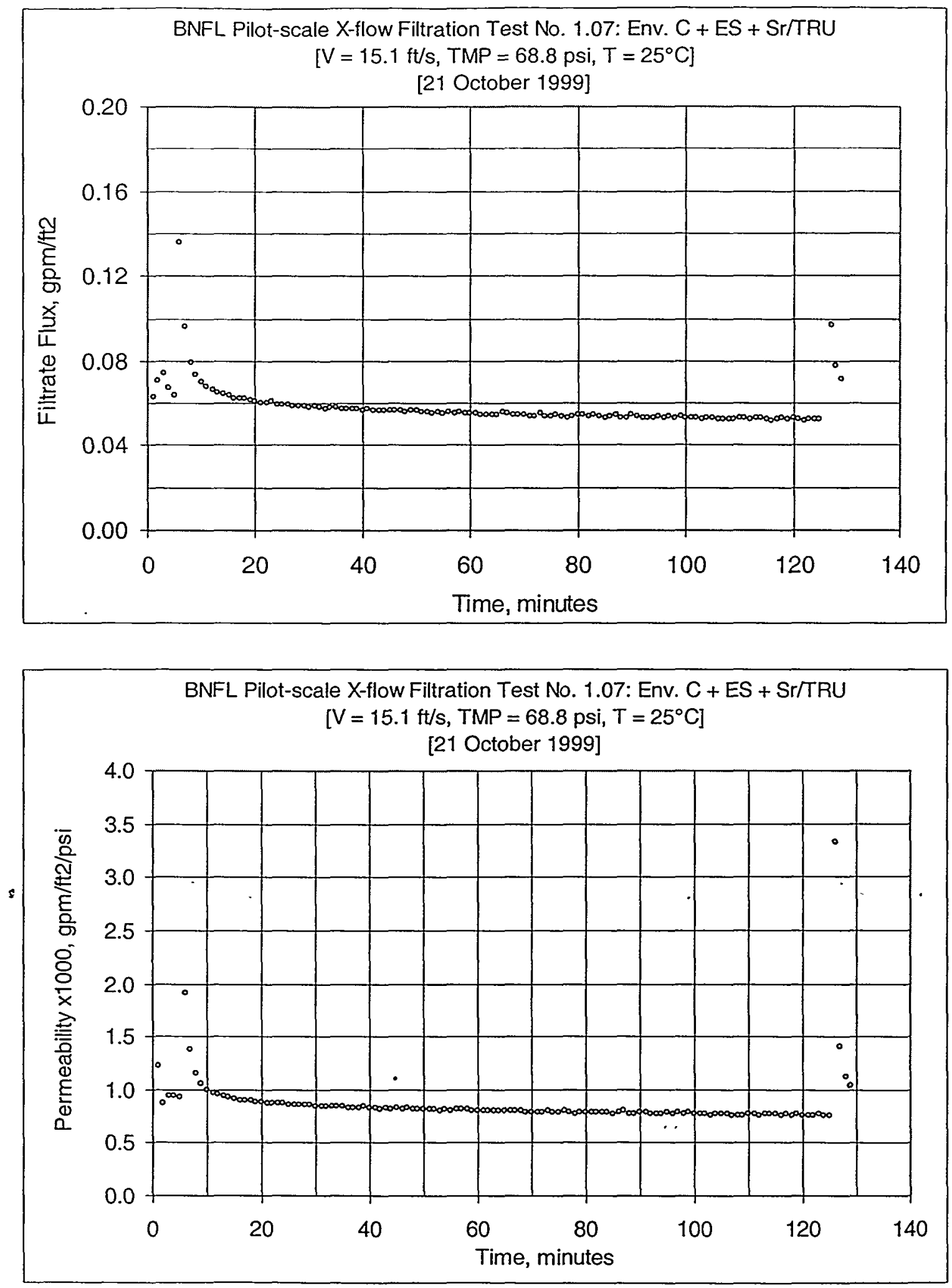

Figure B7: Test Run 1.07, 2 wt\% Insoluble Solids Concentration 
Pilot scale X-flow: EnvC+ES+St/TRU Page 106 of 256

BNF-003-98-0226

Revision 0

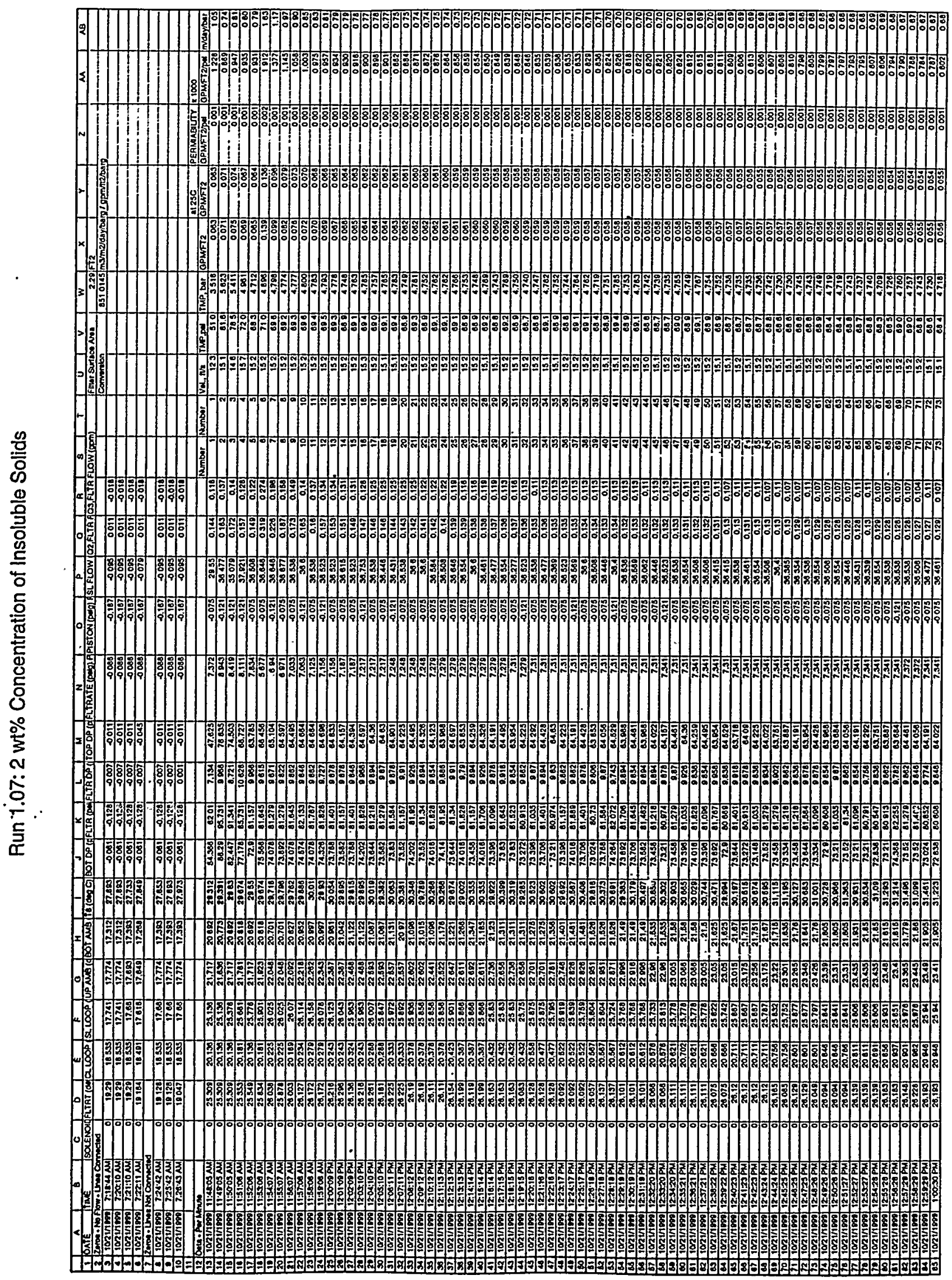


Pilot scale X-flow: EnvC+ES+Sr/TRU Page 107 of 256

BNF-003-98-0226

Revision 0

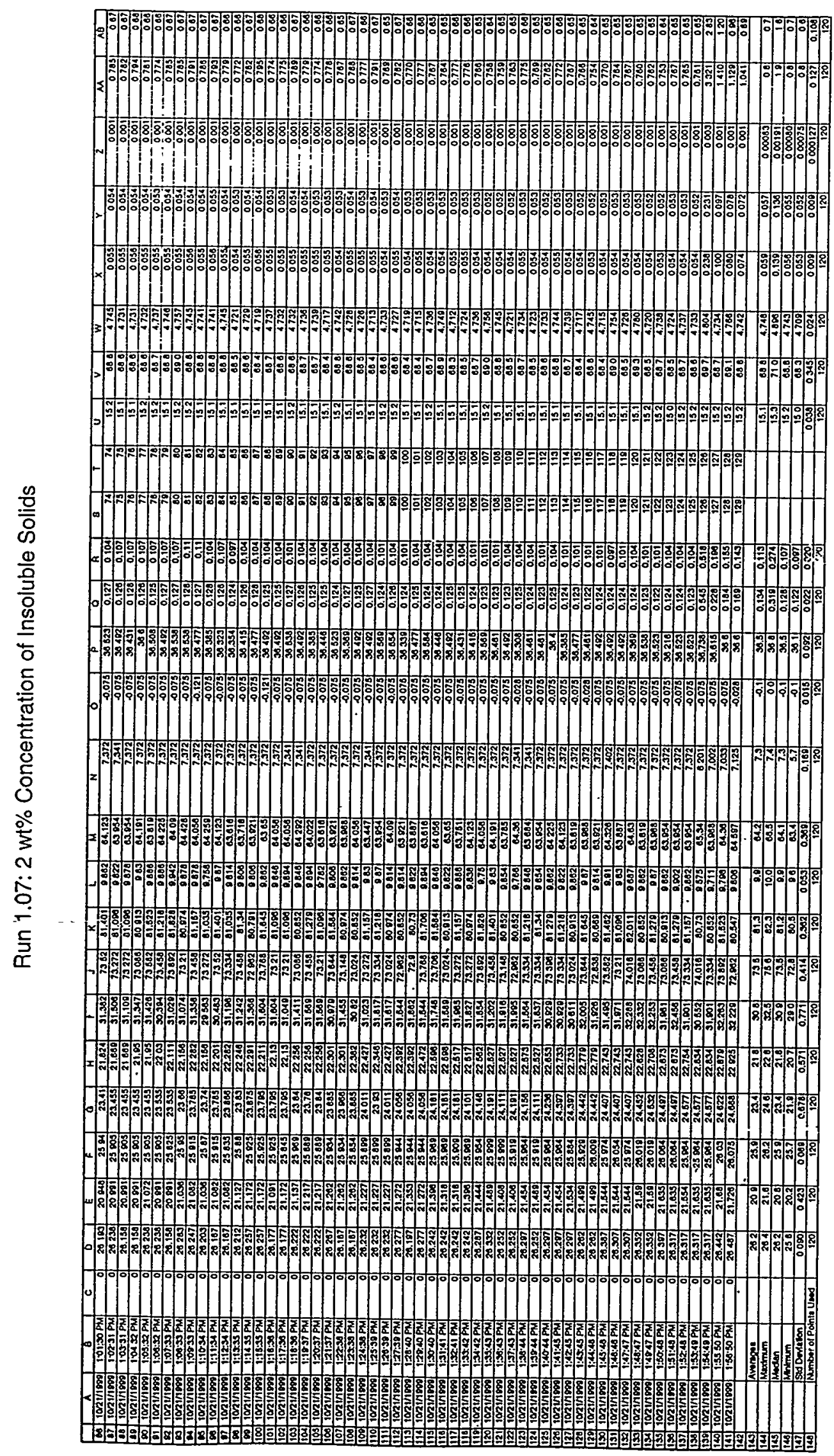



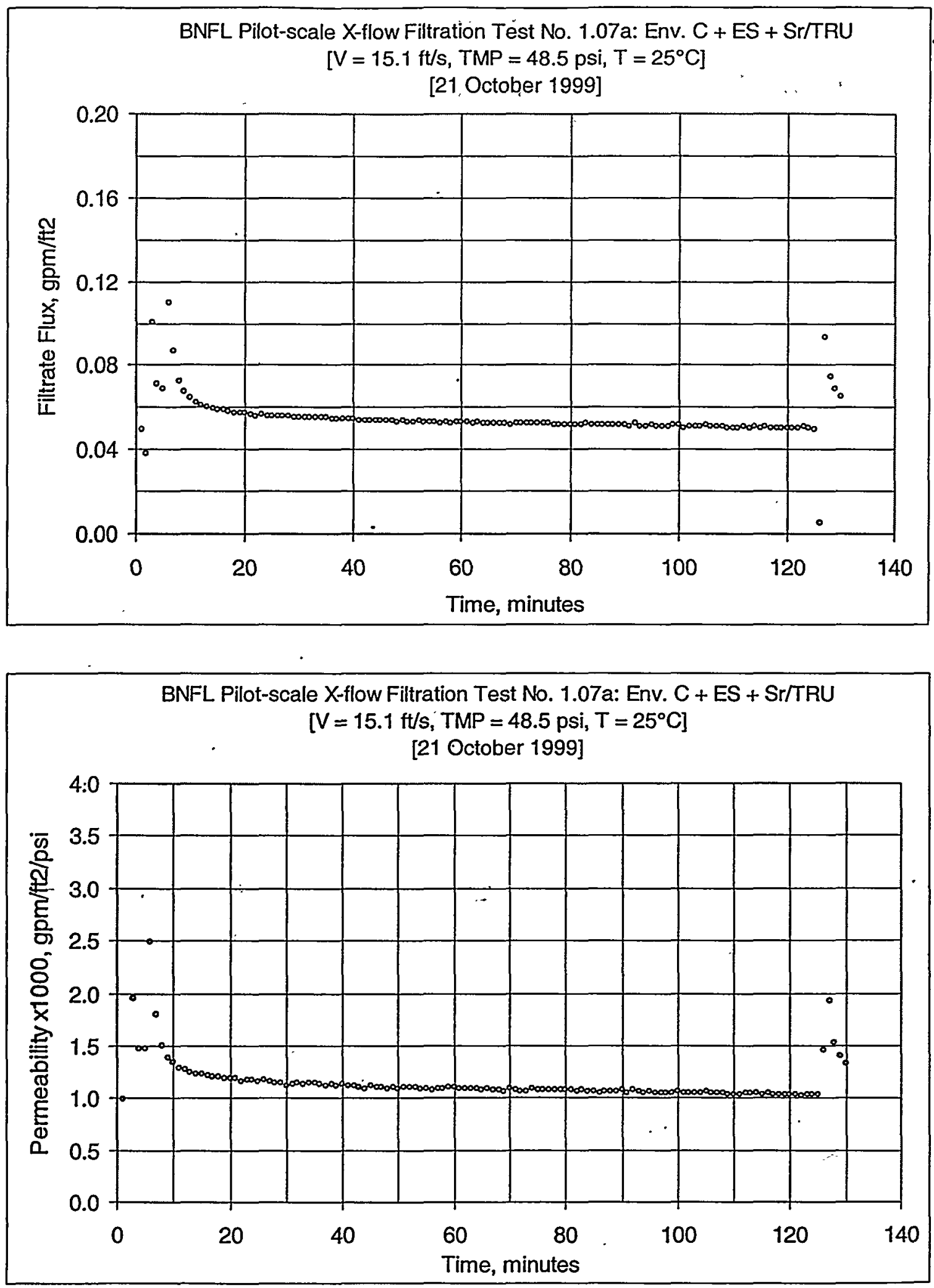

Figure B8: Test Run 1.07a, 2 wt\% Insoluble Solids Concentration 


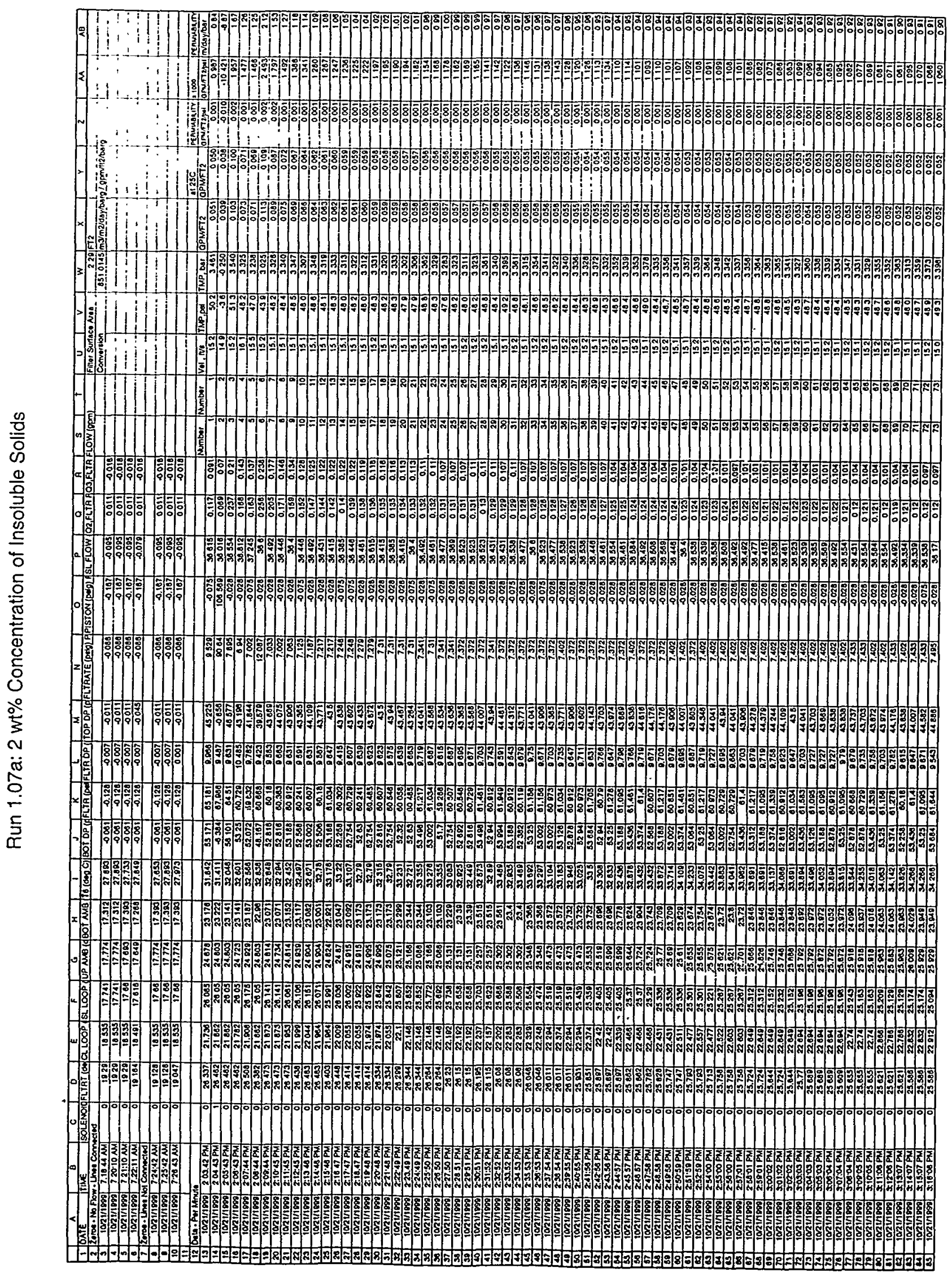


Pilot scale X-flow: EnvC+ES+Sr/TRU Page 110 of 256

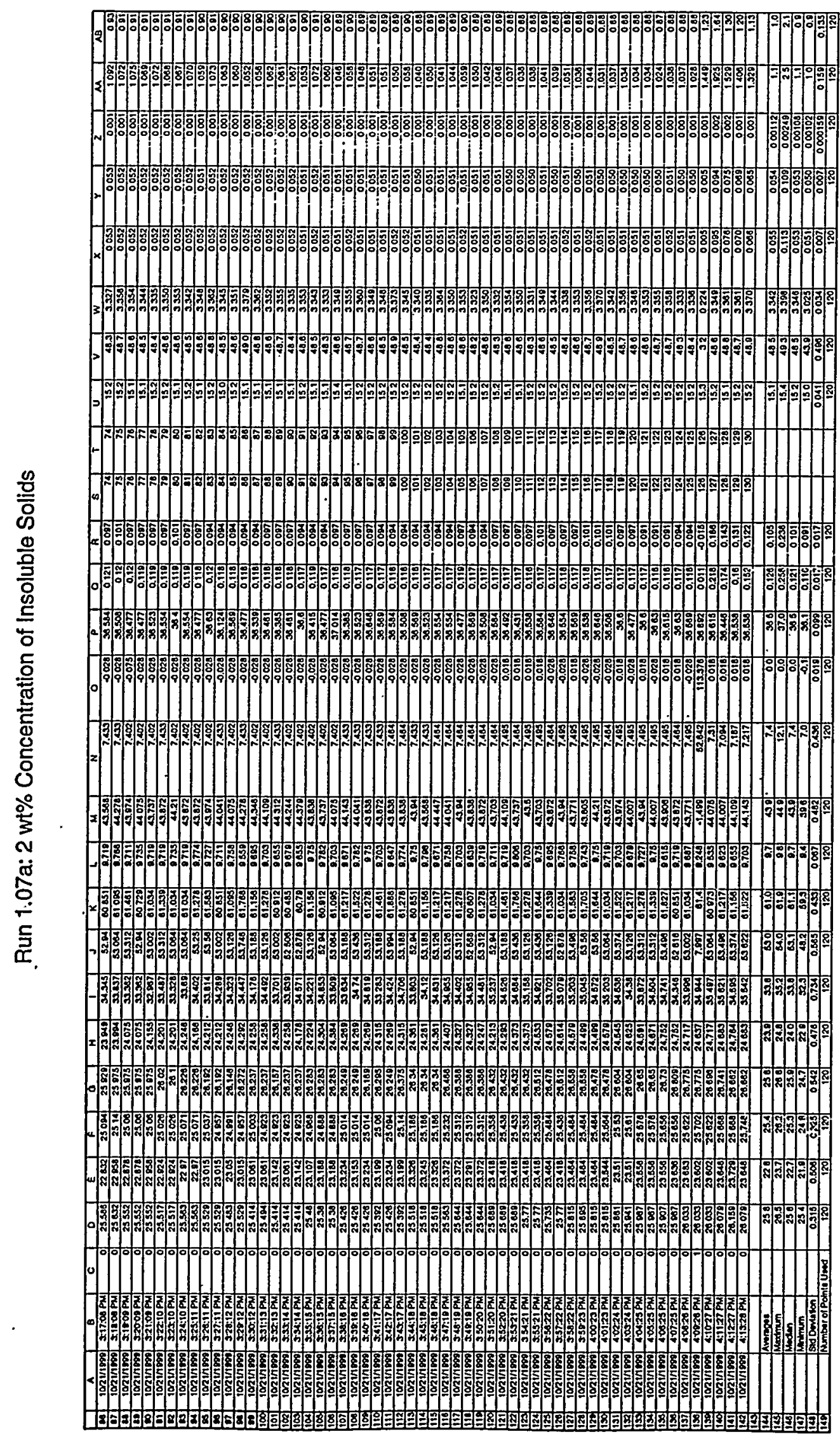



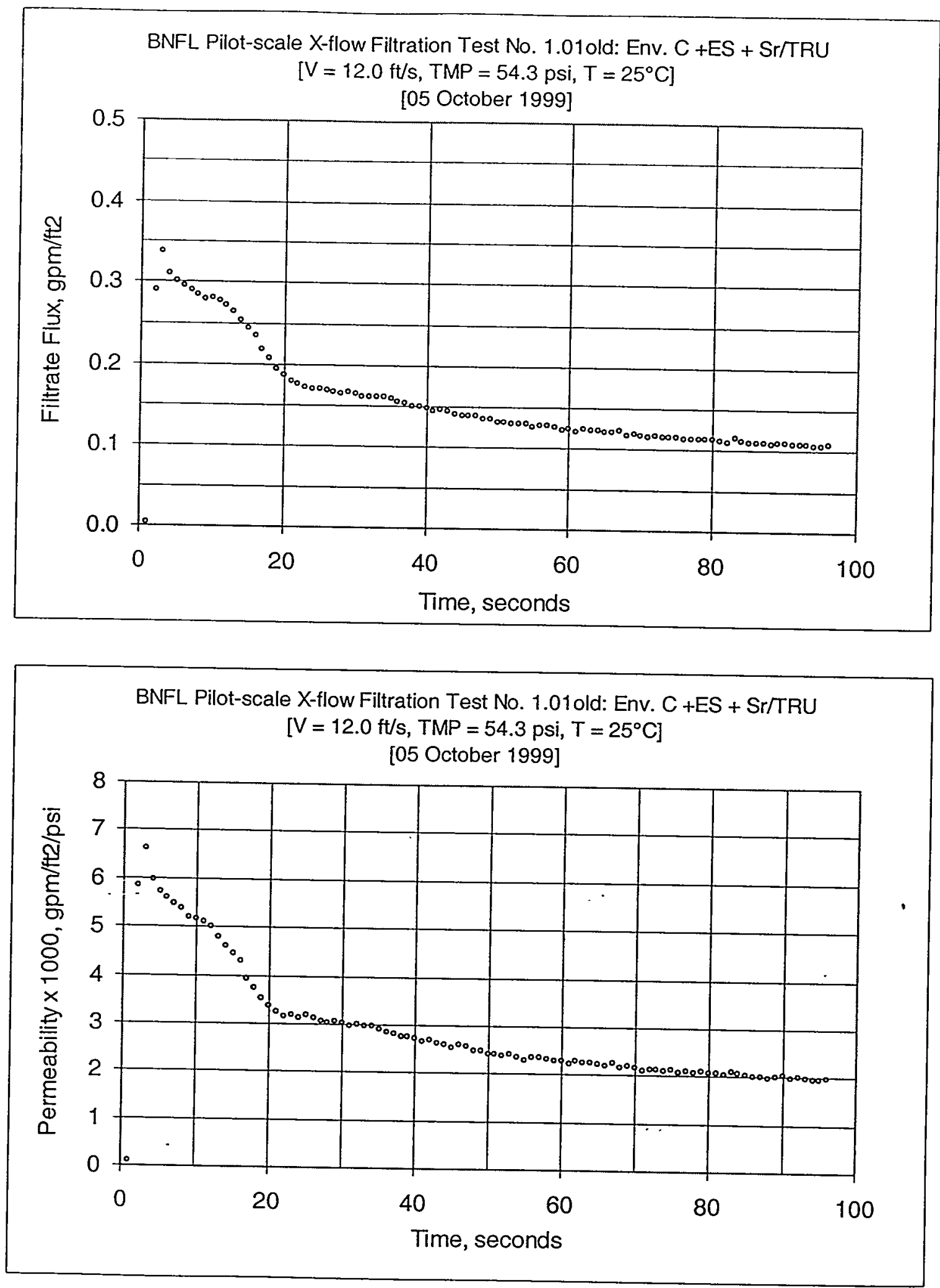

Figure B9a: Test Run 1.01(old), 2 wt\% Insoluble Solids Concentration (in seconds) 

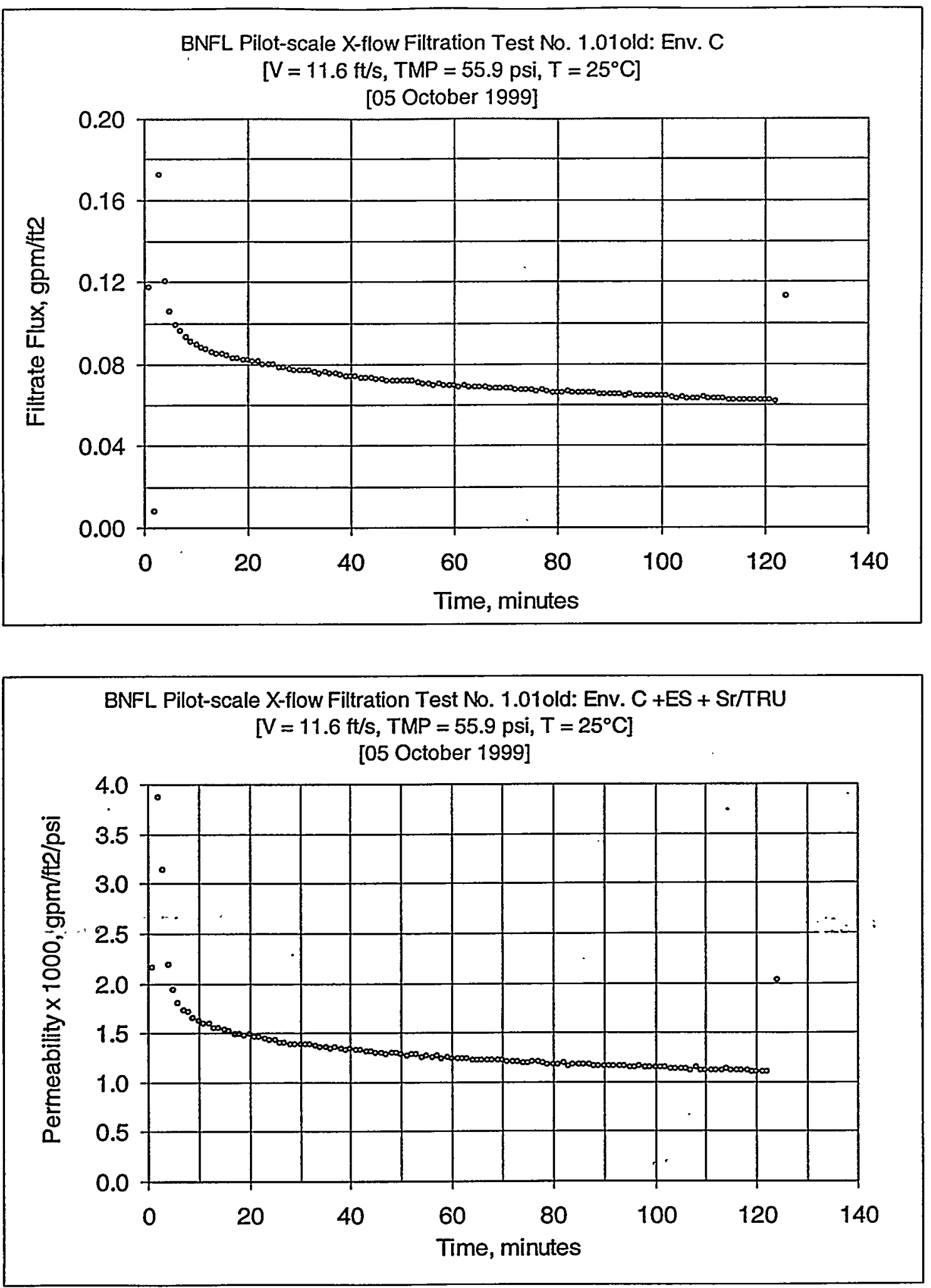

Figure B9b: Test Run 1.01(old), 2 wt\% Insoluble Solids Concentration (in minutes) 
Pilot scale X-flow: EnvC+ES+St/TRU Page 113 of 256

BNF-003-98-0226

Revision 0

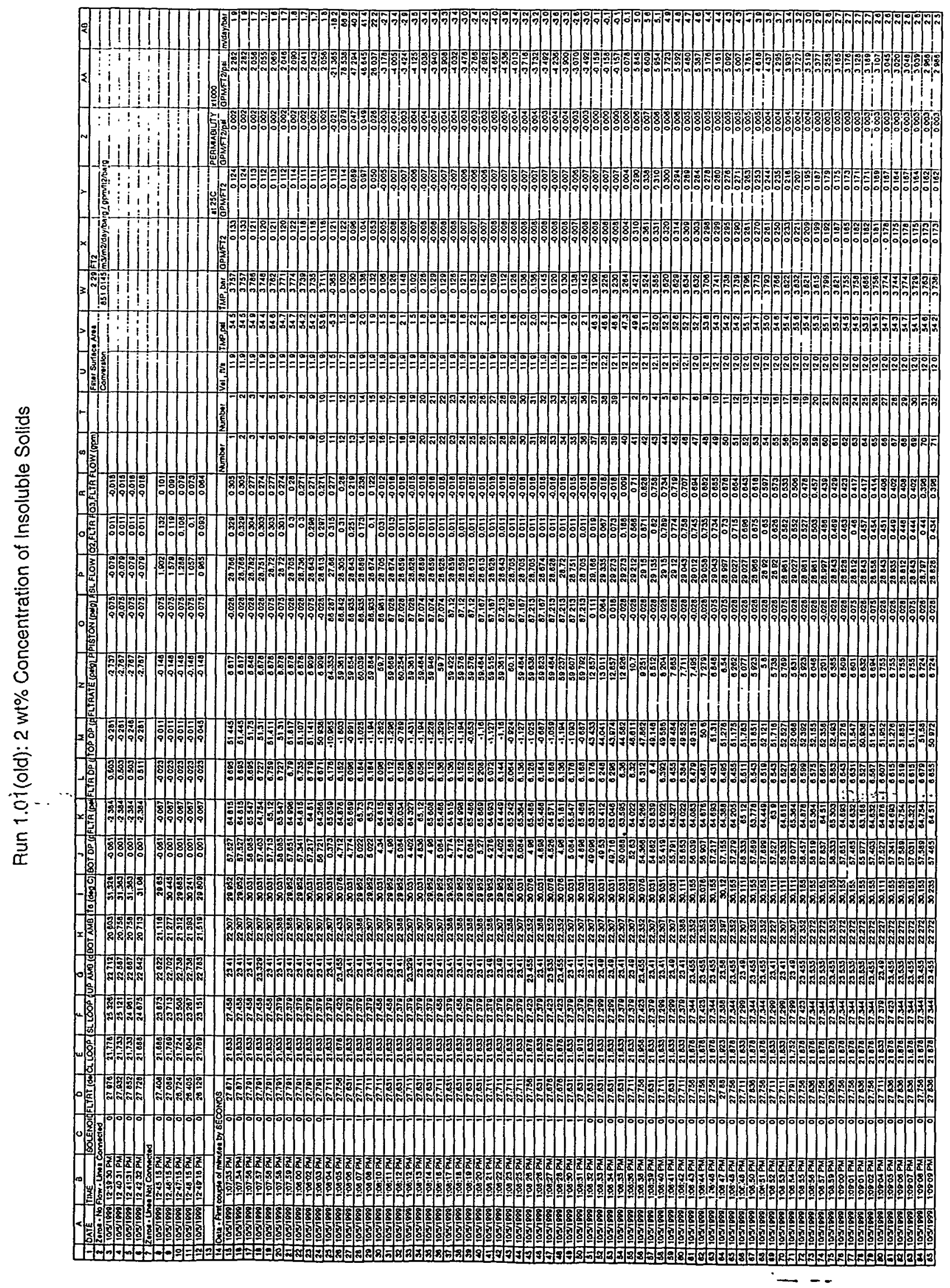


Pilot scale X-flow: EnvC+ES+Sr/TRU Page 114 of 256

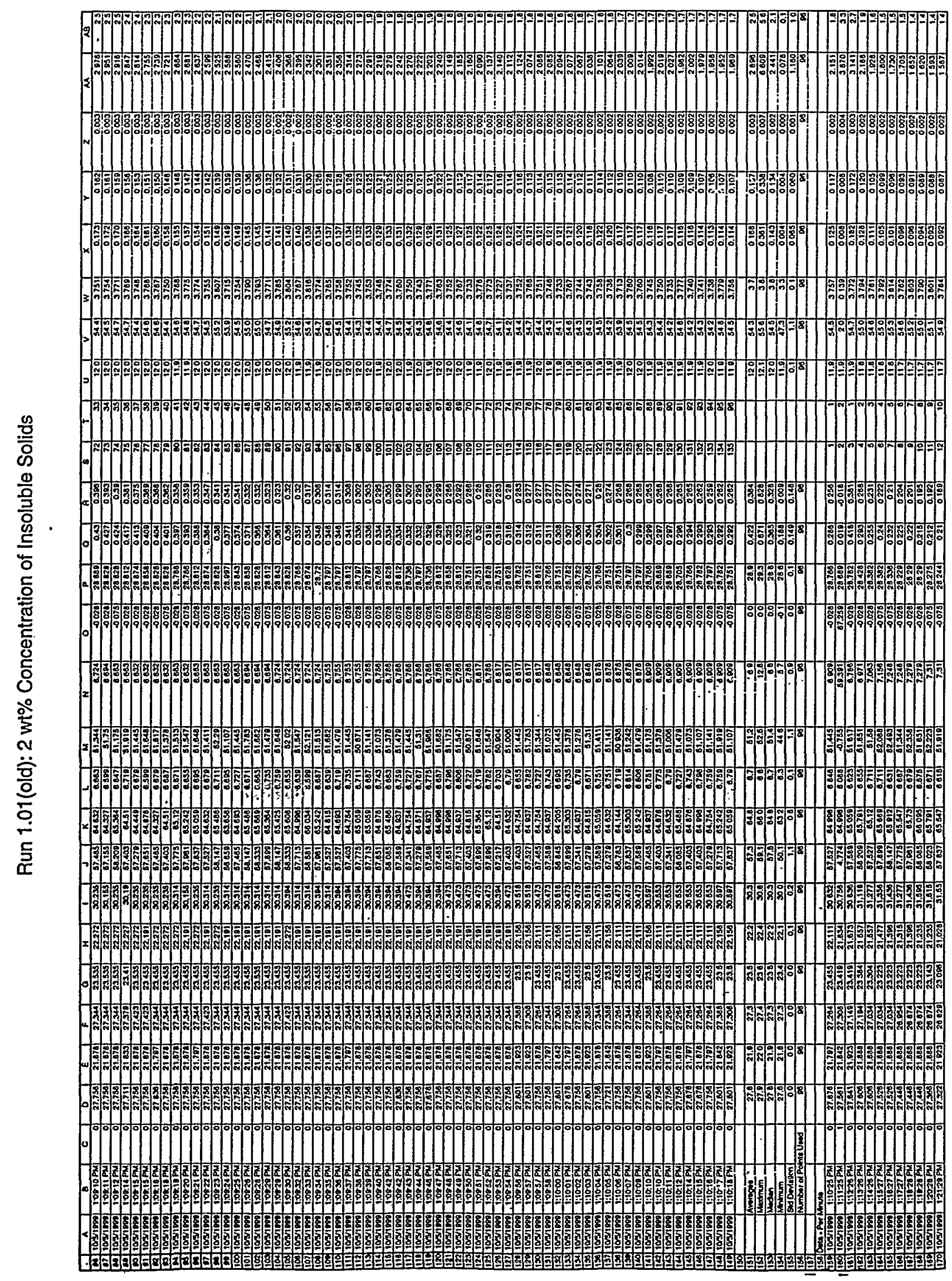


Pilot scale X-flow: EnvC+ES+Sr/TRU Page 115 of 256

BNF-003-98-0226

Revision 0

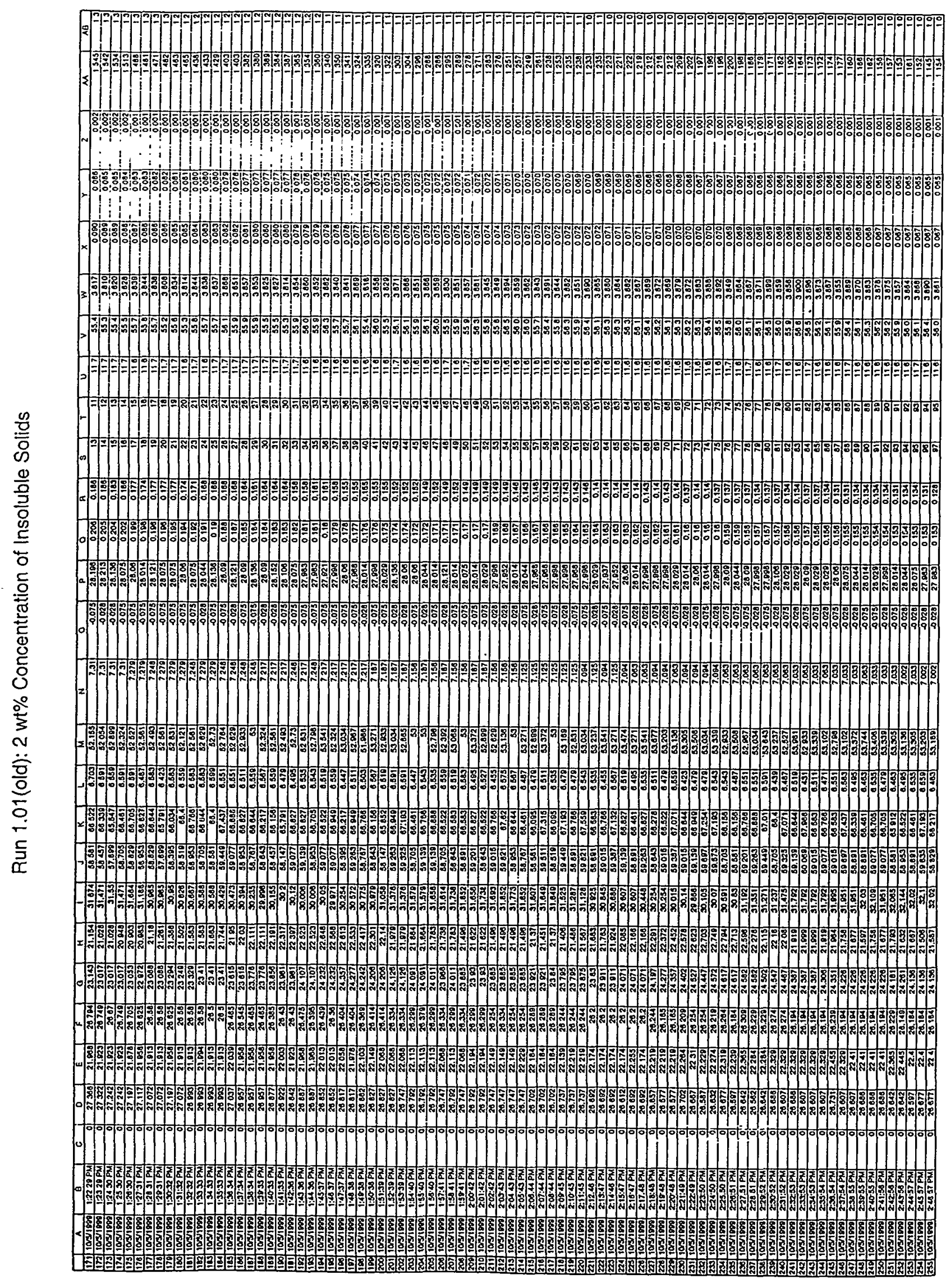




\section{Run 1.01(old): 2 wt\% Concentration of Insoluble Solids}

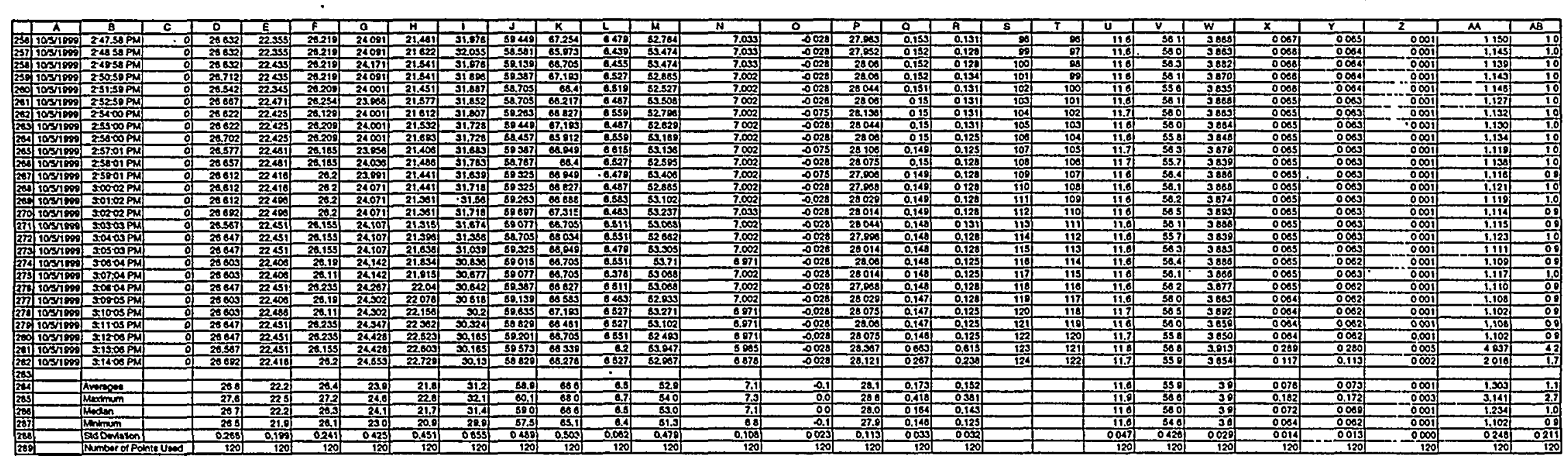


Pilot scale X-flow: EnvC+ES+Sr/TRU Page 117 of 256
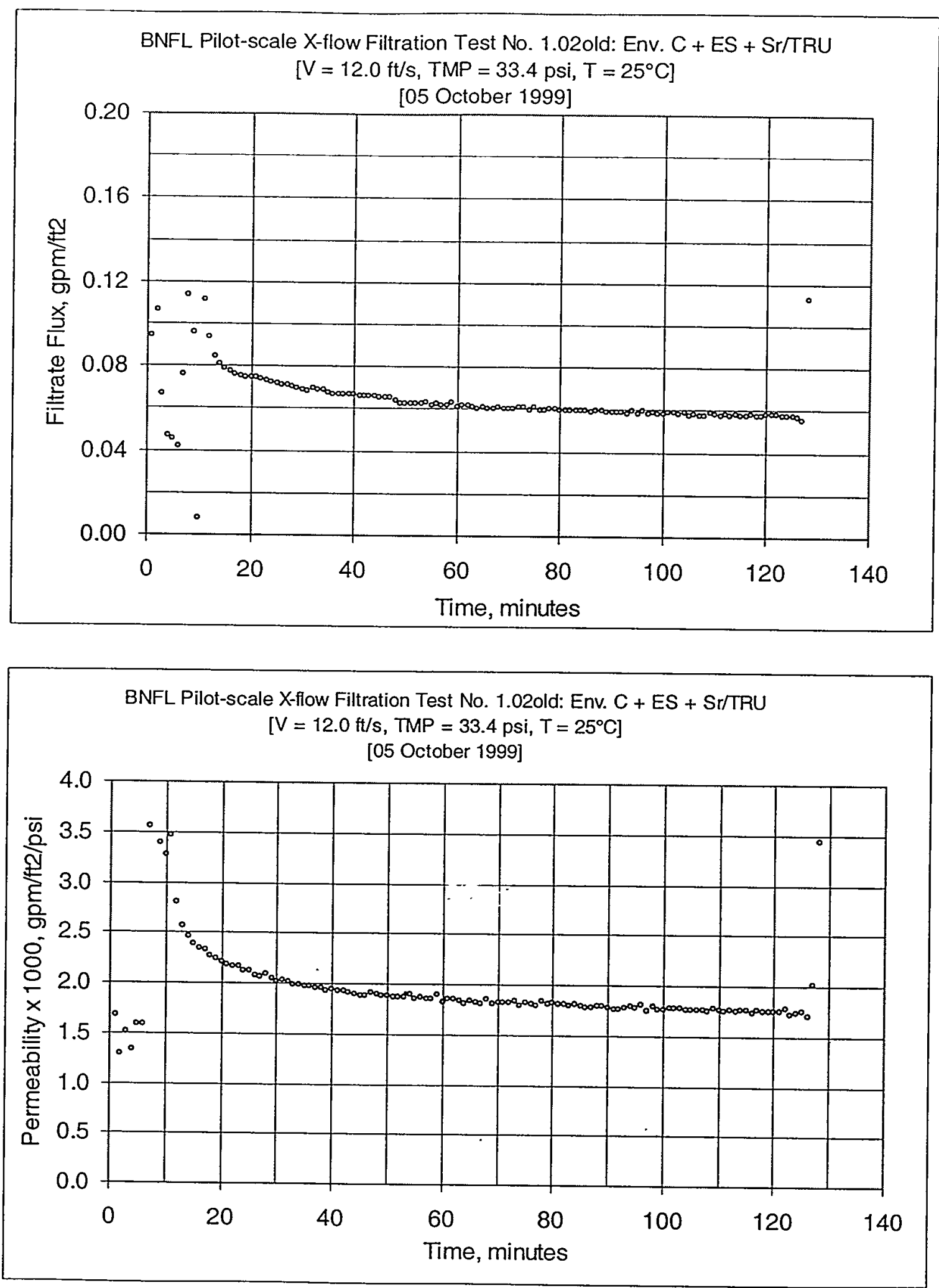

Figure B10: Test Run 1.02(old), 2 wt\% Insoluble Solids Concentration 
Pilot scale X-flow: EnvC+ES+Sr/TRU Page 118 of 256

BNF-003-98-0226

Revision 0

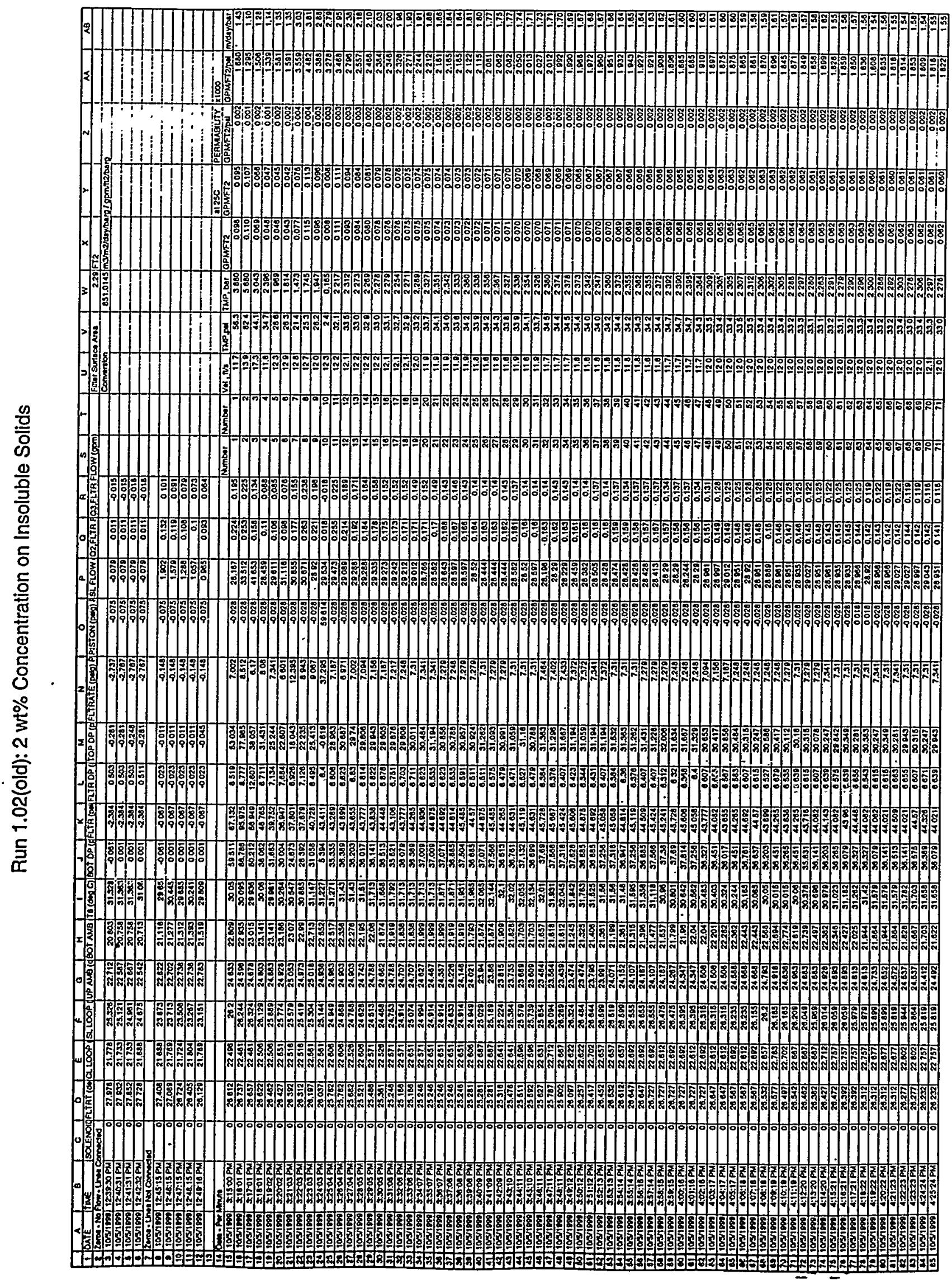


Pilot scale X-flow: EnvC+ES+Sr/TRU Page 119 of 256

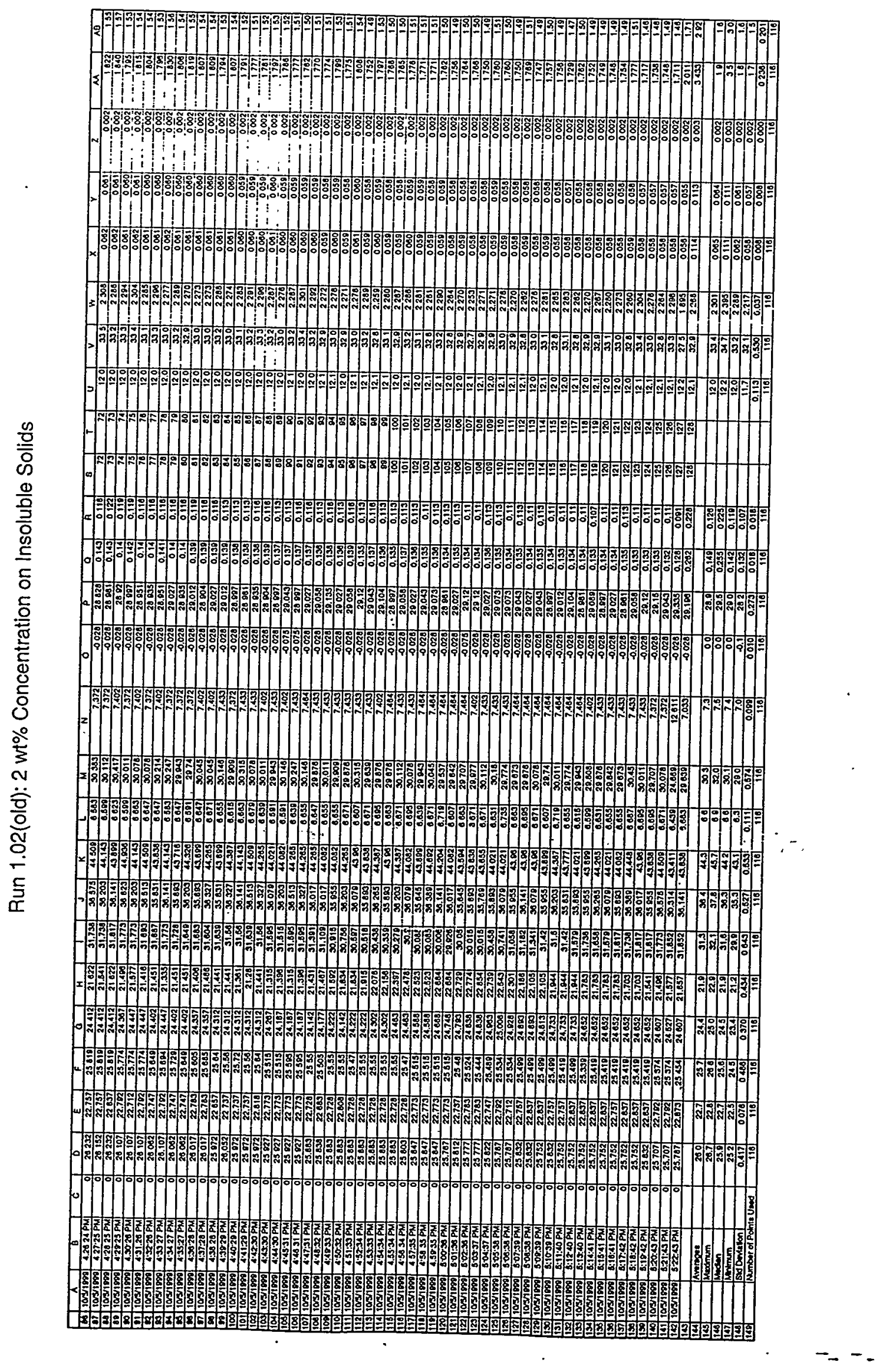



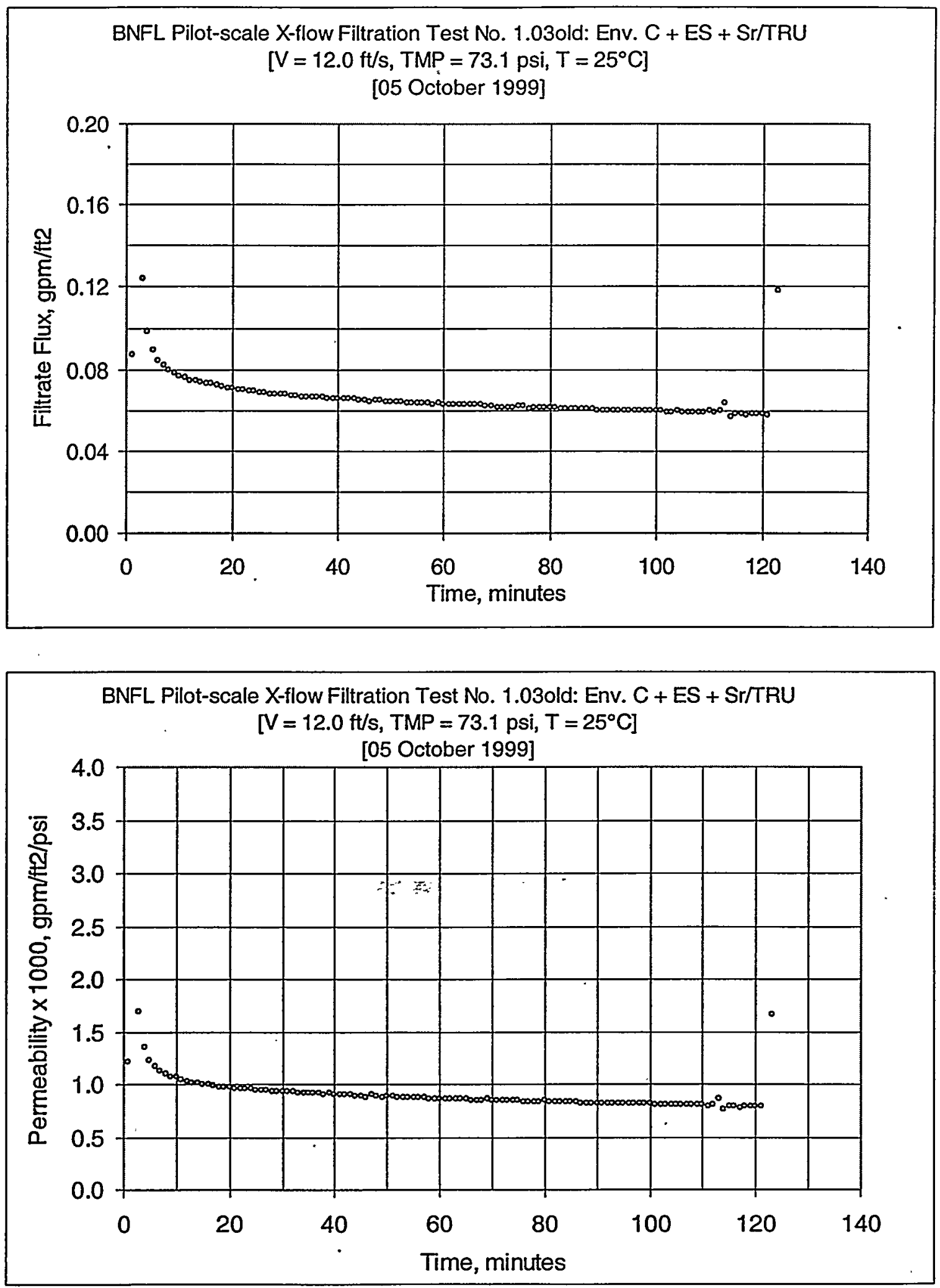

Figure B11: Test Run 1.03(old), 2 wt\% Insoluble Solids Concentration 
Pilot scale X-flow: EnvC+ES+Sr/TRU Page 121 of 256

BNF-003-98-0226

Revision 0

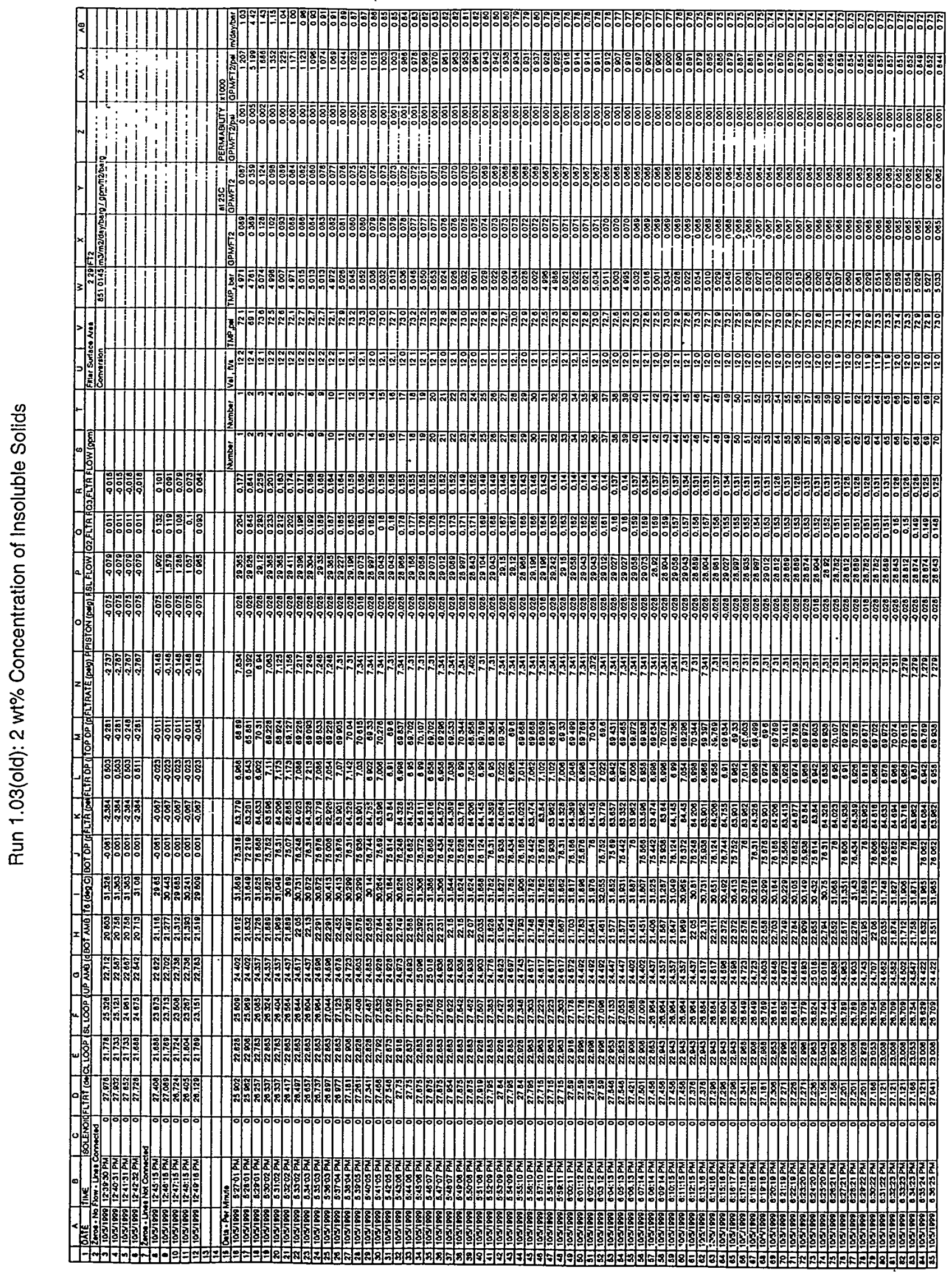


Pilot scale X-flow: EnvC+ES+Sr/TRU Page 122 of 256

BNF-003-98-0226

Revision 0

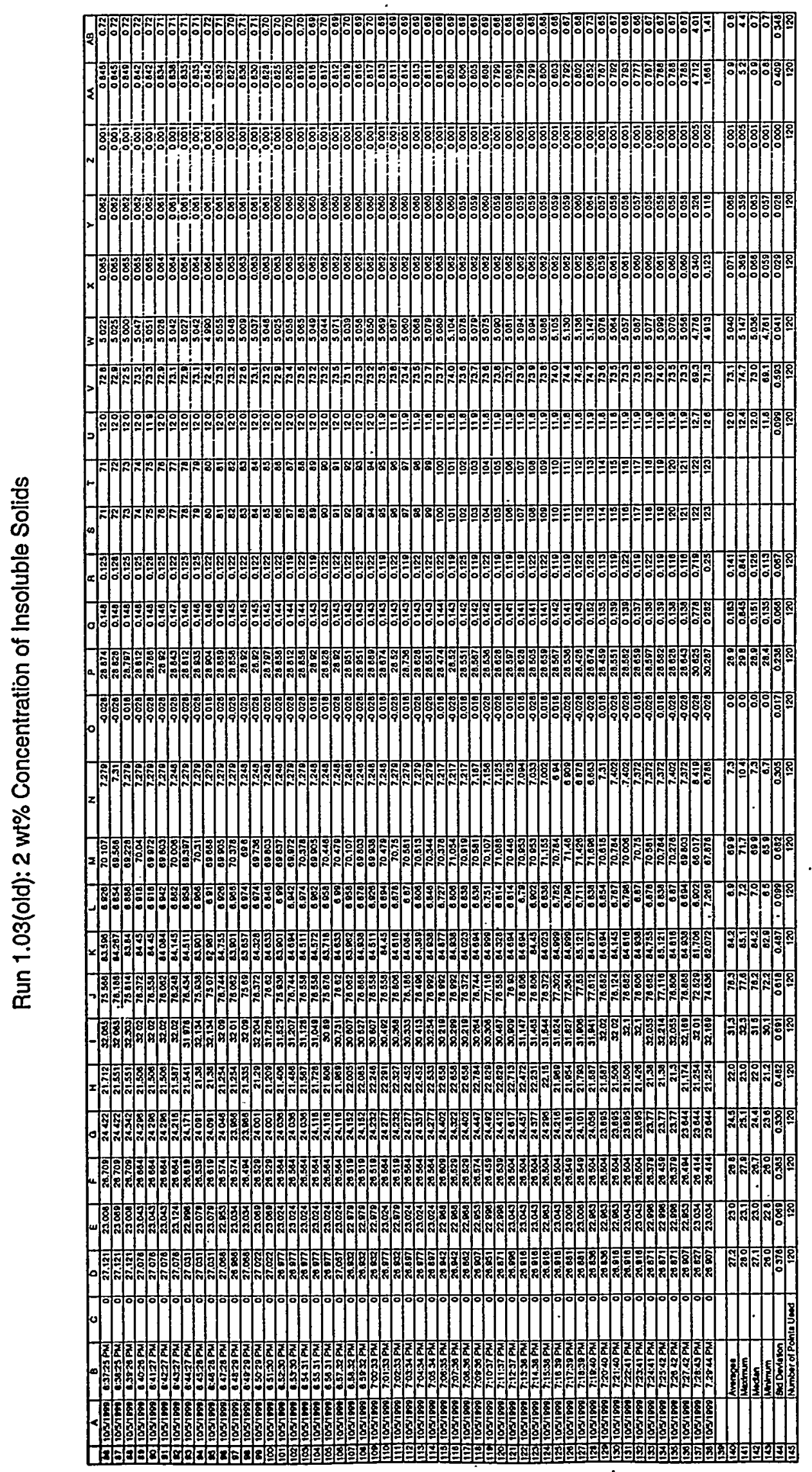



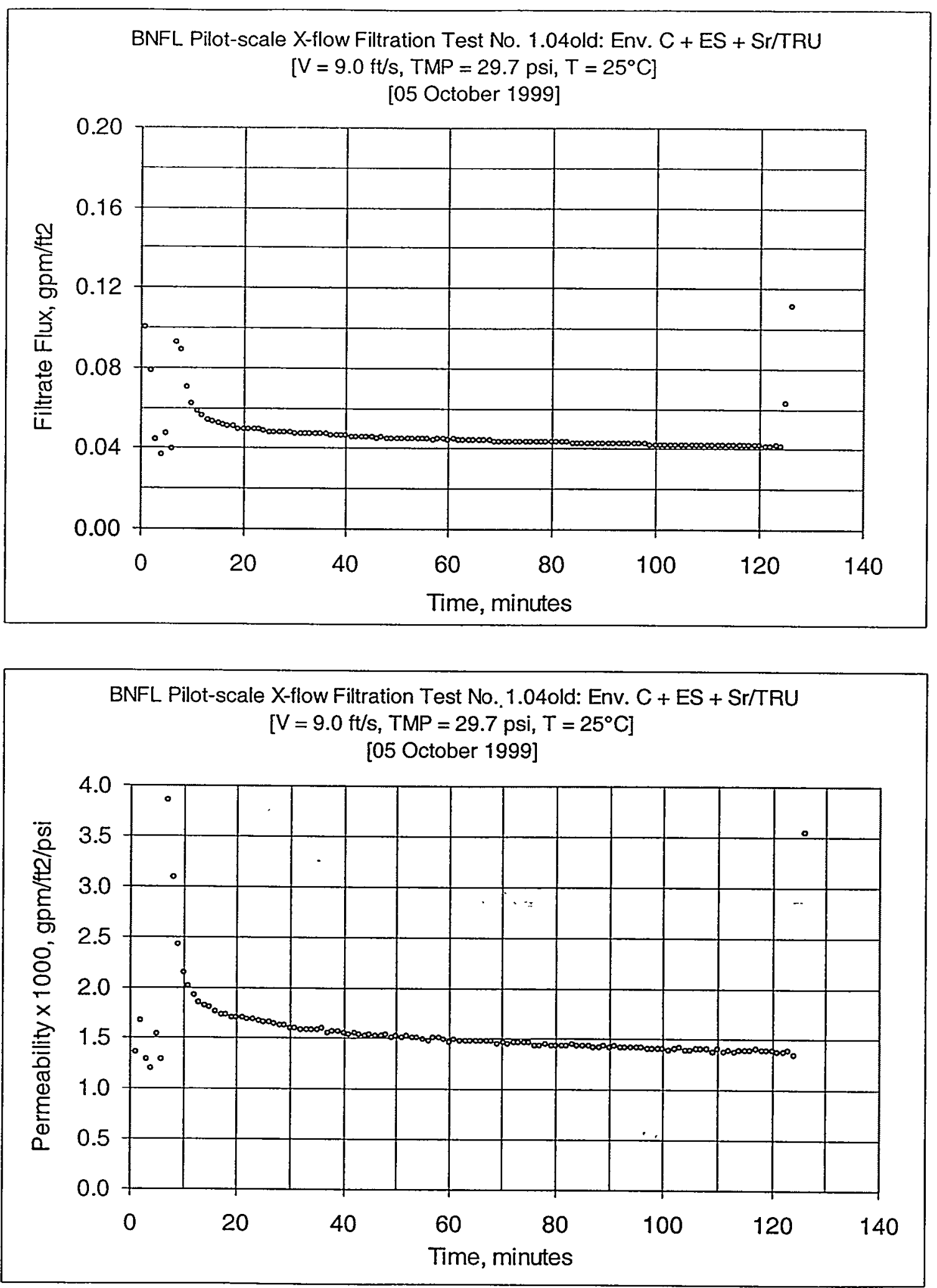

Figure B12: Test Run 1.04(old), 2 wt\% Insoluble Solids Concentration 
Pilot scale X-flow: EnvC+ES+St/TRU Page 124 of 256

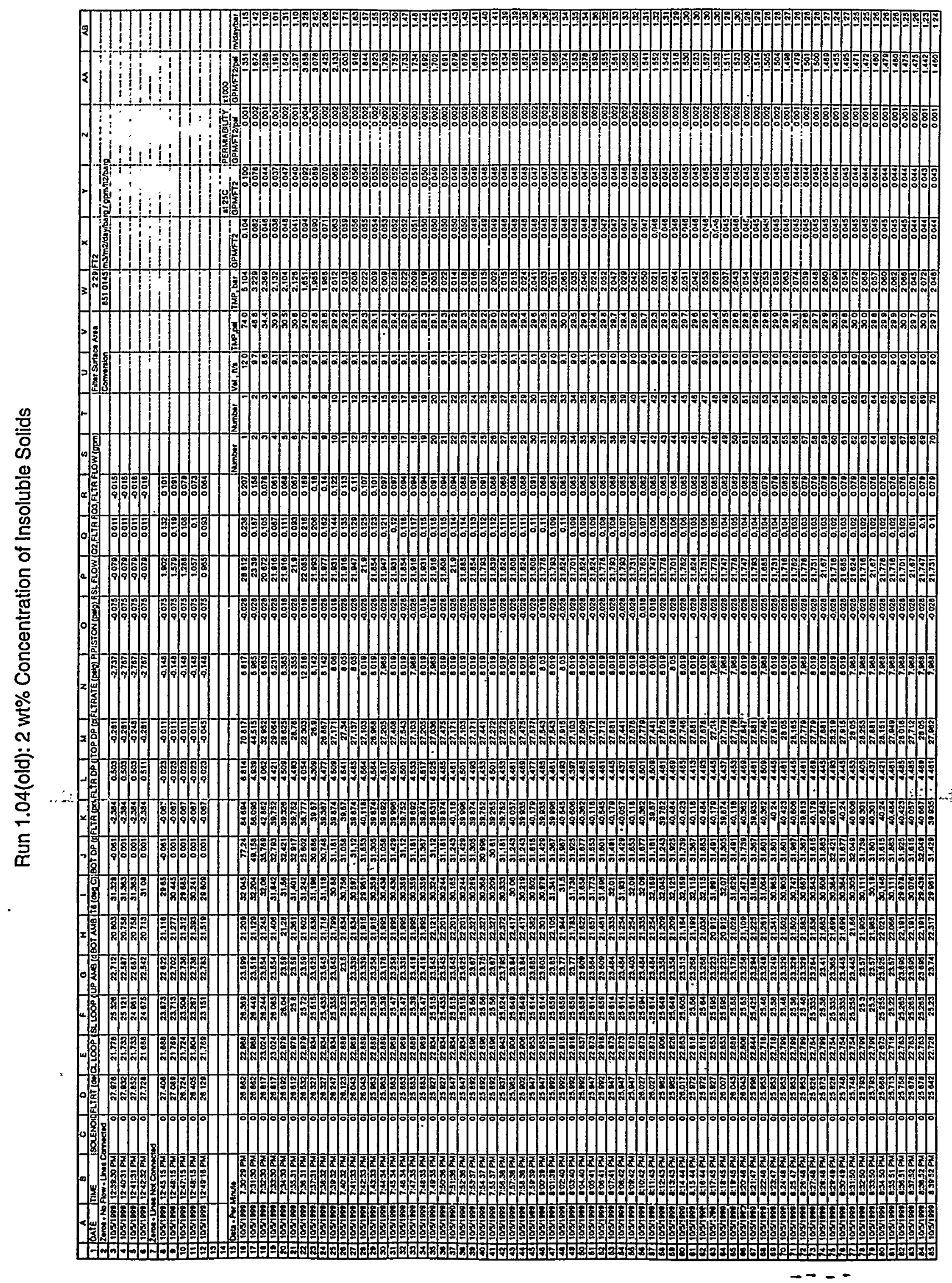


Pilot scale X-flow: EnvC+ES+Sr/TRU Page 125 of 256

BNF-003-98-0226

Revision 0

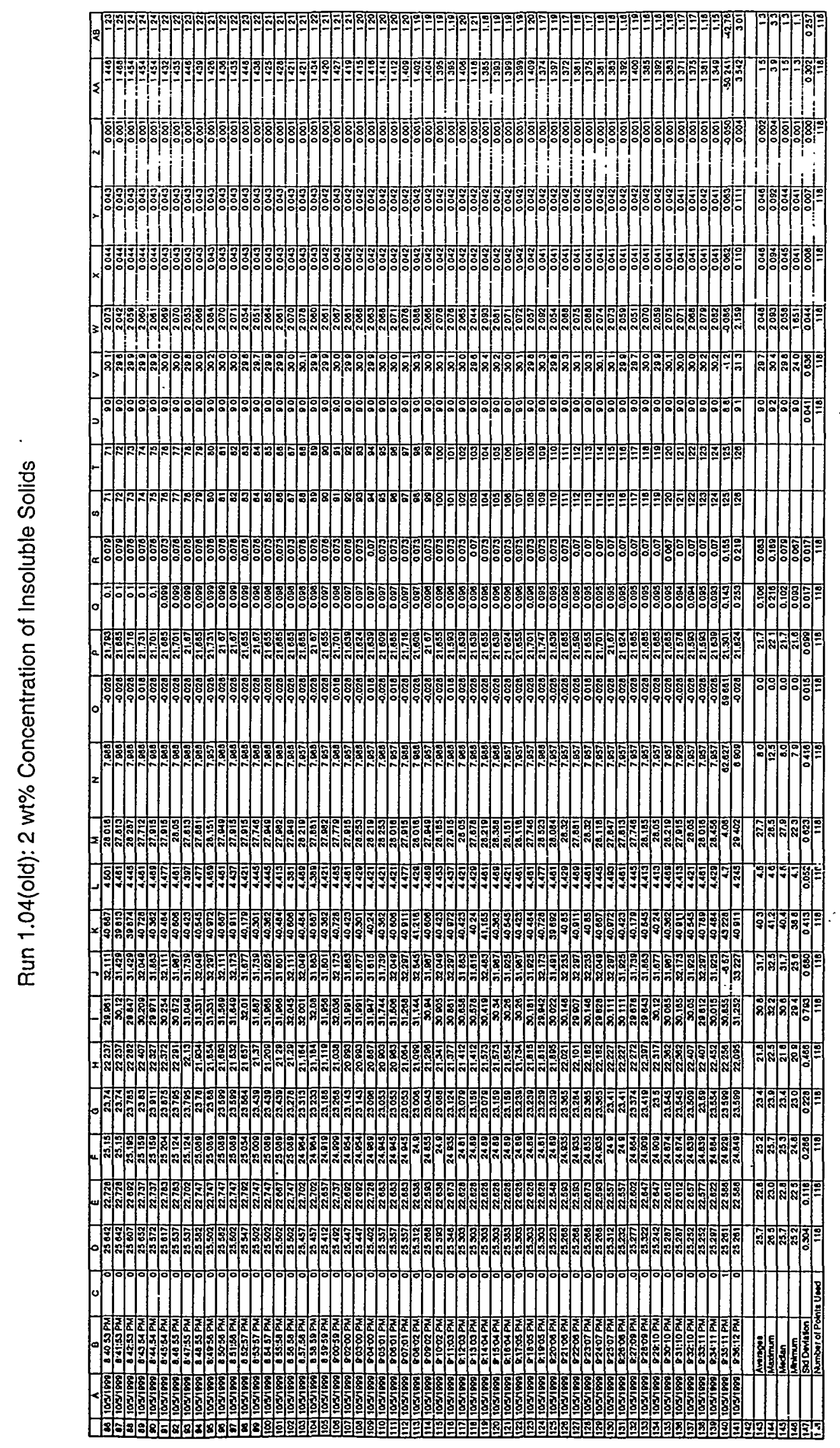



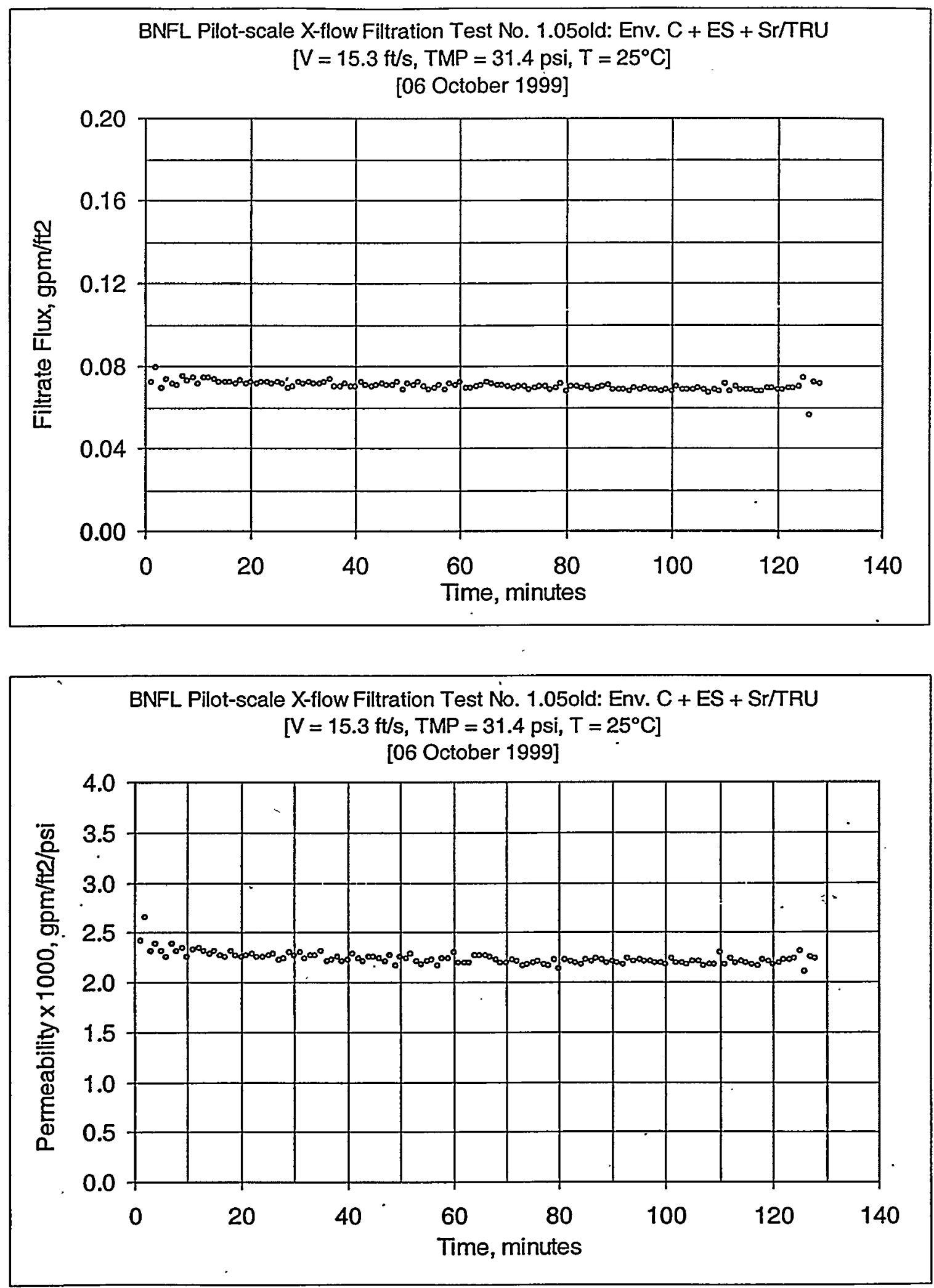

Figure B13: Test Run 1.05(old), 2 wt\% Insoluble Solids Concentration 
Pilot scale X-flow: EnvC+ES+Sr/TRU Page 127 of 256

BNF-003-98-0226

Revision 0

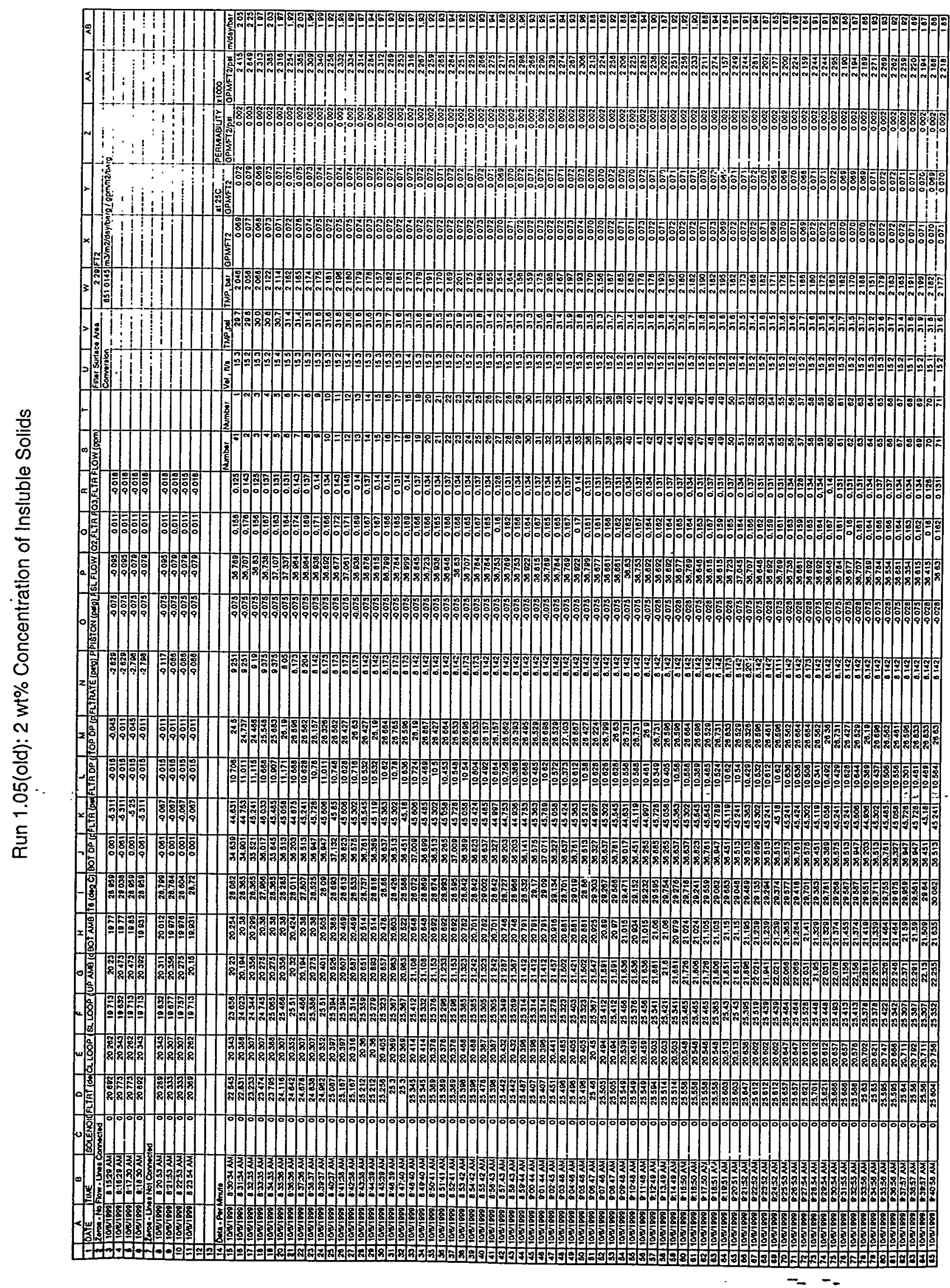




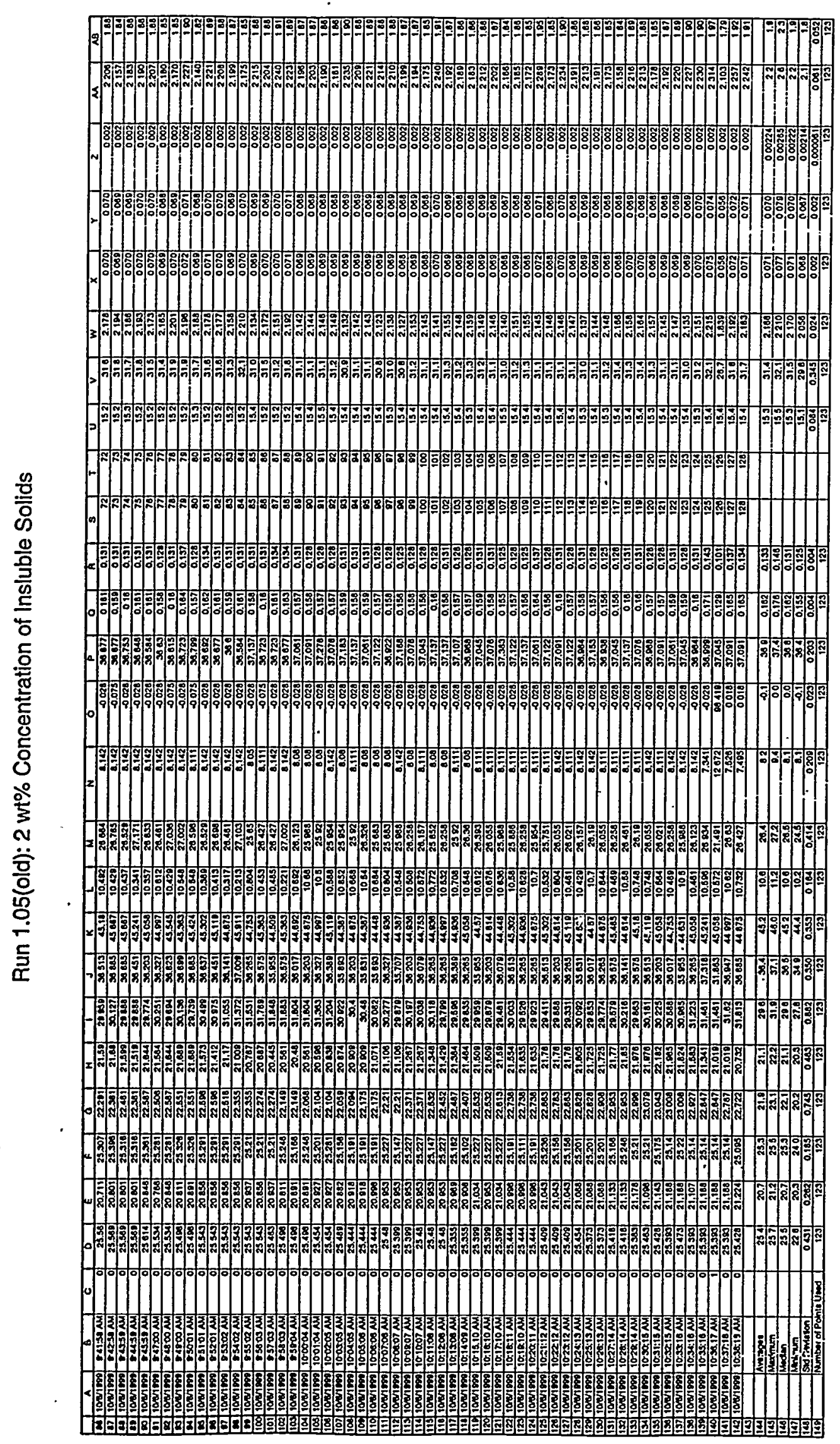




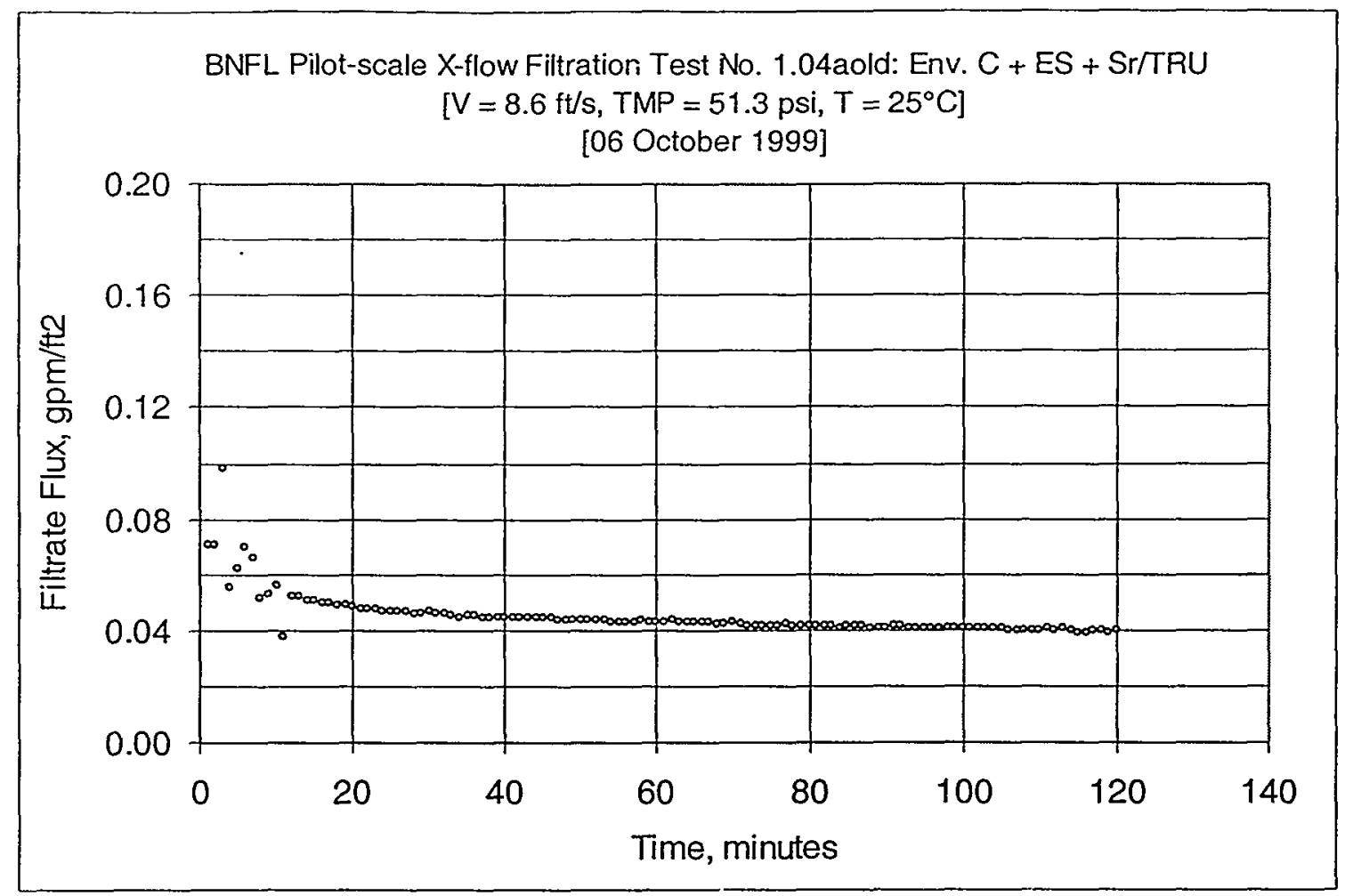

BNFL Pilot-scale X-flow Filtration Test No. 1.04aold: Env. C $+\mathrm{ES}+\mathrm{Sr} / \mathrm{TRU}$ $\left[\mathrm{V}=8.6 \mathrm{ft} / \mathrm{s}, \mathrm{TMP}=51.3 \mathrm{psi}, \mathrm{T}=25^{\circ} \mathrm{C}\right]$

[06 October 1999]

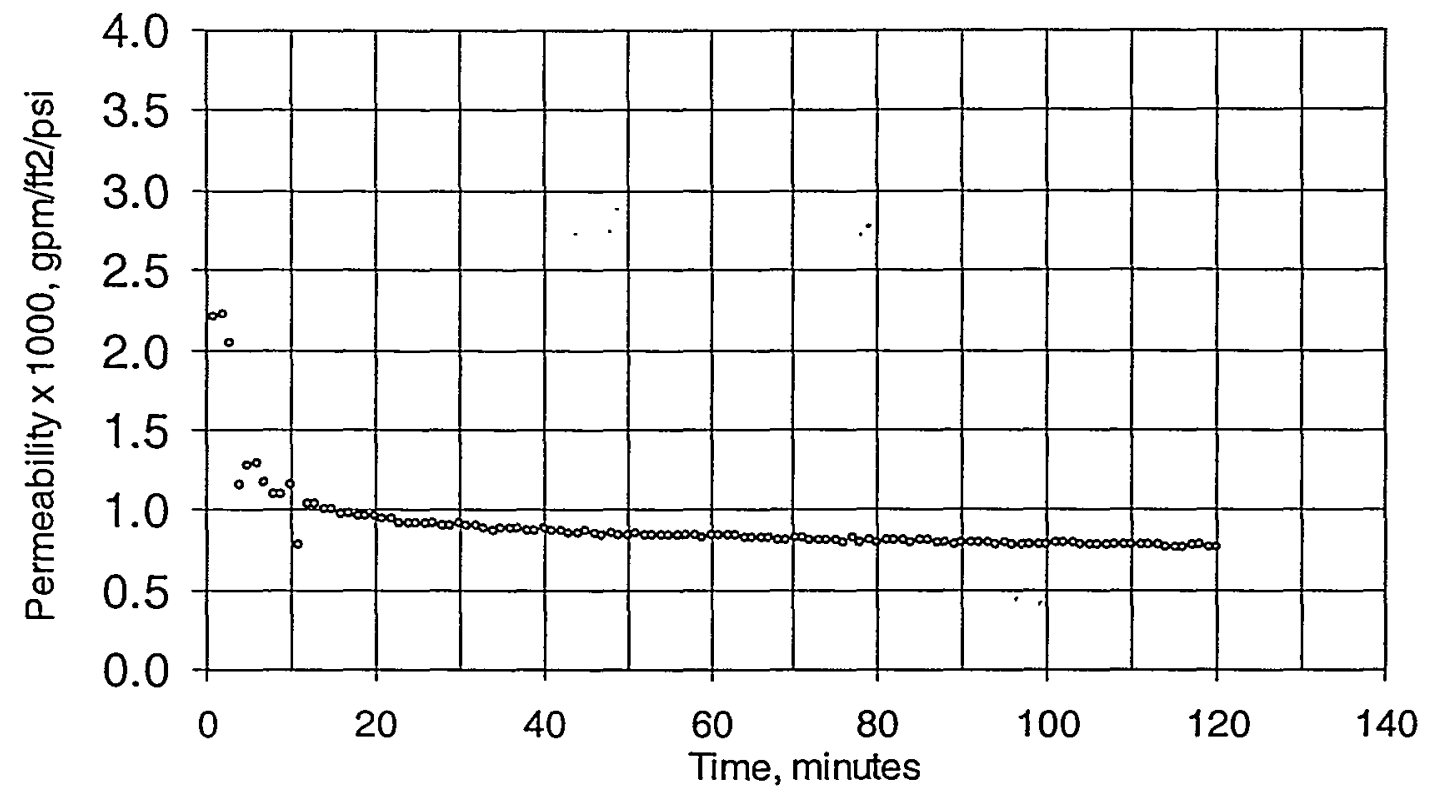

Figure B14: Test Run 1.04a(old) 2 wt\% Insoluble Solids Concentration 
Pilot scale X-flow: EnvC+ES+Sr/TRU Page 130 of 256

BNF-003-98-0226

Revision 0

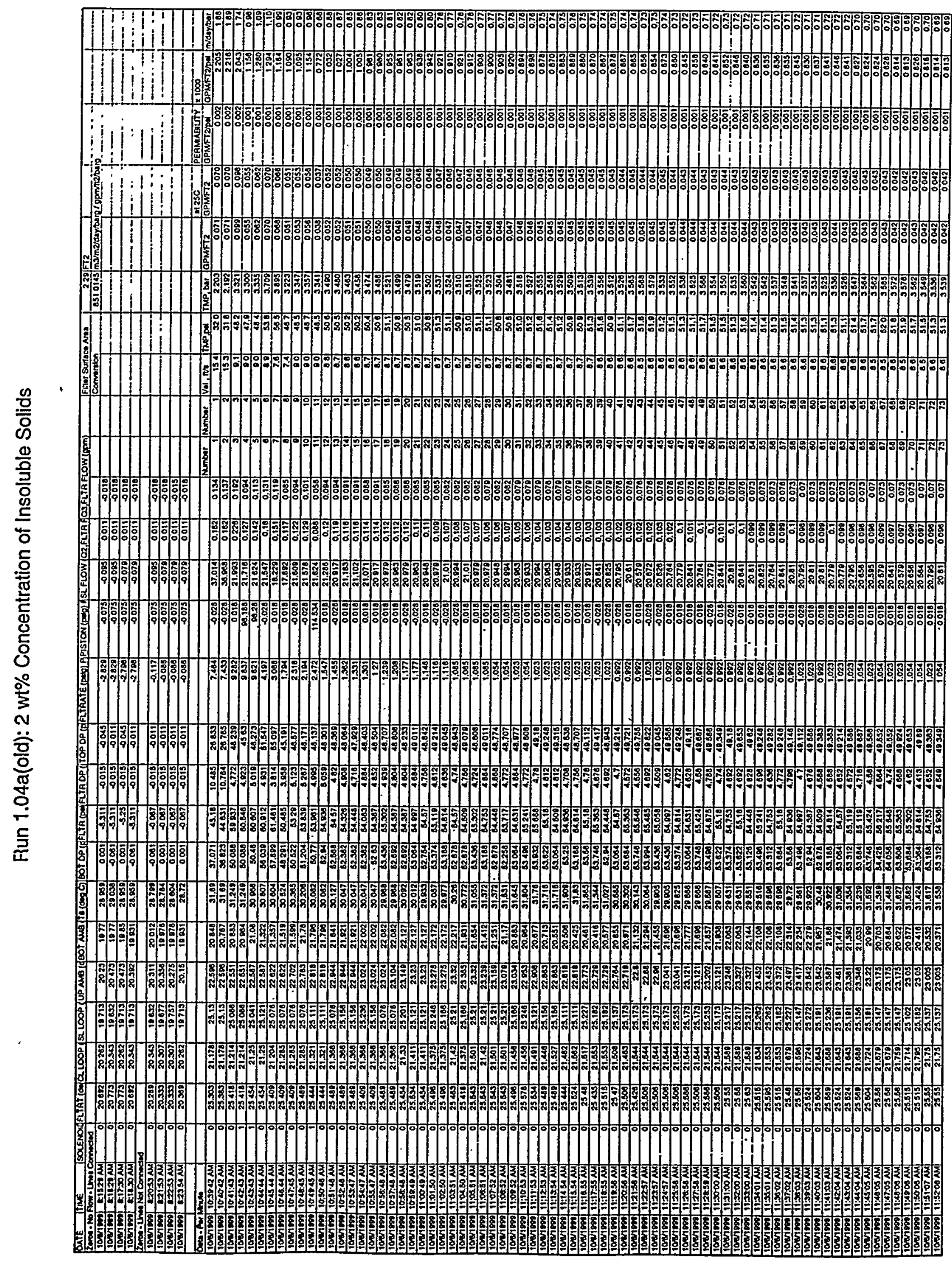


Pilot scale X-flow: EnvC+ES+Sr/TRU Page 131 of 256

BNF-003-98-0226

Revision 0

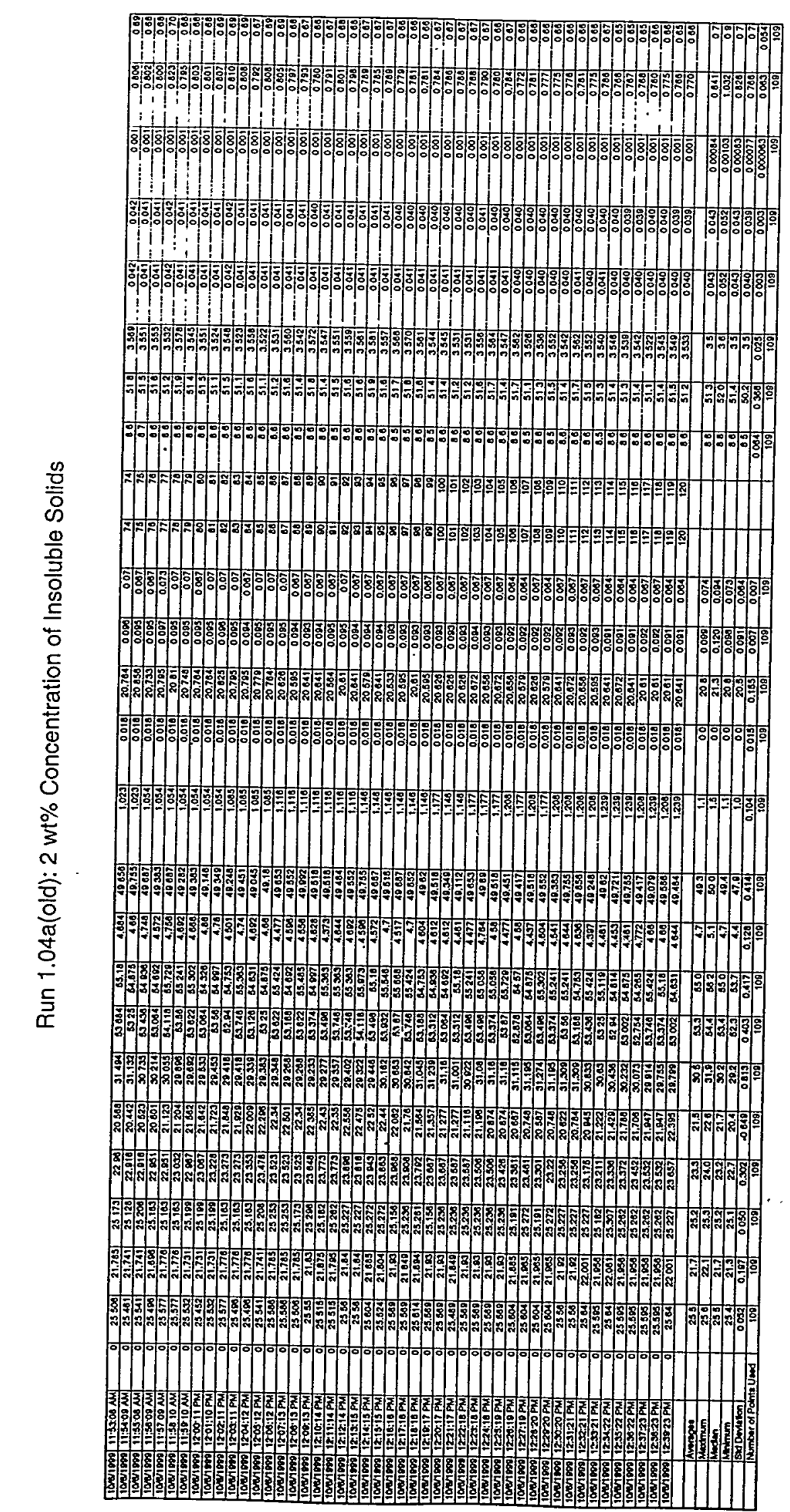



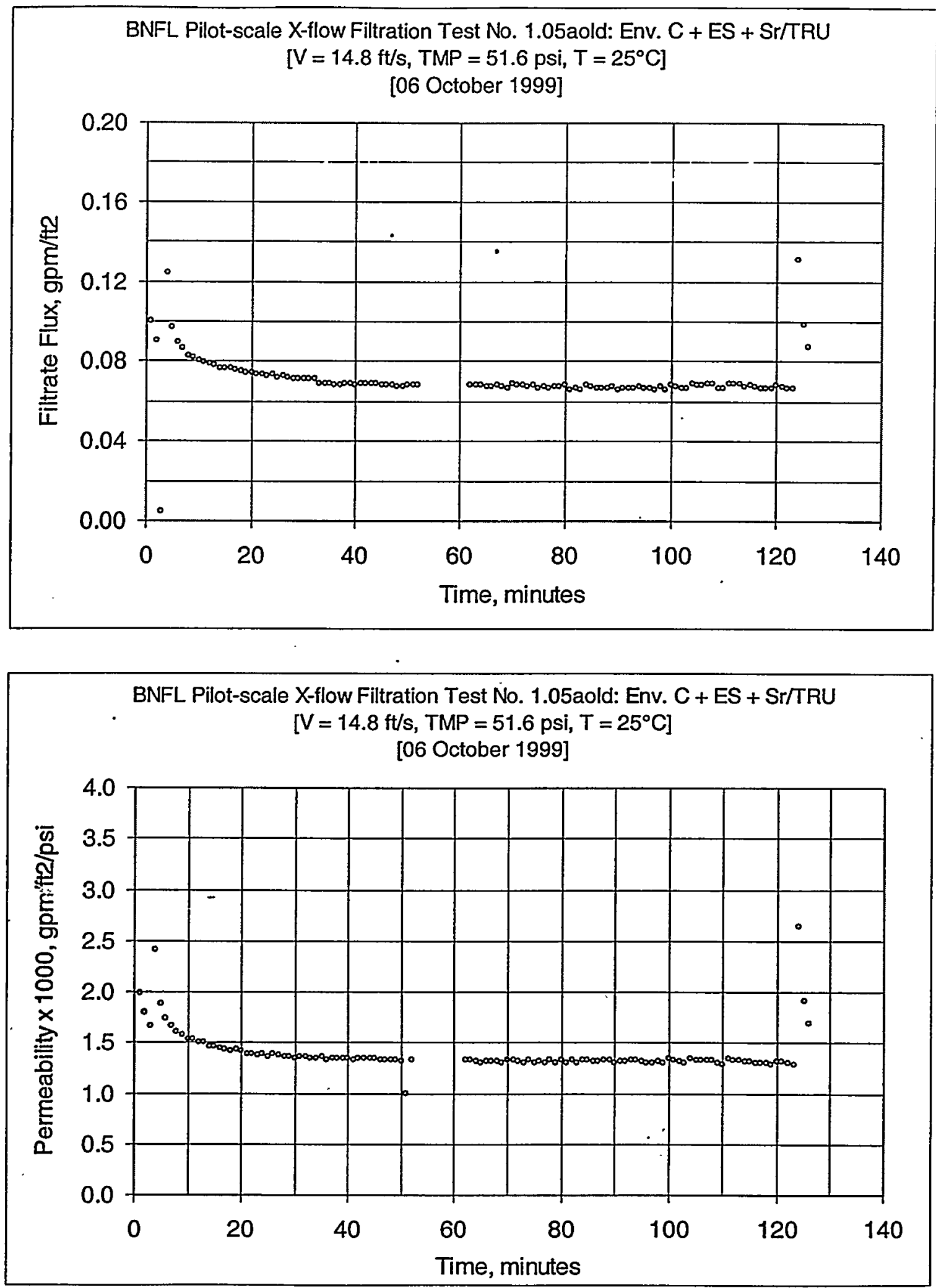

Figure B15: Test Run 1.05a(old), 2 wt\% Insoluble Solids Concentration 


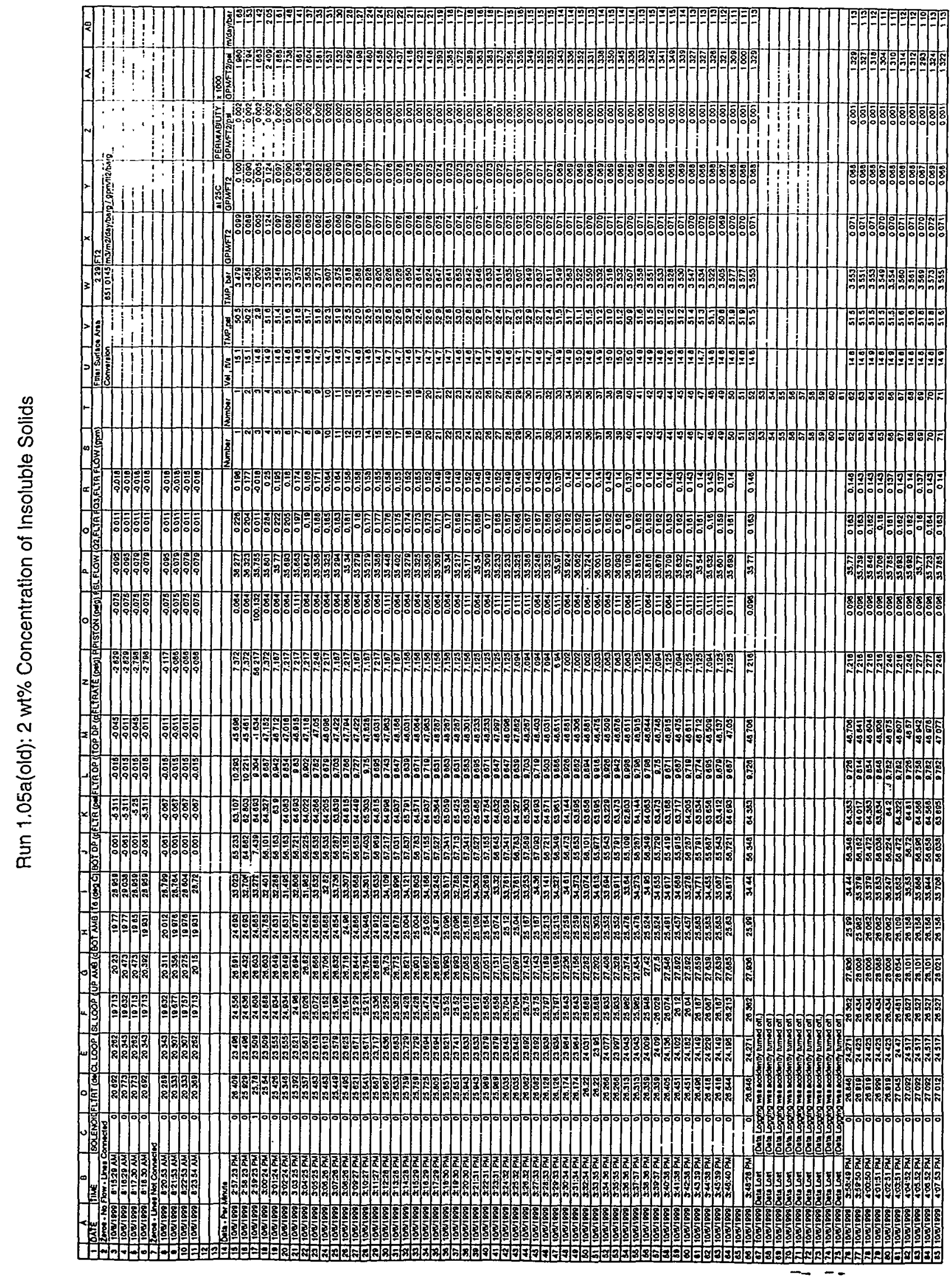


Pilot scale X-flow: EnvC+ES+Sr/TRU Page 134 of 256

BNF-003-98-0226

Revision 0

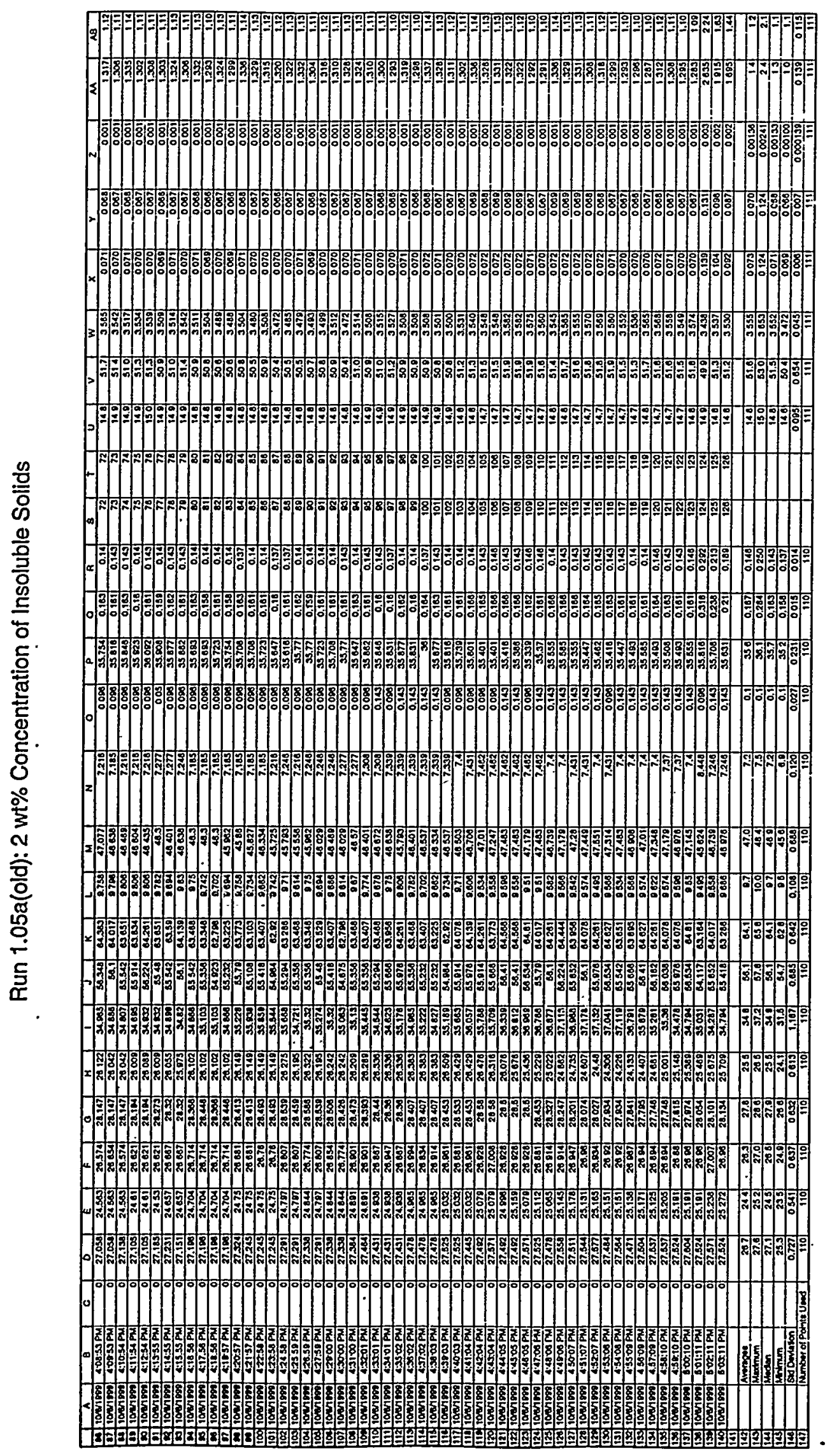



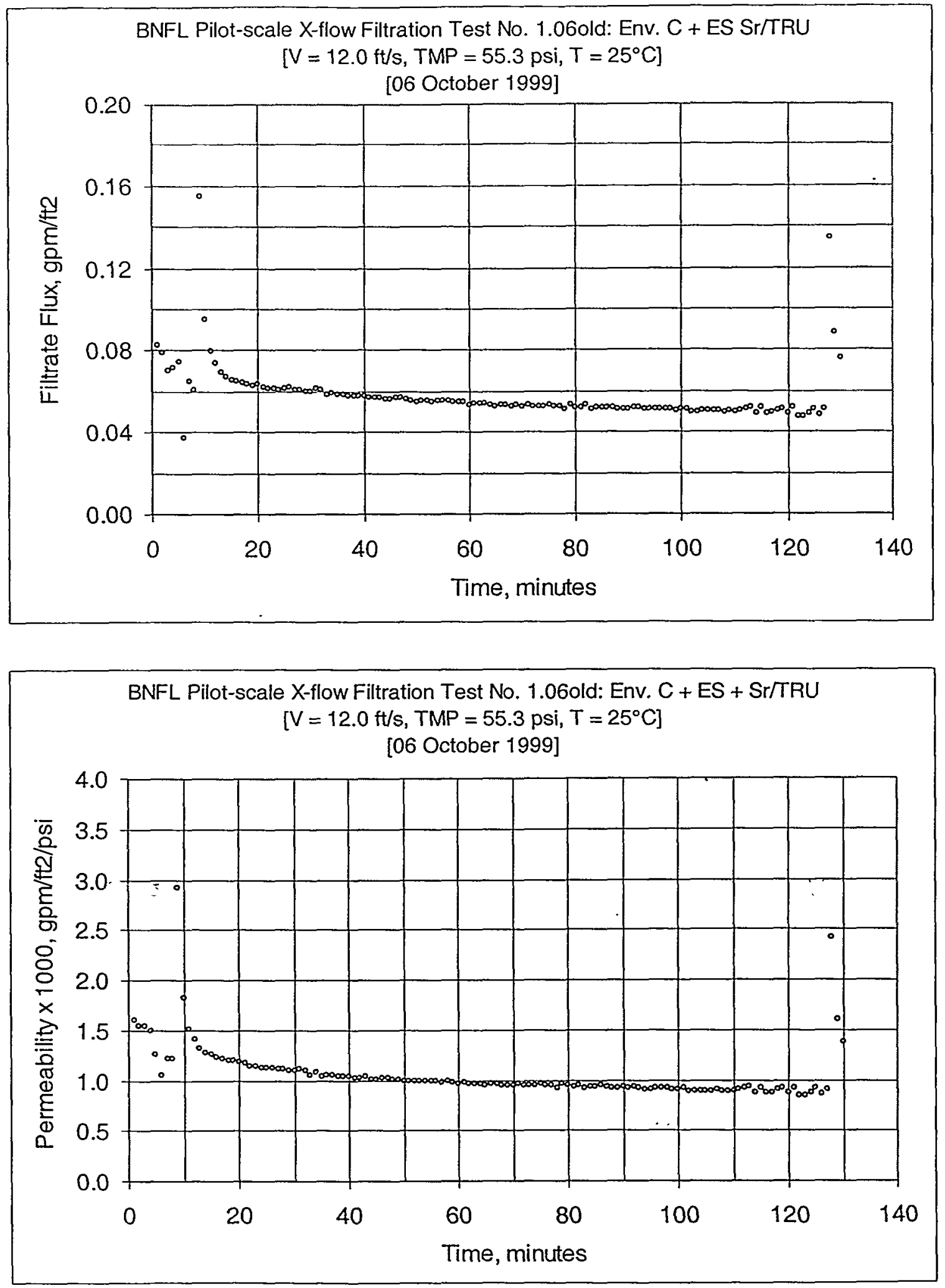

Figure B16: Test Run 1.06(old), 2 wt\% Insoluble Solids Concentration 
Pilot scale X-flow: EnvC+ES+Sr/TRU Page 136 of 256

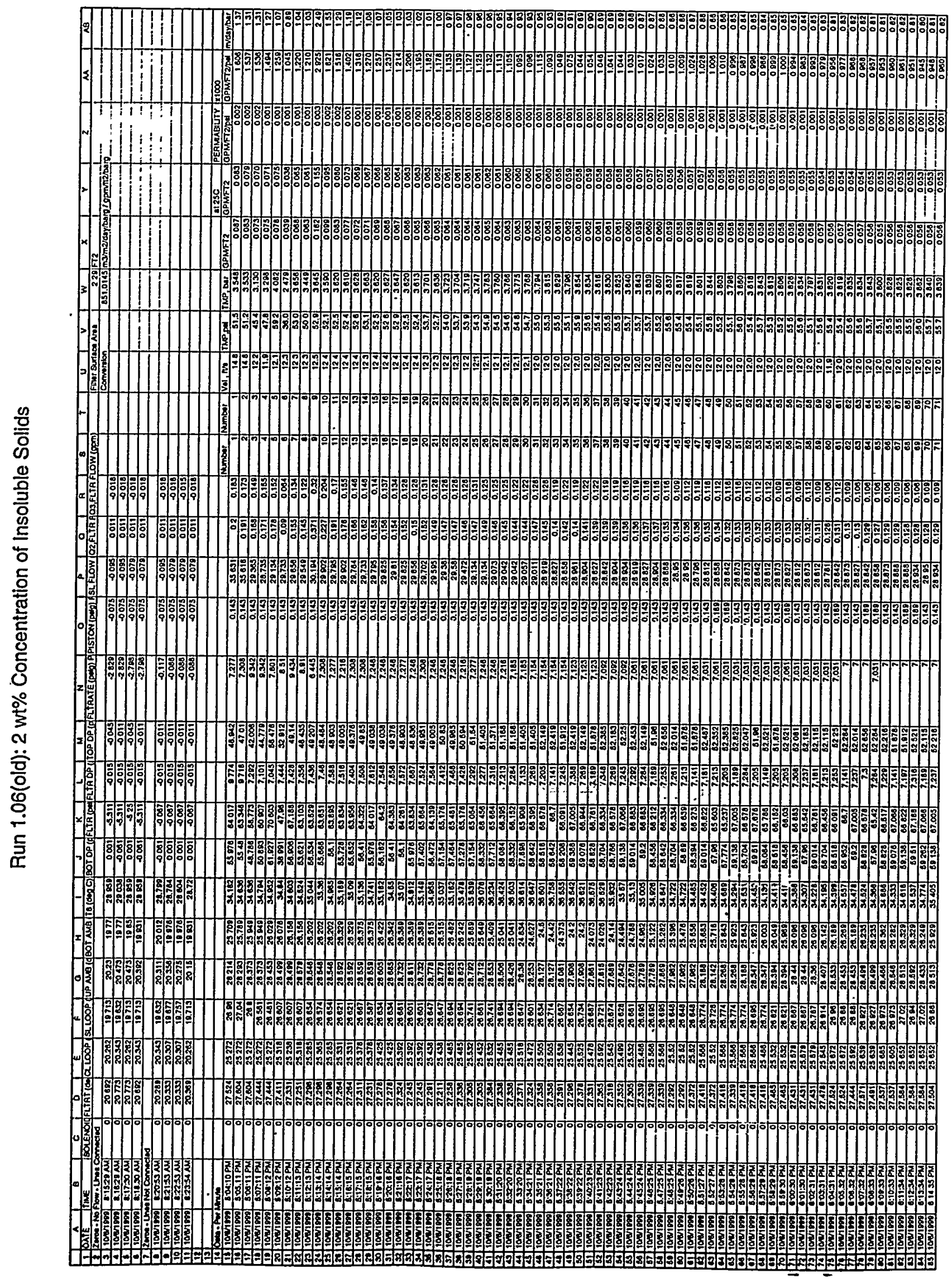


Pilot scale X-flow: EnvC+ES+Sr/TRU Page 137 of 256

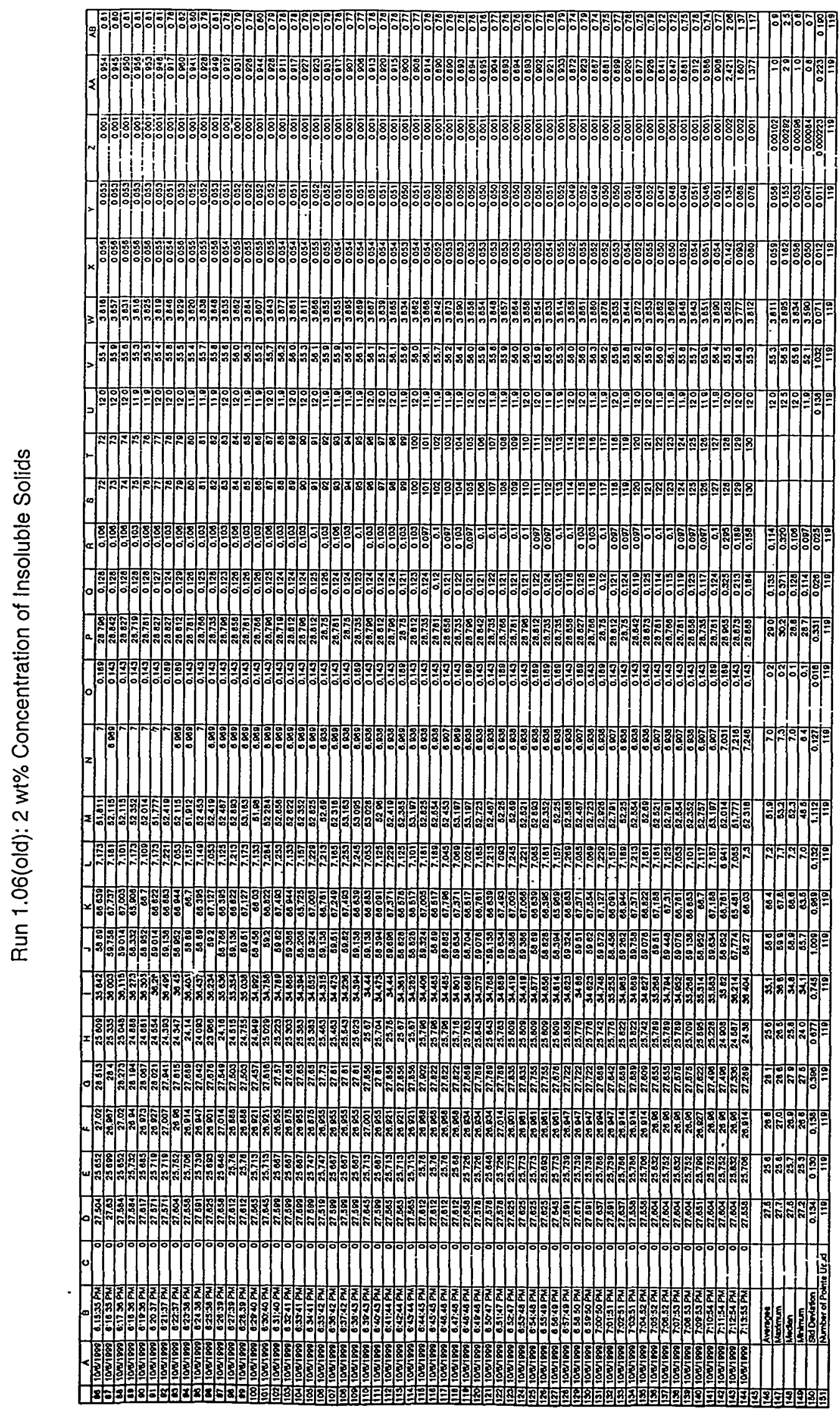




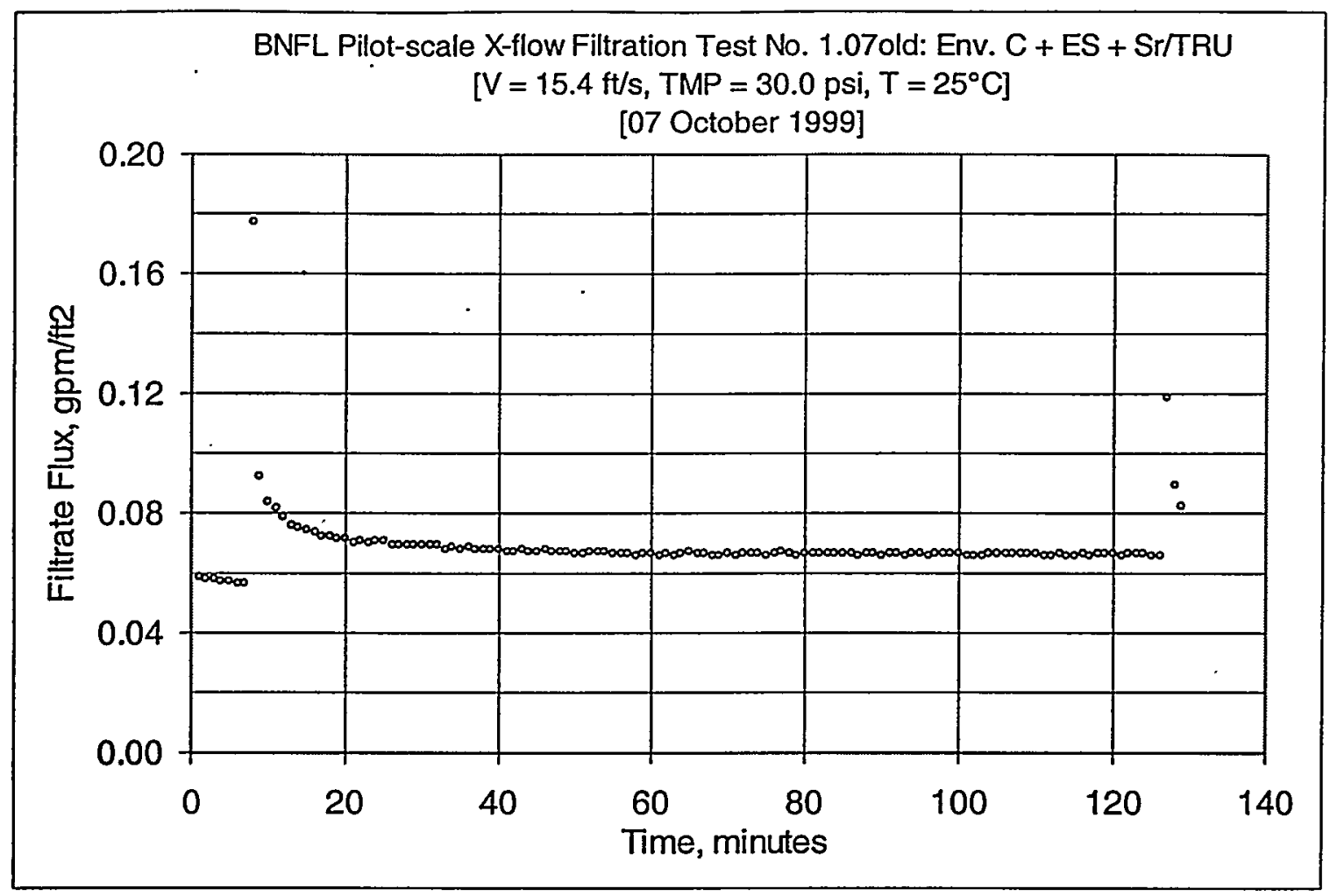

'BNFL Pilot-scale X-flow Filtration Test No. 1.07old: Env. C + ES + Sr/TRU $\left[\mathrm{V}=15.4 \mathrm{ft} / \mathrm{s}, \mathrm{TMP}=30.0 \mathrm{psi}, \mathrm{T}=25^{\circ} \mathrm{C}\right]$

[07 October 1999]

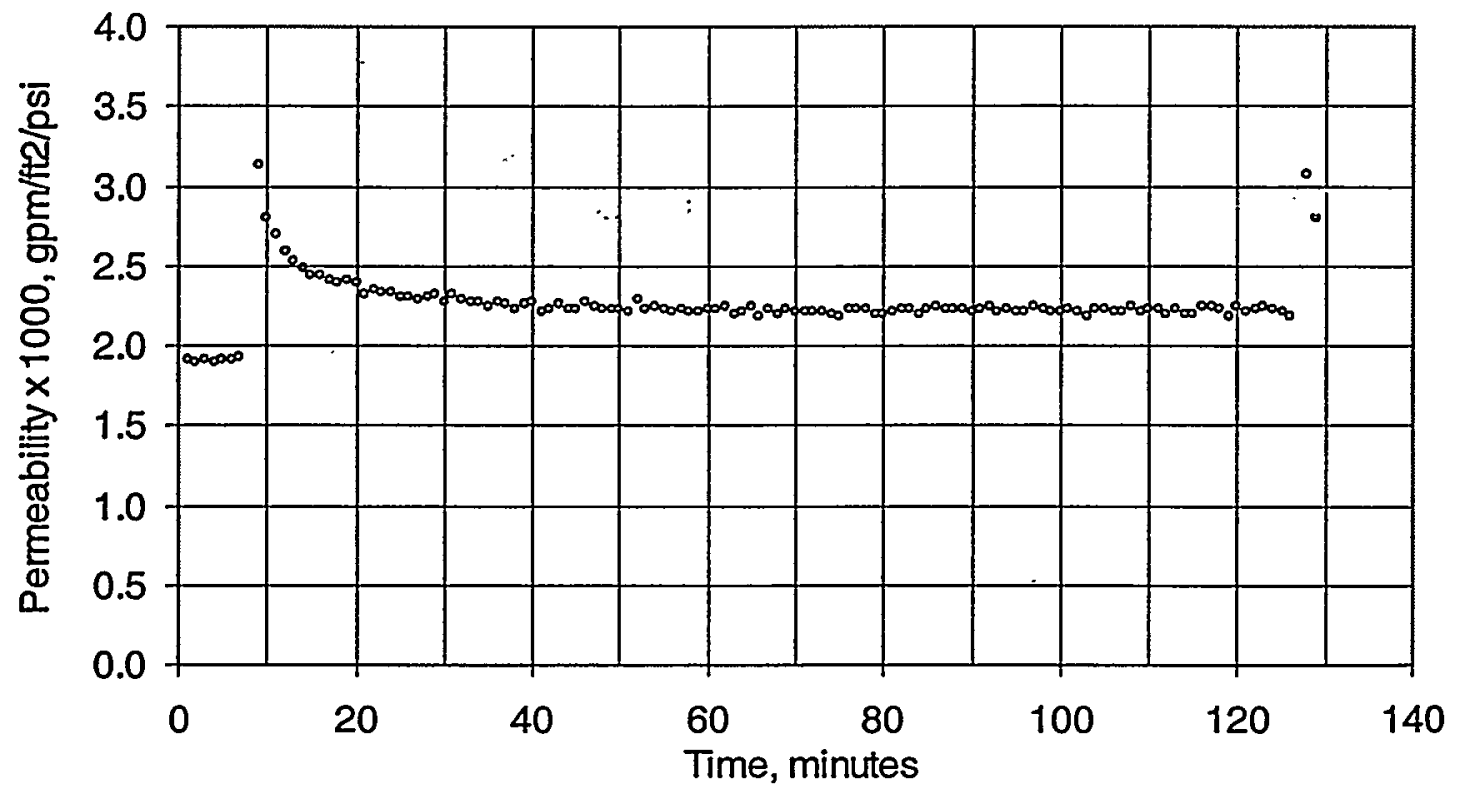

Figure B17: Test Run 1.07(old), 2 wt\% Insoluble Solids Concentration 
Pilot scale X-flow: EnvC+ES+Sr/TRU Page 139 of 256

BNF-003-98-0226

Revision 0

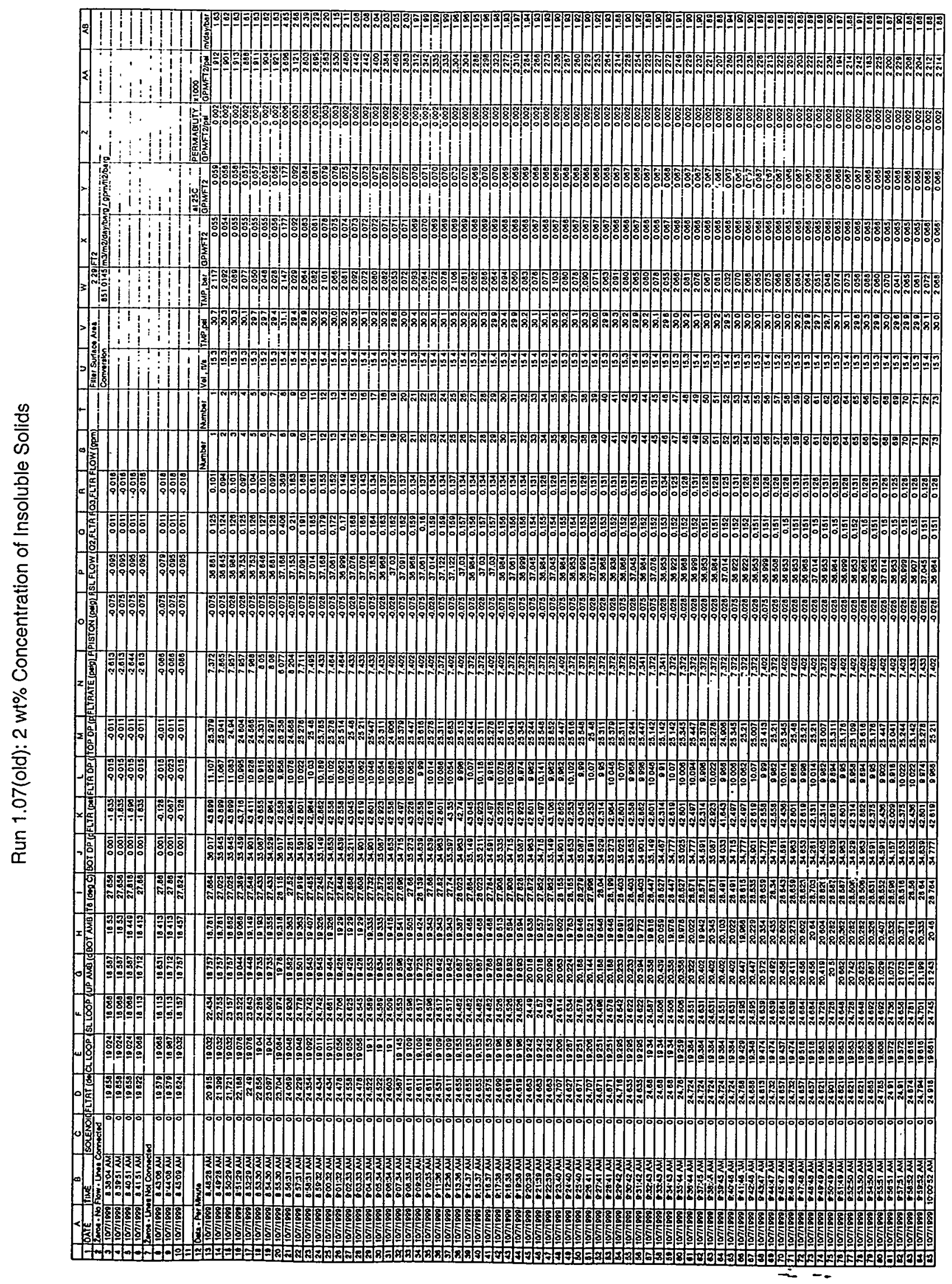


Pilot scale X-flow: EnvC+ES+Sr/TRU Page 140 of 256

BNF-003-98-0226

Revision 0

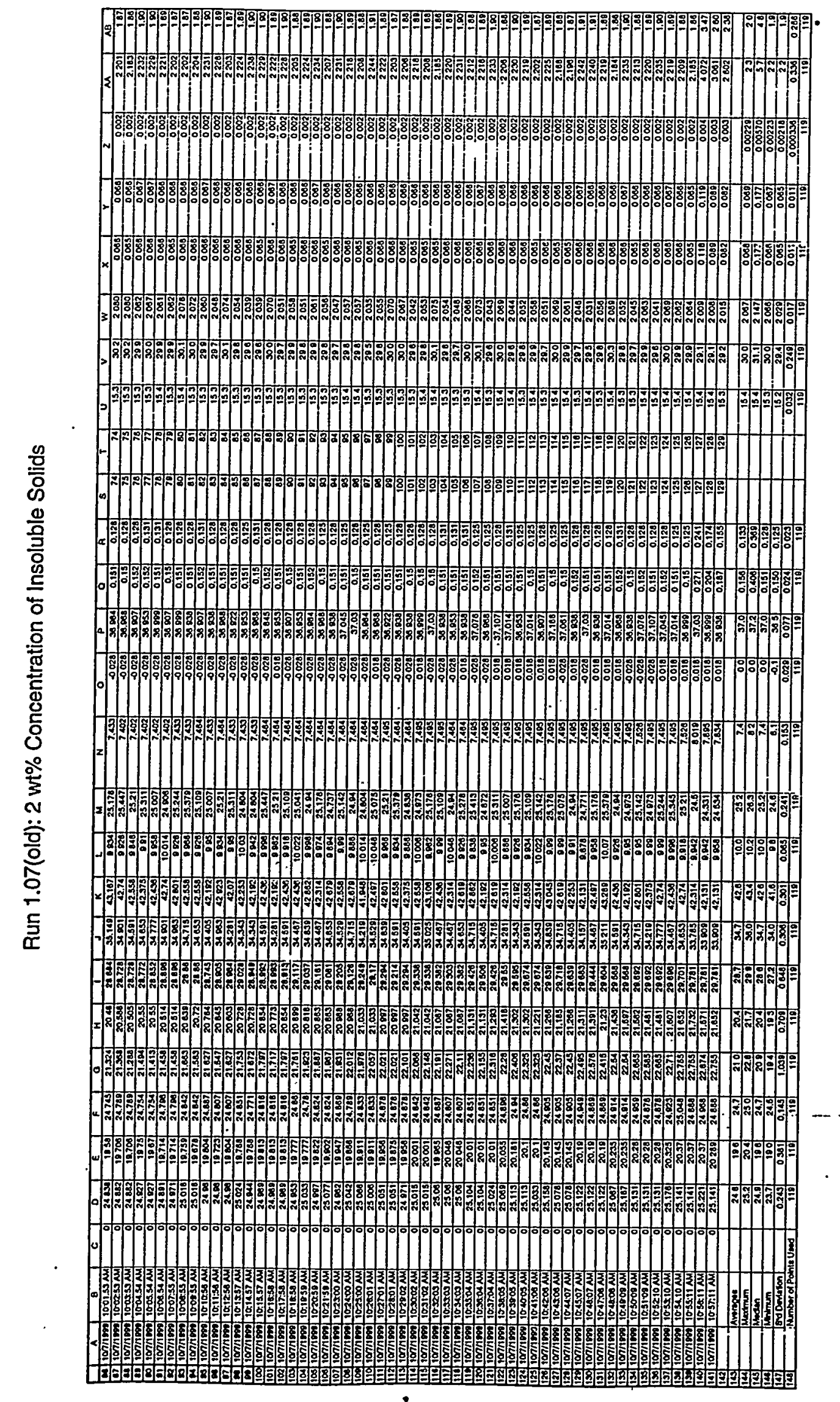



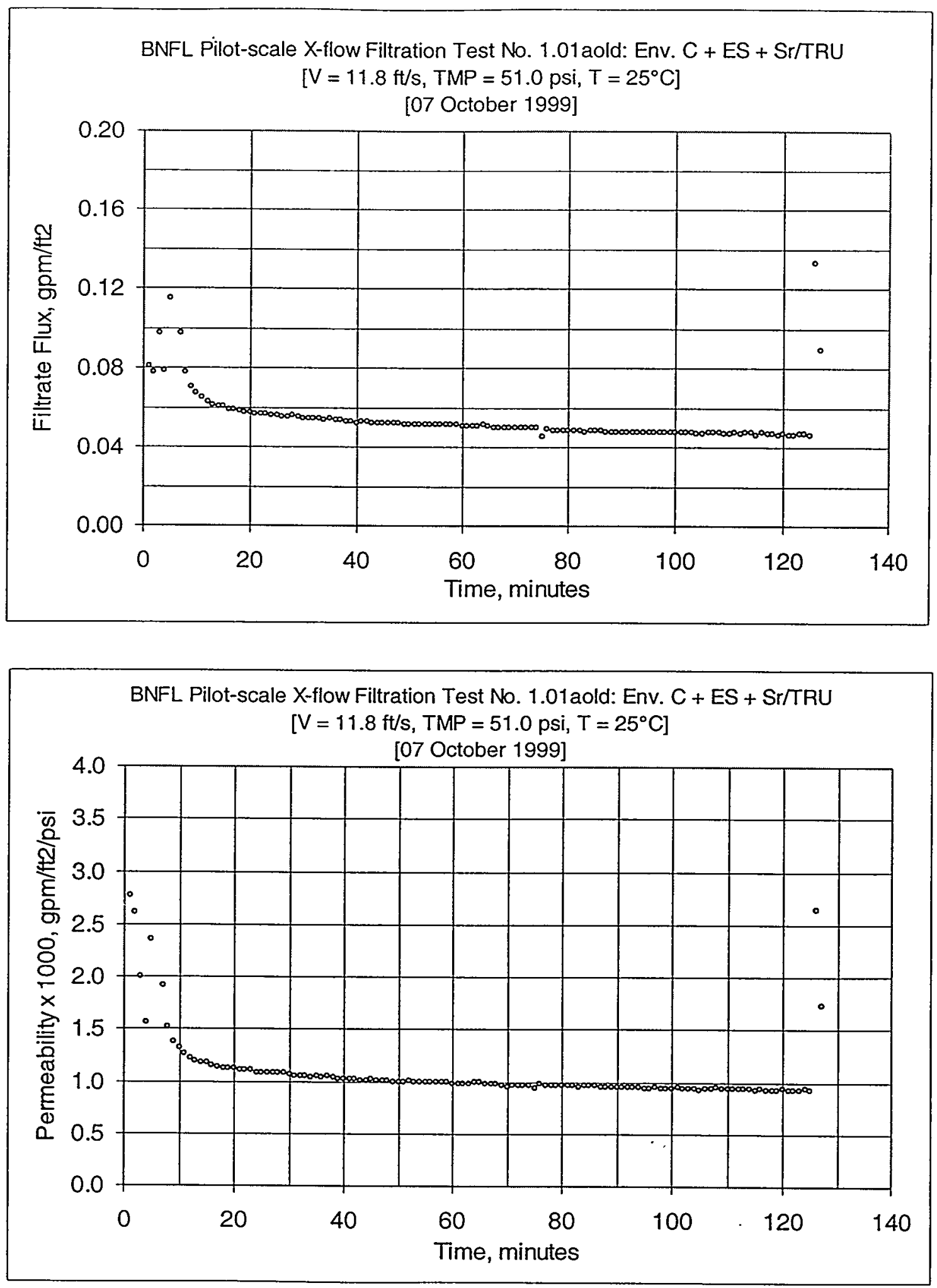

Figure B18: Test Run 1.01a(old), 2 wt\% Insoluble Solids Concentration 
Pilot scale X-flow: EnvC+ES+Sr/TRU Page 142 of 256

BNF-003-98-0226

Revision 0

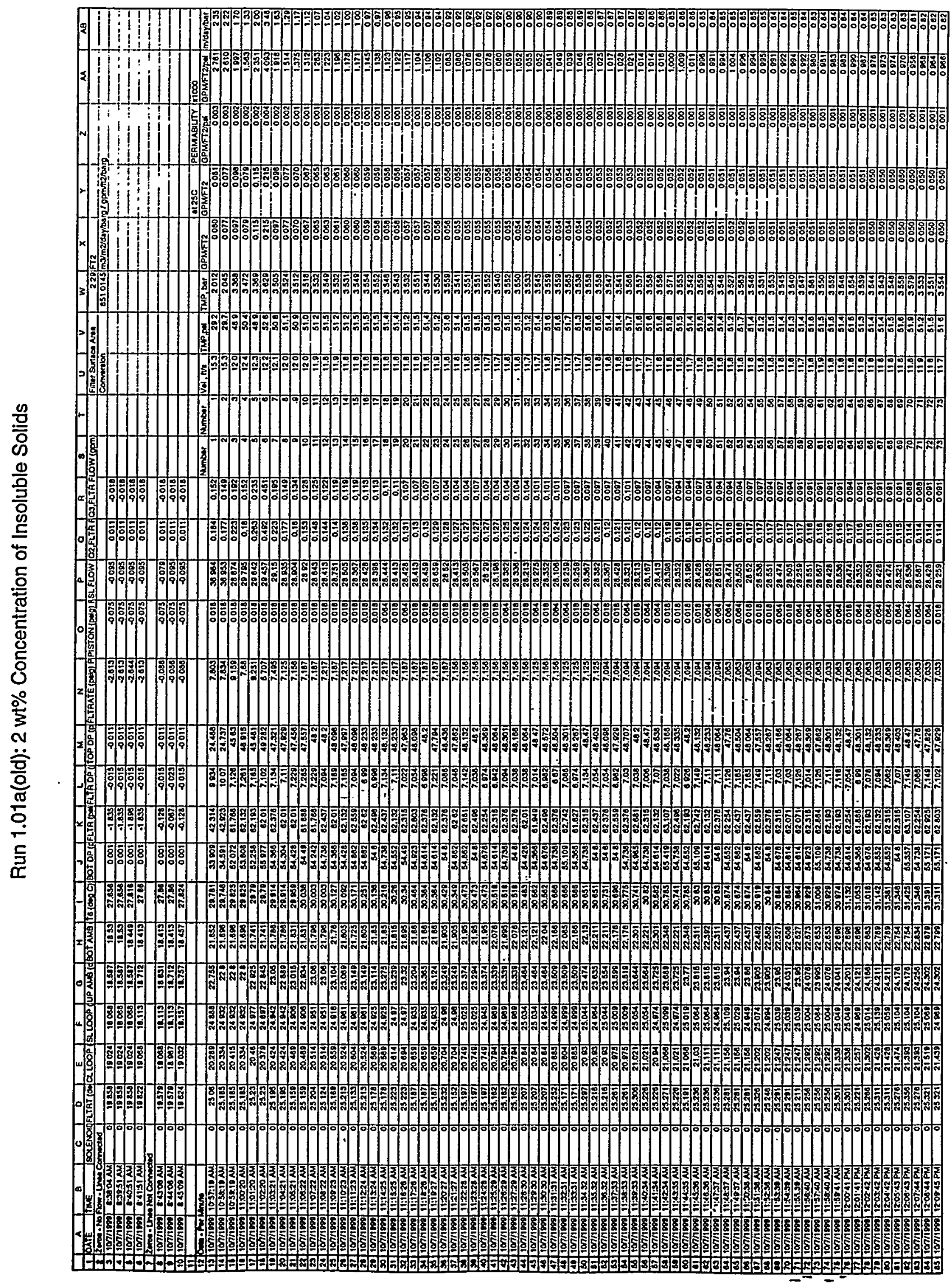


Pilot scale X-flow: EnvC+ES+Sr/TRU Page 143 of 256

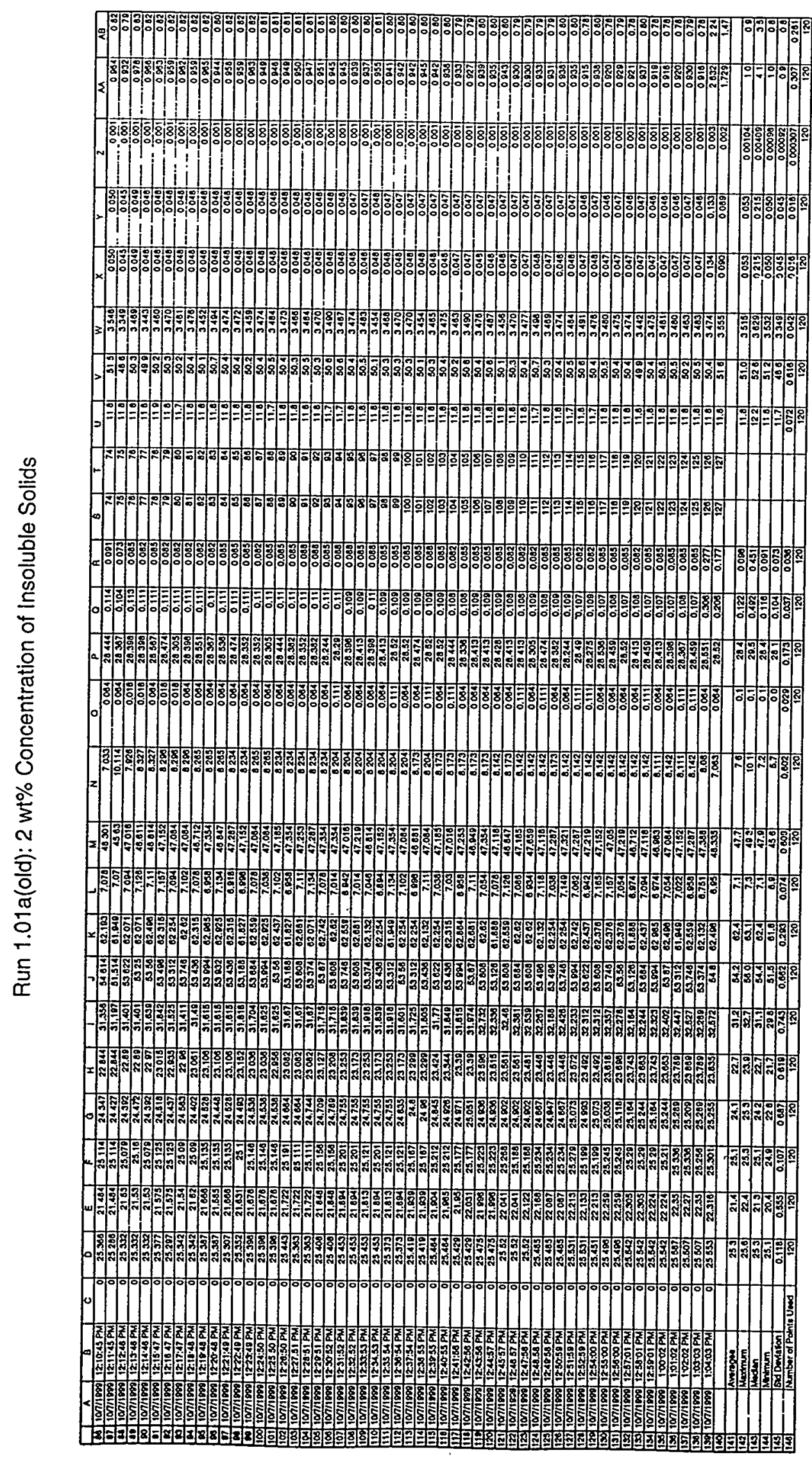




\section{APPENDIX C}

\section{EXPERIMENTAL DATA: HIGH SOLIDS CONCENTRATION}

Appendix Contents

1. Nomeclature sheet for data tables

2. Experimental data:

$\begin{array}{llll}\text { Fig. } & \text { Run } & \text { Solution } & \text { Done on } \\ \text { C1 } & 1.08 & 2 \text { to } 22 \text { wt\% Solids } & 11 / 30 \text { to } 12 / 01 / 99 \text { (Prewash Dewatering) } \\ \text { C2 } & 1.09 / 1.10 & 22 \text { wt\% Solids } & 12 / 01 / 99 \\ \text { C3 } & 1.09 & 14 \text { wt\% Solids } & 12 / 02 / 99 \\ \text { C4 } & 1.10 & 14 \text { wt\% Solids } & 12 / 02 / 99 \\ \text { C5 } & 1.11 & 14 \text { wt\% Solids } & 12 / 02 / 99 \\ \text { C6 } & 1.12 & 14 \text { wt\% Solids } & 12 / 02 / 99 \\ \text { C7 } & 1.13 & 14 \text { wt\% Solids } & 12 / 03 / 99 \\ \text { C8 } & 1.14 & 14 \text { wt\% Solids } & 12 / 03 / 99 \\ \text { C9 } & 1.15 & 14 \text { to } 38 \text { wt\% Solids } & 12 / 09 / 99 \text { (Postwash Dewatering) }\end{array}$

General Note: For measurement uncertainties see Appendix F

Special Notes:

a. In the top graph of Fig. $\mathrm{Cl}$ there is a line of data just above the zero Filtrate Flux line and in the bottom graph there is a large amount of scattered data above the permeability line, these data points were due to backpulsing.

b. Explanation for run 1.09/1.10 - On December 1, at the end of the concentrating run, 1.08 , a final concentration of $22 \mathrm{wt} \%$ of insoluble solids and $49 \mathrm{wt} \%$ of total solids was attained. The first steady-state high concentration test run (1.09) began immediately. However, two of the three pumps were leaking slightly, so run 1.09 was done using run 1.10 flow conditions (i.e., slurry velocity of $9 \mathrm{ft} / \mathrm{s}$ and a TMP of 30 psid) because a pump failure was feared if the flow conditions of run 1:09 (i.e., 12 $\mathrm{ft} / \mathrm{s}$ and $55 \mathrm{psid}$ ) were used. That is, it appeared that any run was not going to last long with the conditions of the pumps. Despite the leaking, the run was attempted because data at this higher slurry solids loading were desirable. Therefore, the least taxing flow conditions on the pumps were chosen (i.e., run 1.10). As can be seen in Fig. C2, only 36 minutes of data were obtained. The temperature of the slurry could not be maintained because of its viscous nature and because the small volume of the concentrated slurry was not sufficient to cover the cooling coils in the slurry reservoir. Also, the pumps began to leak profusely, so the run was stopped to change the pump seals and to dilute the slurry. The slurry was diluted to approximately 15 wt\%; a subsequent analytical measurement put the insoluble solids loading at 14.3 $w t \%$ and the total solids at $44.1 \mathrm{wt} \%$. On the following day, with the more dilute slurry, run 1.09 was redone.

c. Backpulsing - For run 1.09, Fig. C3, a backpulse frequency of 20 minutes was used. However, the backpulse seemed ineffective because after a backpulse, the filtrate flowrate would decrease, within a few minutes, to a steady (low) flux. Therefore, for 
runs 1.10 to 1.14 , Figs. $C 4$ to $C 8$, only an initial and final backpulse was used. Moreover, the data indicate that the filtrate flux was a bit erratic. This was caused by the temperature increases. At this higher solids loading the slurry had a Bingham plastic type character and therefore in the slurry reservoir the slurry movement was minimal because of the yield stress, thus making the cooling coils ineffective. A run would be started at around $23^{\circ} \mathrm{C}$ and end up above $30^{\circ} \mathrm{C}$.

d. The data for every test run are highlighted with two graphs: Filtrate Flux vs. Time and Permeability vs. Time. Those graphs include all the data taken during the run period.

e. The beginning and end of the data for most graphs show large deviations from the overall series of points. Those deviations were caused by backpulsing the filter that temporarily stopped the flow of filtrate.

f. All columns of data, in all the tables, are ended with several statistical values of that column, i.e., Average, Maximum, Median, Minimum, Standard Deviation, and Number of Points Used (in calculating the 5 statistical quantities). Most of the data with time were maintain constant, and therefore the statistics are meaningful for normally distributed data, however Filtrate Flux and Permeability decrease with time and therefore are not normally distributed.

g. To calculate those quantities mentioned in the preceding item, only those data points that start from the end of a backpulse to just before the ending backpulse were included. This is the reason why the quantity of Number of Points Used was given.

h. The data for the graphs, and all the data taken for the individual test run that the graphs represent, immediately follow the specific figure.

Nomenclature For Data Sheets

(See Figure 1: Main Test Rig - Pllot Scale Cross Flow for the Instrument Location)

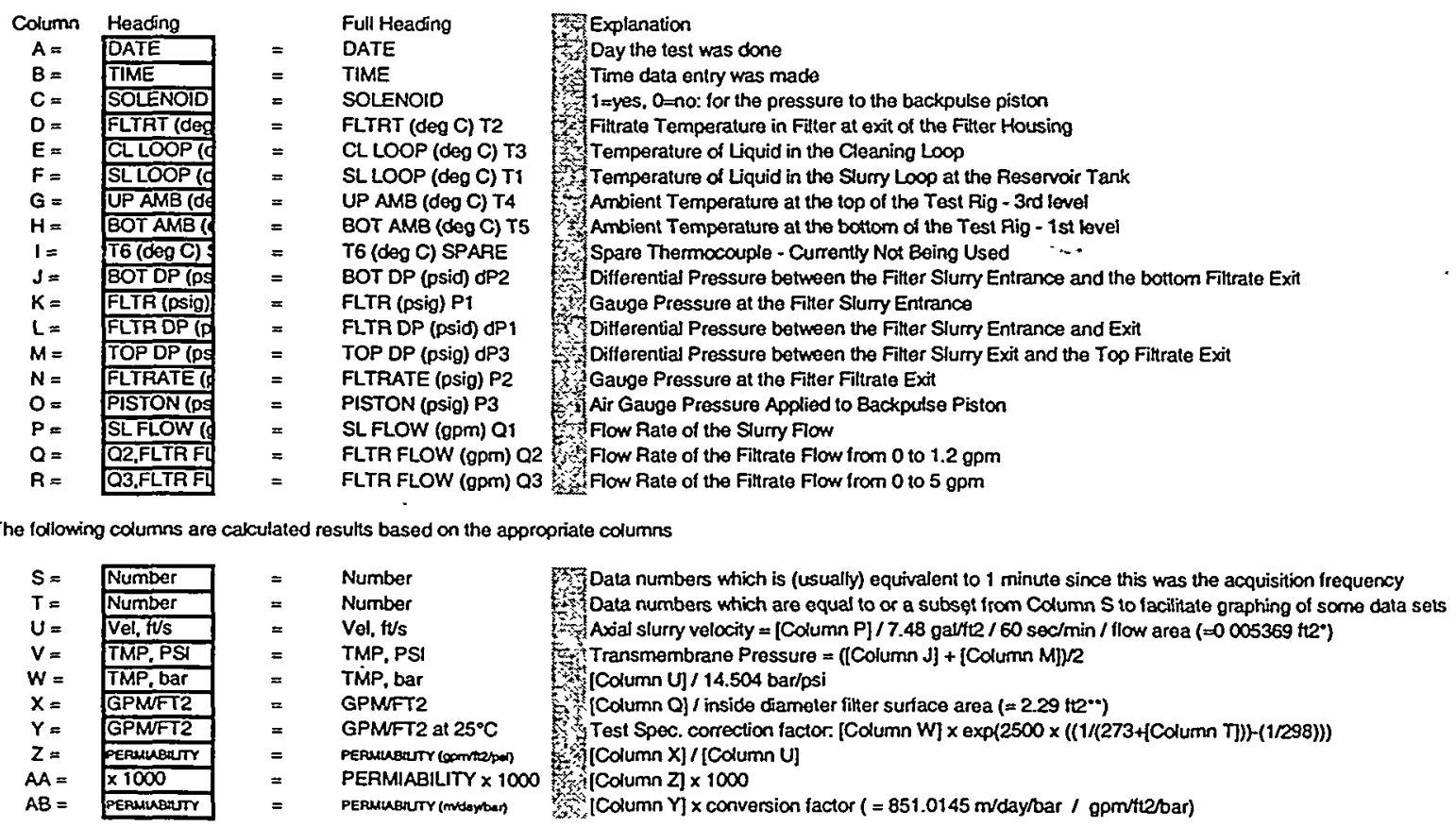

-Axial slurry flow area is based on 7 porous tubes with an inside diameter of $3 / 8$ inch: $7 \times$ pi/ $4 \cdot(0.375 \text { inch } / 12 \text { inches/tit })^{\wedge}=0.005369$ ft2

-Inside diameter fitter surface area for 7 tubes with an inside diameter of $3 / 8$ inch, 40 -inches long: $7 \times$ pi $\times(0375$ inch $) \times 40$ inches $/ 144$ in $2 / 112=229$ ft2 

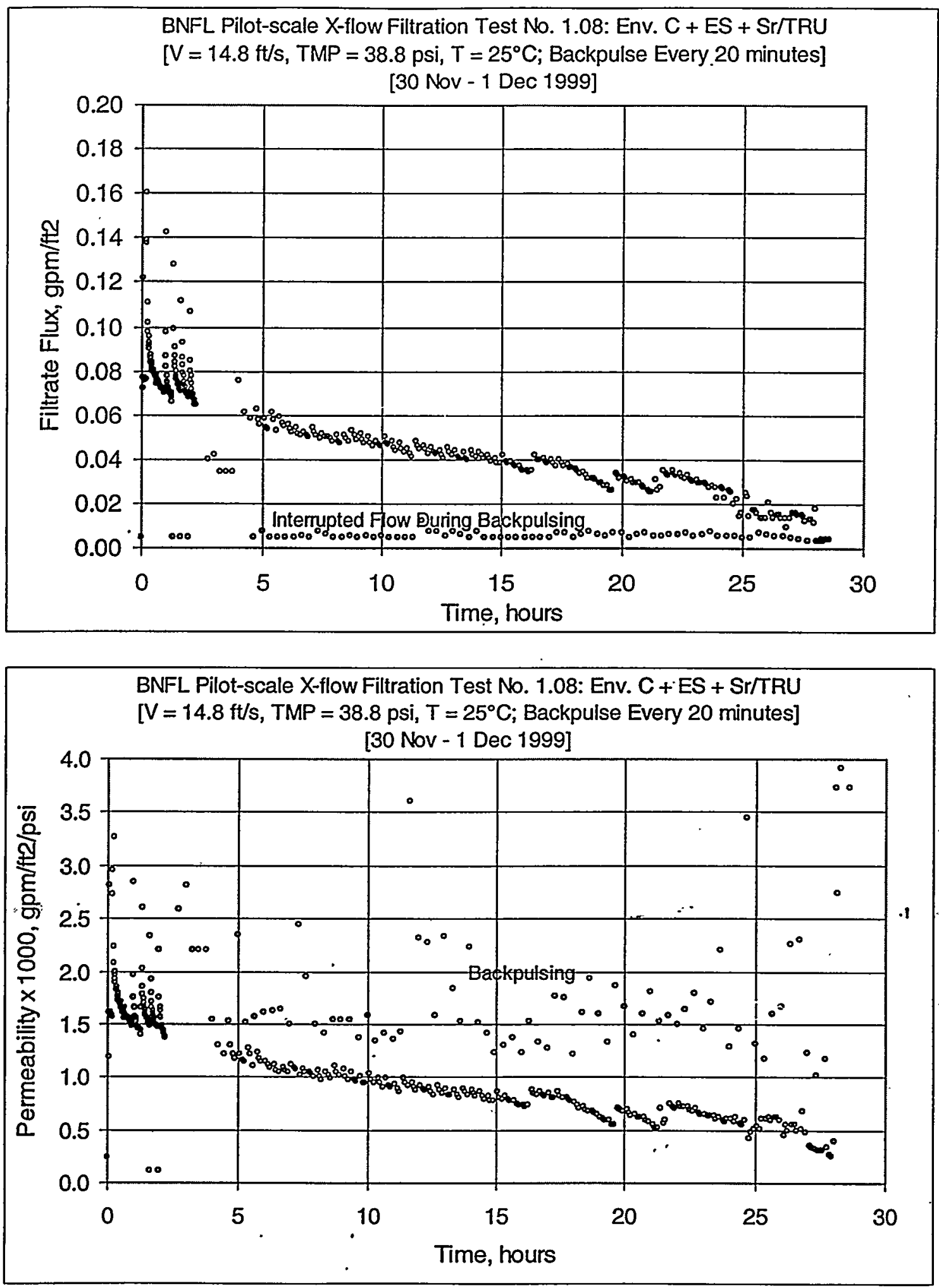

Figure.C1: Test Run 1.08, Dewatering from 2 to $22 \mathrm{wt} \%$ Insoluble Solids Concentration 
Pilot scale X-flow: EnvC+ES+St/TRU Page 147 of 256

BNF-003-98-0226

Revision 0

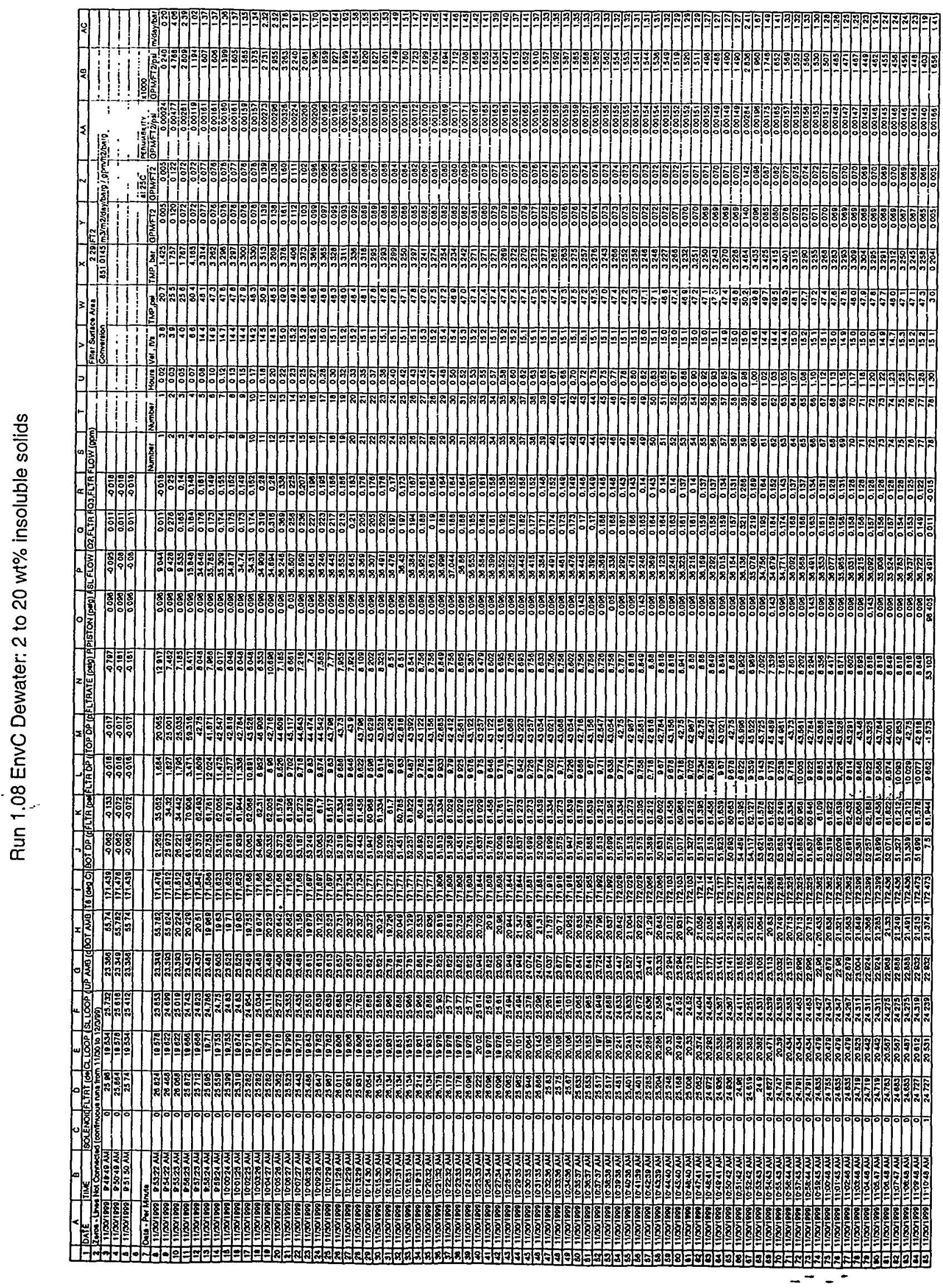


Pilot scale X-flow: EnvC+ES+Sr/TRU Page 148 of 256

BNF-003-98-0226

Revision 0

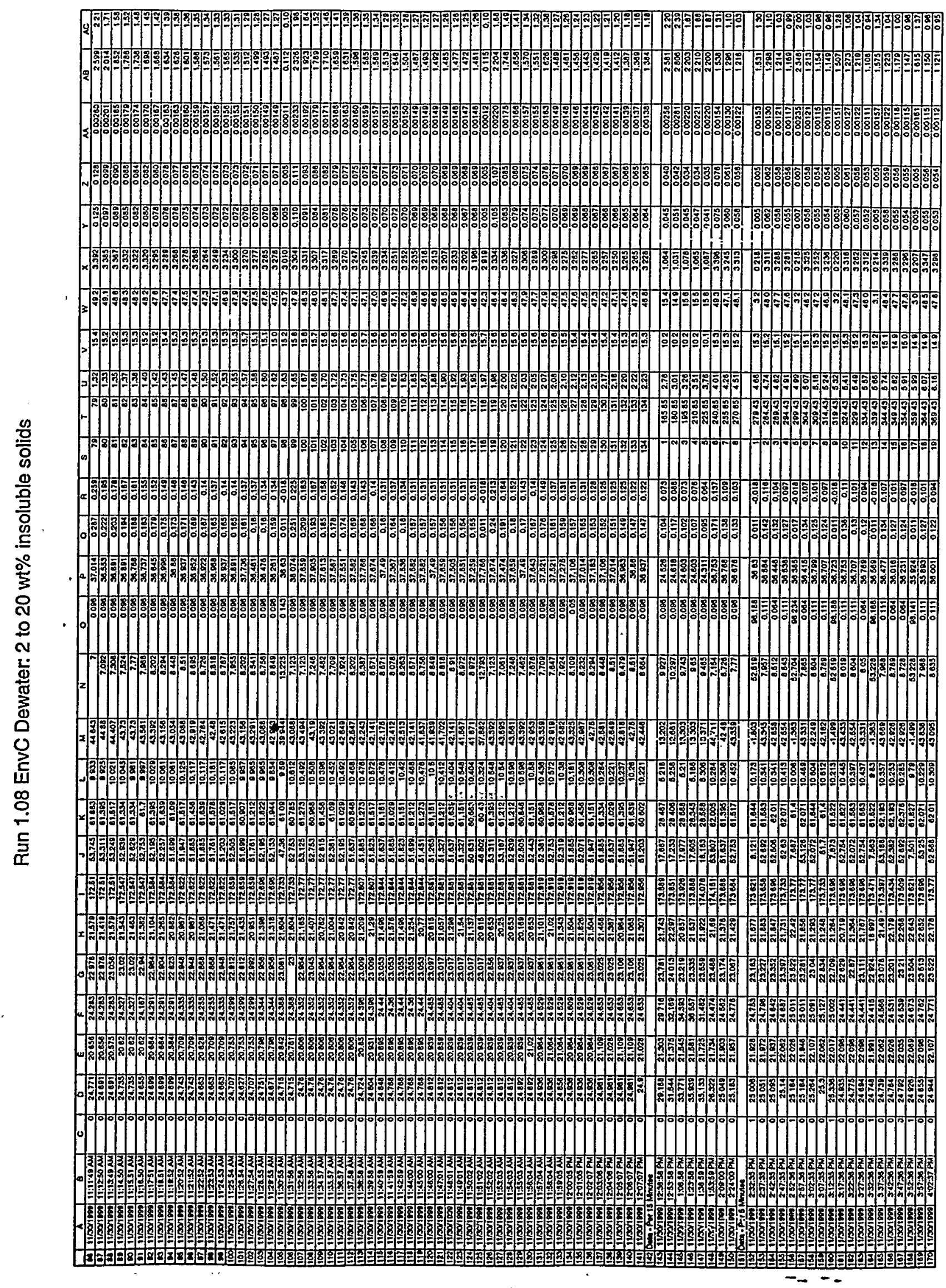


Pilot scale X-flow: EnvC+ES+Sr/TRU Page 149 of 256

BNF-003-98-0226

Revision 0

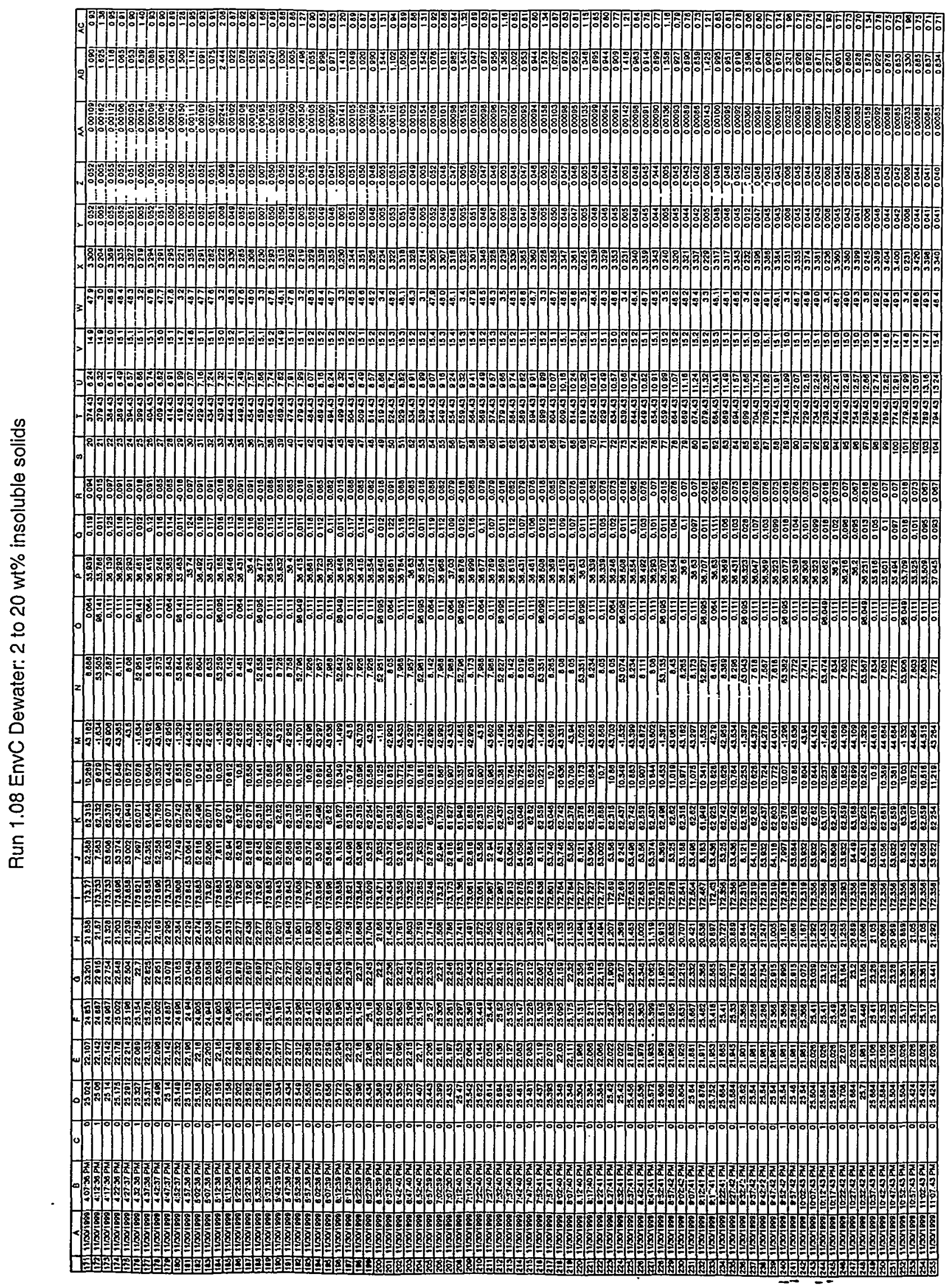


Pilot scale X-flow: EnvC+ES+St/TRU Page 150 of 256

BNF-003-98-0226

Revision 0

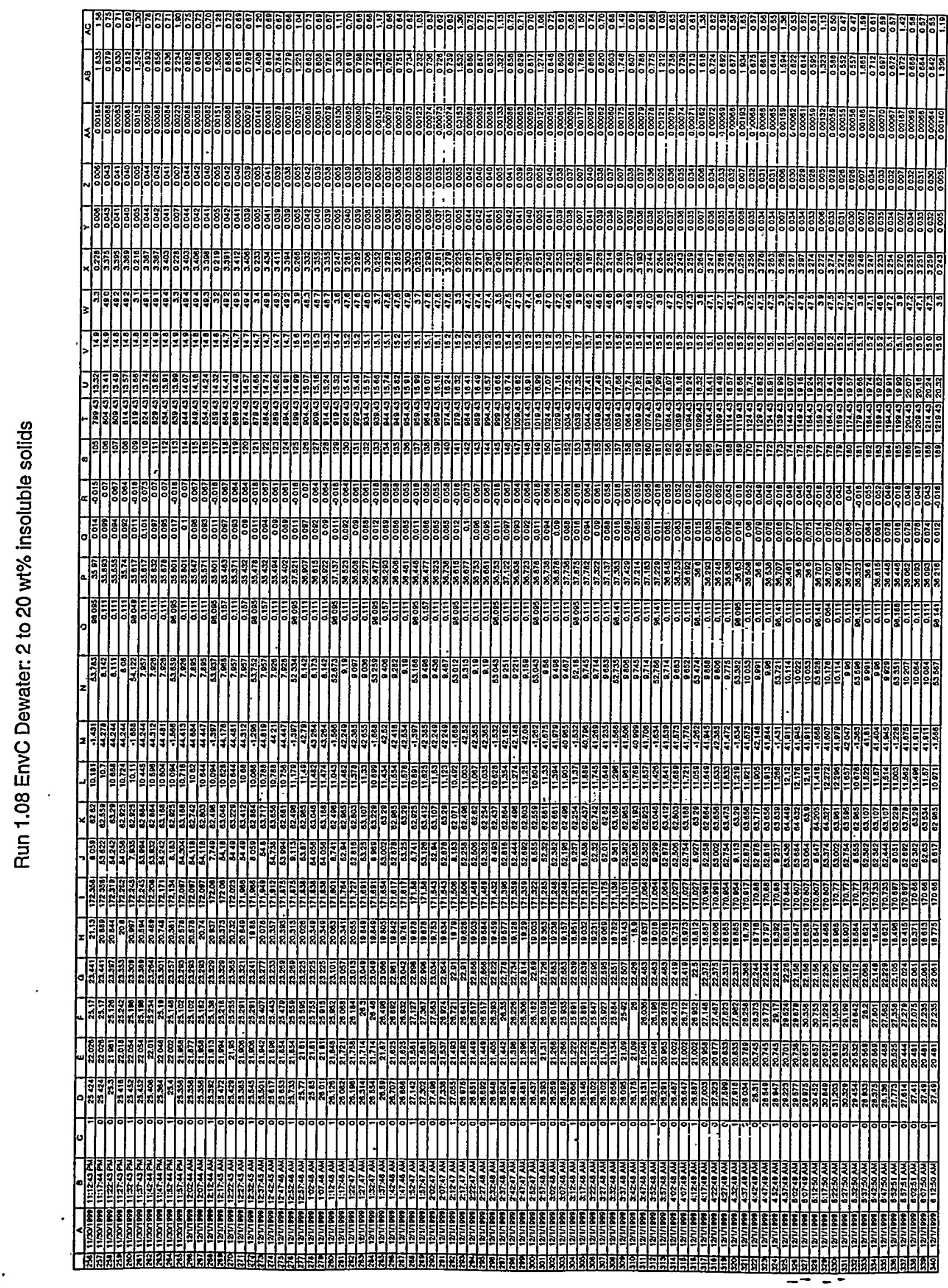


Pilot scale X-flow: EnvC+ES+Sr/TRU Page 151 of 256

BNF-003-98-0226

Revision 0

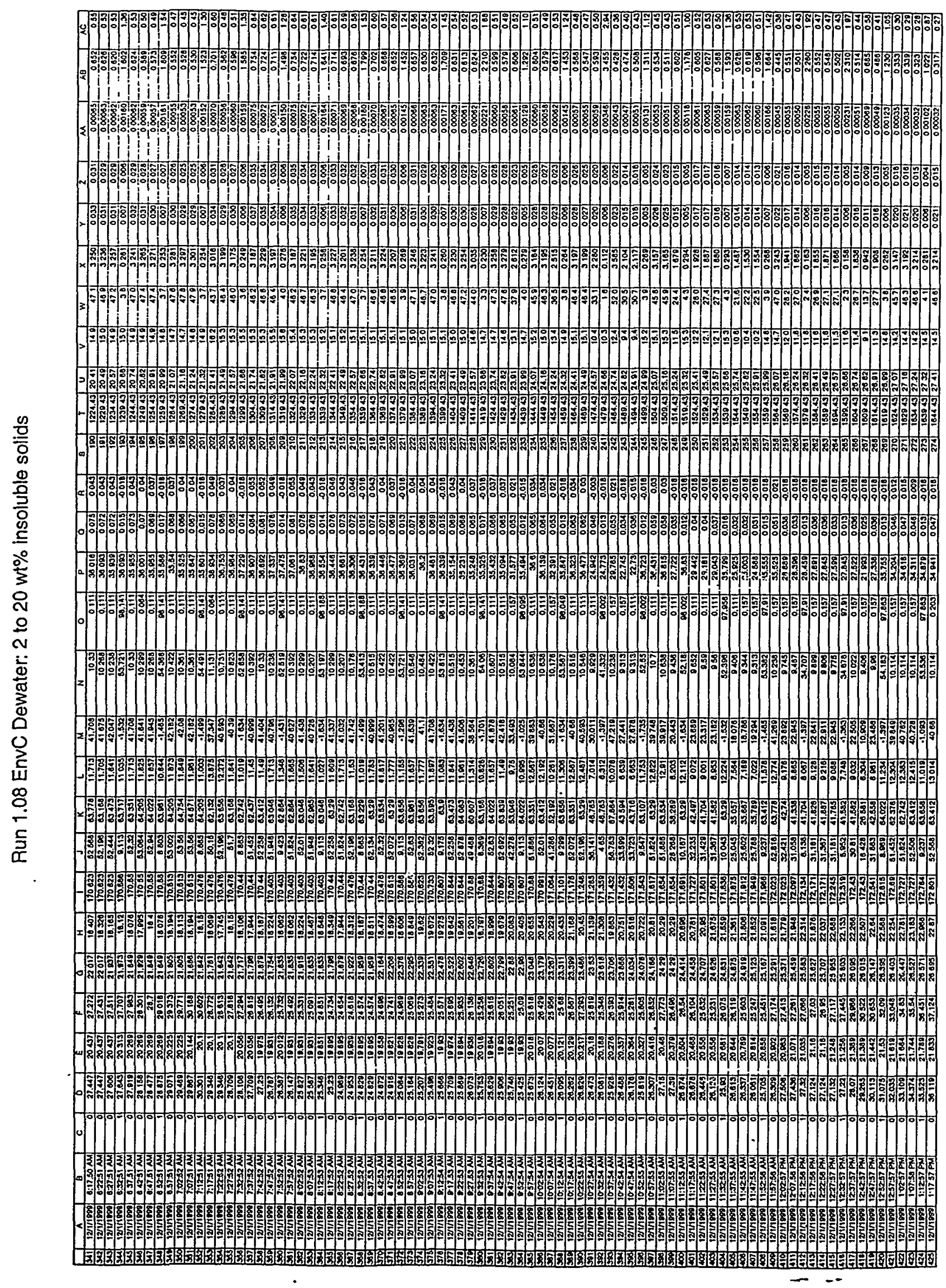




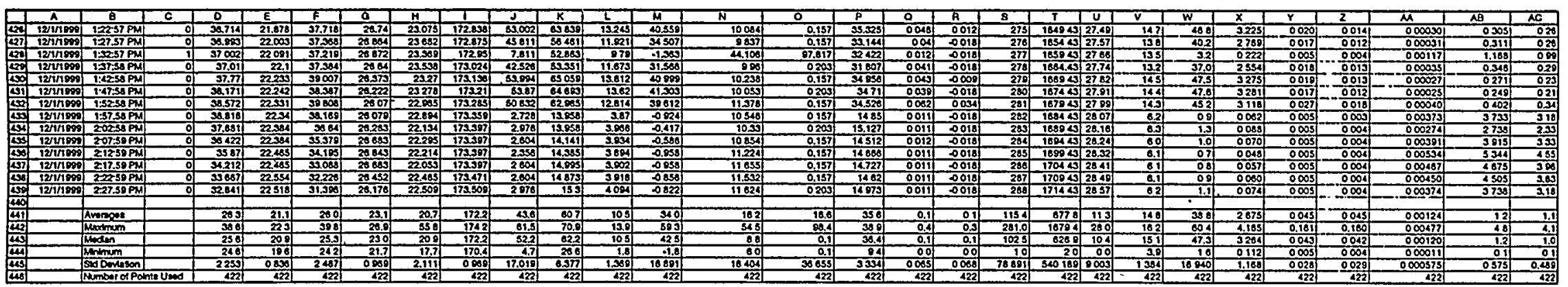


Pilot scale X-flow: EnvC+ES+Sr/TRU Page 153 of 256
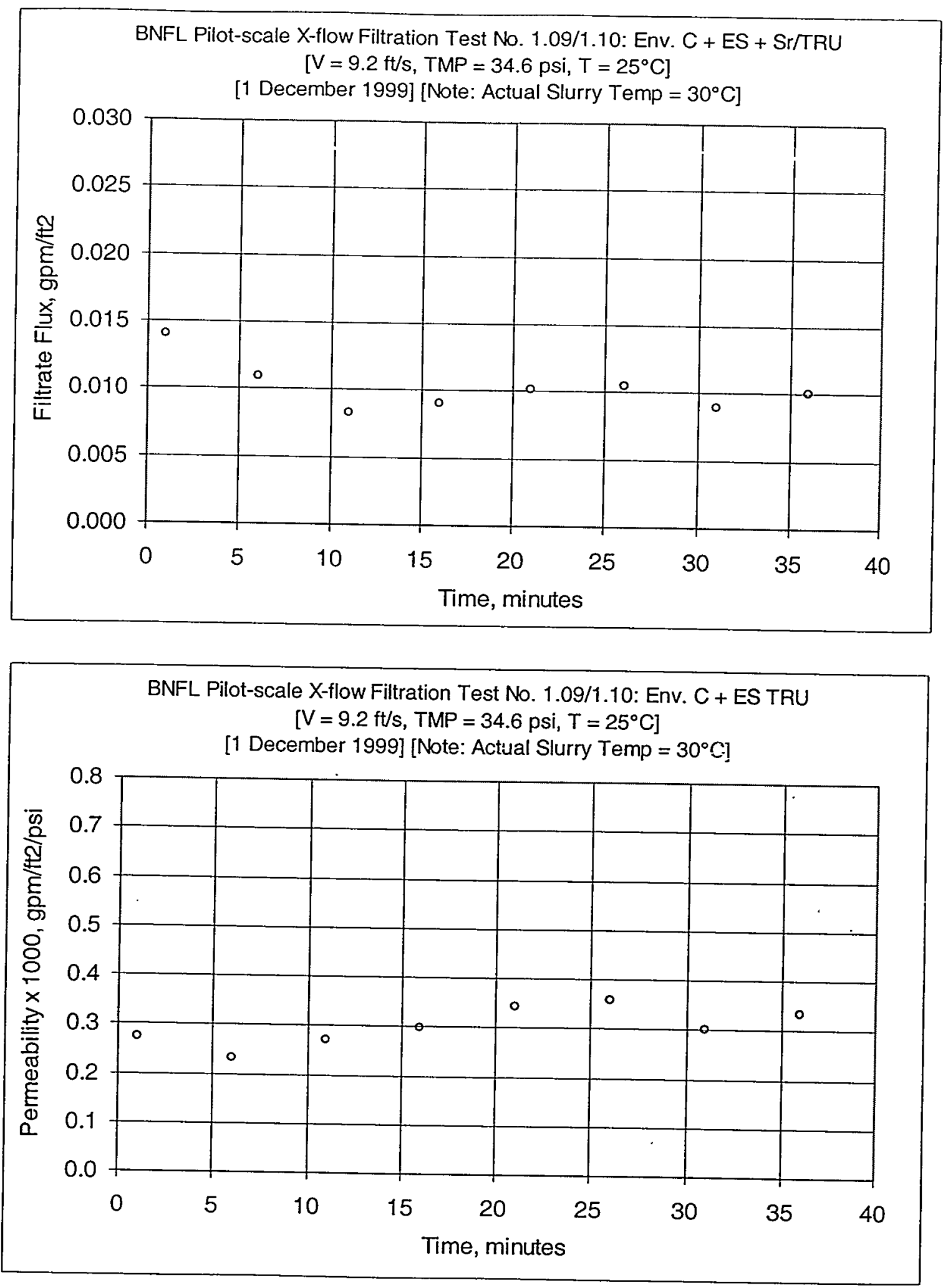

Figure C2: Test Run 1.09/1.10, 22 wt\% Insoluble Solids Concentration 


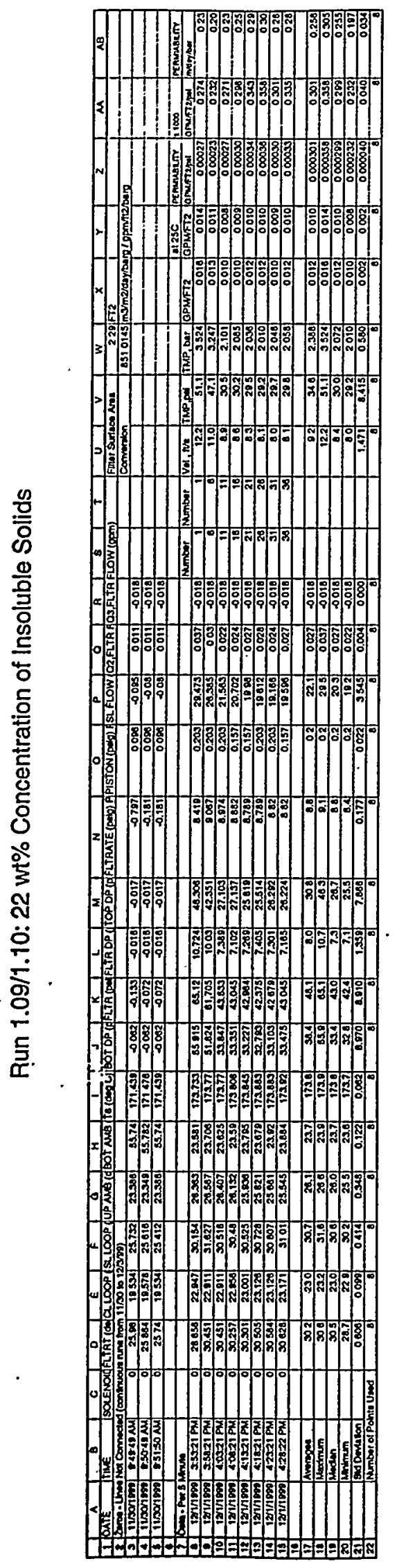



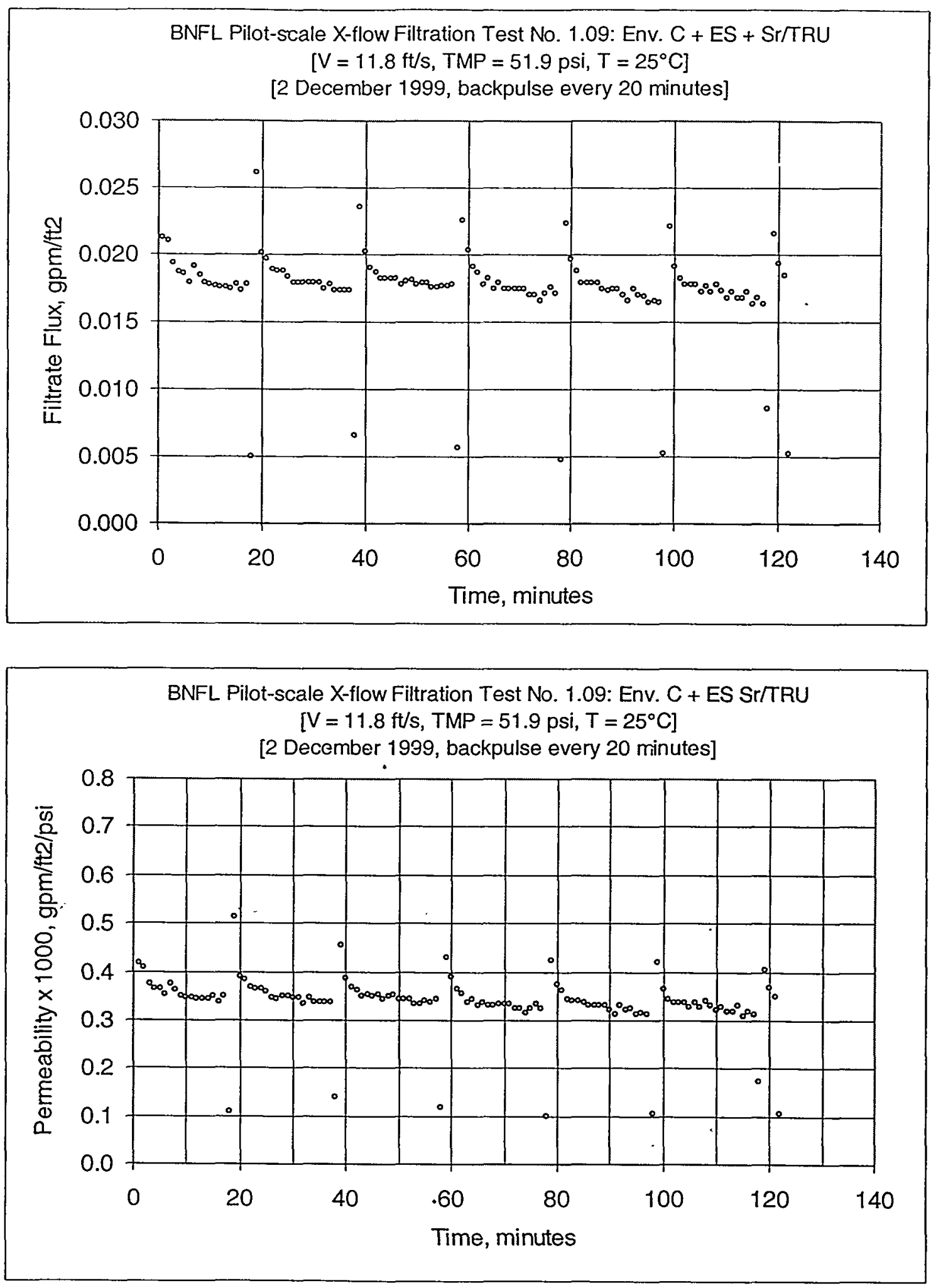

Figure C2: Test Run 1.09, 14 wt\% Insoluble Solids Concentration 
Pilot scale X-flow: EnvC+ES+Sr/TRU Page 156 of 256

BNF-003-98-0226

Revision 0

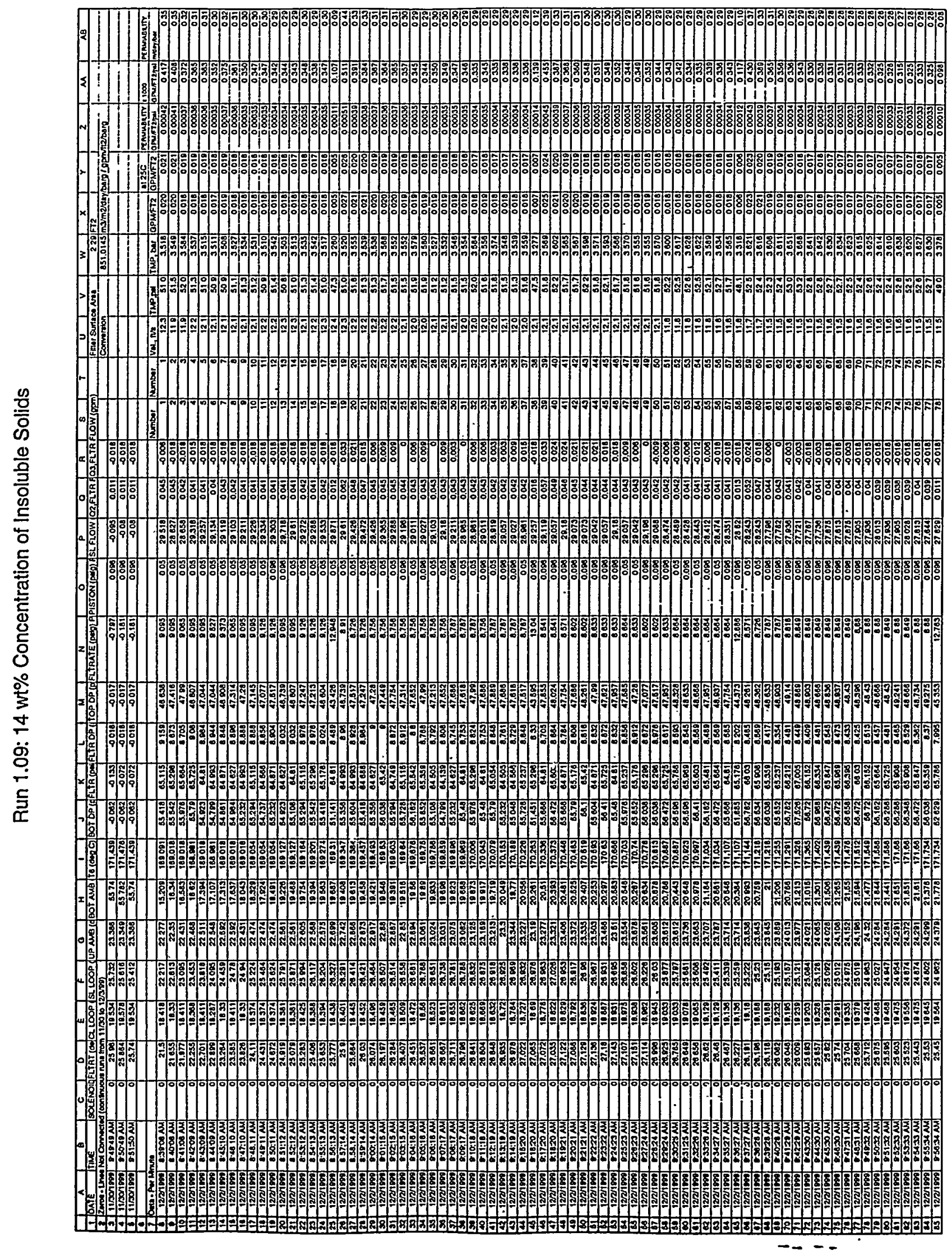


Pilot scale X-flow: EnvC+ES+Sr/TRU Page 157 of 256

BNF-003-98-0226

Revision 0

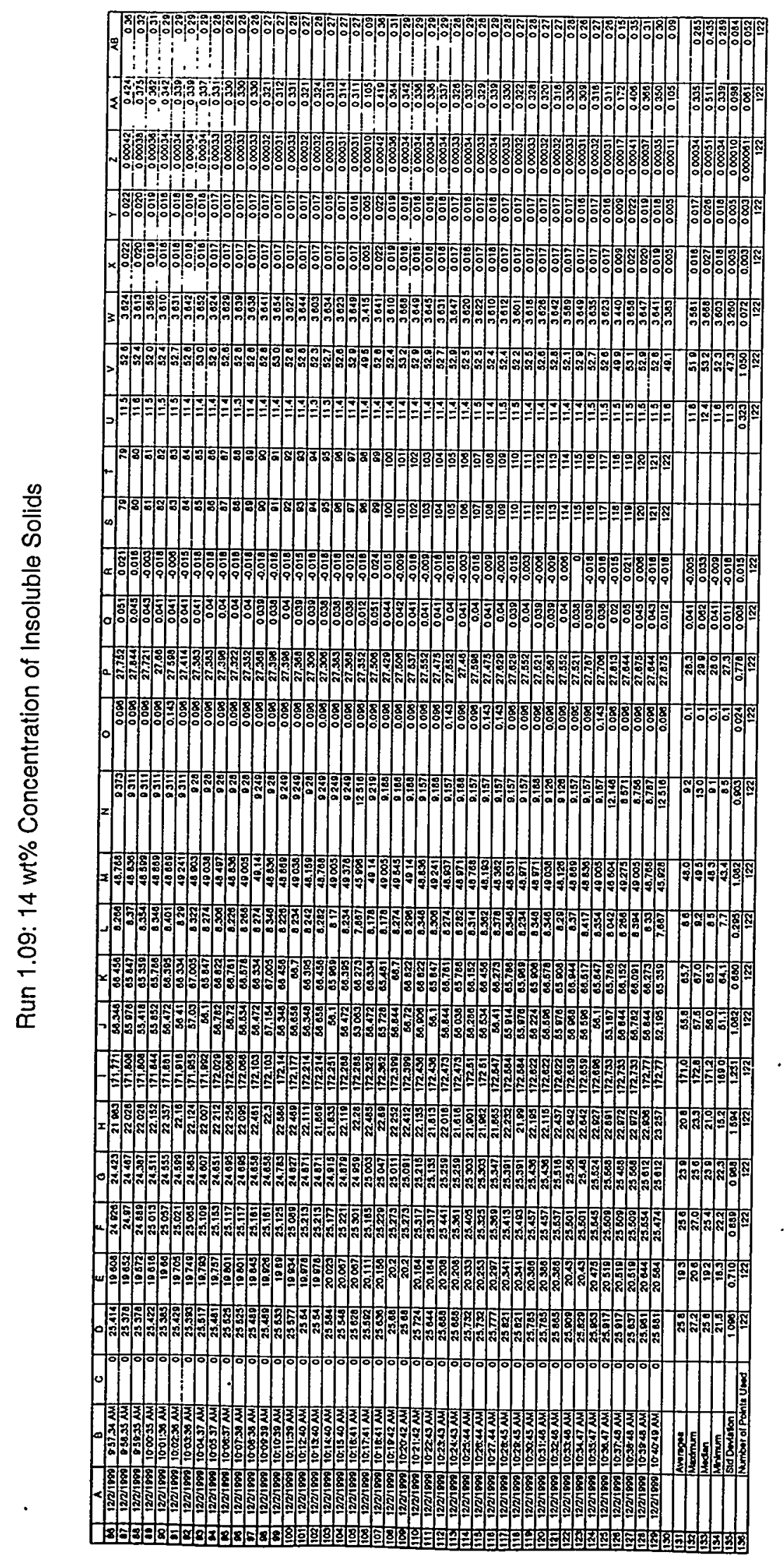



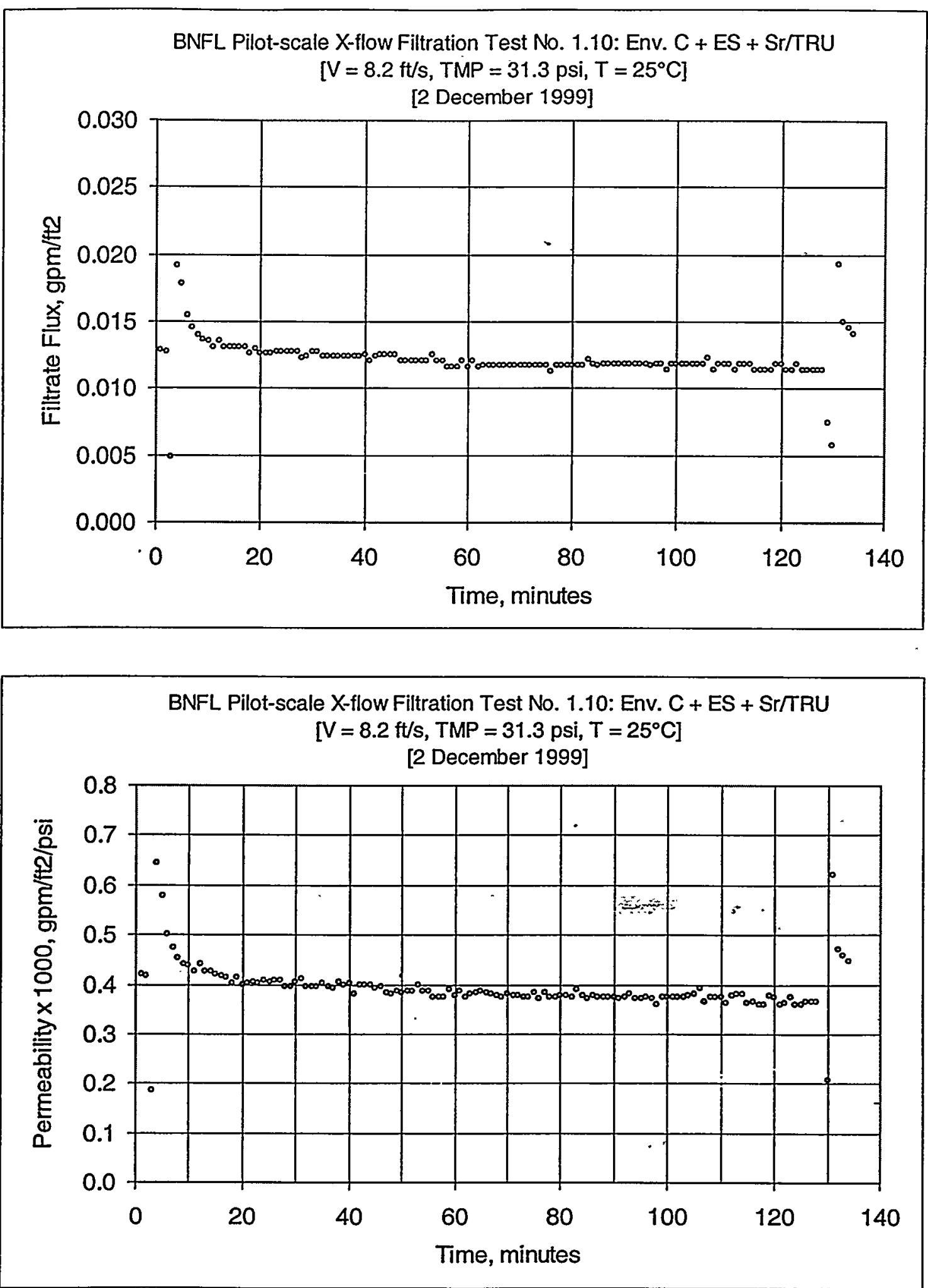

Figure C3: Test Run 1.10, 14 wt\% Insoluble Solids Concentration 
Pilot scale X-flow: EnvC+ES+Sr/TRU Page 159 of 256

BNF-003-98-0226

Revision 0

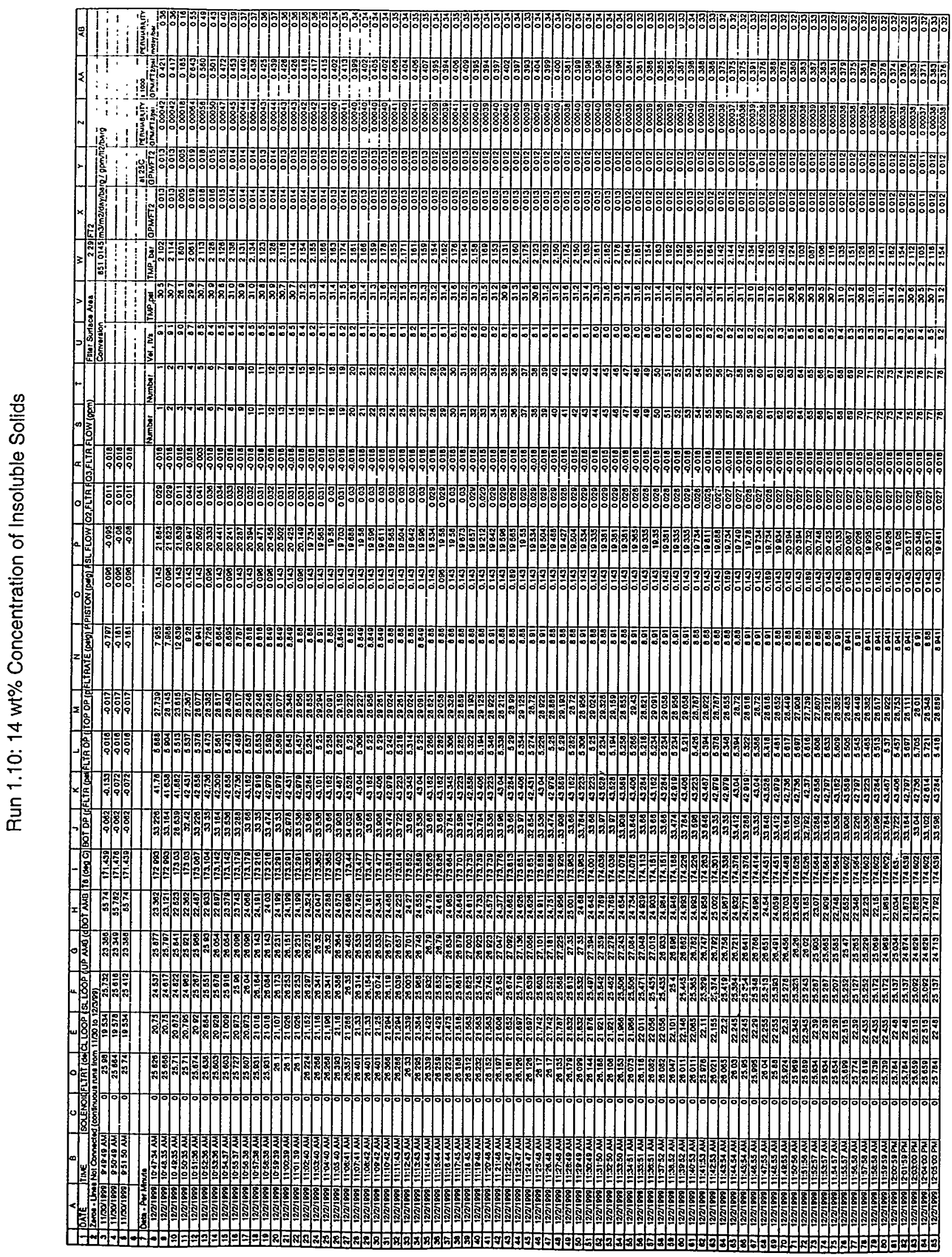


Pilot scale X-flow: EnvC+ES+Sr/TRU Page 160 of 256

BNF-003-98-0226

Revision 0

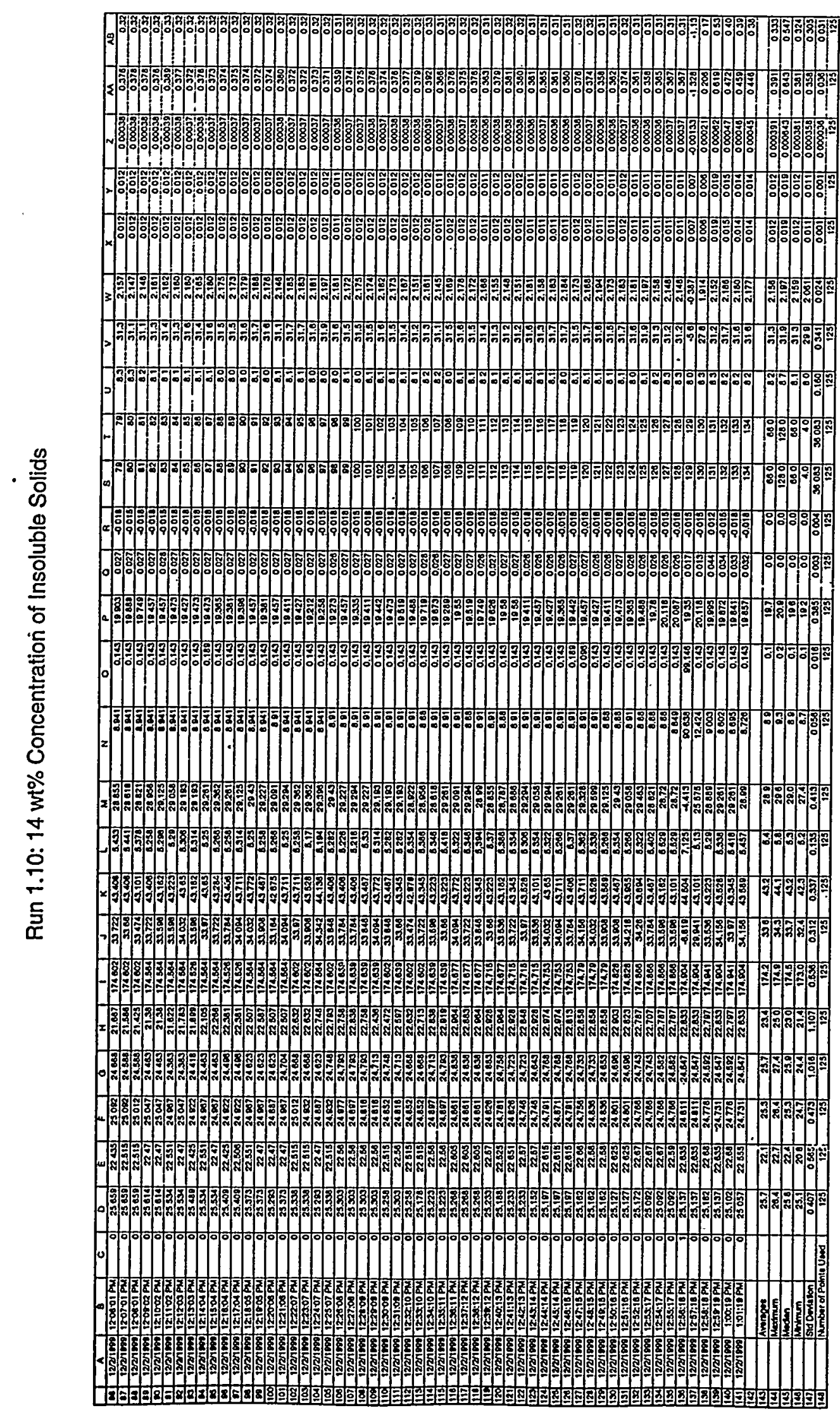



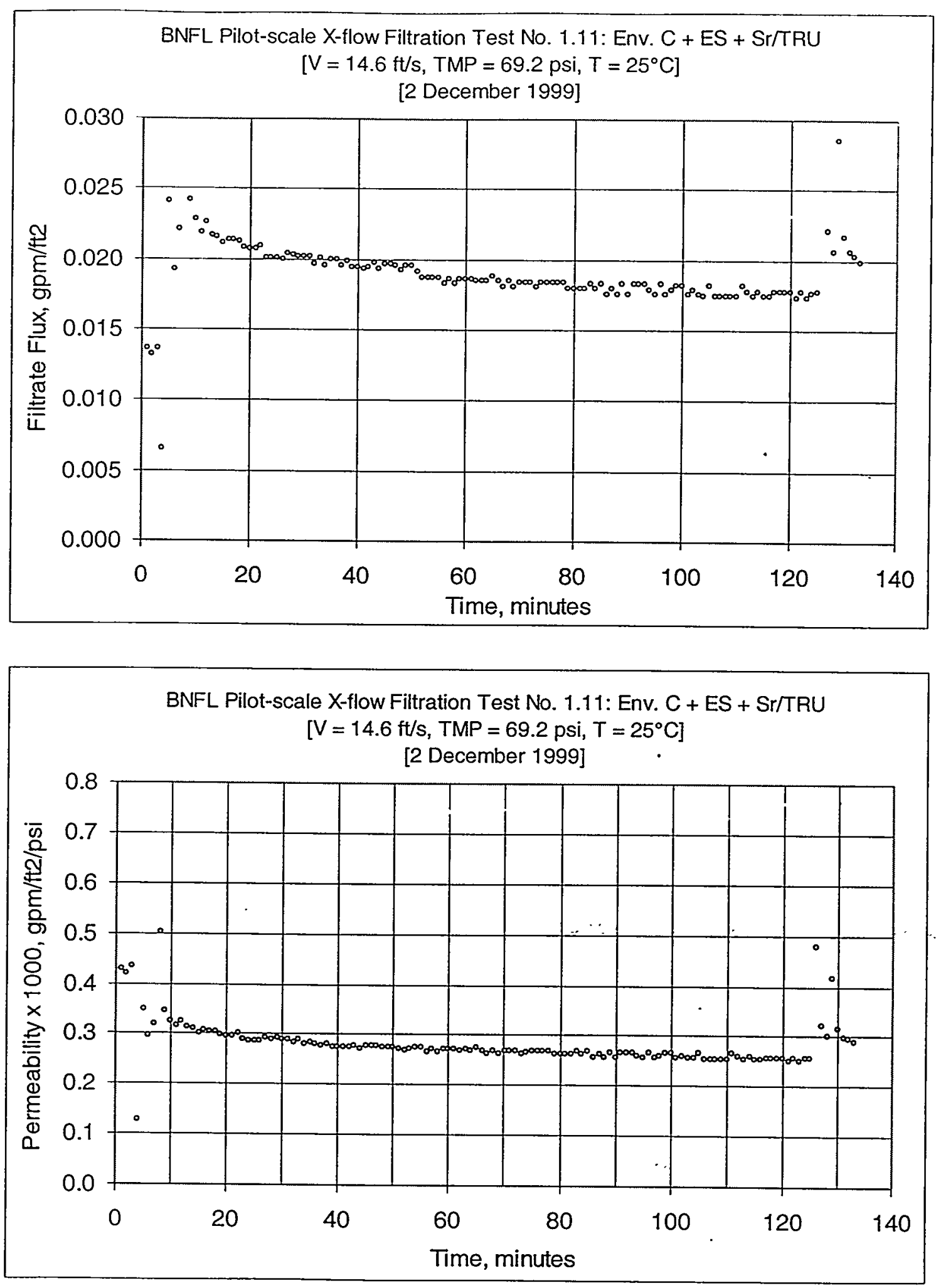

Figure C4: Test Run 1.11, 14 wt\% Insoluble Solids Concentration 


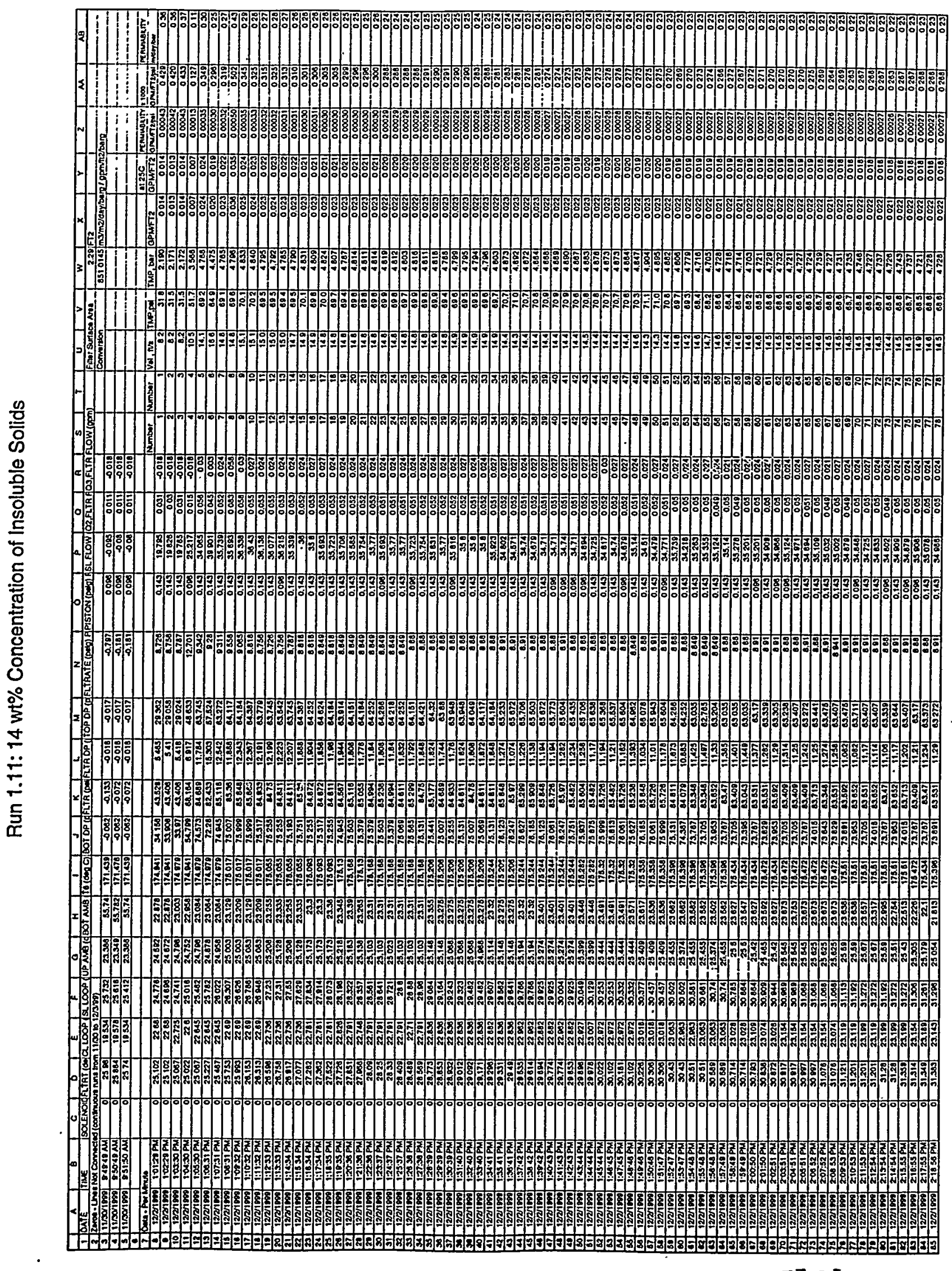


Pilot scale X-flow: EnvC+ES+Sr/TRU Page 163 of 256

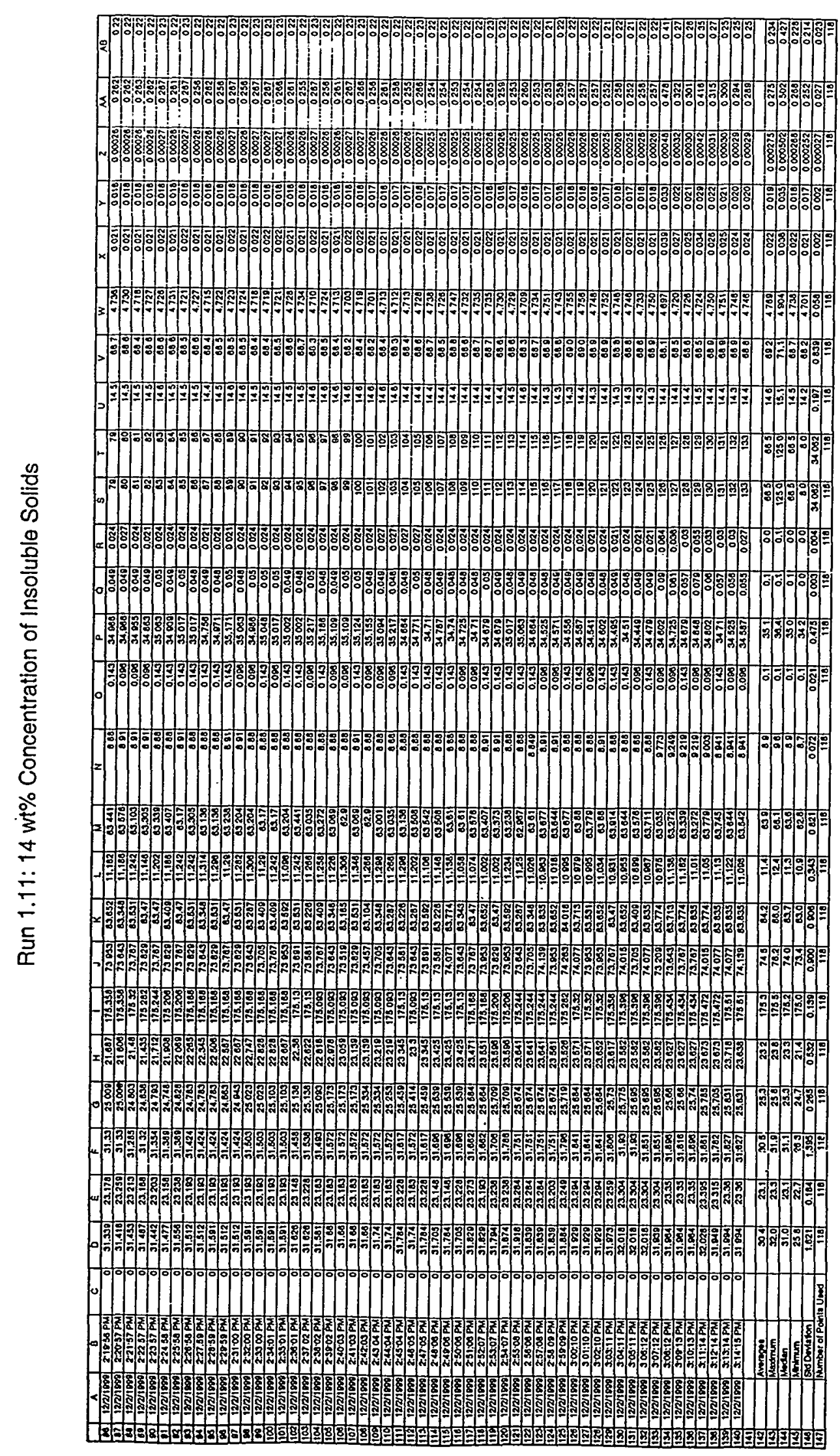




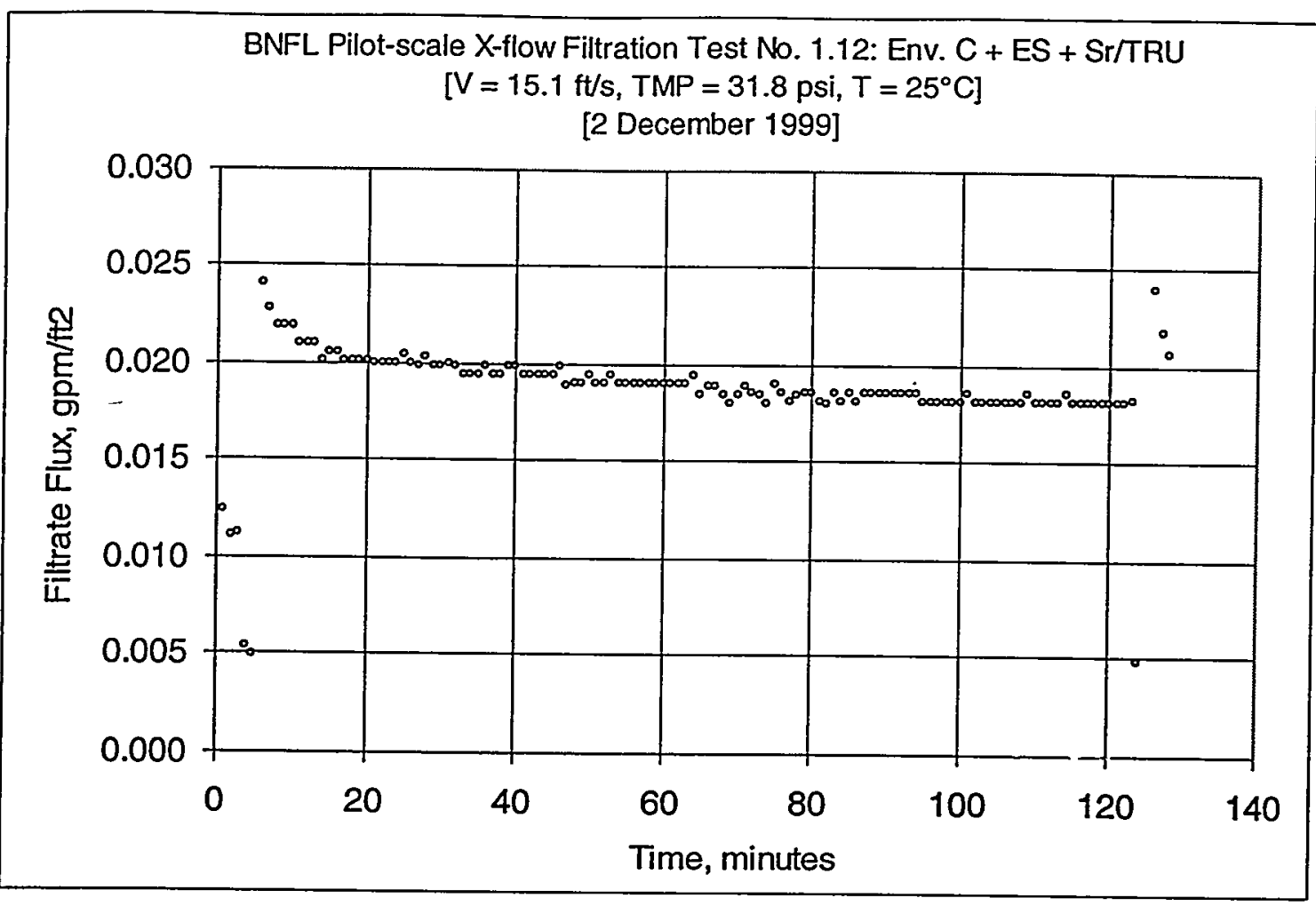

BNFL Pilot-scale X-flow Filtration Test No. 1.12: Env. $C+E S+S r / T R U$

$\left[\mathrm{V}=15.1 \mathrm{ft} / \mathrm{s}, \mathrm{TMP}=31.8 \mathrm{psi}, \mathrm{T}=25^{\circ} \mathrm{C}\right]$

[2 December 1999]

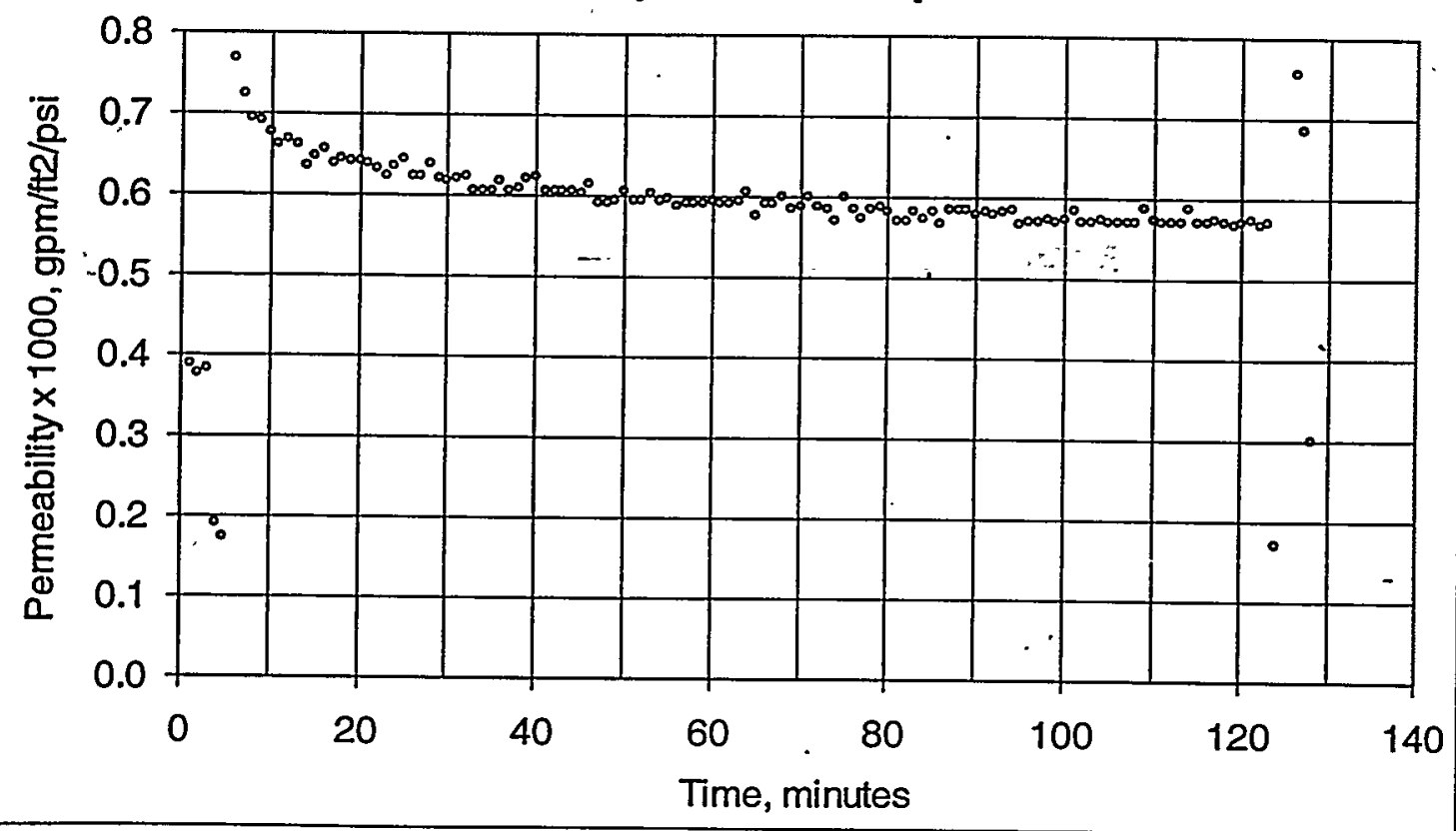

Figure C5: Test Run 1:12, 14 wt\% Insoluble Solids Concentration 


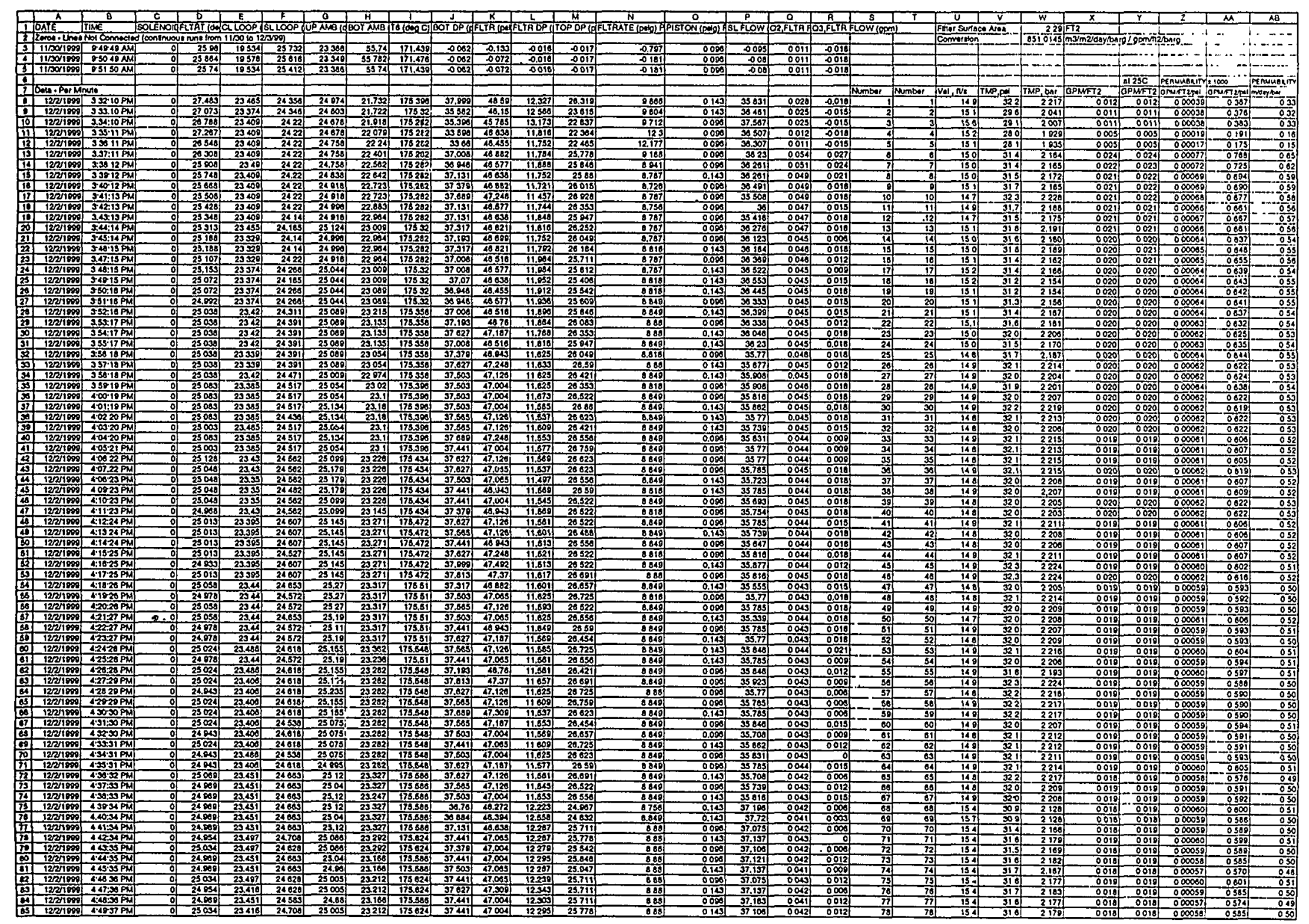




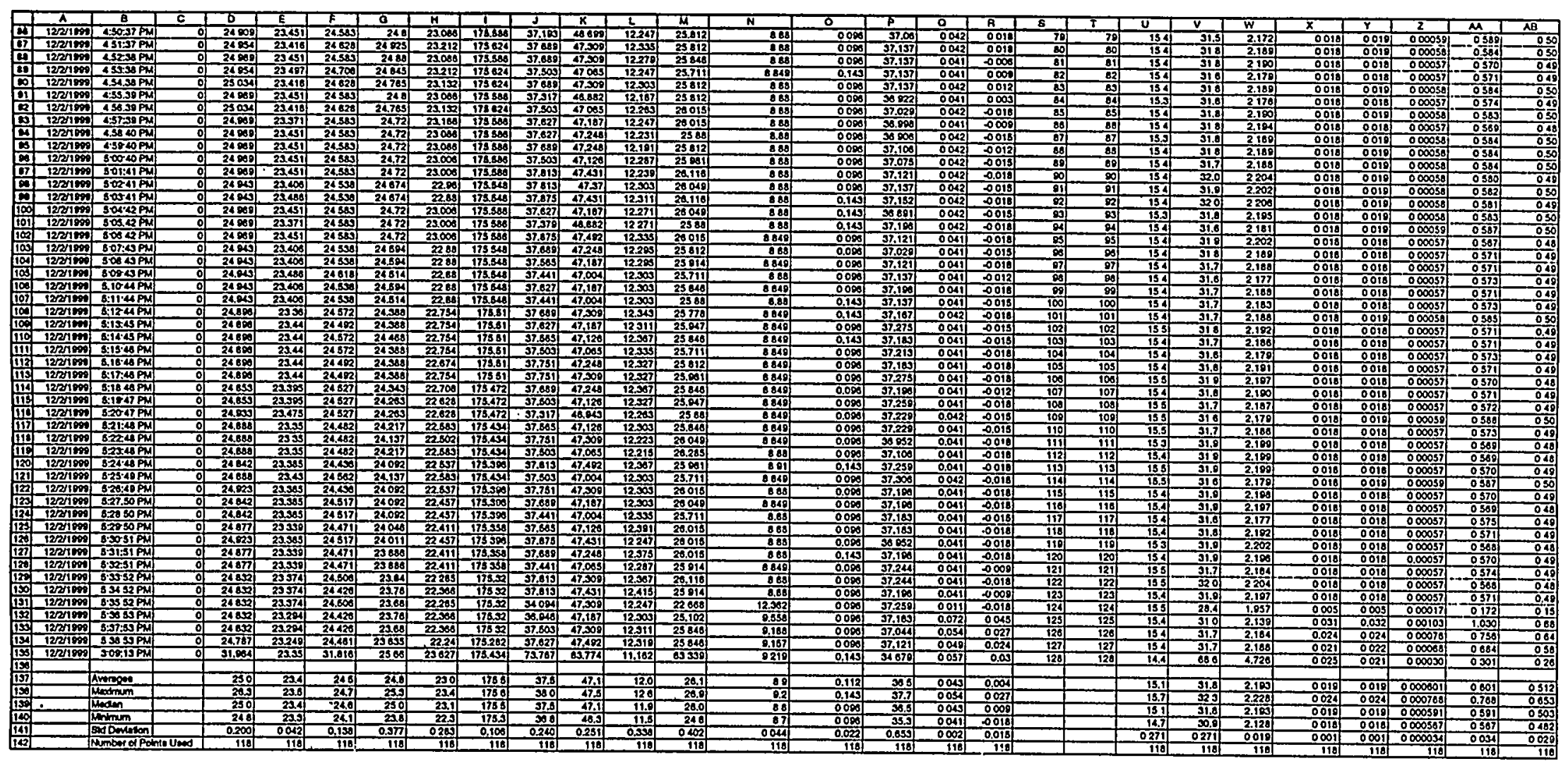



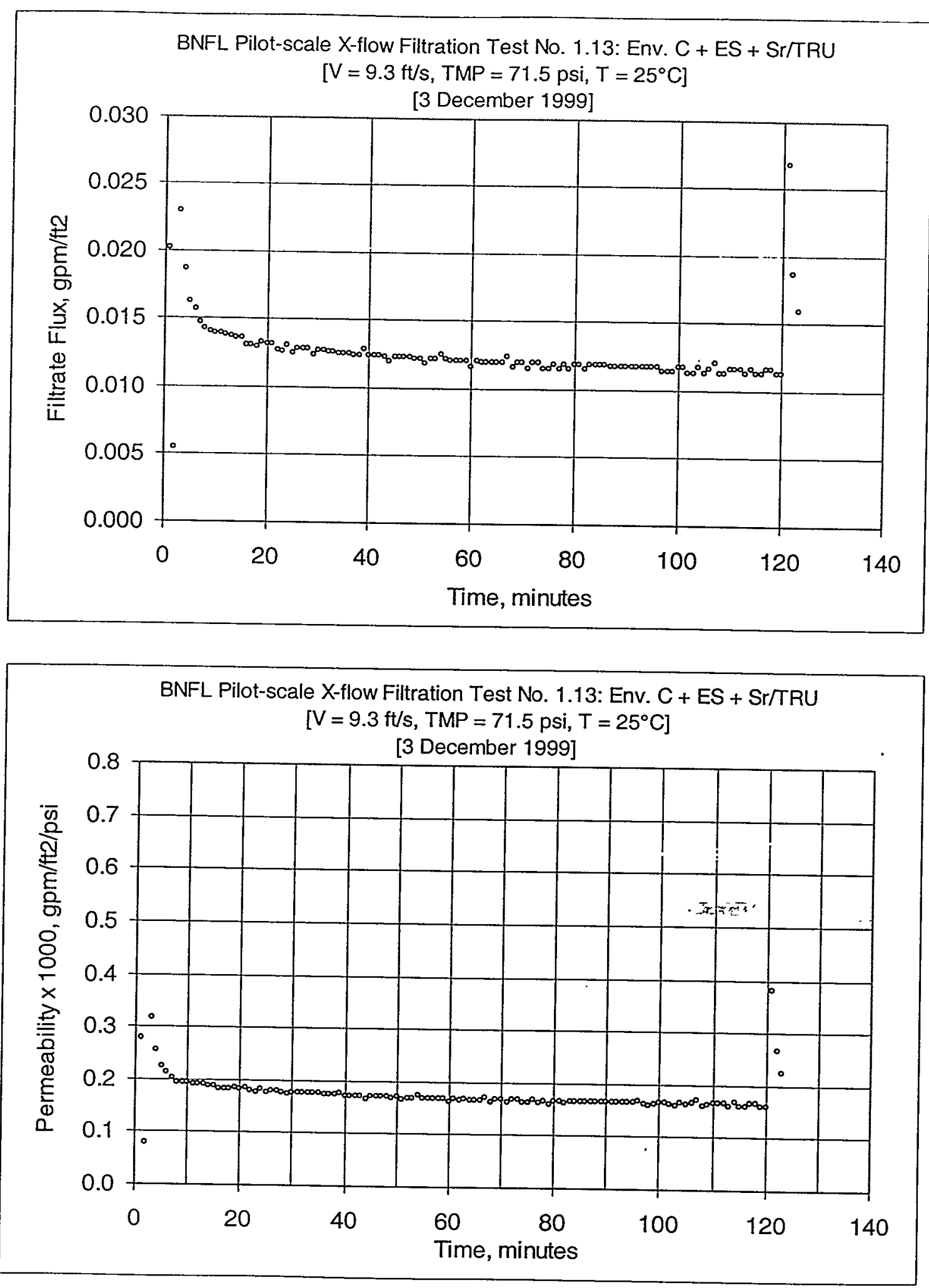

Figure C6: Test Run 1.13, 14 wt\% Insoluble Solids Concentration 
Pilot scale X-flow: EnvC+ES+Sr/TRU Page 168 of 256

BNF-003-98-0226

Revision 0

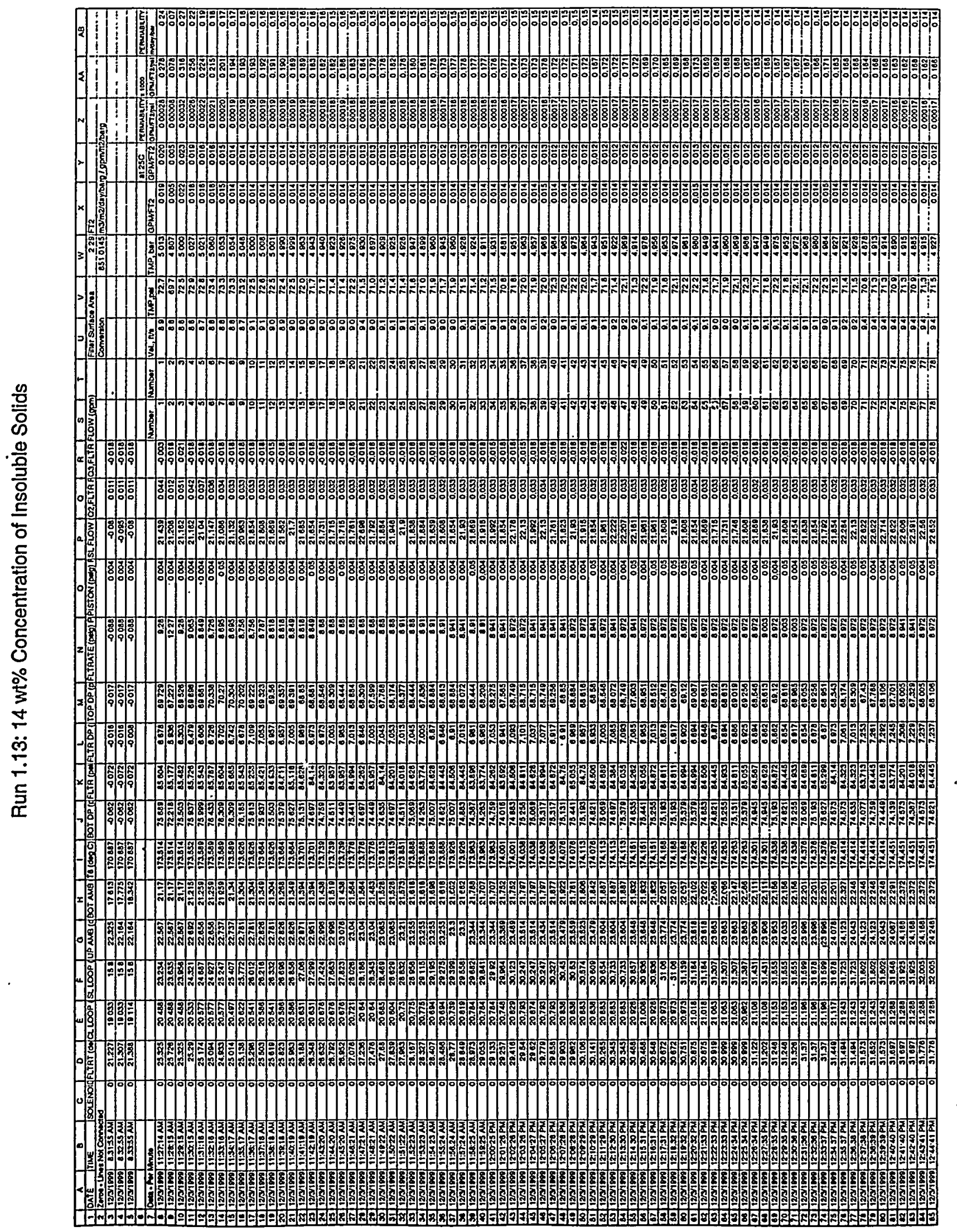


Pilot scale X-flow: EnvC+ES+Sr/TRU Page 169 of 256

BNF-003-98-0226

Revision 0

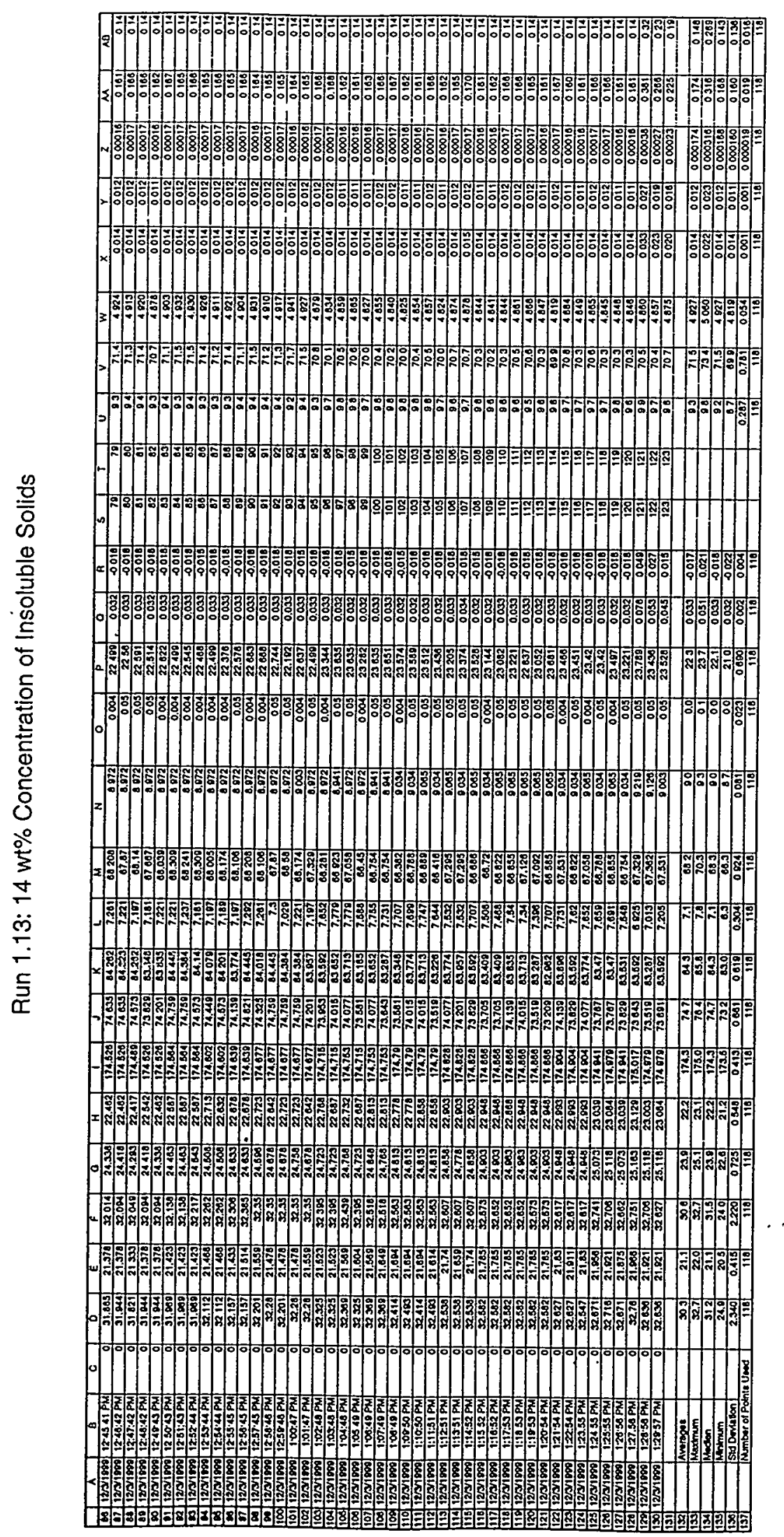



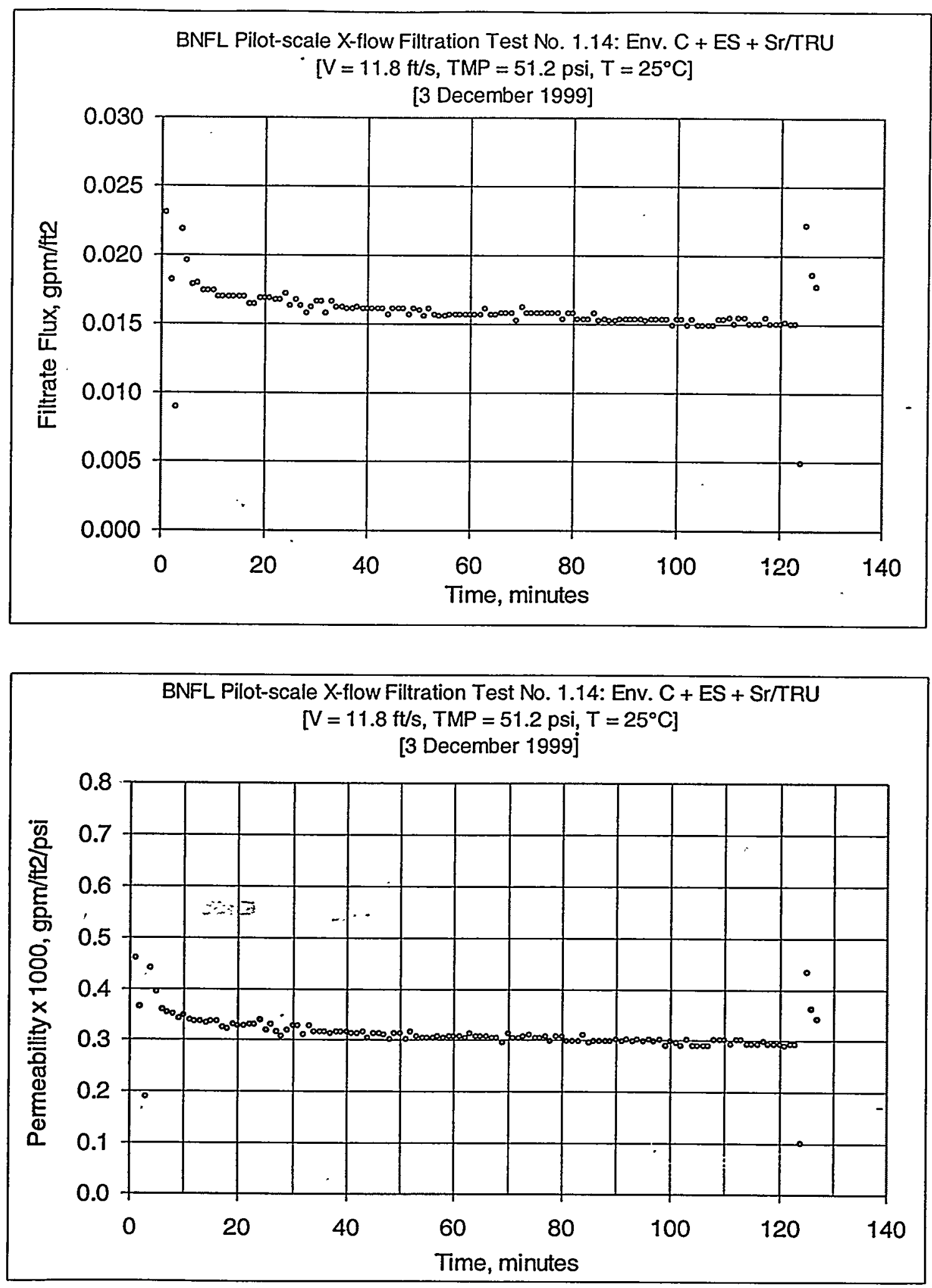

Figure C7: Test Run 1.14, 14 wt\% Insoluble Solids Concentration 
Pilot scale X-flow: EnvC+ES+Sr/TRU Page 171 of 256

BNF-003-98-0226

Revision 0

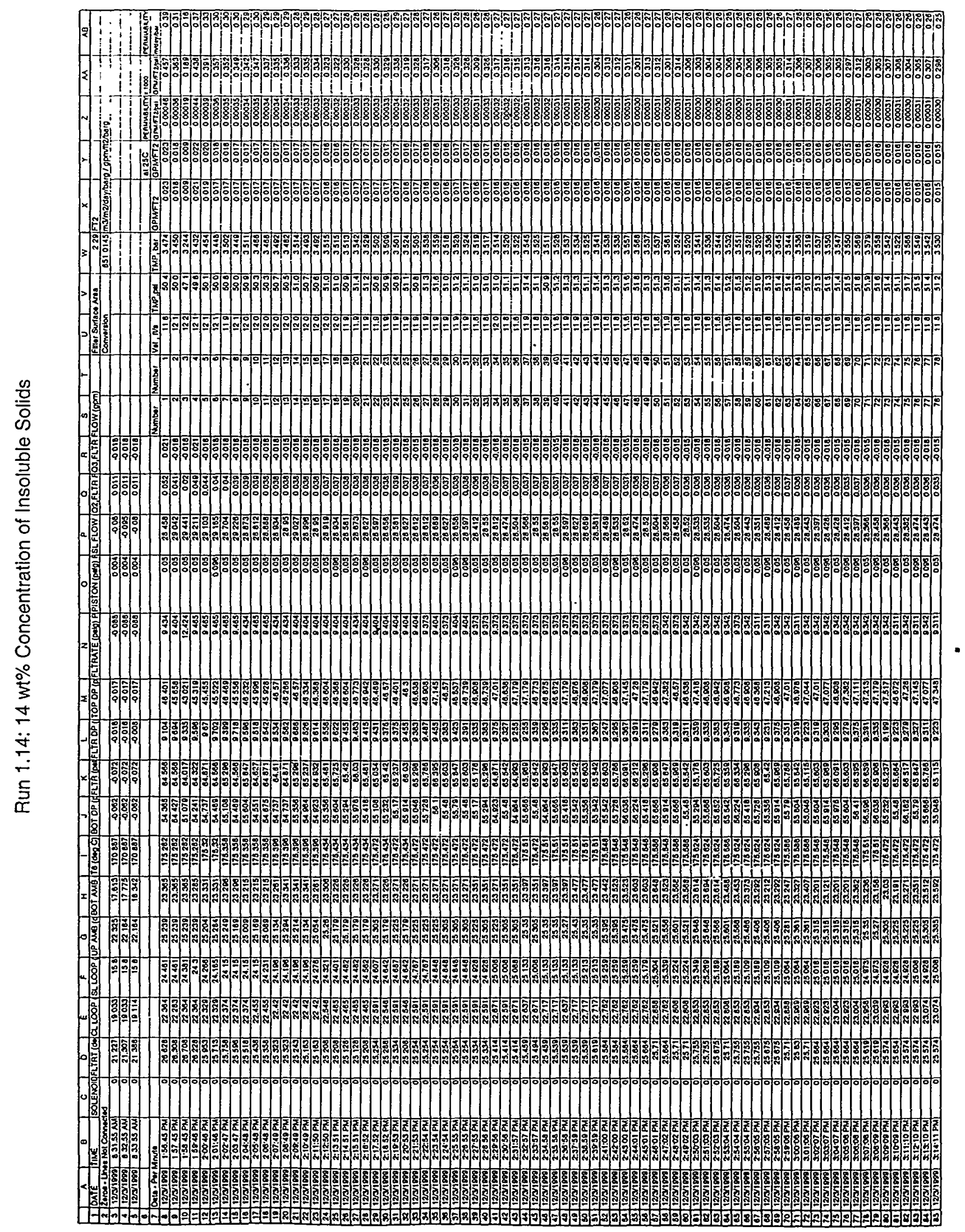




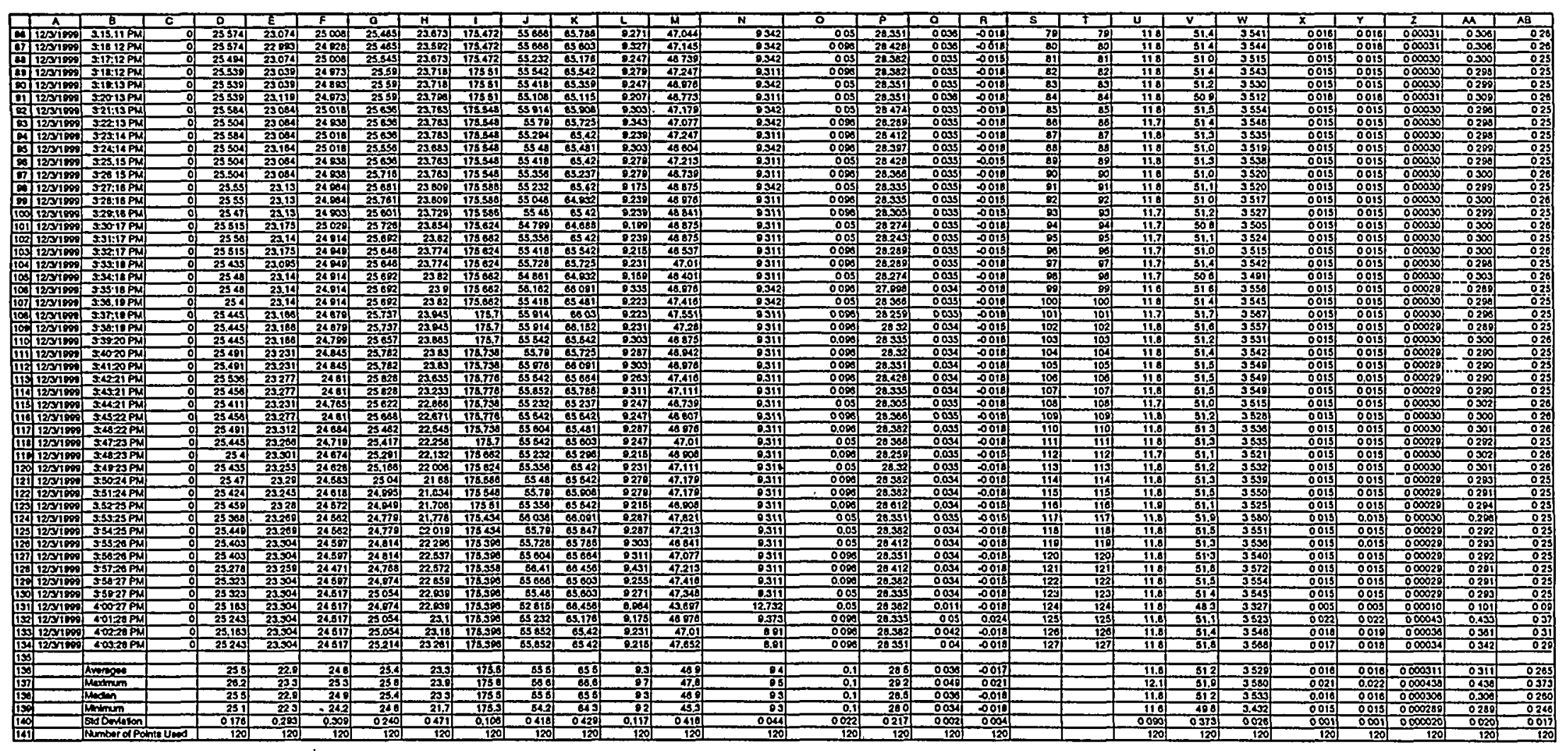



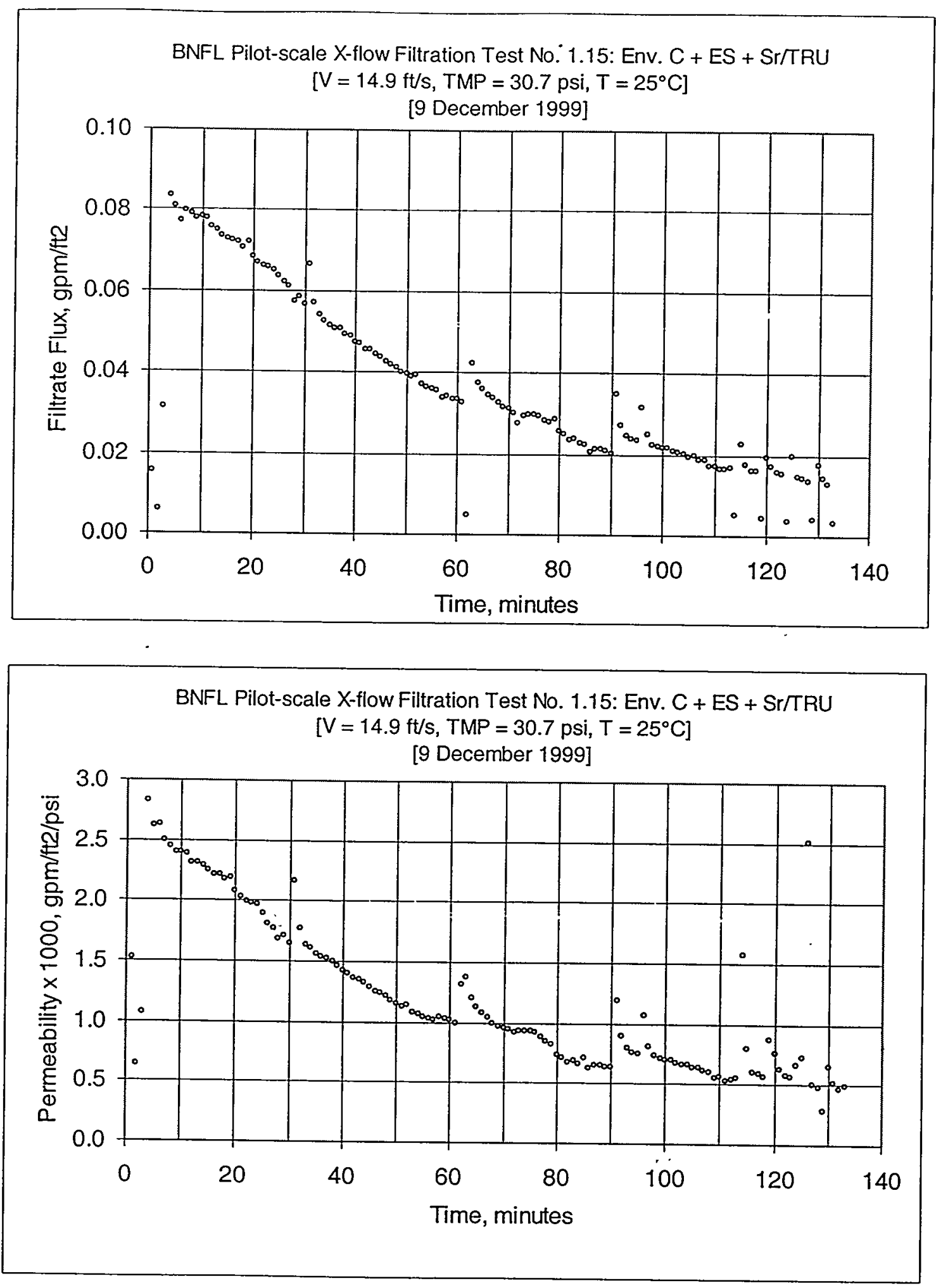

Figure C8: Test Run 1.15, 14 wt\% to 38 wt\% Insoluble Solids Concentration 
Pilot scale X-flow: EnvC+ES+Sr/TRU Page 174 of 256

BNF-003-98-0226

Revision 0

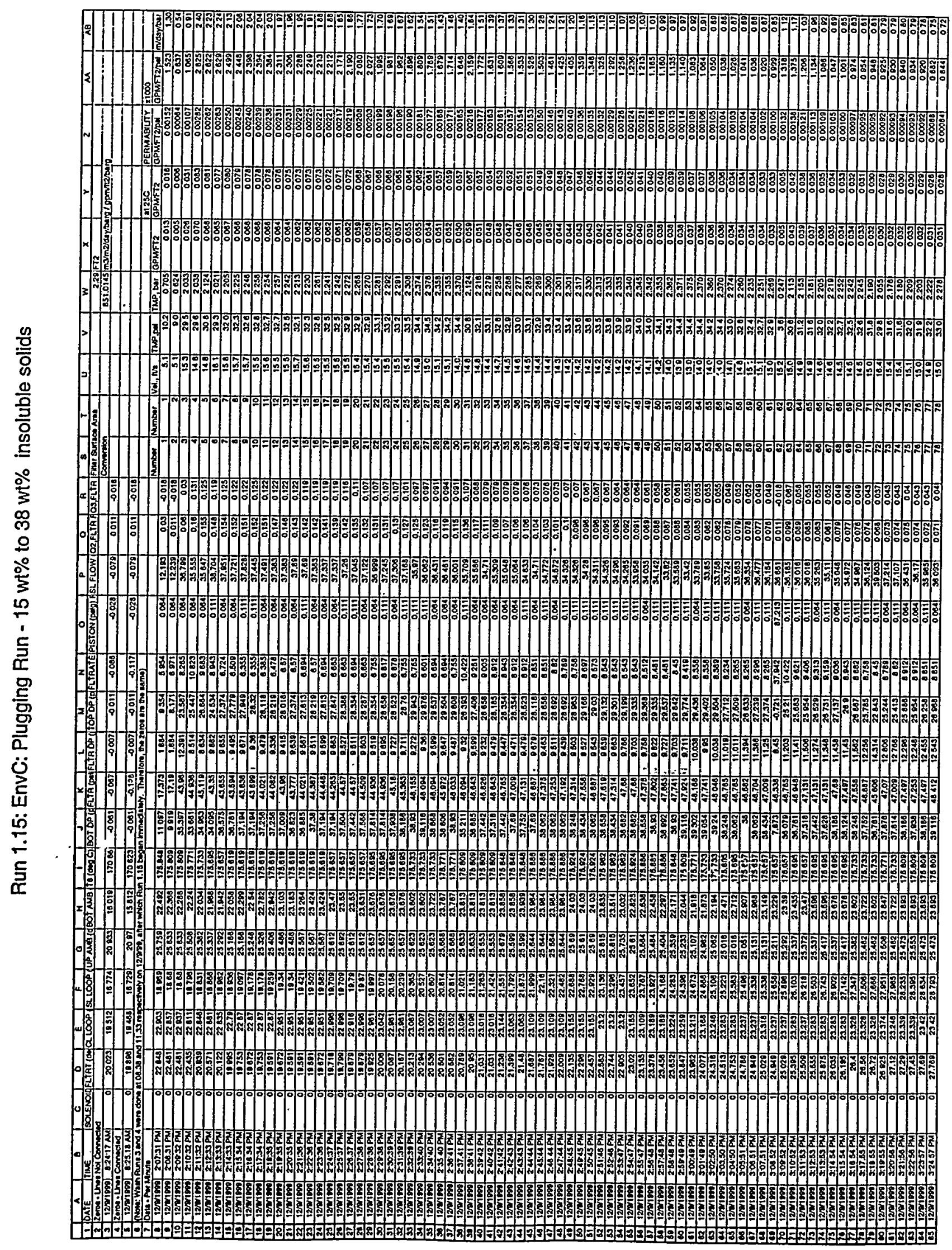


Pilot scale X-flow: EnvC+ES+Sr/TRU Page 175 of 256

BNF-003-98-0226

Revision 0

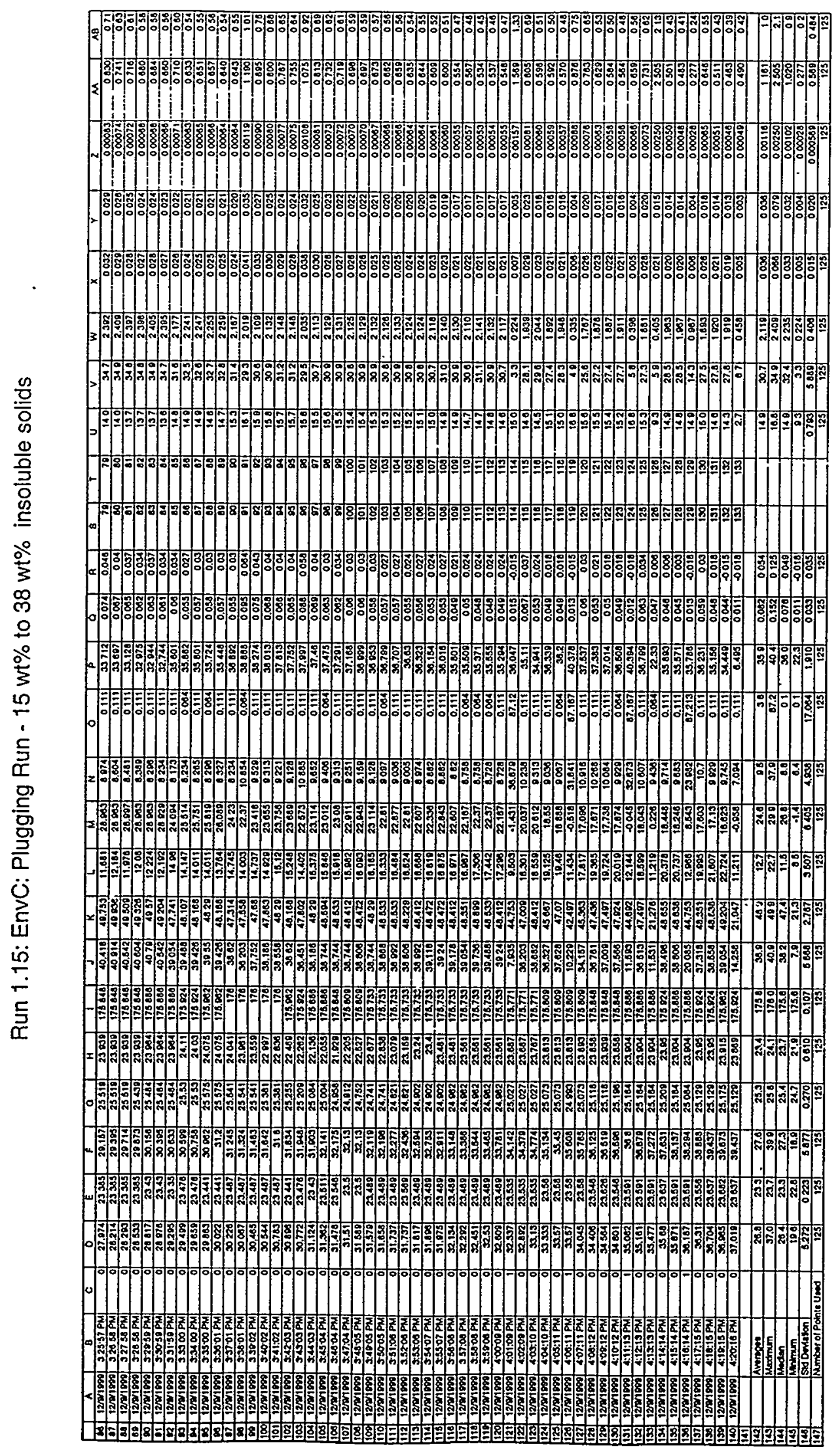




\section{APPENDIX D}

\section{EXPERIMENTAL DATA: SLURRY WASH}

\section{Appendix Contents}

1. Nomeclature sheet for data tables

2. Experimental data:

Fig. Run Done on

D1 First Wash 12/08/99

D2 Second Wash 12/08/99

D3 Third Wash 12/09/99

D4 Fourth Wash 12/09/99

General Note: For measurement uncertainties see Appendix F

Special Notes:

a. As per customer request, the wash water contained a small concentration of Sodium Hydroxide, i.e., $0.01 \mathrm{M} \mathrm{NaOH}$.

b. Backpulsing was only done in regular intervals for the first-wash run. That run started at a low filtrate flux of approximately $0.03 \mathrm{gpm} / \mathrm{ft}^{2}$, Fig. D1. Therefore, a backpulse frequency of 15 minutes was used which increase the flux to slightly above $0.04 \mathrm{gpm} / \mathrm{ft}^{2}$. By the fourth-wash run the starting flux increased to above 0.11 $\mathrm{gpm} / \mathrm{ft}^{2}$, Fig. D4.

c. The data for every test run are highlighted with two graphs: Filtrate Flux vs. Time and Permeability vs. Time. Those graphs include all the data taken during the run period.

d. The beginning and end of the data for most graphs show large deviations from the overall series of points. Those deviations were caused by backpulsing the filter that temporarily stopped the flow of filtrate.

e. All columns of data, in all the tables, are ended with several statistical values of that column; i,e., Average, Maximum, Median, Minimum, Standard.Deviation, and Number of Points used (in calculating the 5 statistical quantities). Most of the data with time were maintain constant, and therefore the statistics are meaningful for normally distributed data, however Filtrate Flux and Permeability decrease with time and therefore are not normally distributed.

f. To calculate those quantities mentioned in the preceding item, only those data points that start from the end of a backpulse to just before the ending backpulse were included. This is the reason why the quantity of Number of Points Used was given. However, because of the large number of backpulses, around fifteen, for the firstwash run, all of the internal backpulse data points were used. Those points only represent about $5 \%$ of all the points throughout the 4.3 -hour test.

g. The data for the graphs, and all the data taken for the individual test run that the graphs represent, immediately follow the specific figure. 
Nomenclature For. Data Sheets

(See Figure 1: Main Test Rig - Pilot Scale Cross Flow for the Instrument Location)

\begin{tabular}{|c|c|}
\hline Column & Heading \\
\hline$A=$ & DATE \\
\hline $8=$ & TIME \\
\hline$C=$ & SOLENOID \\
\hline$D=$ & FLTRT (deg \\
\hline$E=$ & CL LOOP (C \\
\hline$F=$ & SLLOOP (O \\
\hline$G=$ & UP AMB (dd \\
\hline$H=$ & BOT AMB \\
\hline $1=$ & $T 6(\operatorname{deg} C)$ \\
\hline$J=$ & BOT DP ( $\rho$ S \\
\hline$K=$ & FLTR (psig) \\
\hline$L=$ & FLTRDP (p \\
\hline$M=$ & TOP DP (pS \\
\hline$N=$ & FLTRATE \\
\hline $0=$ & PISTON (pS \\
\hline$P=$ & SLFLOW ( \\
\hline$Q=$ & Q2,FLTR FL \\
\hline $\mathbf{R}=$ & Q3,FLTR F \\
\hline
\end{tabular}

Full Heading
DATE
TIME
SOLENOID
FLTRT (deg C) T2
CL LOOP (deg C) T3
SL LOOP (deg C) T1
UP AMB (deg C) T4
BOT AMB (deg C) T5
T6 (deg C) SPARE
BOT OP (psid) dP2
FLTR (psig) P1
FLTR DP (psid) dP1
TOP OP (psig) dP3
FLTRATE (psig) P2
PISTON (psig) P3
SLFLOW (gpm) Q1
FLTR FLOW (gpm) Q2
FLTR FLOW (gpm) Q3

"Explanation

Day the lest was done

Time data entry was made

$1=$ yes, $0=$ no for the pressure to the backpuise piston

Filtrate Temperature in Filter at exit of the Filter Housing

Temperature of Liquid in the Cleaning Loop

Temperature of Liquid in the Slurry Loop at the Resenorr Tank

Ambient Temperature at the top of the Test Rig - 3ro level

Ambient Temperature at the bottom of the Test Rig - 1st level

Spare Thermocouple - Currently Not Being Used

Differential Pressure between the Filter Slurry Entrance and the bottom Fitrate Ext

Gauge Pressure at the Fitter Slurry Entrance

Difterential Pressure between the Filter Slurry Entrance and Exit

Differential Pressure between the Filter Slumy Exit and the Top Fitrate Ext

Gauge Pressure at the Filter Filtrate Exit

Air Gauge Pressure Applied to Backpulse Piston

Flow Rate of the Slurry Flow

Flow Rate of the Fittrate Flow from 0 to $1.2 \mathrm{gpm}$

Flow Rate of the Fittrate Flow from 0 to $5 \mathrm{gpm}$

The followng columns are calculated results based on the appropriate columns

\begin{tabular}{|c|c|c|c|c|}
\hline $\mathbf{S}=$ & Number & $=$ & Number & $\therefore$ Data numbers which is (usually) equivalent to 1 minute since this was the acquisition frequency \\
\hline$T=$ & Number & $=$ & Number & Data numbers which are equal to or a subset from Column $S$ to faciltate graphing of some data sets \\
\hline $\mathbf{U}=$ & Vel, tt/s & $=$ & Vel, fts & Axial slurry velocity $=[$ Column $P] / 7.48 \mathrm{gal} / \mathrm{f} 12 / 60 \mathrm{sec} / \mathrm{min} /$ flow area $\left(=0.005369 \mathrm{ft} 2^{\circ}\right)$ \\
\hline$V=$ & TMP,PSI & $=$ & TMP,PSI & Transmembrane Pressure $=([$ Column $\mathrm{J}]+[$ Column $M \mid) / 2$ \\
\hline $\mathbf{W}=$ & TMP. bar & $=$ & TMP. bar & [Column U]/14 504 bar/psi \\
\hline$x=$ & GPMFT2 & $=$ & GPMFT2 & 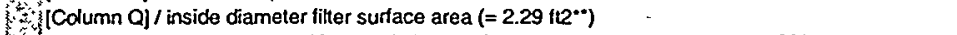 \\
\hline$Y=$ & GPMFT2 & $=$ & GPMFT2 at $25^{\circ} \mathrm{C}$ & Test Spec. correction factor: [Column W] $\times \exp (2500 \times((1 /(273+\mid$ Column $T]))-(1 / 298)))$ \\
\hline$Z=$ & PERUИB:UTY & $=$ & 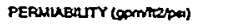 & 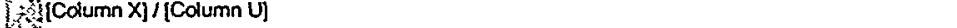 \\
\hline$A A=$ & $\times 1000$ & $=$ & PERMIABIUTY $\times 1000$ & Fi: [Column Z] $\times 1000$ \\
\hline$A B=$ & PERALEUTYY & $=$ & PERSALE:UTY (mbleytan & [E[ (Column Y] x conversion factor ( = $851.0145 \mathrm{~m} /$ day/bar $/ \mathrm{gpm} / \mathrm{ti} 2 \mathrm{bar}$ ) \\
\hline
\end{tabular}

-Axial slumy flow area is based on 7 porous tubes with an inside diameter of $3 / 8 \mathrm{inch}: 7 \times \mathrm{pi} / 4 \cdot(0.375 \mathrm{inch} / 12$ inches/ft) $2=0.005369 \mathrm{ft} 2$

- Inside diameter filter surface area for 7 tubes with an inside diameter of $3 / 8$ inch, 40 -inches long $7 \times$ pi $\times(0.375$ inch $) \times 40$ inches $/ 144$ in/2/1^2 $=2.29$ ft2 

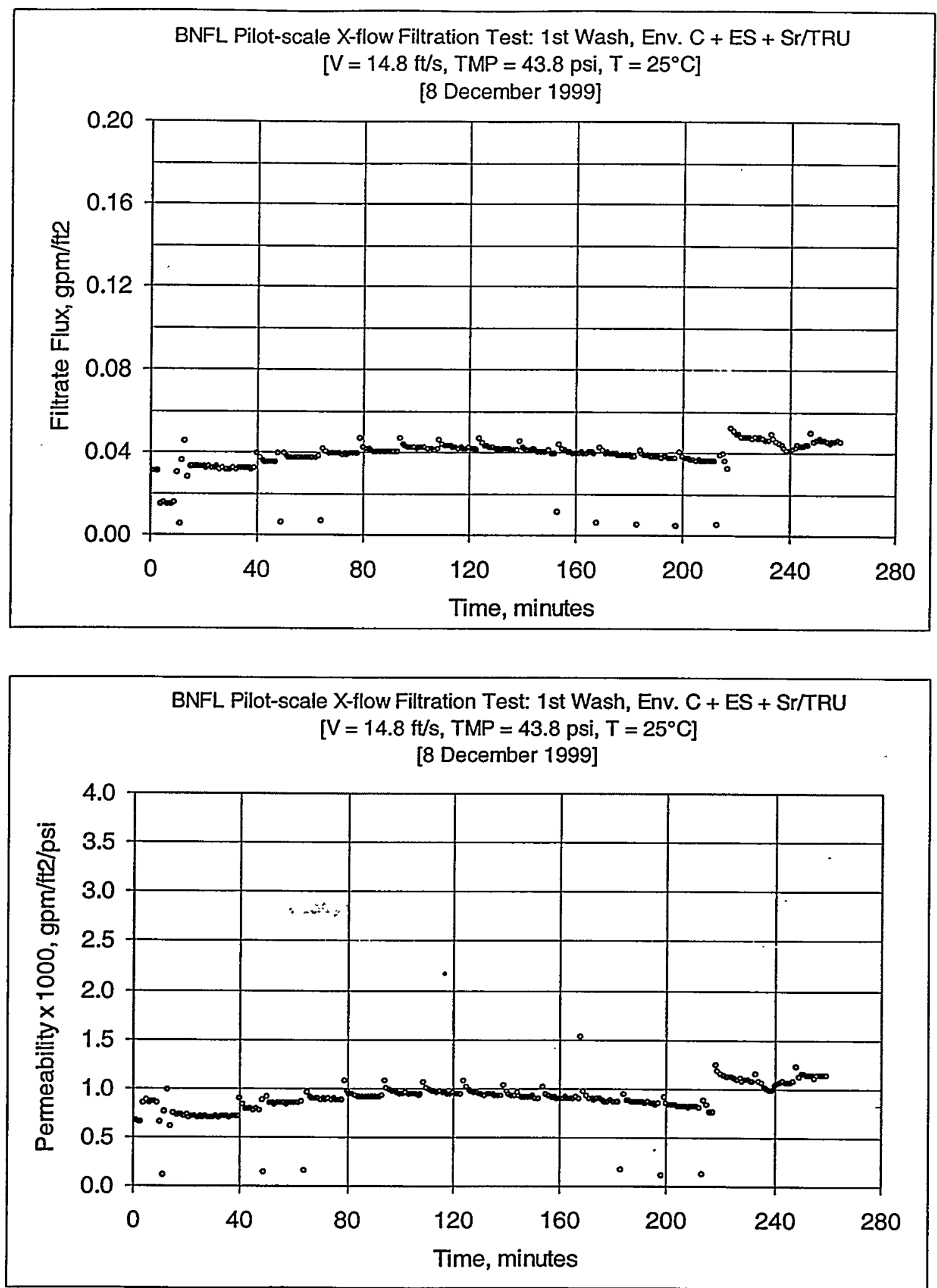

Figure D1: First Wash: 75 liters of Deionized/Filtered Water with $0.01 \mathrm{M} \mathrm{NaOH}$ 


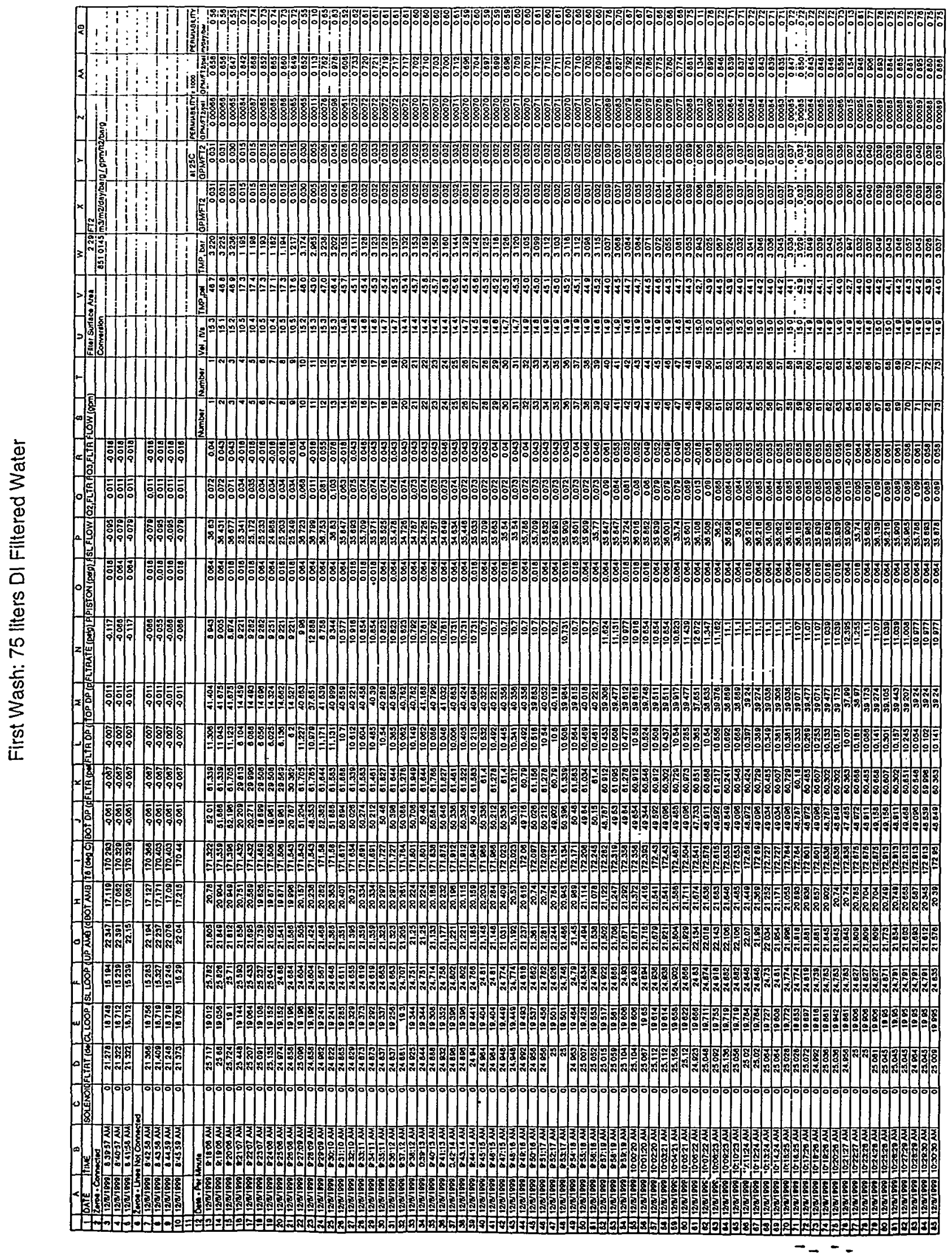


Pilot scale X-flow: EnvC+ES+St/TRU Page 180 of 256

BNF-003-98-0226

Revision 0

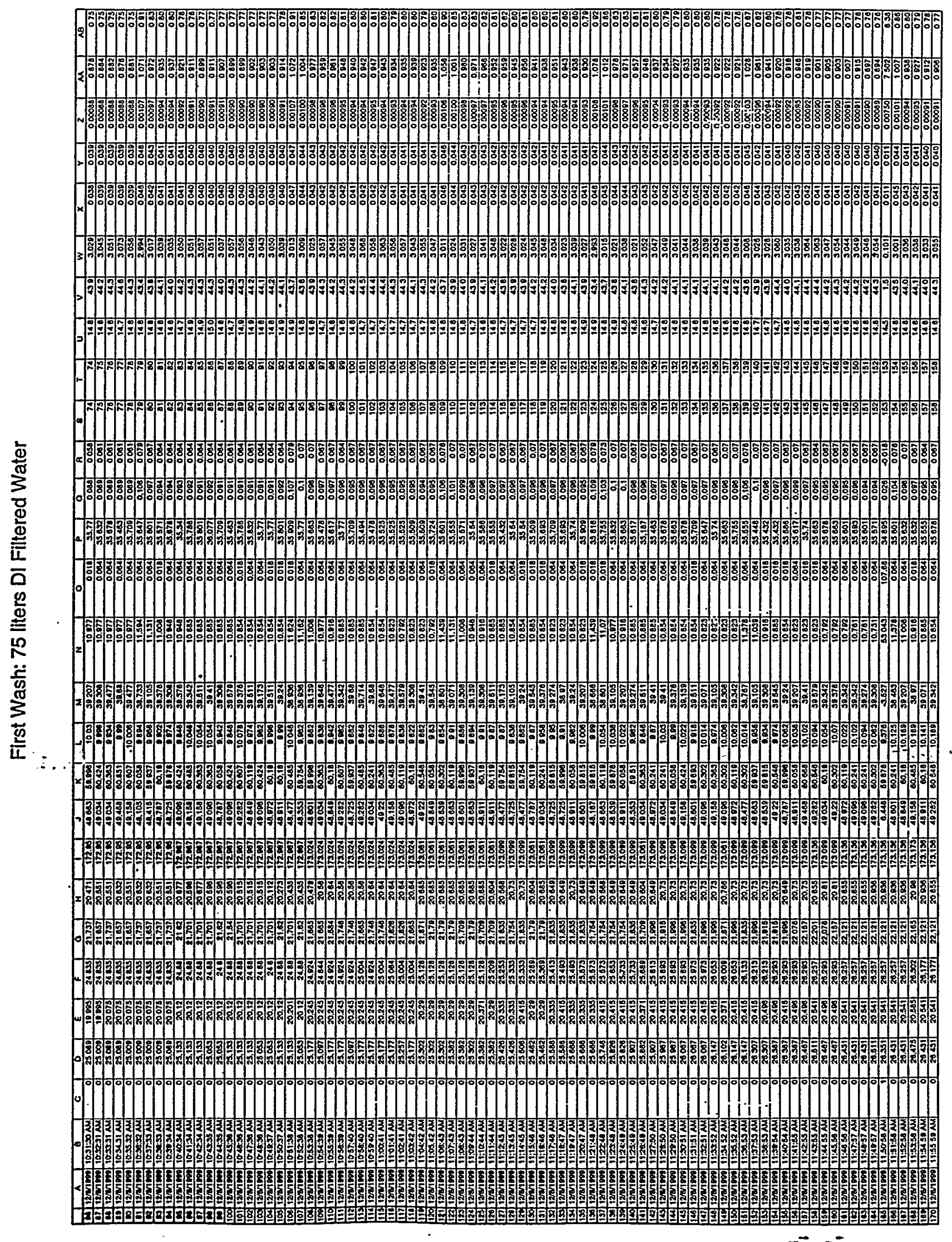


Pilot scale X-flow: EnvC+ES+Sr/TRU Page 181 of 256

BNF-003-98-0226

Revision 0

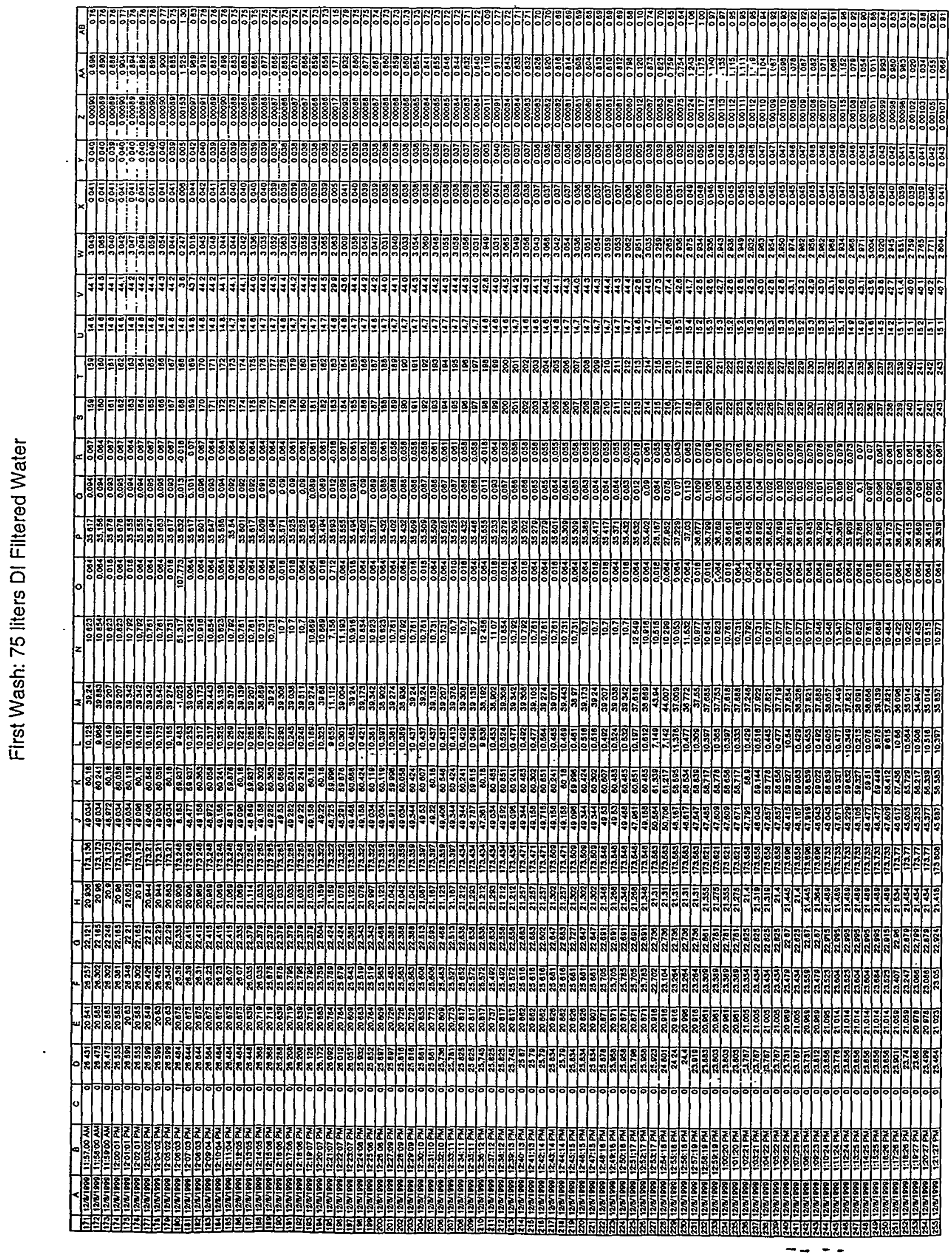




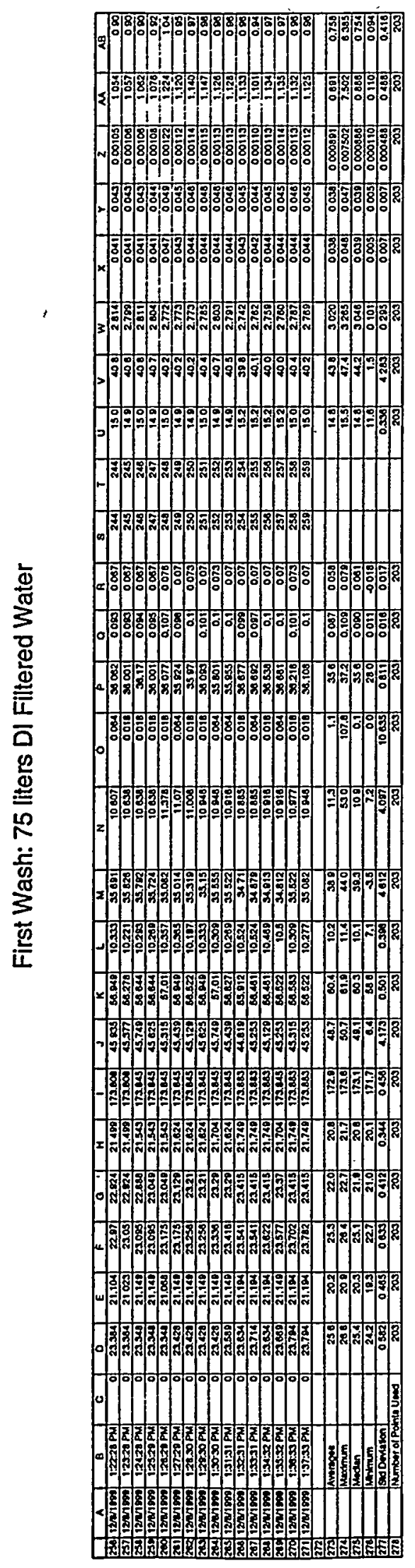



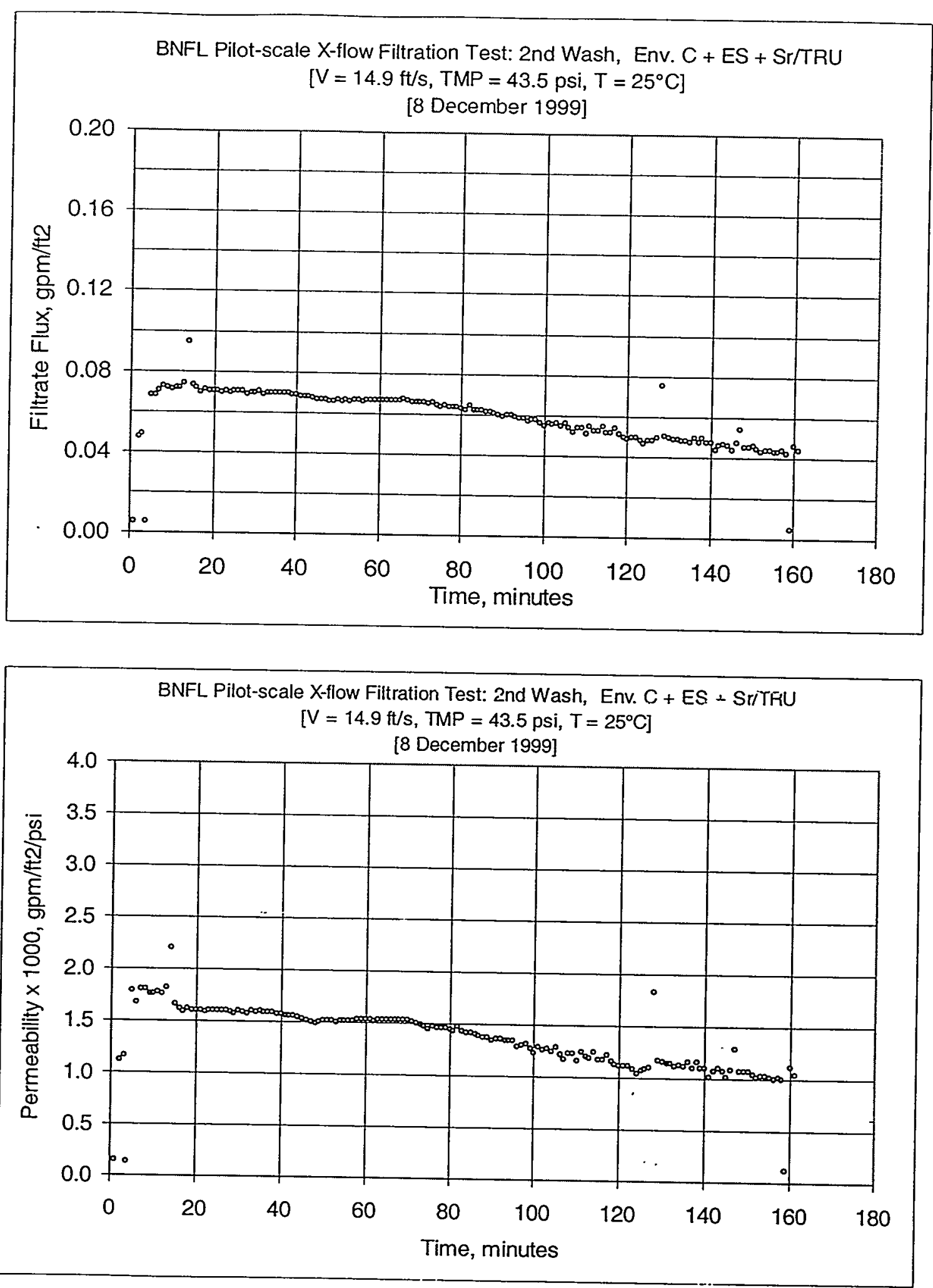

Figure D2: Second Wash: 75 liters of Deionized/Filtered Water with $0.01 \mathrm{M} \mathrm{NaOH}$ 


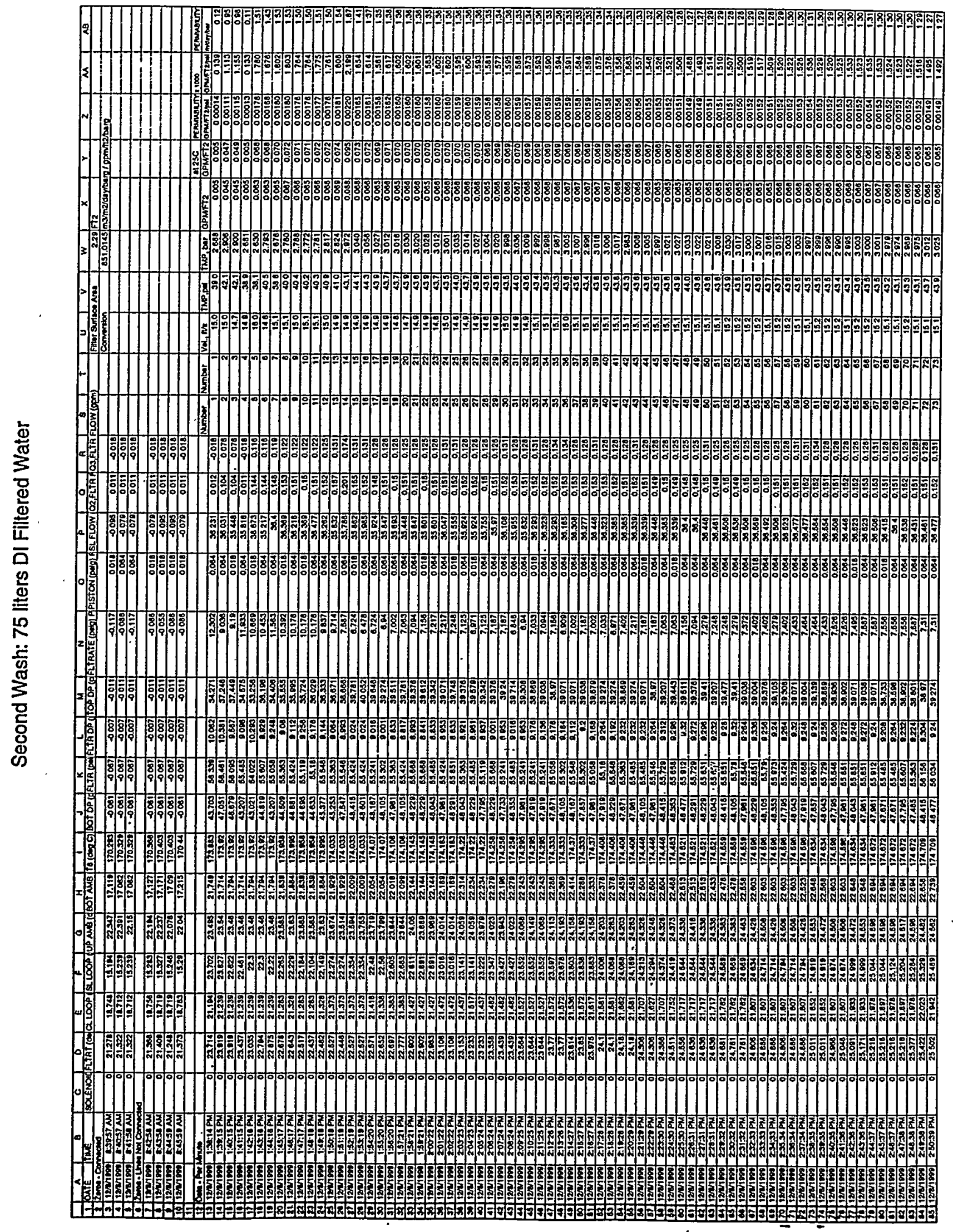


Pilot scale X-flow: EnvC+ES+Sr/TRU Page 185 of 256

BNF-003-98-0226

Revision 0

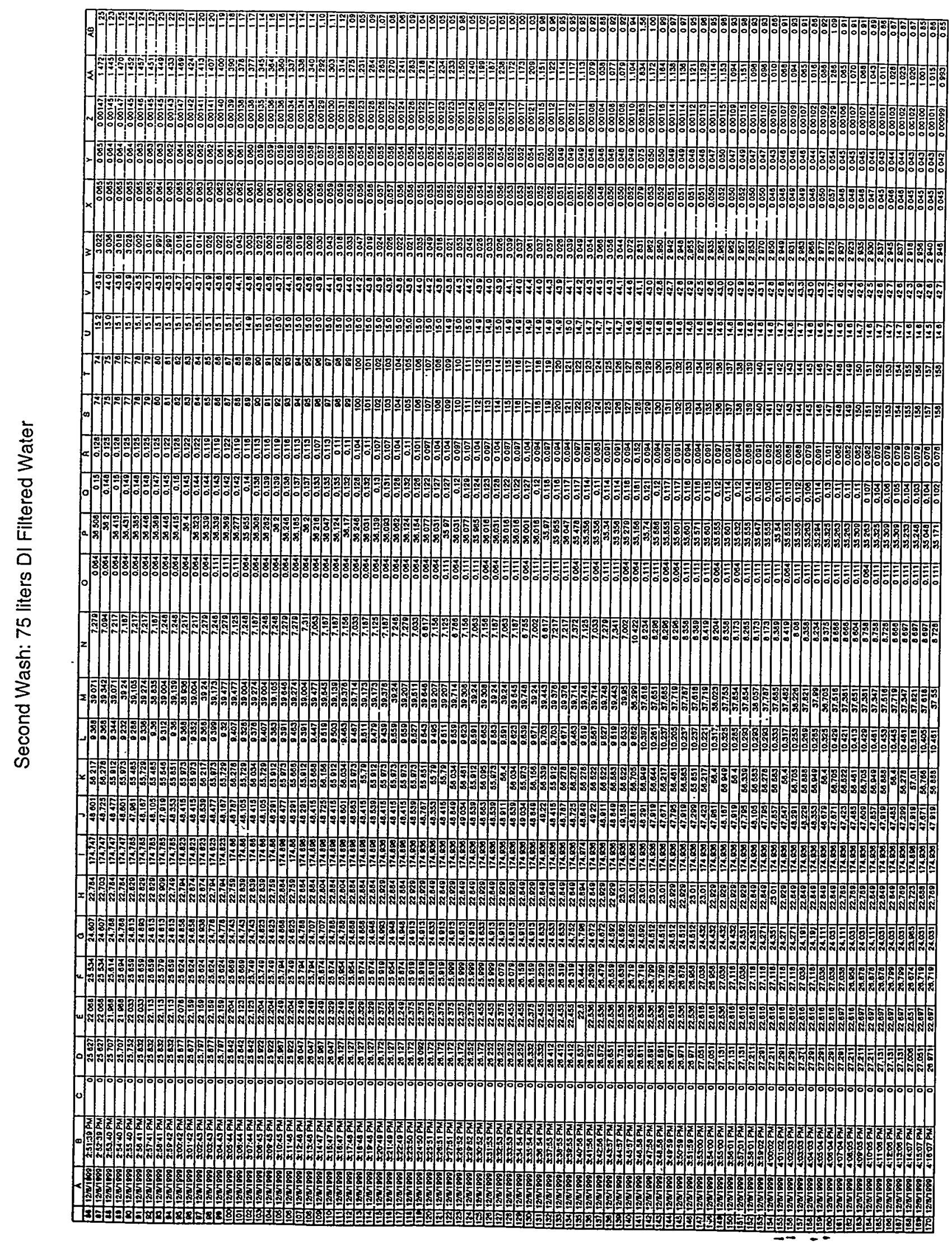


Pilot scale X-flow: EnvC+ES+Sr/TRU Page 186 of 256

BNF-003-98-0226

Revision 0

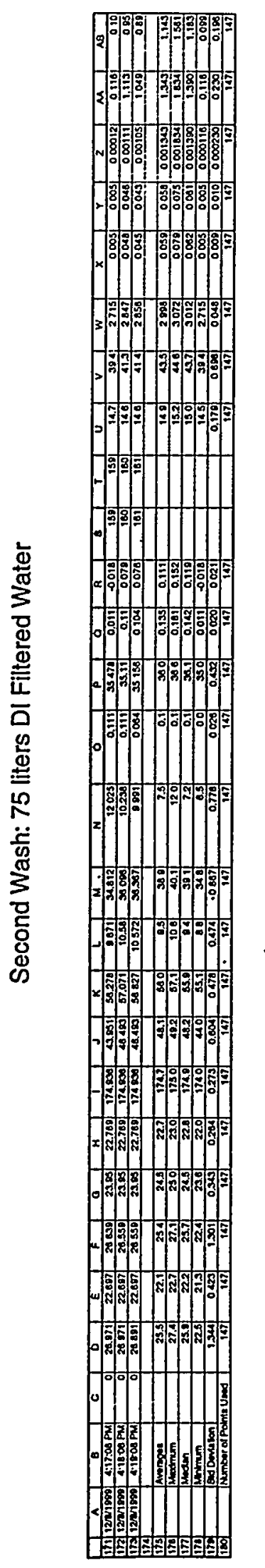



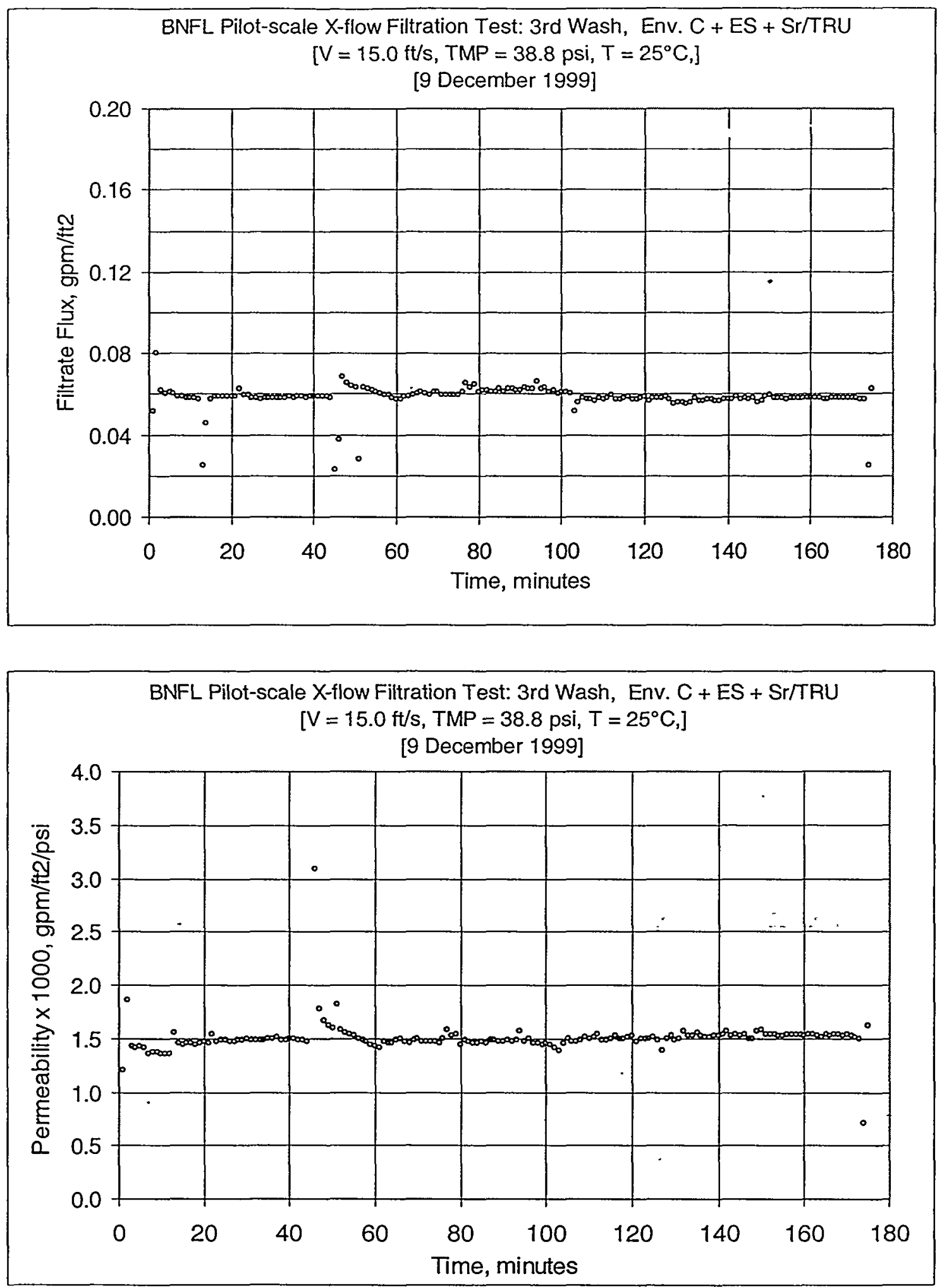

Figure D3: Third Wash: 75 liters of Deionized/Filtered Water with $0.01 \mathrm{M} \mathrm{NaOH}$ 
Pilot scale X-flow: EnvC+ES+Sr/TRU Page 188 of 256

BNF-003-98-0226

Revision 0

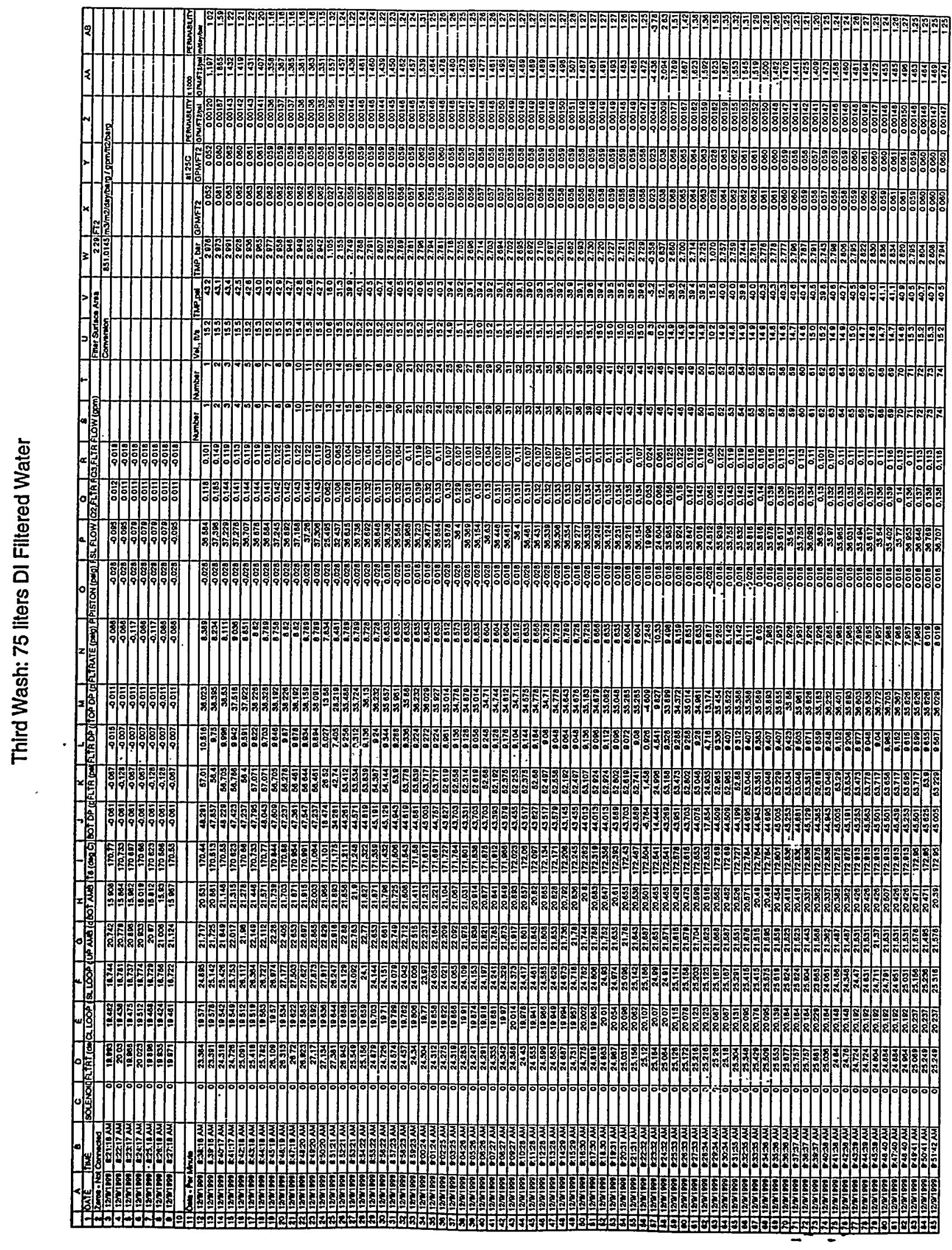


Pilot scale X-flow: EnvC+ES+Sr/TRU Page 189 of 256

BNF-003-98-0226

Revision 0

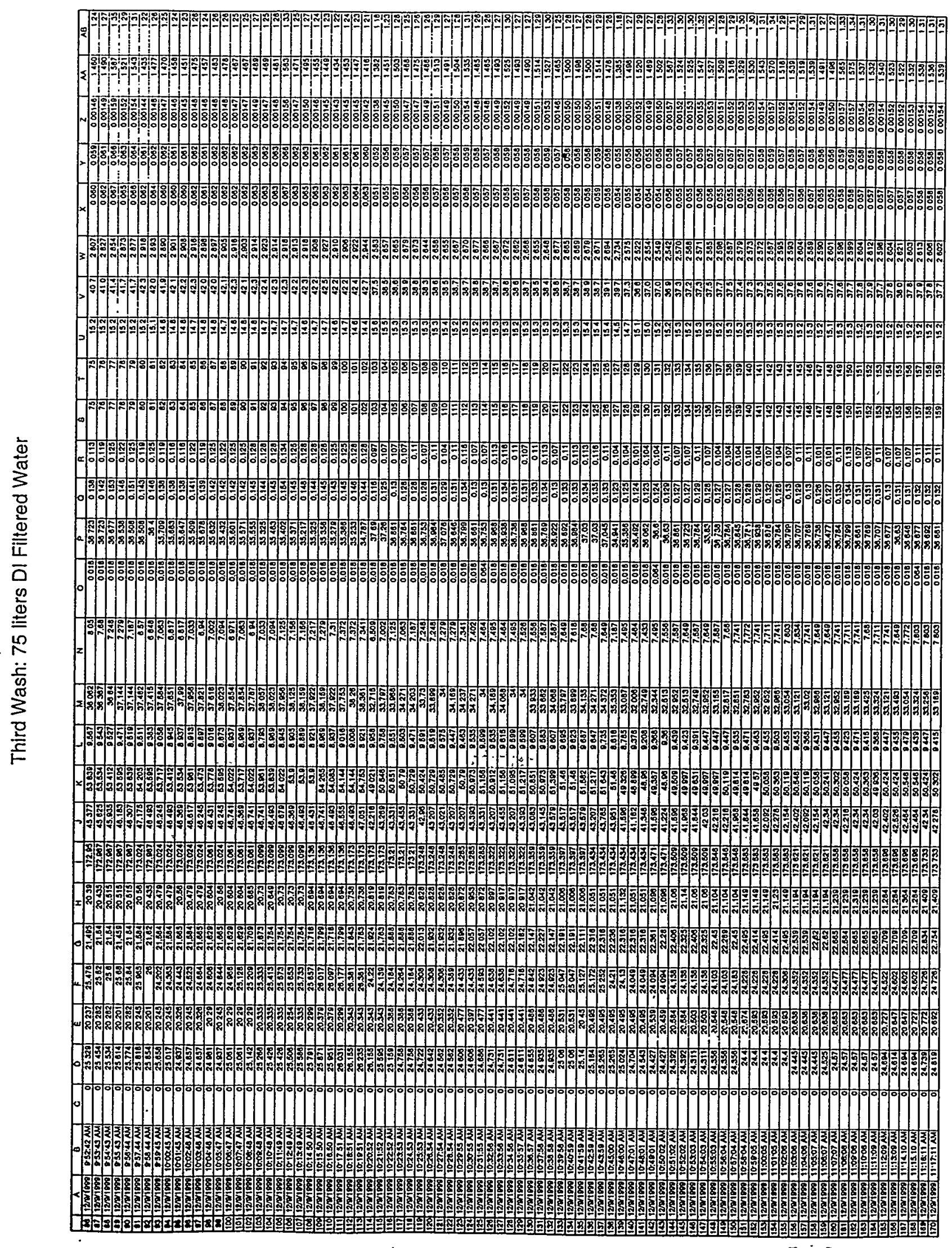




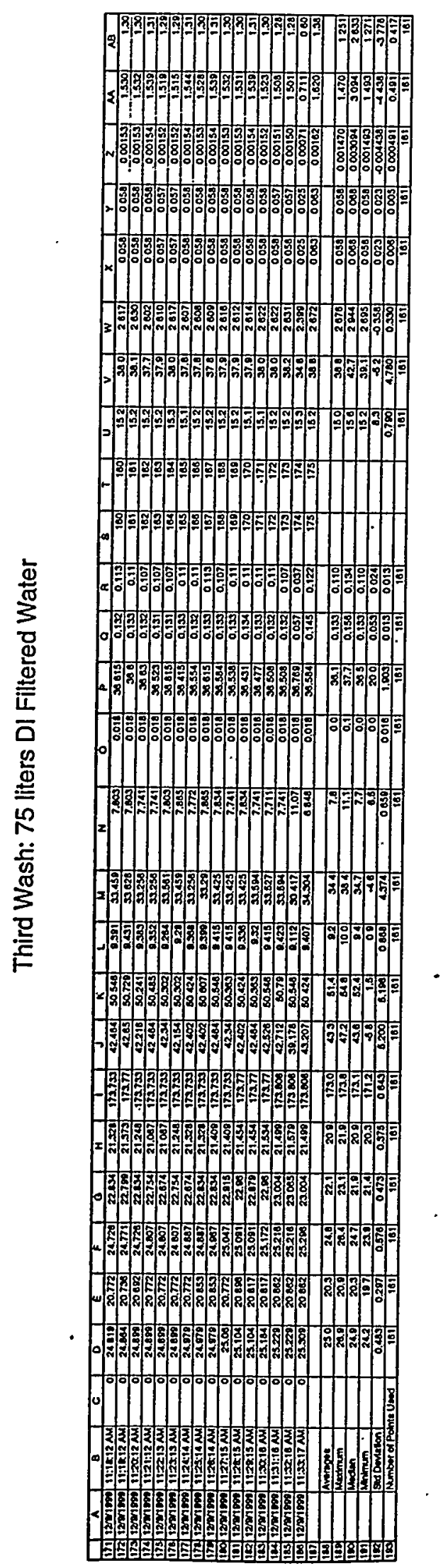



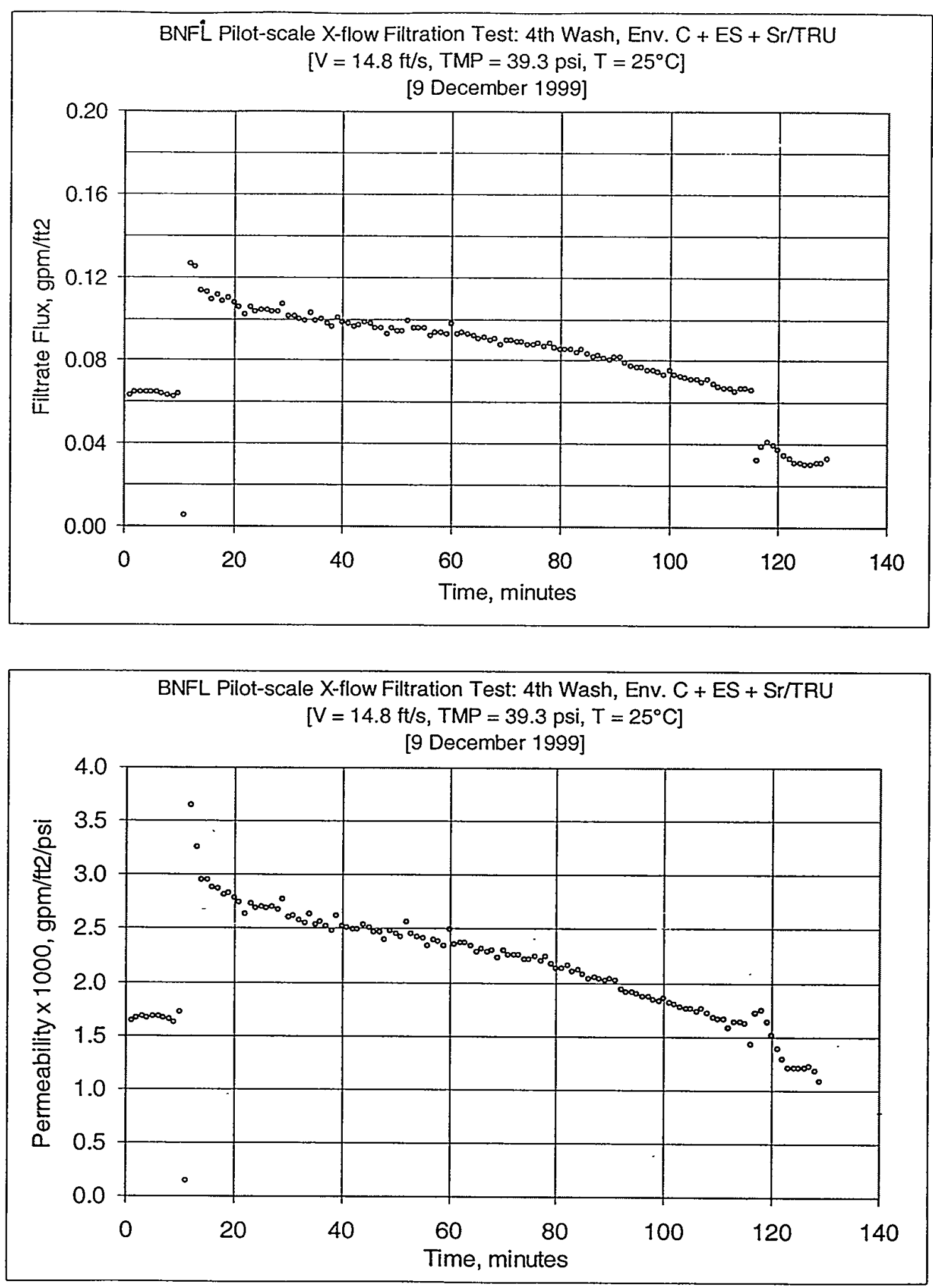

Figure D4: Fourth Wash: 75 liters of Deionized/Filtered Water with $0.01 \mathrm{M} \mathrm{NaOH}$ 
Pilot scale X-flow: EnvC+ES+St/TRU Page 192 of 256

BNF-003-98-0226

Revision 0

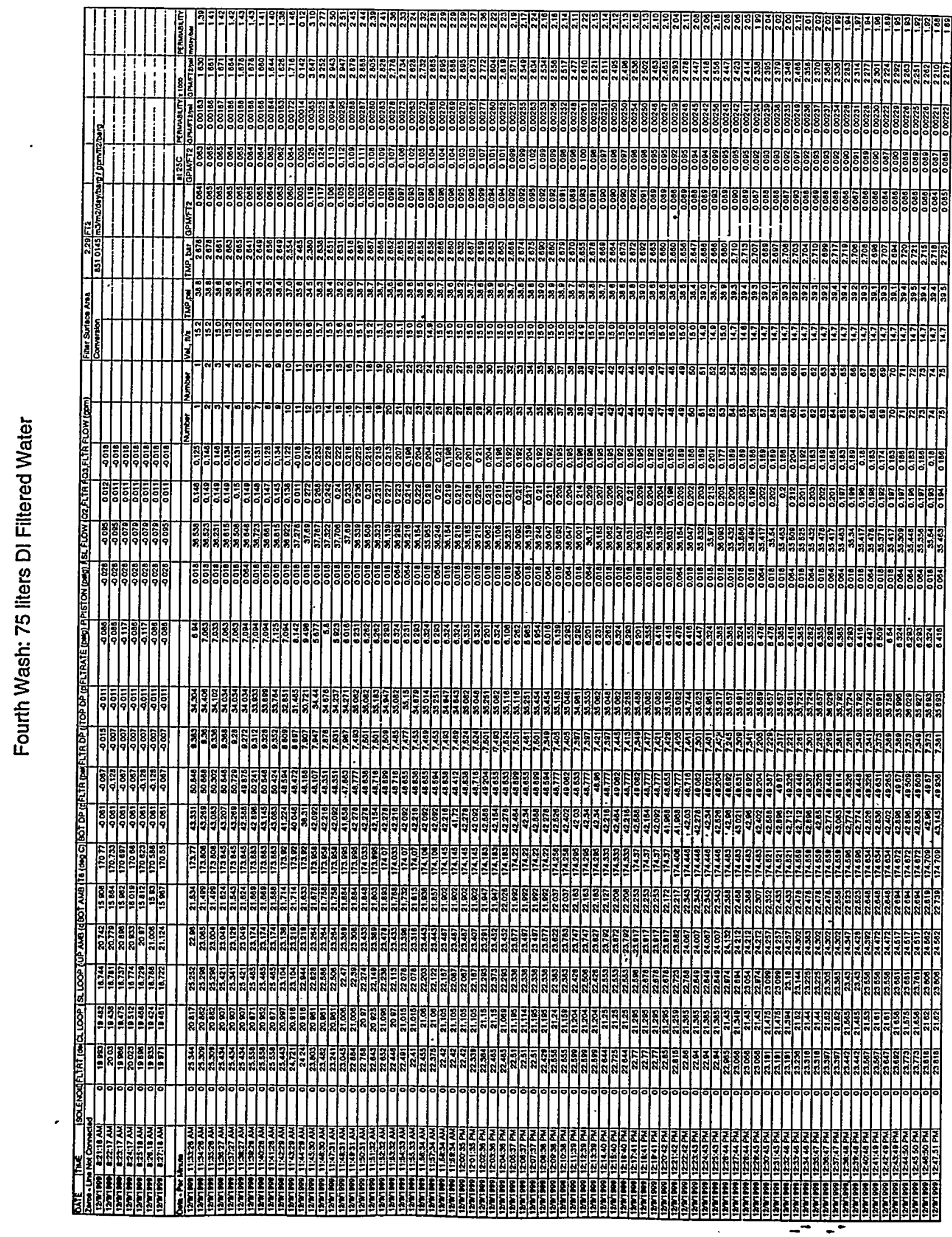


Pilot scale X-flow: EnvC+ES+Sr/TRU Page 193 of 256

BNF-003-98-0226

Revision 0

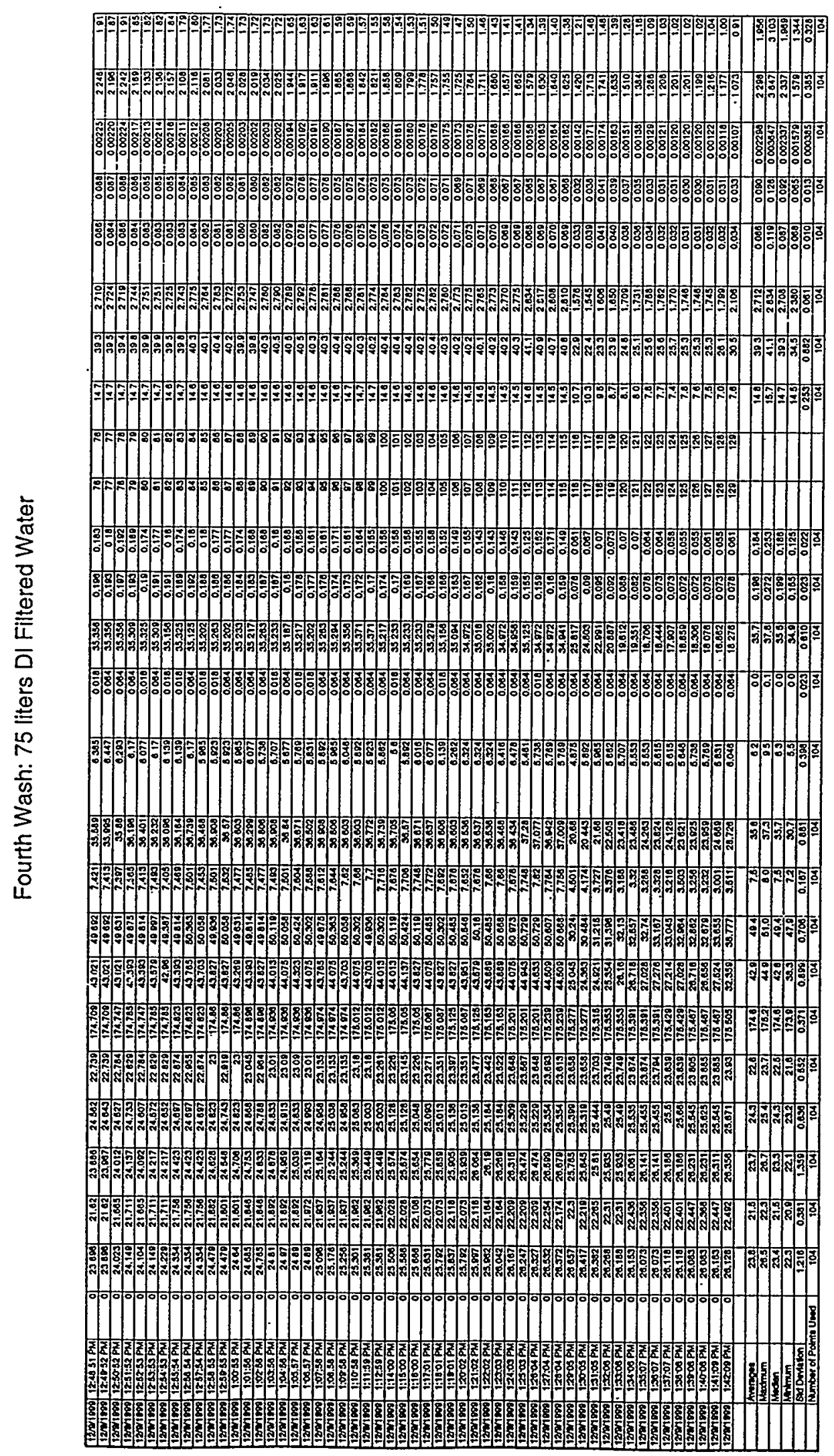




\section{APPENDIX E}

\section{ANALYTICAL DATA}

Appendix Contents

1. Thirteen pages of Table E1 contain all of the analytical data.

2. Slurry Rheology: Figures E1 and E2

3. Graphs of selected chemical element concentrations throughout the test by molarity

Figures E3-E17 are $\mathrm{Al}, \mathrm{Ca}, \mathrm{Cl}, \mathrm{Cr}, \mathrm{F}, \mathrm{Fe}, \mathrm{La}, \mathrm{Mn}, \mathrm{Mo}, \mathrm{Ni}, \mathrm{P}, \mathrm{K}, \mathrm{Si}, \mathrm{Na}$, and $\mathrm{Sr}$

4. Graphs of selected chemical compounds and other concentrations throughout the test by molarity.

Figures E18-E23 are: Formate, Oxalate, Phosphate, Sulfate, Nitrate/Nitrite, and Total Inorganic/Organic concentrations.

5. Graphs and tabular data on the particle distributions throughout the test

Figures E24A, E24B, to E30A, E30B are for test runs: Pre-test, 1.01, 1.07, $1.08 \mathrm{mid}$ ( $9 \mathrm{wt} \%$ insoluble solids), 1.08end ( $22 \mathrm{wt} \%$ insoluble solids), 1.10, 1.15 .

Special Notes:

a. There are no measurement uncertainties listed because the measurement uncertainties for analytical data are beyond the scope and control of this task. There is reason to believe that all analytical data can be at least $15 \%$ accurate but no quantitative data are given to this effect. Density and filtrate viscosity are the only slurry property data that were obtained at the test rig location and the uncertainty of those data can be stated as:

Density: $\leq 0.5 \%$ of reading by calibration Viscosity: 0.34 wt\% of reading by manufacturer's statement.

b. Figures for the siurry theology, Figs. E1 and E2, do not include the slurry used for test runs 1.01 to 1.07 becaúse at the low insoluble solids concentration of 2 wt $\%$ the slurry exhibited Newtonian characteristics and therefore is defined by its viscosity value given in Table E1.

c. For the graphs shown as the figures mentioned in items 4 and 5 above, i.e., selected chemical and compounds, a page of explanation that leads those figures should be read to better understand the data. Those graphs show a combination of slurry, filtrate, and target concentrations. Understanding the placement of information on the graphs will make them more useful.

d. Each particle analysis was done by a Volume and a Number distribution, thus there are two figures for each, e.g., 24A and 24B.) 


\begin{tabular}{|c|c|c|c|c|c|c|}
\hline & $A$ & $B$ & $\mathrm{C}$ & $\mathrm{D}$ & $E$ & $F$ \\
\hline 1 & \multicolumn{2}{|c|}{ 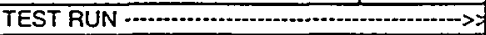 } & Most Recent Entry Date: 01-Mar-2000 & Pre-Test Sample & 1.00 & 1.00 \\
\hline 2 & \multicolumn{2}{|c|}{ BNFL Sample ID } & Prefix = BNF-SXF2115-C+ES+Sr/TRU & Pre-Test Sample & Prefix 019 & Prefix_01b \\
\hline 3 & \multicolumn{2}{|c|}{ ADS Sample ID } & & BNF-CSOLIDS-Pre-Test & $3-133990$ & $3-133991$ \\
\hline 4 & \multicolumn{2}{|c|}{ Type Sample ............... } & & insoluble solids in $\mathrm{H} 2 \mathrm{O}$ & slurry loop & slurry loop \\
\hline 5 & Sample Size & $\mathrm{mL}$ & & 5 & 15 & 15 \\
\hline 6 & Measurement(s) Made .........->> & \multicolumn{2}{|c|}{ (SEE NOMECLATURE TO EXPLAIN TEST SYMBOL) } & MICROTRAC & ICP-ES/IC-ANIONS & AANIC-TOCISE \\
\hline 7 & Item Measured & Units & Analyst Name & 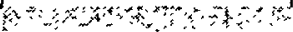 & & $=0$ \\
\hline 8 & Density & $\mathrm{g} / \mathrm{mL}$ & Thermal Fluids Lab & $\pi / a$ & $\mathrm{na}$ & na \\
\hline 9 & Al & $\mathrm{ug} / \mathrm{mL}$ & Frank Pennebaker & $n / a$ & $<0.3$ & $n / a$ \\
\hline 10 & $\mathrm{~B}$ & $\mathrm{ug} / \mathrm{mL}$ & Frank Pennebaker & $n / 2$ & $<0.13$ & $n / a$ \\
\hline 11 & $B a$ & $\mathrm{ug} / \mathrm{mL}$ & Frank Pennebaker & $n / a$ & $<0.02$ & Na \\
\hline 12 & $\mathrm{Ca}$ & $\mathrm{ug} / \mathrm{mL}$ & Frank Pennebaker & na & $<0.2$ & $n / a$ \\
\hline 13 & Cd & $\mathrm{ug} / \mathrm{mL}$ & Frank Pennebaker & na & $<0.02$ & $\mathrm{n} / \mathrm{a}$ \\
\hline 14 & $\mathrm{Cl}$ & $\mathrm{ug} / \mathrm{mL}$ & Robert Ray/Joyce Cartledge & $\overline{n a}$ & 10 & $\mathrm{n} / \mathrm{a}$ \\
\hline 15 & CI Sample & $\mathrm{ug} / \mathrm{mL}$ & Robert Ray/Sarah Brown & $n / 2$ & $n / a$ & 2.8 \\
\hline 16 & Co & $\mathrm{ug} / \mathrm{mL}$ & Frank Pennebaker & $n / a$ & $<0.05$ & $\mathrm{n} / \mathrm{a}$ \\
\hline 17 & $\mathrm{Cr}$ & $\mathrm{ug} / \mathrm{mL}$ & Frank Pennebaker & $n / a$ & $<0.05$ & $\pi / a$ \\
\hline 18 & $\mathrm{Cu}$ & $\mathrm{ug} / \mathrm{mL}$ & Frank Pennebaker & $n / a$ & $<0.02$ & $n / a$ \\
\hline 19 & F (Fluoride) [not accurate] & $\mathrm{ug} / \mathrm{mL}$ & Robert Ray/Joyce Cartledge & $\mathrm{n} / \mathrm{a}$ & $<2$ & Na \\
\hline 20 & F Sample (more accurate result) & $\mathrm{ug} / \mathrm{mL}$ & Robert Ray/Sarah Brown & $n / a$ & $\mathrm{n} / \mathrm{a}$ & $<1$ \\
\hline 21 & $\mathrm{Fe}_{\mathrm{e}}$ & $\mathrm{ug} / \mathrm{mL}$ & Frank Pennebaker & $n / a$ & $<0.06$ & $n / a$ \\
\hline 22 & HCOO (Formate) & $\mathrm{ug} / \mathrm{mL}$ & Robert Ray/Joyce Cartledge & $n / a$ & $<10$ & $n / a$ \\
\hline 23 & $\mathrm{~K}$ & $\mathrm{ug} / \mathrm{mL}$ & Sarah Brown & n/a & $n / a$ & $<0.135$ \\
\hline 24 & La & $\mathrm{ug} / \mathrm{mL}$ & Frank Pennebaker & $n / a$ & $<0.14$ & $\mathrm{na}$ \\
\hline 25 & $\mathrm{Li}$ & $\mathrm{ug} / \mathrm{mL}$ & Frank Pennebaker & $\mathrm{n} / \mathrm{a}$ & $<0.7$ & $\mathrm{n} / \mathrm{a}$ \\
\hline 26 & $\mathrm{Mg}$ & $\mathrm{ug} / \mathrm{mL}$ & Frank Pennebaker & $n / a$ & $<0.05$ & na \\
\hline 27 & $\mathrm{Mn}$ & $\mathrm{ug} / \mathrm{mL}$ & Frank Pennebaker & $n / a$ & $<0.02$ & $\pi / a$ \\
\hline 28 & Mo & $\mathrm{ug} / \mathrm{mL}$ & Frank Pennebaker & $\mathrm{n} / \mathrm{a}$ & $<0.04$ & n/a \\
\hline 29 & $\mathrm{Na}$ & $\mathrm{ug} / \mathrm{mL}$ & Frank Pennebaker & $\mathrm{N} / \mathrm{a}$ & 2.60 & $\mathrm{n} / \mathrm{a}$ \\
\hline 30 & $\mathrm{Ni}$ & $\mathrm{ug} / \mathrm{mL}$ & Frank Pennebaker & $n / a$ & $<0.06$ & $n / a$ \\
\hline 31 & NO2 (Nitrite) & $\mathrm{ug} / \mathrm{mL}$ & Robert Ray/Joyce Cartledge & n/a & $<10$ & $n / a$ \\
\hline 32 & NO3 (Nitrate) & $\mathrm{ug} / \mathrm{mL}$ & Robert Ray/Joyce Cartledge & $\mathrm{n} / \mathrm{a}$ & 15 & $n / a$ \\
\hline 33 & C2O4 (Oxalate) & $u g / m L$ & Robert Ray/Joyce Cartledge & na & $<10$ & na \\
\hline 34 & $\mathrm{P}$ & $\mathrm{ug} / \mathrm{mL}$ & Frank Pennebaker & $n / a$ & $<0.9$ & $n / a$ \\
\hline 35 & PO4 (Phosphate) & $\mathrm{ug} / \mathrm{mL}$ & Robert Ray/Joyce Cartledge & $n / a$ & $<10$ & $n / a$ \\
\hline 36 & $\mathrm{~Pb}$ & $\mathrm{ug} / \mathrm{mL}$ & Frank Pennebaker & $n / a$ & $<0.5$ & $n / a$ \\
\hline 37 & Si & $\mathrm{ug} / \mathrm{mL}$ & Frank Pennebaker & $n / a$ & $<0.6$ & $n / a$ \\
\hline 38 & Sn & $\mathrm{ug} / \mathrm{mL}$ & Frank Pennebaker & $\mathrm{n} / \mathrm{a}$ & $<0.4$ & $\mathrm{n} / \mathrm{a}$ \\
\hline 39 & SO4 (Sulfate) & $\mathrm{ug} / \mathrm{mL}$ & Robert Ray/Joyce Cartledge & $n / 2$ & 13 & n/a \\
\hline 40 & $\mathrm{Sr}$ & $\mathrm{ug} / \mathrm{mL}$ & Frank Pennebaker & $n \sqrt{a}$ & $<0.05$ & $n / a$ \\
\hline 41 & $\mathrm{Ti}$ & $\mathrm{ug} / \mathrm{mL}$ & Frank Pennebaker & $n / a$ & $<0.05$ & $\mathrm{n} / \mathrm{a}$ \\
\hline 42 & $\mathrm{v}$ & $\mathrm{ug} / \mathrm{mL}$ & Frank Pennebaker & $n / a$ & $<0.12$ & $n / a$ \\
\hline 43 & $\overline{Z n}$ & $\mathrm{ug} / \mathrm{mL}$ & Frank Pennebaker & $n / a$ & $<0.05$ & $n / a$ \\
\hline 44 & $\mathrm{Zr}$ & ug/mL & Frank Pennebaker & na & $<0.15$ & $n / a$ \\
\hline 45 & Total Organic Carbon & $\mathrm{ug} / \mathrm{mL}$ & Robert Ray & $\mathrm{n} / \mathrm{a}$ & $n / a$ & 428 \\
\hline 46 & Total Inorganic Carbon & $\mathrm{ug} / \mathrm{mL}$ & Robert Ray & $n / a$ & $n / a$ & 14.6 \\
\hline 47 & Suspended Solids & $w t \%$ & Beventy Burch & $n / a$ & $<0.002$ & $\mathrm{n} / \mathrm{a}$ \\
\hline 48 & Total Solids & $w+\%$ & Beverty Burch & $\mathrm{n} / \mathrm{a}$ & $n / a$ & $n / a$ \\
\hline 49 & Mean Particle Size by Volume & micron & Don Blankenship & $1.527(44 \%) / 5.603(56 \%)$ & $\mathrm{n} / \mathrm{a}$ & na \\
\hline 50 & Mean Particle Size by Number & micron & Don Blankenship & 1.00 & $\mathrm{n} / \mathrm{a}$ & $\mathrm{n} / \mathrm{a}$ \\
\hline 51 & Kinematic Viscosity & centistoke & CONETTN-GAPILLARYITFL & $n / s$ & $\mathrm{n} / \mathrm{a}$ & Na \\
\hline 52 & Dynamic Viscosity / Consistency & $\mathrm{cP}$ & Calculated $=$ Kin. Visc $\times$ Density & $n / a$ & $n / \mathbf{a}$ & $n / a$ \\
\hline 53 & Comment & & & high pH diluent/sonication & water before & water after \\
\hline
\end{tabular}

Table E1: Analytical - All data, Page1 . 


\begin{tabular}{|c|c|c|c|c|c|c|c|}
\hline & G & $\mathrm{H}$ & 1 & $\mathbf{J}$ & K & $\mathrm{L}$ & $\mathbf{M}$ \\
\hline 1 & TEST RUN & -....---->> & 1.01(old) & 1.01 (old) & 1.01(old) & 1.01 (old) & 1.01 (old) \\
\hline 2 & BNFL Sample ID & $m \cdots$ & Prefix_02 & Prefix_03 & Prefix_04 & Prefix_05a & Prefix_05b \\
\hline 3 & ADS Sample ID & $\ldots$ & $3 \cdot 133992$ & N/A & 3-133993 & 3-133994 & 3-133995 \\
\hline 4 & Type Sample & $m-m>$ & slurry & slurry & slurry & filtrate & filtrate \\
\hline 5 & Sample Size $\ldots$ & $\mathrm{mL}$ & 15 & 250 & 15 & 15 & 15 \\
\hline 6 & Measurement(s) Made & 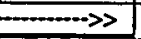 & MICROTRAC & TS/SS-VISCOSITY & TSISS & ICP-ES/IC-ANIONS & AATIC-TOCASE \\
\hline 7 & Item Measured & Units & 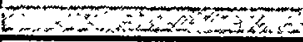 & $\therefore \cos x+1$ & 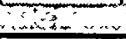 & 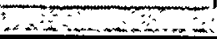 & 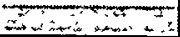 \\
\hline 8 & Density & $g / m L$ & 1.290 & 1.291 & 1.290 & 1.272 & 1.272 \\
\hline 9 & $\mathbf{A}$ & $\mathrm{ug} / \mathrm{mL}$ & Na & $n / a$ & $n / a$ & 220 & $\mathrm{n} / \mathrm{a}$ \\
\hline 10 & $B$ & $\mathrm{ug} / \mathrm{mL}$ & $\mathrm{n} / \mathrm{a}$ & $n / a$ & $n \sqrt{a}$ & 20.8 & $n / a$ \\
\hline 11 & $\mathrm{Ba}$ & $\mathrm{ug} / \mathrm{mL}$ & ra & $\mathrm{n} / \mathrm{a}$ & $\mathrm{n} / \mathrm{a}$ & $<0.02$ & n/a \\
\hline 12 & $\overline{\mathrm{Ca}}$ & $\mathrm{ug} / \mathrm{mL}$ & na & $n / a$ & $n / a$ & 124 & n/a \\
\hline 13 & $\mathrm{Cd}$ & $\mathrm{ug} / \mathrm{mL}$ & $n / a$ & $\mathrm{n} / \mathrm{a}$ & na & $<0.02$ & $\mathrm{n} / \mathrm{a}$ \\
\hline 14 & $\mathrm{Cl}$ & $u g / m L$ & $n / a$ & $\mathrm{n} / \mathrm{a}$ & $\mathrm{n} / \mathrm{a}$ & 816 & $n / a$ \\
\hline 15 & Cl Sample & $\mathrm{ug} / \mathrm{mL}$ & $n / a$ & n/a & n/a & $\mathrm{n} / \mathrm{a}$ & 934 \\
\hline 16 & Co & $\mathrm{ug} / \mathrm{mL}$ & $n / a$ & n/a & $n / a$ & $<0.05$ & na \\
\hline 17 & $\mathrm{Cr}$ & $\mathrm{ug} / \mathrm{mL}$ & $n / a$ & $n / a$ & $\mathrm{n} / \mathrm{a}$ & 0.49 & na \\
\hline 18 & $\mathrm{Cu}$ & $\mathrm{ug} / \mathrm{mL}$ & na & n/a & $n / a$ & 9.2 & n/a \\
\hline 19 & F (Fluoride) [not accurate] & $\mathrm{ug} / \mathrm{mL}$ & $n / a$ & n/a & $n / a$ & 957 & $\mathrm{n} / \mathrm{a}$ \\
\hline 20 & F Sample (more accurate result) & ug/mL & $\mathrm{n} / \mathrm{a}$ & n/a & n/a & n/a & 272.2 \\
\hline 21 & $\mathrm{Fe}$ & $\mathrm{ug} / \mathrm{mL}$ & $n / a$ & $\mathbf{n} / \mathbf{a}$ & $n \sqrt{a}$ & 35 & n/a \\
\hline 22 & HCOO (Formate) & $\mathrm{ug} / \mathrm{mL}$ & n/a & n/a & n/a & 5591 & n/a \\
\hline 23 & $\mathrm{~K}$ & $\mathrm{ug} / \mathrm{mL}$ & $\mathrm{n} / \mathrm{a}$ & n/a & $n / a$ & n/a & 1220.86 \\
\hline 24 & La & $u g / m L$ & $\mathrm{n} / \mathrm{a}$ & $n / a$ & $n / a$ & 1.3 & $\mathbf{n} / \mathbf{a}$ \\
\hline 25 & L & $\mathrm{ug} / \mathrm{mL}$ & n/a & $n / a$ & na & $<0.7$ & $\mathrm{n} / \mathrm{a}$ \\
\hline 26 & $\overline{\mathrm{Mg}}$ & $u g / m L$ & n/a & $n / a$ & n/a & 0.41 & $\mathrm{n} / \mathrm{a}$ \\
\hline 27 & $\mathrm{Mn}$ & $\mathrm{ug} / \mathrm{mL}$ & $\mathrm{n} / \mathrm{a}$ & $\mathrm{n} / \mathrm{a}$ & nua & 9.4 & $n / a$ \\
\hline 28 & Mo & $\mathrm{ug} / \mathrm{mL}$ & n/a & $n / a$ & na & 20.3 & $n / 2$ \\
\hline 29 & $\mathrm{Na}$ & $\mathrm{ug} / \mathrm{mL}$ & n/a & $\mathrm{n} / \mathrm{a}$ & $\mathrm{n} / \mathrm{a}$ & 127500 & $\mathrm{n} / \mathrm{a}$ \\
\hline 30 & $\mathrm{Ni}$ & $\mathrm{ug} / \mathrm{mL}$ & $n / a$ & $n / a$ & $n / a$ & 283 & $n / a$ \\
\hline 31 & NO2 (Nitrite) & $u g / m L$ & $n / a$ & $\mathrm{n} / \mathrm{a}$ & $\pi / a$ & 34089 & n/a \\
\hline 32 & NO3 (Nitrate) & $\mathrm{ug} / \mathrm{mL}$ & n/a & $n / a$ & $n / a$ & 13020 & n/a \\
\hline 33 & C2O4 (Oxalate) & $\mathrm{ug} / \mathrm{mL}$ & n/a & n/a & $n / a$ & 2024 & n/a \\
\hline 34 & $\mathrm{P}$ & $\mathrm{ug} / \mathrm{mL}$ & na & $n / a$ & $n / a$ & 318 & n/a \\
\hline 35 & PO4 (Phosphate) & ug/mL & $\mathrm{n} / \mathrm{a}$ & n/a & $\mathrm{n} / \mathrm{a}$ & 1534 & n/a \\
\hline 36 & $\mathrm{~Pb}$ & $\mathrm{ug} / \mathrm{mL}$ & $n / a$ & $n / a$ & $\mathrm{n} / \mathrm{a}$ & $<1.0$ & n/a \\
\hline 37 & Si & $\mathrm{ug} / \mathrm{mL}$ & n/a & $\mathrm{n} / \mathrm{a}$ & n/a & 10.2 & $n / a$ \\
\hline 38 & Sn & $\mathrm{ug} / \mathrm{mL}$ & $n / a$ & $n / a$ & na & $<0.4$ & na \\
\hline 39 & SO4 (Sulfate) & $\mathrm{ug} / \mathrm{mL}$ & $n / a$ & n/a. & n/a & 4830 & na \\
\hline 40 & Sr & $.4 \mathrm{~g} / \mathrm{mL}$ & $\mathbf{n} / \mathbf{a}$ & ñà & na & 87 & $\mathrm{n} / \mathrm{a}$ \\
\hline 41 & $\mathrm{Ti}$ & $u g / m L$ & $\mathrm{n} / \mathrm{a}$ & $n / a$ & $n / a$ & $<0.05$ & $\mathrm{n} / \mathrm{a}$ \\
\hline 42 & $\bar{v}$ & $\mathrm{ug} / \mathrm{mL}$ & $\mathrm{n} / \mathrm{a}$ & $n / a$ & $n / a$ & $<0.12$ & Na \\
\hline 43 & $2 n$ & $\mathrm{ug} / \mathrm{mL}$ & na & $\mathrm{n} / \mathrm{a}$ & $\mathrm{n} / \mathrm{a}$ & 17 & n/a \\
\hline 44 & $\mathrm{Zr}$ & $\mathrm{ug} / \mathrm{mL}$ & N/a & n/a & $n / a$ & 0.85 & $n / a$ \\
\hline 45 & Total Organic Carbon & $u g / m L$ & $\mathrm{n} / \mathrm{a}$ & $n / a$ & $\mathrm{n} / \mathrm{a}$ & n/a & 9618 \\
\hline 46 & Total Inorganic Carbon & $\mathrm{ug} / \mathrm{mL}$ & $n / a$ & $\mathrm{n} / \mathrm{a}$ & $\mathrm{n} / \mathrm{a}$ & n/a & 12044 \\
\hline 47 & Suspended Solids & $w t \%$ & $\mathrm{n} / \mathrm{a}$ & 1.78 & 1.93 & $n / a$ & $n / a$ \\
\hline 48 & Total Solids & $w t \%$ & $\mathrm{n} / \mathrm{a}$ & 33.98 & 33.88 & n/a & $\mathrm{n} / \mathrm{a}$ \\
\hline 49 & Mean Particle Size by Volume & micron & $1.471(75 \%) / 5.581(23 \%)$ & $\mathrm{n} / \mathrm{a}$ & na & na & $\mathrm{n} / \mathrm{a}$ \\
\hline 50 & Mean Particle Size by Number & micron & 0.97 & $\mathrm{n} / \mathrm{a}$ & n/a & $\mathrm{n} / \mathrm{a}$ & n/a \\
\hline 51 & Kinematic Viscosity & centistoke & $\mathrm{n} / \mathrm{a}$ & 3.0 & $\mathrm{n} / \mathrm{a}$ & 2.62 & 2.62 \\
\hline 52 & Dymamic Viscosity/Consistency & $\mathbf{C P}$ & $\begin{array}{c}\mathrm{n} / \mathrm{a} \\
\end{array}$ & 3.9 & . $\sqrt{a}$ & 3.33 & 3.33 \\
\hline 53 & Comment & & high pH diluent/sonication & & & & \\
\hline
\end{tabular}

Table E1: Analytical - All data, Page2 


\begin{tabular}{|c|c|c|c|c|c|c|c|}
\hline & $\mathrm{N}$ & $\mathrm{O}$ & $\mathrm{P}$ & $\mathbf{Q}$ & $R$ & $\mathrm{~S}$ & $\mathrm{~T}$ \\
\hline 1 & TEST RUN - & -......->> & 1.07 (old) & 1.07(old) & 1.07 (old) & 1.07 (old) & 1.07(old) \\
\hline 2 & BNFL Sample ID & 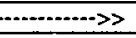 & Prefix_06 & Prefix_07 & Prefix_08 & Prefix_09a & Prefix_09b \\
\hline 3 & 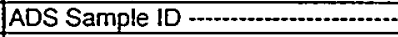 & $\cdots \cdots$ & $3 \cdot 133996$ & N/A & $3-133997$ & 3-133998 & $3-133999$ \\
\hline 4 & 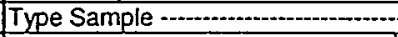 & $m-\cdots \cdots$ & slurry & slurry & slurry & filtrate & filtrate \\
\hline 5 & Sample Size & $\mathrm{mL}$ & 15 & 250 & 15 & 15 & 15 \\
\hline 6 & Measurement(s) Made ................ & $m-\cdots>>$ & MICROTRAC & TSISS-VISCOSITY & TS/SS & ICP-ES/IC-ANIONS & AATIC-TOCIISE \\
\hline 7 & Item Measured & Units & 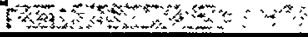 & 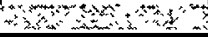 & 20 & 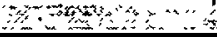 & 6 \\
\hline 8 & Density & $\mathrm{g} / \mathrm{mL}$ & 1.285 & \begin{tabular}{|l|}
1.305 \\
\end{tabular} & 1.285 & 1.270 & 1.270 \\
\hline 9 & Al & $\mathrm{ug} / \mathrm{mL}$ & n/a & $\mathrm{n} / \mathrm{a}$ & $\mathrm{n} / \mathrm{a}$ & 219 & $\mathrm{n} / \mathrm{a}$ \\
\hline 10 & $\mathrm{~B}$ & $\mathrm{ug} / \mathrm{mL}$ & $n / a$ & $\mathrm{n} / \mathrm{a}$ & $\mathrm{n} / \mathrm{a}$ & 21.1 & na \\
\hline 11 & $\mathrm{Ba}$ & $\mathrm{ug} / \mathrm{mL}$ & $n / a$ & n/a & na & $<0.02$ & $\mathrm{n} / \mathrm{a}$ \\
\hline 12 & $\mathrm{Ca}$ & $\mathrm{ug} / \mathrm{mL}$ & $\mathrm{n} / \mathrm{a}$ & $\mathrm{n} / \mathrm{a}$ & na & 128 & $\mathrm{n} / \mathrm{a}$ \\
\hline 13 & $\overline{C d}$ & $\mathrm{ug} / \mathrm{mL}$ & na & na & n/a & $<0.02$ & $\mathrm{n} / \mathrm{a}$ \\
\hline 14 & $\mathrm{Cl}$ & $\mathrm{ug} / \mathrm{mL}$ & $n \sqrt{a}$ & $n / a$ & $\mathrm{n} / \mathrm{a}$ & 818 & $n / a$ \\
\hline 15 & CI Sample & $\mathrm{ug} / \mathrm{mL}$ & n/a & $\mathrm{n} / \mathrm{a}$ & $\sqrt{a}$ & $\mathrm{n} / \mathrm{a}$ & 967 \\
\hline 16 & Co & $\mathrm{ug} / \mathrm{mL}$ & $\mathrm{Na}$ & n/a & n/a & $<0.05$ & $\mathrm{n} / \mathrm{a}$ \\
\hline 17 & $\mathrm{Cr}$ & $\mathrm{ug} / \mathrm{mL}$ & na & $\mathrm{na}$ & $\mathrm{n} / \mathrm{a}$ & 0.53 & $n / a$ \\
\hline 18 & $\mathrm{Cu}$ & $\mathrm{ug} / \mathrm{mL}$ & $n / a$ & $\mathrm{na}$ & $n / a$ & 12.1 & $\mathrm{n} / \mathrm{a}$ \\
\hline 19 & F (Fluoride) \{not accuratel & $\mathrm{ug} / \mathrm{mL}$ & $n / a$ & $\mathrm{n} / \mathrm{a}$ & $n / a$ & 1860 & $n / a$ \\
\hline 20 & F Sample (more accurate result) & $\mathrm{ug} / \mathrm{mL}$ & $\mathrm{n} / \mathrm{a}$ & $\mathrm{n} / \mathrm{a}$ & $n / a$ & $\mathrm{n} / \mathrm{a}$ & 282.5 \\
\hline 21 & $\mathrm{Fe}$ & $\mathrm{ug} / \mathrm{mL}$ & $n / a$ & $n / a$ & na & 41 & n/a \\
\hline 22 & HCOO (Formate) & $\mathrm{ug} / \mathrm{mL}$ & $\mathrm{n} / \mathrm{a}$ & n/a & n/a & 5820 & $n / a$ \\
\hline 23 & $\mathrm{~K}$ & $\mathrm{ug} / \mathrm{mL}$ & $\mathrm{n} / \mathrm{a}$ & n/a & $n / a$ & $n / a$ & 1198.88 \\
\hline 24 & La & $\mathrm{ug} / \mathrm{mL}$ & $n / a$ & $\mathrm{n} / \mathrm{a}$ & $n / a$ & 1.2 & $n / a$ \\
\hline 25 & $\dot{U}$ & $\mathrm{ug} / \mathrm{mL}$ & na & $n / a$ & $n / a$ & $<0.7$ & $\mathrm{n} / \mathrm{a}$ \\
\hline 26 & $\mathrm{Mg}$ & $\mathrm{ug} / \mathrm{mL}$ & na & $\mathrm{n} / \mathrm{a}$ & $\mathrm{n} / \mathrm{a}$ & 0.41 & n/a \\
\hline 27 & $\mathrm{Mn}$ & $\mathrm{ug} / \mathrm{mL}$ & $n / a$ & $\mathrm{n} / \mathrm{a}$ & $\mathrm{n} / \mathrm{a}$ & 14.5 & $\mathrm{n} / \mathrm{a}$ \\
\hline 28 & Mo & $\mathrm{ug} / \mathrm{mL}$ & $\mathrm{n} / \mathrm{a}$ & na & $n / a$ & 20.5 & $n / a$ \\
\hline 29 & $\mathrm{Na}$ & $\mathrm{ug} / \mathrm{mL}$ & $n / a$ & $n / a$ & $\mathrm{n} / \mathrm{a}$ & 126500 & n/a \\
\hline 30 & $\mathrm{Ni}$ & $\mathrm{ug} / \mathrm{mL}$ & $\mathrm{n} / \mathrm{a}$ & $n / a$ & $\mathrm{n} / \mathrm{a}$ & 285 & $n / a$ \\
\hline 31 & NO2 (Nitrite) & $\mathrm{ug} / \mathrm{mL}$ & $n / a$ & $\mathrm{n} / \mathrm{a}$ & $n / a$ & 37431 & n/a \\
\hline 32 & NO3 (Nitrate) & $\mathrm{ug} / \mathrm{mL}$ & $\mathrm{n} / \mathrm{a}$ & $n / a$ & $n / a$ & 131115 & n/a \\
\hline 33 & $\mathrm{C2O4}$ (Oxalate) & $\mathrm{ug} / \mathrm{mL}$ & $n / a$ & $\mathrm{n} / \mathrm{a}$ & $n / a$ & 1449 & n/a \\
\hline 34 & $P$ & $\mathrm{ug} / \mathrm{mL}$ & $\mathrm{n} / \mathrm{a}$ & $\mathrm{n} / \mathrm{a}$ & $n / a$ & 319 & $n / a$ \\
\hline 35 & PO4 (Phosphate) & $\mathrm{ug} / \mathrm{mL}$ & $\mathrm{n} / \mathrm{a}$ & $n / a$ & $\mathrm{n} / \mathrm{a}$ & 1549 & n/a \\
\hline 36 & $\mathrm{PD}$ & $\mathrm{ug} / \mathrm{mL}$ & $n / a$ & $n / a$ & $n / a$ & $<1.0$ & $\mathrm{n} / \mathrm{a}$ \\
\hline 37 & $\mathrm{Si}$ & $u g / \mathrm{mL}$ & na & $\pi / a$ & $n / a$ & 11.0 & n/a \\
\hline 38 & Sn & $u g / m L$ & $\mathrm{n} / \mathrm{a}$ & $\mathrm{n} / \mathrm{a}$ & $n / a$ & $<0.4$ & $\mathrm{n} / \mathrm{a}$ \\
\hline 39 & SO4 (Sulfate) & $u g / m L$ & $\mathrm{n} / \mathrm{a}$ & $n / 2$ & $\mathrm{n} / \mathrm{a}$ & 4883 & $\mathrm{n} / \mathrm{a}$ \\
\hline 40 & Sr & $\mathrm{ug} / \mathrm{mL}$ & $n / a$ & $n / a$ & $n / a$ & 95 & $n / a$ \\
\hline 41 & $\mathrm{Ti}$ & $\mathrm{ug} / \mathrm{mL}$ & $\therefore 6=-$ & $\mathrm{na}$ & $\mathrm{n} / \mathrm{a}$ & $<0.05^{\cdots}-$ & $\mathrm{n} / \mathrm{a}$ \\
\hline 42 & V & $\mathrm{ug} / \mathrm{mL}$ & $\mathrm{n} / \mathrm{a}$ & na & $n / a$ & $<0.12$ & $n / a$ \\
\hline 43 & $\mathbf{Z n}$ & $\mathrm{ug} / \mathrm{mL}$ & $n / a$ & $\mathrm{n} / \mathrm{a}$ & n/a & 17 & n/a \\
\hline 44 & $\mathrm{Zr}$ & $\mathrm{ug} / \mathrm{mL}$ & $n / a$ & n/a & n/a & 79.00 & na \\
\hline 45 & Total Organic Carbon & $\mathrm{ug} / \mathrm{mL}$ & $n / a$ & $n / a$ & $n / a$ & $n / a$ & 9876 \\
\hline 46 & Total Inorganic Carbon & $\mathrm{ug} / \mathrm{mL}$ & $n / a$ & $n / a$ & n/a & n/a & 12362 \\
\hline 47 & Suspended Solids & $w t \%$ & $n / a$ & 2.05 & 1.89 & n/a & $\mathrm{n} / \mathrm{a}$ \\
\hline 48 & Total Solids & $w t \%$ & n/a & 35.84 & 34.47 & $\mathrm{n} / \mathrm{a}$ & $n / a$ \\
\hline 49 & Mean Particle Size by Volume & micron & $1.472(77 \%) / 5.228(23 \%)$ & $n / a$ & $\mathrm{n} / \mathrm{a}$ & n/a & $n / a$ \\
\hline 50 & Mean Particle Size by Number & micron & 0.97 & $n / a$ & $n / a$ & $n / a$ & na \\
\hline 51 & Kinematic Viscosity & centistoke & $n / s$ & 3.4 & $\mathrm{n} / \mathrm{a}$ & 2.47 & 2.47 \\
\hline 52 & Dynamic Viscosity / Consistency & $\mathrm{cP}$ & \begin{tabular}{|c|}
$\mathrm{n} / \mathrm{a}$ \\
\end{tabular} & 4.4 & $\mathrm{n} / \mathrm{a}$ & 3.14 & 3.14 \\
\hline 53 & Comment & & Thigh pH diluent/sonication & & & & \\
\hline
\end{tabular}

Table E1: Analytical - All data, Page 3 


\begin{tabular}{|c|c|c|c|c|c|c|c|}
\hline & $\mathrm{U}$ & V & $W$ & $\mathrm{x}$ & $Y$ & $\mathbf{Z}$ & $A A$ \\
\hline 1 & TEST RUN & $\longrightarrow$ & 1.07 & 1.07 & pre 1.08 & pre 1.08 & pre 1.08 \\
\hline 2 & BNFL Sample ID & $m \ldots$ & N/A & N/A & NA & N/A & Prefix_10 \\
\hline 3 & ADS Sample ID & > $>>$ & NA & N/A & N/A & N/A & $3-135892$ \\
\hline 4 & Type Sample ....................... & $m$ & slurry & filtrate & slurry & slurry & slumy \\
\hline 5 & Sample Size $\cdots . . . . . . . . . .>>$ & $\mathrm{mL}$ & 100 retumed & 100 relumed & 100 retumed & 100 retuned & 15 \\
\hline 6 & Measurement(s) Made - & $\Longrightarrow$ & DENSITY ONLY & DENSITY \& VSCOSITY & DENSITYONLY & DENSITY ONLY & TS/SSICP-ES+HF digest \\
\hline 7 & Item Measured & Units & 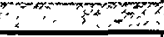 & 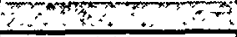 & 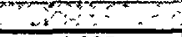 & 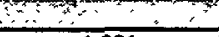 & 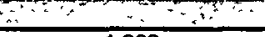 \\
\hline 8 & Density & $g / m L$ & 1.283 & 1.267 & 1.295 & 1.291 & 1.293 \\
\hline 9 & A) & $\mathrm{ug} / \mathrm{mL}$ & $\mathrm{N} / \mathrm{a}$ & $\mathbf{n} / \mathbf{a}$ & $n / a$ & $n / a$ & 235 \\
\hline 10 & $\mathrm{~B}$ & $\mathrm{ug} / \mathrm{mL}$ & n/a & na & $n / a$ & $n / a$ & 18 \\
\hline 11 & $\mathrm{Ba}$ & $\mathrm{ug} / \mathrm{mL}$ & $\mathrm{n} / \mathrm{a}$ & $\mathrm{n} / \mathrm{a}$ & $n / a$ & $n / a$ & 2 \\
\hline 12 & $\mathrm{Ca}$ & $\mathrm{ug} / \mathrm{mL}$ & $n / a$ & $n / a$ & $n / a$ & n/a & 327 \\
\hline 13 & Cd & $\mathrm{ug} / \mathrm{mL}$ & $n / a$ & $\mathrm{n} / \mathrm{a}$ & $\mathrm{na}$ & $n / a$ & $<0.2$ \\
\hline 14 & CI & $\mathrm{ug} / \mathrm{mL}$ & na & $\mathrm{n} / \mathrm{a}$ & Na & $n / a$ & $\mathrm{n} / \mathrm{a}$ \\
\hline 15 & CI Sample & $\mathrm{ug} / \mathrm{mL}$ & $\mathrm{n} / \mathrm{a}$ & $n / a$ & $n / a$ & $n / a$ & $\mathrm{n} / \mathrm{a}$ \\
\hline 16 & Co & $\mathrm{ug} / \mathrm{mL}$ & $n / a$ & $n / a$ & $\mathrm{n} / \mathrm{a}$ & $n / a$ & $<0.6$ \\
\hline 17 & $\mathbf{C r}$ & $u g / m L$ & $\mathrm{n} / \mathrm{a}$ & $n / a$ & $n / a$ & $\mathrm{n} / \mathrm{a}$ & 4.40 \\
\hline 18 & Cu & $\mathrm{ug} / \mathrm{mL}$ & $\mathrm{n} / \mathrm{a}$ & n/a & na & $n / a$ & 18 \\
\hline 19 & F (Fluoride) (not accurate) & $\mathrm{ug} / \mathrm{mL}$ & $\mathrm{n} / \mathrm{a}$ & $\mathrm{n} / \mathrm{a}$ & $\mathrm{n} / \mathrm{a}$ & $n / 2$ & na \\
\hline 20 & F Sample (more accurale resuli) & $\mathrm{ug} / \mathrm{mL}$ & $n / a$ & $n / a$ & $n / a$ & $n / a$ & $n / a$ \\
\hline 21 & $F_{\theta}$ & ug/mL & $n / a$ & na & Na & n/a & 919 \\
\hline 22 & HCOO (Formate) & $\mathrm{ug} / \mathrm{mL}$ & $\mathrm{n} / \mathrm{a}$ & n/a & $\mathrm{n} / \mathrm{a}$ & $n / a$ & $\mathrm{n} / \mathrm{a}$ \\
\hline 23. & $\mathrm{~K}$ & $\mathrm{ug} / \mathrm{mL}$ & na & $n / a$ & $\mathrm{n} / \mathrm{a}$ & n/a & n/a \\
\hline 24 & La & $\mathrm{ug} / \mathrm{mL}$ & na & $n \mathbf{a}^{\circ}$ & na & n/a & 24 \\
\hline 25 & 4 & $\mathrm{ug} / \mathrm{mL}$ & $\mathbf{n a}$ & $\mathrm{n} / \mathrm{a}$ & Na & $n / a$ & $<1$ \\
\hline 28 & $\mathrm{Mg}$ & $\mathrm{ug} / \mathrm{mL}$ & $n / a$ & $\mathrm{~N} / \mathrm{a}$ & $n / a$ & $\mathrm{n} / \mathrm{a}$ & 13 \\
\hline 27 & $\mathrm{Mn}$ & $\mathrm{ug} / \mathrm{mL}$ & $\mathrm{n} / \mathrm{a}$ & naa & $n / 2$ & $n / a$ & 2711 \\
\hline 28 & Mo & $\mathrm{ug} / \mathrm{mL}$ & $\sqrt{2}$ & $n \sqrt{a}$ & $n / a$ & $n / a$ & 15 \\
\hline 29 & $\mathrm{Na}$ & $\mathrm{ug} / \mathrm{mL}$ & $n / a$ & n/a & $\mathrm{na}$ & $n / a$ & 133653 \\
\hline 30 & $\mathrm{Nl}$ & $\mathrm{ug} / \mathrm{mL}$ & $n / a$ & $\mathrm{n} / \mathrm{a}$ & n/a & $n / a$ & 292 \\
\hline 31 & NO2 (Nitrite) & $\mathrm{ug} / \mathrm{mL}$ & $n / a$ & n/a & $n / a$ & $n / a$ & $n / a$ \\
\hline 32 & NO3 (Nitrato) & $\mathrm{ug} / \mathrm{mL}$ & $n / a$ & $n / a$ & $n / a$ & $n / a$ & n/a \\
\hline 33 & C204 (Oxalato) & $\mathrm{ug} / \mathrm{mL}$ & na & n/a & na & $\mathrm{n} / \mathrm{a}$ & $n / a$ \\
\hline 34 & $P$ & $\mathrm{ug} / \mathrm{mL}$ & $\mathrm{n} / \mathrm{a}$ & $n / a$ & $\mathrm{~N} / \mathrm{a}$ & $\mathrm{n} / \mathrm{a}$ & 275 \\
\hline 35 & PO4 (Phosphate) & $\mathrm{ug} / \mathrm{mL}$ & n/a & na & $\mathbf{n a}$ & $\mathrm{n} / \mathrm{a}$ & $n / a$ \\
\hline 36 & $\mathrm{~Pb}$ & $\mathrm{ug} / \mathrm{mL}$ & N/a & $n / a$ & $n / a$ & $\mathrm{n} / \mathrm{a}$ & $<6$ \\
\hline 37 & SI & $\mathrm{ug} / \mathrm{mL}$ & $n / a$ & na & $n / a$ & $n / a$ & 15 \\
\hline 38 & Sn & $\mathrm{ug} / \mathrm{mL}$ & $n / a$ & n/a & n/a & $n / a$ & 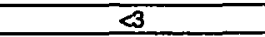 \\
\hline 39 & SO4(Sulfate) & $\mathrm{ug} / \mathrm{mL}$ & n/a & n/a & $n / a$ & $n / a$ & $n / a$ \\
\hline 40 & Sr & $\mathrm{ug} / \mathrm{mL}$ & $n / a$ & na & $\pi / a$ & $\mathrm{n} / \mathrm{a}$ & 6520 \\
\hline 41 & $\mathrm{TI}$ & $\mathrm{Hg} / \mathrm{mL}$ & n/a & $\mathrm{n} / \mathrm{a}$ & $n / a$ & $n / a$ & $\leq 1.5$ \\
\hline 42 & v & $\mathrm{ug} / \mathrm{mL}$ & n/a & $\mathrm{n} / \mathrm{a}$ & $n / a$ & $n \sqrt{a}$ & $<1.4$ \\
\hline 43 & $Z_{n}$ & $\mathrm{ug} / \mathrm{mL}$ & n/a & $n / a$ & $\mathrm{n} / \mathrm{a}$ & $n / a$ & 25 \\
\hline 44 & $\mathrm{Zr}$ & $u g / \mathrm{mL}$ & n/a & na & $n / a$ & $n / a$ & 32 \\
\hline 45 & Total Organic Carbon & $\mathrm{ug} / \mathrm{mL}$ & n/a & n/a & $n / a$ & $\mathrm{n} / \mathrm{a}$ & $n / 2$ \\
\hline 46 & Total Inorganic Carbon & $\mathrm{ug} / \mathrm{mL}$ & $\mathrm{n} / \mathrm{a}$ & n/a & $\mathrm{N} / \mathrm{a}$ & $\pi / a$ & $n / a$ \\
\hline 47 & Suspended Solids & $w+\%$ & $n \sqrt{a}$ & $\mathrm{n} / \mathrm{a}$ & $\mathbf{n} / \mathbf{a}$ & $n / a$ & 1.75 \\
\hline 48 & Total Solids & $w t \%$ & n/a & $\mathrm{n} / \mathrm{a}$ & n/a & $n / a$ & 37.72 \\
\hline 49 & Mean Particle Size by Volume & micron & na & nla & na & $n \sqrt{a}$ & $\mathrm{n} / \mathbf{a}$ \\
\hline 50 & Mean Particlo Slzo by Number & micron & n/a & $\mathrm{n} / \mathrm{a}$ & n/a & $n / a$ & $n / a$ \\
\hline 51 & Kinematic Viscosity & centistoke & n/a & 2.41 & n/a & $\mathrm{n} / \mathrm{a}$ & $\mathrm{n} / \mathrm{a}$ \\
\hline 52 & Dymamic Viscosity / Consistency & CP & na & 3.05 & $\mathbf{n} / \mathbf{a}$ & n/a & $n / a$ \\
\hline 53 & Comment & & & & First Batch Made & Second Batch Made & \\
\hline
\end{tabular}




\begin{tabular}{|c|c|c|c|c|c|c|c|}
\hline & $\mathrm{AB}$ & $A C$ & $\mathrm{AD}$ & $\mathrm{AE}$ & $A F$ & AG & $\mathrm{AH}$ \\
\hline 1 & 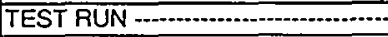 & $\cdots \cdots+\cdots$ & mid 1.08 & mid 1.08 & mid 1.08 & mid 1.08 & mid 1.08 \\
\hline 2 & BNFL Sample IO & $\cdots \cdots$ & N/A & N/A & Prefix_11 & Prefix_12 & Prefix_13 \\
\hline 3 & ADS Sample ID & $\cdots$ & N/A & N/A & $3-135893$ & N/A & $3-135894$ \\
\hline 4 & Type Sample -....... & $\cdots$ & slurry & filtrate & slurry & slurry & slurry \\
\hline 5 & Sample Size -................ & $\mathrm{mL}$ & 100 returned & 100 returned & 15 & 250 & 15 \\
\hline 6 & Measurement(s) Made .................... & $\ldots \rightarrow>$ & DENSITY ONLY & DENSITY \& VISCOSITY & MICROTRAC & TS/SS-VISCOSITY & TS/SS \\
\hline 7 & Item Measured & Units & 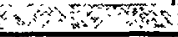 & 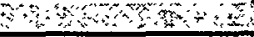 & 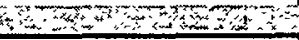 & 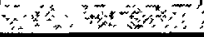 & 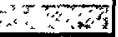 \\
\hline 8 & Density & $g / m L$ & 1.355 & 1.276 & 1.355 & 1.357 & 1.355 \\
\hline 9 & $\mathrm{Al}$ & $u g / m L$ & $\mathrm{n} / \mathrm{a}$ & $\mathbf{n} / \mathbf{a}$ & $\mathrm{n} / \mathrm{a}$ & Na & na \\
\hline 10 & 8 & $u g / \mathrm{mL}$ & $n / a$ & $\mathrm{n} / \mathrm{a}$ & $\mathrm{n} / \mathrm{a}$ & $n / a$ & $n / a$ \\
\hline 11 & $\mathrm{Ba}$ & $\mathrm{ug} / \mathrm{mL}$ & $\mathrm{n} / \mathrm{a}$ & $\mathrm{n} / \mathrm{a}$ & $\mathrm{n} / \mathrm{a}$ & n/a & na \\
\hline 12 & $\mathrm{Ca}$ & $u g / \mathrm{mL}$ & nia & $\mathrm{n} / \mathrm{a}$ & $n / a$ & Na & na \\
\hline 13 & $\operatorname{cod}$ & $\mathrm{ug} / \mathrm{mL}$ & $\mathrm{n} / \mathrm{a}$ & $\mathrm{n} / \mathrm{a}$ & $n / a$ & n/a & na \\
\hline 14 & $\mathrm{Cl}$ & $\mathrm{ug} / \mathrm{mL}$ & $\mathrm{n} / \mathrm{a}$ & $\mathrm{n} / \mathrm{a}$ & $\mathrm{n} / \mathrm{a}$ & $\mathrm{Na}$ & $\mathrm{n} / \mathrm{a}$ \\
\hline 15 & Cl Sample & $\mathrm{ug} / \mathrm{mL}$ & $n / a$ & $\mathrm{n} / \mathrm{a}$ & $\mathrm{n} / \mathrm{a}$ & n/a & na \\
\hline 16 & Co & $\mathrm{ug} / \mathrm{mL}$ & $n / a$ & $n / a$ & $\mathrm{n} / \mathrm{a}$ & $n \sqrt{a}$ & $\mathrm{n} / \mathrm{a}$ \\
\hline 17 & $\mathrm{Cr}$ & $u g / \mathrm{mL}$ & $\mathrm{n} / \mathrm{a}$ & $n / a$ & na & $n \sqrt{a}$ & $n / a$ \\
\hline 18 & $\mathrm{Cu}$ & $\mathrm{ug} / \mathrm{mL}$ & $\mathrm{n} / \mathrm{a}$ & $\mathrm{n} / \mathrm{a}$ & $\mathrm{n} / \mathrm{a}$ & nia & na \\
\hline 19 & F (Fluoride) [not accurate] & $\mathrm{ug} / \mathrm{mL}$ & na & $n / a$ & $\mathrm{n} / \mathrm{a}$ & $n / a$ & $n \sqrt{a}$ \\
\hline 20 & F Sample (more accurate result) & $\mathrm{ug} / \mathrm{mL}$ & na & $n / a$ & n/a & na & $n / a$ \\
\hline 21 & $\mathrm{Fe}$ & $\mathrm{ug} / \mathrm{mL}$ & $\mathrm{n} / \mathrm{a}$ & $\mathrm{n} / \mathrm{a}$ & $\mathrm{n} / \mathrm{a}$ & $\mathrm{n} / \mathrm{a}$ & $n \sqrt{2}$ \\
\hline 22 & HCOO (Formate) & $\mathrm{ug} / \mathrm{mL}$ & $\mathrm{n} / \mathrm{a}$ & $\mathrm{n} / \mathrm{a}$ & $\mathrm{n} / \mathrm{a}$ & $n / a$ & $n / a$ \\
\hline 23 & $\mathrm{~K}$ & $\mathrm{ug} / \mathrm{mL}$ & $\mathrm{n} / \mathrm{a}$ & $\mathrm{n} / \mathrm{a}$ & $\mathrm{n} / \mathrm{a}$ & na & $n / a$ \\
\hline 24 & La & ug $/ \mathrm{mL}$ & $n / a$ & $\mathrm{~N} / \mathrm{a} \cdot$ & n/a & $n / a$ & $n / a$ \\
\hline 25 & $\mathrm{Li}$ & $\mathrm{ug} / \mathrm{mL}$ & na & $n / a$ & $\mathrm{n} / \mathrm{a}$ & n/a & $n / a$ \\
\hline 26 & $\mathrm{Mg}$ & $u g / m L$ & $\mathrm{~N} / \mathrm{a}$ & na & $\mathrm{n} / \mathrm{a}$ & n/a & $n / a$ \\
\hline 27 & $\mathrm{Mn}$ & $u g / m L$ & $\mathrm{~N} / \mathrm{a}$ & na & $\mathrm{n} / \mathrm{a}$ & $n / a$ & $n / a$ \\
\hline 28 & Mo & $\mathrm{ug} / \mathrm{mL}$ & $\mathrm{n} / \mathrm{a}$ & Na & $n / a$ & $\mathrm{n} / \mathrm{a}$ & $n / a$ \\
\hline 29 & $\mathrm{Na}$ & $\mathrm{ug} / \mathrm{mL}$ & $n / a$ & $n / a$ & $\mathrm{n} / \mathrm{a}$ & $\mathrm{n} / \mathrm{a}$ & $n / a$ \\
\hline 30 & $\mathrm{Ni}$ & $\mathrm{ug} / \mathrm{mL}$ & $n / a$ & $n / a$ & $\mathrm{n} / \mathrm{a}$ & $\mathrm{n} / \mathrm{a}$ & $n / a$ \\
\hline 31 & NO2 (Nitrite) & $\mathrm{ug} / \mathrm{mL}$ & $n / a$ & $\mathrm{na}$ & $n / a$ & Na & $\mathrm{na}$ \\
\hline 32 & NO3 (Nitrate) & $\mathrm{ug} / \mathrm{mL}$ & $n / a$ & $n \sqrt{a}$ & $n / a$ & $\pi \sqrt{a}$ & $n / a$ \\
\hline 33 & C204 (Oxalate) & $\mathrm{ug} / \mathrm{mL}$ & $n / a$ & n/a & $\mathrm{n} / \mathrm{a}$ & $\mathrm{n} / \mathrm{a}$ & $n / a$ \\
\hline 34 & $\mathrm{P}$ & $\mathrm{ug} / \mathrm{mL}$ & $\mathrm{Na}$ & $\mathrm{na}$ & $n / a$ & $n / a$ & Na \\
\hline 35 & PO4 (Phosphate) & $\mathrm{ug} / \mathrm{mL}$ & $\mathrm{n} / \mathrm{a}$ & na & $\mathrm{n} / \mathrm{a}$ & n/a & $\mathrm{n} / \mathrm{a}$ \\
\hline 36 & $\mathrm{~Pb}$ & $\mathrm{ug} / \mathrm{mL}$ & $\mathrm{n} / \mathrm{a}$ & na & $\mathrm{n} / \mathrm{a}$ & Na & Na \\
\hline 37 & Si & $\mathrm{ug} / \mathrm{mL}$ & $n / a$ & $\mathrm{n} / \mathrm{a}$ & $n / a$ & $\sqrt{a}$ & na \\
\hline 38 & $\mathrm{Sn}$ & $\mathrm{ug} / \mathrm{mL}$ & na & $\mathrm{n} / \mathrm{a}$ & $\mathrm{n} / \mathrm{a}$ & $\sqrt{a}$ & na \\
\hline 39 & SO4 (Sulfate) & $\mathrm{ug} / \mathrm{mL}$ & Na & $n \mathrm{a}$ & $\mathrm{n} / \mathrm{a}$ & $\mathrm{n} / \mathrm{a}$ & n/a \\
\hline 40 & $\mathrm{Sr}$ & $\mathrm{ug} / \mathrm{mL}$ & n/a & na & $\mathrm{n} / \mathrm{a}$ & na & na \\
\hline 41 & $\pi i$ & $u g / m L$ & $n / a$ & n/a & $\cdots-$ & Na & n/a \\
\hline 42 & $\mathrm{~V}$ & $\mathrm{ug} / \mathrm{mL}$ & $\mathrm{n} / \mathrm{a}$ & $\mathrm{n} / \mathrm{a}$ & $n / a$ & n/a & $n / a$ \\
\hline 43. & Zn & $\mathrm{ug} / \mathrm{mL}$ & $\mathrm{n} / \mathrm{a}$ & $n / a$ & $n \sqrt{a}$ & $\mathrm{n} / \mathrm{a}$ & $n / a$ \\
\hline 44 & $\mathrm{Zr}$ & $\mathrm{ug} / \mathrm{mL}$ & na & $\mathrm{Na}$ & $\mathrm{n} / \mathrm{a}$ & $n / a$ & n/a \\
\hline 45 & Total Organic Carbon & $\mathrm{ug} / \mathrm{mL}$ & na & $n / a$ & n/a & $\mathrm{n} / \mathrm{a}$ & n/a \\
\hline 46 & Total Inorganic Carbon & $\mathrm{ug} / \mathrm{mL}$ & $\mathrm{n} / \mathrm{a}$ & na & $n / a$ & $\mathrm{n} / \mathrm{a}$ & na \\
\hline 47 & Suspended Solids & $w t \%$ & $r / a$ & na & $\mathrm{Na}$ & 8.75 & 10.11 \\
\hline 48 & Total Solids & $w t \%$ & na & na & $\mathrm{n} / \mathrm{a}$ & 40.73 & 41.51 \\
\hline 49 & Mean Particle Size by Volume & micron & $n / a$ & $\mathrm{n} / \mathrm{a}$ & 1.763 & $\mathrm{n} / \mathrm{a}$ & n/a \\
\hline 50 & Mean Particle Size by Number & micron & n/a & $\mathrm{n} / \mathrm{a}$ & 0.98 & Na & $\mathrm{N} / \mathrm{a}$ \\
\hline 51 & Kinematic Viscosity & centistoke & $\mathrm{n} / \mathrm{a}$ & 3.01 & $\mathrm{n} / \mathrm{s}$ & $5.5^{*}-$ & $\mathrm{n} / \mathrm{a}$ \\
\hline 52 & Dynamic Viscosity / Consistency & $\mathrm{cP}$ & na. & 3.84 & \begin{tabular}{|c|}
$\mathrm{N} / \mathrm{a}$ \\
\end{tabular} & $7.4^{*}$ & $n \sqrt{a}$ \\
\hline 53 & Comment & & & & high $\mathrm{pH}$ diluent/sonication & "Consistency & \\
\hline
\end{tabular}

Table E1: Analytical - All data, Page 5 


\begin{tabular}{|c|c|c|c|c|c|c|c|}
\hline & Al & Al & AK & $\mathrm{AL}$ & AM & AN & $\mathrm{AO}$ \\
\hline 1 & TEST RUN & 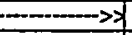 & end 1.08 & end 1.08 & end 1.08 & end 1.08 & end 1.08 \\
\hline 2 & BNFL Sample ID & $\cdots \cdots$ & N/A & N/A & Prefix_14 & Prefix_15 & Prefix_16 \\
\hline 3 & ADS Sample ID & 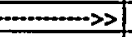 & N/A & N/A & $3-135895$ & N/A & 3-135896 \\
\hline 4 & Type Sample & $\rightarrow$ & slurry & filtrate & slurry & slutry & slumy \\
\hline 5 & Sample Size ............ & \begin{tabular}{|l|l}
$\mathrm{mL}$ & \\
\end{tabular} & 100 returned & 100 returned & 15 & 250 & 15 \\
\hline 6 & Measurement(s) Made .................... & $m>>$ & DENSITY ONLY & DENSITY \& VISCOSITY & MICROTRAC & TS/SS-VISCOSITY & TSISS \\
\hline 7 & Item Measured & Units & $\therefore+\cdots+\cdots$ & 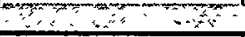 & $\therefore \cdots$ & $\therefore>3+\cdots$ & -2 \\
\hline 8 & Density & $g / m L$ & 1.459 & 1281 & 1.459 & 1.470 & 1.459 \\
\hline 9 & Al & $\mathrm{ug} / \mathrm{mL}$ & $n / a$ & $n / a$ & n/a & $n / a$ & $n / a$ \\
\hline 10. & $B$ & $u g / m L$ & n/a & $n / a$ & n/a & $n / a$ & $\mathrm{n} / \mathrm{a}$ \\
\hline 11 & $\mathrm{Ba}$ & $u g / \mathrm{mL}$ & $n / a$ & $\mathrm{n} / \mathrm{a}$ & $\mathrm{n} / \mathrm{a}$ & n/a & n/a \\
\hline 12 & $\overline{\mathrm{Ca}}$ & $\mathrm{ug} / \mathrm{mL}$ & $n / a$ & $\mathrm{n} / \mathrm{a}$ & $n / a$ & $n / a$ & $\mathrm{n} / \mathrm{a}$ \\
\hline 13 & Cd & $\underline{u} / / \mathrm{mL}$ & $n / a$ & $n / a$ & $\mathbf{n} / \mathbf{a}$ & $n \sqrt{a}$ & $\mathrm{n} / \mathrm{a}$ \\
\hline 14 & $\mathrm{Cl}$ & $\mathrm{ug} / \mathrm{mL}$ & n/a & $\mathrm{n} / \mathrm{a}$ & n/a & $\mathrm{n} / \mathrm{a}$ & $\mathrm{n} / \mathrm{a}$ \\
\hline 15 & Cl Sample & $u g / m L$ & $n / a$ & n/a & n/a & $n / a$ & $n / a$ \\
\hline 16 & $\mathrm{Co}$ & $u g / m L$ & $\mathrm{n} / \mathrm{a}$ & $\mathrm{na}$ & $\mathrm{n} / \mathrm{a}$ & n/a & $n / a$ \\
\hline 17 & Cr & $\mathrm{ug} / \mathrm{mL}$ & $\mathrm{n} / \mathrm{a}$ & $n / a$ & $\mathrm{n} / \mathrm{a}$ & $\mathrm{n} / \mathrm{a}$ & $\mathrm{n} / \mathrm{a}$ \\
\hline 18 & $\mathrm{Cu}$ & $\mathrm{ug} / \mathrm{mL}$ & n/a & $\mathrm{n} / \mathrm{a}$ & $n / a$ & $n / a$ & n/a \\
\hline 19 & F (Fluoride) [not accurate] & $\mathrm{ug} / \mathrm{mL}$ & n/a & $n / a$ & n/a & $\mathrm{n} / \mathrm{a}$ & $\mathrm{n} / \mathrm{a}$ \\
\hline 20 & F Sample (morg accurate result) & $\mathrm{ug} / \mathrm{mL}$ & na & $n / a$ & $\mathrm{n} / \mathrm{a}$ & $n / a$ & $n / a$ \\
\hline 21 & $\mathrm{Fe}$ & $\mathrm{ug} / \mathrm{mL}$ & n/a & $\mathrm{n} / \mathrm{a}$ & na & n/a & na \\
\hline 22 & HCOO (Formate) & $\mathrm{ug} / \mathrm{mL}$ & $n / a$ & $\mathrm{n} / \mathrm{a}$ & $n / a$ & $n / a$ & $n / a$ \\
\hline 23 & $K$ & $u g / m L$ & $n / a$ & $n / a$ & $n / a$ & $\mathrm{n} / \mathrm{a}$ & $n / a$ \\
\hline 24. & La & $u g / \mathrm{mL}$ & $\mathrm{n} / \mathrm{a}$ & n/a & $n / a$ & $n / a$ & $n / a$ \\
\hline 25 & LI & $u g / \mathrm{mL}$ & $n / a$ & n/a & $\mathrm{n} / \mathrm{a}$ & $n / a$ & $n / a$ \\
\hline 26 & $\mathrm{Mg}$ & $\mathrm{ug} / \mathrm{mL}$ & $n / a$ & $\mathrm{n} / \mathrm{a}$ & $\mathrm{n} / \mathrm{a}$ & n/a & $\mathrm{n} / \mathrm{a}$ \\
\hline 27 & $\overline{M n}$ & $\mathrm{ug} / \mathrm{mL}$ & n/a & $\mathrm{Na}$ & $n / a$ & $n / a$ & $\mathrm{n} / \mathrm{a}$ \\
\hline 28. & Mo & $\mathrm{ug} / \mathrm{mL}$ & $n / a$ & $n / a$ & $n / a$ & n/a & n/a \\
\hline 29 & $\mathrm{Na}$ & $u g / \mathrm{mL}$ & $\mathrm{n} / \mathrm{a}$ & $\mathrm{n} / \mathrm{a}$ & n/a & $\mathrm{n} / \mathrm{a}$ & $n / a$ \\
\hline 30 & $\mathrm{NI}$ & $\mathrm{ug} / \mathrm{mL}$ & $n / a$ & $n / a$ & na & $\mathrm{n} / \mathrm{a}$ & $\mathrm{n} / \mathrm{a}$ \\
\hline 31 & NO2 (Nitrite) & $u g / \mathrm{mL}$ & $\mathrm{N} / \mathrm{a}$ & $n / a$ & $n / a$ & $n / a$ & $n / a$ \\
\hline 32 & NO3 (Nitrate) & $u g / \mathrm{mL}$ & $\mathrm{n} / \mathrm{a}$ & $n / a$ & n/a & n/a & $\mathrm{n} / \mathrm{a}$ \\
\hline 33 & C204 (Oxalate) & $u g / \mathrm{mL}$ & $n / a$ & $n / a$ & $n / a$ & $\mathrm{n} / \mathrm{a}$ & n/a \\
\hline 34 & $\mathbf{P}$ & $u g / \mathrm{mL}$ & $n / a$ & n/a & $\mathrm{n} / \mathrm{a}$ & $\mathrm{n} / \mathrm{a}$ & $n / a$ \\
\hline 35 & PO4 (Phosphate) & $\mathrm{ug} / \mathrm{mL}$ & $n / a$ & $n / a$ & $n / a$ & $n / a$ & $\mathrm{n} / \mathrm{a}$ \\
\hline 36 & $\mathrm{~Pb}$ & $\mathrm{ug} / \mathrm{mL}$ & $n / a$ & $n / a$ & $n / a$ & $\mathrm{n} / \mathrm{a}$ & n/a \\
\hline 37 & SI & $\mathrm{ug} / \mathrm{mL}$ & $n / a$ & $\mathrm{n} / \mathrm{a}$ & $n / a$ & $n / a$ & n/a \\
\hline 38 & Sn & $\mathrm{ug} / \mathrm{mL}$ & $n / a$ & $n / a$ & $n / a$ & $n / a$ & $\mathrm{n} / \mathrm{a}$ \\
\hline 39 & SO4 (Sulfate) & $\mathrm{ug} / \mathrm{mL}$ & $\mathrm{n} / \mathrm{a}$ & $n / a$ & $n / a$ & n/a & n/a \\
\hline 40 & Sr & $\mathrm{ug} / \mathrm{mL}$ & $\mathrm{n} / \mathrm{a}$ & $\mathrm{n} / \mathrm{a}$ & $\mathrm{n} / \mathrm{a}$ & n/a & na \\
\hline 41 & $\mathrm{TI}$ & $u g / \mathrm{mL}$ & $n / a$ & $\mathrm{n} / \mathrm{a}$ & $n / a$ & $n / a$ & $\mathrm{n} / \mathrm{a}$ \\
\hline 42 & 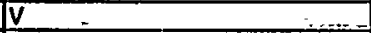 & $-u g / m L$ & $n / a$ & $n / a$ & $\mathrm{n} / \mathrm{a}$ & $n / a$ & $n / a$ \\
\hline 43 & $\mathrm{Zn} \cdot$ & $\mathrm{ug} / \mathrm{mL}$ & $n / a$ & $\mathrm{n} / \mathrm{a}$ & $n / a$ & $n / a$ & $n / a$ \\
\hline 44 & $\mathrm{Zr}$ & $\mathrm{ug} / \mathrm{mL}$ & $\mathbf{n a}$ & $\mathrm{n} / \mathrm{a}$ & n/a & n/a & $\mathrm{n} / \mathrm{a}$ \\
\hline 45 & Total Oiganic Carbon & $\mathrm{ug} / \mathrm{mL}$ & $n / a$ & $n / a$ & $\mathrm{n} / \mathbf{a}$ & n/a & $n / a$ \\
\hline 46 & Total Inorganic Carbon & $\mathrm{ug} / \mathrm{mL}$ & $n / a$ & n/a & $n / a$ & $\mathbf{n} / \mathbf{a}$ & n/a \\
\hline 47 & Suspended Solids & $w t \%$ & $\mathrm{n} / \mathrm{a}$ & $n / a$ & n/a & 22.11 & 18.92 \\
\hline 48 & Total Solids & $w t \%$ & $n / a$ & $n / a$ & n/a & 49.44 & 47.24 \\
\hline 49 & Mean Particlo Sizo by Volume & micron & $\mathrm{n} / \mathrm{a}$ & $\mathrm{n} / \mathrm{a}$ & $1.573(85 \%) / 6.366(15 \%)$ & $n / a$ & $\mathrm{n} / \mathrm{a}$ \\
\hline 50 & Mean Particle Size by Numbor & micron & $n / a$ & n/a & 0.98 & $\mathbf{n} / \mathbf{a}$ & $n / a$ \\
\hline 51 & KInemalic Viscosity & centistoke & $\mathrm{n} / \mathrm{a}$ & 3.08 & $n / s$ & $15.9^{*}$ & $n / a$ \\
\hline 52 & Dynamic Viscosity / Consistency & $\mathrm{CP}$ & $n / a$ & 3.95 & $\mathrm{n} / \mathrm{a}$ & $23.4^{*}$ & $\mathrm{n} / \mathrm{a}$ \\
\hline 53 & Comment & & & & high pH diluent/sonication & "Consistency & SS may be low \\
\hline
\end{tabular}

Table E1: Analytical - All data, Page 6 


\begin{tabular}{|c|c|c|c|c|c|c|c|}
\hline & $\mathrm{AP}$ & $A Q$ & AR & AS & AT & $\mathrm{AU}$ & AV \\
\hline 1 & TEST RUN -... & -...- & end 1.08 & end 1.08 & 1.10 & 1.10 & 1.10 \\
\hline 2 & 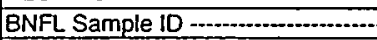 & $\ldots$ & Prefix_COIL & N/A & Prefix_17 & Prefix_18 & Prefix_19 \\
\hline 3 & ADS Sample ID & $-\cdots \cdots$ & $3 \cdot 135942$ & N/A & $3-135938$ & N/A & $3-135939$ \\
\hline 4 & 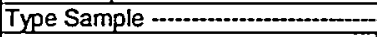 & $-\cdots>>$ & slurry from near coil & slurry from near coil & slurry & slurry & slurry \\
\hline 5 & Sample Size - - & $\mathrm{mL}$ & 15 & 125 & 15 & 250 & 15 \\
\hline 6 & Measurement(s) Made ........... & $\ldots+\cdots$ & TS/SS & TS-VISCOSITY & MICROTRAC & TSISS-VISCOSITY & TSISS \\
\hline 7 & Item Measured & Units & 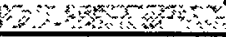 & $\therefore=2+8$ & 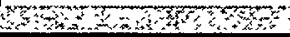 & 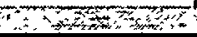 & 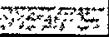 \\
\hline 8 & Density & $g / m L$ & n/a & N/a & 1.360 & 1.393 & 1.360 \\
\hline 9 & Al & $\mathrm{ug} / \mathrm{mL}$ & $\mathrm{n} / \mathrm{a}$ & n/a & $n / a$ & $\mathbf{n} / \mathbf{a}$ & $\mathrm{n} / \mathrm{a}$ \\
\hline 10 & $\mathrm{~B}$ & $\mathrm{ug} / \mathrm{mL}$ & $\mathrm{n} / \mathrm{a}$ & n/a & $n \sqrt{a}$ & $\mathrm{n} / \mathrm{a}$ & n/a \\
\hline 11 & $\mathrm{Ba}$ & $\mathrm{ug} / \mathrm{mL}$ & $\mathrm{n} / \mathrm{a}$ & na & $\mathrm{Na}$ & $\mathrm{n} / \mathrm{a}$ & $n / a$ \\
\hline 12 & $\mathrm{Ca}$ & $\mathrm{ug} / \mathrm{mL}$ & $\mathrm{n} / \mathrm{a}$ & n/a & $n / a$ & n/a & $\mathrm{n} / \mathrm{a}$ \\
\hline 13 & Cd & $\mathrm{ug} / \mathrm{mL}$ & $\mathrm{n} / \mathrm{a}$ & $\mathrm{n} / \mathrm{a}$ & $n \sqrt{a}$ & $\mathrm{n} / \mathrm{a}$ & $\mathrm{n} / \mathrm{a}$ \\
\hline 14 & $\mathrm{Cl}$ & $\mathrm{ug} / \mathrm{mL}$ & n/a & n/a & n/a & $n / a$ & $n / a$ \\
\hline 15 & Cl Sample & $\mathrm{ug} / \mathrm{mL}$ & na & $\mathrm{n} / \mathrm{a}$ & n/a & $n / a$ & $\mathrm{n} / \mathrm{a}$ \\
\hline 16 & Co & $\mathrm{ug} / \mathrm{mL}$ & na & na & $\mathrm{n} / \mathrm{a}$ & $n / a$ & $\mathrm{n} / \mathrm{a}$ \\
\hline 17 & $\mathrm{Cr}$ & $\mathrm{ug} / \mathrm{mL}$ & na & na & $\mathrm{n} / \mathrm{a}$ & n/a & n/a \\
\hline 18 & $\mathrm{Cu}$ & $\mathrm{ug} / \mathrm{mL}$ & $\mathrm{n} / \mathrm{a}$ & n/a & na & $\mathrm{n} / \mathrm{a}$ & n/a \\
\hline 19 & F (Fiuoride) [not accurate] & $\mathrm{ug} / \mathrm{mL}$ & $\mathrm{n} / \mathrm{a}$ & na & n/a & na & n/a \\
\hline 20 & F Sample (more accurate result) & $\mathrm{ug} / \mathrm{mL}$ & $\mathrm{Na}$ & n/a & Na & $n / a$ & n/a \\
\hline 21 & $\mathrm{Fe}$ & $\mathrm{ug} / \mathrm{mL}$ & Na & n/a & $n / a$ & $n / a$ & n/a \\
\hline 22 & HCOO (Formate) & $\mathrm{ug} / \mathrm{mL}$ & na & na & na & $\mathrm{n} / \mathrm{a}$ & n/a \\
\hline 23 & $\mathrm{~K}$ & $\mathrm{ug} / \mathrm{mL}$ & $\mathrm{n} / \mathrm{a}$ & $\mathrm{n} / \mathrm{a}$ & n/a & n/a & $n / a$ \\
\hline 24 & La & $\mathrm{ug} / \mathrm{mL}$ & $n / a$ & na & n/a & na & $\mathrm{n} / \mathrm{a}$ \\
\hline 25 & i & $\mathrm{ug} / \mathrm{mL}$ & $\sqrt{a}$ & $\mathrm{n} / \mathrm{a}$ & n/a & $\mathrm{n} / \mathrm{a}$ & na \\
\hline 26 & $\mathrm{Mg}$ & $\mathrm{ug} / \mathrm{mL}$ & $n / a$ & $\mathrm{n} / \mathrm{a}$ & $\mathrm{n} / \mathrm{a}$ & $\mathrm{Na}$ & $n / a$ \\
\hline 27 & $M n$ & $\mathrm{ug} / \mathrm{mL}$ & $n / a$ & $\mathrm{na}$ & $\mathrm{n} / \mathrm{a}$ & $n / a$ & na \\
\hline 28 & Mo & $\mathrm{ug} / \mathrm{mL}$ & n/a & $\pi / a$ & Na & n/a & n/a \\
\hline 29 & $\mathrm{Na}$ & $\mathrm{ug} / \mathrm{mL}$ & $n / a$ & na & n/a & n/a & $\mathrm{Na}$ \\
\hline 30 & $\mathrm{Ni}$ & $\mathrm{ug} / \mathrm{mL}$ & $n / a$ & $\mathrm{n} / \mathrm{a}$ & na & na & $n / a$ \\
\hline 31 & NO2 (Nitrite) & $\mathrm{ug} / \mathrm{mL}$ & $n / a$ & $n / a$ & $\mathrm{n} / \mathrm{a}$ & na & na \\
\hline 32 & NO3 (Nitrate) & $\mathrm{ug} / \mathrm{mL}$ & n/a & $n / a$ & $n / a$ & na & $n / a$ \\
\hline 33 & C2O4 (Oxalate) & $\mathrm{ug} / \mathrm{mL}$ & na & $\mathrm{n} / \mathrm{a}$ & $\mathrm{n} / \mathrm{a}$ & n/a & $n / a$ \\
\hline 34 & $P$ & $\mathrm{ug} / \mathrm{mL}$ & $\mathrm{na}$ & na & n/a & $\mathrm{na}$ & $n / a$ \\
\hline 35 & PO4 (Phosphate) & $u g / m L$ & $\mathrm{n} / \mathrm{a}$ & $\mathrm{n} / \mathrm{a}$ & na & Na & $n \sqrt{a}$ \\
\hline 36 & $\mathrm{~Pb}$ & $\mathrm{ug} / \mathrm{mL}$ & $\mathrm{n} / \mathrm{a}$ & $\mathrm{na}$ & na & na & $n / a$ \\
\hline 37 & Si & $\mathrm{ug} / \mathrm{mL}$ & $n / a$ & $n / a$ & $n / a$ & n/a & $n \sqrt{a}$ \\
\hline 38 & Sn & $\mathrm{ug} / \mathrm{mL}$ & $n / 2$ & $n / a$ & $n / a$ & $\mathrm{n} / \mathrm{a}$ & na \\
\hline 39 & SO4 (Sulfate) & $\mathrm{ug} / \mathrm{mL}$ & $n / a$ & $n / a$ & $n / a$ & na & $n / a$ \\
\hline 40 & $\mathrm{Sr}$ & $\mathrm{ug} / \mathrm{mL}$ & n/a & $n / a$ & $n / a$ & $\mathrm{na}$ & $n / a$ \\
\hline 41 & $\pi$ & $\mathrm{ug} / \mathrm{mL}$ & $\mathrm{n} / \mathrm{a}$ & $\mathrm{n} / \mathrm{a}$ & na & $\mathrm{Na}$ & $\mathrm{n} / \mathrm{a}$ \\
\hline 42 & $\underline{V}$ & $\mathrm{ug} / \mathrm{mL}$ & $\mathrm{n} / \mathrm{a}$ & $n / a$ & $\cdots n a$ & $\mathrm{Na}$ & na \\
\hline 43 & $\mathrm{Zn}$ & $\mathrm{ug} / \mathrm{mL}$ & $n / a$ & $\mathrm{n} / \mathrm{a}$ & $n / a$ & $\mathrm{n} / \mathrm{a}$ & na \\
\hline 44 & $\mathrm{Zr}$ & $\mathrm{ug} / \mathrm{mL}$ & $n / a$ & $n / a$ & $n / a$ & na & n/a \\
\hline 45 & Total Organic Carbon & $\mathrm{ug} / \mathrm{mL}$ & na & $n / a$ & na & $\mathrm{Na}$ & na \\
\hline 46 & Total Inorganic Carbon & $\mathrm{ug} / \mathrm{mL}$ & $\mathrm{n} / \mathrm{a}$ & $\mathrm{n} / \mathrm{a}$ & $\mathrm{n} / \mathrm{a}$ & $\mathrm{na}$ & na \\
\hline 47 & Suspended Solids & wt\% & 17.15 & not measurable & $\mathrm{N} / \mathrm{a}$ & 14.25 & 11.80 \\
\hline 48 & Total Solids & $w+\%$ & 46.43 & 49.60 & $\mathrm{~N} / \mathrm{a}$ & 44.14 & 45.02 \\
\hline 49 & Mean Particle Size by Volume & micron & $n / a$ & $\mathrm{n} / \mathrm{a}$ & $1.543(85 \%) / 6.411(15 \%)$ & $\mathrm{n} / \mathrm{a}$ & na \\
\hline 50 & Mean Particle Size by Number & micron & na & $\mathrm{N} / \mathrm{a}$ & 0.795 & $\mathrm{na}$ & $n / a$ \\
\hline 51 & Kinematic Viscosity & centistoke & $n / a$ & $15.8^{\star}$ & $n / s$ & $8.3^{*}$ & $\mathrm{n} / \mathrm{a}$ \\
\hline 52 & Dynamic Viscosity / Consistency & $\mathrm{CP}$ & $\mathrm{n} / \mathrm{a}$ & $23^{*}$ & $\mathrm{~N} / \mathrm{a}$ & $11.6^{*}$ & $n / a$ \\
\hline 53 & Comment & & & "Consistency & high $\mathrm{pH}$ diluent/sonication & "Consistency & \\
\hline
\end{tabular}




\begin{tabular}{|c|c|c|c|c|c|c|c|}
\hline & AW & AX & AY & $A Z$ & $\mathrm{BA}$ & $\mathrm{BB}$ & BC \\
\hline 1 & TEST RUN & $\cdots+\cdots$ & 1.10 & 1.10 & WASH 1 & WASH 1 & WASH 1 \\
\hline 2 & 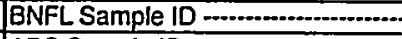 & $m \cdots \cdots$ & Prefix_20a & Prefix_20b & N/A & Prefix_21 & Prefix_22a \\
\hline 3 & ADS Sample ID & $\ldots-\cdots>$ & $3-135940$ & 3-135941 & N/A & 3-136211 & $3-136212$ \\
\hline 4 & Type Sample & $\ldots$ & filtrate & filtrate & filtrate & filtrate & filtrate \\
\hline 5 & Sample Size $\ldots$ & $\mathrm{mL}$ & 15 & 15 & 100 retumed & 15 & 15 \\
\hline 6 & 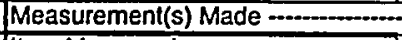 & 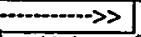 & ICP-ESNC-ANIONS & AATIC-TOC/ISE & DENSITY \& VISCOSITY & TSISS & ICP-ESIC-ANIONS \\
\hline 7 & Item Measured & Units & 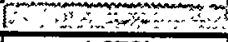 & 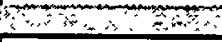 & 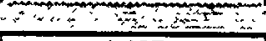 & $\because-3+3$ & 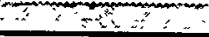 \\
\hline 8 & Density & $\mathrm{g} / \mathrm{mL}$ & $1.276^{\circ}$ & $1.276^{*}$ & 1.127 & 1.127 & \begin{tabular}{|l|}
1.127 \\
\end{tabular} \\
\hline 9 & A & $\mathrm{ug} / \mathrm{mL}$ & 224 & $n / a$ & $n / a$ & $n / a$ & 96 \\
\hline 10 & $B$ & $\mathrm{ug} / \mathrm{mL}$ & 22 & $\mathrm{n} / \mathrm{a}$ & $\mathrm{n} / \mathrm{a}$ & $\mathrm{n} / \mathrm{a}$ & 8.4 \\
\hline 11 & $B a$ & $\mathrm{ug} / \mathrm{mL}$ & $<0.02$ & $n / 2$ & $\mathrm{n} / \mathrm{a}$ & $n / a$ & 0.14 \\
\hline 12 & $\mathrm{Ca}$ & $\mathrm{ug} / \mathrm{mL}$ & 132 & $n / a$ & $n / a$ & $n / a$ & 65 \\
\hline 13. & Cd & $u g / m L$ & $<0.02$ & $n / a$ & $\mathrm{n} / \mathrm{a}$ & $\mathrm{na}$ & $<0.02$ \\
\hline 14 & $\mathrm{Cl}$ & $\mathrm{ug} / \mathrm{mL}$ & 1517 & $n / a$ & $n / a$ & $n / a$ & 508 \\
\hline 15 & Cl Sample & $\mathrm{ug} / \mathrm{mL}$ & $n / a$ & 1368 & n/a & $\mathrm{n} / \mathrm{a}$ & $\mathrm{n} / \mathbf{a}$ \\
\hline 16 & Co & $\mathrm{ug} / \mathrm{mL}$ & $<0.05$ & $n / a$ & $n / a$ & na & $<0.05$ \\
\hline 17 & $\overline{C r}$ & $\mathrm{ug} / \mathrm{mL}$ & 0.62 & $n / a$ & $\mathrm{n} / \mathrm{a}$ & n/a & 0.32 \\
\hline 18 & $\mathrm{Cu}$ & $\mathrm{ug} / \mathrm{mL}$ & 12.6 & $\mathrm{n} / \mathrm{a}$ & $\mathrm{n} / \mathrm{a}$ & n/a & 9.18 \\
\hline 19 & F (Fluoride) [not accurate] & $\mathrm{ug} / \mathrm{mL}$ & 2388 & $n / a$ & $\mathbf{n} / \mathbf{a}$ & $n / a$ & 921 \\
\hline 20 & F Sample (more accurate result) & $\mathrm{ug} / \mathrm{mL}$ & $\mathrm{n} / \mathrm{a}$ & 286 & n/a & $\mathrm{n} / \mathrm{a}$ & n/a \\
\hline 21 & $\mathrm{Fe}$ & $\mathrm{ug} / \mathrm{mL}$ & 29.5 & na & n/a & $\mathrm{n} / \mathrm{a}$ & 7.32 \\
\hline 22 & HCOO (Formate) & $\mathrm{ug} / \mathrm{mL}$ & 6852 & n/a & $\mathrm{n} / \mathrm{a}$ & $\mathrm{n} / \mathrm{a}$ & 2996 \\
\hline 23 & $\mathrm{~K}$ & $\mathrm{ug} / \mathrm{mL}$ & n/a & 1157.35 & $n / a$ & na & $n / a$ \\
\hline 24 & La & $U \mathrm{~g} / \mathrm{mL}$ & 0.82 & $\mathrm{n} / \mathrm{a}$ & na & $\pi / a$ & 0.24 \\
\hline 25 & $\overline{\mathrm{i}}$ & $\mathrm{ug} / \mathrm{mL}$ & $<0.7$ & $\mathrm{n} / \mathrm{a}$ & $n / a$ & n/a & 0.10 \\
\hline 26 & $\overline{M g}$ & $\mathrm{ug} / \mathrm{mL}$ & 0.6 & $n / a$ & na & na & $<0.09$ \\
\hline 27 & $\mathrm{Mn}$ & $\mathrm{ug} / \mathrm{mL}$ & 15.3 & $n / a$ & $n / a$ & $\mathrm{n} / \mathrm{a}$ & 11.6 \\
\hline 28 & Mo & $\mathrm{ug} / \mathrm{mL}$ & 20.7 & $n / a$ & $\mathrm{n} / \mathrm{a}$ & $\mathrm{n} / \mathrm{a}$ & 8.6 \\
\hline 29 & $\mathrm{Na}$ & $\mathrm{ug} / \mathrm{mL}$ * & 126500 & na & $n / a$ & $n / a$ & 57551 \\
\hline 30 & $\mathrm{Ni}$ & $\mathrm{ug} / \mathrm{mL}$ & 287 & na & $n / a$ & $\mathrm{n} / \mathrm{a}$ & 123 \\
\hline 31 & NO2 (Nitrite) & $\mathrm{ug} / \mathrm{mL}$ & 35347 & $\mathrm{n} / \mathrm{a}$ & $n / a$ & $\mathrm{na}$ & 14371 \\
\hline 32 & NO3 (Nitrate) & ug/mL & 132935 & $\mathrm{n} / \mathrm{a}$ & $n / a$ & $\mathrm{n} / \mathrm{a}$ & 58090 \\
\hline 33 & C2O4 (Oxalate) & $\mathrm{ug} / \mathrm{mL}$ & 909 & $\mathrm{n} / \mathrm{a}$ & $\mathrm{n} / \mathrm{a}$ & $\mathrm{n} / \mathrm{a}$ & 3241 \\
\hline 34 & $P$ & $\mathrm{ug} / \mathrm{mL}$ & 269 & $n / a$ & $\mathrm{n} / \mathrm{a}$ & n/a & 114 \\
\hline 35 & PO4 (Phosphate) & $\mathrm{ug} / \mathrm{mL}$ & 1142 & $\mathrm{n} / \mathrm{a}$ & n/a & $n / a$ & 938 \\
\hline 36 & $\mathrm{~Pb}$ & $\mathrm{ug} / \mathrm{mL}$ & $<0.5$ & $\mathrm{n} / \mathrm{a}$ & $\mathrm{n} / \mathrm{a}$ & $n / a$ & $<0.6$ \\
\hline 37 & Si & $\underline{u} / \mathrm{mL}$ & 13 & $\mathrm{n} / \mathrm{a}$ & $n / a$ & $n / a$ & 4.5 \\
\hline 38 & Sn . & $\mathrm{ug} / \mathrm{mL}$ & $<0.4$ & n/a & na & n/a & $<0.26$ \\
\hline 39 & SO4 (Sulfate) & ug/mL & 4572 & $\mathrm{n} / \mathrm{a}$ & na & $\mathrm{n} / \mathrm{a}$ & 1993 \\
\hline 40 & $\mathrm{Sr}$ & $\mathrm{ug} / \mathrm{mL}$ & 87 & $n / a$ & n/a & $n / a$ & 47.1 \\
\hline 41 & $\mathrm{TI}$ & $u g / m L$ & $<0.05$ & na & $\ldots$ n/a. & $n / a$ & $<0.14$ \\
\hline 42 & V & $\mathrm{ug} / \mathrm{mL}$ & $<0.12$ & n/a & n/a & $\mathrm{n} / \mathrm{a}$ & $<0.13$ \\
\hline 43 & Zn & $\mathrm{ug} / \mathrm{mL}$ & 16 & $n / a$ & $\mathrm{n} / \mathrm{a}$ & $\mathrm{n} / \mathrm{a}$ & 6.4 \\
\hline 44 & $\mathrm{Zr}$ & $\mathrm{ug} / \mathrm{mL}$ & 2.7 & $n / a$ & $n \sqrt{a}$ & $\mathrm{n} / \mathbf{a}$ & 0.26 \\
\hline 45 & Total Organic Carbon & $\mathrm{ug} / \mathrm{mL}$ & $n / a$ & 10500 & $\mathrm{n} / \mathrm{a}$ & na & n/a \\
\hline 46 & Total Inorganic Carbon & $u g / m L$ & na & 10080 & na & n/a & $\mathrm{n} / \mathrm{a}$ \\
\hline 47 & Suspended Solids & $w t \%$ & na & $n / a$ & $\mathrm{n} / \mathrm{a}$ & 0.015 & $\mathrm{n} / \mathrm{a}$ \\
\hline 48 & Total Solids & $w t \%$ & $\mathrm{n} / \mathrm{a}$ & na & $n / a$ & 16.86 & $\mathrm{n} / \mathrm{a}$ \\
\hline 49 & Mean Particle Size by Volume & micron & $\mathrm{n} / \mathrm{a}$ & $n / a$ & $n \sqrt{a}$ & $\mathrm{n} / \mathrm{a}$ & $\mathrm{n} / \mathrm{a}$ \\
\hline 50 & Mean Particle Size by Number & micron & na & $\mathrm{n} / \mathrm{a}$ & na & $n / a$ & $\mathrm{n} / \mathrm{a}$ \\
\hline 51 & Kinematic Viscosity & centistoke & $n \sqrt{a}$ & $n / a$ & 1.33 & $\mathrm{n} / \mathrm{a}$ & $\mathrm{n} / \mathrm{a}$ \\
\hline 52 & Dynamic Viscosity/Consistency & $\mathbf{C P}$ & $\mathrm{n} / \mathrm{a}$ & $\mathbf{n} / \mathbf{a}$ & 1.50 & $\mathrm{n} / \mathrm{a}$ & Na \\
\hline 53 & Comment & & "density estimated & "density estimated & & & \\
\hline
\end{tabular}

Table E1: Analytical - All data, Page 8 


\begin{tabular}{|c|c|c|c|c|c|c|c|}
\hline & $\mathrm{BD}$ & $\mathrm{BE}$ & $B F$ & $\mathrm{BG}$ & $\mathrm{BH}$ & $\mathrm{BI}$ & B.J \\
\hline 1 & TEST RUN & $\cdots \cdots \cdots$ & WASH 1 & WASH 2 & WASH 2 & WASH 2 & WASH 2 \\
\hline 2 & BNFL Sample ID & $\cdots \cdots$ & Prefix_22b & N/A & Prefix_23 & Prefix_24a & Prefix_24b \\
\hline 3 & ADS Sample ID & $\cdots \cdots>>$ & $3-136213$ & N/A & $3-136214$ & $3-136215$ & $3-136216$ \\
\hline 4 & Type Sample - - & $\cdots \cdots$ & filtrate & filtrate & filtrate & filtrate & filtrate \\
\hline 5 & Sample Size & $\mathrm{mL}$ & 15 & 100 returned & 15 & 15 & 15 \\
\hline 6 & Measurement(s) Made -............. & $\cdots \cdots$ & AAVTIC-TOC/ISE & DENSITY \& VISCOSITY & .TS/SS & ICP-ES/IC-ANIONS & AATIC-TOC $/ \mathrm{SE}$ \\
\hline 7 & Item Measured & Units & Whatisis & 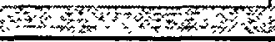 & F & 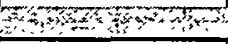 & 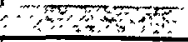 \\
\hline 8 & Density & $g / m L$ & 1.127 & 1.059 & 1.059 & \begin{tabular}{|c|}
1.059 \\
\end{tabular} & 1.059 \\
\hline 9 & Al & $\mathrm{ug} / \mathrm{mL}$ & $\mathrm{n} / \mathrm{a}$ & $n / a$ & $\mathrm{n} / \mathrm{a}$ & 36 & n/a \\
\hline 10 & $\mathrm{~B}$ & $\mathrm{ug} / \mathrm{mL}$ & $\mathrm{n} / \mathrm{a}$ & $n / a$ & n/a & 3.20 & $n / a$ \\
\hline 11 & $\mathrm{Ba}$ & $\mathrm{ug} / \mathrm{mL}$ & $\mathrm{n} / \mathrm{a}$ & $\mathrm{n} / \mathrm{a}$ & n/a & 0.05 & $n / a$ \\
\hline 12 & $\mathrm{Ca}$ & $\mathrm{ug} / \mathrm{mL}$ & $n / a$ & $\mathrm{n} / \mathrm{a}$ & $n / a$ & 26 & $n \sqrt{a}$ \\
\hline 13 & $\mathrm{Cd}$ & $\mathrm{ug} / \mathrm{mL}$ & $\mathrm{n} / \mathrm{a}$ & $n / a$ & $\mathrm{n} / \mathrm{a}$ & $<0.02$ & $n / a$ \\
\hline 14 & $\mathrm{Cl}$ & $\mathrm{ug} / \mathrm{mL}$ & $\mathrm{n} / \mathrm{a}$ & $\mathrm{n} / \mathrm{a}$ & $\mathrm{n} / \mathrm{a}$ & 229 & $n / a$ \\
\hline 15 & CI Sample & $\mathrm{ug} / \mathrm{mL}$ & 546 & $n / a$ & $n / a$ & $n / a$ & 224 \\
\hline 16 & Co & $\mathrm{ug} / \mathrm{mL}$ & $n / a$ & $\mathrm{n} / \mathrm{a}$ & $n / a$ & $<0.05$ & $\mathrm{n} / \mathrm{a}$ \\
\hline 17 & $\mathrm{Cr}$ & $\mathrm{ug} / \mathrm{mL}$ & $n / a$ & $\mathrm{na}$ & $n / a$ & 0.14 & $\mathrm{n} / \mathrm{a}$ \\
\hline 18 & $\mathrm{Cu}$ & $\mathrm{ug} / \mathrm{mL}$ & $n / a$ & $\mathrm{n} / \mathrm{a}$ & $n / a$ & 3.9 & $\mathrm{n} / \mathrm{a}$ \\
\hline 19 & $F$ (Fluoride) [not accurate] & $\mathrm{ug} / \mathrm{mL}$ & $\mathrm{n} / \mathrm{a}$ & $\mathrm{n} / \mathrm{a}$ & $\mathrm{n} / \mathrm{a}$ & 360 & $\mathrm{n} / \mathrm{a}$ \\
\hline 20 & F Sample (more accurate result) & $\mathrm{ug} / \mathrm{mL}$ & 78.11 & $n / a$ & $\mathrm{n} / \mathrm{a}$ & $n / a$ & 40.25 \\
\hline 21 & $\mathrm{Fe}$ & $\mathrm{ug} / \mathrm{mL}$ & $\mathrm{n} / \mathrm{a}$ & $\mathrm{n} / \mathrm{a}$ & $n / a$ & 2.1 & $n / a$ \\
\hline 22 & HCOO (Formate) & $\mathrm{ug} / \mathrm{mL}$ & $\mathrm{n} / \mathrm{a}$ & na & n/a & 1106 & n/a \\
\hline 23. & $\mathrm{~K}$ & $\mathrm{ug} / \mathrm{mL}$ & 436.67 & na. & $n / a$ & $n / a$ & 168.82 \\
\hline 24 & La & $\mathrm{ug} / \mathrm{mL}$ & $\mathrm{n} / \mathrm{a}$ & $\mathrm{n} / \mathrm{a}$ & $n / a$ & 0.08 & $\mathrm{n} / \mathrm{a}$ \\
\hline 25 & $\mathrm{Li}$ & $\mathrm{ug} / \mathrm{mL}$ & $n / a$ & $\mathrm{n} / \mathrm{a}$ & na & $<0.1$ & $\mathrm{n} / \mathrm{a}$ \\
\hline 26 & $\mathrm{Mg}$ & $\mathrm{ug} / \mathrm{mL}$ & $\mathrm{n} / \mathrm{a}$ & $n / a$ & $n / a$ & $<0.09$ & $\mathrm{n} / \mathrm{a}$ \\
\hline 27 & $M n$ & $\mathrm{ug} / \mathrm{mL}$ & $\mathrm{n} / \mathrm{a}$ & $\mathrm{n} / \mathrm{a}$ & $n / a$ & 9.3 & $\mathrm{n} / \mathrm{a}$ \\
\hline 28 & Mo & $\mathrm{ug} / \mathrm{mL}$ & $n / a$ & $\mathrm{n} / \mathrm{a}$ & $\mathrm{n} / \mathrm{a}$ & 3.2 & $\mathrm{n} / \mathrm{a}$ \\
\hline 29 & $\mathrm{Na}$ & $\mathrm{ug} / \mathrm{mL}$ & $\mathrm{Na}$ & $n / a$ & $\mathrm{n} / \mathrm{a}$ & 25825 & $\mathrm{n} / \mathrm{a}$ \\
\hline 30 & $\mathrm{Ni}$ & $\mathrm{ug} / \mathrm{mL}$ & $\mathrm{n} / \mathrm{a}$ & $\mathrm{n} / \mathrm{a}$ & $\mathrm{n} / \mathrm{a}$ & 45 & $n / a$ \\
\hline 31 & NO2 (Nitrite) & $\mathrm{ug} / \mathrm{mL}$ & $\mathrm{n} / \mathrm{a}$ & $\mathrm{n} / \mathrm{a}$ & $n / a$ & 5326 & $\mathrm{n} / \mathrm{a}$ \\
\hline 32 & NO3 (Nitrate) & $\mathrm{ug} / \mathrm{mL}$ & $\mathrm{N} / \mathrm{a}$ & n/a & $\mathrm{n} / \mathrm{a}$ & 21716 & $\mathrm{n} / \mathrm{a}$ \\
\hline 33 & C2O4 (Oxalate) & $\mathrm{ug} / \mathrm{mL}$ & $\mathrm{N} / \mathrm{a}$ & $\mathrm{n} / \mathrm{a}$ & $\mathrm{n} / \mathrm{a}$ & 7672 & $\mathrm{n} / \mathrm{a}$ \\
\hline 34 & $\mathrm{P}$ & $u g / m L$ & $\mathrm{n} / \mathrm{a}$ & $\mathrm{n} / \mathrm{a}$ & $n / a$ & 34 & $\mathrm{n} / \mathrm{a}$ \\
\hline 35 & PO4 (Phosphate) & $\mathrm{ug} / \mathrm{mL}$ & $n / a$ & $n / a$ & $n / a$ & 437 & $\mathrm{n} / \mathrm{a}$ \\
\hline 36 & $\mathrm{~Pb}$ & $\mathrm{ug} / \mathrm{mL}$ & $\mathrm{n} / \mathrm{a}$ & $n / a$ & $n / a$ & $<0.6$ & $\mathrm{n} / \mathrm{a}$ \\
\hline 37 & $\mathrm{Si}$ & $\mathrm{ug} / \mathrm{mL}$ & $\mathrm{n} / \mathrm{a}$ & $\mathrm{n} / \mathrm{a}$ & n/a & 2.0 & $n / a$ \\
\hline 38 & Sn & $\mathrm{ug} / \mathrm{mL}$ & $\mathrm{n} / \mathrm{a}$ & n/a & $n / 2$ & $<0.26$ & $n / a$ \\
\hline 39 & SO4 (Sulfate) & $\mathrm{ug} / \mathrm{mL}$ & $\mathrm{n} / \mathrm{a}$ & $\mathrm{n} / \mathrm{a}$ & n/a & 770 & n/a \\
\hline 40 & $\mathrm{Sr}$ & $\mathrm{ug} / \mathrm{mL}$ & $\mathrm{n} / \mathrm{a}$ & $\mathrm{Na}$ & $\mathrm{n} / \mathrm{a}$ & 19.3 & n/a \\
\hline 41 & $\pi$ & $\mathrm{ug} / \mathrm{mL}$ & $\mathrm{n} / \mathrm{a}$ & $n / a$ & $n / a$ & $<0.14 \ldots .$. & na \\
\hline 42 & $\mathrm{~V}$ & $\mathrm{ug} / \mathrm{mL}$ & $\mathrm{n} / \mathrm{a}$ & $n / a$ & $\mathrm{n} / \mathrm{a}$ & $<0.13$ & $n / a$ \\
\hline 43 & $\mathrm{Zn}$ & $\mathrm{ug} / \mathrm{mL}$ & $\mathrm{n} / \mathrm{a}$ & $\mathrm{n} / \mathrm{a}$ & $\mathrm{n} / \mathrm{a}$ & 3.2 & $\mathrm{n} / \mathrm{a}$ \\
\hline 44 & $\mathrm{Zr}$ & $\mathrm{ug} / \mathrm{mL}$ & $\mathrm{n} / \mathrm{a}$ & na & $\mathrm{n} / \mathrm{a}$ & 0.06 & n/a \\
\hline 45 & Total Organic Carbon & $u g / \mathrm{mL}$ & 5428 & $n / a$ & $\mathrm{n} / \mathrm{a}$ & $\mathrm{n} / \mathrm{a}$ & 4408 \\
\hline 46 & Total Inorganic Carbon & $\mathrm{ug} / \mathrm{mL}$ & 7696 & $\mathrm{Na}$ & $n / a$ & $\mathrm{n} / \mathrm{a}$ & 4038 \\
\hline 47 & Suspended Solids & $w t \%$ & n/a & n/a & $<0.0001$ & $\mathrm{~N} / \mathrm{a}$ & $\mathrm{N} / \mathrm{a}$ \\
\hline 48 & Total Solids & $\mathrm{wt} \%$ & n/a & $\mathrm{n} / \mathrm{a}$ & 7.60 & $n / a$ & $\mathrm{n} / \mathrm{a}$ \\
\hline 49 & Mean Particle Size by Volume & micron & $n / a$ & $\mathrm{n} / \mathrm{a}$ & na & na & $n / a$ \\
\hline 50 & Mean Particle Size by Number & micron & na & $\mathrm{n} / \mathrm{a}$ & $\mathrm{n} / \mathrm{a}$ & $n \sqrt{a}$ & $n / a$ \\
\hline 51 & Kinematic Viscosity & centistoke & n/a & 1.18 & na & $\mathrm{n} / \mathrm{a}$ & na \\
\hline 52 & Dynamic Viscosity / Consistency & $\mathrm{CP}$ & $n / a$ & 1.25 & n/a & $\sqrt{a}$ & Na \\
\hline 53 & Comment & & & & & & \\
\hline
\end{tabular}

Table E1: Analytical - All data, Page 9 


\begin{tabular}{|c|c|c|c|c|c|c|c|}
\hline & BK & $B L$ & $\mathrm{BM}$ & $\mathrm{BN}$ & $\mathrm{BO}$ & $\mathrm{BP}$ & $\mathrm{BQ}$ \\
\hline 1 & 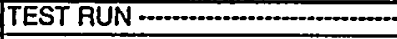 & $\ldots$ & WASH 3 & WASH 3 & WASH 3 & WASH 3 & WASH4 \\
\hline 2 & BNFL Sample ID & $m \cdots$ & N/A & Prefix_25 & Prefix_26a & Prefix_26b & N/A \\
\hline 3 & ADS Sample ID & $\longrightarrow$ & N/A & $3-136252$ & $3-136253$ & 3-136254 & N/A \\
\hline 4 & Type Sample & $m-\infty \infty$ & filtrate & filtrate & filtrate & filtrate & filtrate \\
\hline 5 & Sample Size $\ldots$ & \begin{tabular}{|c|}
$\mathrm{mL}$ \\
\end{tabular} & 100 retumed & 15 & 15 & 15 & 100 retumed \\
\hline 6 & Measurement(s) Made & $\rightarrow \infty$ & DENSITY \& VISCOSITY & TSISS & ICP-ES/IC-ANIONS & AATIC-TOC/ISE & DENSITY \& VISCOSITY \\
\hline 7 & Item Measured & Units & $=2 x^{2}=2 \div$ & $8=2$ & 20 & 8 & 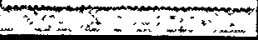 \\
\hline 8 & Density & $g / m L$ & 1.018 & 1.018 & 1.018 & 1.018 & \begin{tabular}{|r|}
1.009 \\
\end{tabular} \\
\hline 9 & $\overline{\mathbf{A}}$ & $u g / m L$ & $\mathrm{n} / \mathrm{a}$ & $n / a$ & 11 & $n / a$ & $\mathrm{n} / \mathrm{a}$ \\
\hline 10 & $\bar{B}$ & $\mathrm{ug} / \mathrm{mL}$ & na & n/a & 1.1 & $n / a$ & $\mathrm{n} / \mathrm{a}$ \\
\hline 11 & $B a$ & $\mathrm{ug} / \mathrm{mL}$ & $\mathrm{n} / \mathrm{a}$ & $n / a$ & $<0.01$ & $\mathrm{n} / \mathrm{a}$ & $\mathrm{n} / \mathrm{a}$ \\
\hline 12 & $\overline{\mathrm{Ca}}$ & $\mathrm{ug} / \mathrm{mL}$ & $\mathrm{n} / \mathrm{a}$ & na & 7.6 & $\mathrm{n} / \mathrm{a}$ & n/a \\
\hline 13 & $\overline{c d}$ & $\mathrm{ug} / \mathrm{mL}$ & n/a & na & $<0.02$ & n/a & $n / a$ \\
\hline 14 & Cl. & $\mathrm{ug} / \mathrm{mL}$ & $n / a$ & n/a & 83 & $n / a$ & $n / a$ \\
\hline 15 & CISample & $\mathrm{ug} / \mathrm{mL}$ & Na & $n / a$ & n/a & 66 & $n / a$ \\
\hline 16 & Co & $\mathrm{ug} / \mathrm{mL}$ & ina & n/a & $<0.05$ & $\mathrm{n} / \mathrm{a}$ & $n / a$ \\
\hline 17 & $\mathrm{Cr}$ & $\mathrm{ug} / \mathrm{mL}$ & $\mathrm{n} / \mathrm{a}$ & $n / a$ & $<0.1$ & $\mathrm{n} / \mathrm{a}$ & n/a \\
\hline 18 & $\mathrm{Cu}$ & $\mathrm{ug} / \mathrm{mL}$ & $n / a$ & n/a & 1.3 & $\mathrm{n} / \mathrm{a}$ & n/a \\
\hline 19 & F (Fluoride) [not accurate] & $\mathrm{ug} / \mathrm{mL}$ & $n / a$ & $\mathrm{n} / \mathrm{a}$ & 115 & $\mathrm{n} / \mathrm{a}$ & $n \sqrt{a}$ \\
\hline 20 & F Sample (more accurate result) & $\mathrm{ug} / \mathrm{mL}$ & $\mathrm{n} / \mathrm{a}$ & $\mathrm{n} / \mathrm{a}$ & $\mathrm{n} / \mathrm{a}$ & 12.75 & na \\
\hline 21 & $\mathrm{Fe}$ & $\mathrm{ug} / \mathrm{mL}$ & $\mathrm{n} / \mathrm{a}$ & n/a & 0.4 & $\mathrm{n} / \mathrm{a}$ & $n / a$ \\
\hline 22 & HCOO (Formate) & ug/mL & $n / a$ & $n / a$ & 325 & na & $\mathrm{N} / \mathrm{a}$ \\
\hline 23 & $\mathrm{~K}$ & $\mathrm{ug} / \mathrm{mL}$ & $n / a$ & n/a & $n / a$ & 54.93 & n/a \\
\hline 24 & La & $\mathrm{ug} / \mathrm{mL}$ & $n / a$ & $n / a$ & $<0.06$ & n/a & $\mathrm{n} / \mathrm{a}$ \\
\hline 25 & 4 & $u \mathrm{~g} / \mathrm{mL}$ & n/a & n/a & $<0.1$ & n/a & $\mathrm{n} / \mathrm{a}$ \\
\hline 26 & $\overline{M g}$ & $\mathrm{ug} / \mathrm{mL}$ & $n / a$ & $n / a$ & $<0.09$ & $\pi \sqrt{a}$ & $n / a$ \\
\hline 27 & $\mathrm{Mn}$ & $\mathrm{ug} / \mathrm{mL}$ & $n / a$ & $n / a$ & 2.40 & $n / a$ & $n / a$ \\
\hline 28 & Mo & $\mathrm{ug} / \mathrm{mL}$ & na & $n / a$ & 1 & $n / a$ & $n / a$ \\
\hline 29 & $\mathrm{Na}$ & $u g / m L$ & n/a & $n / a$ & 8245 & $n / a$ & $n / a$ \\
\hline 30 & $\mathrm{Ni}$ & $\mathrm{ug} / \mathrm{mL}$ & na & $n / a$ & 14 & $n / a$ & $\mathrm{n} / \mathrm{a}$ \\
\hline 31 & NO2 (Nitrite) & $\mathrm{ug} / \mathrm{mL}$ & $\mathrm{n} / \mathrm{a}$ & $n \sqrt{a}$ & 1628 & $n / a$ & $\mathrm{n} / \mathrm{a}$ \\
\hline 32 & NO3 (Nitrate) & $\mathrm{ug} / \mathrm{mL}$ & $n / a$ & $\mathrm{n} / \mathrm{a}$ & 6406 & $n / a$ & n/a \\
\hline 33 & C204 (Oxalate) & $\mathrm{ug} / \mathrm{mL}$ & $n / a$ & n/a & 2798 & n/a & $n / a$ \\
\hline 34 & $\mathrm{P}$ & $u g / m L$ & $n / a$ & n/a & 7 & $n / a$ & $n / a$ \\
\hline 35 & PO4 (Phosphate) & $\mathrm{ug} / \mathrm{mL}$ & $n / a$ & na & 195.00 & n/a & $n / a$ \\
\hline 36 & $\mathrm{~Pb}$ & $u g / \mathrm{mL}$ & $n / a$ & n/a & $<0.6$ & $\mathrm{n} / \mathrm{a}$ & $\mathrm{n} / \mathrm{a}$ \\
\hline 37 & SI & $\mathrm{ug} / \mathrm{mL}$ & n/a & n/a & 1 & $n / a$ & n/a \\
\hline 38 & Sn & $\mathrm{ug} / \mathrm{mL}$ & $n / a$ & $\mathrm{n} / \mathrm{a}$ & $<0.26$ & $\sqrt{a}$ & $n \sqrt{a}$ \\
\hline 39 & SO4 (Sulfate) & $\mathrm{ug} / \mathrm{mL}$ & $n / a$ & n/a & 289 & $n / a$ & n/a \\
\hline 40 & $\mathrm{Sr}$ & $\mathrm{ug} / \mathrm{mL}$ & $n / a$ & $n / a$ & 6 & $\mathrm{n} / \mathrm{a}$ & $n / a$ \\
\hline 41 & $\pi$ & $\mathrm{ug} / \mathrm{mL}$ & $n / a$ & $\mathrm{n} / \mathrm{a}$ & $<0.14$ & $\mathrm{n} / \mathrm{a}$ & $\cdots+\cdots$ \\
\hline 42 & $v$ & $\mathrm{ug} / \mathrm{mL}$ & $n \sqrt{a}$ & $n / a$ & $<0.13$ & na & $n / a$ \\
\hline 43 & $Z n$ & $\mathrm{ug} / \mathrm{mL}$ & $n / a$ & $\mathrm{n} / \mathrm{a}$ & 1 & $\mathrm{n} / \mathrm{a}$ & n/a \\
\hline 44 & Zr & ug/mL & $\mathrm{n} / \mathrm{a}$ & $n / a$ & $<0.05$ & $n / a$ & n/a \\
\hline 45 & Total Organic Carbon & $u g / m L$ & $\mathrm{n} / \mathrm{a}$ & $\mathrm{n} / \mathrm{a}$ & $\mathrm{n} / \mathrm{a}$ & 2290 & $n / a$ \\
\hline 46 & Total Inorganic Carbon & $\mathrm{ug} / \mathrm{mL}$ & $n / a$ & na & $n / a$ & 1123 & n/a \\
\hline 47 & Suspended Solids & $w t \%$ & $n / a$ & $0.054(?)$ & $\mathrm{n} / \mathrm{a}$ & n/a & na \\
\hline 48 & Total Solids & $w t \%$ & $n / a$ & 2.59 & $\mathrm{n} / \mathrm{a}$ & $\mathrm{n} / \mathrm{a}$ & $\mathrm{n} / \mathrm{a}$ \\
\hline 49 & Mean Particle Size by Volume & micron & na. & n/a & $n / a$ & $n / a$ & $n / a$ \\
\hline 50 & Mean Particle Size by Number & micron & $n / a$ & n/a & $\mathrm{n} / \mathrm{a}$ & $n / a$ & $n / a$ \\
\hline 51 & Kinematic Viscosity & centistoke & 0.98 & $\mathrm{n} / \mathrm{a}$ & $n / a$ & $\mathrm{n} / \mathrm{a}$ & 0.98 \\
\hline 52 & Dynamic Viscosity / Consistency & $\mathbf{c P}$ & 1.00 & $\mathrm{n} / \mathrm{a}$ & n/a & n/a & 0.99 \\
\hline 53 & Comment & & & & & & \\
\hline
\end{tabular}




\begin{tabular}{|c|c|c|c|c|c|c|c|}
\hline & BR & BS & BT & $\mathrm{BU}$ & BV & BW & $\mathrm{BX}$ \\
\hline 1 & TEST RUN - & $\cdots+\cdots$ & WASH 4 & WASH 4 & WASH 4 & Pre 1.15 & Pre 1.15 \\
\hline 2 & 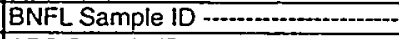 & $\cdots \cdots$ & Prefix_27 & Prefix_28a & Prefix_28b & Prefix_29 & Prefix_30 \\
\hline 3 & ADS Sample ID & $\ldots . . . \cdots>>$ & $3-136255$ & $3-136256$ & $3-136257$ & $3-136258$ & N/A \\
\hline 4 & 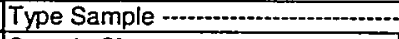 & $\cdots \cdots$ & filtrate & filtrate & filtrate & slurry & slurry \\
\hline 5 & Sample Size & $\mathrm{mL}$ & 15 & 15 & \begin{tabular}{|c|}
15 \\
\end{tabular} & 15 & 250 \\
\hline 6 & Measurement(s) Made & $m \rightarrow \infty$ & TS/SS & ICP-ES/IC-ANIONS & AATTIC-TOC/ISE & MICROTRAC & TS/SS-VISCOSITY \\
\hline 7 & Item Measured & Units & $1+2=3 x+2$ & sar & 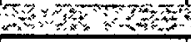 & 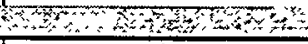 & 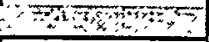 \\
\hline 8 & Density & $g / m L$ & 1.009 & 1.009 & 1.009 & $\mathrm{Na}$ & 1.148 \\
\hline 9 & Al & $\mathrm{ug} / \mathrm{mL}$ & $\mathrm{n} / \mathrm{a}$ & 6 & $\mathrm{n} / \mathrm{a}$ & na & $\mathrm{n} / \mathrm{a}$ \\
\hline 10 & $B$ & $\mathrm{ug} / \mathrm{mL}$ & n/a & 0.5 & $n / a$ & Na & $\mathrm{n} / \mathrm{a}$ \\
\hline 11 & $\mathrm{Ba}$ & $u g / m L$ & na & $<0.01$ & $n / a$ & na & n/a \\
\hline 12 & $\mathrm{Ca}$ & $u g / \mathrm{mL}$ & na & 3.6 & $n / a$ & na & $\mathrm{n} / \mathrm{a}$ \\
\hline 13 & Cd & $u g / m L$ & na & $<0.02$ & $\mathrm{n} / \mathrm{a}$ & na & $n / a$ \\
\hline 14 & $\mathrm{Cl}$ & $u g / m L$ & n/a & 61 & $n / a$ & $n / a$ & $n / a$ \\
\hline 15 & Cl Sample & ug/mL & na & $n / a$ & 33 & $n / a$ & $n / a$ \\
\hline 16 & Co & $\mathrm{ug} / \mathrm{mL}$ & $n / a$ & $<0.05$ & $\mathrm{Na}$ & $\mathrm{n} / \mathrm{a}$ & $\mathrm{n} / \mathrm{a}$ \\
\hline 17 & $\mathrm{Cr}$ & ug/mL & $n / a$ & $<0.1$ & $\mathrm{n} / \mathrm{a}$ & na & $\mathrm{Na}$ \\
\hline 18 & $\mathrm{Cu}$ & $u g / \mathrm{mL}$ & $n / a$ & 0.72 & $\mathrm{n} / \mathrm{a}$ & n/a & $n / a$ \\
\hline 19 & F (Fluoride) [not accurate] & $u g / m L$ & $n / a$ & 56 & $\mathrm{n} / \mathrm{a}$ & n/a & $\mathrm{n} / \mathrm{a}$ \\
\hline 20 & F Sample (more accurate result) & $\mathrm{ug} / \mathrm{mL}$ & $\mathrm{n} / \mathrm{a}$ & $n / a$ & 6.1 & $n / a$ & n/a \\
\hline 21 & $\mathrm{Fe}$ & $\mathrm{ug} / \mathrm{mL}$ & $n / a$ & 0.24 & na & na & n/a \\
\hline 22 & HCOO (Formate) & $u g / m L$ & $n / a$ & 155 & $\mathrm{n} / \mathrm{a}$ & $\mathrm{n} / \mathrm{a}$ & $n / a$ \\
\hline 23 & $\mathrm{~K}$ & $u g / m L$ & $n / a$ & $\mathrm{n} / \mathrm{a}$ & 27.82 & $n / a$ & $n / a$ \\
\hline 24 & La & $u g / m L$ & $n / a$ & $<0.06$ & $\mathbf{n} / \mathbf{a}$ & n/a & na \\
\hline 25 & $\mathrm{Li}$ & $u g / m L$ & $\mathrm{n} / \mathrm{a}$ & $<0.1$ & n/a & $n / a$ & $\mathrm{n} / \mathrm{a}$ \\
\hline 26 & $\overline{\mathrm{Mg}}$ & $u g / m L$ & $n / a$ & $<0.09$ & $n / a$ & $\mathrm{n} / \mathrm{a}$ & $n \sqrt{a}$ \\
\hline 27 & $M n$ & $u g / \mathrm{mL}$ & $n / a$ & 1.61 & $\sqrt{a}$ & $n / a$ & $n / a$ \\
\hline 28 & Mo & $u g / m L$ & $n / a$ & 0.48 & $n / a$ & $\mathrm{n} / \mathrm{a}$ & $n / a$ \\
\hline 29 & $\mathrm{Na}$ & $\mathrm{ug} / \mathrm{mL}$ & $n / a$ & 4550 & $n / a$ & $n / a$ & $n / a$ \\
\hline 30 & $\mathrm{Ni}$ & $\mathrm{ug} / \mathrm{mL}$ & $\mathrm{n} / \mathrm{a}$ & 6.8 & $n / a$ & $n / a$ & $n / a$ \\
\hline 31 & NO2 (Nitrite) & $\mathrm{ug} / \mathrm{mL}$ & $n / a$ & 753 & $n / a$ & $n / a$ & $\mathrm{Na}$ \\
\hline 32 & NO3 (Nitrate) & $\mathrm{ug} / \mathrm{mL}$ & $\mathrm{n} / \mathrm{a}$ & 3313 & $n / a$ & $n / a$ & $n / a$ \\
\hline 33 & C2O4 (Oxalate) & $\mathrm{ug} / \mathrm{mL}$ & $n / a$ & 1367 & $n / a$ & $n / a$ & $\mathrm{n} / \mathrm{a}$ \\
\hline 34 & $P$ & $\mathrm{ug} / \mathrm{mL}$ & $n / a$ & 2.7 & $n \sqrt{a}$ & n/a & n/a \\
\hline 35 & PO4 (Phosphate) & $\mathrm{ug} / \mathrm{mL}$ & $\mathrm{N} / \mathrm{a}$ & 141 & $\mathrm{n} / \mathrm{a}$ & n/a & $\mathrm{n} / \mathrm{a}$ \\
\hline 36 & $\mathrm{~Pb}$ & $\mathrm{ug} / \mathrm{mL}$ & $\mathrm{n} / \mathrm{a}$ & $<0.6$ & $\mathrm{n} / \mathrm{a}$ & n/a & $\mathrm{n} / \mathrm{a}$ \\
\hline 37 & $\mathrm{Si}$ & $\mathrm{ug} / \mathrm{mL}$ & $\mathrm{n} / \mathrm{a}$ & 0.8 & $\mathrm{n} / \mathrm{a}$ & $n / a$ & $\mathrm{n} / \mathrm{a}$ \\
\hline 38 & Sn & $\mathrm{ug} / \mathrm{mL}$ & $\mathrm{n} / \mathrm{a}$ & $<0.26$ & $n / a$ & n/a & $\mathrm{n} / \mathrm{a}$ \\
\hline 39 & SO4 (Sulfate) & $\mathrm{ug} / \mathrm{mL}$ & $\sqrt{a}$ & 189 & $\mathrm{n} / \mathrm{a}$ & na & n/a \\
\hline 40 & $\mathrm{Sr}$ & $\mathrm{ug} / \mathrm{mL}$ & $n \sqrt{a}$ & 2.8 & $\mathrm{n} / \mathrm{a}$ & n/a & n/a \\
\hline 41 & $T i$ & $u g / \mathrm{mL}$ & $n / a$ & $<0.14$ & $\mathrm{n} / \mathrm{a}$ & $n / a-$ & $\mathrm{n} / \mathrm{a}$ \\
\hline 42 & $\mathrm{~V}$ & $\mathrm{ug} / \mathrm{mL}$ & n/a & $<0.13$ & $n / a$ & $n / a$ & $\mathrm{r} / \mathrm{a}$ \\
\hline 43 & $Z n$ & $u g / \mathrm{mL}$ & $n / a$ & 0.57 & n/a & $n / a$ & n/a \\
\hline 44 & $\mathrm{Zr}$ & $\mathrm{ug} / \mathrm{mL}$ & na & $<0.05$ & $\sqrt{a} a$ & $n / a$ & n/a \\
\hline 45 & Tolal Organic Carbon & $\mathrm{ug} / \mathrm{mL}$ & $\mathrm{n} / \mathrm{a}$ & n/a & 1371 & $n / a$ & n/a \\
\hline 46 & Total Inorganic Carbon & $\mathrm{ug} / \mathrm{mL}$ & na & $n / a$ & 661 & na & na \\
\hline 47 & Suspended Solids & $w t \%$ & $<0.0001$ & $n \sqrt{a}$ & $\mathrm{na}$ & n/a & 17.53 \\
\hline 48 & Total Solids & $w t \%$ & 1.37 & n/a & n/a & n/a & 18.94 \\
\hline 49 & Mean Particle Size by Volume & micron & $\mathrm{n} / \mathrm{a}$ & $\mathrm{n} / \mathrm{a}$ & $\pi / a$ & $1.435(90 \%) / 5.570(10 \%)$ & $\mathrm{n} / \mathrm{a}$ \\
\hline 50 & Mean Particle Size by Number & micron & $n \sqrt{a}$ & na & na & 0.96 & na \\
\hline 51 & Kinematic Viscosity & centistoke & $n / a$ & $n / a$ & $n \sqrt{a}$ & $\mathrm{n} / \mathrm{a}$ & $3.6^{\circ}$ \\
\hline 52 & Dynamic Viscosity / Consistency & $\mathrm{CP}$ & $n / a$ & na & na & $\begin{array}{c}\mathrm{n} / \mathrm{a} \\
\end{array}$ & $4.1^{*}$ \\
\hline 53 & Comment & & & & & high $\mathrm{pH}$ diluent/sonication & 'Consistency \\
\hline
\end{tabular}

Table E1: Analytical - All data, Page 11 


\begin{tabular}{|c|c|c|c|c|c|c|c|}
\hline & $\mathrm{BY}$ & $8 Z$ & $\mathrm{CA}$ & $\mathrm{CB}$ & $\mathrm{CC}$ & $\mathrm{CD}$ & $\mathrm{CE}$ \\
\hline 1 & TEST RUN & 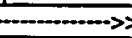 & Pre 1.15 & Pre 1.15 & Pre 1.15 & Pre 1.15 & Pre 1.15 \\
\hline 2 & BNFL Sample ID & $\infty-\infty$ & \begin{tabular}{|l|} 
Prefix_31 \\
\end{tabular} & Prefix 31digest1 & Prefix_31digest2 & Prefix_32a & Prefix_32b \\
\hline 3 & ADS Sample ID & 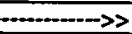 & $3-136259$ & $3-136260$ & $3-136261$ & $3-136262$ & $3-136263$ \\
\hline 4 & Iype Sample & $-\infty$ & slurry & slurry & slurry & filtrate & filtrate \\
\hline 5 & Sample Size & $\mathrm{mL}$ & 15 & 15 & 15 & 15 & \begin{tabular}{|c|}
15 \\
\end{tabular} \\
\hline 6 & Measurement(s) Made & 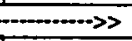 & TS/SS & ICP-ES/IC-ANIONS & AAMIC-TOC/ISE & ICP-ES/C-ANIONS & AATIC-TOC/SE \\
\hline 7 & iltem Measured & Units & andes & 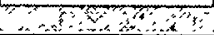 & 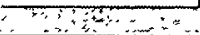 & 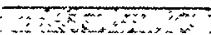 & $5 m-8=6$ \\
\hline 8 & Density & $g / \mathrm{mL}$ & $n / a$ & $\mathrm{na}$ & $\mathrm{Na}$ & $n / a$ & $\mathrm{n} / \mathrm{a}$ \\
\hline 9 & Al & $\mathrm{ug} / \mathrm{mL}$ & na & 236 & $\mathrm{n} / \mathrm{a}$ & 7.6 & $n / a$ \\
\hline 10 & $B$ & $\mathrm{ug} / \mathrm{mL}$ & n/a & $<21$ & $\mathrm{n} / \mathrm{a}$ & $<2.1$ & $\mathrm{n} / \mathrm{a}$ \\
\hline 11 & $\overline{B a}$ & $\mathrm{ug} / \mathrm{mL}$ & $n / a$ & $<10$ & $n / a$ & $<0.1$ & $\pi / \mathbf{a}$ \\
\hline 12 & $\mathrm{Ca}$ & $\mathrm{ug} / \mathrm{mL}$ & $n / a$ & 1560 & $n / a$ & 3.9 & $n / a$ \\
\hline 13 & Cd & $\mathrm{ug} / \mathrm{mL}$ & na & $<2$ & $\mathrm{n} / \mathrm{a}$ & $<0.2$ & $n / a$ \\
\hline 14 & Cl & $\mathrm{ug} / \mathrm{mL}$ & $\mathrm{n} / \mathrm{a}$ & 71 & $\mathrm{Na}$ & 64 & na \\
\hline 15 & CI Sample & $\mathrm{ug} / \mathrm{mL}$ & $n / a$ & $\mathrm{n} / \mathrm{a}$ & 51 & $n / a$ & 43 \\
\hline 16 & $C_{0}$ & $\mathrm{ug} / \mathrm{mL}$ & $\mathrm{n} / \mathrm{a}$ & $<5$ & $n / a$ & $<0.5$ & $n / a$ \\
\hline 17 & $\mathrm{Cr}$ & $\mathrm{ug} / \mathrm{mL}$ & na & 88 & $\mathrm{n} / \mathrm{a}$ & $<1$ & na \\
\hline 18 & $\mathrm{Cu}$ & $\mathrm{ug} / \mathrm{mL}$ & $\mathrm{n} / \mathrm{a}$ & 30 & $\mathrm{n} / \mathrm{a}$ & 0.6 & n/a \\
\hline 19 & F (Fluoride) [not accurate] & $\mathrm{ug} / \mathrm{mL}$ & $\mathrm{n} / \mathrm{a}$ & 23 & $\mathrm{n} / \mathrm{a}$ & 63 & $\mathrm{n} / \mathrm{a}$ \\
\hline 20 & F Sample (more accurate result) & $\mathrm{ug} / \mathrm{mL}$ & $\mathrm{n} / \mathrm{a}$ & $\mathrm{n} / \mathrm{a}$ & 7.65 & $\mathrm{n} / \mathrm{a}$ & 15 \\
\hline 21 & $\mathrm{Fe}$ & $\mathrm{ug} / \mathrm{mL}$ & $\mathrm{n} / \mathrm{a}$ & 7850 & na & $<0.6$ & $\mathrm{n} / \mathrm{a}$ \\
\hline 22 & HCOO (Formate) & $\mathrm{ug} / \mathrm{mL}$ & $\mathrm{n} / \mathrm{a}$ & 1002 & $n / a$ & 174 & $\mathrm{n} / \mathrm{a}$ \\
\hline 23. & $\mathrm{~K}$ & $\mathrm{ug} / \mathrm{mL}$ & $n / a$ & na & 66.51 & $n / a$ & 31.06 \\
\hline 24 & La & $4 g / \mathrm{mL}$ & $\pi / a$ & 212 & $\mathrm{n} / \mathrm{a}$ & $<0.6$ & $\mathrm{n} / \mathrm{a}$ \\
\hline 25 & $\underline{4}$ & $\mathrm{ug} / \mathrm{mL}$ & n/a & $<10$ & $n / a$ & $<1$ & n/a \\
\hline 26 & $\mathrm{Mg}$ & $\mathrm{ug} / \mathrm{mL}$ & $n / a$ & 115 & $\mathrm{n} / \mathbf{a}$ & $<0.9$ & $\mathrm{n} / \mathrm{a}$ \\
\hline 27 & $\mathrm{Mn}$ & $\mathrm{ug} / \mathrm{mL}$ & n/a & 22100 & na & 0.7 & $\mathrm{n} / \mathrm{a}$ \\
\hline 28 & Mo & $\mathrm{ug} / \mathrm{mL}$ & $n / a$ & $<10$ & $n / a$ & $<1$ & n/a \\
\hline 29 & $\mathrm{Na}$ & $\mathrm{ug} / \mathrm{mL}$ & $\mathrm{N} / \mathrm{a}$ & 9675 & $\mathrm{n} / \mathrm{a}$ & 4895 & $\mathrm{n} / \mathrm{a}$ \\
\hline 30 & Ni & ug/mL & $\mathrm{n} / \mathrm{a}$ & 40 & $n / a$ & 7.9 & $\mathrm{n} / \mathrm{a}$ \\
\hline 31 & NO2 (Nitrite) & $\mathrm{ug} / \mathrm{mL}$ & $\mathrm{n} / \mathrm{a}$ & 938 & $n / a$ & 846 & n/a \\
\hline 32 & NO3 (Nitrate) & $\mathrm{ug} / \mathrm{mL}$ & $\mathrm{n} / \mathrm{a}$ & 4112 & $\mathrm{n} / \mathrm{a}$ & 3689 & $n / a$ \\
\hline 33 & C204 (Oxalate) & $\mathrm{ug} / \mathrm{mL}$ & $n / a$ & 2107 & $\mathrm{n} / \mathrm{a}$ & 1701 & na \\
\hline 34 & $P$ & $\mathrm{ug} / \mathrm{mL}$ & $\mathrm{n} / \mathrm{a}$ & $<68$ & $n / a$ & $<6.8$ & $n / a$ \\
\hline 35 & PO4 (Phosphate) & $\mathrm{ug} / \mathrm{mL}$ & $n / a$ & 141 & $n / a$ & 145 & $n / a$ \\
\hline 36 & $\mathrm{~Pb}$ & $\mathrm{ug} / \mathrm{mL}$ & na & $<60$ & $\mathrm{n} / \mathrm{a}$ & $<6$ & $\mathrm{n} / \mathrm{a}$ \\
\hline 37 & Si & $\mathrm{ug} / \mathrm{mL}$ & $\mathrm{n} / \mathrm{a}$ & 119 & $n / a$ & $<1.3$ & $n / a$ \\
\hline 38 & Sn & $\mathrm{ug} / \mathrm{mL}$ & $n / a$ & $<26$ & $n / a$ & $<2.6$ & $\mathbf{n} / \mathbf{a}$ \\
\hline 39 & SO4 (Sulfate) & $\mathrm{ug} / \mathrm{mL}$ & $\mathbf{n} \mathbf{a}$ & 214 & $n / a$ & 199 & $n / a$ \\
\hline 40 & $S r$ & $\mathrm{ug} / \mathrm{mL}$ & $n / a$ & 54573 & $n / a$ & 3.3 & $n / a$ \\
\hline 41 & III & $\mathrm{ug} / \mathrm{mL}$ & $\mathbf{n} \mathbf{a}$ & $<14$ & $\mathrm{n} / \mathrm{a}$ & $\leq 1.4$ & $\mathrm{n} / \mathrm{a}$ \\
\hline 42 & $\mathrm{~V}$ & $\mathrm{ug} / \mathrm{mL}$ & $n \mathbf{a}$ & $<13$ & $\sqrt[n]{a}$ & $<1.3$ & $\mathrm{n} / \mathrm{a}$ \\
\hline 43 & $\mathrm{Zn}$ & $\mathrm{ug} / \mathrm{mL}$ & $\pi / a$ & 89 & $\pi / a$ & $<3.7$ & $\mathrm{n} / \mathrm{a}$ \\
\hline$\overline{44}$ & $\mathrm{Zr}$ & $\mathrm{ug} / \mathrm{mL}$ & $\mathrm{n} / \mathrm{a}$ & 202 & $\mathrm{n} / \mathrm{a}$ & $<0.5$ & $\mathrm{n} / \mathrm{a}$ \\
\hline 45 & Tolal Organic Carbon & $\mathrm{ug} / \mathrm{mL}$ & $\pi / a$ & $n / a$ & 20390 & $\mathrm{n} / \mathrm{a}$ & 1374 \\
\hline 46 & Total Inorganic Carbon & $\mathrm{ug} / \mathrm{mL}$ & $n / a$ & $\mathrm{~N} / \mathrm{a}$ & 10265 & $\mathrm{n} / \mathrm{a}$ & 666 \\
\hline 47 & Suspended Solids & $w t \%$ & 14.62 & $\mathrm{n} / \mathrm{a}$ & $n / a$ & $\mathrm{n} / \mathrm{a}$ & $\mathrm{n} / \mathrm{a}$ \\
\hline 48 & Total Solids & $w+\%$ & 16.22 & $\mathrm{n} / \mathbf{a}$ & $n / a$ & $n / a$ & $n / a$ \\
\hline 49 & Mean Particle Size by Volume & micron & na & n/a & $n / a$ & $\mathrm{n} / \mathrm{a}$ & $n / a$ \\
\hline 50 & Mean Particle Size by Number & micron & n/a & n/a & $\mathrm{n} / \mathrm{a}$ & $\mathrm{n} / \mathbf{a}$ & $\mathrm{n} / \mathrm{a}$ \\
\hline 51 & Kinematic Viscosity & centistoke & $\pi / 2$ & $n / a$ & $n / a$ & $\mathrm{n} / \mathrm{a}$ & $\mathrm{n} / \mathrm{a}$ \\
\hline 52 & Dymamic Viscosity / Consistency & CP & $\mathrm{n} / \mathbf{a}$ & $\sqrt{a}$ & $n / a$ & $\mathrm{n} / \mathrm{a}$ & $\mathrm{n} / \mathrm{a}$ \\
\hline 53 & Comment & & & & & & \\
\hline
\end{tabular}

Table E1: Analytical - All data, Page 12 


\begin{tabular}{|c|c|c|c|c|c|c|c|c|}
\hline & CF & CG & $\mathrm{CH}$ & $\mathrm{Cl}$ & $\mathrm{CJ}$ & CK & $\overline{C L}$ & $\mathrm{CM}$ \\
\hline 1 & TEST RUN & $+\cdots$ & Post 1.15 & Post $1 . \overline{15}$ & 1.16 & 1.17 & 1.18 & 1.19 \\
\hline 2 & BNFL Sample ID & 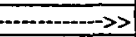 & Prefix_post1.15a & Prefix_post1.15b & N/A & N/A & N/A & Prefix .33 \\
\hline 3 & ADS Sample ID ........................... & $\cdots \cdots>>$ & N/A & $3-136264$ & N/A & N/A & N/A & 136889 \\
\hline 4 & 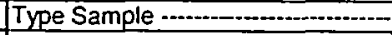 & $-\cdots+\cdots>>$ & thick slurry & thick slurry & slurry & slurry & slurry & slurry \\
\hline 5 & Sample Size & $\mathrm{mL}$ & 250 & 15 & 100 returned & 100 returned & 100 returned & 15 \\
\hline 6 & Measurement(s) Made ................. & 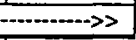 & TSISS-VISCOSITY & TS/SS & DENSITY ONLY & DENSITY ONLY & DENSITY ONLY & TS/SS \\
\hline 7 & Item Measured & $g / m L$ & 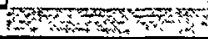 & 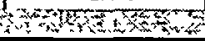 & 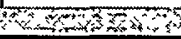 & 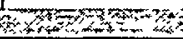 & 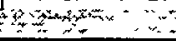 & 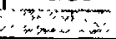 \\
\hline 8 & Density & $\mathrm{ug} / \mathrm{mL}$ & ? & $?$ & 1.016 & 0.998 & 1.029 & 0.999 \\
\hline 9 & Al & $\mathrm{ug} / \mathrm{mL}$ & $\mathrm{n} / \mathrm{a}$ & na & $n / a$ & $\mathrm{~N} / \mathrm{a}$ & $\mathrm{n} / \mathrm{a}$ & $\mathrm{n} / \mathrm{a}$ \\
\hline 10 & $B$ & $\mathrm{ug} / \mathrm{mL}$ & $\mathrm{n} / \mathrm{a}$ & na & $n / a$ & $\mathrm{Na}$ & $\mathrm{na}$ & $\mathrm{n} / \mathrm{a}$ \\
\hline 11 & $\mathrm{Ba}$ & $\mathrm{ug} / \mathrm{mL}$ & $\mathrm{N} / \mathrm{a}$ & Na & na & $\mathrm{Na}$ & na & $\mathrm{n} / \mathrm{a}$ \\
\hline 12 & $\mathrm{Ca}$ & $u g / m L$ & $\mathrm{n} / \mathrm{a}$ & na & $\mathrm{na}$ & $\mathrm{na}$ & $\sqrt{a}$ & $\mathrm{n} / \mathrm{a}$ \\
\hline 13 & $\mathrm{Cd}$ & $\mathrm{ug} / \mathrm{mL}$ & $\mathrm{n} / \mathrm{a}$ & naa & $\mathrm{n} / \mathrm{a}$ & $\mathrm{n} / \mathrm{a}$ & $\mathrm{n} / \mathrm{a}$ & $\mathrm{n} / \mathrm{a}$ \\
\hline 14 & $\mathrm{Cl}$ & $\mathrm{ug} / \mathrm{mL}$ & $n \sqrt{a}$ & $\mathrm{n} / \mathrm{a}$ & na & $\mathrm{na}$ & $\mathrm{Na}$ & $\mathrm{n} / \mathrm{a}$ \\
\hline 15 & Cl Sample & $u g / m L$ & $\mathrm{n} / \mathrm{a}$ & na & na & $\mathrm{n} / \mathrm{a}$ & rva & $\mathrm{n} / \mathrm{a}$ \\
\hline 16 & $C_{0}$ & $\mathrm{ug} / \mathrm{mL}$ & $\mathrm{n} / \mathrm{a}$ & na & $n / a$ & n/a & N/a & $\mathrm{n} / \mathrm{a}$ \\
\hline 17 & $\mathrm{Cr}$ & $\mathrm{ug} / \mathrm{mL}$ & $\mathrm{n} / \mathrm{a}$ & na & $\mathrm{n} / \mathrm{a}$ & $\mathrm{n} / \mathrm{a}$ & $\mathrm{n} / \mathrm{a}$ & $\mathrm{n} / \mathrm{a}$ \\
\hline 18 & $\mathrm{Cu}$ & $\mathrm{ug} / \mathrm{mL}$ & $\mathrm{n} / \mathrm{a}$ & $n / a$ & $n / a$ & $r \sqrt{a}$ & $\mathrm{Na}$ & na \\
\hline 19 & F (Fluoride) [not accurate] & $\mathrm{ug} / \mathrm{mL}$ & $\mathrm{n} / \mathrm{a}$ & $n / a$ & naa & na & $\mathrm{N} / \mathrm{a}$ & $\mathrm{N} / \mathrm{a}$ \\
\hline 20 & F Sample (more accurate result) & $\mathrm{ug} / \mathrm{mL}$ & $\mathrm{n} / \mathrm{a}$ & na & na & $n / a$ & $\mathrm{~N} / \mathrm{a}$ & $\sqrt{a}$ \\
\hline 21 & $\mathrm{Fe}$ & $\mathrm{ug} / \mathrm{mL}$ & $\mathrm{n} / \mathrm{a}$ & n/a & n/a & $\mathrm{n} / \mathrm{a}$ & $\mathrm{n} / \mathrm{a}$ & $\mathrm{na}$ \\
\hline 22 & HCOO (Formate) & $u g / \mathrm{mL}$ & $\mathrm{n} / \mathrm{a}$ & $\mathrm{n} / \mathrm{a}$ & $\mathrm{n} / \mathrm{a}$ & $\mathrm{n} / \mathrm{a}$ & $\mathrm{n} / \mathrm{a}$ & na \\
\hline 23 & $\mathrm{~K}$ & $\mathrm{ug} / \mathrm{mL}$ & $n / a$ & $\mathrm{Na}$ & na & $\mathrm{n} / \mathrm{a}$ & $n / a$ & $\mathrm{n} / \mathrm{a}$ \\
\hline 24 & La & $\mathrm{ug} / \mathrm{mL}$ & $\mathrm{n} / \mathrm{a}$ & Na & na & na & 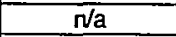 & $n / a$ \\
\hline 25 & Li & $u g / m L$ & $\mathrm{n} / \mathrm{a}$ & $\mathrm{Na}$ & $\mathrm{Na}$ & $\mathrm{na}$ & $\mathrm{N} / \mathrm{a}$ & $\mathrm{n} / \mathrm{a}$ \\
\hline 26 & $\mathrm{Mg}$ & $\mathrm{ug} / \mathrm{mL}$ & $\mathrm{n} / \mathrm{a}$ & $\mathrm{n} / \mathrm{a}$ & $\mathrm{n} / \mathrm{a}$ & $n \mathrm{na}$ & $n / a$ & Na \\
\hline 27. & Mn & $\mathrm{ug} / \mathrm{mL}$ & $\mathrm{n} / \mathrm{a}$ & na & $\mathrm{n} / \mathrm{a}$ & $\sqrt{2}$ & $\mathrm{n} / \mathrm{a}$ & $\mathrm{n} / \mathrm{a}$ \\
\hline 28 & Mo & $u g / \mathrm{mL}$ & $\mathrm{n} / \mathrm{a}$ & $\mathrm{n} / \mathrm{a}$ & na & $n / a$ & $\mathrm{n} / \mathrm{a}$ & $n / a$ \\
\hline 29 & $\mathrm{Na}$ & $\mathrm{ug} / \mathrm{mL}$ & $\mathrm{n} / \mathrm{a}$ & $\mathrm{n} / \mathrm{a}$ & $\mathrm{n} / \mathrm{a}$ & $n / a$ & $\mathrm{n} / \mathrm{a}$ & n/a \\
\hline 30 & $\mathrm{Ni}$ & $\mathrm{ug} / \mathrm{mL}$ & na & naa & n/a & $\mathrm{n} / \mathrm{a}$ & $n / a$ & $\mathrm{n} / \mathrm{a}$ \\
\hline 31 & NO2 (Nitrite) & $\mathrm{ug} / \mathrm{mL}$ & $\mathrm{na}$ & $\mathrm{Na}$ & $\mathrm{n} / \mathrm{a}$ & $\mathrm{n} / \mathrm{a}$ & $\mathrm{n} / \mathrm{a}$ & na \\
\hline 32 & NO3 (Nitrate) & $\mathrm{ug} / \mathrm{mL}$ & $\mathrm{na}$ & $n / a$ & $\mathrm{n} / \mathrm{a}$ & $n / a$ & $n / a$ & $\mathrm{n} / \mathrm{a}$ \\
\hline 33 & C2O4 (Oxalate) & $\mathrm{ug} / \mathrm{mL}$ & na & $\mathrm{Na}$ & $\mathrm{Na}$ & $\mathrm{n} / \mathrm{a}$ & $\mathrm{n} / \mathrm{a}$ & $\mathrm{N} / \mathrm{a}$ \\
\hline 34 & $P$ & $u g / m L$ & $\sqrt{a}$ & $n / a$ & $\mathrm{n} / \mathrm{a}$ & $\mathrm{n} / \mathrm{a}$ & $\mathrm{n} / \mathrm{a}$ & $\mathrm{n} / \mathrm{a}$ \\
\hline 35 & PO4 (Phosphate) & $\mathrm{ug} / \mathrm{mL}$ & Na & $\mathrm{n} / \mathrm{a}$ & Na & $\mathrm{n} / \mathrm{a}$ & $n / a$ & $\mathrm{n} / \mathrm{a}$ \\
\hline 36 & $\mathrm{~Pb}$ & $\mathrm{ug} / \mathrm{mL}$ & $\mathrm{n} / \mathrm{a}$ & $\mathrm{n} / \mathrm{a}$ & $\mathrm{na}$ & $\mathrm{n} / \mathrm{a}$ & $n / a$ & $\mathrm{~N} / \mathrm{a}$ \\
\hline 37 & $S i$ & $\mathrm{ug} / \mathrm{mL}$ & $\mathrm{Na}$ & na & na & $\mathrm{n} / \mathrm{a}$ & na & $\mathrm{n} / \mathrm{a}$ \\
\hline 38 & Sn & $\mathrm{ug} / \mathrm{mL}$ & $\mathrm{na}$ & $\mathrm{n} / \mathrm{a}$ & na & $\mathrm{n} / \mathrm{a}$ & $n / a$ & $\mathrm{~N} / \mathrm{a}$ \\
\hline 39 & SO4 (Sulfate) & $\mathrm{ug} / \mathrm{mL}$ & $n / a$ & $n / a$ & na & $\mathrm{n} / \mathrm{a}$ & $\sqrt{a}$ & $\mathrm{n} / \mathrm{a}$ \\
\hline 40 & $\mathrm{Sr}$ & $\mathrm{ug} / \mathrm{mL}$ & $\mathrm{n} / \mathrm{a}$ & na & $\mathrm{N} / \mathrm{a}$ & $n / a$ & na & $\mathrm{n} / \mathrm{a}$ \\
\hline 41 & $\pi i$ & $\mathrm{ug} / \mathrm{mL}$ & $\mathrm{n} / \mathrm{a}$ & $\mathrm{n} / \mathrm{a}$ & $n \mathrm{a}$ & $n / a$ & $n / a$ & $\mathrm{n} / \mathrm{a}$ \\
\hline 42 & $v$ & $\mathrm{ug} / \mathrm{mL}$ & $\mathrm{n} / \mathrm{a}$ & $n / a$ & $\mathrm{na}$ & $n / a$ & $\mathrm{~N} / \mathrm{a}$ & na \\
\hline 43 & $\mathrm{Zn}$ & $\mathrm{ug} / \mathrm{mL}$ & $\mathrm{na}$ & $\mathrm{nda}$ & $n / a$ & $\mathrm{n} / \mathrm{a}$ & $n / a$ & $\mathrm{n} / \mathrm{a}$ \\
\hline 44 & $\mathrm{zr} \cdot$ & $\mathrm{ug} / \mathrm{mL}$ & $\mathrm{n} / \mathrm{a}$ & na & $\sqrt{a}$ & 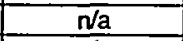 & $\mathrm{n} / \mathrm{a}$ & $\mathrm{n} / \mathrm{a}$ \\
\hline 45 & Total Organic Carbon & $\mathrm{ug} / \mathrm{mL}$ & $\mathrm{n} / \mathrm{a}$ & $n / a$ & $n / a$ & $n / a$ & $\mathrm{na}$ & Na \\
\hline 46 & Total Inorganic Cabon & $w t \%$ & $\mathrm{n} / \mathrm{a}$ & na & na & $\mathrm{N} / \mathrm{a}$ & na & $n / a$ \\
\hline 47 & Suspended Solids & $w t \%$ & 37.57 & $?$ & na & $\mathrm{n} / \mathrm{a}$ & na & $<0.0001$ \\
\hline 48 & Total Solids & micron & 40.54 & 32.18 & $n / a$ & $n / a$ & na & 0.014 \\
\hline 49 & Mean Particle Size by Volume & micron & $\mathrm{Na}$ & $\mathrm{n} / \mathrm{a}$ & $\mathrm{n} / \mathrm{a}$ & $\mathrm{na}$ & $\mathrm{n} / \mathrm{a}$ & $\mathrm{n} / \mathrm{a}$ \\
\hline 50 & Mean Particle Size by Number & centistoke & $\mathrm{n} / \mathrm{a}$ & $\mathrm{Na}$ & na & $n \sqrt{a}$ & $n / a$ & na \\
\hline 51 & Kinematic Viscosity & $\mathrm{CP}$ & $?$ & $\mathrm{Na}$ & $\mathrm{n} / \mathrm{a}$ & $n / a$ & $n / a$ & $\mathrm{n} / \mathrm{a}$ \\
\hline 52 & Dynamic Viscosity / Consistency & $\mathrm{cP}$ & 24 & $\mathrm{~N} / \mathrm{a}$ & $\mathrm{n} / \mathrm{a}$ & $n / a$ & $\mathrm{n} / \mathrm{a}$ & $\mathrm{n} / \mathrm{a}$ \\
\hline 53 & Comment & & & couldn't suspend & & & & \\
\hline
\end{tabular}

Table E1: Analytical - All data, Page 13 
Figures E1 and E2 show some aspects of the slurry rheology. Figure E1 shows the Apparent Viscosity of the slurry versus the Shear Rate and Fig. E2 shows the Shear Stress versus Shear Rate. Data are only shown for the slurry when it reached the point where it exhibited non-Newtonian characteristics. That is, the slurry used for test runs from 1.01 to 1.07 are not shown because with an insoluble solids loading of approximately $2 \mathrm{wt} \%$ the slurry rheological characteristics were close to Newtonian.

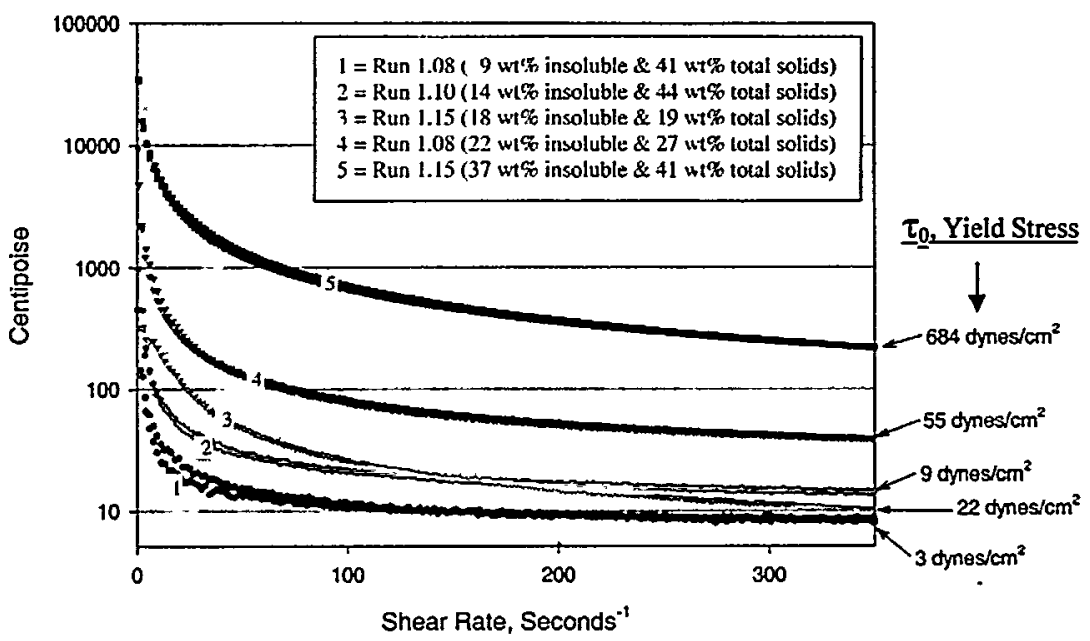

Figure E1. Apparent viscosity of Envelope C + Entrained Solids + Sr/TRU precipitants

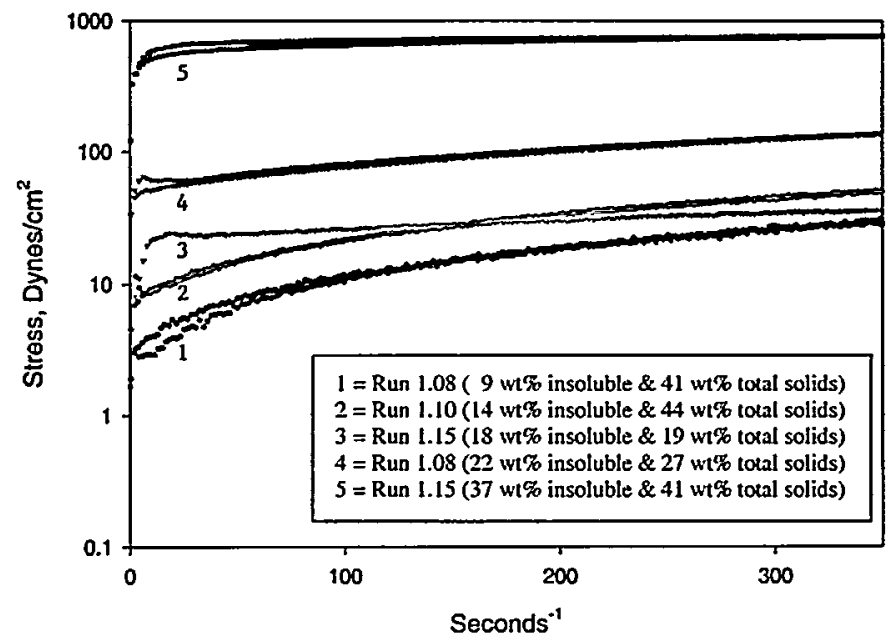

Figure E2. Shear stress vs. shear rate of Envelope C + Entrained Solids + Sr/TRU precipitants

The curves in Fig. E2 indicate that the slurry has similarities to a Bingham plastic (also see Fig. 14), which is known for having a yield stress that then reduces to a Newtonian fluid while in movement. However, this is not exactly true and the slurry is actually a time dependent pseudoplastic (a thixotropic,like ink and some paints) as can be seen in Fig. E2 by the separation of the lines for the same sample (that is, a different relation existed when increasing the shear rate, than when it was decreasing). 


\section{EXPLANATION OF HOW THE DATA ARE ORIENTED ON THE GRAPHS}

\section{THAT ARE FIGS E3 TOE23}

For an example Fig. E3 is reproduced here:

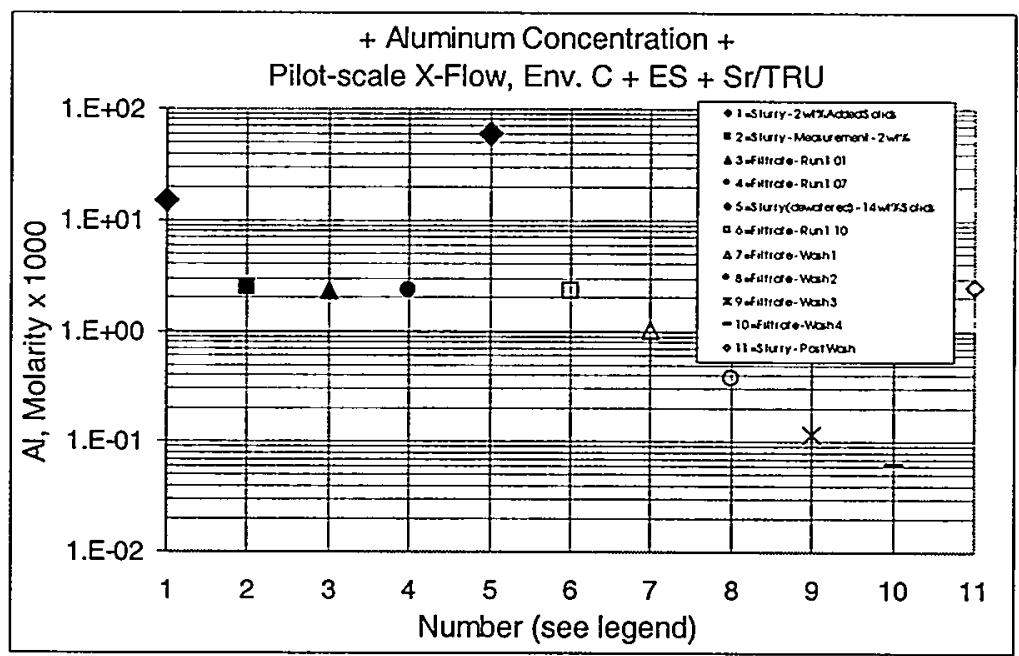

Figure E3. Analytical Data: Aluminum

The symbols have been listed in chronological order with number 1 being the earliest. However, not all data are from analytical measurements. The following two numbers, which are shown as the solid diamonds on the graph, are not analytical measurements, but are considered benchmarks. Those two symbols indicate the concentration of a constituent that was intended for the simulant.

Number 1 - low-solids concentration benchmark: is a measurement of the total amount of moles per liter of Alitminum that were used to make up the simulant ( $2 \mathrm{wt} \%$ insoluble solids), be it in the form of a soluble or insoluble solids. This is the simulant that was used for test runs 1.01 to 1.07 .

Number 5 - high-solids concentration benchmark: is an estimate of the total amount of moles per liter of Aluminum that the simulant ( $2 \mathrm{wt} \%$ insoluble solids) had after it was dewatered to a concentration of approximately $14 \mathrm{wt} \%$ insoluble solids. This is the simulant that was used for test runs 1.09 to 1.14 .

There are no data points for both Numbers 1 and 5 for those quantities difficult to estimate, i.e., Formate, Oxalate, Phosphate, Sulfate, Nitrate/Nitrite, and TIC/TOC.

The remaining symbols indicate analytical measurements of the slurry or the filtrate:

Number 2 (the closed box): is an analytical measurement of a digested sample of $2 \mathrm{wt} \%$ insoluble solids slurry. It should be equal than or less than Number 1. The sample was 
actually taken after test run 1.07 was completed and is listed in Table $\mathrm{E} 1$ as sample BNFSXF2115-C+ES+Sr/TRU_10 (column AA). There are no Number 2 data for F, K, Formate, Oxalate, Phosphate, Sulfate, Nitrate/Nitrite, and TIC/TOC, because they either were not measured or the results were contaminated in the process of dissolving the. sample solids.

Numbers 3 and 4 (the closed diamond and circle): are analytical measurements of the concentration in the filtrate from test runs 1.01 and 1.07 respectively. Both of these results should be equal to or less than Numbers 1 or 2 . When they are not, i.e., $\mathrm{K}$ and Phosphate, measurement uncertainty is a likely cause.

Number 6 (the open square): is the analytical measurement of the concentration in the filtrate from test run 1.10. This result should be equal to or less than Number 5. When it is not, i.e., $\mathrm{Cl}$ and $\mathrm{K}$, measurement uncertainty is a likely cause.

Numbers 7 to 10 (the open triangle, circle, crossed $\mathrm{X}$ and the dash, respectively): are analytical measurements of the concentration in the filtrate from wash runs 1 to 4 . Each successive point should be lower than the preceding point since the washing generally reduces the concentration. The exception is when the washing solution dissolves some of a previously insoluble solid, which may lead to an increase in concentration in the filtrate, e.g., Oxalate.

Number 11 (the open diamond): is an analytical measurement of a digested sample of 18 wt\% insoluble solids post-washed slurry. This result should be less than Number 5. When it is not, i.e., $\mathrm{Ca}, \mathrm{Fe}, \mathrm{La}, \mathrm{Mn}$, measurement uncertainty is a likely cause. The sample was actually taken after the last wash run and before test run 1.15. It is listed in Table E1 as samples BNF-SXF2115-C+ES+Sr/TRU_32digest1 (column CB) and BNFSXF2115-C+ES+Sr/TRU_32digest2 (column CC). There are no Number 5 data for F, K, Formate, Oxalate, Phosphate, Sulfate, Nitrate/Nitrite, and TIC/TOC, because they either were not measured or the results were contaminated in the process of dissolving the sample solids. 

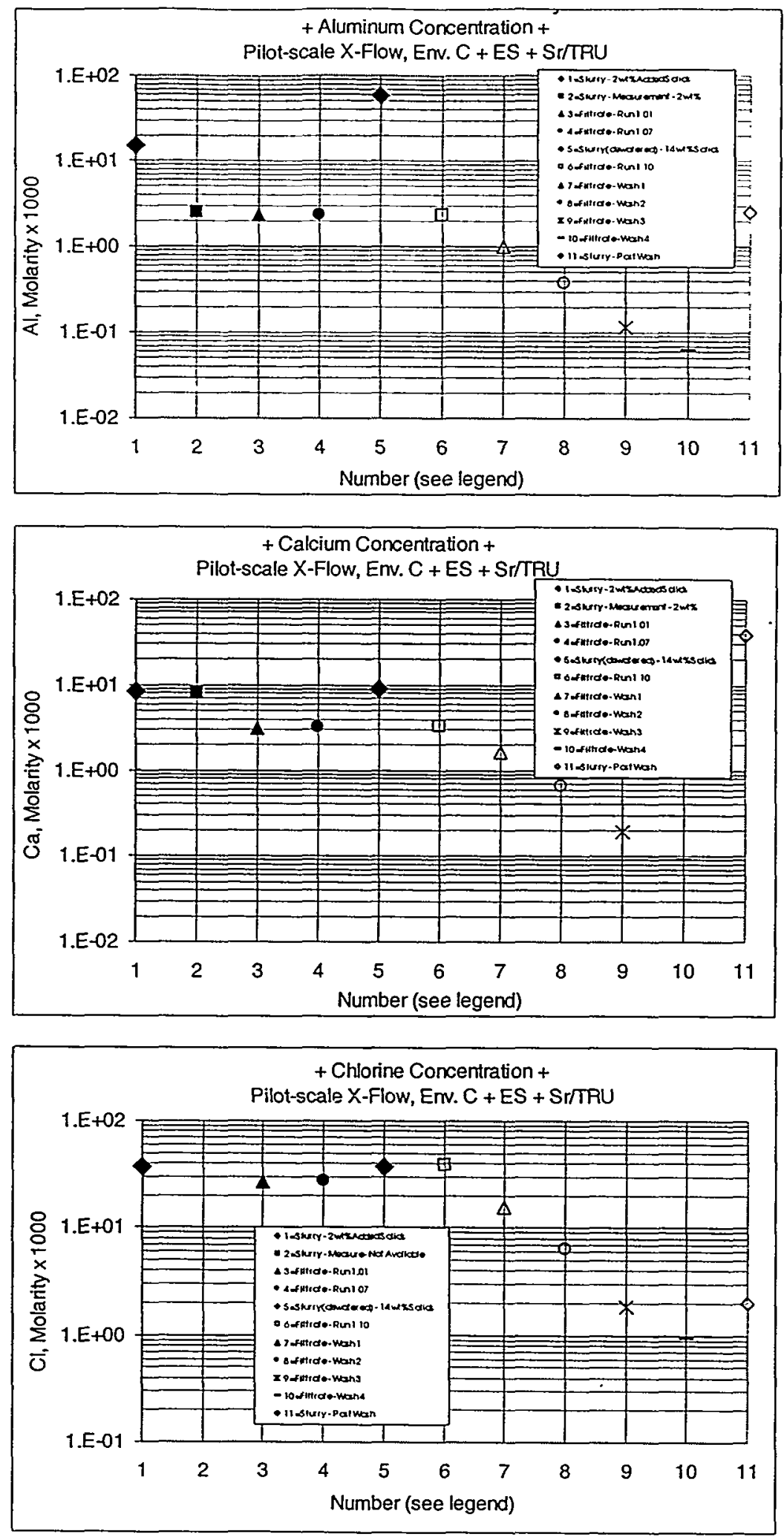

Figure E3, E4, and E5. Aluminum, Calcium, and Chlorine, respectively 

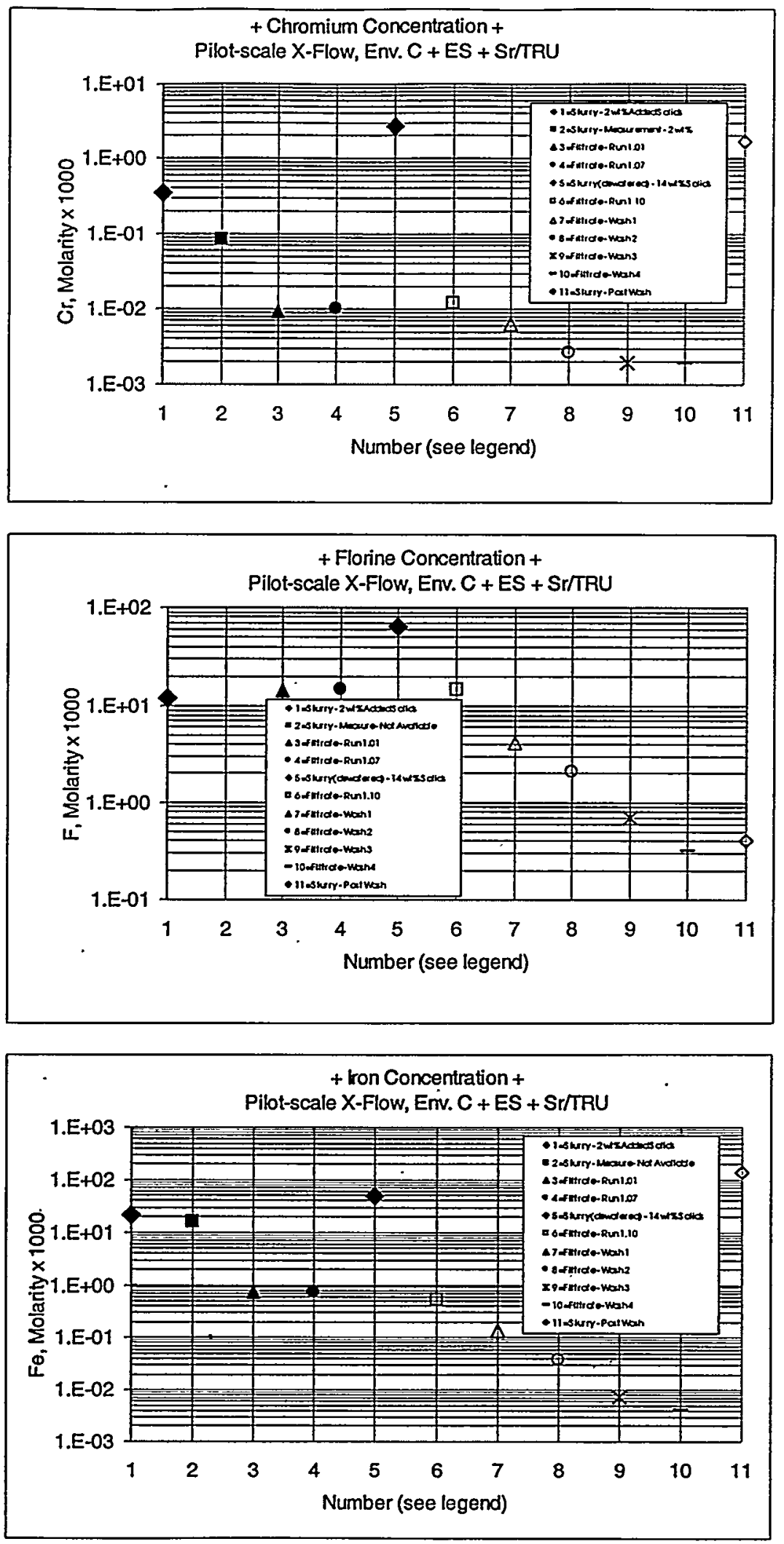

Figure E6, E7, and E8. Chromium, Florine, and Iron, respectively 

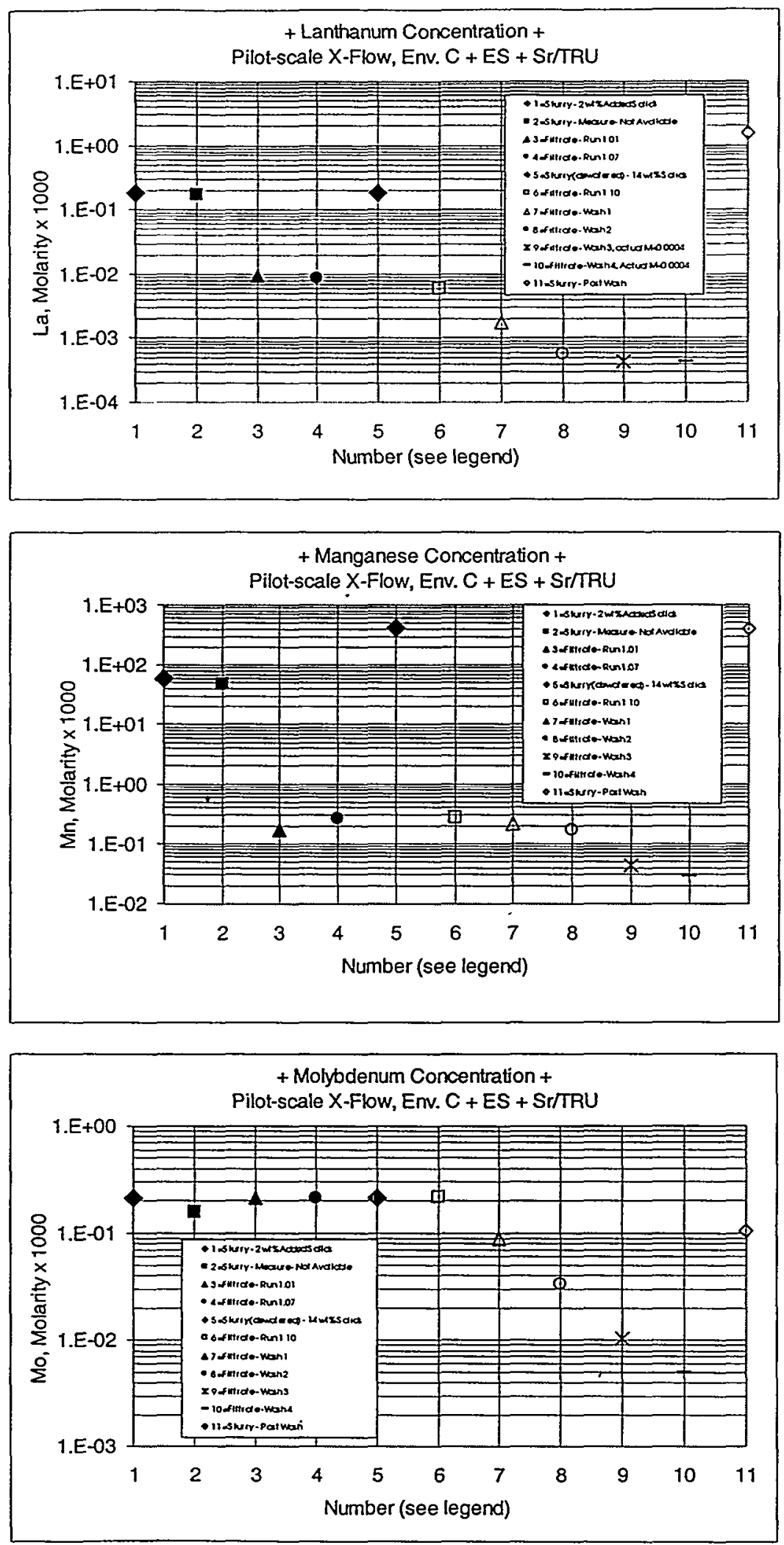

Figure E9, E10, and E11. Lanthanum, Manganese, and Molybdenum, respectively 

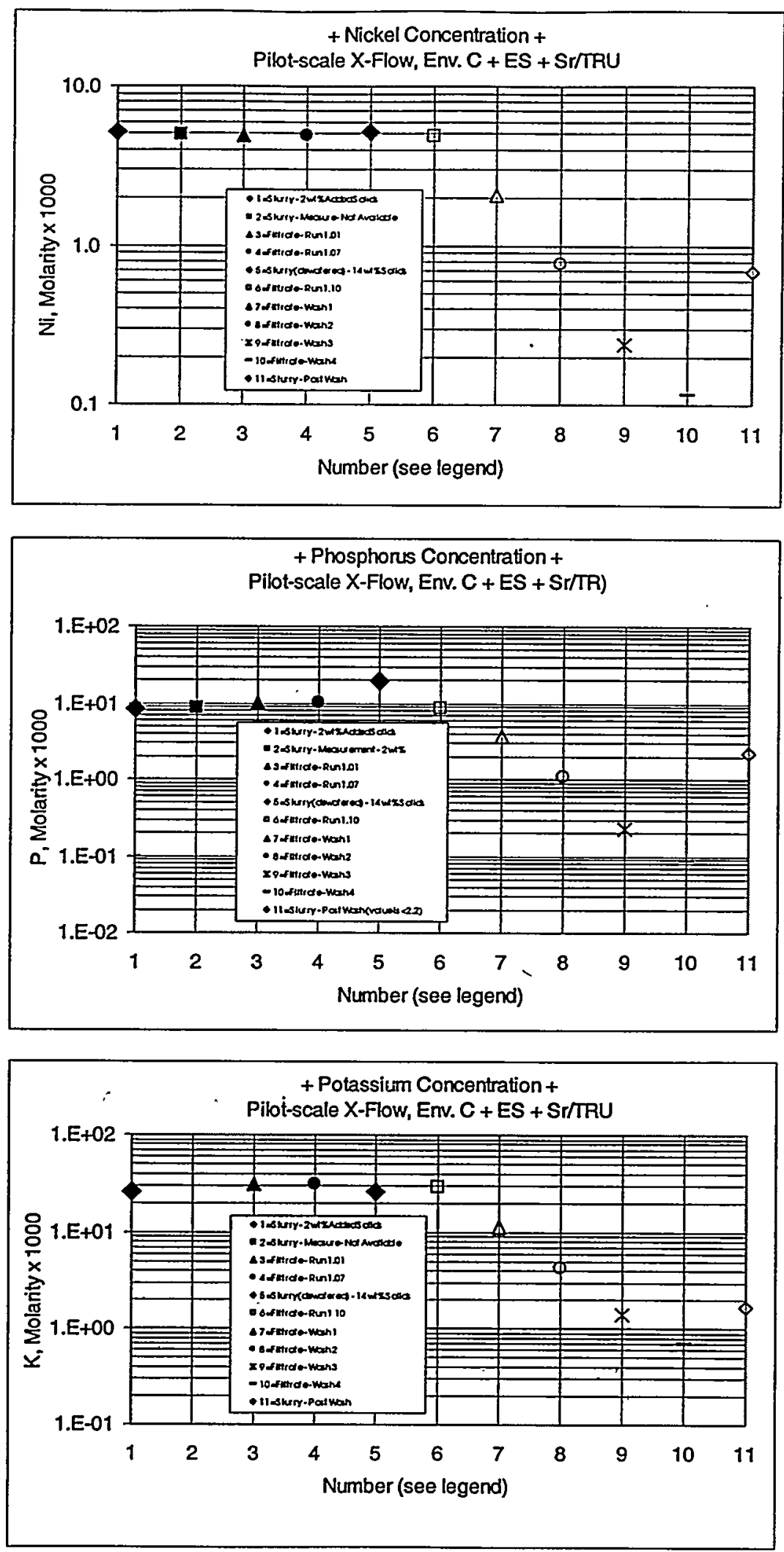

Figure E12, E13, and E14. Nickel, Phosphorous, and Potassium respectively 

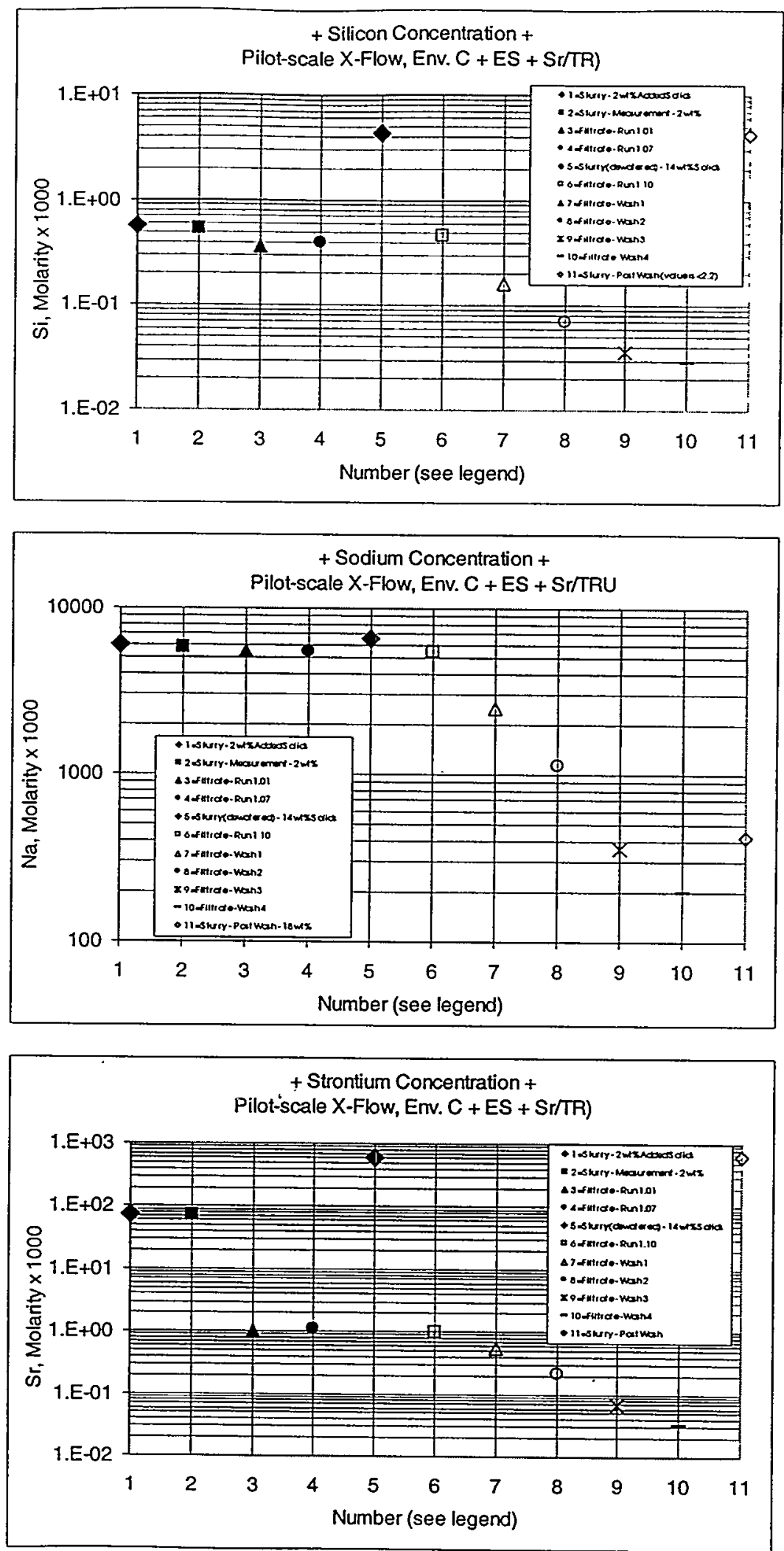

Figure E15, E16, and E17. Silicon, Sodium, and Strontium, respectively 

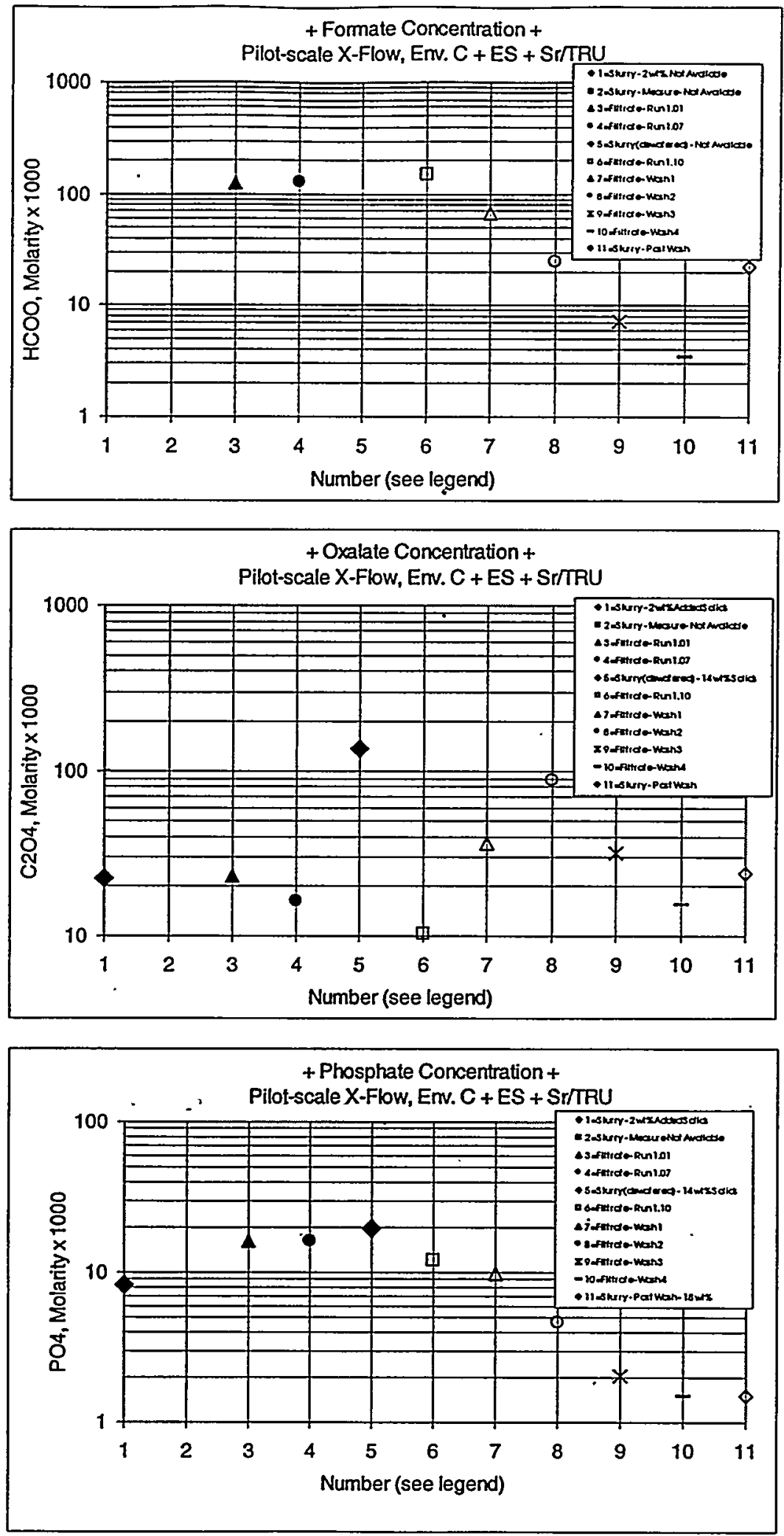

Figure E18, E19, and E20. Formate, Oxalate, and Phosphate, respectively 

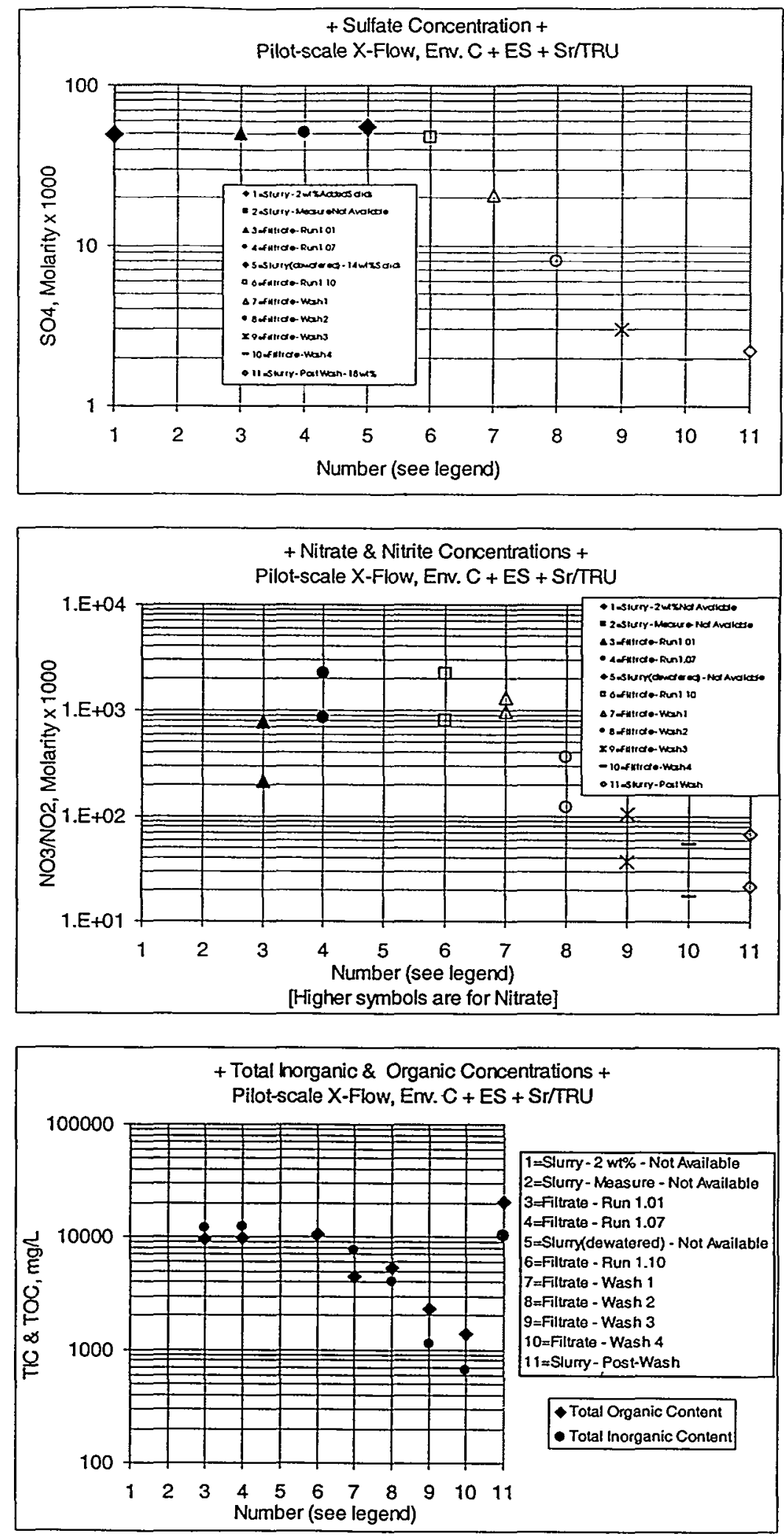

Figure E21, E22, and E23. Sulfate, Nitrate \& Nitrite, and TIC/TOC, respectively 


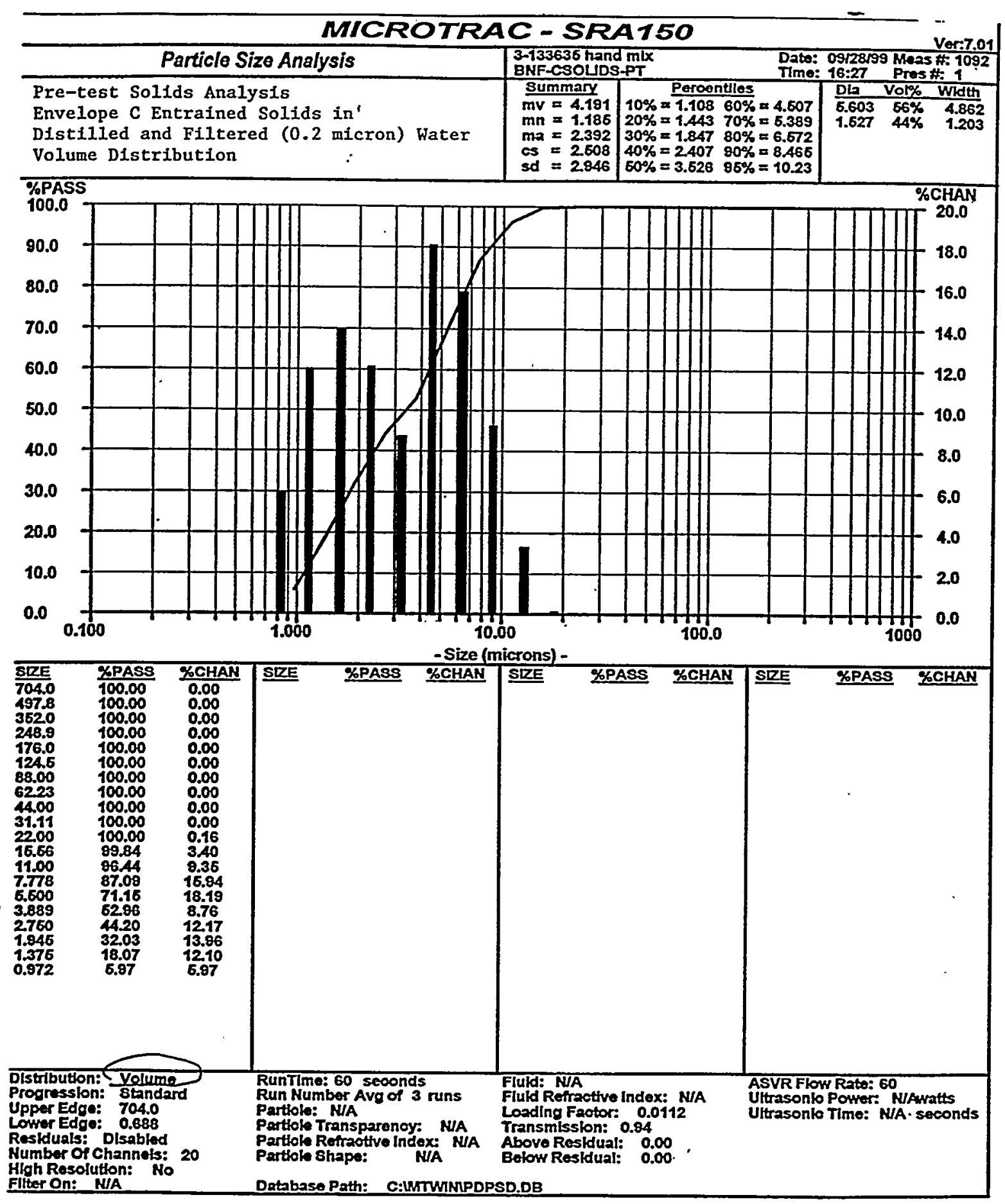

Figure E24A. Insoluble Solids VOLUME Distribution: Pre-test Sample (sample contained only insoluble solids in distilled and fiitered water) 


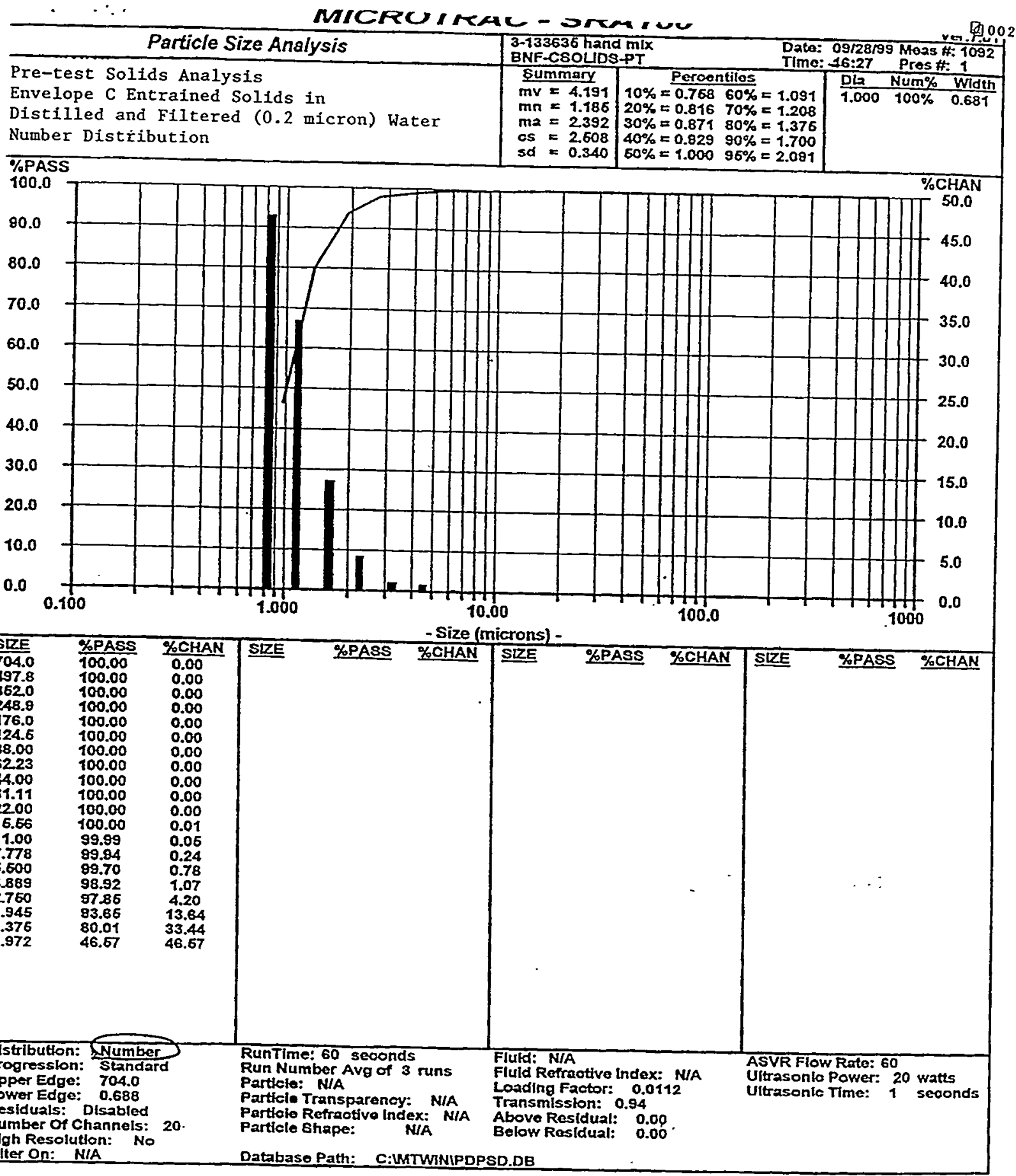

Figure E24B. Insoluble Solids NUMBER Distribution: Pre-test Sample (sample contained only insoluble solids in distilled and filtered water) 


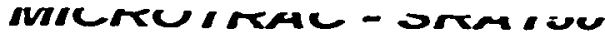

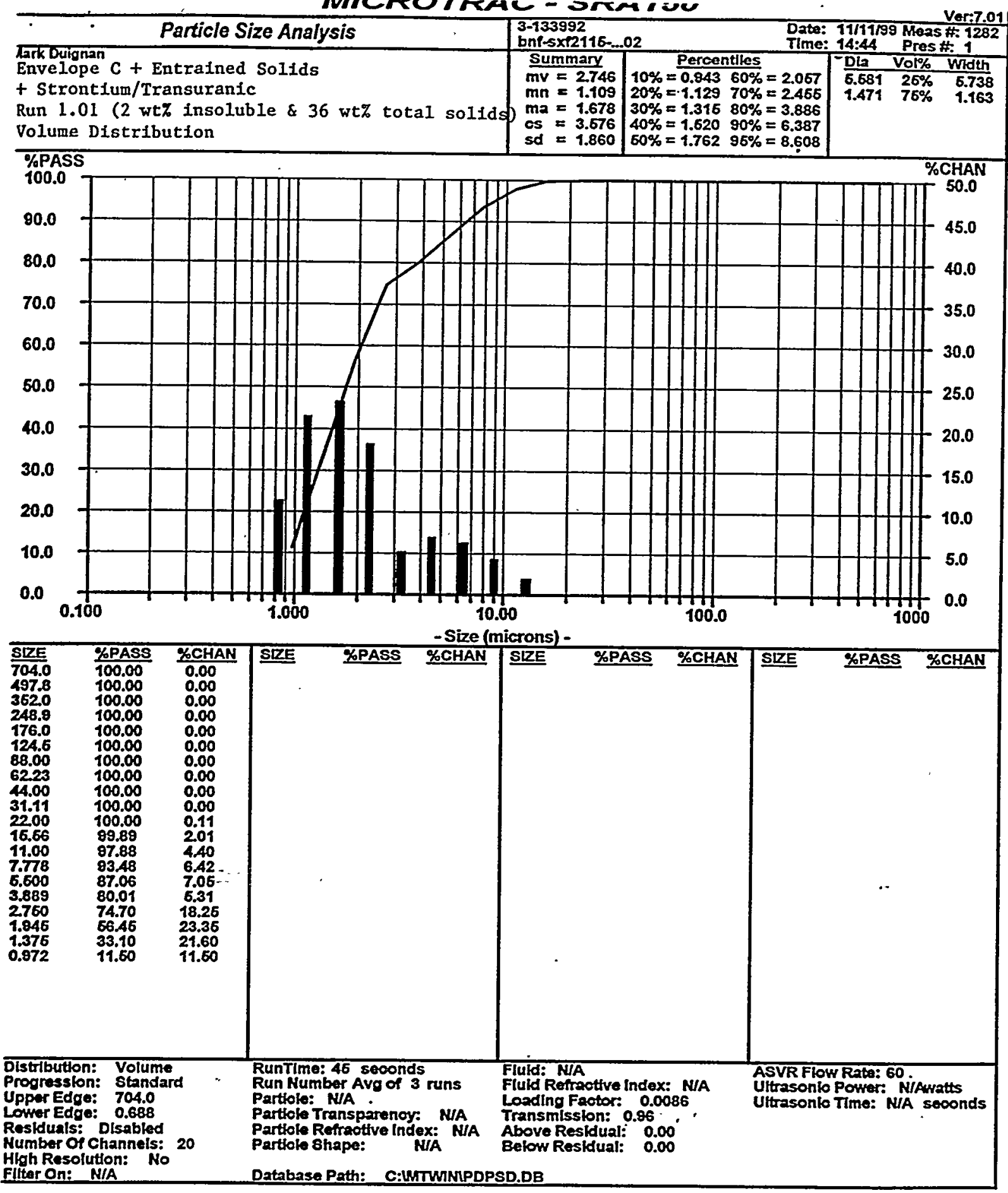

Figure E25A.Insoluble Solids VOLUME Distribution: Run 1.01 ( $2 \mathrm{wt} \%$ insoluble solids slurry experienced about 1 hour of circulation) 


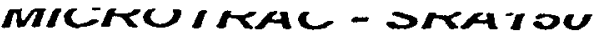

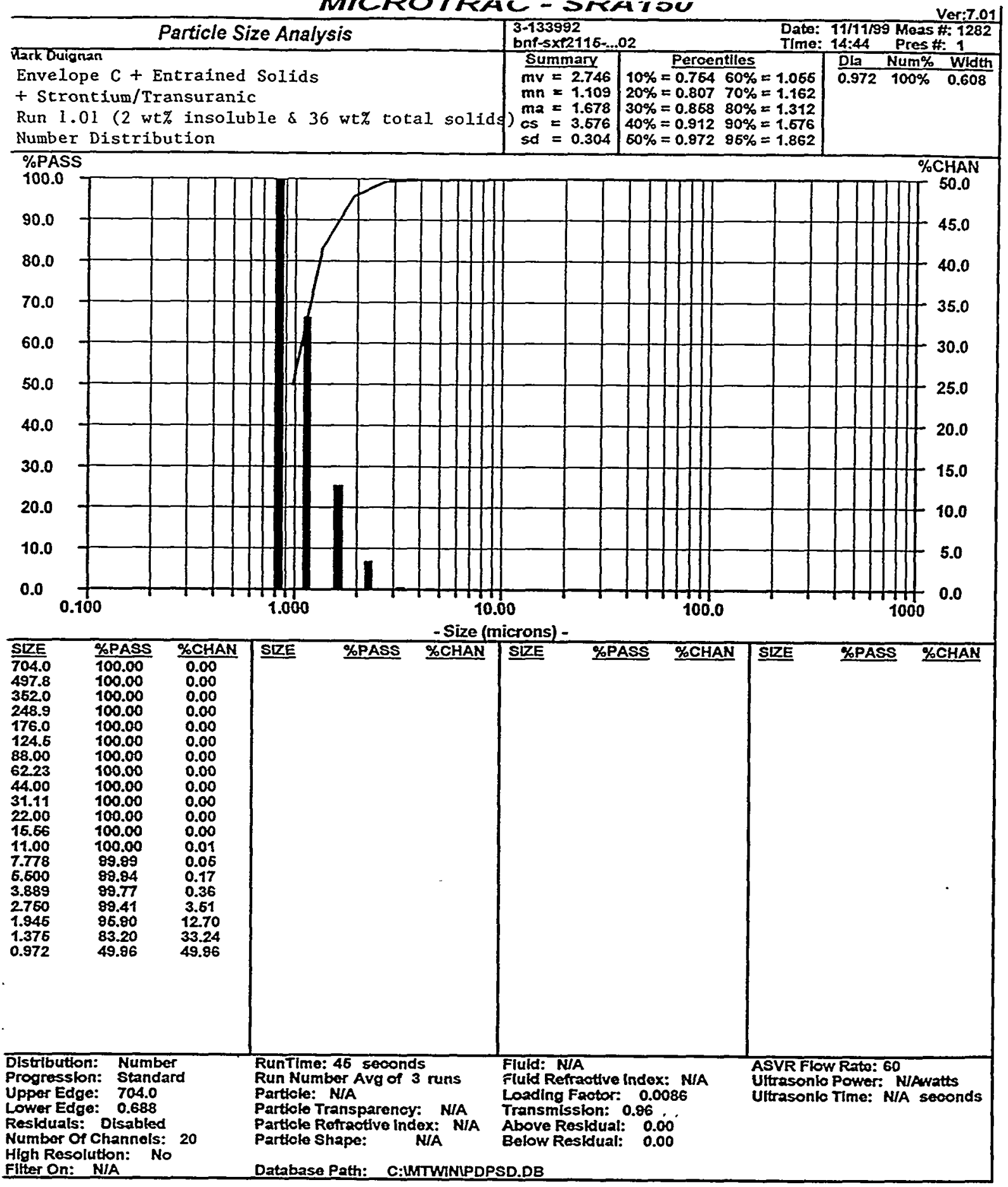

Figure E25B.Insoluble Solids NUMBER Distribution: Run 1.01

( $2 \mathrm{wt} \%$ insoluble solids slurry experienced about 1 hour of circulation) 


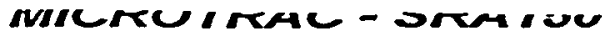

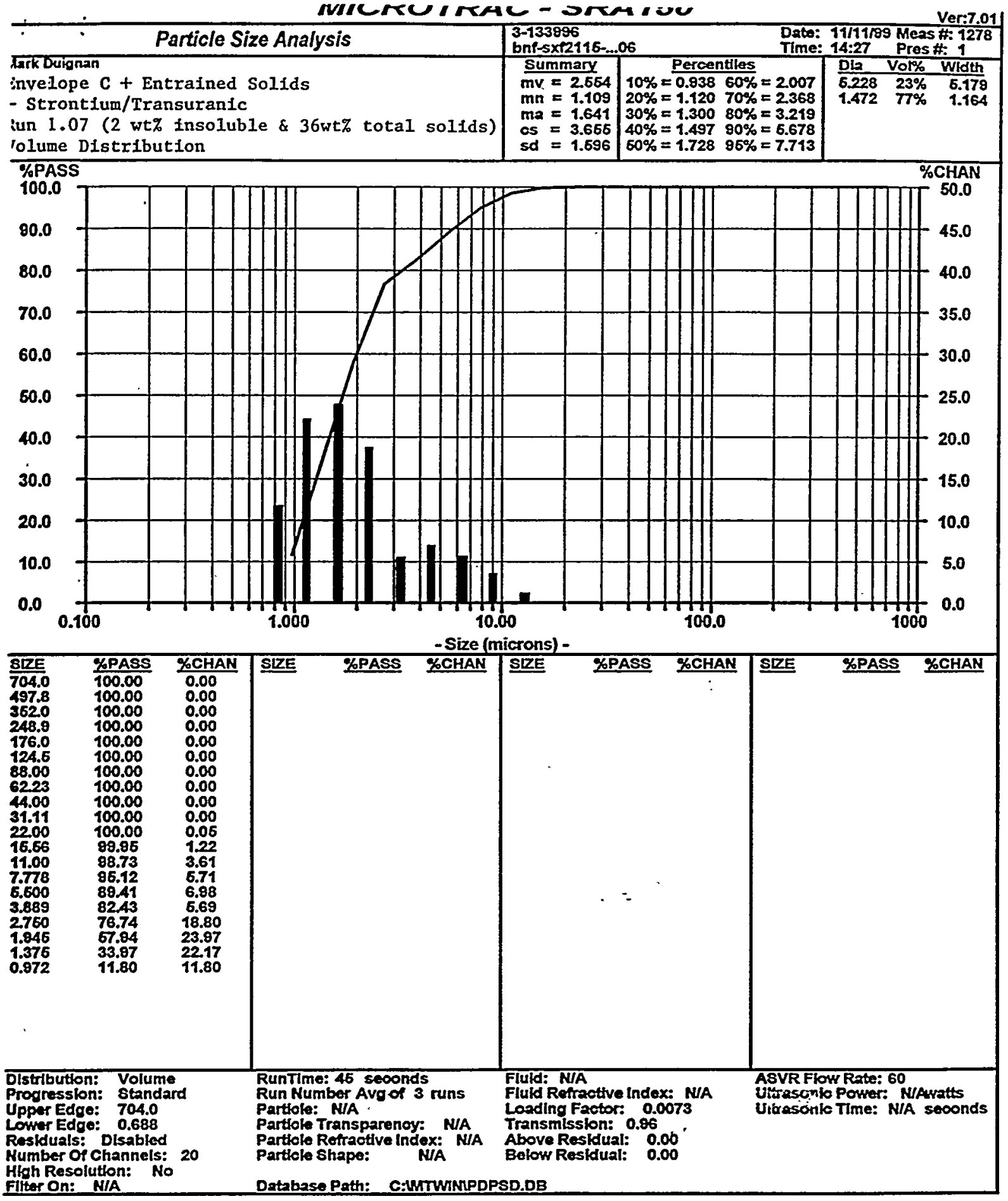

Figure E26A.Insoluble Solids VOLUME Distribution: Run 1.07

( $2 \mathrm{wt} \%$ insoluble solids slurry experienced about 27 hours of circulation) 


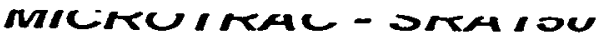

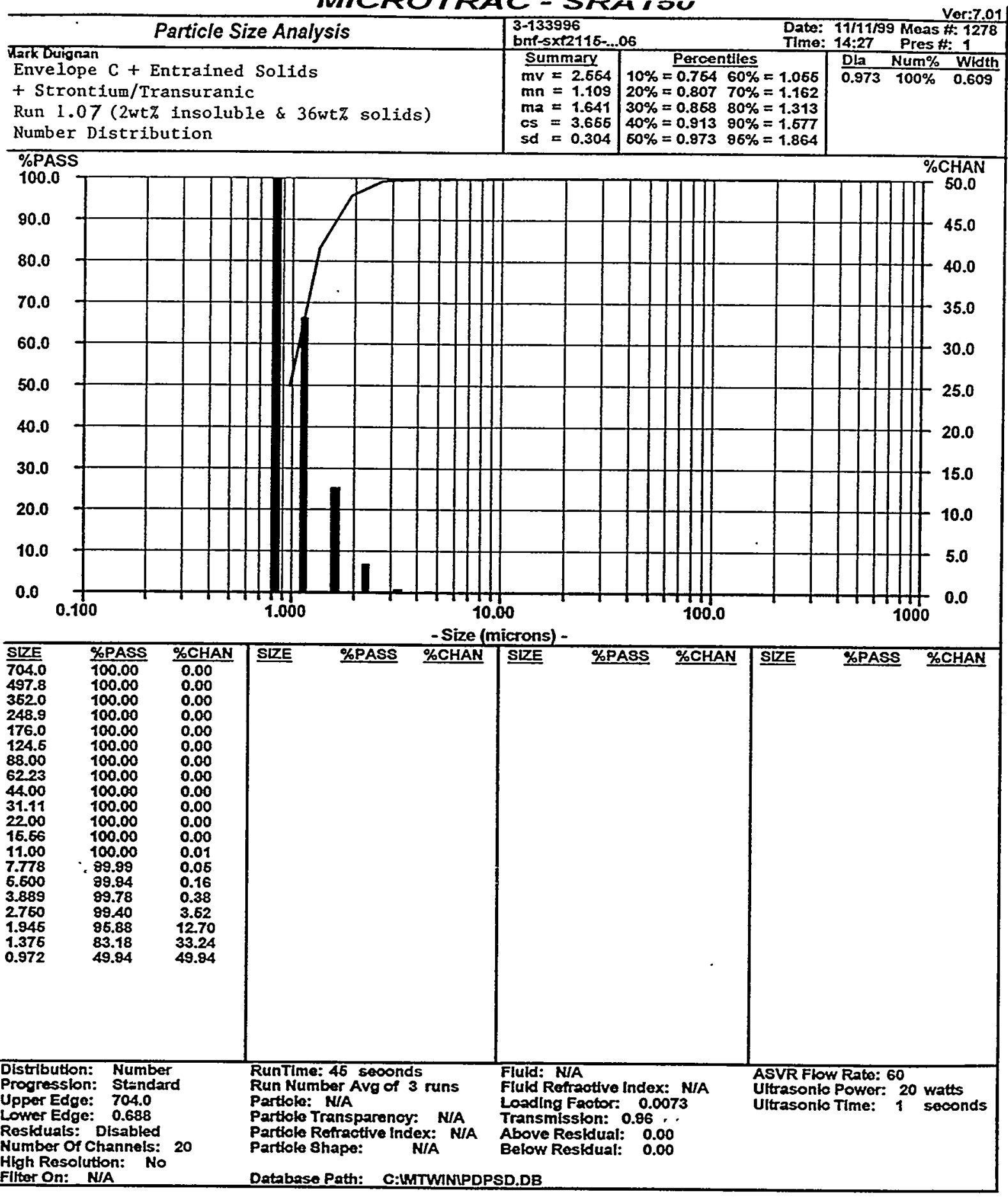

Figure E26B.Insoluble Solids NUMBER Distribution: Run 1.07

( 2 wt\% insoluble solids slurry experienced about 27 hours of circulation) 


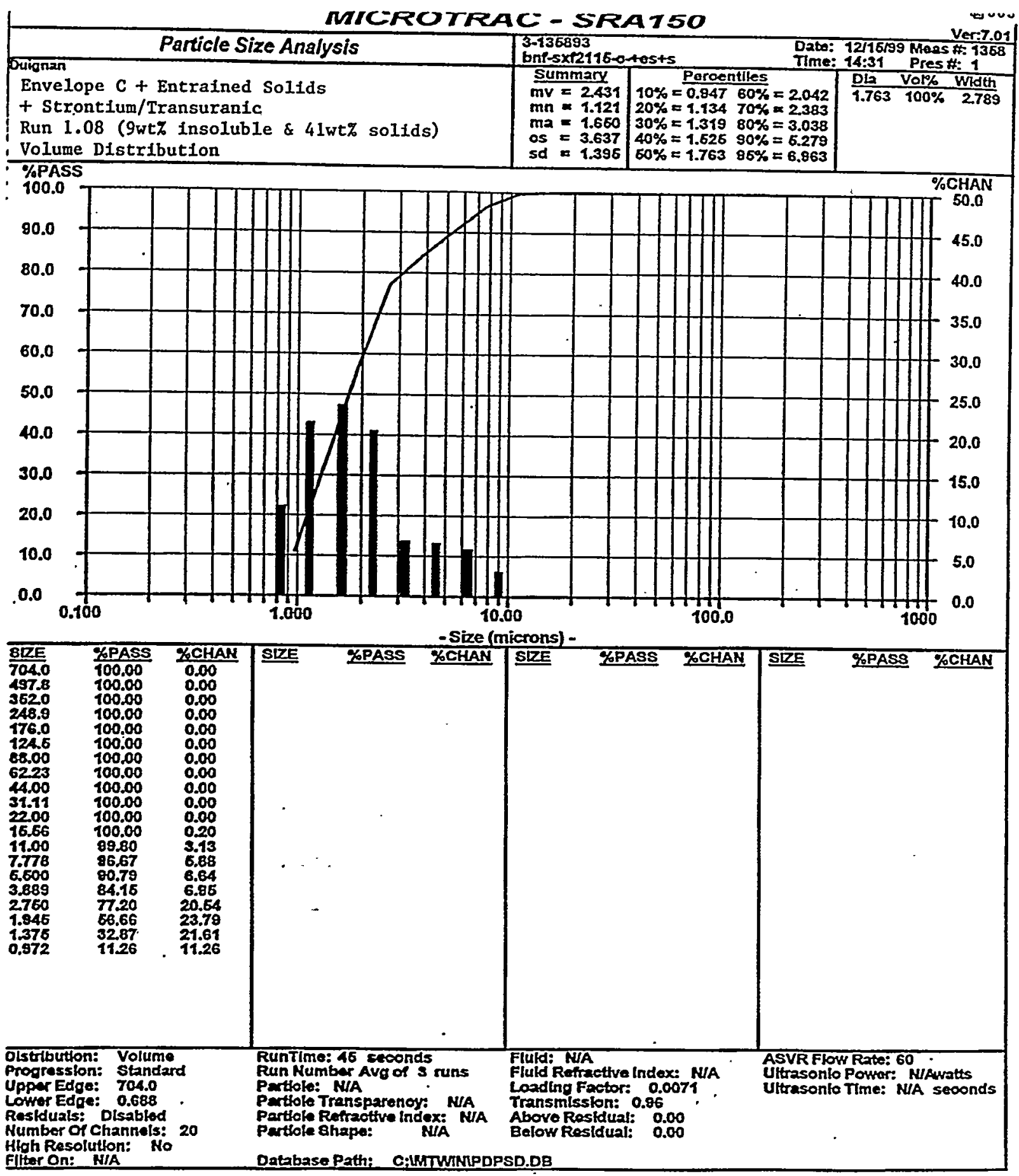

Figure E27A.Insoluble Solids VOLUME Distribution: Run 1.08 ( 9 wt\% insoluble solids slurry experienced about 21 hours of circulation) 


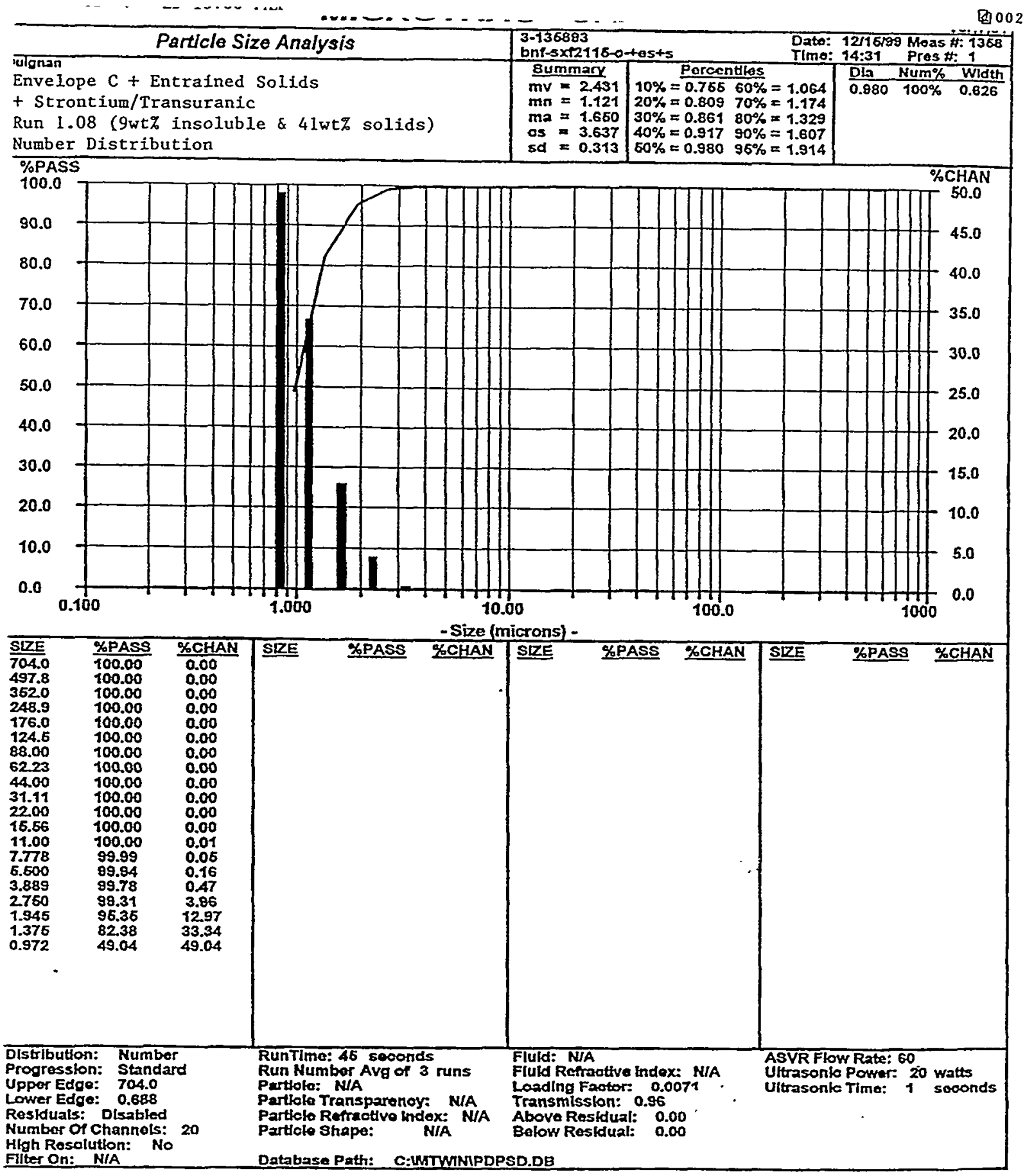

Figure E27B.Insoluble Solids NUMBER Distribution: Run 1.08 ( $9 \mathrm{wt} \%$ insoluble solids slurry experienced about 21 hours of circulation) 


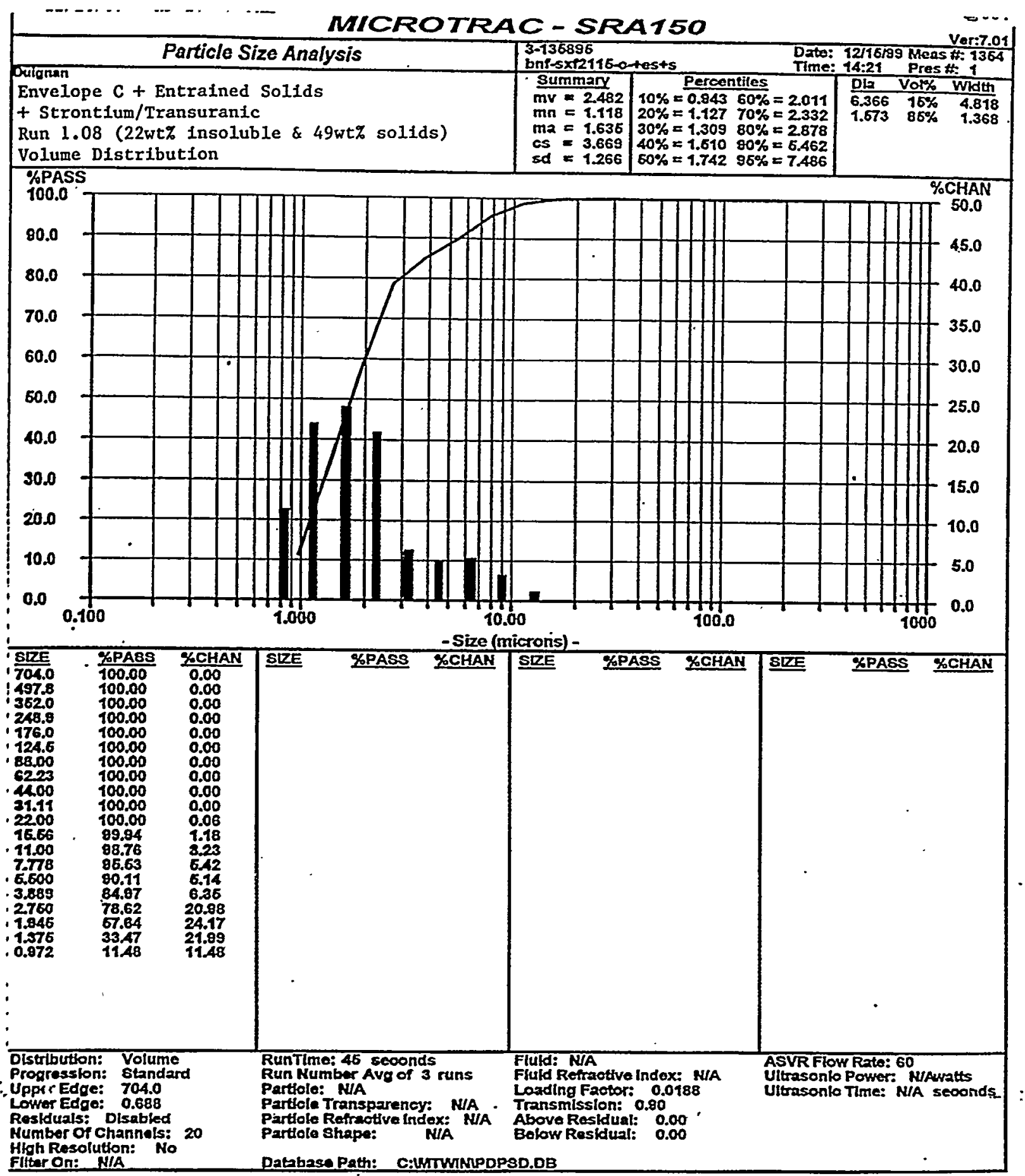

Figure E28A.Insoluble Solids VOLUME Distribution: Run 1.08 (22 wt\% insoluble solids slurry experienced about 30 hours of circulation) 


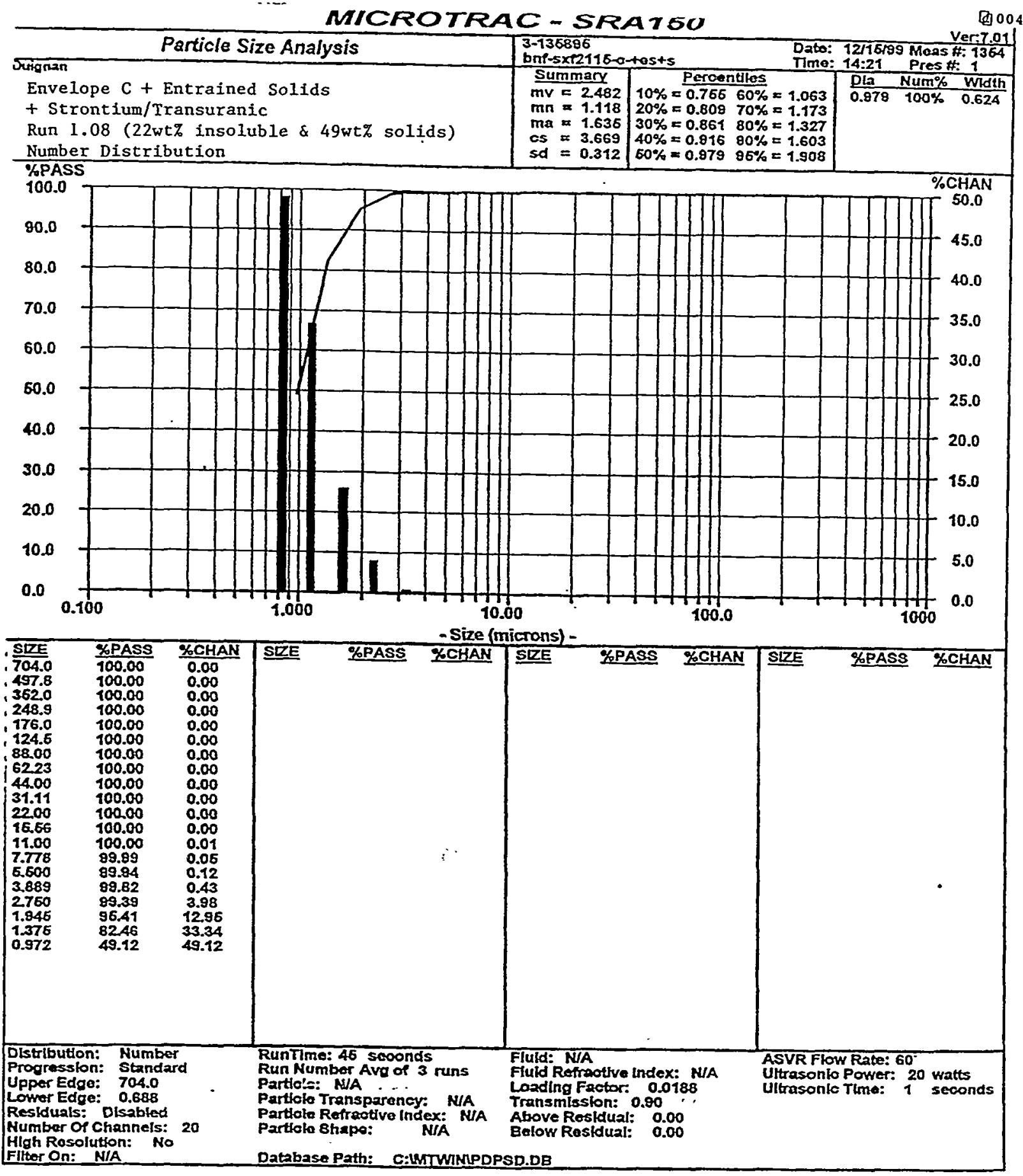

Figure E28B.Insoluble Solids NUMBER Distribution: Run 1.08 (22 wt\% insoluble solids slurry experienced about 30 hours of circulation) 


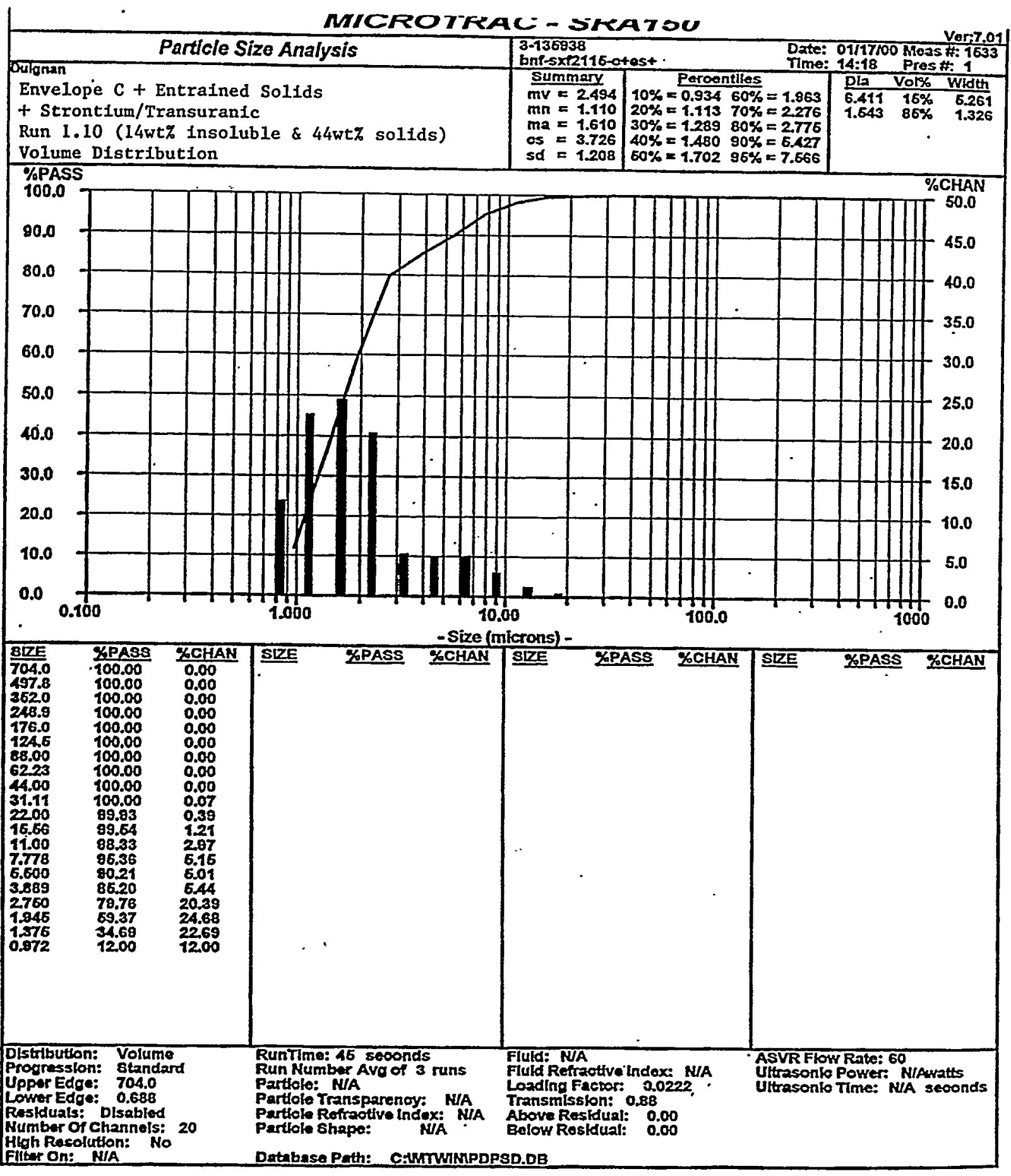

Figure E29A.Insoluble Solids VOLUME Distribution: Run 1.10 (14 wt\% insoluble solids slurry experienced about 34 hours of circulation) 
MICROTRAC - SRAT5O

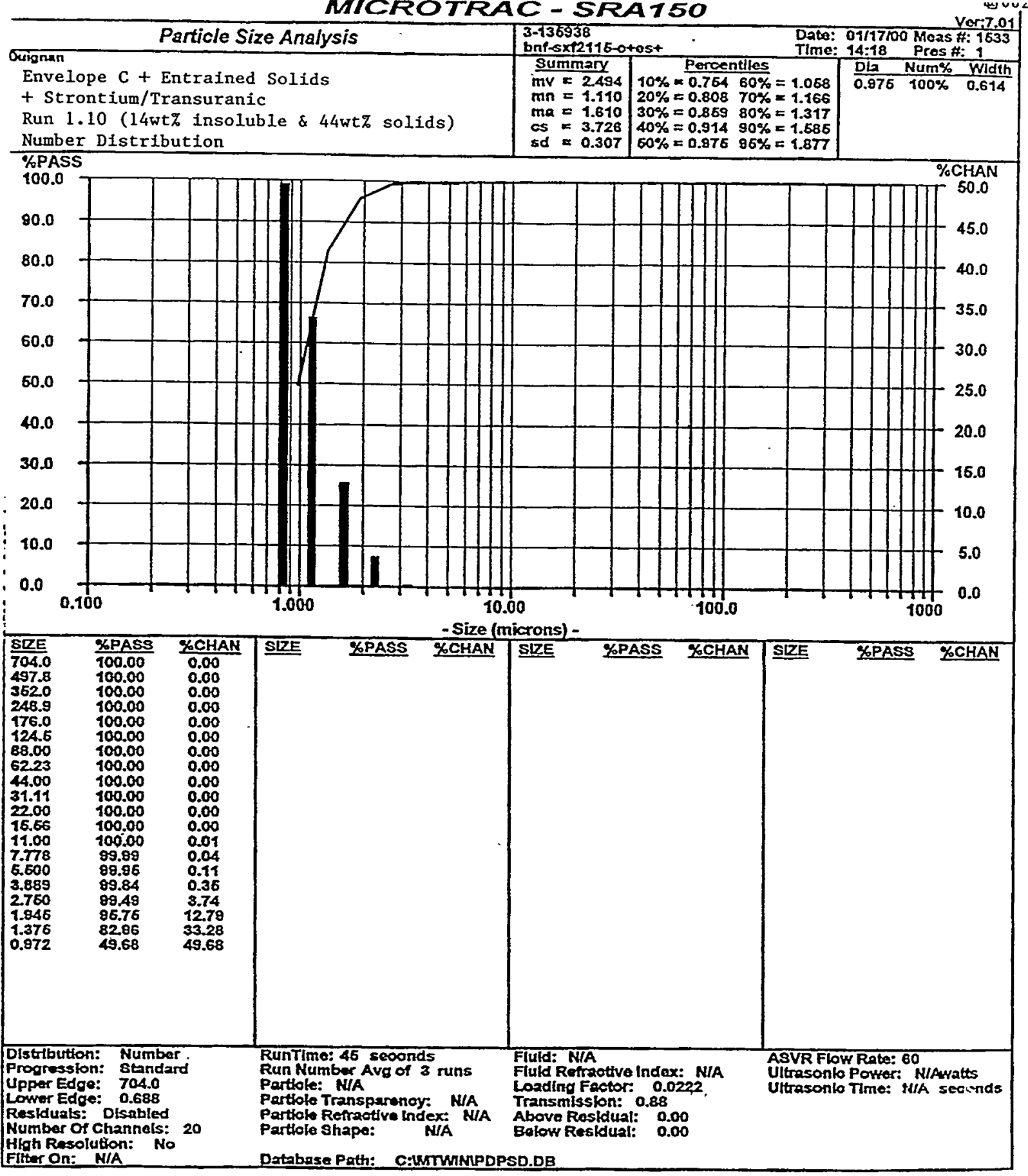

Figure E29B.Insoluble Solids NUMBER Distribution: Run 1.10 (14 wt\% insoluble solids slurry experienced about 34 hours of circulation) 


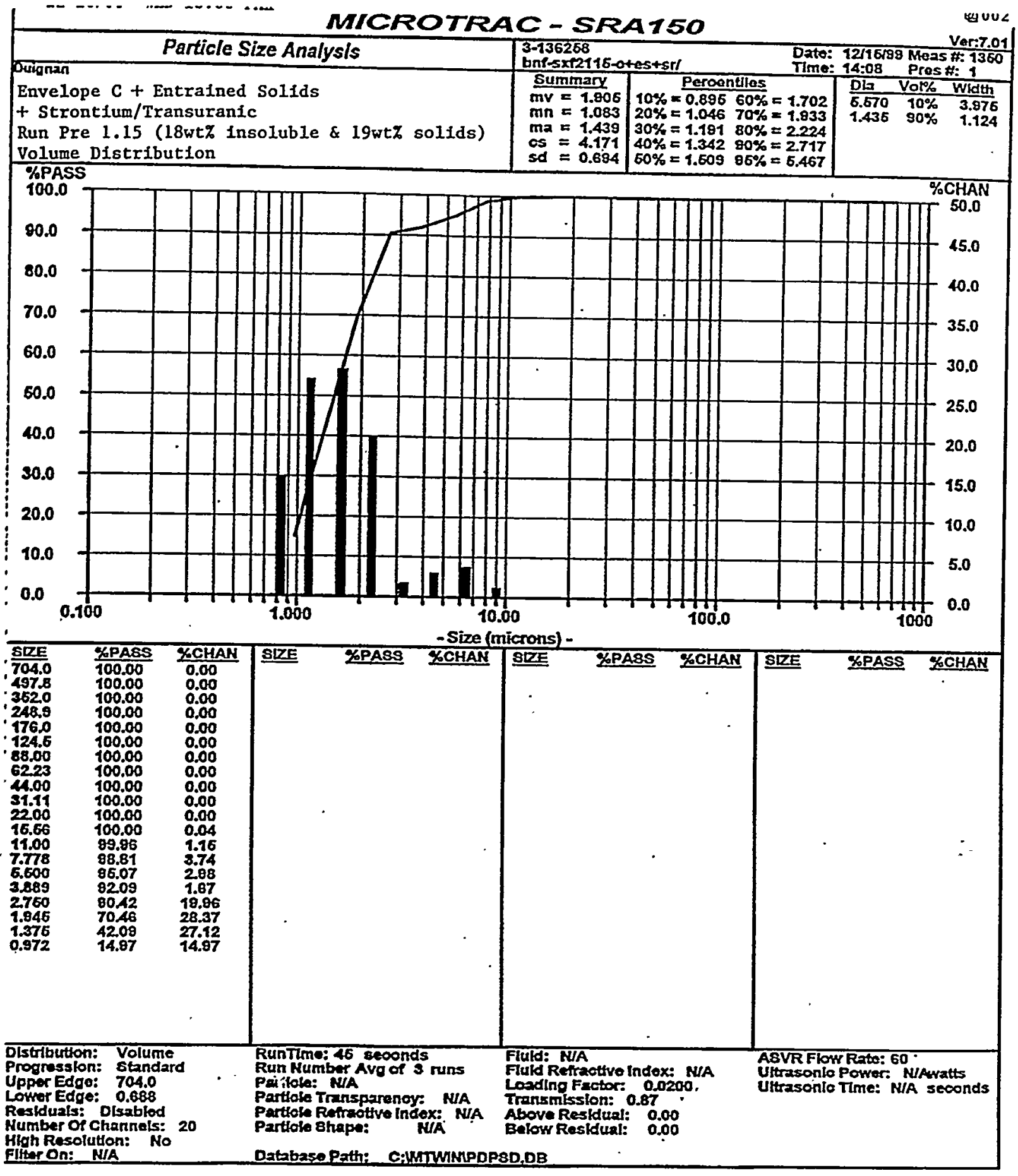

Figure E30A.Insoluble Solids VOLUME Distribution: Run 1.15 (18 wt\% insoluble solids slurry experienced about 55 hours of circulation) 


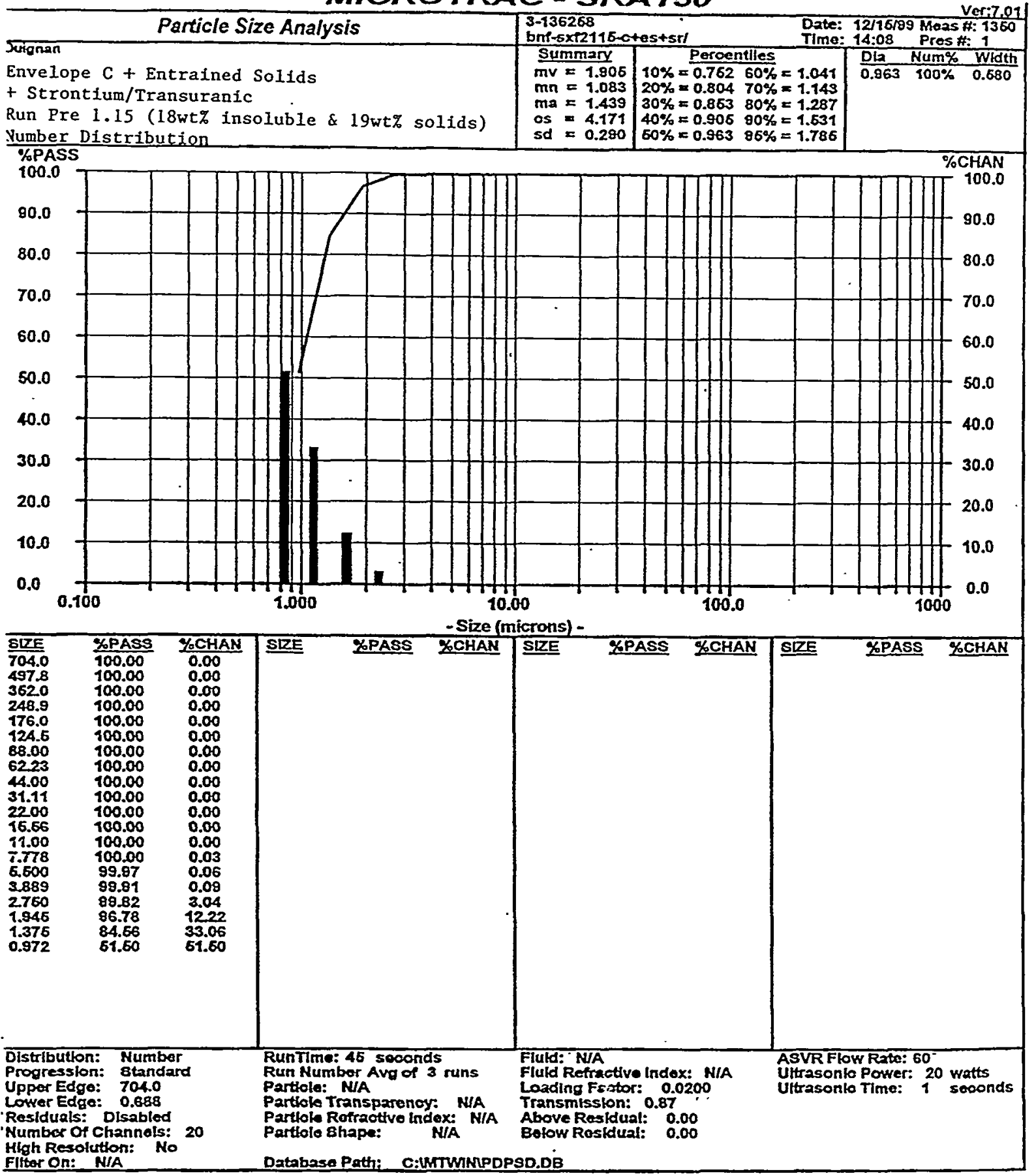

Figure E30B.Insoluble Solids NUMBER Distribution: Run 1.15 (18 wt\% insoluble solids slurry experienced about 55 hours of circulation) 


\section{APPENDIX F}

\section{INSTRUMENTATION AND MEASUREMENT UNCERTAINTY}

\section{Appendix Contents}

1. Experimental measurement uncertainty

2. Figure F1. Instrumentation used with their transfer functions

3. Figure F2. Pressure transducer locations

4. Figures F3 to F16. Calibration sheet for the 14 instruments

Special Note:

As mentioned in Appendix E, there are no measurement uncertainties listed for the analytical data because those uncertainties are beyond the scope and control of this task. There is reason to believe that all analytical data can be at least $15 \%$ accurate, but no quantitative data are given to this effect. 


\section{EXPERIMENTAL MEASUREMENT UNCERTAINTY}

As always, any measurement made has an attributed error which must be known before a level of confidence can be attained for the results obtained. This error may come from one or all of the following: the measurement instrument, the way an instrument is set up to make a measurement in relation to the experimental phenomenon to be measured, and the person using the instrument. It is not the purpose of this section to exhaust all possible avenues of measurement uncertainty, but rather to illustrate the level of measurement uncertainty in the results presented in Appendices $A, B, C, D$. (Outside of density and capillary-viscometer measurements taken, the measurement uncertainty of the analytical data in Appendix $E$ is beyond the scope of this task.) In general, the measurement uncertainties present here are for a reading or calculation at any instant. That is, the fluctuations that occur during experimentation are not addressed here. The magnitude of measurement fluctuations with time that occur during an experimental run can be seen at the bottom of each data table from the preceding appendices. Each column of data includes the average value of those data and their standard deviation.

In all the data sheets included in Appendices A, B, C, D there are raw data columns (all columns to the left of the first Number Column, usually column $S$ ) and there are calculated data columns (all columns to the right of the second Number Column, usually Column T). The uncertainty of a raw data measurement is the calibrated uncertainty of the individual instrument to a $95 \%$ confidence level, Figs. F3 to F16.

Example to find the measurement uncertainty of a raw data point:

1. Find the data column $\mathrm{D}$ in any Appendix $\mathrm{A}$ through $\mathrm{D}$.

2. Check the column heading against the Nomenclature, included in the beginning of each Appendix, to find that the data in column D were obtained by Thermocouple T2.

3. Look up Thermocouple T2 on Fig. F1 in this Appendix to see that the average* calibrated uncertainty is $1.2^{\circ} \mathrm{C}$ (95\% confidence level $\left.{ }^{* *}\right)$. If a closer look on how that specific systematic error was obtained is desired, then check the appropriate calibration sheet. Thermocouple T2 is shown as Fig. F4. (The calibration sheets are in order of the fourteen instruments that are listed in Fig. F1, with the first instrument T1 shown in Fig. F3 and the last instrument Q3 shown in Fig. F16.)

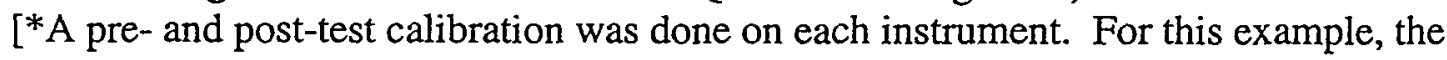
measurement uncertainties for $\mathrm{T} 2$ were $1.3^{\circ} \mathrm{C}$ and $1.1^{\circ} \mathrm{C}$ respectively, see Fig. F1. The true instrument uncertainty was somewhere between the pre- and post-test results. For this task each uncertainty was given equal weight, therefore an "average" of the two numbers was used, i.e., $1.2^{\circ} \mathrm{C}$.

**The confidence level comes from the Student's $t$ distribution function used in determining an instrument uncertainty.]

4. The magnitude of the random error can be obtained from the standard deviation shown at the bottom of each column of raw data. The standard deviation from the average value, obtained from a specific instrument for a specific test run, will be a good indication of random error for all but the filtrate flowrates, Q2 and Q3. Temperatures, pressures, and slurry flowrates were maintained constant, therefore the fluctuations around the mean should be normally distributed. The filtrate flowrates decreased with time, due to the nature of the experiment. Therefore, the random error 
for Q2 and Q3 should only be obtained when the filtrate flowrates reach some asymptote. (In some cases, like on Runs 1.09-1.14 for a thick slurry the temperature could not be held constant, but increased with time. In these cases the standard deviation will not properly represent random fluctuations. To facilitate the evaluation of such occurrences each column of data also has the maximum, minimum, and median values along with the average and standard deviation. Note that the number of points used to determine these values is also given. Extreme points, like when backpulsing occurs were excluded. With the number of data points known the standard error of the mean may be obtained (i.e. standard error = standard deviation / square root (number of points)) [Ref. 28].

Measurement uncertainties for the calculated results can be obtained by the general method of the Law of Propagation of Errors (section 4.7 of Ref. 28). The derivation will not be given here and the following is just one example for one type of relation, albeit a common relation.

For example, a calculated entity has an uncertainty of $\delta a$. The entity a is a function of three measured quantities: $b, c$, and $d$ by the following relationship: $a=b x c / d$ and these quantities have measurement uncertainties of $\delta b, \delta c$, and $\delta d$, respectively. The uncertainty can be shown as:

$$
(\delta \mathrm{a})^{2}=[(\partial \mathrm{a} / \partial \mathrm{b}) \delta \mathrm{b}]^{2}+[(\partial \mathrm{a} / \partial \mathrm{c}) \delta \mathrm{c}]^{2}+[(\partial \mathrm{a} / \partial \mathrm{d}) \delta \mathrm{d}]^{2},
$$

if the error terms are independent and symmetrical. The term $\delta a$ is squared to capture both the negative and positive error terms.

Then for the relation $a=b c / d$ the relative uncertainty can be shown to be:

$$
\delta \mathrm{a} / \mathrm{a}=\left[(\delta \mathrm{b} / \mathrm{b})^{2}+(\delta \mathrm{c} / \mathrm{c})^{2}+(\delta \mathrm{d} / \mathrm{d})^{2}\right]^{1 / 2} .
$$

Using the above the relation (1) an uncertainty for velocity, transmembrane pressure, filtrate flux, and permeability are determined. The method of determining the measurement uncertainty of any of the calculated results will the same as the following analyses. However, only one example of each calculated result is shown below. To show an example, any specific calculated quantity is sufficient. An arbitrary choice (but having lowest slurry flowrate and TMP to obtain the largest uncertainty) of a representative group of results is: Run 1.02 at the $20^{\text {th }}$ minute [The data for Run 1.02 can be found in Appendix B in the first table and the $20^{\text {th }}$ minute is. row 31.]

The measurement uncertainty for the following values will be shown:
$\mathrm{V}, \mathrm{ft} / \mathrm{s}$
TMP, psi
$\mathrm{Fc}$ (at $\left.25^{\circ} \mathrm{C}\right), \mathrm{gpm} / \mathrm{ft}^{2}$,
$\mathrm{P}, \mathrm{gpm} / \mathrm{ft}^{2} / \mathrm{psi}$
9.1
31.2
$0.038^{*}$
0.001210

*actual temperature was $25.2^{\circ} \mathrm{C}$ but was adjusted to $25.0^{\circ} \mathrm{C}$ as per the customer specification, Ref. 3, therefore Fc means the corrected filtrate flux. 
The results of the measurement uncertainties found below at the $95 \%$ confidence level are:

$\begin{array}{llll}\text { Slurry Velocity } & = & \mathrm{V} & \mathbf{8 . 0 9} \% \\ \text { Transmembrane Pressure } & = & \text { TMP } & \pm 1.10 \% \\ \text { Temperature Corrected Filtrate Flux } & = & \text { Fc } & \pm \mathbf{1 1 . 6 9 \%} \\ \text { Permeability } & = & \mathrm{P} & \mathbf{1 1 . 7 4} \%\end{array}$

\section{F.1 Velocity $\left[\mathrm{V}=\mathrm{Q} 1 / \mathrm{A}_{\text {cross-section }}\right]$}

This uncertainty is combination of the instrument, Q1, uncertainty and from the lack of knowledge of the exact inside diameters of the filter tubes. The instrument uncertainty is obtained for that instrument's calibrated uncertainty. An accurate measurement of the average inside diameter of the filtrate tubes was impossible since it may vary down the length for each filter tube and may vary from tube to tube. Even measuring the diameter at the filter tube ends is difficult because of the weldments to the tube sheets. What will be used is the manufacturer's tolerances. For a Mott 3/8-inch tube the diameter tolerances are stated by the vendor to be +0.025 inch and -0.005 inch. The diameter of the filter tubes can presumably vary anywhere between those tolerances therefore for this task the diameter uncertainty will be taken as the average tolerance, i.e., \pm 0.015 inch.

The measurement uncertainty estimate:

Calibrated uncertainty (Figs. F1 and F14): $\delta Q 1= \pm 0.26$ gpm

Slurry flow rate: Q1 $=21.87 \mathrm{gpm}$ [Run 1.02, Row 31, Column P: Appendix B]

Filter tube inside diameter: $\delta d= \pm 0.015$ inch

Filter tube inside diameter: $\mathrm{d}=0.375$ inch

$\mathrm{V}=\mathrm{Q} / \mathrm{A}=\mathrm{Q} 1 /\left(\pi \mathrm{d}^{2} / 2\right)$

In the form of Eq. (1): $\delta \mathrm{V} / \mathrm{V}=\left[(\delta \mathrm{Q} 1 / \mathrm{Q} 1)^{2}+4(\delta \mathrm{d} / \mathrm{d})^{2}\right]^{1 / 2}$

[Note the multiplier 4. This results from the derivation $\partial \mathrm{V} / \partial \mathrm{d}$ because of the exponent]

Therefore, $\left[(0.26 / 21.87)^{2}+4(0.015 / 0.375)^{2}\right]^{1 / 2} \times 100 \%= \pm 8.09 \%$

The uncertainty of the example $V$ is: $\mathbf{9 . 1} \pm \mathbf{0 . 8} \mathrm{ft} / \mathrm{s}$

[since $9.1 \times 0.0809 \sim 0.74$ ]

\section{F.2 Transmembrane Pressure $[\mathrm{TMP}=(\mathrm{dP} 2+\mathrm{dP} 3) / 2]$}

This uncertainty will come from two instruments, $\mathrm{dP} 2$ and $\mathrm{dP} 3$. Also, there is another uncertainty due to location of the pressure taps. As seen in Figs. 1 and F2, dP2 is located at the bottom to the filter housing (upstream to the filter) and $\mathrm{dP} 3$ is located at the top of 
the filter housing (downstream to the filter). Due to fluid being in the pressure lines (water) a liquid-filled system will give approximately* the correct pressure drops, however, the slurry pressures lost upstream to the filter and gained downstream of the filter are not symmetrical and therefore do not cancel out. With this said, this addition to the uncertainty is small compared to the assumption that true TMP is represented by the average of two pressures at the ends of a filter. Because the filter is oriented perpendicular to gravity and the flow causes a pressure and concentration gradient along the entire tube wall it is not clear what TMP would be representative of the entire filter unit. On the other hand, the way measurements were taken probably will be similar to the field use of this filter and therefore a good measurement for design purposes. The uncertainty is actually the uncertainty of two measurement devices, and nothing more. Finally, the Law of Propogation of Errors by Eq. (1) does not lend itself to additive contributions to uncertainties. Fortunately, the two quantities are similar in magnitude and calibrated uncertainty. Equation (1) will be used as long as it give an uncertainty larger than the largest calibrated uncertainty for the two pressure transducers.

[*The correct pressure drop, for any $\mathrm{dP}$, is obtained when the test liquid is the same as the liquid in the pressure lines. Since the slurry was more dense than the water the readings are affected accordingly. For instance, the pressure lines to obtained dP3 are lines 3 and 4, Fig. F2, and their heights were 150.38 inches and 141.75 inches, respectively. With NO flow in a completely water-filled system, then $\mathrm{dP} 3=0$, (that is, the two water columns cancel each other) but with a different density fluid in the test rig there is a differential pressure $\mathrm{dP} 3=\mathrm{P}_{\text {line3 }}-\mathrm{P}_{\text {line4 }}=(150.38-141.75) \times$ (density difference). In the worst case the slurry density was approximately $1.4 \mathrm{~g} / \mathrm{cc}$, therefore the offset could be a maximum of 8.63 inches $\mathrm{x} 0.4=3.5$ inches $\mathrm{H}_{2} \mathrm{O}$ or 0.13 psid. However, the actual magnitude of the offest was probably smaller because the differential height, 8.6 inches, was a combination of slurry and filtrate, which had a lower density. Combining this complication of obtaining the true contribution to the overall uncertainty, along with the measurement fluctuations and other factors, then this quantity to the uncertainty was neglected.]

The measurement uncertainty estimate:

Calibrated uncertainty (Figs. F1 and F12): $\delta \mathrm{dP} 2= \pm 0.23 \mathrm{psi}$

Pressure drop: $\mathrm{dP} 2=33.16$ psid [Run 1.02, Row 31, Column J: Appendix B]

Calibrated uncertainty (Figs. F1 and F13): $\delta \mathrm{dP} 3= \pm 0.25 \mathrm{psi}$

Pressure drop: dP3 $=29.26$ psid [Run 1.02, Row 31, Column M: Appendix B]

$\mathrm{TMP}=(\mathrm{dP} 2+\mathrm{dP} 3) / 2$

In the form of Eq. (1): $\delta \mathrm{TMP} / \mathrm{TMP}=\left[(\delta \mathrm{dP} 2 / \mathrm{dP} 2)^{2}+(\delta \mathrm{dP} 3 / \mathrm{dP} 3)^{2}\right]^{1 / 2}$

Therefore, $\left[(0.23 / 33.16)^{2}+(0.25 / 29.26)^{2}\right]^{1 / 2} \times 100 \%= \pm 1.10 \%$

The uncertainty of the example TMP is: $32.1 \pm 0.4 \mathrm{psid}$ 
[since $32.1 \times 0.0110 \sim 0.35$ ]

\section{F.3 Filtrate Flux $\left[\mathrm{F}=\mathrm{Q} 2 / \mathrm{A}_{\text {inner-surface }}\right]$}

This uncertainty is combination of the instrument, Q2, uncertainty and from the lack of knowledge of the exact inside diameters and length of the filter tubes. The instrument uncertainty is obtained for that instruments calibrated uncertainty. The uncertainty of the inside diameter of the filter tubes has already been addressed in section F.1 and it was estimated at 0.015 inch. The uncertainty of the length of the filter tubes was estimate from in-house measurements. The requested tube length from the manufacturer was 40 inches. Because of weldments at the ends and the center (the 40-inch length was made of two 20 -inch tube sections) the active length seemed closer to $397 / 8$ inches. However, since it was difficult to get an exact measurement, not being able to measure inside, the 40 -inch length was used to determine the inner surface area and the $1 / 8$-inch difference will be used for the length uncertainty.

The measurement uncertainty estimate:

Calibrated uncertainty (Figs. F1 and F15): $\delta \mathrm{Q} 2= \pm 0.009 \mathrm{gpm}$

Filtrate flow rate: Q2 $=0.0 .087 \mathrm{gpm}$ [Run 1.02, Row 31, Column Q: Appendix B]

Tube inside diameter uncertainty: $\delta \mathrm{d}= \pm 0.015$ inch (from manufacturer)

Tube inside diameter: $d=0.375$ inch

Tube length uncertainty: $\delta \mathrm{L}= \pm 0.125$ inch

Tube length: $L=40$ inches

$\mathrm{F}=\mathrm{Q} / \mathrm{A}=\mathrm{Q} 2 / \pi \mathrm{d} \mathrm{L}$

In the form of Eq. $(1): \delta \mathrm{F} / \mathrm{F}=\left[(\delta \mathrm{Q} 2 / \mathrm{dQ} 2)^{2}+(\delta \mathrm{d} / \mathrm{d})^{2}+(\delta \mathrm{L} /)^{2}\right]^{1 / 2}$

Therefore, $\left[(0.009 / 0.087)^{2}+(0.015 / 0.375)^{2}+(0.125 / 40)^{2}\right]^{1 / 2} \times 100 \%= \pm \mathbf{1 1 . 1 0} \%$

The uncertainty of the example $F$ is: $0.038 \pm 0.004 \mathrm{gpm} / \mathrm{ft}^{2}$

[since $0.038 \times 0.1110 \sim 0.0042$ ]

\section{F.3.1 Effect of Temperature on the Measurement Uncertainty on F}

As per the customer specification the filtrate flux was to adjusted such that it would give a result at $25^{\circ} \mathrm{C}$. The equation as was stated is:

$$
\begin{aligned}
& \mathrm{F}=\mathrm{Q} 2(\text { Temperature }) / \text { Area }=\mathrm{Q} 2 \times \text { Correction Factor /Area } \\
& \mathrm{CF}=e^{[2500((1 / 273+\text { Slurry Temperature }))-(1 / 298))]}
\end{aligned}
$$


Only the correction factor's effect on measurement uncertainty is dealt with here. The equation is accepted as error free, i.e., method, constants, etc. Only the uncertainty of the temperature measurement which leads to the correction will be addressed.

Generally, the adjustment to filtrate flux, F, is small because, whenever possible, the slurry's operational temperature was maintained at $25^{\circ} \mathrm{C}$, which would result in a zero adjustment. However, the example chosen to show measurement uncertainty had a temperature difference of $0.2^{\circ} \mathrm{C}$. That is, for Run 1.02 at the $20^{\text {th }}$ minute the slurry temperature was $25.192^{\circ} \mathrm{C}$ [Initial test runs were only cooled with water cooling coils which were not adequate. The temperature was better maintained after the coolant was changed to ethylene glycol.]. Unfortunately, the fact that a temperature correction is applied means the temperature uncertainty will effect the calculated result at any temperature. That is, even if the slurry temperature were exactly $25^{\circ} \mathrm{C}$, which would make the correction $=1.0$, the uncertainty of that temperature and thereby the correction, leads to an inherent uncertainty of value that is being corrected, i.e, F. For this task the slurry temperature was measured with thermocouple $\mathrm{T} 1$, which had a calibrated measurement uncertainty of $\pm 1.3^{\circ} \mathrm{C}$ [see Fig. F1]. If at $25^{\circ} \mathrm{C}$ the temperature has an uncertainty of $\pm 1.3^{\circ} \mathrm{C}$, then the correction can be either 0.9642 to 1.0374 , or approximately $\pm 3.66 \%$ [i.e., $((1-.9642)+(1.0374-1)) / 2 / 1.00=0.0366]$. To show the measurement uncertainty mathematically from the correction equation is beyond the scope of this task, however it can be shown graphically. For a range of slurry temperatures from $15^{\circ} \mathrm{C}$ to $40^{\circ} \mathrm{C}$, then the correction can be shown to change from 1.34 to 0.67 , respectively. However, with a measurement uncertainty of $\pm 1.3^{\circ} \mathrm{C}$ this factor can be in error from approximately $3.9 \%$ to $3.3 \%$, respectively, see the Figure below:

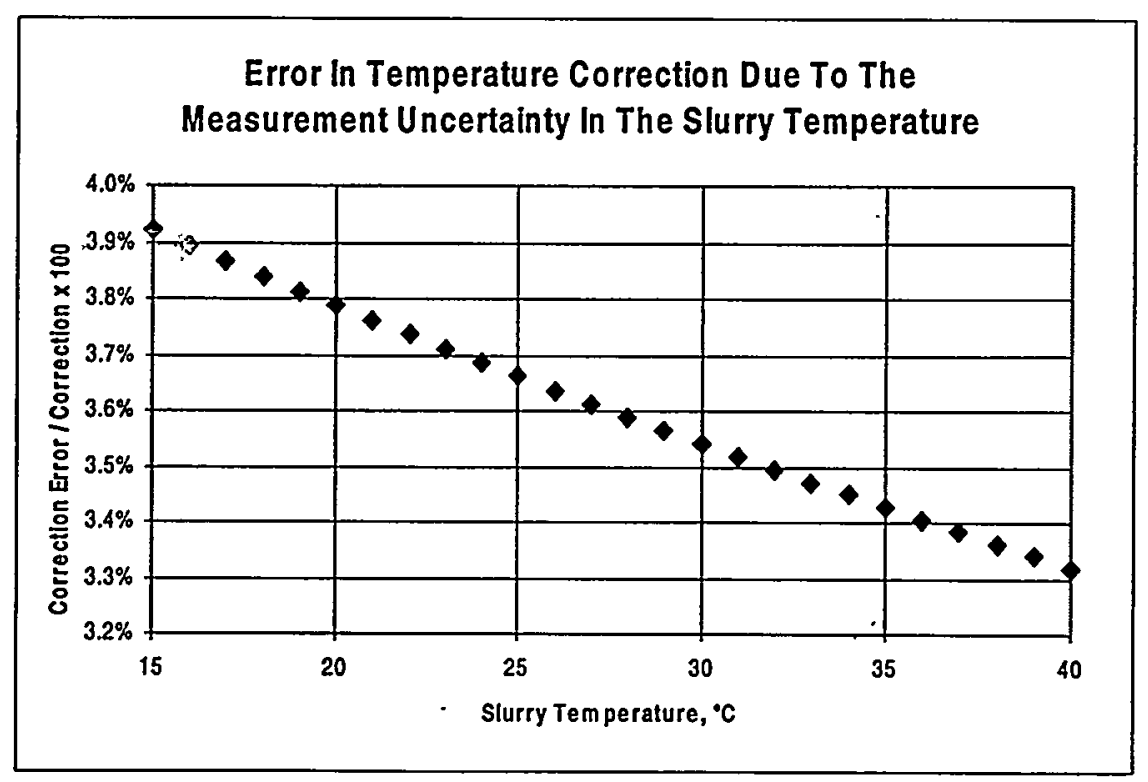

Therefore, for the sake of this example the relative uncertainty of the correction factor do to the temperature will be assumed to be $3.7 \%$, since most of the data were obtained at 
$25^{\circ} \mathrm{C}$. Using this constant value is not a bad assumption because between $20^{\circ} \mathrm{C}$ and $30^{\circ} \mathrm{C}$ this uncertainty only fluctuates by approximately $0.1 \%$.

This increased uncertainty to the filtrate flux is then a combination of two uncertainties already calculated above for $\mathbf{F}$ (section F.3) and the correction factor. The analyses still follows Eq. (1) therefore:

The measurement uncertainty estimate:

Filtrate flux relative uncertainty: $\delta \mathrm{F} / \mathrm{F}= \pm 11.10 \%$ [section F.3]

Correction factor relative uncertainty: $\delta \mathrm{CF} / \mathrm{CF}= \pm 3.66 \%$ [section F.3.1]

$\mathrm{Fc}=$ Fcorrected $=\mathrm{F} \times \mathrm{CF}$

In the form of Eq. $(1): \delta \mathrm{Fc} / \mathrm{Fc}=\left[(\delta \mathrm{F} / \mathrm{F})^{2}+(\delta \mathrm{CF} / \mathrm{CF})^{2}\right]^{1 / 2}$

Therefore, $\left[(11.10 \%)^{2}+(3.66 \%)^{2}\right]^{1 / 2}= \pm 11.69 \%$

The uncertainty of the example Fc is: $0.038 \pm 0.005 \mathrm{gpm} / \mathrm{ft}^{2}$

[since $0.038 \times 0.1169 \sim 0.0044$ ]

\section{F.4 Permeability $[\mathrm{P}=\mathrm{Fc} / \mathrm{TMP}]$}

This uncertainty is combination of two uncertainties already calculated above, in sections F.2 and F.3. The analyses still follows Eq. (1) therefore:

The measurement uncertainty estimate:

Filtrate flux relative uncertainty: $\delta \mathrm{Fc} / \mathrm{Fc}= \pm 11.69 \%$ [section $\mathrm{F} .3$ ]

TMP relative uncertainty: $\delta$ TMP/TMP $= \pm 1.10 \%$ [section F.2]

$\mathrm{P}=\mathrm{Fc} / \mathrm{TMP}$

In the form of Eq. $(1): \delta P / P=\left[(\delta \mathrm{Fc} / \mathrm{Fc})^{2}+(\delta \mathrm{TMP} / \mathrm{TMP})^{2}\right]^{1 / 2}$

Therefore, $\left[(11.69 \%)^{2}+(1.10 \%)^{2}\right]^{1 / 2}= \pm 11.74 \%$

The uncertainty of the example $P$ is: $0.00121 \pm 0.00014 \mathrm{gpm} / \mathrm{ft}^{2} / \mathrm{psi}$

[since $0.00121 \times 0.1174 \sim 0.000154$ ] 


\section{F.5 Second-Order Effects to Measurement Uncertainty}

There were other effects on the measurement uncertainty which are not included because they are thought to be of second order. For example, since the test rig was very tall, approximately $30 \mathrm{feet}$, it was subjected an ambient temperature gradient. Ambient temperatures at the bottom of the rig were usually less than at the top. For the example used in this section, [Run 1.02, Row 31, Columns G and H: Appendix B], the temperatures were $23.2^{\circ} \mathrm{C}$ and $22.3^{\circ} \mathrm{C}$, respectively. This gradient varied hourly and daily for several reasons. Most importantly, the $0.9^{\circ} \mathrm{C}$ temperature variation shown in this example is on the same order of magnitude as the calibrated uncertainties for the thermocouples. Further, the slurry in the loop generally flowed fast, so the residence time in any one section of the rig was small. For Run 1.02 the flow rate was, Q1 $=21.9$ $\mathrm{gpm}$. The loop volume was approximately 5 gallons so a fluid particle traversed the loop every $5 / 21.9 \times 60 \sim 14$ seconds. [Note that the slurry flow rate for Run 1.02 was one of the slowest.] In this example, the slurry temperature was measured to be $25.2^{\circ} \mathrm{C}$, from one thermocouple located in the suction line of the pumps. While it is certain that the ambient temperatures had an effect on the slurry temperature it was small, and at steady state the effect is incorporated in the slurry temperature. The same is true for the ambient temperature gradient but to a lesser extent and therefore not considered. 


\begin{tabular}{|c|c|c|c|}
\hline Test Rig No & Instument & MRTE \# & Make \\
\hline TI & Thermocouple & TR.02925 & OMEGA \\
\hline$\pi 2$ & Thermocouple & $\pi R .02926$ & OMEGA \\
\hline T了 & Thermocouple & TR-02929 & OMEGA \\
\hline TA & Thermocouple & TR-02930 & OMEGA \\
\hline 75 & Thermocouple & TR-02927 & OMEGA \\
\hline $\mathbf{P l}$ & Pies Transducer & TR-002917 & Rosemount \\
\hline P2 & Pres Transducer & TR-03108 & Rosemount \\
\hline$P_{3}$ & Pres Transducer & TR.02145 & Rosemount \\
\hline API & Pies Transduces & TR 03495 & Rosemount \\
\hline$d P 2$ & Pres Transducer & $T R=00532$ & Rosemound \\
\hline dP2 (atter 3/2599) & Pres Transducer & TR-00532 & Rosemount \\
\hline $\begin{array}{l}\mathrm{OP3} \\
\mathrm{O} 1 \\
02 \\
\mathrm{Q}\end{array}$ & $\begin{array}{l}\text { Pres Transducer } \\
\text { Mag Flowmeter } \\
\text { Mag Flowmeter }\end{array}$ & $\begin{array}{l}\text { TR-03115 } \\
\text { TR-20350 } \\
\text { TR-200353 }\end{array}$ & $\begin{array}{l}\text { Rosemount } \\
\text { Fischer-Ponter } \\
\text { Fischer-Porter }\end{array}$ \\
\hline
\end{tabular}

DAS Channel

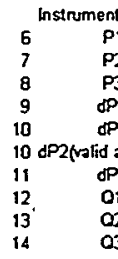

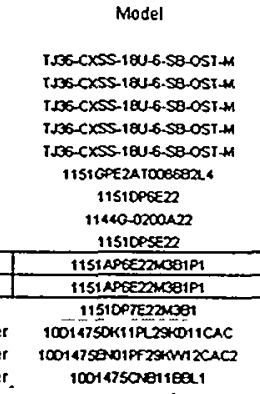

DAS Catibration

Chan $06=0$ 4975mA. SE -15 Champ $=04988 \mathrm{~mA}+0003$ Chan08 $=0.496 \mathrm{~mA}+0002$ Chan $09=0.4988 \mathrm{~mA}+0000$ Chan $09=0.4983 \mathrm{~mA}+0000$
Chan $10=0.4975 \mathrm{~mA}+0002$ Chanio $=04975 m A+0002$
Chanio $=0.4975 m A+0002$

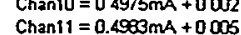
Chan11 $=0.4963 \mathrm{~mA}+0005$ Chan $12=0.4968 \mathrm{~mA}+0007$
Chant $3=0.4975 \mathrm{~mA}+001$ $\begin{aligned} \text { Codded on } \quad 7 / 4 / 1999 & \text { Chan1 } 14=0.4975 \mathrm{~mA}+001 \\ \text { a } & =0.4968 \mathrm{~mA}+0003\end{aligned}$
Calibrated Range Uncertanty. Uncertainty Uncertanty

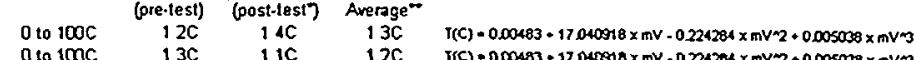

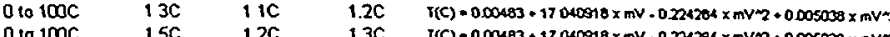

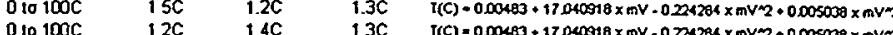

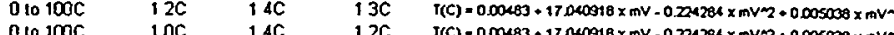

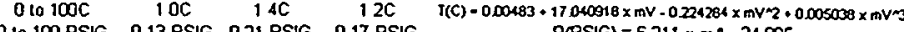
0 to 100 PSIG 013 PSIG 0.21 PSIG 017 PSIG $\quad$ P(PSIG $)=6211 \times \mathrm{mA} .24895$ -10 to 90 PSIG 0 Q PSIG 0 17PSIG 013 PSIG. $\quad P(P S I G)=6293 \times \mathrm{ma}=35524$ DI 0 to 26 PSID O02 PSID O068 PSID 0056 PSID $\quad P(P S I D)=16249 \times \mathrm{mA}-64930$ \begin{tabular}{l|l|l|l|l|l}
0 10 250 PSIG & 042 PSID & NA & 042 PSID & $P(P S D)=15648 \times \mathrm{mA}-62.400$
\end{tabular} \begin{tabular}{l|l|l|l|l}
010100 PSIG & 013 PSID & 033 PSID & 023 PSID & P(PSID $)=6314 \times \mathrm{mA}-25227$
\end{tabular}

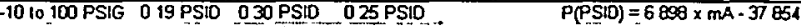
O TO50 GPM 019 GPM O33 GPM OT6 GPM $\quad Q(G P M)=3137 \times \mathrm{mA}-12509$ $01012 \mathrm{GPM} \quad 0005 \mathrm{GPM} 0.019 \mathrm{GPM} \quad 0012 \mathrm{GPM} \quad \mathrm{O}(\mathrm{GPM})=0.075 \times \mathrm{mA}-0.299$ 0 105 GPM 002 GPM 001 GPM 0015 GPM $O(G P M)=0311 \times \mathrm{mA}-1.297$

Iransfer Functions Used with the $D A$ Conversion from ma to Vots P(PSTG) $=12 \angle 041 \times \mathrm{V}-24 \mathrm{Bg}$ $P(P S \mid G)=12616 \times Y-35.561$ $P(P S I G)=18960 \times V-37.750$ $P(P S D)=326 \times V-6503$ $P(P S D)=31450 \times V-62.463$ $P(P S: D)=12691 \times V-25231$ $P(P S D)=13.843 \times V-37923$ $O(G P M)=6209 \times V-12563$ Q(GPM) $=0.6235 \times \vee-12553$

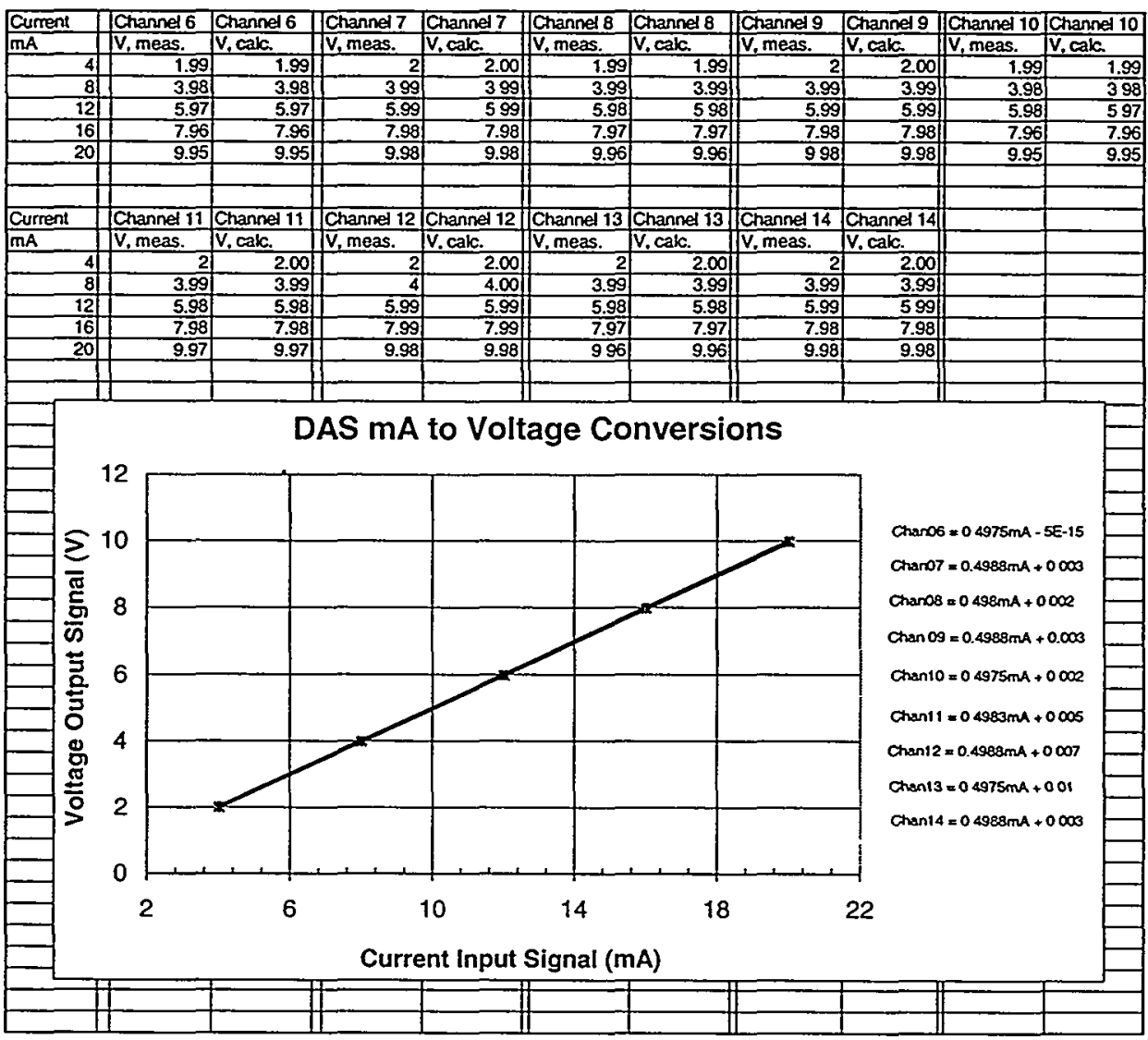

Figure F1. Instrumentation Used with their Transfer Functions 


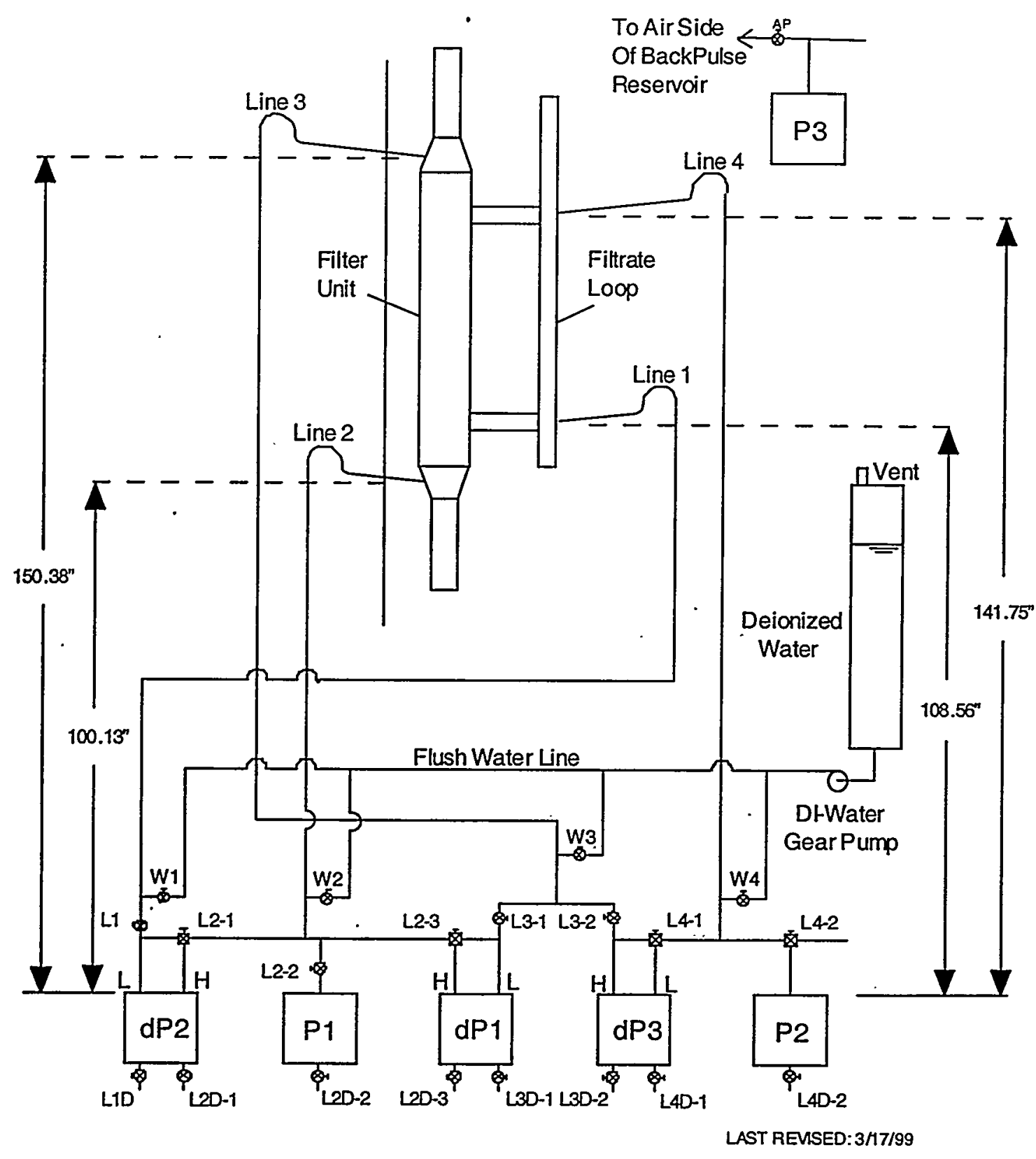

Figure F2. Pressure Transducer Locations 
UNCERTAINTY ANALYSIS

REF. WSRC-TR-91-106

TR-2925

Calibration Data

\begin{tabular}{|c|c|c|c|c|c|}
\hline \multirow{3}{*}{$\begin{array}{l}\text { Temperature } \\
\text { Medium }\end{array}$} & \multirow{3}{*}{$\begin{array}{l}\text { Standard } \\
\text { Temperature } \\
\text { (C) }\end{array}$} & \multicolumn{4}{|c|}{ Calculated } \\
\hline & & Voltage & \multicolumn{2}{|c|}{ Temperature } & \\
\hline & & $\begin{array}{l}\text { Output } \\
\text { (mV) }\end{array}$ & \multicolumn{2}{|c|}{$\begin{array}{l}\text { (eq. 1) } \\
\text { (C) }\end{array}$} & $\begin{array}{l}\text { Error } \\
\text { (C) }\end{array}$ \\
\hline Boiling Water & 100.70 & 6.338 & \multicolumn{2}{|l|}{100.28} & -0.4 \\
\hline Boiling Water & 100.70 & 6.357 & \multicolumn{2}{|l|}{100.56} & -0.1 \\
\hline Boiling Water & 100.70 & 6.345 & \multicolumn{2}{|l|}{100.39} & -0.3 \\
\hline Boiling Water & 100.70 & 6.340 & \multicolumn{2}{|l|}{100.31} & -0.4 \\
\hline Ice Point & 0.00 & -0.023 & \multicolumn{2}{|l|}{-0.39} & -0.4 \\
\hline Ice Point & 0.00 & -0.017 & \multicolumn{2}{|l|}{-0.28} & -0.3 \\
\hline Ice Point & 0.00 & -0.009 & \multicolumn{2}{|l|}{-0.15} & -0.1 \\
\hline Ice Point & 0.00 & -0.018 & \multicolumn{2}{|l|}{-0.30} & -0.3 \\
\hline Room Temp & 23.80 & 1.404 & \multicolumn{2}{|l|}{23.50} & -0.3 \\
\hline Room Temp & 23.80 & 1.428 & \multicolumn{2}{|l|}{23.90} & 0.1 \\
\hline Room Temp & 23.90 & 1.495 & \multicolumn{2}{|l|}{25.00} & 1.1 \\
\hline Room Temp & 23.90 & 1.466 & \multicolumn{2}{|l|}{24.52} & 0.6 \\
\hline \multicolumn{6}{|c|}{$\begin{array}{l}\mathrm{T}(\mathrm{C})=0.00483+17.040918^{*} \mathrm{mV}-0.224284^{*} \mathrm{mV} \wedge 2+0.005038^{*} \mathrm{mV} / 3 \text { (eq. 1) } \\
\text { (Limited Curve Fit, 0-100 C. From N.I.S.T. Reference Tables) }\end{array}$} \\
\hline \multirow{4}{*}{\multicolumn{2}{|c|}{ Uncertainty of the Standards: }} & Temperature Curve Fit: +/- & \multirow{2}{*}{\multicolumn{3}{|c|}{$0.010 \mathrm{C}$}} \\
\hline & & Thermometer $+1-$ & \multirow{2}{*}{0.40} & & \\
\hline & & Ice Bath: +/- & & $\mathrm{c}$ & \\
\hline & & Multimeter: $+/-($ & 0.0045 & $\% R D G+$ & 0.0005 \\
\hline
\end{tabular}

Accepted Tolerance: $+/-\quad 1.7 \quad$ C

Statistical Info.

\begin{tabular}{|c|c|c|c|c|c|c|c|}
\hline$a$ & b & $\mathrm{n}$ & $\mathrm{T}$ & $\begin{array}{l}\text { Xbar } \\
\text { (C) }\end{array}$ & $\begin{array}{c}\text { Sxx } \\
\left(C^{\wedge} 2\right)\end{array}$ & $\begin{array}{c}\text { SEE } \\
\left(C^{\wedge} 2\right)\end{array}$ & $\begin{array}{l}\text { MSE } \\
\text { (C^2) }\end{array}$ \\
\hline-0.05 & 1.00 & 11.00 & 2.262 & 43.12 & 21815.1 & 1.809 & 0.2010 \\
\hline
\end{tabular}

Calculated Uncertainties:

\section{standard}

uncertainty

(C)
0.41

(C)
0.41

curve-fit

uncertainty

(C)

1.13

PASS CALIBRATION?

$\begin{array}{ll}\text { fixed } & \text { total } \\ \text { uncertainty } & \text { uncertainty } \\ \text { (C) } & \text { (C) } \\ 0.24 & 1.2\end{array}$

YES

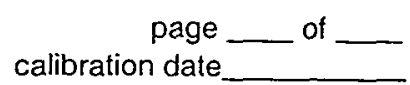


UNCERTAINTY ANALYSIS REF. WSRC-TR-91-106
TR-2926

Calibration Data

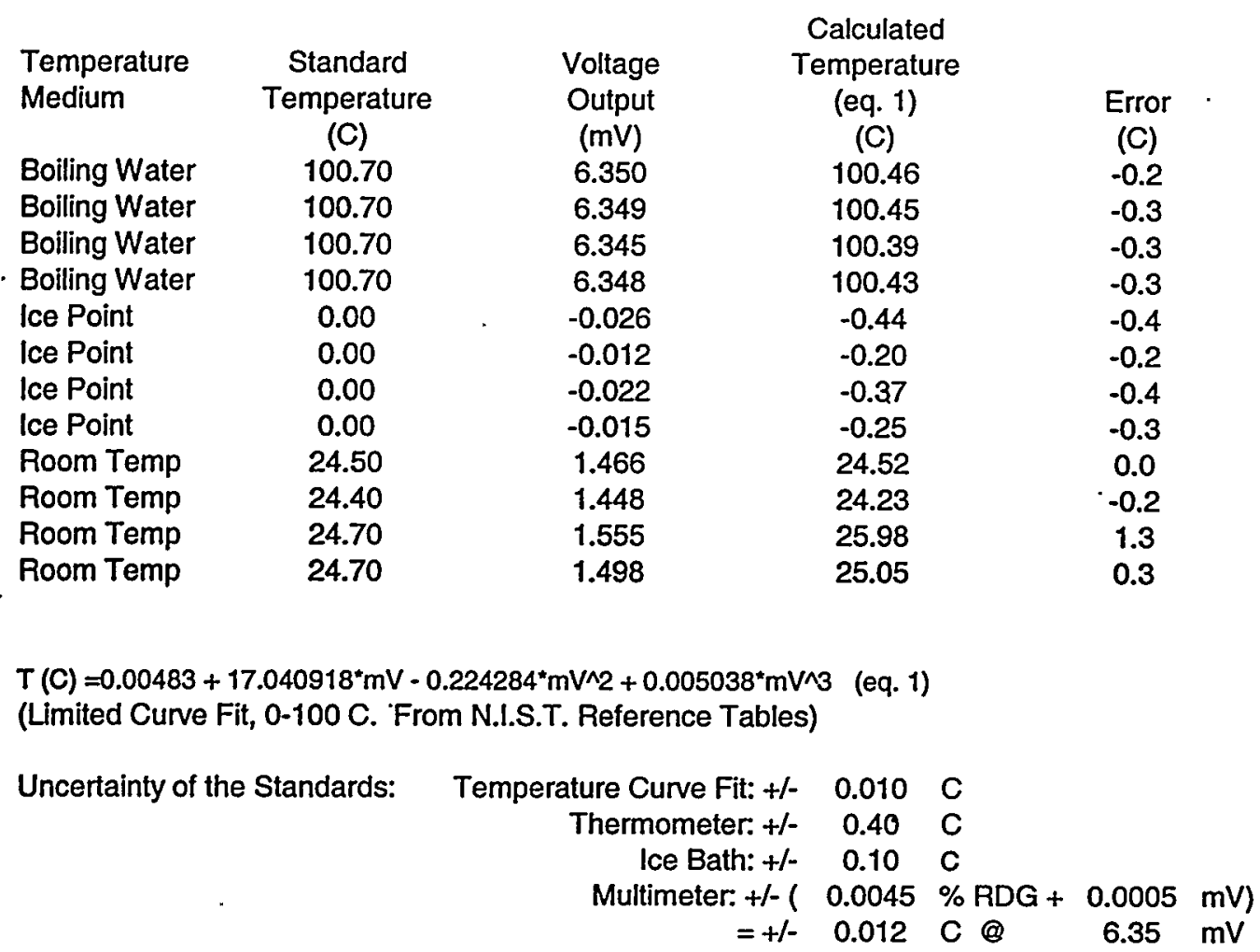

Accepted Tolerance: +/- $\quad 1.7 \quad$ C

Statistical Info.

$\begin{array}{cccccccc} & & & & \text { Xbar } & \text { Sxx } & \text { SEE } & \text { MSE } \\ \mathrm{a} & \mathrm{b} & \mathrm{n} & \mathrm{T} & (\mathrm{C}) & \left(\mathrm{C}^{\wedge}\right) & \left(\mathrm{C}^{\wedge} 2\right) & \left(\mathrm{C}^{\wedge}\right) \\ -0.05 & 1.00 & 11.00 & 2.262 & 43.31 & 21735.2 & 2.225 & 0.2472\end{array}$

Calculated Uncertainties:

$\begin{array}{llll}\text { standard } & \text { curve-fit } & \text { fixed } & \text { total } \\ \text { uncertainty } & \text { uncertainty } & \text { uncertainty } & \text { uncertainty } \\ \text { (C) } & \text { (C) } & \text { (C) } & \text { (C) } \\ 0.41 & 1.26 & 0.18 & 1.3\end{array}$

PASS CALIBRATION? YES

Figure F4. Pre-test Calibration Data of Thermocouple T2 
UNCERTAINTY ANALYSIS

REF. WSRC-TR-91-106

TR-2929

page
calibration date

\section{Calibration Data}

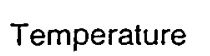

Medium

Boiling Water

Boiling Water

Boiling Water

Boiling Water

Ice Point

Ice Point

Ice Point

Ice Point

Room Temp

Room Temp

Room Temp

Room Temp

Standard
Temperature

(C)

100.70

100.70

100.70

100.70

0.00

0.00

0.00

0.00

21.10

21.30

21.30

21.30
Voltage

Output

(mV)

6.350

6.352

6.349

6.350

$-0.026$

$-0.023$

$-0.019$

$-0.021$

1.211

1.178

1.182

1.188
Calculated Temperature (eq. 1)

(C)

100.46

100.49

100.45

100.46

$-0.44$

$-0.39$

$-0.32$

$-0.35$

20.32

19.78

19.84

19.94
Error

(C)

$-0.2$

$-0.2$

$-0.3$

$-0.2$

$-0.4$

$-0.4$

$-0.3$

$-0.4$

$-0.8$

$-1.5$

$-1.5$

$T(C)=0.00483+17.040918^{\star} m V-0.224284^{\star} m v^{\wedge} 2+0.005038^{\star} m m^{\wedge} 3$ (eq. 1 )

(Limited Curve Fit, 0-100 C. From N.I.S.T. Reference Tables)

Uncertainty of the Standards: Temperature Curve Fit: $+/-\quad 0.010$ C

Thermometer. $+/-\quad 0.40 \quad \mathrm{C}$

Ice Bath: $+/-\quad 0.10 \quad \mathrm{C}$

Multimeter: $+/-(0.0045 \% R D G+0.0005 \mathrm{mV})$

$$
=+/-\quad 0.012 \mathrm{C} @ \quad 6.35 \mathrm{mV}
$$

Accepted Tolerance: +/- $\quad 1.7 \quad \mathrm{C}$

Statistical Info.

$\begin{array}{cccccccc} & & & & \text { Xbar } & S x x & \text { SEE } & \text { MSE } \\ a & b & n & T & (C) & \left(C^{\wedge} 2\right) & \left(C^{\wedge} 2\right) & (C \wedge 2) \\ -0.73 & 1.00 & 11.00 & 2.262 & 42.41 & 22130.7 & 2.000 & 0.2222\end{array}$

Calculated Uncertainties:

standard

uncertainty

(C)

0.41

curve-fit

uncertainty

(C)

1.18

PASS CALIBRATION?

$\begin{array}{ll}\text { fixed } & \text { total } \\ \text { uncertainty } & \text { uncertainty } \\ \text { (C) } & \text { (C) }\end{array}$

$\begin{array}{ll}0.73 & 1.5\end{array}$

Figure F5. Pre-test Calibration Data of Thermocouple T3 
UNCERTAINTY ANALYSIS

REF. WSRC-TR-91-106
TR-2930

Calibration Data

$\begin{array}{lcccc}\begin{array}{l}\text { Temperature } \\ \text { Medium }\end{array} & \begin{array}{c}\text { Standard } \\ \text { Temperature }\end{array} & \begin{array}{c}\text { Voltage } \\ \text { Output } \\ (\mathrm{mV})\end{array} & \begin{array}{c}\text { Calculated } \\ \text { Temperature } \\ (\text { eq. } 1)\end{array} & \begin{array}{c}\text { Error } \\ (\mathrm{C})\end{array} \\ \text { Boiling Water } & 100.70 & 6.350 & 100.46 & -0.2 \\ \text { Boiling Water } & 100.70 & 6.360 & 100.61 & -0.1 \\ \text { Boiling Water } & 100.70 & 6.365 & 100.68 & 0.0 \\ \text { Boiling Water } & 100.70 & 6.348 & 100.43 & -0.3 \\ \text { Ice Point } & 0.00 & -0.015 & -0.25 & -0.3 \\ \text { Ice Point } & 0.00 & -0.009 & -0.15 & -0.1 \\ \text { Ice Point } & 0.00 & -0.003 & -0.05 & 0.0 \\ \text { Ice Point } & 0.00 & -0.009 & -0.15 & -0.1 \\ \text { Room Temp } & 23.80 & 1.416 & 23.70 & -0.1 \\ \text { Room Temp } & 23.80 & 1.442 & 24.13 & 0.3 \\ \text { Room Temp } & 23.90 & 1.501 & 25.09 & 1.2 \\ \text { Room Temp } & 23.90 & 1.475 & 24.67 & 0.8\end{array}$

$T(C)=0.00483+17.040918^{*} \mathrm{mV}-0.224284^{*} \mathrm{mV}^{\wedge} 2+0.005038^{*} \mathrm{mV} \wedge 3$ (eq. 1) (Limited Curve Fit, 0-100 C. From N.I.S.T. Reference Tables)

calibration date___ of

Unicertainty of the Standards: Temperature Curve Fit: $+1-0.010 \mathrm{C}$

Thermometer: $+/-\quad 0.40 \quad C$ Ice Bath: $+1-0.10 \quad \mathrm{C}$

Multimeter: $+/-(0.0045 \% \mathrm{RDG}+0.0005 \mathrm{mV})$

$$
=+/-0.012 \mathrm{C} @ \quad 6.37 \mathrm{mV}
$$

Accepted Tolerance: +/- $\quad 1.7 \quad$ C

Statistical Info.

$\begin{array}{cccccccc} & & & & \text { Xbar } & S \times x & \text { SEE } & \text { MSE } \\ a & b & n & T & (C) & (C \wedge 2) & (C \wedge 2) & (C \wedge 2) \\ 0.09 & 1.00 & 11.00 & 2.262 & 43.12 & 21815.1 & 1.724 & 0.1916\end{array}$

Calculated Uncértainties:

standard curve-fit

uncertainty uncertainty

(C)

0.41

(C)

1.11

PASS CALIBRATION?

$\begin{array}{ll}\text { fixed } & \text { total } \\ \text { uncertainty } & \text { uncertainty } \\ \text { (C) } & \text { (C) } \\ 0.09 & 1.2\end{array}$

YES

Figure F6. Pre-test Calibration Data of Thermocouple T4 
UNCERTAINTY ANALYSIS

REF. WSRC-TR-91-106

TR-2927

\section{Calibration Data}

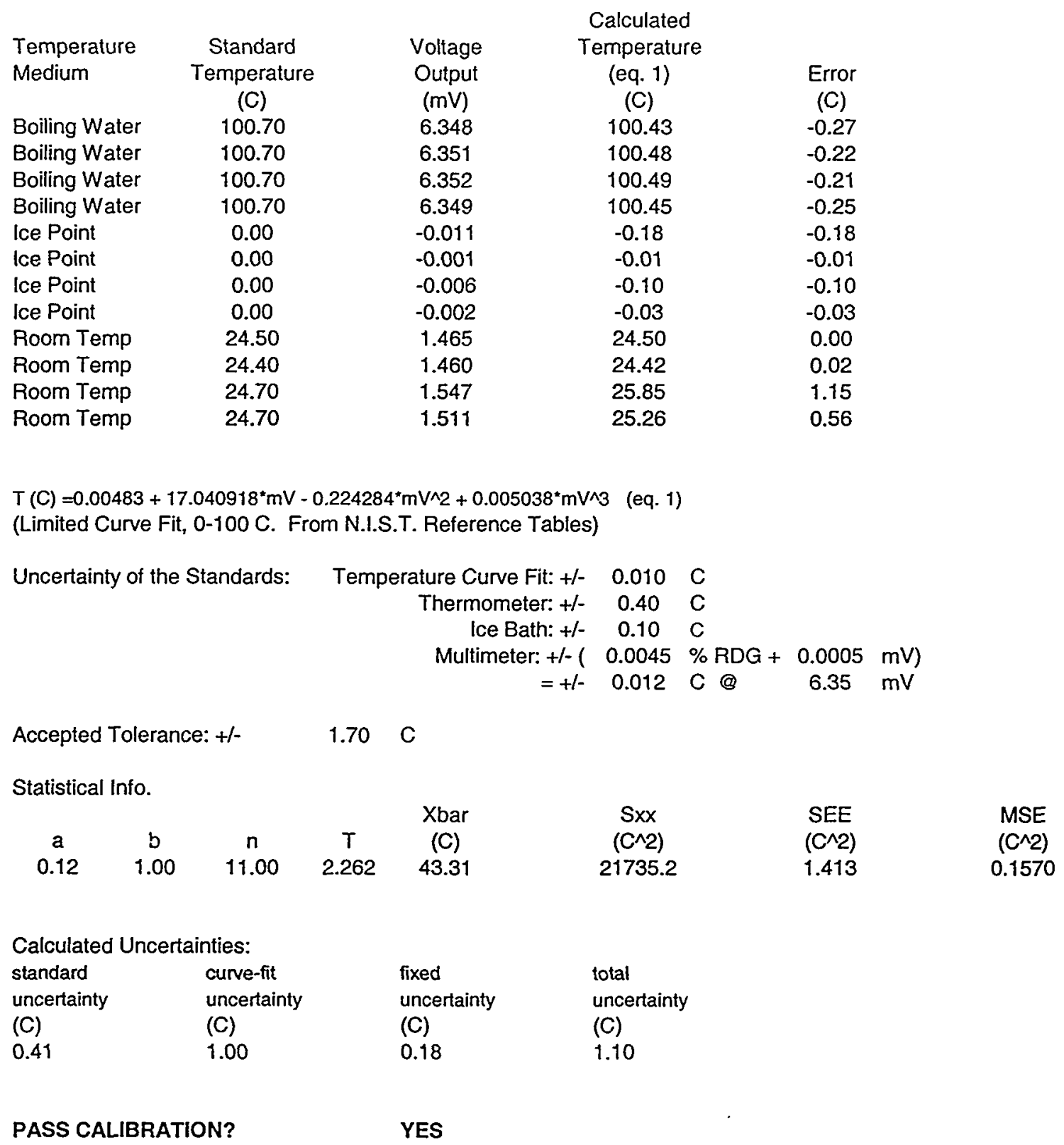

Figure F7. Pre-test Calibration Data of Thermocouple T5 
UNCERTAINTY ANALYSIS

REF. WSRC-TR-91-106, REV. 0
TR-2917

Calibration Data

\begin{tabular}{cccc}
\hline $\begin{array}{c}\text { Nominal } \\
\text { Pressure }\end{array}$ & $\begin{array}{c}\text { Correction } \\
\text { (psig) }\end{array}$ & $\begin{array}{c}\text { Applied } \\
\text { Pressure }\end{array}$ & $\begin{array}{c}\text { Gage } \\
\text { Reading } \\
\text { (psig) }\end{array}$ \\
(mADC) \\
21.00 & 0 & 0.00 & 4.01 \\
41.00 & -0.71 & 20.29 & 7.28 \\
61.00 & -0.71 & 40.29 & 10.49 \\
81.00 & -0.71 & 60.29 & 13.71 \\
100.00 & -0.71 & 80.29 & 16.93 \\
0.00 & -0.71 & 99.29 & 20.00 \\
21.00 & -0.71 & 0.00 & 4.01 \\
41.00 & -0.71 & 20.29 & 7.28 \\
61.00 & -0.71 & 60.29 & 10.49 \\
81.00 & -0.71 & 80.29 & 13.71 \\
100.00 & -0.71 & 99.29 & 16.93 \\
0.00 & 0 & 0.00 & 4.01 \\
21.00 & -0.71 & 20.29 & 7.28 \\
41.00 & -0.71 & 40.29 & 10.49 \\
61.00 & -0.71 & 60.29 & 13.71 \\
81.00 & -0.71 & 80.29 & 16.94 \\
100.00 & -0.71 & 99.29 & 20.00 \\
0.00 & 0 & 0.00 & 4.01 \\
21.00 & -0.71 & 20.29 & 7.28 \\
41.00 & -0.71 & -40.29 & 10.49 \\
61.00 & -0.71 & 60.29 & 13.71 \\
81.00 & -0.71 & 80.29 & 16.94 \\
100.00 & -0.71 & 99.29 & 20.00
\end{tabular}

Standard Uncertainties: Multimeter: $+1-1$ Dead Weight Tester: +1-

Statistical Info:

\begin{tabular}{|c|c|c|c|}
\hline $\begin{array}{c}a \\
4.0083\end{array}$ & $\begin{array}{c}b \\
0.1610\end{array}$ & $\begin{array}{c}n \\
24.00\end{array}$ & $\begin{array}{c}T \\
2.07\end{array}$ \\
\hline & & & \\
\hline $\begin{array}{c}\text { standard } \\
\text { psig }\end{array}$ & & $\begin{array}{c}\text { curve-fit } \\
\text { psig }\end{array}$ & \\
\hline 0.11 & & 0.07 & \\
\hline
\end{tabular}

Accepted Tolerance: +/-
$2 \quad$ psig page_of__

cal. date:

$\begin{array}{ccc}\begin{array}{c}\text { Curve } \\ \text { Fit } \\ \text { (mADC) }\end{array} & \begin{array}{c}\text { Error } \\ \text { (mADC) }\end{array} & \begin{array}{c}\text { Error } \\ \text { (psig) }\end{array} \\ 4.01 & -0.002 & -0.01 \\ 7.28 & -0.005 & -0.03 \\ 10.50 & 0.005 & 0.03 \\ 13.72 & 0.006 & 0.03 \\ 16.94 & 0.006 & 0.04 \\ 19.99 & -0.005 & -0.03 \\ 4.01 & -0.002 & -0.01 \\ 7.28 & -0.005 & -0.03 \\ 10.50 & 0.005 & 0.03 \\ 13.72 & 0.006 & 0.03 \\ 16.94 & 0.006 & 0.04 \\ 19.99 & -0.005 & -0.03 \\ 4.01 & -0.002 & -0.01 \\ 7.28 & -0.005 & -0.03 \\ 10.50 & 0.005 & 0.03 \\ 13.72 & 0.006 & 0.03 \\ 16.94 & -0.004 & -0.03 \\ 19.99 & -0.005 & -0.03 \\ 4.01 & -0.002 & -0.01 \\ 7.28 & -0.005 & -0.03 \\ 10.50 & 0.005 & 0.03 \\ 13.72 & 0.006 & 0.03 \\ 16.94 & -0.004 & -0.03 \\ 19.99 & -0.005 & -0.03\end{array}$

$0.04 \% R D G+\quad 0.0001 \quad m A D C)$

$0.1 \quad$ psig

$\begin{array}{lll}\text { Xbar } & S x x & \text { SEE }\end{array}$

$\mathrm{psig}^{2} \quad \mathrm{MADC}^{2} \quad \mathrm{MADC}^{2}$

$\begin{array}{lll}27719.23 & 0.0005 & 0.0000\end{array}$

PASS CALIBRATION? YES

TRANSFER EQUATION PSIG $=\quad 6.211 \quad{ }^{*} \mathrm{~mA} \quad \mathbf{- 2 4 . 8 9 5}$

Figure F8. Pre-test Calibration Data of Gauge Pressure Transducer P1 
UNCERTAINTY ANALYSIS

REF. WSRC-TR-91-106, REV. 0
TR-3109

cal. date:

page_of __

Calibration Data

$\begin{array}{cccc}\begin{array}{c}\text { Nominal } \\ \text { Pressure }\end{array} & \begin{array}{c}\text { Correction } \\ \text { (psid) }\end{array} & \begin{array}{c}\text { Applied } \\ \text { Pressure } \\ \text { (psid) }\end{array} & \begin{array}{c}\text { Gage } \\ \text { Reading } \\ \text { (mADC) }\end{array} \\ -11.00 & 0.71 & -10.29 & 4.01 \\ 0.00 & 0 & 0.00 & 5.65 \\ 11.00 & -0.71 & 10.29 & 7.28 \\ 31.00 & -0.71 & 30.29 & 10.46 \\ 51.00 & -0.71 & 50.29 & 13.63 \\ 71.00 & -0.71 & 70.29 & 16.81 \\ 91.00 & -0.71 & 90.29 & 20.00 \\ -11.00 & 0.71 & -10.29 & 4.01 \\ 0.00 & 0 & 0.00 & 5.65 \\ 11.00 & -0.71 & 10.29 & 7.28 \\ 31.00 & -0.71 & 30.29 & 10.46 \\ 51.00 & -0.71 & 50.29 & 13.63 \\ 71.00 & -0.71 & 70.29 & 16.81 \\ 91.00 & -0.71 & 90.29 & 20.00 \\ -11.00 & 0.71 & -10.29 & 4.01 \\ 0.00 & 0 & 0.00 & 5.65 \\ 11.00 & -0.71 & 10.29 & 7.28 \\ 31.00 & -0.71 & 30.29 & 10.46 \\ 51.00 & -0.71 & 50.29 & 13.63 \\ 71.00 & -0.71 & 70.29 & 16.81 \\ 91.00 & -0.71 & 90.29 & 20.00 \\ -11.00 & 0.71 & -10.29 & 4.01 \\ 0.00 & 0 & 0.00 & 5.65 \\ 11.00 & -0.71 & 10.29 & 7.28 \\ 31.00 & -0.71 & 30.29 & 10.46 \\ 51.00 & -0.71 & 50.29 & 13.63 \\ 71.00 & -0.71 & 70.29 & 16.81 \\ 91.00 & -0.71 & 90.29 & 20.01\end{array}$

Curve

Fit Error Error

(mADC) (mADC) (psid)

$\begin{array}{lll}4.01 & 0.000 & 0.00\end{array}$

$\begin{array}{lll}5.65 & -0.005 & -0.03\end{array}$

$\begin{array}{lll}7.28 & 0.001 & 0.00\end{array}$

$\begin{array}{lll}7.46 & -0.001 & -0.01\end{array}$

$\begin{array}{lll}13.64 & 0.007 & 0.05\end{array}$

$\begin{array}{lll}16.82 & 0.006 & 0.04\end{array}$

$\begin{array}{lll}4.01 & 0.000 & 0.00\end{array}$

$\begin{array}{lll}5.65 & -0.005 & -0.03\end{array}$

$\begin{array}{lll}7.28 & 0.001 & 0.00\end{array}$

$\begin{array}{lll}10.46 & -0.001 & -0.01\end{array}$

$\begin{array}{lll}13.64 & 0.007 & 0.05\end{array}$

$\begin{array}{lll}16.82 & 0.006 & 0.04\end{array}$

$19.99-0.006 \quad-0.04$

$\begin{array}{lll}4.01 & 0.000 & 0.00\end{array}$

$\begin{array}{lll}5.65 & -0.005 & -0.03\end{array}$

$\begin{array}{lll}7.28 & 0.001 & 0.00\end{array}$

$10.46 \quad-0.001 \quad-0.01$

$\begin{array}{lll}13.64 & 0.007 & 0.05\end{array}$

$\begin{array}{lll}16.82 & 0.006 & 0.04\end{array}$

$\begin{array}{lll}19.99 & -0.006 & -0.04\end{array}$

$\begin{array}{lll}4.01 & 0.000 & 0.00\end{array}$

$\begin{array}{lll}5.65 & -0.005 & -0.03\end{array}$

$\begin{array}{lll}10.46 & -0.001 & -0.01\end{array}$

$\begin{array}{lll}13.64 & 0.007 & 0.05\end{array}$

$\begin{array}{lll}16.82 & 0.006 & 0.04\end{array}$

$\begin{array}{lll}19.99 & -0.016 & -0.10\end{array}$
$19.99 \quad-0.006 \quad-0.04$

$\begin{array}{lll}7.28 & 0.001 & 0.00\end{array}$

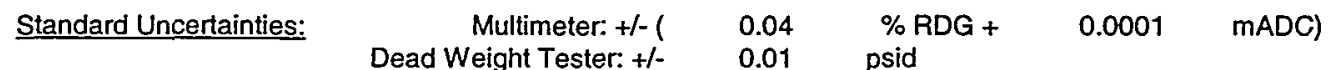

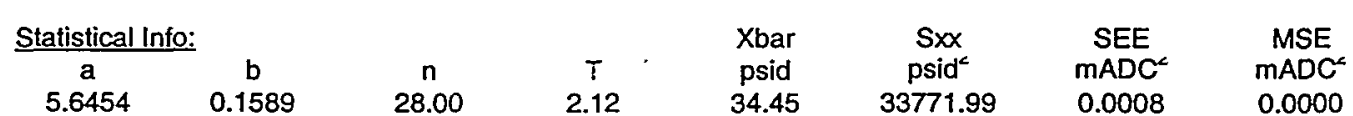

Galculated Uncertainties:

$\begin{array}{cc}\text { standard } & \text { curve-fit } \\ \text { psid } & \text { psid } \\ 0.05 & 0.08\end{array}$

Accepted Tolerance: $+/-$

0.08 fixed

psid

0.00

2 psid

PASS CALIBRATION? YES

TRANSFER EQUATION: $\quad P S I G=$

$6.293 \quad * \mathrm{~mA}$

$-35.524$

Figure F9. Pre-test Calibration Data of Gauge Pressure Transducer P2 
cal. date:

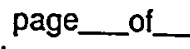

UNCERTAINTY ANALYSIS

REF. WSRC-TR-91-106, REV. 0

Calibration Data

\begin{tabular}{|c|c|c|}
\hline Nominal & Applied & Gage \\
\hline $\begin{array}{l}\text { Pressure } \\
\text { (psig) }\end{array}$ & $\begin{array}{c}\text { Pressure } \\
\text { (psig) }\end{array}$ & $\begin{array}{l}\text { Reading } \\
\text { (mADC) }\end{array}$ \\
\hline 0.00 & 0.00 & 4.01 \\
\hline 31.00 & 31.00 & 7.28 \\
\hline 61.00 & 61.00 & .10 .44 \\
\hline 91.00 & 91.00 & 13.61 \\
\hline 121.00 & 121.00 & 16.80 \\
\hline 151.00 & 151.00 & 20.01 \\
\hline 0.00 & 0.00 & 4.01 \\
\hline 31.00 & 31.00 & 7.28 \\
\hline 61.00 & 61.00 & 10.44 \\
\hline 91.00 & 91.00 & 13.61 \\
\hline 121.00 & 121.00 & 16.80 \\
\hline 151.00 & 151.00 & 20.01 \\
\hline 0.00 & 0.00 & 4.01 \\
\hline 31.00 & 31.00 & 7.28 \\
\hline 61.00 & 61.00 & 10.44 \\
\hline 91.00 & 91.00 & 13.61 \\
\hline 121.00 & 121.00 & 16.80 \\
\hline 151.00 & 151.00 & 20.01 \\
\hline 0.00 & 0.00 & 4.01 \\
\hline 31.00 , & 31.00 & 7.28 \\
\hline 61.00 & 61.00 & 10.44 \\
\hline 91.00 & 91.00 & 13.61 \\
\hline 121.00 & 121.00 & 16.80 \\
\hline 151.00 & 151.00 & 20.01 \\
\hline
\end{tabular}

Standard Uncertainties:

\section{Multimeter: $+1-($} Dead Weight Tester: $+/-$

Statistical Info: 3.9939 $\stackrel{b}{0.1059}$ 24.00

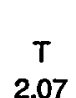

Xbar psig
75.83

Curve (mADC)$$
3.99
$$

7.28

10.45

13.63

16.81

19.99

3.99

7.28

10.45

13.63

16.81

19.99

3.99

7.28

10.45

13.63

16.81

19.99

3.99

7.28

10.45

13.63

16.81

19.99

0.04

0.1

Xar

fixed

psig

0.00 curve-fit
psig
0.35
Calculated Uncertainties: tandard

0.13

dard

Accepted Tolerance: +/-

3

psig

\begin{tabular}{|c|c|c|}
\hline $\begin{array}{c}\text { Error } \\
(\mathrm{mADC})\end{array}$ & $\begin{array}{l}\text { Error } \\
\text { (psig) }\end{array}$ & \\
\hline-0.016 & -0.15 & \\
\hline-0.003 & -0.03 & \\
\hline 0.014 & 0.13 & \\
\hline 0.021 & 0.20 & \\
\hline 0.008 & 0.08 & \\
\hline-0.025 & -0.23 & \\
\hline-0.016 & -0.15 & \\
\hline-0.003 & -0.03 & \\
\hline 0.014 & 0.13 & \\
\hline 0.021 & 0.20 & \\
\hline 0.008 & 0.08 & \\
\hline-0.025 & -0.23 & \\
\hline-0.016 & -0.15 & \\
\hline-0.003 & -0.03 & \\
\hline 0.014 & 0.13 & \\
\hline 0.021 & 0.20 & \\
\hline 0.008 & 0.08 & \\
\hline-0.025 & -0.23 & \\
\hline-0.016 & -0.15 & \\
\hline-0.003 & -0.03 & \\
\hline 0.014 & 0.13 & \\
\hline 0.021 & 0.20 & \\
\hline 0.008 & 0.08 & \\
\hline-0.025 & -0.23 & \\
\hline $\begin{array}{c}\% \text { RDG + } \\
\text { psig }\end{array}$ & 0.0001 & mADC) \\
\hline $\begin{array}{c}\text { Sxx } \\
\text { psig2 }\end{array}$ & $\begin{array}{c}\text { SEE } \\
\text { mADC2 }\end{array}$ & $\begin{array}{l}\text { MSE } \\
\text { mADC2 }\end{array}$ \\
\hline 63603.33 & 0.0063 & 0.0003 \\
\hline
\end{tabular}

PASS CALIBRATION? YES TRANSFER EQUATION PSIG $=$

Figure F10. Pre-test Calibration Data of Gauge Pressure Transducer P3 
UNCERTAINTY ANALYSIS

REF. WSRC-TR-91-106, REV. 0

Calibration Data

\begin{tabular}{|c|c|c|}
\hline $\begin{array}{c}\text { Nominal } \\
\text { Pressure } \\
\text { (psid) }\end{array}$ & $\begin{array}{c}\text { Applied } \\
\text { Pressure } \\
\text { (psid) }\end{array}$ & $\begin{array}{l}\text { Gage } \\
\text { Reading } \\
\text { (mADC) }\end{array}$ \\
\hline 0.00 & 0.00 & 4.00 \\
\hline 1.00 & 1.00 & 4.61 \\
\hline 6.00 & 6.00 & 7.69 \\
\hline 11.00 & 11.00 & 10.76 \\
\hline 16.00 & 16.00 & 13.84 \\
\hline 21.00 & 21.00 & 16.92 \\
\hline 26.00 & 26.00 & 20.00 \\
\hline 0.00 & 0.00 & 4.00 \\
\hline 1.00 & 1.00 & 4.61 \\
\hline 6.00 & 6.00 & 7.69 \\
\hline 11.00 & 11.00 & 10.76 \\
\hline 16.00 & 16.00 & 13.84 \\
\hline 21.00 & 21.00 & 16.92 \\
\hline 26.00 & 26.00 & 20.00 \\
\hline 0.00 & 0.00 & 4.00 \\
\hline 1.00 & 1.00 & 4.61 \\
\hline 6.00 & 6.00 & 7.69 \\
\hline 11.00 & 11.00 & 10.76 \\
\hline 16.00 & 16.00 & 13.84 \\
\hline 21.00 & 21.00 & 16.92 \\
\hline 26.00 & 26.00 & 20.00 \\
\hline 0.00 & 0.00 & 4.00 \\
\hline 1.00 & 1.00 & 4.61 \\
\hline 6.00 & 6.00 & 7.69 \\
\hline 11.00 & 11.00 & 10.76 \\
\hline 16.00 & 16.00 & 13.84 \\
\hline 21.00 & 21.00 & 16.92 \\
\hline 26.00 & 26.00 & 20.00 \\
\hline
\end{tabular}

TR-3495

\begin{tabular}{|c|c|c|}
\hline Curve & & \\
\hline $\begin{array}{c}F i t \\
(m A D C)\end{array}$ & $\begin{array}{c}\text { Error } \\
(\mathrm{mADC})\end{array}$ & $\begin{array}{l}\text { Error } \\
\text { (psid) }\end{array}$ \\
\hline 4.00 & -0.004 & -0.01 \\
\hline 4.61 & 0.001 & 0.00 \\
\hline 7.69 & -0.002 & 0.00 \\
\hline 10.77 & 0.005 & 0.01 \\
\hline 13.84 & 0.003 & 0.00 \\
\hline 16.92 & 0.000 & 0.00 \\
\hline 20.00 & -0.003 & -0.01 \\
\hline 4.00 & -0.004 & -0.01 \\
\hline 4.61 & 0.001 & 0.00 \\
\hline 7.69 & -0.002 & 0.00 \\
\hline 10.77 & 0.005 & 0.01 \\
\hline 13.84 & 0.003 & 0.00 \\
\hline 16.92 & 0.000 & 0.00 \\
\hline 20.00 & -0.003 & -0.01 \\
\hline 4.00 & -0.004 & -0.01 \\
\hline 4.61 & 0.001 & 0.00 \\
\hline 7.69 & -0.002 & 0.00 \\
\hline 10.77 & 0.005 & 0.01 \\
\hline 13.84 & 0.003 & 0.00 \\
\hline 16.92 & 0.000 & 0.00 \\
\hline 20.00 & -0.003 & -0.01 \\
\hline 4.00 & -0.004 & -0.01 \\
\hline 4.61 & 0.001 & 0.00 \\
\hline 7.69 & -0.002 & 0.00 \\
\hline 10.77 & 0.005 & 0.01 \\
\hline 13.84 & 0.003 & 0.00 \\
\hline 16.92 & 0.000 & 0.00 \\
\hline 20.00 & -0.003 & -0.01 \\
\hline
\end{tabular}

cal. date:

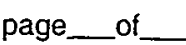

Standard Uncertainties:

Statistical info:

\begin{tabular}{ccc}
$\begin{array}{cc}\text { Statistical Info: } \\
\text { a }\end{array}$ & b & $\mathbf{n}$ \\
3.9959 & 0.6154 & 28.00 \\
& \\
Calculated Uncertainties: & \\
\hline standard & curve-fit \\
psid & psid \\
0.017 & 0.011
\end{tabular}

Accepted Tolerance: +1 -
Multimeter: $+/-($
Dead Weight Tester: $+/-$

0.04

0.01

Xbar

psid

11.57

fixed

psid

0.000

0.500 psid

PASS CALIBRATION? YES

TRANSFER EQUATION: PSID =

$1.6249 \quad{ }^{*} \mathrm{~mA}$

$-6.4930$

Figure F11. Pre-test Calibration Data of Differential Pressure Transducer dP1 
UNCERTAINTY ANALYSIS

REF. WSRC-TR-91-106, REV. 0

Calibration Data

\begin{tabular}{ccc}
\hline $\begin{array}{c}\text { Nominal } \\
\text { Pressure } \\
\text { (psid) }\end{array}$ & $\begin{array}{c}\text { Applied } \\
\text { Pressure } \\
\text { (psid) }\end{array}$ & $\begin{array}{c}\text { Gage } \\
\text { Reading } \\
\text { (mADC) }\end{array}$ \\
0.00 & 0.00 & 4.00 \\
21.00 & 21.00 & 7.32 \\
41.00 & 41.00 & 10.49 \\
61.00 & 61.00 & 13.65 \\
81.00 & 81.00 & 16.82 \\
101.00 & 101.00 & 20.00 \\
0.00 & 0.00 & 4.00 \\
21.00 & 21.00 & 7.32 \\
41.00 & 41.00 & 10.49 \\
61.00 & 61.00 & 13.65 \\
81.00 & 81.00 & 16.82 \\
101.00 & 101.00 & 20.00 \\
0.00 & 0.00 & 4.00 \\
21.00 & 21.00 & 7.32 \\
41.00 & 41.00 & 10.49 \\
61.00 & 61.00 & 13.65 \\
81.00 & 81.00 & 16.82 \\
101.00 & 101.00 & 20.00 \\
0.00 & 0.00 & 4.00 \\
21.00 & 21.00 & 7.32 \\
41.00 & 41.00 & 10.49 \\
61.00 & 61.00 & 13.65 \\
81.00 & 81.00 & 16.82 \\
101.00 & 101.00 & 20.00
\end{tabular}

Standard Uncertainties: $\quad$ Multimeter: $+/-($ - Dead Weight Tester: +/-

Statistical Info:

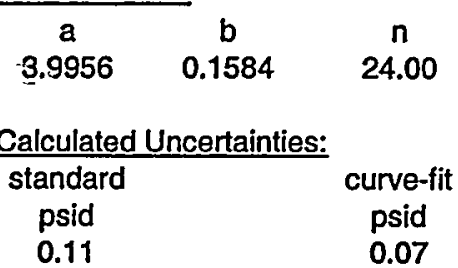

Accepted Tolerance: +/-

0.07
TR-532

$\begin{array}{ccc}\begin{array}{c}\text { Curve } \\ \text { Fit } \\ \text { (mADC) }\end{array} & \begin{array}{c}\text { Error } \\ \text { (mADC) }\end{array} & \begin{array}{c}\text { Error } \\ \text { (psid) }\end{array} \\ 4.00 & -0.004 & -0.03 \\ 7.32 & 0.002 & 0.01 \\ 10.49 & -0.001 & 0.00 \\ 13.66 & 0.007 & 0.04 \\ 16.82 & 0.005 & 0.03 \\ 19.99 & -0.008 & -0.05 \\ 4.00 & -0.004 & -0.03 \\ 7.32 & 0.002 & 0.01 \\ 10.49 & -0.001 & 0.00 \\ 13.66 & 0.007 & 0.04 \\ 16.82 & 0.005 & 0.03 \\ 19.99 & -0.008 & -0.05 \\ 4.00 & -0.004 & -0.03 \\ 7.32 & 0.002 & 0.01 \\ 10.49 & -0.001 & 0.00 \\ 13.66 & 0.007 & 0.04 \\ 16.82 & 0.005 & 0.03 \\ 19.99 & -0.008 & -0.05 \\ 4.00 & -0.004 & -0.03 \\ 7.32 & 0.002 & 0.01 \\ 10.49 & -0.001 & 0.00 \\ 13.66 & 0.007 & 0.04 \\ 16.82 & 0.005 & 0.03 \\ 19.99 & -0.008 & -0.05\end{array}$

cal. date:

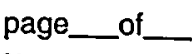

$0.04 \% R D G+\quad 0.0001 \quad m A D C)$

$0.1 \quad$ psig

Xbar Sxx SEE MSE

psid psid $^{2} \quad \mathrm{mADC}^{2} \quad \mathrm{mADC}^{2}$

$\begin{array}{lllll}50.83 & 28403.33 & 0.0006 & .0 .0000\end{array}$

Total Uncertainty

psid

0.13 fixed

psid

0.00

psid

PASS CALIBRATION? YES

TRANSFER EQUATION: , PSID =

$6.314 \quad{ }^{*} \mathrm{~mA} \quad \ldots-25.227$

Figure F12. Pre-test Calibration Data of Differential Pressure Transducer dP2 
UNCERTAINTY ANALYSIS

REF. WSRC-TR-91-106, REV. 0

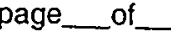

Calibration Data

\begin{tabular}{|c|c|c|c|}
\hline $\begin{array}{c}\text { Nominal } \\
\text { Pressure } \\
\text { (psid) }\end{array}$ & $\begin{array}{l}\text { Correction } \\
\text { (psid) }\end{array}$ & $\begin{array}{c}\text { Applied } \\
\text { Pressure } \\
\text { (psid) }\end{array}$ & $\begin{array}{c}\text { Gage } \\
\text { Reading } \\
\text { (mADC) }\end{array}$ \\
\hline-11.00 & 0.71 & -10.29 & 3.99 \\
\hline 0.00 & 0 & 0.00 & 5.48 \\
\hline 21.00 & -0.71 & 20.29 & 8.43 \\
\hline 41.00 & -0.71 & 40.29 & 11.34 \\
\hline 61.00 & -0.71 & 60.29 & 14.24 \\
\hline 81.00 & -0.71 & 80.29 & 17.13 \\
\hline 101.00 & -0.71 & 100.29 & 20.01 \\
\hline-11.00 & 0.71 & -10.29 & 3.99 \\
\hline 0.00 & 0 & 0.00 & 5.48 \\
\hline 21.00 & -0.71 & 20.29 & 8.43 \\
\hline 41.00 & -0.71 & 40.29 & 11.34 \\
\hline 61.00 & -0.71 & 60.29 & 14.24 \\
\hline 81.00 & -0.71 & 80.29 & 17.13 \\
\hline 101.00 & -0.71 & 100.29 & 20.01 \\
\hline-11.00 & 0.71 & -10.29 & 3.99 \\
\hline 0.00 & 0 & 0.00 & 5.48 \\
\hline 21.00 & -0.71 & 20.29 & 8.43 \\
\hline 41.00 & -0.71 & 40.29 & 11.34 \\
\hline 61.00 & -0.71 & 60.29 & 14.24 \\
\hline 81.00 & -0.71 & 80.29 & 17.13 \\
\hline 101.00 & -0.71 & 100.29 & 20.01 \\
\hline-11.00 & 0.71 & -10.29 & 3.99 \\
\hline 0.00 & 0 & 0.00 & 5.48 \\
\hline 21.00 & -0.71 & 20.29 & 8.43 \\
\hline 41.00 & -0.71 & 40.29 & 11.34 \\
\hline 61.00 & -0.71 & 60.29 & 14.24 \\
\hline 81.00 & -0.71 & 80.29 & 17.13 \\
\hline 101.00 & -0.71 & 100.29 & 20.01 \\
\hline
\end{tabular}

Standard Uncertainties:

Multimeter: $+/-1$ Dead Weight Tester: $+/$

Statistical Info:

\begin{tabular}{ccc}
$a$ & $b$ & $n$ \\
5.4875 & 0.1450 & 28.00 \\
& & \\
Calculated Uncertainties: & \\
\hline standard & & curve-fit \\
psid & & psid \\
0.11 & 0.16
\end{tabular}

Accepted Tolerance: $+/$ cal. date:

TR-3115

Curve

$\begin{array}{ccc}\begin{array}{c}\text { Fit } \\ \text { (mADC) }\end{array} & \begin{array}{c}\text { Error } \\ \text { (mADC) }\end{array} & \begin{array}{c}\text { Error } \\ \text { (psid) }\end{array} \\ 4.00 & 0.006 & 0.04 \\ 5.49 & 0.007 & 0.05\end{array}$

$\begin{array}{lll}8.43 & -0.001 & -0.01\end{array}$

$\begin{array}{lll}11.33 & -0.012 & -0.08\end{array}$

$14.23 \quad-0.013 \quad-0.09$

$\begin{array}{lll}17.13 & -0.003 & -0.02\end{array}$

$\begin{array}{lll}20.03 & 0.016 & 0.11\end{array}$

$\begin{array}{lll}4.00 & 0.006 & 0.04\end{array}$

$\begin{array}{lll}5.49 & 0.007 & 0.05\end{array}$

$8.43 \quad-0.001 \quad-0.01$

$\begin{array}{lll}11.33 & -0.012 & -0.08\end{array}$

$14.23 \quad-0.013 \quad-0.09$

$17.13 \quad-0.003 \quad-0.02$

20.03

$\begin{array}{lll}4.00 & 0.006 & 0.04\end{array}$

$\begin{array}{lll}5.49 & 0.007 & 0.05\end{array}$

$8.43 \quad-0.001 \quad-0.01$

$\begin{array}{lll}11.33 & -0.012 & -0.08\end{array}$

$\begin{array}{lll}14.23 & -0.013 & -0.09\end{array}$

$\begin{array}{lll}17.13 & -0.003 & -0.02\end{array}$

$\begin{array}{lll}20.03 & 0.016 & 0.11\end{array}$

$\begin{array}{lll}4.00 & 0.006 & 0.04\end{array}$

$\begin{array}{lll}5.49 & 0.007 & 0.05\end{array}$

$\begin{array}{lll}8.43 & -0.001 & -0.01\end{array}$

$\begin{array}{lll}11.33 & -0.012 & -0.08\end{array}$

$\begin{array}{lll}14.23 & -0.013 & -0.09\end{array}$

$17.13 \quad-0.003 \quad-0.02$

$20.03 \quad 0.016 \quad 0.11$

$0.04 \% R D G+\quad 0.0001$ mADC)

psid

$\begin{array}{cccc}\text { Xbar } & \text { Sxx } & \text { SEE } & \text { MSE } \\ \text { psid } & \text { psid } & \text { mADC } & \text { mADC } \\ 41.59 & 40678.85 & 0.0026 & 0.0001\end{array}$

Total Uncertainty

$\begin{array}{ll}\text { psid } & \text { psid } \\ 0.00 & 0.19\end{array}$

$\begin{array}{ll}\text { psid } & \text { psid } \\ 0.00 & 0.19\end{array}$
2 psid

\section{PASS CALIBRATION? YES}

TRANSFER EQUATION: PSID =

$6.898 \quad{ }^{*} \mathrm{~mA}$

$-37.854$

Figure F13. Pre-test Calibration Data of Differential Pressure Transducer dP3 
UNCERTAINTY ANALYSIS

REF. WSRC-TR-91-106

\begin{tabular}{llll} 
& \multicolumn{3}{l}{ Calibration Data } \\
Meter & Water & Water & Time \\
Output & Temp & Weight & Duration \\
(mA) & (C) & (lbs) & (min) \\
3.977 & 21.40 & 0 & 0.50 \\
7.115 & 21.40 & 1228 & 15.00 \\
10.434 & 21.80 & 1682 & 10.01 \\
13.535 & 22.00 & 1246 & 5.00 \\
16.807 & 22.00 & 1679 & 5.01 \\
19.889 & 21.50 & 2078 & 5.00 \\
19.887 & 21.40 & 2079 & 5.00 \\
16.740 & 21.00 & 1664 & 5.00 \\
13.594 & 20.90 & 1254 & 5.00 \\
10.325 & 20.80 & 1652 & 10.00 \\
7.194 & 20.70 & 1257 & 15.01 \\
3.978 & 20.70 & 0 & 0.50 \\
7.216 & 20.80 & 1264 & 15.00 \\
10.379 & 21.30 & 1669 & 10.01 \\
13.628 & 21.90 & 1258 & 5.00 \\
16.724 & 21.70 & 1663 & 5.00 \\
19.813 & 20.90 & 2070 & 5.00 \\
3.979 & 20.90 & 0 & 0.50
\end{tabular}

TR-20350

\begin{tabular}{|c|c|c|c|c|}
\hline & & calibratior & $\begin{array}{c}\text { page } \\
\text { n date_ }\end{array}$ & of \\
\hline & Calcu & ated $\mathrm{Da}$ & & \\
\hline Mass & Water & Volume & Volume & Curve Fit \\
\hline $\begin{array}{l}\text { Flow } \\
\text { (lbs/min) }\end{array}$ & $\begin{array}{l}\text { Density } \\
\text { (lb/tin3) }\end{array}$ & $\begin{array}{l}\text { Flow } \\
\text { (ft^ } 3 / \mathrm{min})\end{array}$ & $\begin{array}{l}\text { Flow } \\
\text { (GPM) }\end{array}$ & $\begin{array}{l}\text { Ouput } \\
\text { (mA) }\end{array}$ \\
\hline 0.0 & 62.29 & 0.00 & 0.00 & 3.99 \\
\hline 81.9 & 62.28 & 1.31 & 9.83 & 7.12 \\
\hline 168.1 & 62.28 & 2.70 & 20.19 & 10.42 \\
\hline 249.0 & 62.28 & 4.00 & 29.91 & 13.52 \\
\hline 335.3 & 62.29 & 5.38 & 40.27 & 16.83 \\
\hline 415.5 & 62.29 & 6.67 & 49.90 & 19.90 \\
\hline 415.6 & 62.29 & 6.67 & 49.90 & 19.90 \\
\hline 332.6 & 62.30 & 5.34 & 39.94 & 16.72 \\
\hline 250.6 & 62.30 & 4.02 & 30.09 & 13.58 \\
\hline 165.2 & 62.30 & 2.65 & 19.83 & 10.31 \\
\hline 83.8 & 62.30 & 1.34 & 10.06 & 7.19 \\
\hline 0.0 & 62.30 & 0.00 & 0.00 & 3.99 \\
\hline 84.3 & 62.29 & 1.35 & 10.12 & 7.21 \\
\hline 166.8 & 62.29 & 2.68 & 20.03 & 10.37 \\
\hline 251.5 & 62.28 & 4.04 & 30.21 & 13.62 \\
\hline 332.6 & 62.29 & 5.34 & 39.95 & 16.72 \\
\hline 413.9 & 62.30 & 6.64 & 49.70 & 19.83 \\
\hline 0.0 & 62.30 & 0.00 & 0.00 & 3.99 \\
\hline
\end{tabular}

Density: $\square=62.441-1.374 E-3^{*} T-271.818 E-6^{*} T \wedge 2+194.093 E-9^{*} T^{\wedge} 3$ 7.4805 gallons $=1 \mathrm{ft}^{\wedge} 3$

Uncertainty of the Standards:

Weight:+/- 7.0

Temperature: $+/-0.40 \mathrm{C}$.

Density: $+1 /=0.06 \quad \mathrm{lbm} / \mathrm{ti} / 3$

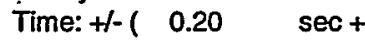

0.50 GPM

Accepted Tolerance: +1-

Xbar

Statistical Info.

$\begin{array}{cccc}a & b & n & T \\ 3.988 & 0.319 & 18.00 & 2.120\end{array}$

Calculated Uncertainties:

(GPM)

25.00

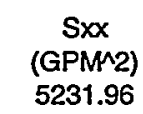

500.00 [sec/sec)

PASS CALIBRATION?

TRANSFER EQUATION

standard
uncertainty
(GPM)

0.17

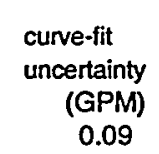

YES
$3.137 \mathrm{~mA}$

GPM $=$

\footnotetext{
3.137

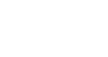

\begin{abstract}
$-12.509$
\end{abstract}
Figure F14. Pre-test Calibration Data of Magnetic Flowmeter Q1 
UNCERTAINTY ANALYSIS

REF. WSRC-TR-91-106

Calibration Data

\begin{tabular}{|c|c|c|c|}
\hline Meter & Water & Water & Time \\
\hline $\begin{array}{l}\text { Output } \\
\text { (mA) }\end{array}$ & $\begin{array}{l}\text { Temp } \\
\text { (C) }\end{array}$ & $\begin{array}{l}\text { Weight } \\
\text { (lbs) }\end{array}$ & $\begin{array}{l}\text { Duration } \\
\text { (min) }\end{array}$ \\
\hline 4.00 & 15.50 & 0.00 & 0.00 \\
\hline 8.21 & 15.50 & 13.25 & 5.03 \\
\hline 12.18 & 16.30 & 25.48 & 5.00 \\
\hline 16.17 & 19.50 & 37.83 & 5.00 \\
\hline 20.18 & 22.50 & 50.38 & 5.00 \\
\hline 20.18 & 23.00 & 50.44 & 5.00 \\
\hline 16.12 & 23.10 & 37.94 & 5.01 \\
\hline 12.28 & 22.80 & 25.95 & 5.00 \\
\hline 8.09 & 22.90 & 12.83 & 5.00 \\
\hline 4.00 & 22.90 & 0.00 & 0.00 \\
\hline 4.00 & 22.90 & 0.00 & 0.00 \\
\hline 8.15 & 22.90 & 12.95 & 5.00 \\
\hline 12.02 & 23.00 & 25.12 & 5.00 \\
\hline 16.05 & 25.20 & 37.63 & 5.00 \\
\hline 20.05 & 25.20 & 49.98 & 5.00 \\
\hline
\end{tabular}

TR-20353

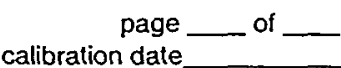

Calculated Data

\begin{tabular}{|c|c|c|c|c|c|c|}
\hline Mass & Water & Volume & Volume & Curve Fit & & \\
\hline $\begin{array}{l}\text { Flow } \\
\text { (lbs/min) }\end{array}$ & $\begin{array}{l}\text { Density } \\
\left(\mathrm{lb} / \mathrm{ft}^{\wedge} 3\right)\end{array}$ & $\begin{array}{l}\text { Flow } \\
(\mathrm{f} \wedge 3 / \mathrm{min})\end{array}$ & $\begin{array}{l}\text { Flow } \\
\text { (GPM) }\end{array}$ & $\begin{array}{l}\text { Ouput } \\
(\mathrm{mA})\end{array}$ & $\begin{array}{l}\text { Error } \\
(m A)\end{array}$ & $\begin{array}{l}\text { Error } \\
\text { (GPM) }\end{array}$ \\
\hline 0.00 & 62.36 & 0.00 & 0.00 & 3.99 & -0.01 & -0.001 \\
\hline 2.64 & 62.36 & 0.04 & 0.32 & 8.21 & 0.01 & 0.000 \\
\hline 5.09 & 62.35 & 0.08 & 0.61 & 12.16 & -0.03 & -0.002 \\
\hline 7.56 & 62.31 & 0.12 & 0.91 & 16.13 & -0.04 & -0.003 \\
\hline 10.07 & 62.27 & 0.16 & 1.21 & 20.15 & -0.03 & -0.002 \\
\hline 10.08 & 62.27 & 0.16 & 1.21 & 20.18 & 0.00 & 0.000 \\
\hline 7.58 & 62.27 & 0.12 & 0.91 & 16.16 & 0.04 & 0.003 \\
\hline 5.19 & 62.27 & 0.08 & 0.62 & 12.31 & 0.04 & 0.003 \\
\hline 2.56 & 62.27 & 0.04 & 0.31 & 8.10 & 0.01 & 0.001 \\
\hline 0.00 & 62.27 & 0.00 & 0.00 & 3.99 & -0.01 & -0.001 \\
\hline 0.00 & 62.27 & 0.00 & 0.00 & 3.99 & -0.01 & -0.001 \\
\hline 2.59 & 62.27 & 0.04 & 0.31 & 8.14 & -0.01 & -0.001 \\
\hline 5.02 & 62.27 & 0.08 & 0.60 & 12.05 & 0.03 & 0.003 \\
\hline 7.52 & 62.24 & 0.12 & 0.90 & 16.07 & 0.03 & 0.002 \\
\hline 909 & ค? & & 120 & 2003 & 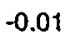 & \\
\hline
\end{tabular}

Density: $\left[=62.441-1.374 E-3^{*} T-271.818 E-6^{*} T^{\wedge} 2+194.093 E-9^{*} T^{\wedge} 3\right.$ 7.4805 gallons $=1 \mathrm{ft}^{\wedge} 3$

Uncertainty of the Standards:

Weight: + - 0.1

Temperature: $+/-0.40$

Density: $+1-0.06$ lbm/t/^3

Time: $+/-(0.20 \mathrm{sec}+500.00$ osec/sec $)$

Accepted Tolerance: $+/-\quad 0.01$ GPM

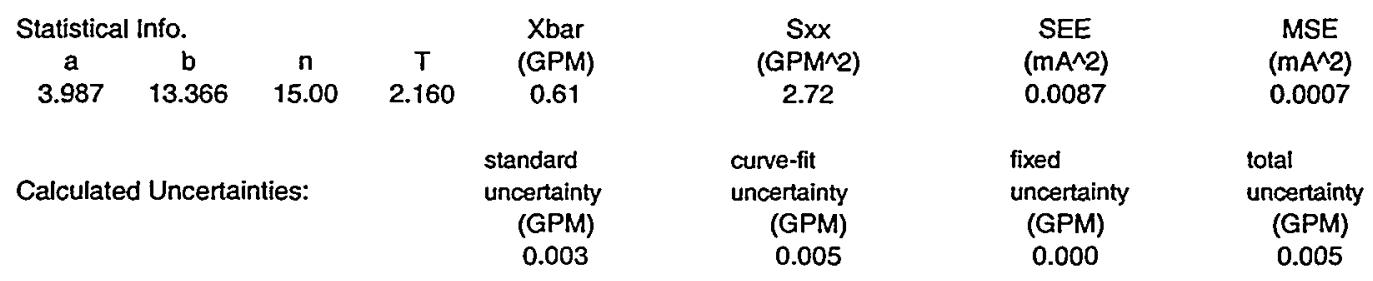

PASS CALIBRATION?

YES

TRANSFER EQUATION: $\quad$ GPM $=\quad 0.075 \quad \mathrm{~mA} \quad-0.298$
(GPM)

0.005

Figure F15. Pre-test Calibration Data of Magnetic Flowmeter Q2 
UNCERTAINTY ANALYSIS

REF. WSRC-TR-91-106

Calibration Data

\begin{tabular}{|c|c|c|c|}
\hline Meter & Water & Water & Time \\
\hline $\begin{array}{l}\text { Output } \\
(\mathrm{mA})\end{array}$ & $\begin{array}{l}\text { Temp } \\
\text { (C) }\end{array}$ & $\begin{array}{l}\text { Weighht } \\
\text { (lbs) }\end{array}$ & $\begin{array}{l}\text { Duration } \\
\text { (min) }\end{array}$ \\
\hline 3.97 & 24.60 & 0.00 & 0.00 \\
\hline 7.97 & 25.60 & 51.79 & 5.00 \\
\hline 11.96 & 25.20 & 103.40 & 5.00 \\
\hline 16.08 & 25.40 & 125.52 & 4.00 \\
\hline 19.98 & 25.70 & 124.58 & 3.00 \\
\hline 3.98 & 25.90 & 0.00 & 0.00 \\
\hline 8.01 & 25.90 & 52.35 & 5.00 \\
\hline 12.00 & 25.90 & 103.82 & 5.00 \\
\hline 15.97 & 25.90 & 124.28 & 4.00 \\
\hline 20.03 & 25.90 & 124.64 & 3.00 \\
\hline 3.98 & 25.70 & 0.00 & 0.00 \\
\hline B.11 & 25.70 & 53.48 & 5.00 \\
\hline 12.04 & 25.80 & 104.44 & 5.00 \\
\hline 15.99 & 25.80 & 124.75 & 4.01 \\
\hline 20.05 & 21.70 & 125.64 & 3.00 \\
\hline 3.98 & 23.00 & 0.00 & 0.00 \\
\hline 7.97 & 23.00 & 51.92 & 5.00 \\
\hline 11.96 & 22.90 & 103.69 & 5.00 \\
\hline 15.9 & 22.70 & 124.62 & 4.00 \\
\hline 19.92 & 22.70 & 124.36 & 3.00 \\
\hline
\end{tabular}

TR-3562

page
calibration date

Calculated Data

\begin{tabular}{|c|c|c|c|c|c|c|}
\hline $\begin{array}{l}\text { Mass } \\
\text { Flow } \\
\text { (lbs/min) }\end{array}$ & $\begin{array}{l}\text { Water } \\
\text { Density } \\
\text { (lb/t^3) }\end{array}$ & $\begin{array}{l}\text { Volume } \\
\text { Flow } \\
(\mathrm{ft} \wedge / \mathrm{min})\end{array}$ & $\begin{array}{l}\text { Volume } \\
\text { Flow } \\
\text { (GPM) }\end{array}$ & $\begin{array}{l}\text { Curve Fit } \\
\text { Ouput } \\
\text { (mA) }\end{array}$ & $\begin{array}{l}\text { Error } \\
(\mathrm{mA})\end{array}$ & $\begin{array}{c}\text { Error } \\
\text { (GPM) }\end{array}$ \\
\hline 0.00 & 62.25 & 0.00 & 0.00 & 3.98 & 0.01 & 0.004 \\
\hline 10.36 & 62.23 & 0.17 & 1.25 & 7.98 & 0.01 & 0.002 \\
\hline 20.67 & 62.24 & 0.33 & 2.48 & 11.95 & -0.01 & -0.002 \\
\hline 31.36 & 62.23 & 0.50 & 3.77 & 16.07 & -0.01 & -0.002 \\
\hline 41.48 & 62.23 & 0.67 & 4.99 & 19.98 & 0.00 & -0.001 \\
\hline 0.00 & 62.23 & 0.00 & 0.00 & 3.98 & 0.00 & 0.001 \\
\hline 10.47 & 62.23 & 0.17 & 1.26 & 8.02 & 0.01 & 0.003 \\
\hline 20.75 & 62.23 & 0.33 & 2.49 & 11.99 & -0.01 & -0.004 \\
\hline 31.05 & 62.23 & 0.50 & 3.73 & 15.96 & -0.01 & -0.005 \\
\hline 41.55 & 62.23 & 0.67 & 4.99 & 20.01 & -0.02 & -0.008 \\
\hline 0.00 & 62.23 & 0.00 & 0.00 & 3.98 & 0.00 & 0.001 \\
\hline 10.69 & 62.23 & 0.17 & 1.29 & 8.11 & 0.00 & -0.001 \\
\hline 20.87 & 62.23 & 0.34 & 2.51 & 12.03 & -0.01 & -0.002 \\
\hline 31.13 & 62.23 & 0.50 & 3.74 & 15.98 & -0.01 & -0.004 \\
\hline 41.87 & 62.29 & 0.67 & 5.03 & 20.11 & 0.06 & 0.020 \\
\hline 0.00 & 62.27 & 0.00 & 0.00 & 3.98 & 0.00 & 0.001 \\
\hline 10.37 & 62.27 & 0.17 & 1.25 & 7.98 & 0.01 & 0.003 \\
\hline 20.73 & 62.27 & 0.33 & 2.49 & 11.97 & 0.01 & 0.004 \\
\hline 31.13 & 62.27 & 0.50 & 3.74 & 15.98 & 0.01 & 0.003 \\
\hline 41.43 & 62.27 & 0.67 & 4.98 & 19.95 & 0.03 & 0.009 \\
\hline
\end{tabular}

Density: $D=62.441-1.374 E-3^{*} \mathrm{~T}-271.818 \mathrm{E}-6^{*} \mathrm{~T} \wedge 2+194.093 \mathrm{E}-9^{*} \mathrm{~T} \wedge 3$ 7.4805 gallons $=1 \mathrm{ft}^{\wedge} 3$

Uncertainty of the Standards:

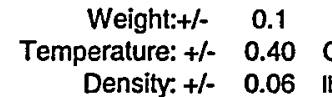

$\mathrm{lbm} / \mathrm{ft} 3$

Time: $+/-10.20 \quad \mathrm{sec}+$

0.05 GPM

Accepted Tolerance: $+\%$

Statistical Info.

$\begin{array}{ccc}a & b & n \\ 3.982 & 3.208 & 15.00\end{array}$

Xbar

$T$
2.160

(GPM)

Calculated Uncertainties:

standard

uncertainty

(GPM)

0.007

PASS CALIBRATION?

TRANSFER EQUATION:
YES

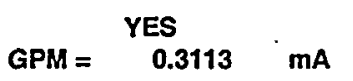

500.00 asec/sec)

Sxx
(GPMM2)
46.80
curve-fit
uncertainty
(GPM)
0.02

$-1.2370$

\begin{tabular}{cc} 
SEE & \multicolumn{1}{c}{ MSE } \\
(mA^2) & $\left(\mathrm{MA}^{\wedge} 2\right)$ \\
0.0056 & 0.0004 \\
& \\
fixed & total \\
uncertainty & uncertainty \\
(GPM) & (GPM) \\
0.00 & 0.02
\end{tabular}

(mA^2)

0004

certainty

0.02

Figure F16. Pre-test Calibration Data of Magnetic Flowmeter Q3 


\section{DISTRIBUTION:}

D. B. Burns, 786-5A

T. B. Calloway, Jr., 704-1T

J. J. Connelly, 773-41A

M. R. Duignan, 786-5A

M. A. Ebra, 773-42A

H. N. Guerrero, 786-5A

M. E. Johnson, BNFL, Inc.

C. A. Nash, 773-42A

L. M. Nelson, 773-43A

T. J. Steeper, 786-5A

J. L. Steimke, 786-5A

H. F. Sturm, 773-A

P. S. Townson, BNFL, Inc.

S. T. Wach, 773-42A

EESD Job File No. 22699, 730-A

BNFL File, 773-41A, Room 260

ETF File, 786-5A 